\title{
Adquisición y Seguimiento en Tiempo Real para Receptores GNSS Multiantena
}

Autor:

Gerardo Ludovico Puga
Directores:

Dr. Pedro Agustín Roncagliolo Dr. Miguel Ángel Mayosky

Jurados de Tesis:

Ing. Eduardo Paolini

Ing. Esp. Roberto Costantini

Dr. Javier A. Areta

Presentada ante la Facultad de Ingeniería de la Universidad Nacional de La Plata como requisito para la obtención del grado académico de Magíster en Ingeniería

Laboratorio LEICI

Departamento de Electromecánica

Facultad de Ingeniería 

"A Rube Goldberg machine, contraption, invention, device, or apparatus is a deliberately over-engineered or overdone machine that performs a very simple task in a very complicated fashion, usually including a chain reaction. The expression is named after American cartoonist and inventor Rube Goldberg (1883-1970)."

From the Wikipedia article on Rube Goldberg Machines.

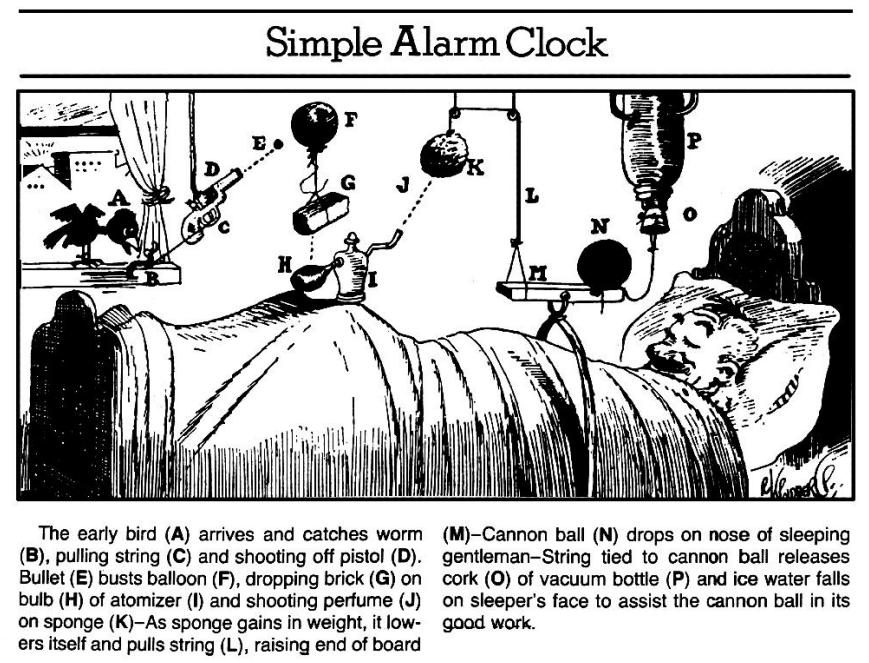





\section{UNIVERSIDAD NACIONAL DE LA PLATA}

\section{Resumen}

Facultad de Ingeniería

Departamento de Electromecánica

Magíster en Ingeniería

\section{Adquisición y Seguimiento en Tiempo Real para Receptores GNSS Multiantena}

por Gerardo Ludovico Puga

El presente trabajo consiste en el desarrollo y la implementación de los algoritmos de adquisición y seguimiento de señales para un receptor GNSS GPS/GLONASS con múltiples antenas de entrada apto para ser integrado como instrumento de a bordo de un vehículo de tipo cohete como los utilizados para realizar la puesta en órbita de cargas satelitales.

Son cuatro los requerimientos más importantes que deben satisfacer los algoritmos diseñados. El primero es la capacidad de operar correctamente bajo las condiciones dinámicas dominantes durante la misión de un vehículo de esta categoría. El segundo es la capacidad de procesar de forma simultánea y coordinada las señales recibidas a través de un sistema de cuatro antenas distribuidas en la periferia del cuerpo del vehículo, y ser capaz de mantener el sincronismo con las señales incluso cuando cambios en la orientación del vehículo modifiquen las condiciones de visibilidad del conjunto de antenas. En tercer lugar, el receptor debe poder procesar las señales civiles transmitidas por los satélites de los dos sistemas de posicionamiento operativos en la actualidad, el estadounidense GPS y el ruso GLONASS. Por último, todo el procesamiento debe realizarse en un sistema embebido y en tiempo real.

Estos algoritmos, serán implementados sobre la base de un prototipo del hardware y software del receptor GPS/GLONASS multiantena y serán ensayados para verificar su correcto funcionamiento en una serie de condiciones tanto dinámicas como estáticas. 



\section{Agradecimientos}

Mis más sinceros agradecimientos a toda la gente que de una forma u otra hizo que este trabajo fuera posible:

- A mis directores, Agustín y Miguel, por su apoyo y paciencia a lo largo de todo el proceso de desarrollo y escritura del trabajo.

- A la Comisión Nacional de Actividades Espaciales (CONAE), su empresa VENG S.A., y a la gente que forma parte de ambas, porque apuestan al desarrollo nacional de tecnologías de punta y hacen posibles desarrollos como éste.

- Al laboratorio LEICI, que me brindó el espacio físico y los recursos materiales necesarios para el trabajo diario.

Y muy especialmente a mis compañeros de trabajo, sin cuyo esfuerzo las mejores partes de este trabajo serían sólo ideas en el aire: Jorge, Ramón, Juan, Javier G., Javier S., Santiago y Pablo. 



\section{Índice general}

Resumen $\quad$ V

$\begin{array}{lll}\text { Agradecimientos } & \text { VII }\end{array}$

Contenidos VII

Índice de figuras $\quad$ XV

$\begin{array}{lll}\text { Índice de cuadros } & \text { XXI }\end{array}$

$\begin{array}{lll}\text { Abreviaturas } & \text { XXIII }\end{array}$

1. Introducción 1

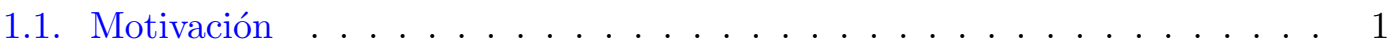

1.1.1. Introducción a los sistemas GNSS . . . . . . . . . . . . . 1

1.1.2. Aplicación en sistemas aeroespaciales . . . . . . . . . . . . . 3

1.2. Objetivos de la tesis . . . . . . . . . . . . . . . . . . 7

1.3. Estructura de la tesis . . . . . . . . . . . . . . . . . 8

2. Sistemas GNSS

2.1. Introducción a GNSS . . . . . . . . . . . . . . . . . . . . 11

2.1.1. Antecedentes . . . . . . . . . . . . . . . . . 11

2.1.2. Sistemas actuales . . . . . . . . . . . . . . . 13

2.2. Sistema NAVSTAR GPS . . . . . . . . . . . . . . . . . 17

2.2.1. Estructura . . . . . . . . . . . . . . . 17

2.2.1.1. Segmento de control . . . . . . . . . . . . . . . 17

2.2.1.2. Segmento espacial . . . . . . . . . . . . . . 18

2.2.1.3. Segmento de usuario . . . . . . . . . . . . . . 22

2.2.2. Tiempo GPS . . . . . . . . . . . . . . . . 22

2.2.3. Modernización del sistema . . . . . . . . . . . . . . . . 23

2.2.4. Señales transmitidas . . . . . . . . . . . . . . . 26

2.2.4.1. Señal C/A . . . . . . . . . . . . 28

2.2.4.2. Señal $\mathrm{P}(\mathrm{Y}) \ldots \ldots \ldots \ldots$

2.2.4.3. Señal M-Code . . . . . . . . . . . . . . . . . . 30

2.2.4.4. Señal L1C . . . . . . . . . . . . . . . . . . . 31 
2.2.4.5. Señal L2C . . . . . . . . . . . . . . . . . . 32

2.2.4.6. Señal L5 . . . . . . . . . . . . . . . . . 33

2.2.5. Estructura de la señal señal C/A . . . . . . . . . . . . . . 34

2.2.5.1. Función de código . . . . . . . . . . . . . . . . 34

2.2.5.2. Mensaje de navegación . . . . . . . . . . . . . . 37

2.2.5.3. Estructura . . . . . . . . . . . . . 40

2.3. Sistema GLONASS . . . . . . . . . . . . . . . . . . . 43

2.3.1. Estructura . . . . . . . . . . . . . . . . . 43

2.3.1.1. Segmento de control . . . . . . . . . . . . . . . . 43

2.3.1.2. Segmento espacial . . . . . . . . . . . . . . . 44

2.3.1.3. Segmento de usuario . . . . . . . . . . . . . . 46

2.3.2. Tiempo GLONASS . . . . . . . . . . . . . . . . 46

2.3.3. Evolución del sistema . . . . . . . . . . . . . . . . . . . . 47

2.3.4. Señales transmitidas . . . . . . . . . . . . . . . . . . . . 49

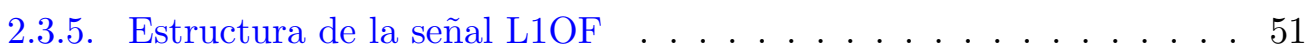

2.3.5.1. Función de código . . . . . . . . . . . . . . 52

2.3.5.2. Mensaje de navegación . . . . . . . . . . . . 53

2.3.5.3. Sincronismo . . . . . . . . . . . . . 56

2.4. Segmento de Usuario GPS y GLONASS . . . . . . . . . . . . . . . . 57

2.4.1. Modelo de funcionamiento . . . . . . . . . . . . . . . . . 58

2.4.2. Aplicaciones . . . . . . . . . . . . . . . . . 63

2.5. Resumen de capítulo . . . . . . . . . . . . . . . . . . . 65

3. Receptores GNSS convencionales $\quad \mathbf{6 7}$

3.1. Introducción . . . . . . . . . . . . . . . . . . . 67

3.2. Etapas de un receptor convencional . . . . . . . . . . . . . . . . . 67

3.3. Sistema de antenas . . . . . . . . . . . . . . . . . . . 68

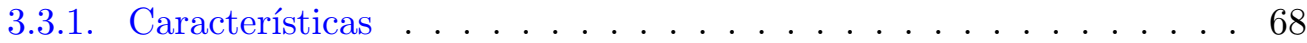

3.3.1.1. Bandas sensibles . . . . . . . . . . . . . . 69

3.3.1.2. Patrón de radiación . . . . . . . . . . . . . . . 69

3.3.1.3. Polarización . . . . . . . . . . . . . . . . 70

3.3.1.4. Alimentación . . . . . . . . . . . . . . . . . . 70

3.3.2. Modelo de señal . . . . . . . . . . . . . . . . . . . . . 71

3.4. Acondicionamiento y amplificación . . . . . . . . . . . . . . 72

3.5. Muestreo . . . . . . . . . . . . . . . . . . . . . . . . . . 74

3.6. Procesamiento digital de alta tasa . . . . . . . . . . . . . . 75

3.6.1. Correlación de una señal GNSS aislada . . . . . . . . . . . . . . . 77

3.6.2. Correlación con múltiples señales GNSS y ruido . . . . . . . . . . . 80

3.7. Estimación de parámetros de señal . . . . . . . . . . . . . . . . . 82

3.7.1. Adquisición . . . . . . . . . . . . . . . . . . 85

3.7.1.1. Búsqueda de señal . . . . . . . . . . . . . . . . 85

3.7.1.2. Verificación de candidatos . . . . . . . . . . . . . . 89

3.7.1.3. Sincronización inicial . . . . . . . . . . . . . 90

3.7.2. Seguimiento . . . . . . . . . . . . . . . 91

3.7.2.1. Lazo de seguimiento de portadora . . . . . . . . . . . 93

3.7.2.2. Lazo de seguimiento de código . . . . . . . . . . . . . . 93

3.7.2.3. Implementación discreta de los lazos . . . . . . . . . . . 94 
3.7.2.4. Respuesta dinámica de los lazos . . . . . . . . . . . 98

3.7.2.5. Condición de enganche . . . . . . . . . . . . . . . . . . . . 101

3.7.2.6. Asistencia de lazo de portadora . . . . . . . . . . . . 102

3.7.2.7. Extracción del mensaje de navegación . . . . . . . . . . . 103

3.8. Cálculo de Navegación . . . . . . . . . . . . . . . . . . . . . . . . 105

3.8.1. Obtención de mediciones . . . . . . . . . . . . . 106

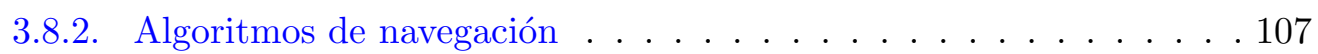

3.8.3. Tasa de generación de soluciones . . . . . . . . . . . . . 108

3.8.4. Pulso por segundo . . . . . . . . . . . . . . . . . . . . . . . . . . . . . . . . . . . . . . . . .

3.9. Control y monitoreo . . . . . . . . . . . . . . . . . . . . . 109

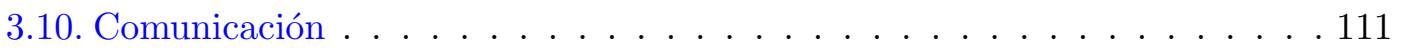

3.11. Resumen de capítulo . . . . . . . . . . . . . . . . . . . 113

4. Contexto de aplicación del receptor $\mathbf{1 1 5}$

4.1. Introducción . . . . . . . . . . . . . . . . . . . . . 115

4.2. Perfil de misión . . . . . . . . . . . . . . . . . . . . 115

4.2.1. Características de los vehículos . . . . . . . . . . . . . . . . . . . . . . . . . . . . . . .

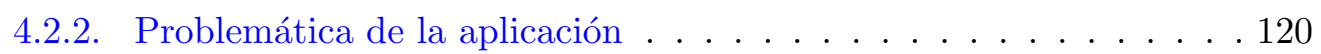

4.2.2.1. Sistema de antenas . . . . . . . . . . . . 120

4.2.2.2. Dinámica acelerada . . . . . . . . . . . . . . . . . . . . . . . . . . . . . . . . . .

4.2.2.3. Otras problemáticas . . . . . . . . . . . . . 124

4.3. Requerimientos mínimos . . . . . . . . . . . . . . . . . . . . 125

4.3.1. Procesamiento en tiempo real . . . . . . . . . . . . . . . . . . . . . . . . . . . . . . . . . .

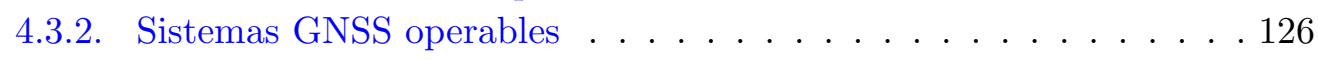

4.3.3. Sistema de antenas . . . . . . . . . . . . . . . 126

4.3.4. Dinámica esperada . . . . . . . . . . . . . . . . . . . . . . . . . . . . . . . . . . . . . . . . . . . . . . . .

4.4. Diseño propuesto . . . . . . . . . . . . . . . . . . . 126

4.4.1. Arreglo de antenas . . . . . . . . . . . . . . . . . . . . . . . . . . . . . . . . . . . . . . . . . .

4.4.2. Mediciones de rango/deltarango . . . . . . . . . . . . . . . . . . . . . . . . . . . . . . . . .

4.4.3. Algoritmos . . . . . . . . . . . . . . . . . . . . . . . . . . . . . . . . . . . . . . .

4.4.3.1. Adquisición . . . . . . . . . . . . . . . . . 135

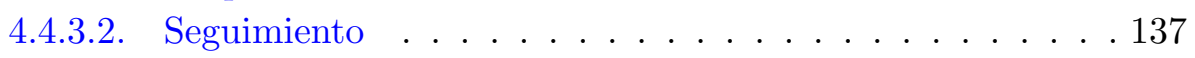

4.5. Resumen de capítulo . . . . . . . . . . . . . . . . . . . . 139

5. Hardware del prototipo 141

5.1. Introducción . . . . . . . . . . . . . . . . . . . . . . 141

5.2. Etapa de acondicionamiento de señal y muestreo . . . . . . . . . . . . . . . . . 142

5.2.1. Filtrado y amplificación . . . . . . . . . . . . . . . . . 142

5.2.2. Bajada a frecuencia intermedia . . . . . . . . . . . . . 143

5.2.2.1. Plan de frecuencias en frecuencia intermedia . . . . . . . 144

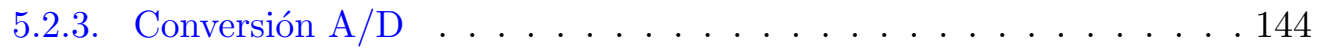

5.2.3.1. Doppler negativo y positivo . . . . . . . . . . 146

5.2.3.2. Plan de frecuencias discreto . . . . . . . . . . . . . . . . . . . . . . . . . . . . . . . . .

5.3. Etapa de correlación multiantena . . . . . . . . . . . . . . . . . . . 149

5.3.1. Módulo de adquisición . . . . . . . . . . . . . . . . . 151

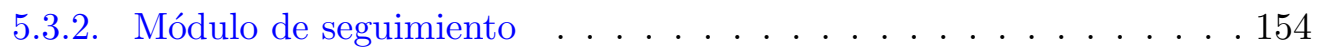

5.4. Etapa de cómputo . . . . . . . . . . . . . . . . . . . 158 
5.5. Sistema completo . . . . . . . . . . . . . . . . . . . . . 159

5.6. Resumen de capítulo . . . . . . . . . . . . . . . . . . . . 161

$\begin{array}{lr}\text { 6. Algoritmos de Seguimiento Multiantena } & 163\end{array}$

6.1. Introducción . . . . . . . . . . . . . . . . . . 163

6.2. Arquitectura general del sistema de seguimiento . . . . . . . . . . . . . . . 164

6.2.1. Actividades de la TSS . . . . . . . . . . . . . . . . . . 165

6.2.1.1. Seguimiento multiantena . . . . . . . . . . 166

6.2.1.2. Selección de antena activa . . . . . . . . . . . 166

6.2.1.3. Monitoreo de divergencia de los estimadores de frecuencia 167

6.2.1.4. Unificación de los parámetros de portadora . . . . . . . 168

6.2.1.5. Monitoreo de coherencia de polaridad del mensaje de navegación . . . . . . . . . . . . . . 171

6.2.2. Actividades de la TSI . . . . . . . . . . . . . . . . . . . 173

6.3. Diseño de los lazos de seguimiento . . . . . . . . . . . . . . . . 175

6.3.1. Lazos de seguimiento de portadora . . . . . . . . . . . . . . . . 176

6.3.1.1. Filtro de lazo . . . . . . . . . . . . . . . 176

6.3.1.2. Discriminador de fase UFA . . . . . . . . . . . . . 178

6.3.1.3. Falsos enganches de frecuencia . . . . . . . . . . . . . 181

6.3.1.4. Diseño del filtro de lazo . . . . . . . . . . . . . . . . 183

6.3.2. Lazo de seguimiento de código . . . . . . . . . . . . . . . . . . 191

6.3.2.1. Detector de falsos enganches . . . . . . . . . . . . . 193

6.3.2.2. Diseño del filtro de lazo . . . . . . . . . . . . . . . . 197

6.4. Resumen de capítulo . . . . . . . . . . . . . . . . . . . . . 200

7. Algoritmos de adquisición multiantena 203

7.1. Introducción . . . . . . . . . . . . . . . . . . . . . . 203

7.2. Características de la adquisición multiantena . . . . . . . . . . . . . 204

7.2.1. Entrelazado de planos de búsqueda entre antenas . . . . . . . . . 207

7.2.2. Recorrido del plano de búsqueda . . . . . . . . . . . . . . . . . 208

7.2.3. Verificación inmediata de candidatos . . . . . . . . . . . . . . . 209

7.2.4. Umbral de detección . . . . . . . . . . . . . . . . . . . . . . 210

7.2.5. Procesamiento segmentado . . . . . . . . . . . . . . . . . . 210

7.3. Arquitectura del sistema de adquisición . . . . . . . . . . . . . . . 212

7.3.1. Etapa de estimación de ruido . . . . . . . . . . . . . . . . 215

7.3.2. Etapa de búsqueda . . . . . . . . . . . . . . . . . . . . 217

7.3.3. Etapa de verificación . . . . . . . . . . . . . . . . . . . . 220

7.3.4. Etapa de sincronización . . . . . . . . . . . . . . . . . . . . 222

7.3.4.1. Centrado de lóbulo . . . . . . . . . . . . . . . . 222

7.3.4.2. Captura de lóbulo . . . . . . . . . . . . . . . . . . . . . . . 226

7.3.4.3. Seguimiento y detección de flancos . . . . . . . . . . . . . . . . . . 230

7.4. Resumen de capítulo . . . . . . . . . . . . . . . . . . . . 234

8. Ensayos de funcionamiento 237

8.1. Introducción . . . . . . . . . . . . . . . . . . . 237

8.2. Interfaz de comunicación con el receptor . . . . . . . . . . . . . . 238

8.3. Seguimiento de señales con antena estática . . . . . . . . . . . . . . . . . . 242 
8.4. Ensayos dinámicos con señal simulada . . . . . . . . . . . . . . . . . . 243

8.4.1. Conmutación de antenas con vehículo rotando a velocidad angular

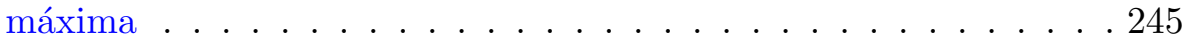

8.4.2. Escalón de aceleración con rotación . . . . . . . . . . . . . . . . 250

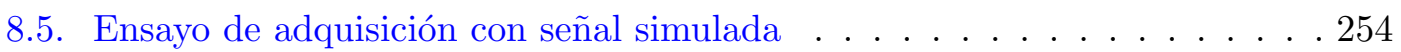

8.6. Resumen de capítulo . . . . . . . . . . . . . . . . . . . 256

A. Detector de falsos enganches $\mathbf{2 6 5}$

A.1. Introducción . . . . . . . . . . . . . . . . . . . . 265

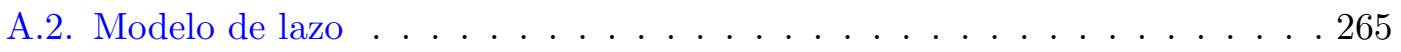

A.3. Transferencias de lazo . . . . . . . . . . . . . . . . 266

A.4. Ancho de banda de ruido . . . . . . . . . . . . . . . . . . . . 267

A.4.1. Estimación de fase . . . . . . . . . . . . . . . . . . . . . . . . . . . . . . . . . . . . . . . . . .

A.4.2. Estimación de frecuencia . . . . . . . . . . . . . . . . . . . . . . . . . . . . . . . . . . . .

A.5. Caracterización de ruido de referencia . . . . . . . . . . . . . 271

A.5.1. Ruido en las muestras de correlación . . . . . . . . . . . . . . 271

A.5.2. Ruido en el discriminador de código . . . . . . . . . . . . . . . . 273

A.6. Ruido de la estimación de frecuencia . . . . . . . . . . . . . . . . . . 277

A.7. Velocidad de respuesta del detector . . . . . . . . . . . . . . . . . . . 277

A.7.1. Respuesta al escalón de frecuencia . . . . . . . . . . . . . . 278

B. Probabilidad de falsa alarma de detección no coherente 281

B.1. Introducción . . . . . . . . . . . . . . . . . . . . . . . . . . . . 281

B.2. Modelo estadístico de correlación no coherente sin señal . . . . . . . . . 281

B.3. Probabilidad de falsa alarma . . . . . . . . . . . . . . . . 283

C. Algoritmo de detección de flancos en señal GNSS 285

C.1. Introducción . . . . . . . . . . . . . . . . . . . . . . . . 285

C.2. Modelo de señal . . . . . . . . . . . . . . . . . . . . . . 286

C.3. Determinación del alineamiento . . . . . . . . . . . . . . . . . 287

C.3.1. Criterio de selección . . . . . . . . . . . . . . . . . 288

C.3.2. Recorrido del espacio de búsqueda . . . . . . . . . . . . . . . . . . . . . . . . . . . . . . . . . . . . . . . . . . . . . . .

C.4. Implementación . . . . . . . . . . . . . . . . . . . . . . . . . 290

C.4.1. Mecanización del Trellis . . . . . . . . . . . . . . . . . . . . 291

C.4.2. Algoritmo de procesamiento . . . . . . . . . . . . . . . . . . . 293

C.5. Expresión analítica de probabilidad de error . . . . . . . . . . . . . . . 294

C.6. Simulaciones . . . . . . . . . . . . . . . . . . . . . . . 298

C.6.1. Evaluación de la expresión analítica . . . . . . . . . . . . . . 298

C.6.2. Comparación contra otros métodos . . . . . . . . . . . . . . 300

C.6.3. Efecto de normalización no ideal . . . . . . . . . . . . . . . . 302 



\section{Índice de figuras}

2.1. Distribución de bases del Segmento de Control . . . . . . . . . . . . . . . 19

2.2. Diseño de los satélites de los Bloques IIA, IIR, IIR-M, IIF Y GPS III. . . 20

2.3. Efecto de la disponibilidad selectiva. . . . . . . . . . . . . . . . . 24

2.4. Espectro aproximado de las señales GPS transmitidas en L1. . . . . . . . 26

2.5. Espectro aproximado de las señales GPS transmitidas en L2. . . . . . . . 27

2.6. Espectro aproximado de la señal GPS transmitida en L5. . . . . . . . . . 28

2.7. Diagrama de los generadores de código Gold. . . . . . . . . . . . . . . . . 35

2.8. Codificación NRZ bipolar de 50 bps utilizada para transmitir el mensaje de navegación GPS. . . . . . . . . . . . . . . . . 37

2.9. Alineamiento entre función de código y bits de datos GPS. . . . . . . . . . 41

2.10. Diagrama del generador de código utilizado en GLONASS L1OF. . . . . . 53

2.11. Formato de un string GLONASS L1OF . . . . . . . . . . . . . 53

2.12. Codificación Manchester bipolar de 50 bps utilizada para transmitir los 85 bits de datos de las líneas L1OF GLONASS. . . . . . . . . . . . . . . 54

2.13. Codificación NRZ bipolar de 100 bps utilizada para transmitir la palabra de sincronismo de las líneas L1OF GLONASS. . . . . . . . . . . . . 54

2.14. Alineamiento entre función de código y bits de datos GLONASS. . . . . . 56

2.15. Ejemplo de trilateración en el plano . . . . . . . . . . . . . . . 59

2.16. Factores forma de receptores GNSS . . . . . . . . . . . . . . . . 64

3.1. Etapas de procesamiento en un receptor GNSS convencional. . . . . . . . 68

3.2. Etapa de radiofrecuencia típica con una única etapa de conversión. . . . . 73

3.3. Conversión A/D fase/cuadratura con dos conversores. . . . . . . . . . . 74

3.4. Conversión A/D con pseudomuestreo. . . . . . . . . . . . . . 75

3.5. Esquema de las partes principales de un canal de correlación. . . . . . . . 76

3.6. Esquema de la operación de correlación. . . . . . . . . . . . . . . . 77

3.7. Modelo analógico aproximado de la operación de correlación, válido si la frecuencia de muestreo es lo suficientemente alta. . . . . . . . . . . . . 78

3.8. Perfil de la dependencia en frecuencia de la función de correlación, en

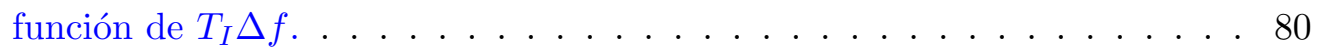

3.9. Potencia de correlación del lóbulo principal . . . . . . . . . . . . . 82

3.10. Potencia de correlación del lóbulo principal; corte a lo largo del eje $\Delta \tau$. $\quad 83$

3.11. Potencia de correlación del lóbulo principal; corte a lo largo del eje $T_{I} \Delta f . \quad 83$

3.12. Etapas de procesamiento de una señal GNSS. . . . . . . . . . . . . . . . 84

3.13. Registro de la desviación de la frecuencia portadora de satélites GPS durante intervalo de $20 \mathrm{hs} \ldots \ldots$. . . . . . . . . . . 87

3.14. Plano retardo-frecuencia utilizado para representar el espacio de búsqueda 88 
3.15. Estructura general de los lazos realimentados utilizados para estimar los parámetros de la señal. . . . . . . . . . . . . . . . . . . . . 93

3.16. Versión completa del funcionamiento conjunto de los lazos de portadora y de código . . . . . . . . . . . . . . . . . . . . 94

3.17. Funcionamiento del discriminador coherente de la expresión (3.16) . . . . . 96

3.18. Plantillas para el diseño de los filtros de lazos de seguimiento analógicos óptimos . . . . . . . . . . . . . . . . . . . 100

3.19. Esquema de asistencia de lazos. . . . . . . . . . . . . . . . . . . . . . . . . . . 102

3.20. Pasos de la resolución de la solución de navegación. . . . . . . . . . . . . 106

3.21. Relación entre el hardware, el sistema operativo y la aplicación. . . . . . . . 110

4.1. Perfil de aceleración de vehículo Saturn V. . . . . . . . . . . . . . . . . . 117

4.2. Perfil de aceleración de vehículo Vega. . . . . . . . . . . . . . . . . . . 119

4.3. Arreglo de cuatro antenas en modo suma. . . . . . . . . . . . . . . . . 121

4.4. Arreglo de cuatro antenas en modo diversidad. . . . . . . . . . . . . . . . . 121

4.5. Representación esquemática de la ubicación de las antenas en el cuerpo del vehículo. . . . . . . . . . . . . . . . . . . . . 127

4.6. Detalle de la distribución de las antenas en la periferia del cuerpo del vehículo. . . . . . . . . . . . . . . . . . . . 128

4.7. Patrón de radiación típico de una antena parche . . . . . . . . . . . . 129

4.8. Superposición de patrones de antenas en modo diversidad . . . . . . . . 130

4.9. Cobertura angular del conjunto de antenas en modo diversidad. . . . . . . . 131

4.10. Cobertura del arreglo de antenas de modo diversidad para todas las direcciones de arribo . . . . . . . . . . . . . . . . . . 132

4.11. Representación 3D de la cobertura del arreglo de antenas de modo diversidad para todas las direcciones de arribo . . . . . . . . . . . . 133

5.1. Bloques principales de hardware del prototipo del receptor GPS/GLONASS multiantena. . . . . . . . . . . . . . . . . . . . . . . 142

5.2. Solapamiento entre réplicas que ocurre durante el muestreo de la señal en frecuencia intermedia del prototipo . . . . . . . . . . . . . . . 147

5.3. Efecto del muestreo pasabanda de $20 \mathrm{MHz}$ sobre dos señales de $25 \mathrm{MHz}$ y $35 \mathrm{MHz} \ldots \ldots \ldots \ldots \ldots \ldots$. . . . . . . . . . . . . . . . . . . . . . . . . .

5.4. Organización interna del hardware de correlación del prototipo de receptor multiantena. . . . . . . . . . . . . . . . . 150

5.5. Canal de adquisición multiantena. . . . . . . . . . . . . . . . 151

5.6. Entrelazado entre intervalos de correlación y de procesamiento. . . . . . . 153

5.7. Canal de seguimiento multiantena. . . . . . . . . . . . . . . . . 155

5.8. Diagrama de demostración de la obtención de correlaciones parcial y total para minimizar el impacto de las transiciones de fase del mensaje de navegación en el valor integrado . . . . . . . . . . . . . . 156

5.9. Foto del prototipo del hardware del receptor completamente ensamblado. 160

6.1. Diagrama simplificado de la relación entre las tareas de seguimiento superior e inferior, y la arquitectura interna de ellas. . . . . . . . . . . . . . . 165

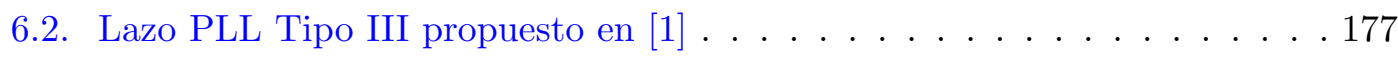

6.3. Representación conceptual del discriminador UFA. . . . . . . . . . . . . 180

6.4. Simulación del comportamiento del lazo de seguimiento de portadora ante un escalón de fase $180^{\circ}$ en la referencia: errores de fase y frecuencia. . . . 185 
6.5. Simulación del comportamiento del lazo de seguimiento de portadora ante un escalón de fase $180^{\circ}$ en la referencia: frecuencia y aceleración. . . . . . 186

6.6. Simulación del comportamiento del lazo de seguimiento de portadora ante un escalón de frecuencia de $10 \mathrm{~Hz}$ en la referencia: errores de fase y frecuencia 187

6.7. Simulación del comportamiento del lazo de seguimiento de portadora ante un escalón de frecuencia de $10 \mathrm{~Hz}$ en la referencia: frecuencia y aceleración 188

6.8. Simulación del comportamiento del lazo de seguimiento de portadora ante un escalón de aceleración de $10 \mathrm{~g}$ en la referencia: errores de fase y frecuencia189

6.9. Simulación del comportamiento del lazo de seguimiento de portadora ante un escalón de aceleración de $10 \mathrm{~g}$ en la referencia: frecuencia y aceleración 190

6.10. Modelo analítico del lazo discreto Tipo II de seguimiento de código . . . . 192

6.11. Desviación estándar de la estimación de error de frecuencia de portadora en función del ancho de banda $B_{n}$ del lazo de código y de la relación $C / N_{o}$ de la señal, y para el caso de GPS. . . . . . . . . . . . . . . . . . 196

6.12. Desviación estándar de la estimación de error de frecuencia de portadora en función del ancho de banda $B_{n}$ del lazo de código y de la relación $C / N_{o}$ de la señal, y para el caso de GLONASS (canal $k=0$ ) . . . . . . . . . 196

6.13. Probabilidad de falsa alarma del detector de falsos enganches en función del ancho de banda $B_{n}$ del lazo de código y de la relación $C / N_{o}$ de la señal, para el caso de GPS. . . . . . . . . . . . . . . . . . . 198

6.14. Probabilidad de falsa alarma del detector de falsos enganches en función del ancho de banda $B_{n}$ del lazo de código y de la relación $C / N_{o}$ de la señal, para el caso de GLONASS (canal $k=0$ ). . . . . . . . . . . . . 198

6.15. Respuesta al impulso del lazo de seguimiento de código simulado. . . . . . 199

6.16. Respuesta al escalón del lazo de seguimiento de código simulado. . . . . . . 199

7.1. Etapas principales en que se divide el proceso de adquisición. . . . . . . . 204

7.2. Representación en forma de diagrama de ocupación de un pipeline del procesamiento de las muestras de correlación . . . . . . . . . . . . 211

7.3. Diagrama statechart que representa el funcionamiento en alto nivel de algoritmo de adquisición implementado en el prototipo de receptor. . . . . 213

7.4. Diagrama statechart de la máquina de estado anidada dentro del estado compuesto ESTIMACIÓN DE RUIDO de la Figura 7.3. . . . . . . . . . . 216

7.5. Diagrama statechart de la máquina de estado anidada dentro del estado compuesto BÚSQUEDA de la Figura 7.3. . . . . . . . . . . . . . . . 218

7.6. Diagrama statechart de la máquina de estado anidada dentro del estado compuesto VERIFICACIÓN de la Figura 7.3. . . . . . . . . . . . . . 220

7.7. Diagrama statechart de la máquina de estado anidada dentro del estado compuesto SINCRONIZACIÓN de la Figura 7.3. . . . . . . . . . . . . . 223

7.8. Diagrama statechart de la máquina de estado anidada dentro del estado compuesto CENTRAR_LÓBULO de la Figura 7.7. . . . . . . . . . . . . . 224

7.9. Captura de envolvente del lóbulo de correlación obtenida con tiempos de integración de $3 \mathrm{~ms}$ y paso de frecuencia de $33 \mathrm{~Hz}$. . . . . . . . . . . . . . 227

7.10. Vista en frecuencia del mismo lóbulo que se ve la Figura 7.9 . . . . . . . 227

7.11. Vista en retardo del mismo lóbulo que se ve en la Figura 7.9 . . . . . . . 228

7.12. Diagrama statechart de la máquina de estado anidada dentro del estado compuesto CAPTURA de la Figura 7.7. . . . . . . . . . . . . . . . 229

7.13. Diagrama statechart de la máquina de estado anidada dentro del estado compuesto SEGUIMIENTO de la Figura 7.7. . . . . . . . . . . . . 231 
8.1. Captura de pantalla mostrando una condición de trabajo típica del prototipo de receptor multiantenna GPS/GLONASS . . . . . . . . . . . . 239

8.2. Vista en detalle de la terminal donde se presenta la información de consola transmitida por el receptor. . . . . . . . . . . . . . . . . . . 239

8.3. Vista en detalle de la terminal donde se presenta la información de navegación GPS transmitida por el receptor . . . . . . . . . . . . . . . 240

8.4. Vista en detalle de la terminal donde se presenta la información de estado de canales transmitida por el receptor . . . . . . . . . . . . . . . 241

8.5. Vista en detalle de la terminal donde se muestra un volcado de los mensajes transmitidos por el receptor a través de su protocolo de comunicación binario.

8.6. Desviación de frecuencia respecto del valor nominal de portadora para todos los satélites GPS observados por el receptor durante un intervalo de funcionamiento continuo de 24 horas . . . . . . . . . . . . . . . 242

8.7. Desviación de frecuencia respecto del valor nominal de portadora para todos los satélites GLONASS observados por el receptor durante un intervalo de funcionamiento continuo de 24 horas . . . . . . . . . . . . . . . 243

8.8. Captura de pantalla del software de control del simulador de señales GNSS utilizado para realizar las simulaciones dinámicas. . . . . . . . . . . . . . 244

8.9. Amplitud de la envolvente de la señal recibida a través de cada una de las cuatro antenas de entrada durante el ensayo de conmutación de antenas con simulador GNSS. . . . . . . . . . . . . . . . . . . . 246

8.10. Asignación del rol de antena activa a lo largo del tiempo, durante el ensayo de conmutación de antenas con simulador GNSS. . . . . . . . . . . . .

8.11. Señal en banda base recibida a través de cada una de las cuatro antenas de entrada, durante el ensayo de conmutación de antenas con simulador GNSS.

8.12. Error de fase de cada uno de los cuatros PLLs encargados del seguimiento de portadora de cada antena de entrada, durante el ensayo de conmutación de antenas con simulador GNSS . . . . . . . . . . . . . . . . . . . 249

8.13. Mensaje de navegación demodulado durante el ensayo de conmutación de antenas con simulador GNSS . . . . . . . . . . . . . 2

8.14. Error de fase de antena activa durante el ensayo de conmutación de antenas con simulador GNSS . . . . . . . . . . . . . . . . 2

8.15. Error de lazo de código durante el ensayo de conmutación de antenas con simulador GNSS. . . . . . . . . . . . . . . . . . . . 252

8.16. Amplitud de la envolvente de la señal recibida a través de cada una de las cuatro antenas de entrada durante el ensayo de escalón de aceleración con simulador GNSS. . . . . . . . . . . . . . . . . . . 253

8.17. Asignación del rol de antena activa a lo largo del tiempo, durante el ensayo de escalón de aceleración con simulador GNSS. . . . . . . . . . . . . . . 254

8.18. Señal en banda base recibida a través de cada una de las cuatro antenas de entrada, durante el ensayo de escalón de aceleración con simulador GNSS.

8.19. Error de fase de cada uno de los cuatros PLLs encargados del seguimiento de portadora de cada antena de entrada, durante el ensayo de escalón de aceleración con simulador GNSS . . . . . . . . . . . . . 256

8.20. Error de fase de antena activa durante el ensayo de escalón de aceleración con simulador GNSS . . . . . . . . . . . . . . . . . . 257 
8.21. Mensaje de navegación unificado, durante el ensayo de escalón de aceleración con simulador GNSS . . . . . . . . . . . . . . . 258

8.22. Error de lazo de código durante el ensayo de escalón de aceleración con simulador GNSS. . . . . . . . . . . . . . . . . . . . 259

8.23. Comparación de las curvas de probabilidad de adquisición relevadas experimentalmente para señales GPS y GLONASS contra la curva teórica calculada utilizando un modelo matemático simplificado del proceso de adquisición. . . . . . . . . . . . . . . . . . . . . 260

A.1. Modelo analógico de un lazo de seguimiento Tipo II como el utilizado para el seguimiento de la fase de la función de código . . . . . . . . . . 266

A.2. Curva $C_{c}$ utilizada para rodear el semiplano izquierdo por infinito. . . . . 269

A.3. Modelo analógico aproximado de la operación de correlación, válido si la frecuencia de muestreo es lo suficientemente alta . . . . . . . . . . . . . 272

A.4. Efecto de la superposición parcial de las funciones de código durante el tiempo de integración $T_{I}$ en la expresión (A.17) cuando $\Delta<T_{\text {chip }} \ldots \ldots 275$

A.5. Respuesta de la estimación de frecuencia del lazo de seguimiento de código a un escalón unitario de frecuencia . . . . . . . . . . . . . . . 280

B.1. Probabilidad de falsa alarma en una correlación no coherente, en función del umbral normalizado $u \mathrm{y}$ de la cantidad de integraciones no coherentes sumadas, $N_{c o h} \ldots \ldots \ldots \ldots \ldots \ldots \ldots \ldots$

C.1. Esquema de denominación de estados utilizado para la mecanización de la generación del trellis. . . . . . . . . . . . . . . . . . . . 292

C.2. Trellis de transición de estados para el caso de tiempos de integración de $3 \mathrm{~ms}(N=3) \ldots \ldots \ldots \ldots \ldots \ldots \ldots$

C.3. Valores finales de los errores cuadráticos acumulados al final de una corrida de simulación con parámetros $N=5$ y $C / N_{o}=35 \mathrm{~dB}-\mathrm{Hz}$. . . . . . 295

C.4. Simulación de la probabilidad de error del método de detección de alineamiento presentado, con $F=50$ y para variantes con tiempos de integración $N=1$ a $N=10$ en función de la relación $C / N_{o} \ldots$. . . . . . . . 299

C.5. Simulación de la probabilidad de error del método de detección de alineamiento presentado, con $F=25$ y para variantes con tiempos de integración $N=1$ a $N=10$ en función de la relación $C / N_{o} \ldots . . . . . .300$

C.6. Simulación de la probabilidad de error del método de detección de alineamiento presentado, con $F=10$ y para variantes con tiempos de integración $N=1$ a $N=10$ en función de la relación $C / N_{o} \ldots$. . . . . . . 301

C.7. Simulación de las probabilidades de error con $F=50$ de los métodos histograma, máxima energía de bit y dos variantes del método de máxima verosimilitud presentado en este apéndice para valores $N=1$ y $N=3$. . . 302

C.8. Simulación de las probabilidades de error con $F=25$ de los métodos histograma, máxima energía de bit y dos variantes del método de máxima verosimilitud presentado en este apéndice para valores $N=1$ y $N=3$. . 303

C.9. Simulación de las probabilidades de error con $F=10$ de los métodos histograma, máxima energía de bit y dos variantes del método de máxima verosimilitud presentado en este apéndice para valores $N=1$ y $N=3$. . 304

C.10.Efecto de la utilización de normalización no ideal sobre la probabilidad de error del método de detección de alineamiento para $N=3$ y $F=25$. 



\section{Índice de cuadros}

2.1. Disponibilidad de señales GPS clásicas y modernizadas en función de la generación a la que pertenece el satélites transmisor. . . . . . . . . . 25

2.2. Parámetros de generación de los códigos Gold utilizados en GPS C/A. [2] 38

2.3. Utilización de bandas de señal según generación GLONASS, según composición de diversas fuentes de información. . . . . . . . . . . . . 50

4.1. Algunos ejemplos de vehículos lanzadores de cargas satelitales, ordenados por su capacidad de carga máxima a órbitas LEO o similares. . . . . . . . 116

5.1. Valores de las frecuencias portadoras nominales luego de realizada la conversión a FI. . . . . . . . . . . . . . . . . . . . . . . . . . . . 144

5.2. Ocupación de frecuencias luego del muestreo pasa-banda real. . . . . . . . 149

6.1. Cálculo de los coeficientes $v, f_{1}, f_{2}$ y $p_{3}$ en función del ancho de banda $B_{n}$, cuando el tiempo de integración es $T_{I}=10 \mathrm{~ms} \ldots \ldots \ldots \ldots$

7.1. Parámetros más relevantes del proceso de adquisición de una señal GNSS GPS/GLONASS en el receptor multiantena. . . . . . . . . . . . . . 205 



\section{Abreviaturas}

A/D Analog/Digital Converter.

AFSCN $\quad$ Air Force Satellite Control Network.

AGC Automatic Gain Control.

ASCII American Standard Code for Information Interchange.

AWGN Additive White Gaussian Noise.

BOC Binary Offset Carrier.

BPF Band Pass Filter.

bps Bauds Per Second.

C/A Coarse Acquisition.

CDMA Code Division Multiple Access.

CONAE COmisión NAcional de Actividades Espaciales.

DNSS Defense Navigation Satellite System.

DoD Departament Of Defense.

DOP Dilution Of Precision.

ECEF Earth Centered, Earth Fixed.

ESA European Space Agency.

FDMA Frequency Division Multiple Access.

FEC Forward Error Correction.

FI Frecuencia Intermedia.

FPGA Field-Programmable Gate Array.

GLONASS GLObalnaya NAvigatsionnaya Sputnikovaya Sistema

(Global Navigation Satellite System).

GNSS Global Navigation Satellite System.

GPS Global Positioning System.

HOW Hand Over Word. 
HPF High Pass Filter.

IERS International Earth Rotation and Reference Systems Service.

IF

Intermediate Frequency.

IP

Intelectual Property.

IODC Issue Of Data, Clock.

IRNSS Indian Regional Navigation Satellite System.

LEO Low Earth Orbit.

LLA Latitude Longitude Altitude.

LNA Low Noise Amplifier.

LPF Low Pass Filter.

LST Low Side Tuning.

MEO Medium Earth Orbit.

MGGR Multi-antenna GPS/GLONASS Receiver.

OCXO Oven-Controlled Cristal Oscilator.

OFDM Orthogonal Frequency Division Multiplexing.

NAVSTAR NAVigation using Signal Time And Ranging.

NMEA National Marine Electronics Association.

NRZ Non Return to Zero.

OCXO Oven Controlled X-tal (Crystal) Oscillator.

PPS Precise Positioning Service.

PRN Pseudo-Random Noise.

PVT Position, Velocity and Time.

QZSS Quasi-Zenith Satellite System.

RF Radio Frequency.

RTCA Radio Technical Comission for Aeronautics.

RTCM Radio Technical Comission for Maritime Services.

TIMATION TIMe navigATION.

TMBOC Time Multiplexed Binary Offset Carrier.

TOW Time Of the Week.

SA Selective Availability.

SNR Signal-to-Noise Ratio.

SoC System-on-Chip.

SPS Standard Positioning Service. 
SysML System Modeling Language.

TAI Temps Atomique Internationa (International Atomic Time)

TCXO Temperature Compensated X-tal (Crystal) Oscillator.

TLM TeLeMetry word.

UML Universal Modeling Language.

USAF US Air Force.

UTC Extraoficialmente en inglés Coordinated Universal Time, o en francés Universel Temps Coordonné. Oficialmente la sigla no tiene significado, ya que es un compromiso entre las siglas CUT (que correspondería en inglés) y TUC (que correspondería en francés).

WCET Worst Case Execution Time. 

Dedicado a mis padres, por su eterno apoyo incondicional, y a Alicia de León, que a la distancia pero cerca me acompañó a lo largo de todo este camino. 



\section{Capítulo 1}

\section{Introducción}

\subsection{Motivación}

\subsubsection{Introducción a los sistemas GNSS}

Los Sistemas Globales de Navegación por Satélite, llamados por sus siglas en inglés GNSS (Global Navigation Satellite Systems) permiten a cualquier usuario que posea un receptor adecuado determinar su ubicación desde cualquier lugar del planeta a partir del procesamiento de las señales transmitidas por una constelación de satélites que orbitan la tierra. La utilidad inmediata de este tipo de sistema es por supuesto la localización de vehículos y personas, pero existe también una cantidad creciente de aplicaciones derivadas del procesamiento de las soluciones de navegación. Una lista incompleta, pero que sirve de ejemplo para ver lo variado de las aplicaciones, puede ser la siguiente: geolocalización, seguimiento de cargas, asistencia de ruta, navegación automática, armas inteligentes, sincronización de tiempo entre estaciones remotas, determinación de orientación, caracterización de desplazamientos tectónicos, relevamiento de estado atmosférico, y otras.

En la actualidad existen dos sistemas GNSS en condiciones totalmente operativas y con cobertura global: NAVSTAR GPS de los Estados Unidos, y GLONASS perteneciente a Rusia. Otros dos sistemas de alcance global se encuentran en desarrollo y se espera que estén en pleno funcionamiento hacia fines de la década: Beidou-2/COMPASS (perteneciente a China), y Galileo (Unión Europea).

Debido a la enorme importancia estratégica (militar y económica) que tienen este tipo de sistemas es factible esperar que en las próximas décadas otras potencias sumen sus propios sistemas de navegación globales al conjunto de los ya disponibles. Varios países 
han dado ya sus primeros pasos en esta dirección con el desarrollo de sistemas de navegación regionales, restringidos a prestar servicio solamente sobre los países propietarios del sistema y las zonas aledañas. Por su alcance limitado estos sistemas no entran en la categoría GNSS aunque están basados en principios semejantes. Los países que han puesto en marcha sistemas de este tipo son Japón (con su sistema QZSS) e India (IRNSS) [3].

Todos los sistemas GNSS pueden ser pensados en términos de tres segmentos bien diferenciados llamados Segmento Espacial, Segmento de Control y Segmento de Usuario. El Segmento Espacial está conformado por una constelación de satélites orbitando la tierra. En los sistemas actuales estas constelaciones constan de entre 24 y los 32 vehículos activos en todo momento. La cantidad exacta de satélites y su distribución orbital pueden variar en el tiempo dentro de ciertos márgenes, pero siempre garantizando la disponibilidad del sistema en toda la superficie del planeta. Los satélites del Segmento Espacial transmiten una serie de señales hacia la tierra en forma permanente. Estas pueden clasificarse en señales civiles de libre utilización y señales restringidas codificadas que sólo pueden ser utilizadas por usuarios autorizados.

El Segmento Espacial recibe instrucciones de control y configuración desde el Segmento de Control. Este último se encarga de monitorizar el estado del sistema, realizar correcciones de órbita, administrar los satélites activos, calcular la corrección de los relojes de a bordo, etc. El Segmento de Control además es el encargado de definir la Hora del Sistema, que es un patrón de tiempo de muy alta precisión con el cual se mantienen sincronizados los relojes de a bordo de todos los satélites. El Segmento de Control depende políticamente de forma directa del gobierno o entidad internacional propietaria del sistema, y se encuentra subordinado su poder político.

El llamado Segmento de Usuario es una denominación abstracta que abarca el conjunto de todos los receptores de un dado sistema GNSS. La única interacción posible entre los receptores del Segmento de Usuario y el resto del sistema es la recepción de las señales transmitidas por los satélites del Segmento Espacial, sin que exista ningún tipo de comunicación en la dirección opuesta. En su formato más habitual los receptores GNSS decodifican las señales transmitidas por cuatro o más satélites de un mismo sistema (GPS, GLONASS, etc.) y mediante su procesamiento determinan la posición y velocidad del usuario.

Si bien todos los sistemas GNSS poseen una arquitectura semejante, el diseño y desarrollo de cada uno de ellos fue llevado a cabo por actores internacionales independientes, de forma no cooperativa, e incluso en algunos casos en competencia directa unos con otros. Una consecuencia de esta situación es que en la actualidad los diferentes sistemas existentes son mayormente incompatibles unos con otros. Cada sistema cuenta con su propio 
Segmento de Control y su propio Segmento Espacial, así como su propia arquitectura de señales utilizadas, bandas de frecuencia, formato de datos, etc.

La medición del tiempo es una parte fundamental de la operación de todos los sistemas GNSS. Cada satélite cuenta con una referencia de tiempo de muy alta calidad a bordo, a partir de la cual se deriva la frecuencia de todas las señales transmitidas. El Segmento de Control de cada sistema se encarga de mantener los relojes de todos los satélites sincronizados con una referencia de tiempo central que recibe el nombre de Hora del Sistema. Cada satélite anuncia de forma continua la hora de sistema codificada en las señales que transmite y con precisión del orden de algunos nanosegundos.

Además de la hora del sistema, las señales transmitidas también portan de forma modulada el llamado Mensaje de Navegación, el cual contiene información sobre el estado operativo del satélite transmisor, los parámetros de su órbita, los coeficientes de un modelo analítico del reloj de a bordo, el estado de los demás satélites de la constelación y otra información de utilidad para el usuario del sistema [3][4].

A partir del procesamiento de las señales de los satélites el receptor GNSS es capaz de calcular la posición del usuario mediante un proceso similar a la multilateración. En la multilateración convencional la posición del usuario se calcula conociendo las distancias entre este último y una serie de puntos de referencia cuyas coordenadas son conocidas. Similarmente los receptores GNSS son capaces de calcular la posición del usuario mediante la determinación de las distancias que separan a este último de un conjunto de satélites cuya posición es conocida por sus parámetros orbitales. La imposibilidad de realizar la medición de las distancias entre el receptor y los satélites de forma directa hace que el proceso sea necesariamente un poco más complejo que este modelo elemental, pero se posterga para más adelante la discusión de los mecanismos utilizados para resolver este problema.

\subsubsection{Aplicación en sistemas aeroespaciales}

En vehículos de aplicaciones aeronáuticas y aeroespaciales es crítico el conocimiento del estado del vehículo (posición, velocidad, orientación) para realizar el control y seguimiento de la trayectoria, garantizando al mismo tiempo la seguridad y la integridad del mismo. Históricamente los sensores utilizados para determinar estas variables han sido sistemas basados en la medición directa de parámetros físicos elementales, como acelerómetros, altímetros, brújulas, giróscopos, tubos de Pitot, etc., complementados con sistemas de apoyo externos, como radares o faros de radio-localización. Hoy día es posible realizar estas mismas funciones mediante receptores GNSS montados en los vehículos, 
con importantes ventajas en la exactitud, precisión y fiabilidad de las mediciones de posición, velocidad y orientación que se pueden lograr.

Sin embargo al menos dos problemas han demorado la aceptación de la navegación mediante GNSS en sistemas aeronáuticos. La primera razón es de índole política: hasta ahora los sistemas GNSS disponibles con cobertura global se han restringido a dos posibilidades, GPS y GLONASS; ambos sistemas se encuentran bajo el control exclusivo de sus gobiernos propietarios (Estados Unidos y Rusia, respectivamente) y por lo tanto pueden ser suspendidos o modificados sin previo aviso ni discusión en los foros internacionales. La dependencia estratégica que esto implica ha generado una más que comprensible reticencia por parte todo tipo de organismos internacionales para incorporar la utilización de sistemas GNSS como parte vital de los sistemas críticos que se encuentran a su cargo.

Este tipo de temores se han visto mayormente minimizados en años recientes gracias al desarrollo de nuevos sistemas de posicionamiento alternativos que multiplican la oferta de sistemas (Estados Unidos, Rusia, China, la Unión Europea), y a los compromisos asumidos por sus autoridades de control respecto de la disponibilidad de dichos sistemas en el mediano y largo plazo. La coexistencia de diversos sistemas de posicionamiento permite también el desarrollo de receptores multiconstelación capaces de utilizar las señales de múltiples sistemas. Esta redundancia de sistemas permite a dichos receptores continuar operando independientemente de la suspensión, la degradación o la avería de los servicios provistos por los sistemas GNSS individuales.

El segundo problema, de índole más técnica, tiene que ver con la confiabilidad y la disponibilidad del servicio que puede proveer un receptor GNSS al vehículo donde está montado: a diferencia de los sensores pasivos, como acelerómetros y giróscopos, que funcionan a partir de fundamentos físicos elementales, los receptores GNSS son instrumentos complejos formados por grandes cantidades de hardware y software, y cuyo funcionamiento está condicionado por factores externos totalmente fuera de su control. Algunas de las dependencias que se pueden nombrar son la cantidad y calidad de las señales recibidas, el correcto funcionamiento de los satélites de la constelación, la existencia de interferencias externas e internas en la señal de radiofrecuencia, etc.

Desde el punto de vista de la confiabilidad de los equipos, el nivel de penetración de los sistemas digitales en la navegación aeronáutica se ha visto forzado a aumentar año tras año para hacer frente a la creciente complejidad de los sistemas de transporte de cargas y pasajeros. Por su propia naturaleza, y especialmente en la escala de complejidad necesaria para estas aplicaciones, la utilización de este tipo de soluciones está signada por la existencia de fallas en los sistemas de hardware y de software, las cuales pueden tener consecuencias catastróficas si se manifiestan durante etapas críticas de la operación del 
sistema. Por esta razón es que se han desarrollado infinidad de procesos de diseño estandarizados, normativas de calidad para hardware y software, protocolos de verificación de sistemas, técnicas de tolerancia a fallas, etc. La aplicación rigurosa de estas metodologías permite por lo tanto atenuar fuertemente las objeciones que pudieran aparecer respecto de la aptitud de instrumentos digitales complejos, como es el caso de los receptores GNSS, para ser utilizados en el corazón de sistemas aeronáuticos y aeroespaciales.

En cuanto a la disponibilidad del servicio, debe considerarse que los receptores GNSS sólo pueden generar soluciones de navegación si reciben la señal de al menos cuatro satélites de un mismo sistema. La calidad de las soluciones de navegación obtenidas también depende de la cantidad de señales recibidas, mejorando marcadamente la primera al aumentar la segunda desde el mínimo necesario. A su vez, la cantidad de señales recibidas depende de la cantidad de satélites en línea de vista con el receptor, del patrón de radiación de la o las antenas utilizadas, y de la existencia de interferencia, entre otros factores.

La cantidad de satélites en vista es una función de las características de la constelación de que se trate (cantidad y distribución de satélites en órbita), de la altura a la que se encuentre el vehículo respecto de la superficie, de las obstrucciones debidas a estructuras, edificios o elevaciones del terreno en el entorno inmediato, y de otras eventualidades de índole técnica (como por ejemplo, satélites fuera de servicio durante intervalos de mantenimiento, desperfectos técnicos, etc.). Al igual que ocurre con la dependencia política, los receptores multiconstelación tienen una clara ventaja en este sentido, al poder alternar entre constelaciones si fuera necesario sin perjuicio de la disponibilidad del servicio provisto por el receptor.

La visibilidad de señales hacia la o las antenas receptoras no es un factor menor, especialmente en aplicaciones aeroespaciales. En general en receptores GNSS montados a bordo de vehículos aeroespaciales no es suficiente con utilizar una única antena receptora con patrón hemisférico orientada hacia el cénit, como se hace en receptores para vehículos terrestres e incluso en aplicaciones aeronáuticas comerciales. La razón es que los vehículos utilizados tienen dinámicas de vuelo ricas en movimientos de rotación sobre sus tres ejes, y por lo tanto no es posible en general encontrar una posición del cuerpo del vehículo que pueda garantizar visibilidad de cielo abierto plena durante todas las fases de la operación del vehículo para una antena ubicada allí.

La solución habitual para este problema consiste en la utilización de arreglos de múltiples antenas individuales que son combinadas en un punto suma antes de ser procesadas por el receptor. Las antenas conectadas de esta forma se comportan entonces como una única antena equivalente con un patrón de radiación que depende de las características físicas del arreglo. Eligiendo adecuadamente la cantidad y distribución de las antenas del conjunto se pueden lograr patrones de radiación aproximadamente esféricos que 
permitan recibir señales independientemente de su dirección de arribo. Soluciones de este tipo han sido utilizadas en múltiples oportunidades para vehículos de tipo cohete sonda, como se ve en las referencias [5][6][7][8].

Sin embargo estas configuraciones de antenas combinadas en un punto suma no están libres de problemas. Una debilidad particularmente importante es que los patrones de radiación logrados de esta forma suelen presentar diagramas de ganancia poco uniformes para las bandas utilizadas en GNSS, presentando grandes variaciones de ganancia en función de la dirección de arribo [9]. La razón de este problema es que las dimensiones físicas del arreglo (determinadas principalmente por las dimensiones del vehículo) son comparables con la longitud de onda de las frecuencias portadoras utilizadas en las bandas de frecuencias de los sistemas GNSS (bandas L1, L2 y otras cercanas), por lo que existen diferencias no despreciables en la fase instantánea con la que una misma señal puede llegar a diferentes antenas del arreglo. Las fases con las que la señal arriba a diferentes antenas del conjunto de entrada es a su vez una función de la dirección de arribo y de la configuración geométrica de las antenas. Estas diferencias en la fase de arribo provocan un efecto de cancelación o suma destructiva para algunas direcciones de arribo particulares, lo que se manifiesta en el patrón de radiación de la antena equivalente como direcciones de arribo con bajos valores de ganancia.

Este tipo de características en el patrón de radiación de la antena equivalente puede provocar la existencia de direcciones de arribo ciegas, desde las cuales la ganancia de la antena no permite la recepción de señales. En vehículos cuya orientación se modifica a lo largo de la misión el problema puede ser aún mayor, debido a que el patrón de antena rota de forma solidaria con el cuerpo del vehículo, por lo que la potencia de las señales recibidas puede sufrir amplias fluctuaciones que dificulten su demodulación.

Existe una aproximación alternativa al diseño multiantena descripto anteriormente. En esta variante en lugar de unir todas las antenas en un punto suma antes de ser procesadas como una unidad, cada antena se encuentra unida a su propia una etapa de radiofrecuencia y procesamiento digital separada, y es el software el encargado de combinar los resultados del procesamiento de la señal de unas y otras antenas de forma coherente. Un ejemplo de esta aproximación se puede ver en [10].

Esta aproximación permite a cada antena conservar su patrón de radiación individual sin que ocurran cancelaciones con la señales recibidas por otras antenas del conjunto. En [11] se compara esta aproximación (a la cual llama "diversity mode" o Modo Diversidad) contra la utilización de la combinación de antenas ("sum mode" o Modo Suma) y también contra la utilización de beamforming (un método que explota la diversidad espacial para lograr ganancia en la dirección de los satélites y/o rechazo en la dirección de señales interferentes) en términos de cobertura obtenida. La conclusión de ese trabajo 
es que beamforming es el mejor de los tres métodos pero requiere de mucha información adicional, mientras que los esquemas de Modo Diversidad logran una cobertura adecuada sin la complejidad del beamforming; los arreglos de tipo Modo Suma tienen cobertura mucho menor que cualquiera de los dos anteriores.

La arquitectura de Modo Diversidad tiene costos tanto en hardware como en software. En hardware, el esquema de antenas con procesamiento independiente significa que el receptor debe contar con tantas etapas de radiofrecuencia y de procesamiento digital como antenas se deban procesar. En términos de software, la complejidad del receptor también se ve incrementada ya que los algoritmos utilizados por los receptores GNSS convencionales deben ser extendidos al caso multiantena, y nuevos algoritmos de selección de antena y procesamiento deben ser añadidos para garantizar la coherencia de las mediciones obtenidas a través de todas ellas. Sin embargo estos costos se ven compensados no sólo por una mejora en términos de las características ya enunciadas (ausencia de acoplamientos indeseados entre antenas y mejor cobertura de todas las direcciones de arribo posibles), sino también por la aparición de nuevas formas de procesamiento de la señal habilitadas por el hecho de disponer simultáneamente de las mediciones realizadas a través de múltiples antenas separadas espacialmente. Un ejemplo de esto es el cálculo de la orientación de la aeronave (inclinación en los tres ejes), el cual puede realizarse a partir de procesar las diferencias en las fases de arribo a cada una de las antenas de entrada [12][13].

\subsection{Objetivos de la tesis}

Se propone desarrollar los algoritmos específicos de bajo nivel de un receptor GNSS GPS/GLONASS multiantena para aplicaciones espaciales. El principal objetivo del receptor es servir de apoyo a la computadora de navegación de cohetes inyectores satelitales, lo que impone requerimientos de funcionamiento (dinámica del vehículo, modos de operación, etc.).

Deben desarrollarse los algoritmos de adquisición, seguimiento y procesamiento de datos aptos para ser utilizados en receptores con múltiples antenas de entrada en configuración de Modo Diversidad, siendo necesario que el software del receptor coordine el procesamiento de las señales de cada una de ellas.

Por requerimiento del tipo de aplicaciones a las que está destinado el receptor, los algoritmos deben ser tales que se adapten dinámicamente a las condiciones de vuelo del vehículo, como rotaciones, cambios en la situación de visibilidad, etc. para maximizar la disponibilidad del servicio del receptor hacia los sistemas de navegación del vehículo. 
Además, para minimizar la dependencia de una única constelación GNSS el receptor debe ser capaz de procesar las señales de cualquiera de los dos sistemas GNSS predominantes en la actualidad, GPS y GLONASS.

Este tipo de receptores para aplicaciones de tiempo real funcionan iterando lazos realimentados discretos que se encargan de mantener siempre actualizadas las estimaciones de frecuencia y fase de portadora, y retardo de la función de expansión de código, los cuales son utilizados para generar las mediciones de tiempo de transmisión de cada satélite que a su vez se convierten en la entrada de los algoritmos de navegación. Estos lazos de seguimiento discretos deben funcionar en tiempo real, siendo necesario actualizar la estimación de todos ellos entre cientos y miles de veces por segundo, dependiendo de cual sea la etapa de procesamiento de la señal (adquisición, sincronización inicial, seguimiento, etc.) y la dinámica del vehículo para el que esté diseñado el receptor.

La dinámica de movimiento de los vehículos tipo cohete tiene la característica de tener etapas de aceleración intensa, con cambios repentinos de su valor cuando se encienden o se apagan motores propulsores, se desprenden etapas, etc. Estas variaciones dinámicas introducen perturbaciones en los lazos de seguimiento de señal debido a la variación de la frecuencia aparente de la misma por efecto Doppler. Si la perturbación es lo suficientemente intensa para sacar a los lazos de seguimiento de sus regiones lineales de operación antes de ser rechazadas, se produce el desenganche de los lazos y la pérdida de la señal del satélite correspondiente; esto puede a su vez afectar la disponibilidad de la solución de navegación que el receptor entrega a los sistemas de navegación del vehículo. Es necesario por lo tanto un correcto diseño de los lazos realimentados para minimizar la probabilidad de este tipo de problemas, conformando adecuadamente su respuesta dinámica ante los efectos de la aceleración repentina del vehículo.

El correcto funcionamiento del modelo desarrollado debe ser validado mediante la utilización de ensayos con señal real de satélites GPS/GLONASS, así como también mediante la utilización de trayectorias generadas mediante un simulador de señales GNSS.

\subsection{Estructura de la tesis}

La estructura de los capítulos siguientes de la presente tesis es la que se describe a continuación:

- En el Capítulo 2 se lleva adelante una introducción al funcionamiento de los sistemas GNSS en general, y en particular a los dos sistemas de interés para el presente trabajo: GPS y GLONASS. 
- En el Capítulo 3 se expone la arquitectura dominante utilizada para el diseño de receptores GNSS monoantena convencionales, para sentar una base mínima sobre la que sea posible discutir de la arquitectura del sistema a diseñar.

- Las características del entorno de aplicación de un receptor como el que es el objetivo de esta tesis se discuten en el Capítulo 4, y se establecen una serie de requerimientos mínimos que debe cumplir el diseño.

- El Capítulo 5 presenta de forma resumida las características del hardware disponible para llevar adelante la implementación de los algoritmos diseñados, ya que su diseño (realizado de forma independiente al presente trabajo de tesis) conforma en sí mismo una condición de contorno que restringe el espacio de posibilidades de los algoritmos presentados en los capítulos siguientes.

- Los algoritmos de seguimiento multiantena se presentan en el Capítulo 6, mientras que los algoritmos de adquisición se exponen en el Capítulo 7. Esta inversión respecto del orden natural obedece a que los lazos de seguimiento forman parte también de las últimas etapas del proceso de adquisición, y su discusión previa permitirá minimizar el solapamiento entre capítulos.

- El Capítulo 8 presenta una serie de ensayos realizados sobre la implementación de los algoritmos de adquisición y seguimiento multiantena en un modelo de desarrollo de receptor GPS/GLONASS para aplicaciones espaciales que se encuentra en proceso de construcción.

- Por último, el Capítulo 9 está dedicado a la conclusión que da cierre a este trabajo.

Además del contenido central de la tesis que se encuentra englobado por los capítulos anteriores, existen también una serie de apéndices que tratan temas laterales:

- En el Apéndice A se hace un tratamiento estadístico de la probabilidad de falsa alarma de un detector de falsos enganches de frecuencia que es utilizado en el Capítulo 6.

- El Apéndice B establece las expresiones necesarias para determinar la probabilidad de falsa alarma del detector de señal utilizado durante el proceso de adquisición no coherente, utilizado en el Capítulo 7.

- El Apéndice C expone el funcionamiento de un nuevo algoritmo de detección de flancos de bit con aplicación a señales GNSS, el cual es un desarrollo auxiliar que forma parte de la implementación de los algoritmos de adquisición presentados en el Capítulo 7. El contenido de este apéndice es una versión resumida y adaptada de lo publicado por el autor de esta tesis en las referencias [14] y [15]. 



\section{Capítulo 2}

\section{Sistemas GNSS}

\subsection{Introducción a GNSS}

\subsubsection{Antecedentes}

Los sistemas GNSS son un conjunto de sistemas de navegación que tienen sus raíces en las investigaciones realizadas por las dependencias del Departamento de Defensa (DoD, Department of Defense) de los Estados Unidos en las décadas del '60 y '70. El objetivo de estas investigaciones era el de desarrollar una tecnología que permitiera la determinación de la posición y velocidad de un vehículo en tres dimensiones, con cobertura global, y de forma independiente de las condiciones climáticas imperantes. Estos esfuerzos culminaron en la creación del sistema NAVSTAR GPS (generalmente llamado simplemente GPS) a mediados de la década del '70.

Si bien por escala y características GPS es con toda justicia el primero de los sistemas modernos de navegación satelital, en su origen se nutre de la experiencia adquirida a través del diseño y la operación de tres sistemas que habían sido implementados en la década anterior: TRANSIT, TIMATION y System 621B.

TRANSIT era un sistema de navegación satelital que permitía la determinación de la posición bidimensional (sobre la superficie terrestre) del usuario a partir de las señales transmitidas por una constelación de satélites dedicados. La determinación de la solución de navegación se lograba a partir de la medición del desplazamiento Doppler de un tono continuo transmitido en $400 \mathrm{MHz}$ por alguno de los satélites del sistema. El sistema permitía la determinación de la posición del usuario en dos dimensiones en el instante de mayor aproximación entre satélite y usuario. Para alcanzar una cobertura global con un nivel de disponibilidad aceptable, el sistema requería de al menos 5 satélites funcionales en órbita. Durante el cálculo de posición el receptor del sistema debía descontar 
el efecto de la velocidad propia del vehículo (obtenida por medios independientes) de las mediciones de desviación Doppler de la portadora de la señal del satélite, lo que complejizaba el proceso de cálculo. La precisión del sistema se encontraba en el rango de algunas centenas de metros, y se limitaba a obtener una solución de posición por hora (aproximadamente). Una limitación importante del sistema es que requería además del conocimiento previo de la altura a la que se encontraba el vehículo. Por esta última razón TRANSIT era de poca utilidad para la aeronavegación y su aplicación se restringía principalmente a la navegación terrestre y marítima. El sistema operó de forma continua entre 1964 y 1996, cuando fue reemplazado en todas sus aplicaciones por el por ese entonces ya completamente funcional sistema GPS. [3]

TIMATION fue un proyecto de investigación de sistemas de transferencia precisa de tiempo y medición de rangos satelitales, desarrollado durante la segunda mitad de la década del '60. El proyecto consistió en la puesta en órbita de sucesivas generaciones de satélites provistos de relojes de a bordo de muy alta estabilidad. El primero de estos satélites, TIMATION I, contaba con un reloj de cuarzo, mientras que los dos satélites posteriores (TIMATION II y NTS-II/TIMATION III) fueron los primeros satélites en contar con relojes de patrón atómico. Estos vehículos transmitían en una banda cercana a la banda de TRANSIT (400 MHz) una portadora modulada con una señal compuesta por varios tonos de entre $100 \mathrm{~Hz}$ y $1 \mathrm{MHz}$. Tanto la portadora como los tonos de la señal moduladora eran obtenidos a partir de una única referencia temporal (el reloj de alta estabilidad de a bordo), por lo que la relación entre todas las frecuencias del sistema estaba perfectamente definida. Las frecuencias de los tonos presentes en la señal moduladora estaban elegidas de forma tal que esta última era una señal periódica que se repetía 12,5 veces por segundo. Gracias a esa periodicidad el receptor podía determinar la hora del sistema con una ambigüedad de $80 \mathrm{~ms}$ y una precisión del orden de $10 \mathrm{~ns}$, y eliminar posteriormente esa ambigüedad al decodificar la señal de datos también transmitida por el satélite.

El proyecto TIMATION también investigó qué tipo de órbitas favorecían la predictibilidad de los desplazamientos del satélite, que es determinante para elegir la periodicidad con la que es necesario actualizar los parámetros orbitales necesarios para poder calcular la ubicación del mismo. En los receptores que contaran con información externa sobre la hora del sistema (por ejemplo, gracias a una referencia de tiempo de estabilidad moderada que hubiera sido sincronizada con el patrón de tiempo del sistema recientemente) el conocimiento del tiempo de tránsito de la señal (diferencia entre los tiempos de transmisión y recepción) se podía utilizar para determinar el rango (distancia) entre el usuario y el satélite con una precisión de $10 \mathrm{~m}$. Muchos de los conceptos desarrollados en este proyecto fueron de aplicación casi directa al incipiente sistema GPS, al punto tal que el 
tercero de los satélites TIMATION (el NTS-II/TIMATION III) sirvió de demostrador tecnológico para el sistema GPS. [3][16]

De forma aproximadamente simultánea con el proyecto TIMATION se llevó a cabo el proyecto de la Fuerza Aerea denominado Project 621B, cuya misión era la de investigar las bases tecnológicas necesarias para un sistema de posicionamiento satelital de alcance global que permitiera el cálculo de posición no sólo en las coordenadas horizontales, sino también en altura. Este programa desarrolló el concepto de la utilización de códigos pseudoaleatórios (PRN, Pseudo-Random Noise) para permitir la determinación del rango entre el receptor y los satélites transmisores. La utilización de códigos ortogonales permitía a múltiples satélites transmisores utilizar la misma banda de frecuencias, lo que simplificaba las etapas de radiofrecuencia del receptor y minimizaba el ancho de banda requerido del canal de comunicación. Codificando el tiempo de transmisión en la fase del código PRN el receptor podía determinar el tiempo de transmisión de la señal de forma continua y con excelente resolución, y mediante cuatro o más mediciones determinar la posición y la hora sin ningún tipo de sincronización previa entre los relojes del transmisor y el receptor. La utilización de estos códigos además le otorgaba al sistema una elevada resistencia a la interferencia accidental, lo que es de suma importancia para garantizar la disponibilidad en aplicaciones críticas. Se llevaron a cabo experimentos utilizando cuatro pseudolitos (transmisores terrestres de señal que simulan ser satélites) y receptores montados en aviones para evaluar el concepto de cálculo de posición mediante este tipo de sistema. El proyecto incorporó la idea de patrones de tiempo de alta estabilidad como los utilizados en TIMATION para minimizar la necesidad de monitorear permanentemente el estado de los relojes de bordo de los satélites, minimizando así la infraestructura terrestre de apoyo necesaria. [3][4]

\subsubsection{Sistemas actuales}

El sistema NAVSTAR GPS incorporó el fruto de las investigaciones realizadas a través de TIMATION y Project 621B, así como la experiencia operativa obtenida gracias a TRANSIT para lograr un sistema de navegación satelital de alta precisión, alta disponibilidad, alcance global, y con capacidad de determinación tridimensional de navegación (posición, velocidad y tiempo). Formalmente el proyecto tuvo su inicio en 1973, luego de la creación del programa Defense Navigation Satellite System (DNSS). Los primeros diez satélites del sistema (llamados satélites del Bloque I) fueron puestos en órbita entre los años 1978 y 1985, seguidos posteriormente de nuevas series Bloque II, Bloque IIA, Bloque IIR, y Bloque IIR-M. 
El sistema provee dos servicios diferenciados: un servicio civil, llamado SPS (Standard Positioning Service) y un servicio militar PPS (Precise Positioning Service). Si bien inicialmente la exactitud del sistema civil estaba limitada artificialmente utilizando una técnica conocida como Selective Availability (SA), esta distorsión fue suspendida en el año 2000 para permitir un mayor desarrollo comercial de las aplicaciones GPS. La precisión nominal de peor caso del servicio SPS es de $13 \mathrm{~m}$ en las coordenadas horizontales y $22 \mathrm{~m}$ en la vertical; para PPS las cifras correspondientes son $28 \mathrm{~m}$ y $22 \mathrm{~m}$ respectivamente [4]. Estas especificaciones son cotas válidas al menos el $95 \%$ del tiempo, y corresponden a la señal en espacio libre (no contemplan errores adicionales debidos a efectos atmosféricos ni errores del receptor).

El sistema GPS original utilizaba señales transmitidas en las bandas L1 y L2, pero las versiones más modernas incorporan nuevas señales también en la banda L5. En cada banda todos los satélites transmiten en la misma frecuencia portadora nominal, y utilizan señales de espectro expandido utilizando la técnica Direct Sequence Spread Spectrum $(D S-S S)$ con códigos diferentes para cada satélite transmisor para multiplexar el acceso al medio mediante Code Division Multiple Access (CDMA).

Poco tiempo luego de la puesta en marcha del proyecto NAVSTAR GPS la por entonces Unión Soviética (hoy Rusia) comenzó el desarrollo de su propio sistema de navegación satelital de alcance global, el sistema GLONASS. El primer satélite de este sistema fue puesto en órbita en 1983, y el sistema alcanzó una condición totalmente operativa (24 satélites) en 1995, apenas un año después que su contraparte americana. Sin embargo las dificultades económicas y políticas que atravesó Rusia durante la década del '90 limitaron seriamente los fondos con los que contaba el proyecto. Debido a esto durante la década siguiente el sistema sufrió de un deterioro progresivo que lo llevó a tocar su punto más bajo en los primeros años del nuevo milenio cuando apenas una docena de satélites GLONASS se encontraban operativos en órbita.

En el año 2001 el presidente Vladimir Putin decretó que se implementase un plan de restauración del sistema GLONASS de forma tal de lograr la recuperación de su capacidad operativa plena antes del año 2010. Este nuevo impulso permitió alcanzar nuevamente un estado nominal de la constelación con cobertura global hacia el final de la década, contando actualmente el sistema con una constelación de 27 satélites en órbita compuesta por 24 vehículos activos y 3 de repuesto.

Al igual que GPS los satélites GLONASS transmiten en las bandas L1 y L2 del espectro, brindando servicios diferenciados para usuarios civiles y militares. La modulación de datos en GLONASS es diferente de la utilizada en GPS: mientras que en GPS todos los satélites comparten la portadora y utilizan cada uno un código diferente para ensanchar la señal, todos los satélites GLONASS utilizan el mismo código de ensanchamiento de 
espectro pero modulan utilizando una portadora diferente cada uno (un esquema Frequency Division Multiple Access o FDMA). Esto complica levemente el hardware de los receptores del sistema, ya que sus etapas de radiofrecuencia deben poder trabajar con anchos de banda mayores que en el caso GPS. [17][4]

En 1998 la Unión Europea dio arranque al desarrollo del sistema Galileo, un sistema de navegación satelital diseñado específicamente para su utilización por parte del segmento civil. Si bien el plan original apuntaba a lograr capacidad operativa plena en 2008, debido a una serie de dificultades de tipo organizativo y financiero, problemas técnicos, e incluso presiones por parte de otros actores internacionales [18] el proyecto ha sufrido de serie de demoras y se encuentra todavía lejos de alcanzar un estado operacional completo. Según se puede ver en el sitio web la European Space Agency (ESA), la información más actualizada del cronograma de puesta en marcha del sistema dice que durante el año 2015 se espera poner en órbita los primeros 18 satélites del sistema, y para el 2020 los restantes que completan la constelación de 30 vehículos. [19][20]

En un estadío mucho más avanzado que Galileo se encuentra el sistema GNSS perteneciente China, Beidou-2 (previamente llamado COMPASS). Este sistema viene a reemplazar un sistema anterior (Beidou-1), el cual es un sistema de posicionamiento regional que tiene cobertura solamente dentro del territorio de la República Popular China y territorios adyacentes. El nuevo sistema ya se encuentra en condición operativa como sistema regional, cubriendo actualmente Asia y el Pacífico, y está planeado que alcance operatividad global plena en el año 2020 cuando se complete el proceso de puesta en órbita de los satélites del sistema. [20]

Al conjunto de los sistemas de navegación satelital de alcance global actuales (GPS, GLONASS, Galileo, Beidou-2/COMPASS) se los denomina colectivamente sistemas GNSS, por las siglas en inglés para Global Navigation Satellite System. Quedan excluidos de esta categoría otros sistemas menores, como los sistemas de posicionamiento regional QZSS perteneciente a Japón, el IRNSS propiedad de India, y el precursor de Beidou2/COMPASS de China, el sistema Beidou-1.

La coexistencia de todos estos sistemas -globales y regionales- puede analizarse en términos de dos conceptos importantes. El primero es la compatibilidad entre los sistemas, que se define como la capacidad de que varios sistemas de posicionamiento puedan operar en conjunto o por separado sin producir interferencia unos en los otros. Este concepto es de suma importancia dada la tendencia a que la cantidad de sistemas de posicionamiento se incremente en el futuro, aumentando por lo tanto la cantidad de satélites que comparten las bandas más pobladas, como es el caso de L1 y L2. La compatibilidad está dada por los niveles de potencia transmitidos por los satélites, la cantidad de satélites, las frecuencias de portadora utilizadas y la codificación. En este sentido se han firmado múltiples 
acuerdos internacionales para definir criterios de diseño que garanticen la coexistencia entre todos los sistemas, actuales y futuros. [20][21]

El segundo término es la interoperatividad, que es la capacidad de dos o más sistemas de poder brindar a un usuario un servicio conjunto con mejores prestaciones que lo que podría brindar cualquiera de los sistemas individuales por separado. Un ejemplo de interoperatividad ocurre en la utilización de receptores GNSS en el corazón de las grandes ciudades, los llamados cañones urbanos: si bien cualquiera de los sistemas GNSS individuales garantiza por diseño que un receptor de cielo abierto pueda determinar una solución de navegación (posición y velocidad) en cualquier parte del planeta, dentro de las grandes ciudades la propagación de las señales se encuentra obstruida por la edificación circundante, impidiendo a los receptores monosistema adquirir suficientes señales para poder calcular una solución de navegación. En presencia de varios sistemas interoperativos un receptor puede combinar las señales de satélites de diferentes sistemas (como por ejemplo GPS y Galileo) para obtener una solución de navegación conjunta en condiciones donde no hubiese sido posible obtenerla utilizando cualquiera de los dos sistemas de forma individual. En efecto, la capacidad de interoperatividad de varios sistemas GNSS incrementa la disponibilidad del servicio de posicionamiento del Sistema de Sistemas formado por el conjunto de sistemas GNSS. [21].

En su nivel más general se habla de Interoperatividad de Sistema, que consiste simplemente en la posibilidad de calcular una solución de navegación con varios sistemas de forma separada, lo cual trae beneficios en términos de redundancia, reducción de cotas de error, y disponibilidad. En este nivel se puede decir que todos los sistemas de la actualidad son interoperables. Definiciones menos laxas de interoperatividad hablan de Interoperatividad a nivel de Señal, de Marco de Referencia, y Referencia Temporal. [21].

Dos sistemas son interoperativos a nivel de señal si las diferencias en codificación, formas de onda, y estructura de los mensajes transmitidos por sus satélites pueden ser reducidos a un problema de software. Por diseño, las transmisiones de Galileo en las bandas L1 y L5/E5a son interoperativas a nivel de señal con las señales GPS de las mismas bandas; GPS y GLONASS, por otro lado, no lo son, ya que la utilización de FDMA en GLONASS con múltiples frecuencias portadoras hace que las etapas de RF (Radio-Frequency o radio-frecuencia) de los receptores de este sistema sean relativamente más complejas que las de sus contrapartes GPS diseñadas para CDMA.

La interoperatividad a nivel de sistemas de coordenadas requiere que la diferencia entre los sistemas de referencia utilizados por cada sistema GNSS (WGS84 para GPS, PZ90 para GLONASS, y ITRF96 para Galileo) no representen una cantidad significativa 
comparado con el error de las soluciones de navegación de esos sistemas; esta interoperatividad garantiza entonces la comparabilidad entre las soluciones que se pueden obtener por un sistema y otro.

De forma similar, la utilización de referencias temporales individuales para cada sistema GNSS mantenidas por sus respectivos Segmentos de Control (la Hora GPS, Hora GLONASS y la Hora Galileo) requiere de una definición de compatibilidad en este sentido que provea de herramientas a los diseñadores de receptores para determinar la relación entre unas referencias y otras.

Con el fin de mantener acotada la extensión de esta introducción en las siguientes secciones la discusión se restringirá a los sistemas que son de mayor interés para el presente trabajo, GPS y GLONASS, poniendo sobre todo énfasis en sus servicios de aplicación civil.

\subsection{Sistema NAVSTAR GPS}

\subsubsection{Estructura}

El sistema NAVSTAR GPS es el sistema de posicionamiento global por satélite más antiguo. Con cuarenta años de historia y más de 20 de operación ininterrumpida es el más maduro de los sistemas GNSS existentes en la actualidad. El control del sistema GPS se encuentra bajo la órbita del GPSW (Global Positioning System Wing) ${ }^{1}$, que a su vez es una dependencia de la USAF (US Air force).

El sistema puede dividirse en tres partes principales, llamados segmentos: el Segmento Espacial, el Segmento de Control, y el Segmento de Usuario.

\subsubsection{Segmento de control}

El Segmento de Control GPS se encuentra compuesto por una red de instalaciones terrestres encargadas del control operativo de la constelación, seguimiento de la trayectoria de los satélites, monitoreo de su estado, predicción de órbitas, y actualización de los mensajes de navegación transmitidos por los satélites. Actualmente el Segmento de Control está formado por una Estación de Control Maestra, una Estación de Control Maestra Alternativa, doce Estaciones de Comando y Control y dieciséis Estaciones de Monitoreo Remoto.

\footnotetext{
${ }^{1}$ Previamente llamado GPS JPO (GPS Joint Program Office)
} 
La estación de Control Maestra se encarga del procesamiento de los datos recopilados por todas las demás estaciones, la determinación de la trayectoria de todos los satélites de la constelación, y la generación de los mensajes de navegación (almanaques, efemérides y correcciones de reloj) que deben ser cargados en la memoria de los satélites periódicamente. Además la Estación de Control Maestra tiene a su cargo el mantenimiento del patrón de tiempo del sistema, llamado la Hora GPS, y la sincronización de los patrones atómicos de todos los satélites del sistema contra dicha referencia.

Las estaciones de Comando y Control distribuidas por todo el planeta realizan mediciones de rango y deltarango (distancia geométrica y su tasa de variación, respectivamente) a todos los satélites en vista y las envían a la Estación de Control Maestra para su procesamiento, a la vez que reciben los comandos y mensajes de navegación generados por esta última y realizan la carga hacia los satélites a través de antenas de comunicación de Banda S.

Por último, las Estaciones de Monitoreo Remoto también realizan mediciones del rango y deltarango de los satélites para enviarlas a la Estación de Control Maestra para su procesamiento, pero a diferencia de las Estaciones de Comando y Control carecen de la posibilidad de enviar comandos a los satélites.

Para lograr una amplia cobertura y una capacidad de monitoreo permanente de todos los satélites de la constelación las estaciones de Comando y Control se encuentran distribuidas a lo largo y ancho de la superficie del planeta. En la Figura 2.1 se puede ver un mapa con la distribución actual de instalaciones del Segmento de Control. [3][22]

\subsubsection{Segmento espacial}

El Segmento Espacial se compone de la totalidad de los satélites del sistema GPS que están orbitando el planeta en un momento dado. El mínimo operativo del sistema se logra con 24 satélites activos en órbita, que es la cantidad mínima necesaria para garantizar que un usuario con un receptor a cielo abierto tenga al menos cuatro satélites en vista en cualquier lugar del planeta y pueda por lo tanto lograr una solución de navegación.

Esta configuración mínima no es conveniente ya que cualquier problema que ocurra durante la operación de uno de los satélites activos provocará problemas de disponibilidad del sistema para los usuarios en tierra. Por esta razón para poder garantizar una condición operativa permanente normalmente la constelación GPS mantiene una cantidad de satélites activos superior a la mínima, además de contar con satélites inactivos en órbita que pueden ser utilizados como repuestos. Este tipo de operatoria permite realizar reemplazos cuando ocurre algún desperfecto, y minimiza así el impacto que puedan tener las operaciones de mantenimiento de la constelación en el nivel de servicio del sistema. 


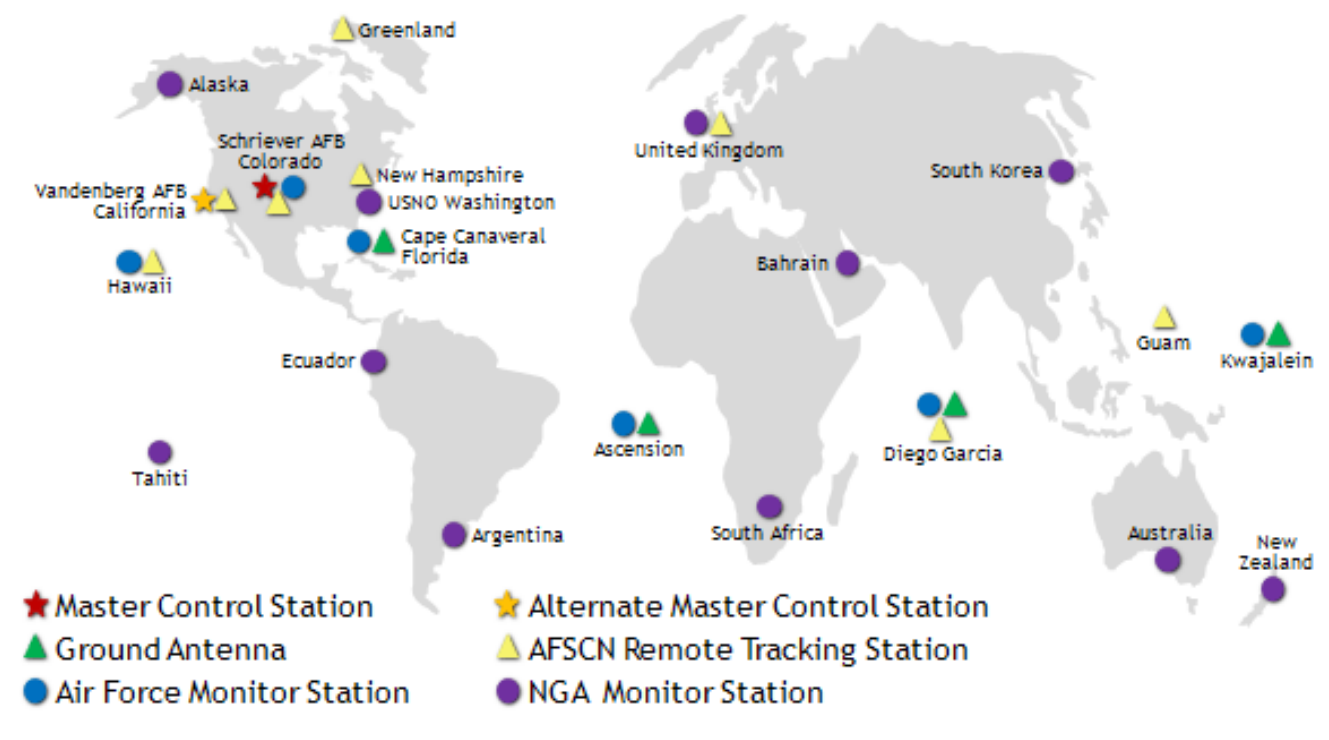

Figura 2.1: Distribución de bases del Segmento de Control, extraída de [22]. En el mapa las Estaciones de Comando y Control están diferenciadas en dedicadas y compartidas. Las primeras son las ubicaciones dedicadas estrictamente al control y monitoreo de los satélites de la constelación GPS; en el mapa están indicados por un círculo azul junto con triángulo verde. Las segundas son instalaciones compartidas que pertenecen a la red AFSCN (Air Force Satellite Control Network); estas últimas se encuentran indicadas mediante triángulos amarillos.

La configuración actual del sistema consta de 27 satélites activos más 4 reemplazos. Estos vehículos se encuentran agrupados en seis planos orbitales diferentes, cada uno de los cuales forma un ángulo de $55^{\circ}$ respecto del Ecuador terrestre, y con rotaciones que están espaciadas a intervalos de $60^{\circ}$. Dentro de cada plano los satélites orbitan la tierra siguiendo trayectorias prácticamente circulares de $26,600 \mathrm{~km}$ de radio y con un período orbital de $11 \mathrm{~h} 58 \mathrm{~m}$.

De acuerdo con la etapa tecnológica a la que pertenecen los satélites, estos se encuentran agrupados en bloques. A la fecha actual ya han existido seis generaciones de satélites diferentes: Bloque I, Bloque II, Bloque IIA, Bloque IIR, Bloque IIR-M, y Bloque IIF. Se encuentra en proceso de diseño la generación siguiente, que será denominada GPS III.

Los satélites del Bloque I fueron los satélites de validación de concepto, mientras que desde el Bloque II en adelante los diseños utilizados son considerados de producción. Los satélites del Bloque I y del II original ya han sido descontinuados por completo, habiendo sido reemplazados por satélites de los bloques más modernos. La constelación actual se encuentra formada por 8 satélites del Bloque IIA, 12 del Bloque IIR, 7 del Bloque IIR-M y 4 del Bloque IIF $^{2}$. Esta diversidad en las generaciones de satélites en

\footnotetext{
${ }^{2}$ En el año transcurrido desde que se escribió esta oración, la constelación siguió renovándose y ahora (mayo de 2015) el recuento es el siguiente: 3 satélites del Bloque IIA, 12 del Bloque IIR, 7 del Bloque IIR-M y 9 del Bloque IIF. Se puede apreciar que a esta tasa de actualización es probable que en los próximos meses los satélites del Bloque IIA sean descontinuados completamente.
} 


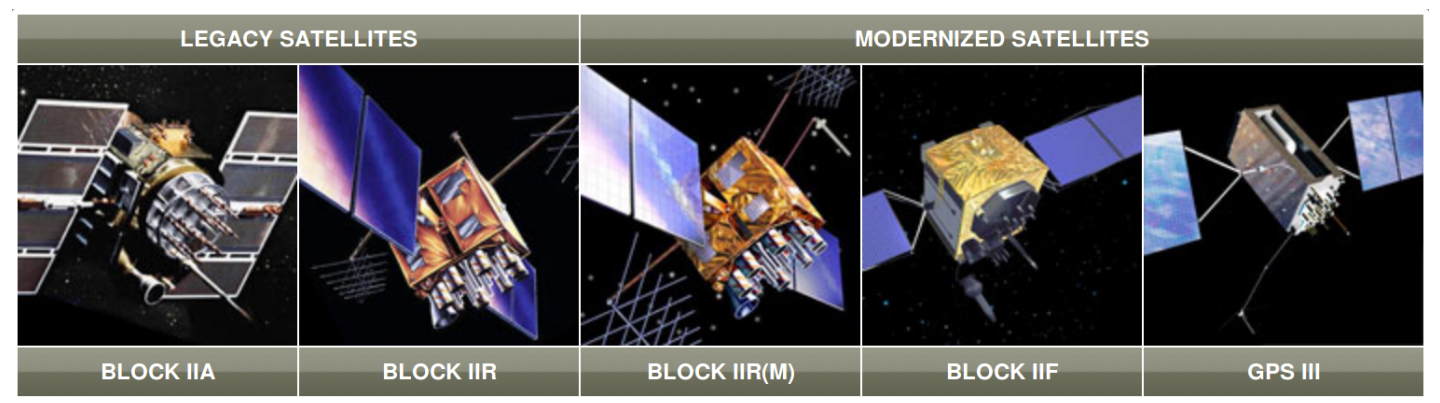

Figura 2.2: Diseño de los satélites de los Bloques IIA, IIR, IIR-M, IIF Y GPS III. Representación tomada de [23]

órbitas se debe a que muchos satélites han alcanzado vidas útiles muy por encima de sus valores de diseño, por lo que la tasa de renovación de la flota se encuentra principalmente determinada por el cronograma de trabajo del esfuerzo de modernización de las señales que será discutido más adelante. Por ejemplo, el último de los satélites del Bloque IIA en ser puesto en órbita entró en actividad en 1997, lo que significa que los 8 satélites de ese bloque que todavía se encuentran en servicio activo llevan al menos 17 años de operación, muy por encima de la vida útil esperada para los vehículos de esa generación que era solamente de 7 años y medio.

Los satélites GPS son esencialmente relojes de muy alta estabilidad en órbita, anunciando de forma continua la hora de a bordo a través de sus transmisiones en las bandas L1, L2 y L5 (esta última sólo presente en los satélites más modernos). Los satélites transmiten también sus parámetros orbitales individuales (llamados efemérides), los parámetros del reloj de a bordo (desviación y deriva respecto de la Hora GPS), y un estado resumido del resto de los satélites de la constelación (llamado almanaque).

La referencia temporal de a bordo proviene de un par de relojes atómicos de muy alta estabilidad, de los cuales se derivan todas las señales utilizadas en las transmisiones (frecuencias de portadoras, tasa de la función de código, tasas de bits, etc.), así como también la hora transmitida por el satélite. [4][23]

Si bien los patrones atómicos utilizados en los relojes de a bordo de todos los satélites son sumamente estables y precisos, es inevitable la existencia de una cierta dispersión en sus características. Debido a esto en un instante dado algunos de los relojes de a bordo se encontrarán adelantados respecto a la hora del sistema y otros atrasados, cuando más no sea por algunos nanosegundos. El Segmento de Control monitorea de forma permanente el estado los relojes atómicos de los satélites para establecer la relación entre la hora de a bordo de cada satélite con la hora GPS oficial, y carga periódicamente en cada satélite los parámetros de un modelo que le permiten al usuario corregir el error del reloj de bordo. El modelo utilizado es una aproximación de segundo orden donde el error en 
la hora de a bordo respecto de la Hora GPS, $\delta(t)$, en las cercanías de un instante de referencia $t_{k}$ es:

$$
\delta(t)=t^{(\mathrm{sat})}-t^{(\mathrm{gps})} \approx b_{t_{k}}+d_{t_{k}}\left(t-t_{k}\right)+\frac{a_{t_{k}}^{2}}{2}\left(t-t_{k}\right)^{2} .
$$

Debido a la estabilidad de los relojes involucrados esta aproximación da resultados satisfactorios durante varias horas alrededor del instante $t_{k}$. En condiciones normales el Segmento de Control actualiza los parámetros de este modelo $\left(t_{k}, b_{t_{k}}, d_{t_{k}}\right.$ y $\left.a_{t_{k}}\right)$ mucho antes de que el error de la aproximación comience a ser apreciable. Usando este modelo los usuarios pueden descontar prácticamente la totalidad del error del reloj de a bordo de todas sus mediciones.

Las estaciones del Segmento de Control también realizan un seguimiento de la trayectoria de cada satélite. Con los datos de trayectoria recopilados por las estaciones terrenas la estación de Control Maestra genera una estimación de la trayectoria futura que seguirá cada satélite, llamada efeméride del satélite, la cual contiene los parámetros de su órbita y permite calcular una estimación de su posición y velocidad en el futuro cercano. Debido a que las efemérides son una predicción basada en parámetros orbitales estimados, el error resultante en la posición y velocidad calculadas aumenta con la antigüedad de las efemérides. Por esta razón, para mantener acotada la magnitud de los errores, la Estación de Control Maestra actualiza las efemérides de todos los satélites varias veces al día.

La Estación de Control Maestra también actualiza periódicamente el llamado Almanaque de la constelación; éste contiene información de baja precisión de la órbita de todos los satélites activos, así como su estado operativo, información de la Hora GPS, relación entre la Hora GPS y UTC, y otra información administrativa. El margen de error admisible para los datos en el Almanaque es mayor que para las efemérides, por lo que su actualización es menos frecuente.

Cada vez que se actualiza la estimación de los parámetros del reloj de a bordo o de las efemérides de un dado satélite, esta información es cargada por el Segmento de Control en la memoria del vehículo cuando este pasa por encima de alguna de las estaciones de Monitoreo y Control. Las actualizaciones al almanaque, comunes a toda la constelación, son cargadas en todos los satélites por medios semejantes. Este proceso de actualización continua garantiza que la información del reloj de a bordo, las efemérides y el almanaque transmitidos por cada satélite siempre son la versión más reciente disponible.

La antena transmisora utilizada en los satélites es una antena direccional cuyo cenit apunta en dirección a la tierra. La apertura del patrón radiación de la antena es tal que permite la recepción de señal en toda la cara del planeta que es visible desde el satélite, 
más una franja circular al alrededor del mismo; esto último permite la utilización de la señal GPS no solamente en sistemas terrestres sino también a bordo de vehículos espaciales que se desplacen por las órbitas más bajas.

Se verá posteriormente que las características de intercorrelación de los códigos CDMA utilizados en la señal GPS hacen deseable que las señales de diferentes satélites arriben a cualquier receptor con valores de potencia aproximadamente semejantes. Por esta razón el patrón de radiación de las antenas transmisoras tiene una pequeña depresión de ganancia en la dirección del cenit, de aproximadamente $2,1 \mathrm{~dB}$ por debajo de la máxima ganancia de la antena. Esta diferencia en la ganancia en el centro compensa la diferencia en la pérdida de espacio libre ${ }^{3}$ que sufren un usuario sobre el punto de la superficie terrestre más cercano al satélite transmisor y otro en la periferia de la cara visible, de forma que ambos reciban la señal del satélite aproximadamente con la misma potencia. $[3][24]$

\subsubsection{Segmento de usuario}

El Segmento de Usuario GPS es la identificación que recibe el conjunto abstracto de todos los receptores capaces de recibir y procesar las señales del sistema GPS, tanto civiles como restringidas. Por sus similaridades con el Segmento de Usuario del sistema GLONASS, la discusión de este segmento se postergará hasta la Sección 2.4 cuando ya se haya realizado la introducción de este último sistema.

\subsubsection{Tiempo GPS}

El Tiempo GPS se indica según el número de semana GPS y la hora dentro de la semana (Time of The Week, TOW). La primer Semana GPS coincidió con las 00hs del Sábado 5 de Enero de 1980 en el marco de tiempo UTC.

El Tiempo UTC no es un patrón temporal monotónicamente creciente, sino que esporádicamente inserta un ajustes (leap seconds) que alargan ${ }^{4}$ la duración de un día en un segundo para compensar las variaciones en la velocidad de giro del planeta. El Tiempo GPS, por otro lado, es rigurosamente monotónico. Esto simplifica la utilización de la base de tiempo GPS, pero también significa que a medida que transcurren los años las bases de tiempo GPS y UTC han divergido por una cantidad entera de segundos: a

\footnotetext{
${ }^{3}$ Reducción de la potencia recibida con el cuadrado de la distancia entre transmisor y receptor.

${ }^{4}$ Estrictamente el ajuste podría también consistir en quitar segundos, pero la tendencia de la tierra es a atrasar.
} 
fines del 2013 el Tiempo GPS se encuentra 16 segundos adelantado respecto de la hora $\mathrm{UTC}^{5} \cdot[25]$

El número de semana GPS indica la cantidad de semanas transcurridas desde el 5 de Enero de 1980. Debido a la diferencia entre los patrones de tiempo UTC y GPS, a fines del 2013 una nueva semana GPS estaba comenzando 16 segundos antes de la medianoche de cada sábado. El TOW, por otro lado, indica la cantidad de segundos transcurridos desde el comienzo de la semana GPS; el rango va por lo tanto de 0 a 604799 segundos.

\subsubsection{Modernización del sistema}

Las generaciones originales de satélites del sistema NAVSTAR GPS transmitían solamente dos tipos de señales distribuidas en las bandas L1 y L2.

- En banda L1 se transmitían en fase con la portadora una señal codificada llamada señal $\mathrm{P}(\mathrm{Y})$, y en cuadratura con ésta otra señal civil de uso público llamada señal $\mathrm{C} / \mathrm{A}$.

- En L2 se transmitía una réplica de la señal codificada $\mathrm{P}(\mathrm{Y})$ en fase con la portadora, pero en cuadratura en lugar de transmitirse la señal C/A se transmitía una portadora sin modulación.

Esta configuración de las señales transmitidas permitía a los usuarios civiles utilizar solamente la señal C/A de banda L1, mientras que los usuarios autorizados podían decodificar señales en ambas bandas L1 y L2.

La capacidad de recepción en dos bandas permite al usuario desafectar por procesamiento conjunto de las señales recibidas a través de ambas una de las principales fuentes de error de la solución de posición y velocidad, el retardo ionosférico. Así, la disponibilidad de la señal $\mathrm{P}(\mathrm{Y})$ en las bandas L1 y L2 permite a los usuarios autorizados mejorar sustancialmente la calidad de la solución de navegación que pueden lograr comparado con lo que puede lograr un usuario civil. La no inclusión de una réplica de la señal civil C/A en la banda L2 fue una medida deliberada tomada con el propósito de no facilitar la utilización del sistema GPS como mecanismo de navegación en armamento que pudiera ser utilizado con intereses contrarios a los de los Estados Unidos por sus adversarios militares.

\footnotetext{
${ }^{5}$ El tiempo UTC está definido a partir de otro patrón de tiempo internacional, el TAI (del francés Temps Atomique International). Al igual que ocurre con el tiempo GPS, el tiempo TAI y el tiempo UTC divergen a medida que este último inserta leap seconds. A fines del 2013 la diferencia era de 35 segundos a favor de TAI. La relación entre tiempo TAI y GPS es invariable por ser ambos ambos monotónicos: el tiempo TAI está siempre 19 segundos adelantado respecto de GPS, ya que esa era la relación entre el tiempo UTC y el tiempo TAI a comienzos de 1980.
} 
May 1 - With Selective Availability

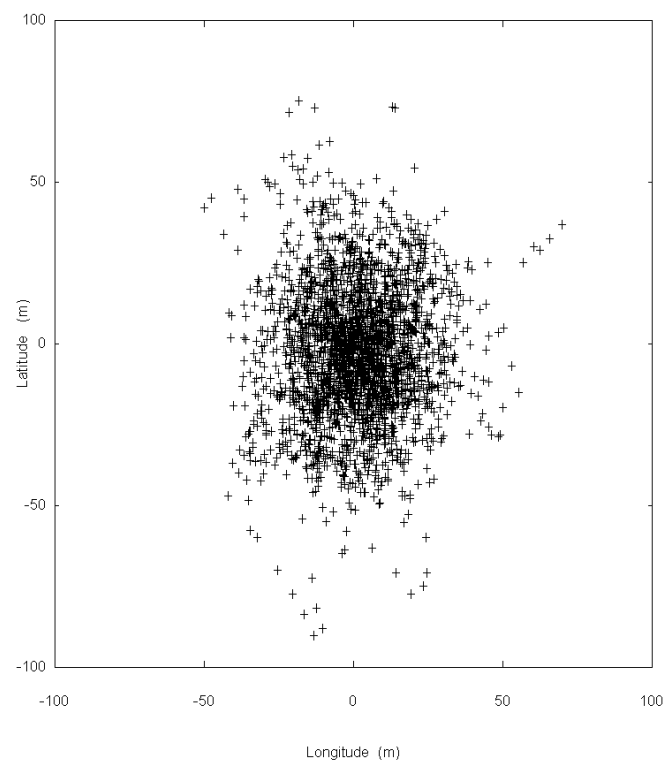

May 3 -- No Selective Availability

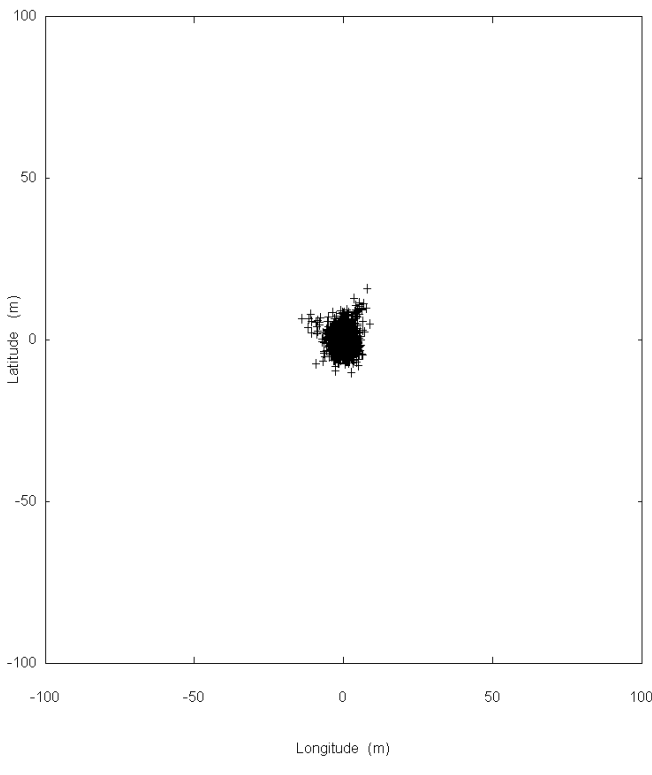

FigurA 2.3: Efecto de la disponibilidad selectiva. A la izquierda, gráfica de nube de los errores en las coordenadas de latitud y longitud en una serie de soluciones de posición obtenidas el día 1ro de Mayo del 2000, antes de que la degradación SA fuera desactivada. A la derecha, la misma gráfica con mediciones realizadas el día 3 de Mayo del 2000, luego de que se desactivara la degradación. [26]

Incluso así el error en la solución de posición de un receptor civil utilizando solamente la señal C/A puede tomar valores inferiores a la decena de metros, por lo que para limitar aún más el valor militar de la señal civil, se incorporó por diseño una degradación intencional llamada Disponibilidad Selectiva (Selective Availability o SA) que permite incrementar artificialmente el error de las soluciones de posición hasta valores del orden de las centenas metros. [4]

En 1998, habiendo ya cubierto el sistema todas sus metas iniciales, se anunció el comienzo de una nueva etapa en el desarrollo del sistema NAVSTAR GPS. Se estableció que esta nueva etapa apuntaría a la modernización del sistema con el objeto de mejorar sus prestaciones para todos los usuarios, a ampliar el campo de aplicación civil y a renovar y expandir la infraestructura del sistema.

En línea con este esfuerzo de modernización del sistema, en mayo del 2000 se anunció que con el objetivo de fomentar de forma inmediata la aplicación del sistema NAVSTAR GPS en aplicaciones civiles, científicas y comerciales, se suspendería de forma indefinida la degradación SA. En la Figura 2.3 se puede ver el efecto que tuvo esta modificación sobre la precisión de las soluciones de navegación. [4][26]

Para el mediano y largo plazo, la renovación del sistema trajo aparejada la creación de un nuevo conjunto de señales que se agregarían a las ya transmitidas anteriormente: 


\begin{tabular}{|c|c|c|c|c|c|c|}
\hline Banda & Portadora & Fase & $\begin{array}{c}\text { Bloque } \\
\text { I, II, IIA }\end{array}$ & $\begin{array}{c}\text { Bloque } \\
\text { IIAM }\end{array}$ & $\begin{array}{c}\text { Bloque } \\
\text { IIF }\end{array}$ & GPS III \\
\hline \hline L1 & $1575,42 \mathrm{MHz}$ & fase & P(Y) & P(Y) & P(Y) & P(Y) \\
\hline L1 & $1575,42 \mathrm{MHz}$ & cuadratura & C/A & $\begin{array}{c}\text { C/A } \\
\text { M-Code }\end{array}$ & $\begin{array}{c}\text { C/A } \\
\text { M-Code }\end{array}$ & $\begin{array}{c}\text { C/A } \\
\text { M-Code } \\
\text { L1C }\end{array}$ \\
\hline L2 & $1227,60 \mathrm{MHz}$ & fase & P(Y) & P(Y) & P(Y) & P(Y) \\
\hline L2 & $1227,60 \mathrm{MHz}$ & cuadratura & - & $\begin{array}{c}\text { L2C } \\
\text { M-Code }\end{array}$ & $\begin{array}{c}\text { L2C } \\
\text { M-Code }\end{array}$ & $\begin{array}{c}\text { L2C } \\
\text { M-Code }\end{array}$ \\
\hline L5 & $1176,45 \mathrm{MHz}$ & fase & - & - & L5 I5 & L5 I5 \\
\hline L5 & $1176,45 \mathrm{MHz}$ & cuadratura & - & - & L5 Q5 & L5 Q5 \\
\hline
\end{tabular}

CUADRo 2.1: Disponibilidad de señales GPS clásicas y modernizadas en función de la generación a la que pertenece el satélites transmisor.

tres nuevas señales civiles, llamadas L1C, L2C y L5, y una señal militar modernizada M-Code. El agregado de la señal L5 en la banda homónima además llevó además la cantidad de las bandas utilizadas por el sistema de dos a tres.

El nuevo conjunto de señales ofrece mejoras en las prestaciones, facilita la utilización de posicionamiento satelital en condiciones de baja relación señal a ruido, permite la recepción doble banda en aplicaciones civiles, provee de tolerancia incrementada en escenarios de interferencia, y además posibilita la utilización de redundancia de señal en aplicaciones críticas, entre otras mejoras. Todas estas señales son compatibles con las señales originales C/A y P(Y) (que pasaron a ser denominadas legacy signals) por lo que los receptores actuales no requieren de modificaciones para funcionar con los satélites modernizados.

En el Cuadro 2.1 se puede ver la distribución de señales en las diferentes portadoras en función de la generación de satélites en que fue incorporada cada una. Como se puede ver en dicho cuadro, la señal L1C todavía no está disponible porque que no existen al día de hoy satélites del Bloque GPS III en órbita. Por otro lado las señales L2C, L5 y M-Code ya se encuentran disponibles, pero son transmitidas solamente por los satélites más modernos.

A medida que la constelación de satélites GPS vaya siendo actualizada se incrementará la cantidad de satélites capaces de transmitir las señales modernizadas. Se estima que las nuevas señales podrán ser consideradas útiles cuando la cantidad de satélites que las transmitan sea de entre 18 y 24. Hasta que se alcance ese punto los receptores actuales seguirán funcionando a partir de las señales legacy, C/A y P(Y). [27] 


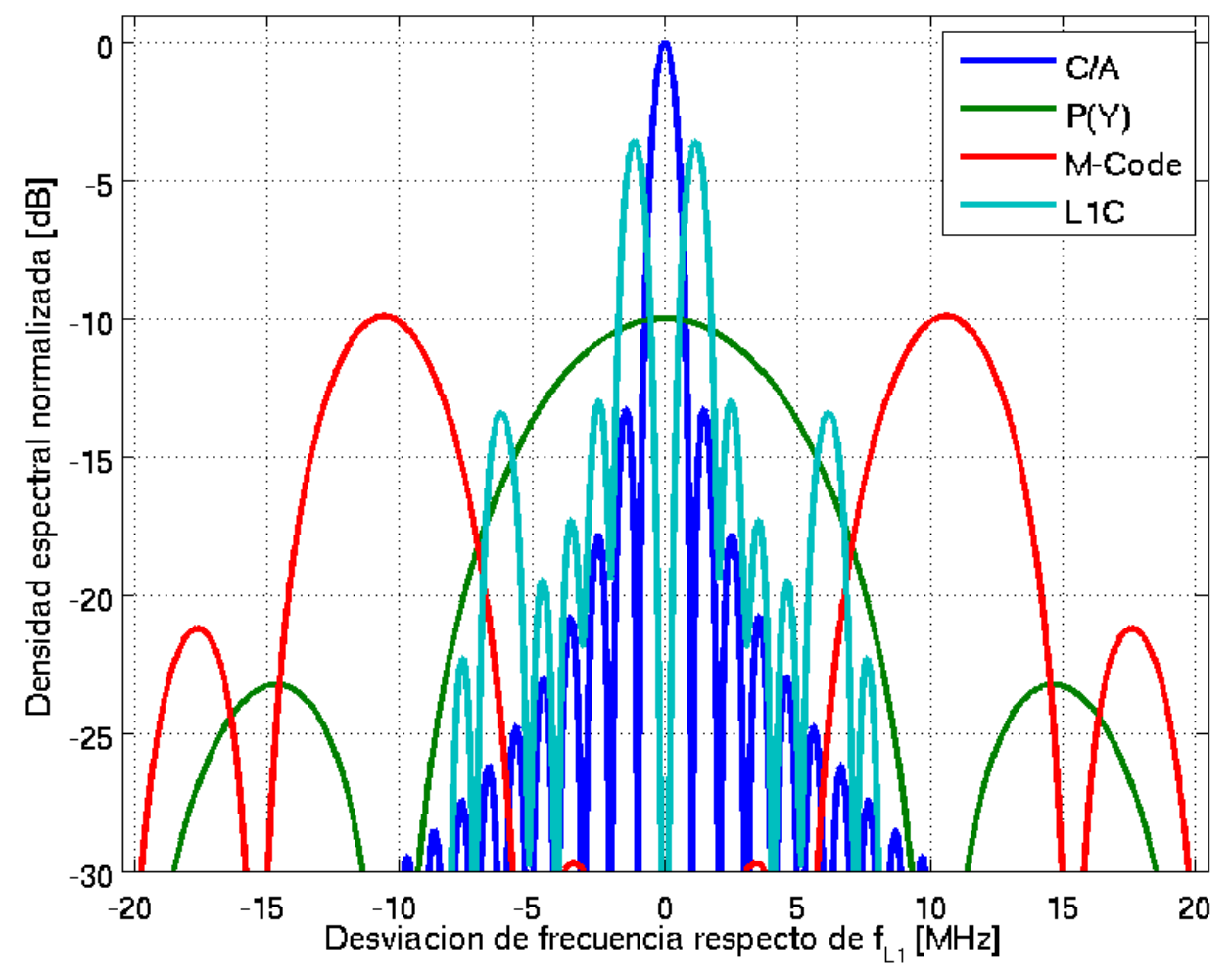

FigurA 2.4: Espectro aproximado de las señales GPS transmitidas a través de la banda L1. Las amplitudes están expresadas en magnitudes relativas a la de la señal C/A. El eje horizontal es relativo a la frecuencia portadora nominal, $f_{L 1}$.

\subsubsection{Señales transmitidas}

Son tres las frecuencias portadoras utilizadas por el sistema, una por cada banda: L1, L2 y L5. Las frecuencias portadoras utilizadas son las mismas para todos los satélites transmisores: $f_{L 1}=1575,42 \mathrm{MHz}$ en L1, $f_{L 2}=1227,60 \mathrm{MHz}$ en L2 y $f_{L 5}=1176,45 \mathrm{MHz}$ en L5. A su vez cada portadora transporta múltiples señales individuales separadas entre sí por fase/cuadratura y por la utilización de codificación para multiplexar la utilización del espectro.

Las señales transmitidas en banda L1 son cuatro: C/A, P(Y), M-Code y L1C. Las dos primeras están presentes desde el diseño original del sistema, la tercera se agregó en el Bloque IIA-M, y la cuarta será agregada en los satélites de Bloque GPS III. El modelo de la señal transmitida en L1 es

$$
\begin{aligned}
s_{L 1}(t)= & A_{p} m_{p}(t) \cos \left(2 \pi f_{L 1} t+\phi\right) \\
& +\left(A_{c a} m_{c a}(t)+A_{m} m_{m}(t)+A_{l 1 c} m_{l 1 c}(t)\right) \sin \left(2 \pi f_{L 1} t+\phi\right)
\end{aligned}
$$




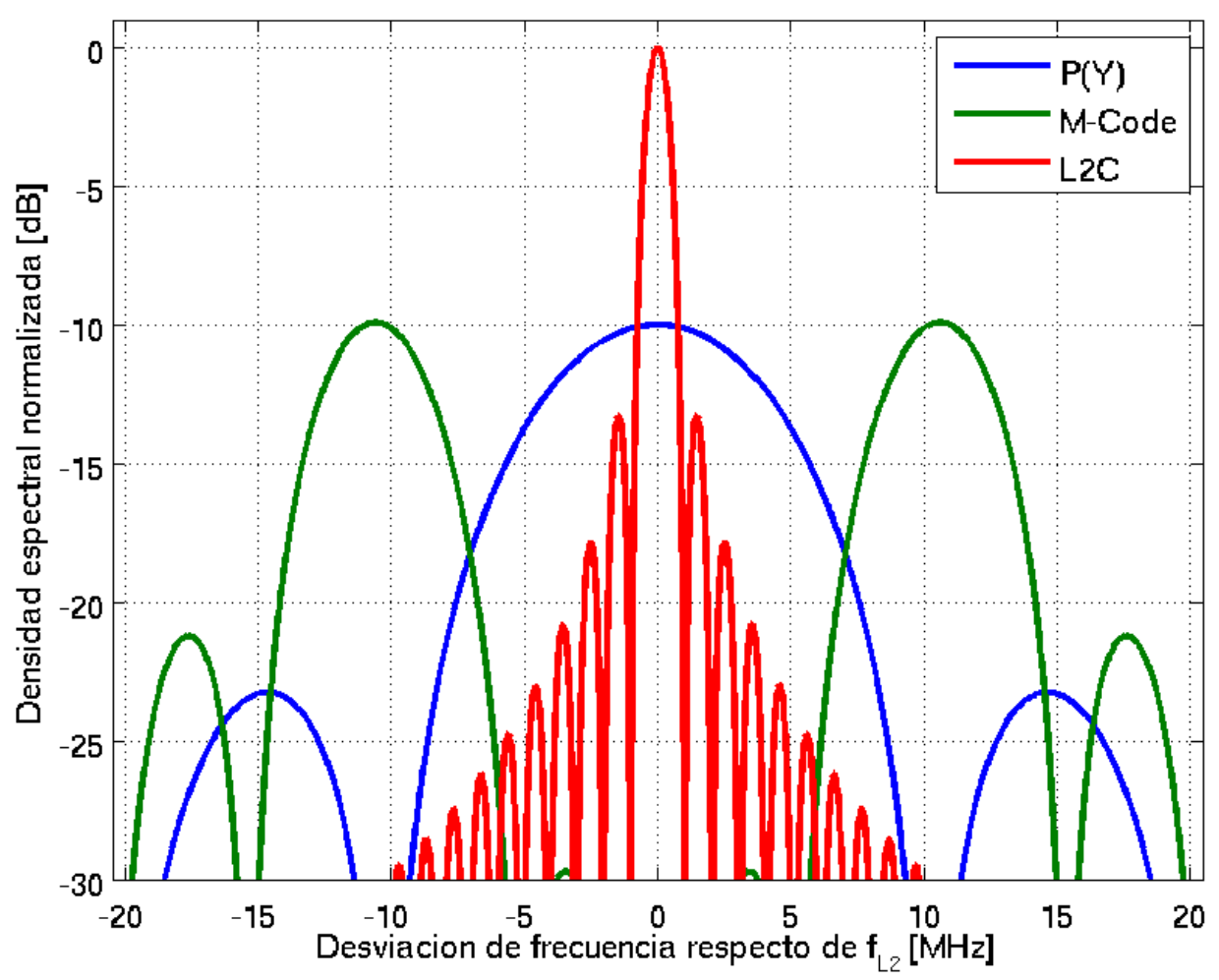

FiguRA 2.5: Espectro aproximado de las señales GPS transmitidas en la banda L2. Las amplitudes están expresadas en magnitudes relativas a la de la señal L2C. El eje horizontal es relativo a la frecuencia portadora nominal, $f_{L 2}$.

donde los coeficientes $A_{p}, A_{c a}, A_{m}, A_{l 1 c}$ modelan las amplitudes (y por lo tanto potencias) con que se transmite cada señal, y los mensajes $m_{p}(t), m_{c a}(t), m_{m}(t), m_{l 1 c}(t)$ representan la señal codificada en banda base correspondiente a cada señal. Se puede ver en el modelo que $\mathrm{P}(\mathrm{Y})$ es transmitida en fase, mientras que las otras tres son moduladas en cuadratura. En la Figura 2.4 se puede ver la densidad espectral resultante.

En la banda L2 se transmiten tres señales: P(Y), M-Code y L2C. Las dos primeras son réplicas de sus señales homólogas transmitidas en la banda L1. El modelo de la señal transmitida es el siguiente:

$$
\begin{aligned}
s_{L 2}(t)= & A_{p} m_{p}(t) \cos \left(2 \pi f_{L 2} t+\phi\right) \\
& +\left(A_{m} m_{m}(t)+A_{l 2 c} m_{l 2 c}(t)\right) \sin \left(2 \pi f_{L 2} t+\phi\right)
\end{aligned}
$$

donde los coeficientes $A_{p}, A_{m}, A_{l 2 c}$ modelan las amplitudes con que es transmitida cada señal, y los mensajes $m_{p}(t), m_{m}(t), m_{l 2 c}(t)$ representan al modelo en banda base correspondiente a cada una. En la Figura 2.5 se puede ver un esquema de la distribución en el espectro de las señales presentes. 


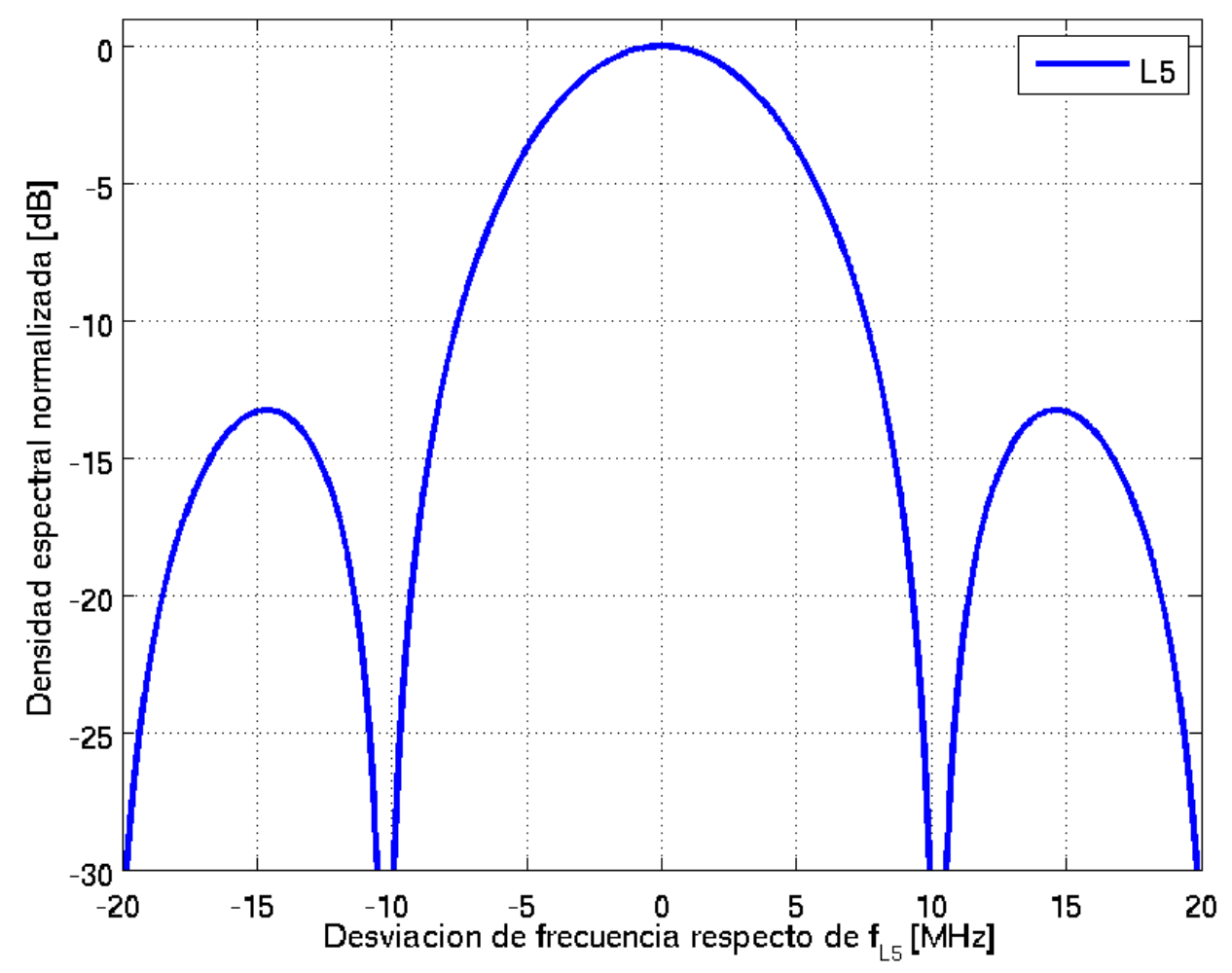

FigurA 2.6: Espectro aproximado de la señal GPS transmitida en la banda L5. Las amplitudes están en magnitudes relativas al centro de la componente de la señal. El eje horizontal es relativo a la frecuencia portadora nominal, $f_{L 5}$.

En la banda L5 se transmite solamente la señal L5. A diferencia de las anteriores esta se encuentra formada por dos canales transmitidos en cuadratura uno con otro: I5 y Q5.

$$
\begin{aligned}
s_{L 2}(t)= & A_{i 5} m_{i 5}(t) \cos \left(2 \pi f_{L 5} t+\phi\right) \\
& +A_{q 5} m_{q 5}(t) \sin \left(2 \pi f_{L 5} t+\phi\right)
\end{aligned}
$$

donde los coeficientes $A_{i 5}$ y $A_{q 5}$ modelan las amplitudes de las componentes fase y cuadratura de la señal L5, y $m_{i 5}(t), m_{q 5}(t)$ son los modelos en banda base de cada una. En la Figura 2.6 se puede ver la densidad espectral de potencia resultante en esta banda.

\subsubsection{Señal $\mathrm{C} / \mathrm{A}$}

La señal C/A es la señal de utilización civil más antigua que forma parte de la especificación del sistema GPS. En banda base la señal C/A se puede expresar como el producto entre una señal de datos $d_{c a}(t)$ y función de código $c_{c a}(t)$.

$$
m_{c a}(t)=d_{c a}(t) c_{c a}(t)
$$


La señal de datos $d_{c a}(t)$ es una secuencia de tipo NRZ antipodal de tasa 50 bps. La función de código $c_{c a}(t)$ es una secuencia periódica de pulsos NRZ de tasa 1,023 MHz y 1023 pulsos de largo, lo que da un período de repetición de $1 \mathrm{~ms}$. El ancho de banda resultante de esta codificación es un espectro pasabajo con un lóbulo principal de $2 \mathrm{MHz}$ de ancho (medido entre ceros); ver Figura 2.4. Para que los satélites compartan el acceso al medio de comunicación sin interferirse mutuamente, las secuencias binarias con las que se genera la función de código de cada satélite son diferentes unas de otras y de muy baja intercorrelación entre sí.

Por su importancia para el presente trabajo la señal C/A será descripta en más detalle en la Sección 2.2.5.

\subsubsection{Señal $P(Y)$}

La señal $\mathrm{P}(\mathrm{Y})$ es una señal de uso restringido a la cual sólo tienen acceso usuarios especialmente autorizados. De forma semejante a la señal $\mathrm{C} / \mathrm{A}$, la señal $\mathrm{P}(\mathrm{Y})$ puede modelarse en banda base como:

$$
m_{p}(t)=d_{p}(t) c_{p}(t)
$$

donde un mensaje de navegación $d_{p}(t)$ es expandido en espectro con una función de código $c_{p}(t)$ de tasa 10,23 MHz llamada código P (por Precise). El mensaje de navegación se encuentra además codificado mediante un código llamado Y que sólo es conocido por los usuarios autorizados. El conjunto de señal expandida y codificada recibe el nombre de código $\mathrm{P}(\mathrm{Y})$.

La tasa de la función de código utilizada hace que el espectro de la señal $\mathrm{P}(\mathrm{Y})$ sea diez veces mayor que el ocupado por la señal $\mathrm{C} / \mathrm{A}$, por lo que un receptor de esta señal debe tener un ancho de banda de entrada de al menos 20,46 MHz para no distorsionar la señal. La secuencia binaria utilizada para generar la función de código es de un largo tal que la función de código tiene un período de repetición de una semana completa. Al igual que en $\mathrm{C} / \mathrm{A}$, cada satélite utiliza una secuencia diferente de los demás para multiplexar el acceso al medio por CDMA.

El mayor ancho de banda de la señal $\mathrm{P}(\mathrm{Y})$ le brinda mayor inmunidad frente a la interferencia de banda angosta, algo que es fundamental dada la aplicación principalmente militar de esta señal, y también permite lograr mejores estimaciones de tiempo de transmisión que su contraparte civil a igual condición de relación señal a ruido en el receptor, mejorando entonces la calidad de las soluciones de navegación que se pueden obtener. 
La decodificación de una señal de espectro expandido requiere que el receptor previamente haya determinado la fase de la función de código utilizada para expandir la señal. En ausencia de otra información, la determinación de esta fase debe realizarse por prueba y error, lo cual consume una cantidad de tiempo que es proporcional a la cantidad de posibilidades a ensayar. Por este motivo, dada la enorme longitud de la función de código utilizada en la señal $\mathrm{P}(\mathrm{Y})$ no es posible su adquisición directa en un tiempo razonable.

Asistir en esta adquisición era la función inicial de la señal C/A (de ahí su nombre, Coarse Acquisition): antes de comenzar la decodificación de la señal $\mathrm{P}(\mathrm{Y})$, un receptor adquiere y decodifica previamente la señal C/A que la acompaña en cuadratura. Dado que la longitud de la secuencia utilizada en la función de código de la señal C/A es mucho más corta (1023 chips), la determinación por prueba y error de la fase de su función de código puede realizarse en un tiempo reducido.

Una vez decodificada la señal C/A el receptor puede determinar el TOW con una exactitud de décimas de nanosegundos. Dado que por diseño la fase cero de la función de código $\mathrm{P}(\mathrm{Y})$ coincide con el comienzo de la semana GPS, el conocimiento del TOW permite acotar los posibles valores de fase de la función de código $\mathrm{P}(\mathrm{Y})$ y así reducir enormemente el tiempo de búsqueda ${ }^{6}$.

La señal $\mathrm{P}(\mathrm{Y})$ se transmite tanto en la banda L1 como en la banda L2. Como se anticipó anteriormente, la razón de esta redundancia es permitir a los usuarios de $\mathrm{P}(\mathrm{Y})$ eliminar el error por retardo ionosférico de las soluciones de navegación. Este último es un retardo adicional, dependiente de las condiciones atmosféricas, que aparece en la propagación de la señal de radiofrecuencia entre el satélite y el usuario debido a que una vez que la señal entra en la atmósfera la velocidad de la onda se reduce por debajo de la velocidad de la luz. Adicionalmente, la disponibilidad de la señal $\mathrm{P}(\mathrm{Y})$ en dos bandas separadas incrementa la tolerancia del sistema frente interferencias que afecten alguna de ellas.

\subsubsection{Señal M-Code}

La señal M-Code se encuentra presente en los satélites desde el Bloque IIA-M en adelante. Es una nueva señal de aplicación militar que reemplazará a la señal $\mathrm{P}(\mathrm{Y})$ una vez que se haya completado el proceso de renovación de los satélites de las generaciones más antiguas.

Esta señal, además de contar con un mensaje de navegación $d_{m}(t)$ y una función de código $c_{m}(t)$, utiliza también una subportadora de onda cuadrada $p_{m}(t)$. El modelo de

\footnotetext{
${ }^{6}$ Por supuesto, si el receptor cuenta con un medio alternativo para determinar el TOW el paso intermedio de la adquisición del código $\mathrm{C} / \mathrm{A}$ puede ser eliminado.
} 
la señal en banda base es

$$
m_{m}(t)=d_{m}(t) c_{m}(t) p_{m}(t)
$$

La codificación de la señal M-Code pertenece a la familia BOC (Binary Offset Carrier), siendo más concretamente una codificación $\operatorname{BOC}(10,5)$. Esto último significa que la subportadora $p_{m}(t)$ es una señal cuadrada de tasa de $10 \times 1,023 \mathrm{MHz}$, y la función de código $c_{m}(t)$ es de tasa $5 \times 1,023 \mathrm{MHz}$. Esta subportadora provoca una conformación de tipo pasabanda en el espectro de la señal M-Code que reduce el solapamiento con las otras señales transmitidas en la misma banda; ver Figura 2.4. [28]

Esta distribución espectral tiene varias ventajas. Desde una perspectiva defensiva, le permite a la Estación de Control Maestra elevar la potencia de M-Code transmitida por los satélites GPS sobre alguna región de conflicto (por ejemplo, para minimizar el impacto de una eventual interferencia intencional) sin crear interferencia para los usuarios de las demás señales del sistema en otras regiones.

Por otro lado, desde una perspectiva ofensiva, esta distribución le permite a los Estados Unidos introducir interferencia en la banda de las señales civiles de L1 sin comprometer la integridad de su propia señal militar ${ }^{7}$.

Al igual que ocurre con la señal $\mathrm{P}(\mathrm{Y})$, la señal M-Code es transmitida tanto en banda L1 como en banda L2. Las razones de esto ya fueron discutidas anteriormente y no serán repetidas aquí.

\subsubsection{Señal L1C}

La señal L1C es la futura versión de la señal civil GPS en banda L1 destinada a reemplazar a la señal C/A una vez que se complete el período de transición de los satélites legacy a los que transmiten las señales modernizadas.

La codificación de la señal L1C usa una codificación similar al de la señal M-Code, con una subportadora piloto agregada a la mezcla para producir un desplazamiento espectral de la señal respecto del centro de la banda. La potencia de señal se encuentra dividida en dos canales: el $25 \%$ de la potencia de señal se utiliza para transmitir un canal con

\footnotetext{
${ }^{7}$ Galileo y las señales de GLONASS modernizadas tienden a elegir la misma banda de frecuencias que la señal C/A para sus transmisiones civiles con el fin de simplificar la compatibilidad de las etapas de radiofrecuencia de los futuros receptores multisistema. Eso también significa que interferir la banda próxima a la frecuencia portadora de L1 interfiere no sólo con GPS civil, sino también GLONASS y Galileo, dejando al adversario sin la posibilidad de utilizar ningún tipo de posicionamiento satelital. Conservar esta ventaja ofensiva fue una de las razones por las que el proceso de diseño de Galileo se viera obstruido por fuertes presiones por parte de Estados Unidos. [18]
} 
modulación de datos y codificación $\mathrm{BOC}(1,1)$, mientras que el $75 \%$ restante se usa para transmitir un segundo canal dataless con codificación TMBOC (Time Multiplexed $B O C)$. La codificación TMBOC de este último multiplexa en el tiempo la utilización de $\operatorname{BOC}(1,1)$ y $\operatorname{BOC}(6,1)$.

La utilización de canales separados con y sin modulación de datos es una técnica que repiten otras señales modernizadas como la L2C y la L5. Es una mejora frente a las señales clásicas, en particular $\mathrm{C} / \mathrm{A}$, donde la presencia de la secuencia de datos introduce una serie de dificultades de procesamiento que limitan su utilización en escenarios de baja relación señal a ruido (SNR, Signal-to-Noise Ratio).

Al dividir la señal en dos canales, uno con modulación de datos y otro sin ella, L1C extiende los límites de operación del sistema. Se simplifica la adquisición de señales con muy baja SNR, y el umbral funcionamiento de los lazos de estimación de fase de portadora mejora $6 \mathrm{~dB}$. Alternativamente, en igualdad de condiciones de nivel de potencia de señal, un receptor L1C puede soportar escenarios de operación con mayor dinámica (velocidades y aceleraciones altas del vehículo) que $\mathrm{C} / \mathrm{A}$; esto es importante en el caso de receptores utilizados en vehículos rápidos, como ocurre en aeronáutica y en aplicaciones aeroespaciales. [29][30]

\subsubsection{Señal L2C}

Es la señal modernizada para aplicaciones civiles en banda L2. Se encuentra presente en los satélites de las generaciones del Bloque IIA-M en adelante. Es la primera señal GPS para uso civil fuera de la banda L1 (la implementación de L5 fue posterior), y su introducción permitió el desarrollo irrestricto de receptores doble banda capaces de eliminar el error ionosférico de las soluciones de navegación, algo que previamente sólo podían hacer los usuarios autorizados utilizando la señal $\mathrm{P}(\mathrm{Y})$.

Espectralmente la señal L2C es semejante a C/A. Su ancho de banda (entre ceros del lóbulo principal) es de $2,046 \mathrm{MHz}$ y los niveles de potencia transmitidos son similares. $\mathrm{Su}$ codificación, sin embargo, es totalmente diferente. Al igual que L1C y L5, la señal L2C separa la potencia transmitida en un canal con modulación de datos y otro sin ella, pero a diferencia de lo que ocurre en las otras señales estos dos canales se transmiten multiplexados en el tiempo.

La generación de la señal transmitida puede resumirse de la siguiente forma: 
- El mensaje de navegación de 25 bps atraviesa un codificador convolucional de tasa 1/2. La señal de 50 bps resultante es utilizada para modular la salida de un generador que sintetiza una función de código de tasa $511,5 \mathrm{kHz}$ y período 10230 chips llamada código $C M$.

- Otro generador sintetiza una segunda función de código, de la misma tasa $511,5 \mathrm{kHz}$ pero con período mayor que la anterior (767,250 chips). Esta segunda función de código recibe el nombre de código $C L$.

- Tanto el código $C M$ modulado con datos, como el código $C L$ entran a un multiplexor que los alterna chip a chip a una tasa de 1,023 MHz. La salida de este multiplexor es la señal L2C en banda base.

De acuerdo con lo anterior, la potencia transmitida se reparte en mitades iguales entre el canal $C M$ y el código $C L$, por lo que cada uno tiene la mitad de la potencia que $C / A$. Sin embargo, la utilización de un canal sin modulación de datos y la codificación de canal de tasa $1 / 2$ del mensaje de navegación permiten a L2C funcionar en condiciones de relación señal a ruido más bajas que lo que era posible con el código $\mathrm{C} / \mathrm{A}$.

\subsubsection{Señal L5}

La utilización de la banda L5 para transmisión de señales GPS es una novedad que se agregó en los satélites del Bloque IIF. Esta es una banda destinada a ser utilizada exclusivamente para aplicaciones aeronáuticas, que es justamente el segmento al que está orientada la señal homónima.

Como se dijo anteriormente, la señal L5 está formada por dos canales transmitidos en cuadratura uno con el otro sobre la misma portadora. La componente en fase recibe el nombre I5 y la componente en cuadratura Q5. La señal I5 es un canal con modulación de datos $d_{i 5}(t)$ por donde se transmite el mensaje de navegación del satélite; Q5 en cambio es un canal piloto cuya presencia mejor el desempeño de la señal en condiciones de muy baja SNR.

$$
\begin{aligned}
& m_{i 5}(t)=d_{i 5}(t) c_{i 5}(t) n_{i 5}(t) \\
& m_{q 5}(t)=c_{q 5}(t) n_{q 5}(t)
\end{aligned}
$$

Ambos canales están expandidos utilizando funciones de código $c_{i 5}(t) / c_{q 5}(t)$ de longitud 10230 chips y tasa 10,23 MHz. Esto le da a la señal un espectro similar al de P(Y), con un lóbulo central de ancho 20,46MHz. La densidad espectral de la señal en esta banda se puede ver en la Figura 2.6. La potencia transmitida se divide por igual entre los canales 
I5 y Q5, y es superior en 0,6 dB a la de la señal C/A transmitida en L1. Las funciones de código utilizadas en uno y otro canal son diferentes y ortogonales entre sí para permitir la identificación de los canales. [31]

Ambas señales cuentan con un nivel de estructura adicional, ya que éstas se encuentran moduladas con sendas secuencias Neumann-Hoffman, $n_{i 5}(t)$ y $n_{q 5}(t)$. La secuencia que acompaña a I5 es de largo 10, mientras que la que acompaña a Q5 es de largo 20. En ambos casos la secuencia tiene una tasa de avance de $1 \mathrm{kHz}$ sincronizada con los comienzos de cada período de las funciones de código de los respectivos canales. Su presencia mejora las características de correlación cruzada de las funciones de código utilizadas para expandir el espectro, y simplifican la detección de los instantes de comienzo y fin de los bits del mensaje de navegación durante la sincronización inicial. [32]

\subsubsection{Estructura de la señal señal $\mathrm{C} / \mathrm{A}$}

Es mucho lo que se puede decir sobre la modulación y sobre el mensaje de navegación de la señal C/A transmitida por los satélites GPS. Para mantener acotada la extensión de este capítulo se limitará la descripción a aquellos puntos que son más relevantes para el presente trabajo de tesis: modulación utilizada, estructura del mensaje de navegación, relaciones de sincronismo y codificación del tiempo de transmisión en la señal.

El lector interesado puede encontrar la descripción más completa de la modulación y de la estructura de su mensaje de navegación en el documento de definición del interfaz que está indicado en la referencia [2]. Una discusión acabada del diseño de la señal y la discusión de sus características puede encontrarse en la referencia bibliográfica [3].

\subsubsection{Función de código}

La señal C/A se encuentra formada por un mensaje de navegación $d_{c a}$, de codificación NRZ bipolar y tasa de 50 bps, acompañado de una función periódica de expansión de espectro $c_{c a}(t)$ llamada función de código:

$$
m_{c a}(t)=d_{c a}(t) c_{c a}(t)
$$

La función de código $c_{c a}(t)$ tiene la misión de ensanchar el espectro de la señal de datos, mejorar la tolerancia ante interferencia no intencional de banda angosta, y además permitir a varios satélites compartir el canal de transmisión (espectro de radiofrecuencia) manteniendo acotada la interferencia mutua. Está formada por una secuencia de pulsos NRZ bipolares de longitud finita y periódica. Cada pulso de la secuencia recibe el nombre 


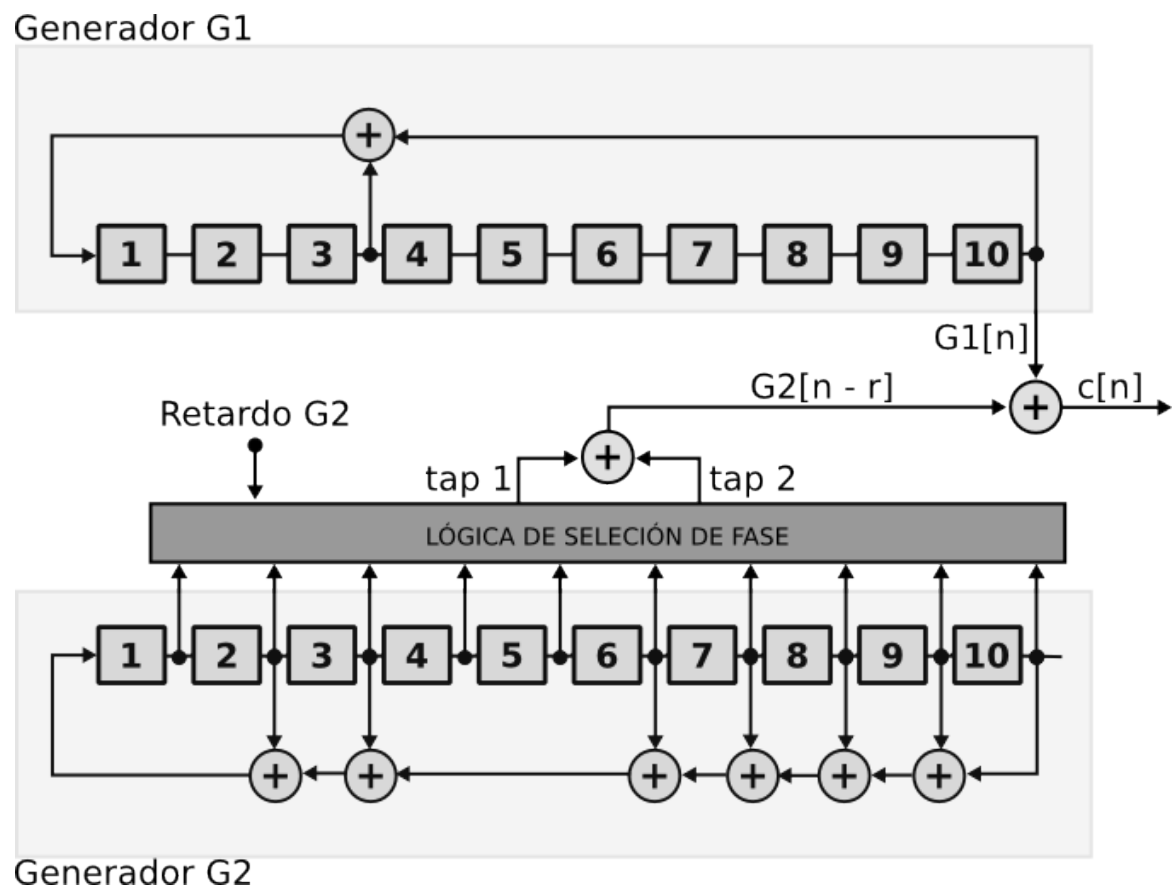

Figura 2.7: Diagrama de los generadores de código Gold utilizados para generar la función de expansión de espectro del código C/A.

de chip, para distinguirlos de los pulsos de datos. La secuencia de valores binarios que toman los chips es una secuencia periódica de largo 1023 y tasa de avance 1,023 MHz, por lo que la secuencia se repite a intervalos de $1 \mathrm{~ms}$.

La secuencia de valores binarios utilizada en la función de código no acarrea información en sí misma, sino que está elegida por sus propiedades espectrales y estadísticas, similares a las de una secuencia binaria aleatoria. Para la señal GPS C/A las secuencias utilizadas pertenecen a una familia de secuencias llamadas Secuencias Gold. Cada satélite GPS tiene asignada su propia secuencia Gold individual diferente de la de todos los demás satélites, la cual es referida por un identificador llamado número PRN (Pseudo-Random Number).

Las secuencias Gold son una familia de secuencias binarias que aunque no cumplen estrictamente con todos los requisitos para ser consideradas secuencias pseudoaleatorias, tienen propiedades estadísticas muy similares a estas últimas, y poseen excelentes propiedades de auto e intercorrelación entre sí. Esto último es crítico para la señal $\mathrm{C} / \mathrm{A}$ ya que como se verá más adelante la característica de autocorrelación de la función de código es fundamental para la obtención precisa de las mediciones de tiempo de transmisión de la señal, y una baja intercorrelación le otorga ortogonalidad a las funciones de código de diferentes satélites transmisores y permite a todos los satélites transmitir sobre la misma banda sin interferirse mutuamente de forma apreciable. 
Las secuencias Gold se generan mediante un esquema formado por dos generadores de secuencias de largo máximo, llamados G1 y G2, tal como se ve en la Figura 2.7. Ambos generadores están conformados por un registro de desplazamiento de 10 bits con realimentación.

Un generador de secuencias de $n$ bits puede ser entendido como una máquina de estados con $2^{n}$ estados posibles, donde el estado está identificado por el contenido de las memorias del registro de desplazamiento. Un generador de este tipo se dice que es de máximo largo si la realimentación es tal que se garantiza que para cualquier estado inicial no nulo (es decir, al menos uno de los bits de registro de desplazamiento es diferente de cero), la máquina de estado itera por los $2^{n}-1$ estados no nulos antes de volver al estado del que partió. El estado que queda fuera de este ciclo es el estado nulo, donde todos los bits del registro de desplazamiento son cero. Se puede ver fácilmente que en una máquina de estados de este tipo, cuyo progreso está regulado por la realimentación, desde el estado nulo no puede alcanzarse ningún otro estado salvo sí mismo.

En el caso de G1 y G2, generadores de secuencias de largo máximo de 10 bits de ancho cada uno, es fácil entender que si se inicializan sus registros de desplazamiento con cualquier valor no nulo estos emitirán secuencia periódica de 1023 bits de largo en su salida.

Los códigos Gold son un subconjunto de las secuencias periódicas que pueden obtenerse al hacer variar la fase inicial de G2 y sumar (módulo 2) las salidas de ambos generadores. Se logran inicializando el registro de desplazamiento de G1 en el estado 1111111111 (denominado estado inicial), y el registro de desplazamiento de G2 de forma tal que alcance su estado inicial dentro de $r$ ciclos. El valor $r$ es entonces el atraso inicial del generador G2 respecto de G1. La secuencia Gold es la que se obtiene al sumar módulo-2 (es decir, utilizando la operación XOR) las salidas de ambos registros de desplazamiento durante las siguientes 1023 iteraciones. De todos los atrasos iniciales posibles, se utilizan para generar códigos Gold solamente el subconjunto de valores de $r$ que da lugar a secuencias con buenas propiedades de auto e intercorrelación. Una secuencia Gold queda entonces definida de forma biunívoca por el atraso inicial $r$.

Las secuencias de máximo largo como las generadas por G1 y G2 tienen una propiedad peculiar: si se suma módulo-2 una secuencia de máximo largo con una versión desplazada circularmente de sí misma, la secuencia resultante es también una versión desplazada circularmente de la original. Esta propiedad se explota en los códigos Gold mediante un esquema como el de la Figura 2.7, donde la salida del generador G2 no se toma de la salida del décimo bit del registro de desplazamiento, sino que proviene de una lógica de selección de fase que tiene acceso a las salidas de las 10 etapas del registro de desplazamiento de G2. En este esquema ambos generadores se inicializan en el estado 11 
11111111 y el atraso relativo de la secuencia G2 respecto de G1 se obtiene mediante la lógica de selección de fase. Para ello esta lógica selecciona dos taps (salidas de las etapas intermedias del registro de desplazamiento de G2) tales que la suma de sus secuencias resulte en una versión de la secuencia G2 con el atraso $r$ deseado.

En el Cuadro 2.2 se pueden ver las secuencias Gold asignadas a cada número PRN y a cada satélite. Allí mismo se pueden ver también el retardo de G2 respecto de G1 que corresponde a esa secuencia particular, y en una columna aparte se indican los taps que deben sumarse para obtener ese retardo.

\subsubsection{Mensaje de navegación}

El mensaje de navegación se transmite como una secuencia de pulsos NRZ bipolares de tasa 50 bps. Ver Figura 2.8. La información presente en dichos pulsos se encuentra estructurada a varios niveles.

La unidad de datos mínima es la palabra, formada por 30 bits consecutivos. 10 palabras forman una subtrama, y cinco subtramas son una trama. Por último, 25 tramas forman una supertrama. A $50 \mathrm{bps}$, el satélite transmite una palabra cada $0,6 \mathrm{~s}$, una subtrama cada $6 \mathrm{~s}$, una trama cada $30 \mathrm{~s}$ y una supertrama cada $12,5 \mathrm{~m}$.

Cada palabra está formada por 24 bits de datos y los restantes corresponden un código de detección y corrección de errores de tipo Hamming extendido $(32,24)$. Este código tiene distancia de Hamming mínima de 4 por lo que es posible detectar y corregir errores simples y detectar errores dobles, o alternativamente detectar errores simples, dobles y triples. [3]

En el siguiente nivel, diez palabras consecutivas forman una subtrama. Éstas se encuentran numeradas I, II, III, IV y V, según el orden que son transmitidas. Cada subtrama

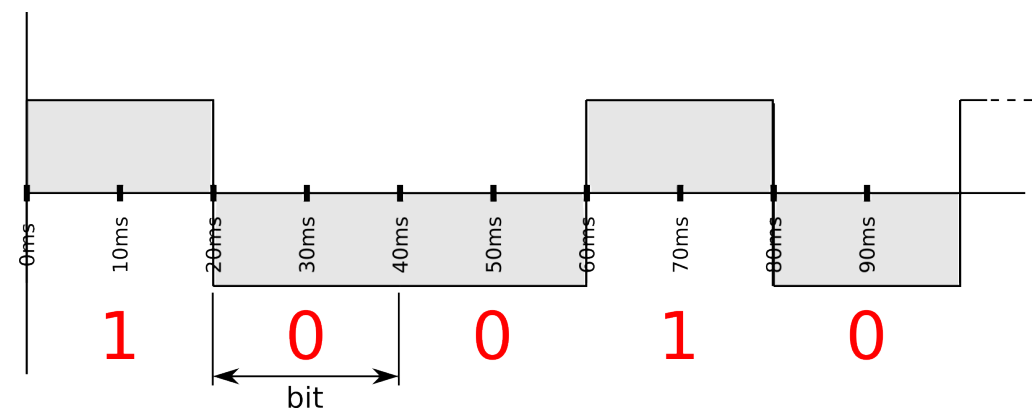

FIGURA 2.8: Codificación NRZ bipolar de 50 bps utilizada para transmitir el mensaje de navegación GPS. 


\begin{tabular}{|c|c|c|c|c|}
\hline $\begin{array}{c}\text { Identificador } \\
\text { de Satélite }\end{array}$ & $\begin{array}{c}\text { Identificador } \\
\text { de PRN }\end{array}$ & $\begin{array}{l}\text { G2 } \\
\text { Taps }\end{array}$ & $\begin{array}{c}\text { Retardo } \\
\text { de G2 }\end{array}$ & $\begin{array}{c}\text { Primeros } 10 \text { chips } \\
\text { C/A (octal) }\end{array}$ \\
\hline 1 & 1 & $2 \oplus 6$ & 5 & 1440 \\
\hline 2 & 2 & $3 \oplus 7$ & 6 & 1620 \\
\hline 3 & 3 & $4 \oplus 8$ & 7 & 1710 \\
\hline 4 & 4 & $5 \oplus 9$ & 8 & 1744 \\
\hline 5 & 5 & $1 \oplus 9$ & 17 & 1133 \\
\hline 6 & 6 & $2 \oplus 10$ & 18 & 1455 \\
\hline 7 & 7 & $1 \oplus 8$ & 139 & 1131 \\
\hline 8 & 8 & $2 \oplus 9$ & 140 & 1454 \\
\hline 9 & 9 & $3 \oplus 10$ & 141 & 1626 \\
\hline 10 & 10 & $2 \oplus 3$ & 251 & 1504 \\
\hline 11 & 11 & $3 \oplus 4$ & 252 & 1642 \\
\hline 12 & 12 & $5 \oplus 6$ & 254 & 1750 \\
\hline 13 & 13 & $6 \oplus 7$ & 255 & 1764 \\
\hline 14 & 14 & $7 \oplus 8$ & 256 & 1772 \\
\hline 15 & 15 & $8 \oplus 9$ & 257 & 1775 \\
\hline 16 & 16 & $9 \oplus 10$ & 258 & 1776 \\
\hline 17 & 17 & $1 \oplus 4$ & 469 & 1156 \\
\hline 18 & 18 & $2 \oplus 5$ & 470 & 1467 \\
\hline 19 & 19 & $3 \oplus 6$ & 471 & 1633 \\
\hline 20 & 20 & $4 \oplus 7$ & 472 & 1715 \\
\hline 21 & 21 & $5 \oplus 8$ & 473 & 1746 \\
\hline 22 & 22 & $6 \oplus 9$ & 474 & 1763 \\
\hline 23 & 23 & $1 \oplus 3$ & 509 & 1063 \\
\hline 24 & 24 & $4 \oplus 6$ & 512 & 1706 \\
\hline 25 & 25 & $5 \oplus 7$ & 513 & 1743 \\
\hline 26 & 26 & $6 \oplus 8$ & 514 & 1761 \\
\hline 27 & 27 & $7 \oplus 9$ & 515 & 1770 \\
\hline 28 & 28 & $8 \oplus 10$ & 516 & 1774 \\
\hline 29 & 29 & $1 \oplus 6$ & 859 & 1127 \\
\hline 30 & 30 & $2 \oplus 7$ & 860 & 1453 \\
\hline 31 & 31 & $3 \oplus 8$ & 861 & 1625 \\
\hline 32 & 32 & $3 \oplus 8$ & 862 & 1712 \\
\hline$\star$ & 33 & $5 \oplus 10$ & 863 & 1745 \\
\hline$\star$ & $34^{*}$ & $4 \oplus 10$ & 950 & 1713 \\
\hline$\star$ & 35 & $1 \oplus 7$ & 947 & 1134 \\
\hline$\star$ & 36 & $2 \oplus 8$ & 948 & 1456 \\
\hline$\star$ & $37^{*}$ & $4 \oplus 10$ & 950 & 1713 \\
\hline
\end{tabular}

CuAdro 2.2: Parámetros de generación de los códigos Gold utilizados en GPS C/A. 
tiene un formato propio: Las subtramas I, II y III se utilizan principalmente para transportar los parámetros de corrección del reloj de a bordo y los datos de la efeméride más reciente del satélite transmisor, mientras que las subtramas IV y V se utilizan para transmitir otra información útil como lo son los parámetros de un modelo ionosférico, el almanaque, estado de la constelación, información sobre los leap seconds, entre otras cosas. Las subtramas se transmiten en orden, repitiéndose cíclicamente.

Para facilitar la sincronización del receptor con el mensaje de navegación transmitido, todas las subtramas comienzan por un campo llamado Telemetry Word (TLM) o palabra de telemetría. La TLM es una secuencia fija de 8 bits de largo que es utilizada por el receptor para sincronizarse con las estructuras de datos del mensaje de navegación. Para ello, durante la sincronización inicial el receptor busca la secuencia de bits de la palabra de telemetría en la secuencia de bits recibidos; una vez encontrada, se sabe que el primer bit de dicha secuencia es entonces el comienzo de la primera palabra de una subtrama. Cabe notar que este proceso de sincronización tiene una alta probabilidad de falsa alarma por lo que una vez encontrada la secuencia TLM el receptor debe validar su hallazgo a través de la verificación de indicadores de sincronismo alternativos (por ejemplo, verificando que los bits de paridad de las palabras).

Otro campo que está presente en todas las subtramas es el llamado Hand Over Word (HOW). El HOW es una contador relacionado con la Hora GPS: indica el tiempo transcurrido desde el comienzo de la semana GPS (el TOW) correspondiente al instante de comienzo de la subtrama siguiente, en unidades de 6 segundos. Dado que el comienzo de la semana GPS coincide con el comienzo de una nueva subtrama y que cada subtrama dura 6 segundos, el HOW puede alternativamente entenderse como el contador de la cantidad de subtramas transmitidas desde el comienzo de la semana GPS.

Las subtramas I, II, III contienen toda la información necesaria para que un receptor pueda hacerse de los parámetros de corrección del reloj y de las efemérides del satélite transmisor, ambos datos fundamentales para el cálculo de la solución de navegación utilizando la señal de un dado satélite. Dado que una trama completa se transmite cada 30 segundos y en ella están incluidas las subtramas I, II y III, eso significa que a partir del momento de comienzo de la demodulación del mensaje de navegación se requieren entre 18 (mejor caso) y 30 (peor caso, asumiendo que no hayan errores de bit) segundos para que el receptor decodifique suficiente información para incorporar el satélite al cálculo de la solución de navegación.

El contenido de los parámetros de corrección del reloj y de las efemérides se repiten con cada nueva retransmisión de las subtramas I, II, III excepto cuando el Segmento de Control realiza la carga de nuevos valores de estos datos. Para mantener acotado el 
error en la solución de navegación el receptor siempre debe utilizar los datos de reloj/efemérides más recientes que estén disponibles. Cada versión de estos datos se encuentra etiquetada con un número llamado IODC (acrónimo para Issue of Data, Clock) que viene indicado en el contenido de las subtramas. Un receptor normalmente solo decodificará los parámetros de corrección de reloj y efemérides del satélite la primera vez, y a partir de ese momento los guarda en una memoria interna. A partir de ese momento el receptor sólo decodifica el número de IODC transmitido por el satélite y lo compara con el número correspondiente a los datos que tiene almacenados; si en algún momento estos difieren significa que se ha producido una actualización del mensaje de navegación transmitido por el satélite, y que por lo tanto es necesario actualizar la información de reloj y efemérides almacenada.

También presente dentro de cada subtrama se encuentra el número de semana GPS. Este número no es necesario para el cálculo de la solución de navegación pero permite a los receptores determinar la fecha de calendario. Debido a que sólo se destinaron 10 bits para almacenar el número en el mensaje de navegación la semana GPS se encuentra indicada en la subtrama en módulo-1024, por lo que la indicación es ambigüa. El primer roll-over (instancia en que la cuenta de semanas supera un múltiplo de 1024) se produjo en 1999, y el siguiente será en el 2019. Dado que los roll-overs ocurren aproximadamente cada 19 años, los receptores comerciales habitualmente infieren el número de semana correcto teniendo en cuenta su propia fecha de fabricación, pero claramente esta aproximación tiene sus limitaciones y puede no ser adecuado en todos los casos.

\subsubsection{Estructura}

Una característica muy importante de la señal C/A es que los diferentes niveles de estructura de la señal guardan relaciones de sincronismo entre sí. Un bit del mensaje de navegación de la señal $\mathrm{C} / \mathrm{A}$ dura un intervalo de exactamente veinte ciclos de la función de código utilizada para expandir el espectro de la señal. El comienzo de un intervalo de bit coincide con el comienzo del primer chip del primero de esos veinte ciclos. Ver Figura 2.9.

Esta relación entre la fase de la función de código y los flancos de los bits del mensaje de navegación es aprovechada por el receptor durante la sincronización inicial con una señal GPS recién adquirida para determinar la posición de los flancos de bit del mensaje de navegación en la señal recibida.

Además, el instante de comienzo de la semana GPS coincide con el comienzo de la primera palabra de la primera subtrama de la primera trama transmitida en la semana. De esta forma la hora GPS correspondiente al instante de transmisión queda codificado de 


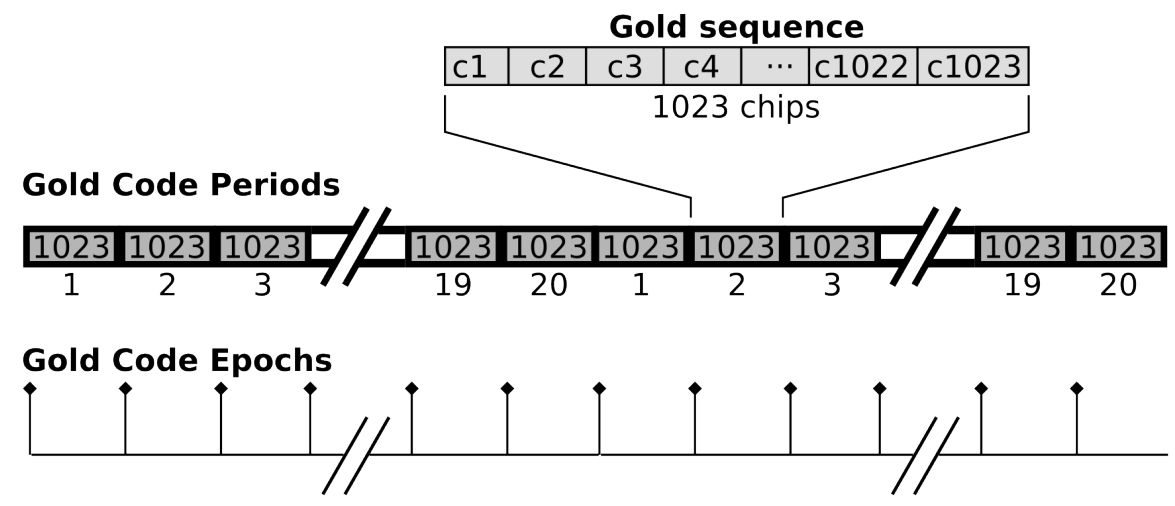

Data bits

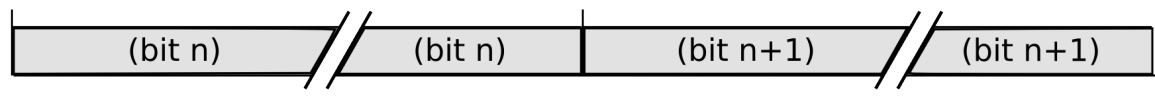

\section{Data bit edges}

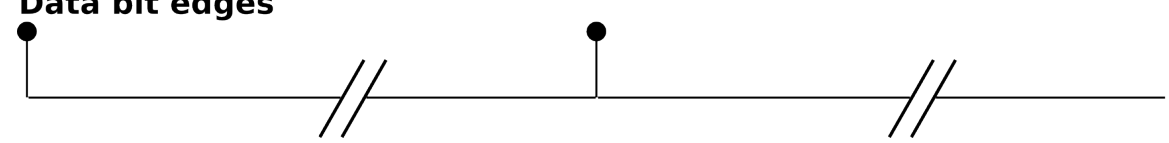

Figura 2.9: Alineamiento entre los períodos de los códigos Gold utilizados en la función de código y los bits de datos del mensaje de navegación de la señal C/A.

forma implícita en la estructura de la señal a través de la cuenta de subtramas, palabras, bits, ciclos de código y chips transcurridos hasta ese momento. La determinación de este tiempo de transmisión $t_{t t}$ de la señal recibida en el instante $t_{r}$ del reloj del receptor es la medición fundamental que permite la obtención de una solución de navegación en el receptor.

La medición del tiempo de transmisión $t_{t t}\left(t_{r}\right)$ se puede separar en dos términos:

$$
t_{t t}\left(t_{r}\right)=t_{t t c}\left(t_{r}\right)+t_{t t f}\left(t_{r}\right)
$$

El término $t_{t t c}$ es la cuenta gruesa de tiempo transcurrido desde el comienzo de la semana. Su valor es obtenido a través de los algoritmos de extracción del mensaje de navegación, que agrupan bits en palabras y las palabras en subtramas, y decodifican su contenido. $\mathrm{Su}$ valor está determinado por los valores $n_{\mathrm{HOW}}$ (valor del campo HOW de la última subtrama recibida completa), $n_{\text {word }}$ (cantidad de palabras completas recibidas desde el fin de la última subtrama completa) y $n_{b i t}$ (cantidad de bits completos recibidos desde el fin de la última palabra completa). En unidades de segundos $t_{t t c}$ se calcula como

$$
t_{t t c}\left(t_{r}\right)=6 \cdot n_{H O W}\left(t_{r}\right)+0,6 \cdot n_{w o r d}\left(t_{r}\right)+20 \cdot 10^{-3} \cdot n_{b i t}\left(t_{r}\right) .
$$

Dado que la unidad mínima en que se mide el tiempo grueso es el bit, su resolución es de $20 \mathrm{~ms}$. 
La resolución en unidades menores a los $20 \mathrm{~ms}$ la da el tiempo fino $t_{t t f}$. Éste se calcula a partir de la información recabada por los lazos de estimación de fase de la función de código. Su cálculo utiliza los términos $n_{m s}$, que es la cantidad de ciclos enteros de la función de código transcurridos desde el último flanco de bit del mensaje de navegación (coincidente con la cantidad de milisegundos transcurridos), y $p_{\text {chips }}$ que es la fase medida en chips transcurridos desde el último fin de ciclo de código.

$$
t_{t t f}\left(t_{r}\right)=1 \cdot 10^{-3} n_{m s}\left(t_{r}\right)+\frac{p_{\text {chips }}\left(t_{r}\right)}{1,023 \cdot 10^{6}} .
$$

En principio la resolución de $t_{t t f}$ es cero, ya que su unidad mínima de representación es la de la estimación de fase de código, que es una variable real. Sin embargo, como se verá más adelante la presencia de ruido en la señal hace que la estimación de la fase instantánea sea una variable aleatoria con media en el valor real de la fase instantánea en el instante $t_{r}$ y una varianza que es función de la relación SNR con la que llega la señal al receptor. Con niveles SNR habituales en receptores de cielo abierto, la desviación estándar de esta estimación está en el orden de 10 ns.

Otra forma importante de sincronismo interno de la señal es la que tienen la frecuencia utilizada para la portadora que modula la señal y la frecuencia de la función de código que la expande. Ambas frecuencias se obtienen de la misma referencia temporal a bordo de satélite transmisor, por lo que relación entre ambas es siempre la misma: para la señal C/A la relación entre la frecuencia portadora nominal $1575,42 \mathrm{MHz}$ y la tasa de la función de código nominal 1,023 MHz es 1540 .

En el receptor los valores observados de frecuencia portadora y tasa de código difieren de los valores nominales principalmente debido al efecto Doppler, el cual es causado por el movimiento relativo entre el receptor y el satélite. Sin embargo, debido a que esta distorsión es proporcional a la frecuencia de la señal, tanto la frecuencia portadora como la tasa de la función de código se ven afectadas en la misma proporción y por la tanto la relación entre ambas permanece invariante.

Se verá más adelante que esto es importante ya que permite los esquemas de seguimiento donde la estimación de frecuencia del lazo de portadora se utiliza para asistir al lazo de código: en lugar de generar estimaciones independientes de frecuencia en el lazo de seguimiento de portadora y otra en el lazo de seguimiento de código, este último utiliza la estimación de la frecuencia de portadora escalada con el factor 1540 para anticipar la tasa de variación de la función de código. Se verá luego que esto presenta una serie de ventajas en términos de sensibilidad al ruido y de respuesta temporal en condiciones de alta dinámica. 


\subsection{Sistema GLONASS}

\subsubsection{Estructura}

La estructura del sistema GLONASS es en gran parte semejante a la de su contraparte occidental GPS. La división funcional del sistema sistema en tres grandes segmentos según el rol de las partes se aplica de la misma forma a este sistema, distinguiendo los segmentos de Control, Espacial y de Usuario.

Administrativamente, el control del sistema GLONASS actualmente pertenece a la agencia espacial rusa conocida como Roscosmos. Este es un organismo civil, que recibió el mando del sistema al comienzo del proceso de desmilitarización, recuperación y modernización del sistema que fue llevado a cabo durante la presidencia de Vladimir Putin en los primeros años del nuevo milenio.

\subsubsection{Segmento de control}

El Segmento de Control GLONASS está compuesto por una serie de instalaciones terrestres encargadas de realizar el control y seguimiento del estado de la constelación de satélites pertenecientes al sistema. Este conjunto de instalaciones se encuentra compuesto por un Centro de Control de Sistema, un Sincronizador Central, cinco Estaciones de Telemetría, Seguimiento y Comando, dos Estaciones de Laser Ranging, y una serie de Estaciones de Monitoreo adicionales.

El Centro de Control del Sistema es el encargado de procesar los datos recibidos desde las demás estaciones para verificar el estado de los satélites del sistema, efectuar la predicción de las órbitas y modelar el comportamiento de los relojes de a bordo de cada vehículo espacial, generar los mensajes de navegación, y llevar a cabo la administración general del sistema.

Las Estaciones de Telemetría se encargan de realizar la subida de comandos hacia los satélites, así como de realizar el proceso de subida de los paquetes de actualizaciones a la memoria de los vehículos espaciales a través de sus enlaces de radiofrecuencia. En estas estaciones se realiza también el monitoreo permanente de todas las señales transmitidas por los satélites, las cuales son recibidas y transferidas al Centro de Control para su análisis.

El sistema cuenta con dos estaciones de Laser Ranging que son capaces de determinar la distancia instantánea entre la estación y cada satélite de forma sumamente precisa. Estas mediciones son utilizadas para validar las mediciones de rango calculadas a partir 
del contenido de las señales transmitidas por el satélite, así también como para calibrar otros medios de determinación de los parámetros orbitales, hacer un un seguimiento preciso del estado de los relojes de a bordo, y otras funciones más.

El Sincronizador Central es la estación encargada de mantener la referencia de tiempo atómica que sirve de patrón de tiempo para todo el sistema. Esta referencia recibe el nombre Hora GLONASS y será descripta en más detalle en las secciones siguientes. [33]

A diferencia del sistema GPS, cuyo Segmento de Control se encuentra distribuido a lo largo y ancho de toda la superficie del planeta, su contraparte del sistema GLONASS históricamente se ha mantenido confinado dentro de las fronteras nacionales de la antigua URSS (actual Rusia y países aledaños). Como parte de los esfuerzos de modernización del sistema emprendidos en la última década está prevista una ampliación de las instalaciones del segmento terrestre, incluyendo por primera vez la instalación de una serie de Estaciones de Monitoreo fuera de las fronteras nacionales de Rusia a través de una serie de convenios con países extranjeros. [34][35]

\subsubsection{Segmento espacial}

El Segmento Espacial GLONASS está actualmente compuesto por 24 satélites operativos, más tres satélites adicionales que se encuentran en reserva en calidad de spares. Adicionalmente se encuentra también en órbita el primer satélite GLONASS de tercera generación (ver más abajo) cuyo estado actual es flight test, ya que está siendo utilizado para validar el diseño del satélite y de las nuevas señales transmitidas por el mismo.

Los satélites se encuentran distribuidos en tres planos orbitales diferentes, cada uno rotado $120^{\circ}$ respecto de los demás, y con $64,8^{\circ}$ de inclinación respecto del ecuador. Estas órbitas fueron seleccionadas para favorecer la disponibilidad del sistema en las latitudes próximas a los polos, debido a la ubicación y distribución del territorio de la Federación Rusa. Esto se complementa con las características del sistema NAVSTAR GPS, que tiende a favorecer latitudes ecuatoriales.

El Segmento Espacial se encuentra bajo control y supervisión del Segmento de Control del sistema, el cual se encarga de seguir la trayectoria de cada vehículo para generar la predicción de sus órbita futura (efemérides), mantener sincronizados los relojes de todos los satélites con el Sicronizador Central, y llevar a cabo la administración general de la flota (modificaciones de órbitas, entrada y salida de satélites, reasignación de códigos y frecuencias, etc.).

Los satélites del sistema GLONASS se pueden dividir en cuatro generaciones principales. Los primeros satélites GLONASS fueron prototipos utilizados para validar el sistema y 
calibrar los sistemas del Segmento de Control. Su vida útil estimada era de apenas un año, y fueron utilizados entre 1982 y 1985. Esta generación recibe el nombre de Generación Cero, Bloque I o según su nombre de diseño, satélites Uragan.

A partir de 1985 se comenzaron a poblar las órbitas con satélites de la primera generación de modelos de producción, los satélites del Bloque II o Generación Uno. Este bloque se dividió a su vez en tres subbloques (IIa, IIb y IIc) que diferían principalmente entre sí por la vida útil de los vehículos. Esta métrica no es menor, ya que en ella radicaba una importante desventaja del sistema GLONASS frente a GPS: la vida media de los vehículos GLONASS Bloque II era de aproximadamente 3 años, mucho menor que los 7 años de vida útil de la generación GPS equivalente, por lo que con una flota mínima de 24 vehículos era necesario poner 8 vehículos en órbita cada 12 meses con el único fin de evitar la degradación operativa del sistema.

En el 2003 como parte de los esfuerzos de modernización se pasó a utilizar un nuevo diseño de satélites, los correspondientes al Bloque GLONASS-M o Segunda Generación. La vida útil de estos vehículos es más larga que la de sus antecesores (7 años) reduciendo por lo tanto el costo de mantenimiento de la flota. Los vehículos de esta generación también agregan una nueva señal civil transmitida en la banda L2 y poseen una referencia atómica de mejor calidad que las generaciones anteriores.

La Tercera Generación de satélites se encuentra actualmente en proceso de ser desplegada; es la generación de satélites del Bloque GLONASS-K. Estos satélites presentan un diseño fundamentalmente diferente de las generaciones anteriores. Son los primeros satélites GLONASS que no funcionan presurizados, lo que reduce el volumen y peso de los vehículos. La vida útil de estos vehículos también es superior a la de los GLONASS-M que los anteceden: 10 años. Esta duración los pone a la par de los satélites del sistema NAVSTAR GPS. Además, esta generación incorpora transmisiones en la banda L3. En las bandas L1 y L2 se mantienen las señales FDMA clásicas, pero se agregan además nuevas señales que utilizan codificación CDMA y que comparten la frecuencia portadora con los sistemas GPS y Galileo para aumentar la interoperabilidad con esos sistemas. El primer satélite de esta generación se encuentra en órbita desde Febrero del 2011. [36]

La constelación actual se encuentra conformada por 27 satélites de GLONASS-M, y un único satélite del GLONASS-K. Este último no se encuentra operativo sino en fase de flight test mientras se realiza la puesta a punto de los sistemas del nuevo diseño del vehículo, así como de las nuevas señales transmitidas y del Segmento de Control ampliado.

Al igual que ocurre en el sistema NAVSTAR GPS, los satélites del sistema GLONASS pueden entenderse como relojes de altísima precisión ubicados en órbita, anunciando 
ininterrumpidamente la hora del sistema codificada dentro de sus transmisiones de radiofrecuencia en las bandas L1, L2 y L3. Junto con la marca de tiempo codificada en las señales, los satélites transmiten también un mensaje de navegación que contiene los parámetros orbitales precisos (efemérides) y los parámetros del reloj de a bordo del satélite transmisor, y un estado resumido del resto de la constelación (almanaque), entre otros datos. Es el Segmento de Control el encargado de mantener estos datos actualizados, realizando cargas varias veces al día de paquetes de información actualizada.

Cada satélite cuenta a bordo con un patrón de tiempo atómico de muy alta estabilidad, del cual se derivan todas las señales transmitidas por el vehículo: frecuencias portadoras, tasas de funciones de código, tasas de bits, etc. Este patrón de tiempo es monitoreado permanentemente por el segmento de control para establecer su relación con la hora del Sincronizador Central. A diferencia de GPS que utiliza un modelo de segundo orden para determinar la diferencia entre el reloj de a bordo y la Hora GPS, GLONASS utiliza un modelo más simple de primer orden consistente en un término constante (desviación) y la primera derivada (deriva) correspondientes a un instante de referencia $t_{k}$ :

$$
\delta(t)=t^{(\mathrm{sat})}-t^{(\mathrm{glo})} \approx b_{t_{k}}+d_{t_{k}}\left(t-t_{k}\right)
$$

Este modelo más simple requiere de actualizaciones más frecuentes de los parámetros del mismo $\left(t_{k}, b_{t_{k}}\right.$ y $\left.d_{t_{k}}\right)$ para mantener acotado el error con la misma precisión.

\subsubsection{Segmento de usuario}

El Segmento de Usuario de GLONASS es un nombre que identifica al conjunto abstracto de todos los receptores capaces de recibir y procesar las señales del sistema GLONASS, tanto civiles como restringidas. Por sus similaridades con el Segmento de Usuario del sistema GPS, la discusión de este segmento se posterga hasta la Sección 2.4 donde serán discutidos ambos de forma conjunta.

\subsubsection{Tiempo GLONASS}

El tiempo GLONASS es la hora oficial del sistema GLONASS. Este patrón de tiempo es generado por el Segmento de Control gracias a una serie de referencias de tiempo atómicas localizadas en la estación llamada Sincronizador Central, ubicada en Mendeleevo, Rusia. Periódicamente los relojes de cada vehículo son comparados contra esta referencia central de tiempo, y mediante procesamiento de las diferencias se generan los parámetros de corrección de los relojes de a bordo que permiten mantener toda la flota sincronizada con la Hora GLONASS. 
Una diferencia muy importante entre la hora del sistema GPS y la hora del sistema GLONASS es que el patrón de tiempo GLONASS no es una función suave monotónicamente creciente, debido a que se encuentra atado a la referencia internacional de tiempo UTC. Tal como se indicó en la Sección 2.2.2, UTC esporádicamente agrega un segundo adicional a la longitud del día (llamado inserción de un leap second) para compensar las irregularidades en la velocidad de giro terrestre. La Hora GLONASS coincide por definición con la hora oficial de Moscú (UTC+3) por lo que debe realizar una corrección equivalente toda vez que la escala UTC se modifica. Este ajuste genera una discontinuidad en el modelo de tiempo utilizado por los receptores.

Debido a que estas discontinuidades pueden provocar problemas en el cálculo de las soluciones de navegación, los receptores del Segmento de Usuario deben ser notificados cada vez que se realiza la inserción de un leap second. Previo a los satélites de generación Glonass-M no había información relativa a estos ajustes en el mensaje de navegación transmitido por los satélites, por lo que los usuarios del sistema debían informarse de ellos a través de canales externos al sistema, como por ejemplo los boletines emitidos por el International Earth Rotation and Reference Systems Service (IERS). Los satélites de la generación Glonass-M en adelante anuncian la ocurrencia de un ajuste, su magnitud y su signo a través de un campo presente en el mensaje de navegación transmitido, lo cual es mucho más conveniente para la utilización masiva del sistema.

\subsubsection{Evolución del sistema}

Las generaciones originales de vehículos espaciales utilizados por el sistema GLONASS transmitían un conjunto de señales semejantes a las de su contraparte occidental GPS. En la banda L1 se transmite una señal abierta de aplicación civil (llamada L1OF) y en cuadratura con ella una señal codificada para uso exclusivo de usuarios autorizados (L1SF). En la banda L2 se transmite solamente una señal segura, L2SF. Este esquema permite la utilización de receptores doble banda solamente a los usuarios autorizados.

Las señales L1OF, L1SF y L2SF son señales de espectro expandido de tipo DS-SS, pero a diferencia del sistema GPS, que multiplexa el acceso al medio mediante CDMA, GLONASS lo hace utilizando FDMA: la función de código utilizada para expandir el espectro es la misma para todos los satélites para cada clase de señal (L1OF o L1SF/L2SF), pero las frecuencias portadoras de cada uno se asigna de entre un conjunto finito de canales de frecuencia disponibles. 
En la banda L1 las frecuencias portadoras nominales posibles son aquellas cuyo valor pertenece al conjunto

$$
f_{L 1}=1602,0 \mathrm{MHz}+0,5625 \mathrm{MHz} \cdot k,
$$

donde $k$ es un número entero. De la misma forma, en banda L2 los valores nominales de portadora son

$$
f_{L 2}=1246,0 \mathrm{MHz}+0,4375 \mathrm{MHz} \cdot k,
$$

donde nuevamente $k$ es un número entero.

A cada satélite se le asigna un canal $k$ sobre el que realizar sus transmisiones; este valor de $k$ determina las frecuencias portadoras utilizadas por el satélite tanto en L1 como en L2.

En el diseño original del sistema GLONASS los canales FDMA disponibles eran 24, correspondientes a los valores $k=1, \ldots, 24$. Este arreglo permitía asignar a cada satélite una frecuencia portadora individual, diferente de la de los demás satélites de la constelación, y garantizar la ausencia de interferencia mutua entre ellos. Un canal adicional, correspondiente al valor $k=0$, estaba reservado para pruebas de ingeniería.

Este esquema debió ser revisado porque las transmisiones GLONASS de los canales L1 $k=16, \ldots, 21$ provocaban interferencia en la banda que va de $1610,6 \mathrm{MHz}$ a $1613,8 \mathrm{MHz}$, una banda que es utilizada en radioastronomía [37]. La resolución de este conflicto tomó varios años y consistió en un proceso gradual de modificación del esquema de frecuencias.

Actualmente los satélites sólo transmiten en los canales con $k=-7, \ldots, 6$. La cantidad de canales disponibles está por lo tanto muy por debajo de la cantidad de satélites GLONASS activos, lo que implica que algunos canales deben ser utilizados por más de un satélite al mismo tiempo. Para evitar problemas de interferencia mutua, los canales repetidos se asignan a pares de satélites ubicados en una misma órbita, pero en posiciones antipodales uno respecto del otro. De esa forma nunca un usuario terrestre tendrá en vista ambos satélites simultáneamente ${ }^{8}$.

La utilización de FDMA para multiplexar el acceso al medio tiene como consecuencia que los receptores del sistema GLONASS deben contar con una etapa de RF con un ancho de banda de entrada mucho mayor que un receptor GPS comparable. Esto impacta fuertemente en el diseño del receptor, su grado de complejidad y por ende en su costo.

\footnotetext{
${ }^{8}$ Notar que un receptor montado en un vehículo espacial (como por ejemplo un satélite de órbita baja o media) puede no contar con esta garantía.
} 
Por otro lado, la utilización de FDMA permite un nivel adicional de protección en caso de interferencia intencional o accidental.

Como se mencionó anteriormente a partir del 2003 comenzó el proceso de modernización de la flota de vehículos GLONASS. Sin embargo, la introducción de los satélites de la generación GLONASS-M no significó grandes cambios en el conjunto de señales transmitidas por el sistema, salvo por la aparición de una segunda señal abierta transmitida en banda L2. Esta modificación no es menor, ya que permitió a los usuarios civiles del sistema realizar la corrección del error ionosférico, algo que en ese momento todavía no era posible para los usuarios del sistema GPS.

Por otro lado, la inminente aparición de los satélites de la generación GLONAS-K trae aparejada una serie de innovaciones muy importantes en el conjunto de señales transmitidas, similar al proceso de renovación que está siendo llevado a cabo por el sistema GPS.

La generación K puede dividirse en tres etapas, llamadas K1, K2 y KM. Los satélites del bloque GLONASS-K1 incorporan la transmisión de una nueva señal abierta llamada L3OC en la banda L3. A diferencia de todas las señales GLONASS utilizadas anteriormente, la nueva señal utiliza CDMA para multiplexar el acceso al medio en lugar de FDMA.

Más profundos son todavía los cambios en GLONASS-K2 [38]. Esta generación agregará cuatro nuevas señales CDMA a las bandas L1 y L2, sin eliminar las señales FDMA de generaciones anteriores. Dos de las nuevas adiciones son señales de uso civil (L1OC y L2OC) y dos son de uso restringido (L1SC y L2SC).

Es poca y a veces contradictoria la información disponible sobre las señales que el futuro bloque GLONASS-KM agregará, ya que esta nueva generación todavía está en fase de desarrollo e investigación. Sin embargo se puede adelantar que se espera que GLONASSKM agregue nuevas señales CDMA moduladas en las portadoras utilizadas por GPS y Galileo en las bandas L1 y L2 con el fin de incrementar el grado de interoperatividad entre los tres sistemas.

\subsubsection{Señales transmitidas}

Tal como ya se mencionó los satélites GLONASS actualmente en servicio transmiten una multitud de señales que utilizan diferentes valores de frecuencia portadora y de tipos de sistemas de modulación, a través de las bandas L1, L2 y L3.

Las señales L1OF y L1SF son la señales originales transmitidas por el sistema en la banda L1, y las más importantes en la actualidad hasta que culmine el proceso de renovación 


\begin{tabular}{|c|c|c|c|}
\hline Generación & Banda L1 & Banda L2 & Banda L3 \\
\hline \hline GLONASS & L1OF, L1SF & L2SF & \\
\hline GLONASS-M & L1OF, L1SF & L2OF, L2SF & \\
\hline GLONASS-K1 & L1OF, L1SF & L2OF, L2SF & L3OC \\
\hline GLONASS-K2 & L1OF, L1SF & L2OF, L2SF & L3OC \\
& L1OC, L1SC & L2SC & \\
\hline GLONASS-KM & L1OF, L1SF & L2OF, L2SF & L3OC \\
& L1OC, L1SC & L2OC, L2SC & \\
& L1OCM & & \\
\hline
\end{tabular}

CuAdro 2.3: Utilización de bandas de señal según generación GLONASS, según composición de diversas fuentes de información.

de la flota satelital. Ambas utilizan FDMA para multiplexar el acceso al medio. Las frecuencias de portadora utilizadas por los satélites toman los valores

$$
f_{L 11}[k]=1602,0 \mathrm{MHz}+0,5625 \mathrm{MHz} \cdot k,
$$

donde $k$ es un número entero en el intervalo $[-7, \ldots, 6]$ correspondiente al canal GLONASS asignado al vehículo transmisor.

Réplicas de estas señales se transmiten también a través de la banda L2, con los nombres L2OF y L2SF. En este caso las frecuencias portadoras utilizadas son

$$
f_{L 21}[k]=1246,0 \mathrm{MHz}+0,4375 \mathrm{MHz} \cdot k,
$$

donde $k$ es nuevamente el canal GLONASS asignado al satélite.

A estas hay que agregar las señales CDMA también transmitidas por las generaciones más modernas. Estas utilizan un esquema semejante al de GPS, donde todos los satélites transmiten sobre la misma frecuencia portadora nominal y cada satélite utiliza una función de código diferente (y ortogonal con las demás). L1OC y L1SC son señales CDMA transmitidas en la banda L1 sobre una portadora que nominalmente es de $f_{L 12}=$ 1600,995 MHz. Correspondientemente, en banda L2 están presentes L2OC y L2SC con portadora en $f_{L 22}=1248,06 \mathrm{MHz}$.

Al conjunto de las transmisiones en L1 se lo puede representar como:

$$
\begin{aligned}
s_{L 1}(t)= & A_{s f 1} m_{s f}(t) \cos \left(2 \pi f_{L 11}[k] t+\phi_{11}\right) \\
& +A_{o f 1} m_{o f}(t) \sin \left(2 \pi f_{L 11}[k] t+\phi_{11}\right) \\
& +A_{s c 1} m_{s c}(t) \cos \left(2 \pi f_{L 12} t+\phi_{12}\right) \\
& +A_{o c 1} m_{o c}(t) \sin \left(2 \pi f_{L 12} t+\phi_{12}\right),
\end{aligned}
$$


y de forma semejante, el conjunto de L2

$$
\begin{aligned}
s_{L 2}(t)= & A_{s f 2} m_{s f}(t) \cos \left(2 \pi f_{L 21}[k] t+\phi_{21}\right) \\
& +A_{o f 2} m_{o f}(t) \sin \left(2 \pi f_{L 21}[k] t+\phi_{21}\right) \\
& +A_{s c 2} m_{s c}(t) \cos \left(2 \pi f_{L 22} t+\phi_{22}\right) \\
& +A_{o c 2} m_{o c}(t) \sin \left(2 \pi f_{L 22} t+\phi_{22}\right) .
\end{aligned}
$$

En la banda L3 los satélites desde el bloque GLONASS-K1 en adelante transmiten la señal L3OC. Esta es una señal CDMA, con frecuencia portadora nominal de $f_{L 3}=$ $1202,25 \mathrm{MHz}$,

$$
s_{L 3}(t)=A_{o c 3} m_{o c}(t) \cos \left(2 \pi f_{L 3} t+\phi_{3}\right) .
$$

A diferencia de lo que ocurre con el sistema GPS, la información disponible sobre el sistema GLONASS es en general limitada. En esto juegan su rol por un lado el escaso nivel de promoción que tuvo el sistema fuera de las fronteras de Rusia hasta hace tan solo un par de años, y por otro la barrera idiomática que implica que toda la documentación técnica del sistema existe primeramente en Ruso y se traduce al inglés algún tiempo después.

Debido a la inexistencia de material técnico autorizado y de calidad acerca de las señales GLONASS modernizadas no se profundizará la descripción de ellas. El resto de la discusión sobre el sistema GLONASS se enfoca de ahora en más en la señal civil L1OF, que es la de principal interés a los fines del tema de la tesis y es de la que más información existe disponible en inglés.

\subsubsection{Estructura de la señal L1OF}

La señal L1OF ha estado disponible desde los primeros bloques de satélites GLONASS puestos en órbita. Se encuentra documentada en la definición de interfaz del sistema que se puede encontrar en la referencia [33], la cual es una traducción autorizada del documento original en idioma ruso. Existen diversas versiones de este documento, que difieren en la información que presentan, y en algunos casos deben utilizarse de forma complementaria para salvar los problemas de traducción que presentan unas y otras.

L1OF es una señal de espectro expandido, de tipo DS-SS, formada por un mensaje de navegación $d_{o f}(t)$ multiplicado por una función de código $c_{o f}(t)$, y modulado con una 
portadora de banda L1. Repitiendo solamente la parte más relevante de la ecuación 2.15:

$$
s_{L 1}(t)=A_{o f 1} m_{o f}(t) \sin \left(2 \pi f_{L 11}[k] t+\phi_{11}\right)+\ldots
$$

A su vez, el mensaje modulado en banda base puede ser descompuesto en el mensaje de navegación $d_{o f}(t)$ y la modulación DS-SS $c_{o f}(t)$ :

$$
m_{o f}(t)=d_{o f}(t) c_{o f}(t)
$$

Al igual que ocurre con la señal civil C/A del sistema GPS, una cobertura completa sobre las características de la señal GLONASS L1OF requeriría de muchas páginas. Con el fin de mantener la brevedad del texto se detallarán en las subsecciones siguientes solamente aquellos elementos de son de mayor interés a los fines del trabajo.

En particular, la Sección 2.3.5.1 presenta las características de la función de código utilizada para expandir el espectro, en 2.3.5.2 se presenta el formato general del mensaje de navegación y por último en 2.3.5.3 se discuten los tópicos de sincronización interna de la señal que serán relevantes más adelante. Información adicional sobre la conformación de la señal y su mensaje de navegación se puede encontrar en definición de la interfaz del sistema [33].

\subsubsection{Función de código}

Al igual que la señal C/A, la señal L1OF es una señal de tipo DS-SS que utiliza una función de código de tasa muy superior a la de la modulación de datos para expandir el espectro de la primera y distribuir su potencia en un ancho de banda más grande. En GLONASS este tipo de modulación se utiliza para incrementar la tolerancia de la señal ante interferencias no intencionales de banda angosta y para codificar en la fase de la función de código parte de la información de tiempo que transmiten los satélites con resolución de nanosegundos.

La función de código $c_{o f}(t)$ utilizada es una secuencia de pulsos NRZ bipolares de tasa $511 \mathrm{kHz}$. Los valores que toman esos pulsos son una secuencia pseudoaleatoria de largo 511 bits generada mediante la utilización del generador de secuencias de máximo largo de la Figura 2.10. El generador se encuentra formado por un registro de desplazamiento de nueve bits y un circuito de realimentación; el polinomio característico de este generador es $P(x)=1+x^{5}+x^{9}$ y la fase inicial (comienzo de la secuencia) de la secuencia se define coincidiendo con el estado 111111111 del registro de desplazamiento. 
Generador G

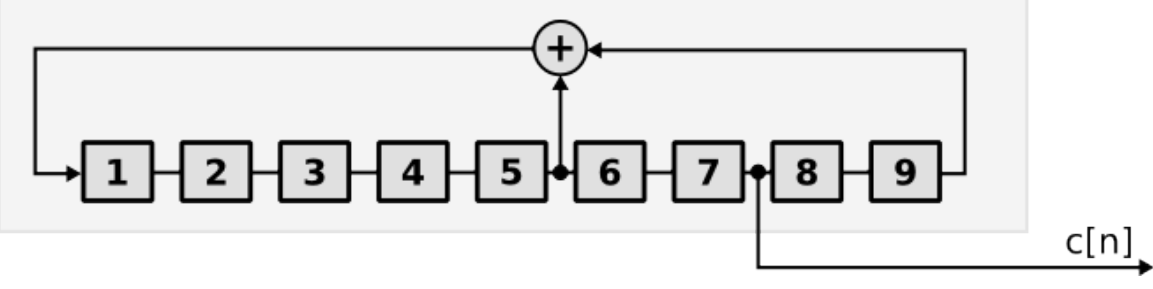

FigurA 2.10: Diagrama del generador de código utilizado en GLONASS L1OF.

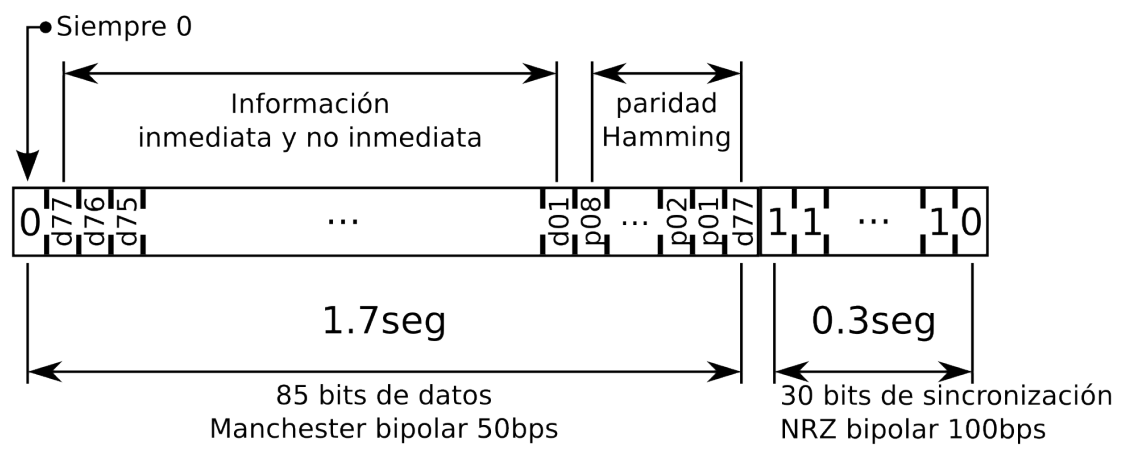

FIGURA 2.11: Formato de un string GLONASS L1OF .

La función de código sintetizada mediante este generador es única, y es utilizada por todos los satélites del sistema para expandir el espectro de sus respectivas señales L1OF.

\subsubsection{Mensaje de navegación}

La unidad básica de datos del mensaje de navegación L1OF GLONASS es el string o línea. Éste tiene una duración de $2 \mathrm{~s}$ y contiene 85 bits de datos más una secuencia fija de 30 bits para permitir al receptor lograr el sincronismo. Los primeros 85 y los siguientes 30 bits se transmiten a tasas diferentes. Ver Figura 2.11.

Los primeros $1,7 \mathrm{~s}$ de la línea se utilizan para transmitir 85 bits de datos a una tasa de 50 bps, utilizando codificación de tipo Manchester bipolar diferencial. Los últimos 0,3 s de la línea están ocupados por una palabra de sincronización (denominada en la traducción al inglés de la referencia del sistema time mark), equivalente a la palabra de telemetría de GPS. Ésta se encuentra formada por una secuencia pseudoaleatoria fija de 30 bits de largo transmitida a 100 bps y utilizando codificación NRZ bipolar. La secuencia utilizada es

111110001101110101000010010110, 


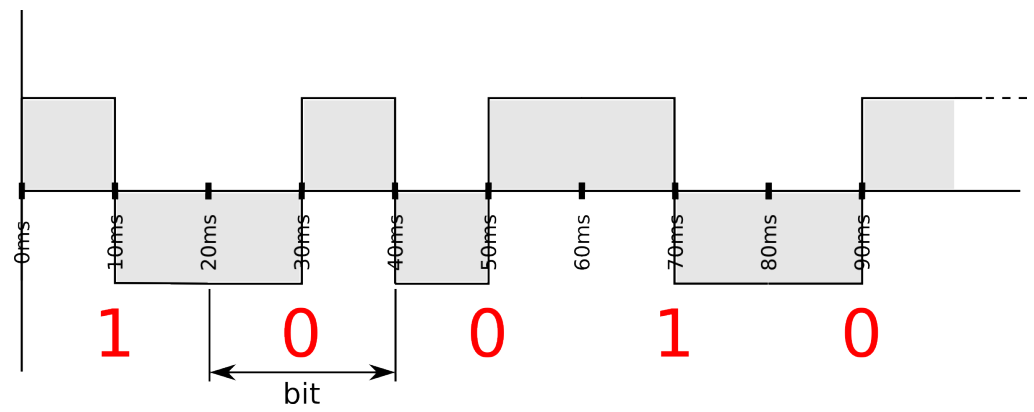

Figura 2.12: Codificación Manchester bipolar de 50 bps utilizada para transmitir los 85 bits de datos de las líneas L1OF GLONASS.

la cual corresponde a los primeros 30 bits de la secuencia de largo 31 generada por un registro de desplazamiento de 5 bits con realimentación dada por el polinomio característico $P(x)=1+x^{3}+x^{5}$. De acuerdo con los documentos de especificación del mensaje de navegación, el bit 31 de la secuencia de máximo largo (un cero) se materializa en los primeros $10 \mathrm{~ms}$ del primero de los 85 bits de datos de la línea siguiente, el cual está definido que siempre valga cero.

Cada línea cuenta con una palabra de paridad que utiliza códigos Hamming para realizar detección y corrección de errores. El código empleado permite la corrección de cualquier error simple y la detección de cualquier error doble ${ }^{9}$.

La combinación de modulaciones utilizadas para los bits de datos (Manchester bipolar a 50 bps) y para la palabra de sincronización (NRZ bipolar a 100 bps) significa que el mensaje de navegación $d_{o f}(t)$ puede tiene transiciones de signo a intervalos de $10 \mathrm{~ms}, \mathrm{y}$ un ancho de banda en banda base de $100 \mathrm{~Hz}$. Ver Figura 2.12 y Figura 2.13.

\footnotetext{
${ }^{9}$ Llamativamente, la documentación del sistema da a entender que la corrección se realiza sobre los datos una vez eliminada la codificación diferencial. Es un hecho conocido que la codificación diferencial tiene problema de multiplicación de errores: dado que para decodificar un bit se requiere tanto el bit codificado actual como el anterior, cualquier error simple en la secuencia recibida se traduce en un error doble en la secuencia decodificada. Esto significaría que la probabilidad de que el algoritmo de corrección de errores simples de GLONASS tenga oportunidad de corregir un error simple es prácticamente nula.
}

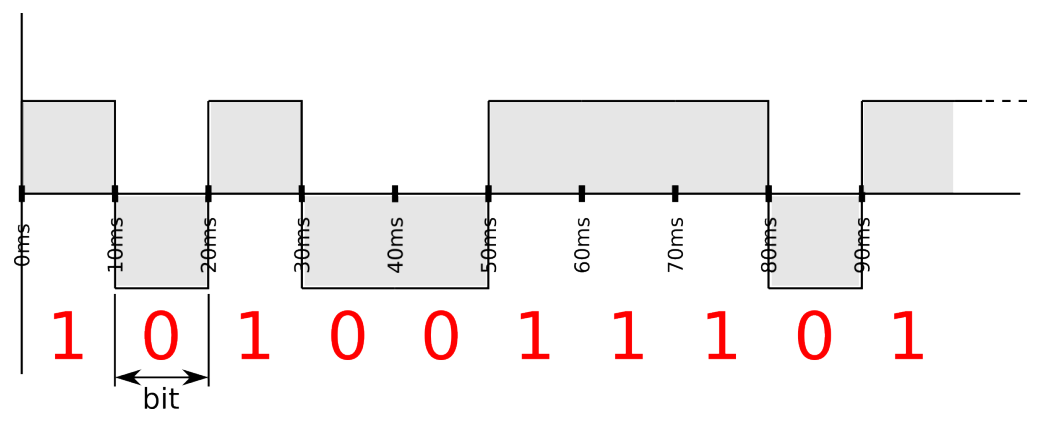

Figura 2.13: Codificación NRZ bipolar de 100 bps utilizada para transmitir la palabra de sincronismo de las líneas L1OF GLONASS. 
Las líneas se agrupan para formar estructuras de datos más largas. Una trama dura $30 \mathrm{~s}$ y se encuentra formada por quince líneas consecutivas. Cinco tramas forman a su vez una supertrama, la cual tiene 2,5 minutos de duración.

En cada trama, las líneas de la I a la IV contienen lo que se denomina Información Inmediata del satélite transmisor. Esto se corresponde aproximadamente con la información de las subtramas I a III de los satélites GPS: información del tiempo GLONASS, estado operativo, parámetros del modelo analítico del reloj de a bordo, y efemérides orbitales correspondientes al satélite transmisor.

La Información Inmediata se transmite de forma completa con cada trama, por lo que un receptor requiere de entre 3 (mejor caso) y 30 segundos (peor caso sin considerar errores de bit en la demodulación) en recopilar la información de corrección del reloj de a bordo y efemérides completas del satélite transmisor.

La Información Inmediata transmitida por el satélite se repite en cada trama, excepto cuando se producen actualizaciones desde el Segmento de Control del sistema.

Las líneas de la V a la XV corresponden a la Información no Inmediata, compuesta por la predicción de las órbitas aproximadas de todos los 24 satélites de la constelación, el estado de cada satélite, y otra información adicional como por ejemplo la relación entre el tiempo GLONASS y el tiempo GPS. Esta información es aproximadamente equivalente a la información de almanaque transmitido por los satélites GPS. Debido a la extensión de estos datos la información se transmite por partes, distribuyéndola a lo largo de todas las tramas de una misma supertrama, siendo necesario 2,5 m para completar una transmisión completa de la información no inmediata.

En este punto cabe señalar que mientras que a los satélites GPS les toma 12,5 m para transmitir la totalidad de su información de almanaque, a los satélites GLONASS les insume apenas 2,5 m transmitir la información no inmediata. La razón de esta diferencia radica por un lado en que la constelación GLONASS consiste nominalmente de solamente 24 satélites, mientras que GPS puede acomodar hasta 32 satélites activos en su almanaque, por lo que es menor la cantidad de información de estado que es necesario transmitir. Por otro lado la información transmitida por los satélites GLONASS utiliza un nivel de precisión inferior a la transmitida por los satélites GPS: los campos utilizan menos bits en punto fijo, algunas aproximaciones suprimen términos de orden superior, hay información omitida, etc. Esta economía significa que los modelos orbitales y de reloj utilizados para determinar la hora y la posición del satélite transmisor tienen una vida útil más corta que la de sus equivalentes en el sistema GPS, por lo que el Segmento de Control GLONASS actualiza los parámetros de los mensajes de navegación de todos los satélites con una frecuencia mayor que su contraparte occidental. 


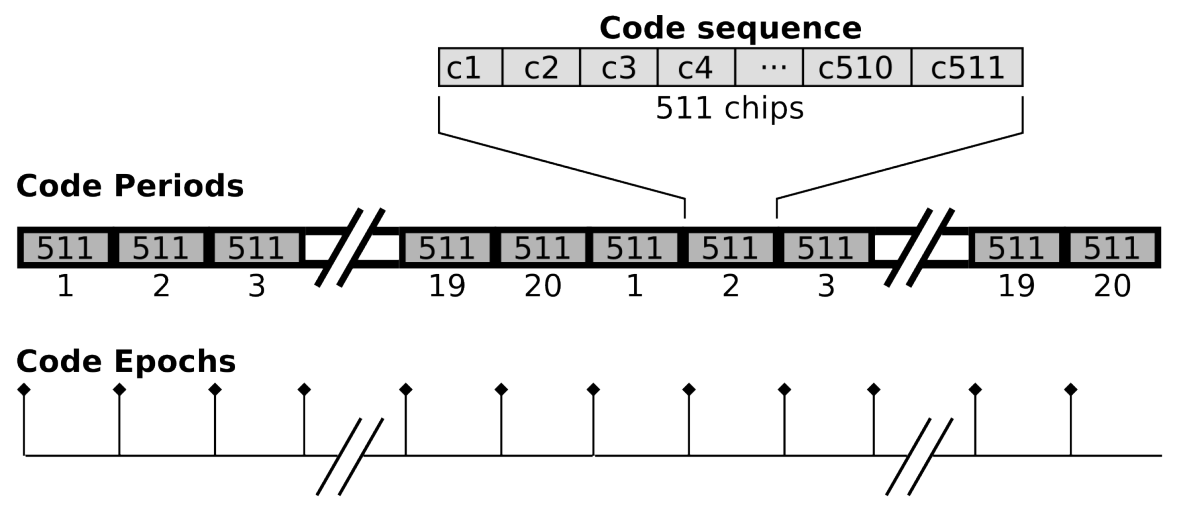

Data bits

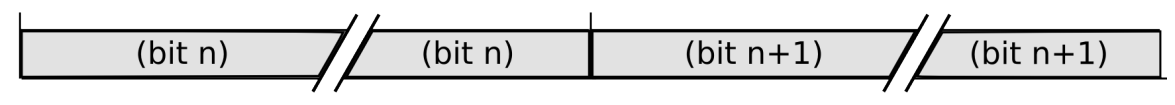

\section{Data bit edges}

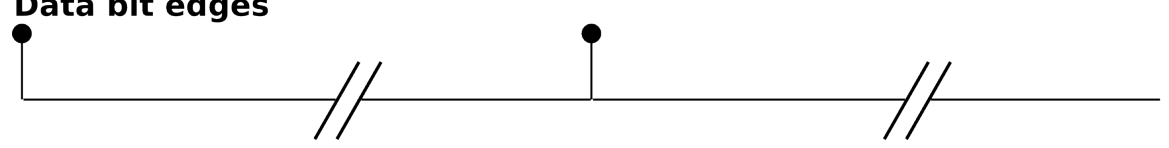

Figura 2.14: Alineamiento entre los períodos de la función de código GLONASS y los bits de datos transmitidos en la señal L1OF.

\subsubsection{Sincronismo}

Al igual que lo que ocurre con la señal GPS C/A (Sección 2.2.5.3), en la señal GLONASS L1OF existen diversas relaciones de sincronismo entre los múltiples niveles de estructura de la señal. Como se puede ver al comparar la Figura 2.14 con la Figura 2.9, estas relaciones son muy semejantes a las vistas para GPS: los comienzos de cada período de la función de código, los bits de datos del mensaje de navegación, y el comienzo del día GLONASS son todos síncronos entre sí.

El generador de código utilizado para expandir el espectro de la señal está alineado con los bits de la modulación de datos. Tal como se adelantó, la función de código se genera con una tasa de $511 \mathrm{kHz}$ y la secuencia de código tiene un largo de 511 chips, por lo que el período de la función de código es de exactamente $1 \mathrm{~ms}$. Los bits de datos (50 bps) y de sincronismo (100 bps) duran exactamente una cantidad entera de estos ciclos y su comienzo coincide con el paso del generador por su fase cero.

El comienzo del día GLONASS coincide con el comienzo de la primera línea de la trama I de la primer subtrama. En cada trama hay un campo $t_{k}$ que indica indica de forma explícita y en unidades de $30 \mathrm{~s}$ el valor TOD (Time Of Day, es la cantidad de tiempo transcurrida desde las 00 : $00 \mathrm{hs}$ del día GLONASS) correspondiente al instante de comienzo de dicha trama. 
Una vez armado del TOD, el receptor ya se encuentra en condiciones de determinar el tiempo de transmisión de la señal recibida correspondiente a cualquier instante de muestreo $t_{r}$ simplemente contando la cantidad de tramas, líneas, bits, chips y fracciones de chips que corresponden a dicho instante. Siguiendo con la clasificación utilizada en 2.2.5.3, el tiempo de transmisión se puede descomponer en dos partes bien definidas por el origen de sus datos: un tiempo grueso $t_{t t c}\left(t_{r}\right)$ y un tiempo fino, $t_{t t f}\left(t_{r}\right)$ :

$$
t_{t t}\left(t_{r}\right)=t_{t t c}\left(t_{r}\right)+t_{t t f}\left(t_{r}\right)
$$

El término $t_{t t c}\left(t_{r}\right)$ corresponde a la estimación del tiempo $t_{r}$ que puede hacerse a partir de información obtenida en la etapa de decodificación del mensaje de navegación: valor del campo $t_{k}$ de la trama que envuelve el instante $t$, la cantidad $n_{s t r i n g}\left(t_{r}\right)$ de líneas de la trama completadas antes de $t_{r}$, la cuenta $n_{b i t}$ de bits recibidos entre el fin de la última trama y el instante $t_{r}$ :

$$
t_{t t c}\left(t_{r}\right)=30 \cdot t_{k}\left(t_{r}\right)+2 \cdot n_{\text {string }}\left(t_{r}\right)+20 \cdot 10^{-3} \cdot n_{b i t}\left(t_{r}\right)
$$

La resolución del término $t_{t t c}\left(t_{r}\right)$ es de $20 \mathrm{~ms}$, equivalente a un tiempo de bit del mensaje de navegación.

El tiempo fino $t_{t t f}$ complementa al anterior, completando la información de tiempo hasta alcanzar una resolución del orden de los nanosegundos. La información para calcular este término proviene del lazo de seguimiento de la función de código del satélite, y se calcula a partir de $n_{m s}$ que es la cantidad de ciclos enteros de la función de código transcurridos desde el último flanco de bit (valor coincidente con la cantidad de milisegundos transcurridos), y $p_{\text {chips }}$ que es la cantidad de chips recibidos desde el último fin de ciclo de código. Notar que $p_{\text {chips }}$ es una variable real, con parte entera y fraccionaria:

$$
t_{t t f}\left(t_{r}\right)=1 \cdot 10^{-3} \cdot n_{m s}\left(t_{r}\right)+\frac{1}{511 \cdot 10^{3}} \cdot p_{\text {chips }}\left(t_{r}\right) .
$$

Dejando de lado cualquier limitación numérica a la resolución de los términos anteriores, la exactitud del tiempo de transmisión así calculado está determinada por la varianza de la estimación de fase de la función de código, que a su vez depende la relación SNR de la señal recibida.

\subsection{Segmento de Usuario GPS y GLONASS}

El Segmento de Usuario de los sistemas GPS y GLONASS es la designación abstracta que reciben el conjunto de los receptores de dichos sistemas. A diferencia de los segmentos de 
Control y Espacial que se encuentran formados por una serie de activos perfectamente definidos y controlados por la autoridad central de los respectivos sistemas, el Segmento de Usuario es solamente el nombre que recibe el conjunto de todos los receptores de un dado sistema, con poca o ninguna relación unos con otros y sin ningún tipo de control por parte de la autoridad central.

Los receptores que forman parte del Segmento de Usuario explotan los servicios ofrecidos por los segmentos de Control y Espacial, recibiendo las señales transmitidas por los satélites y procesándolas. Los receptores son elementos pasivos dentro del sistema, ya que sólo actúan como receptores de las señales transmitidas por los satélites sin transmitir nada en la dirección contraria.

En el pasado los Segmentos de Usuario de los diferentes sistemas GNSS han permanecido separados, pero en la actualidad son cada vez más frecuentes los receptores con la capacidad de procesar las señales de más de un sistema GNSS simultáneamente por lo que puede comenzar a hablarse de un Segmento de Usuario unificado.

La capacidad de procesar las señales de múltiples sistemas GNSS trae aparejadas múltiples ventajas: disponibilidad aumentada, la mejora de la calidad de las soluciones de navegación que se pueden calcular, un grado de independencia de los sistemas individuales aumentado, y la posibilidad de contar con redundancia de sistema. Esta tendencia se profundizará en los años venideros, con la aparición de nuevos sistemas y nuevas señales cuyo diseño contempla la interoperabilidad como uno de sus requerimientos base. Es el caso de las futuras señales transmitidas por los sistemas GPS, GLONASS y Galileo, que por diseño utilizarán frecuencias portadoras y codificaciones compatibles entre sí.

\subsubsection{Modelo de funcionamiento}

Los receptores GNSS para los sistemas GPS y GLONASS funcionan sobre principios semejantes. En su forma más simplificada, la función del receptor es determinar la posición del usuario a partir de conocer la distancia de éste hasta una serie de puntos de referencia cuya posición es conocida. Esta forma de navegación es conocida como multilateración. En la Figura 2.15 se puede ver un ejemplo de este concepto. Allí la posición del punto $U$ es determinada a partir de conocer las distancias $d_{1}, d_{2}$ y $d_{3}$ entre este punto y tres puntos de referencia, $R_{1}, R_{2}$ y $R_{3}$, localizando la intersección de los lugares geométricos que cumplen con las distancias a cada una de las referencias individuales. En el caso particular de utilizarse solamente tres mediciones de distancia el proceso de multilateración recibe el nombre de trilateración. 


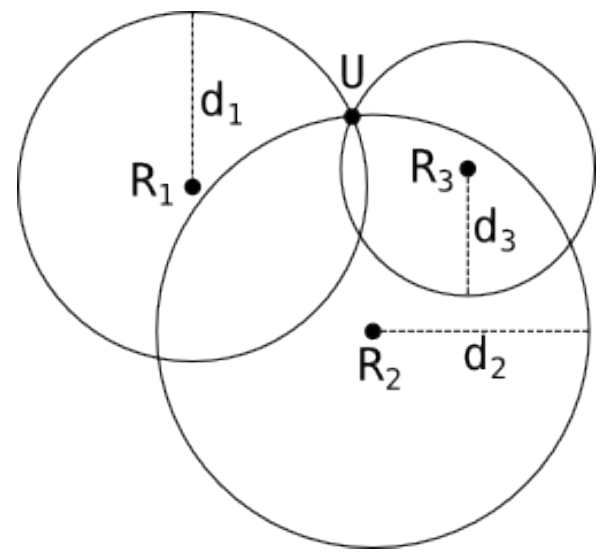

Figura 2.15: Ejemplo de trilateración en el plano. Dados tres puntos de referencia se encuentra la posición del usuario, $U$, mediante la intersección de los lugares geométricos que puntos que se encuentran a distancias $d_{1}, d_{2}$ y $d_{3}$ de los puntos de referencia respectivos.

Los receptores GNSS utilizan los satélites del segmento espacial de la constelación correspondiente (GPS o GLONASS) como referencia para ubicar su posición. Cada satélite transmite codificada en su señal transmitida dos tipos de información:

- El mensaje de navegación, que contiene suficiente información para que el receptor pueda determinar con enorme precisión trayectoria orbital del vehículo espacial en un marco de coordenadas bien definido (ECEF, por ejemplo).

- El tiempo de transmisión de la señal, codificado de forma implícita en los diversos niveles de estructura de la señal.

Utilizando el tiempo de transmisión $t_{t}^{(i)}$ del i-ésimo satélite y sus correspondientes parámetros orbitales el receptor calcula la posición que tenía cada uno de los satélites cuya señal está recibiendo en el instante de transmisión de la señal.

El receptor debe entonces determinar la distancia que lo separa de cada uno de los satélites. Como primera aproximación se puede decir que el cálculo de dicha distancia se realiza de forma indirecta, mediante la medición del tiempo que le toma a la onda electromagnética viajar desde el satélite hasta el receptor. Para eso el receptor realiza en un mismo instante de recepción $t_{r}$ el muestreo de los tiempos de transmisión $t_{t}^{(i)}$ de todas las señales que llegan en ese momento. El tiempo de propagación por lo tanto será:

$$
t_{p}^{(i)}=t_{r}-t_{t}^{(i)}
$$

y la distancia entre el i-ésimo satélite y el receptor (conocido como rango al satélite) será

$$
\rho_{i}=t_{p}^{(i)} c
$$


donde $c$ es la velocidad de la luz en el vacío.

Es fácil ver que resolver la posición de un usuario a partir de estas mediciones de distancia a una serie de puntos de referencia en un marco de referencia tridimensional equivale a buscar la intersección de una serie de esferas centradas en los puntos de referencia y cuyos radios son las distancias del usuario a cada uno de ellos. Para que el lugar geométrico de la intersección sea una única solución es suficiente con tener mediciones a cuatro puntos de referencia ${ }^{10}$.

Dicho problema de intersección se puede plantear de forma analítica. A partir de cuatro mediciones de rango $\rho_{i}$ el usuario puede resolver sus coordenadas calculando las incógnitas las incógnitas $\left(x_{u}, y_{u}, z_{u}\right)$ del siguiente sistema de ecuaciones no lineal:

$$
\begin{aligned}
\rho_{1} & =\sqrt{\left(x_{s}^{(1)}-x_{u}\right)^{2}+\left(y_{s}^{(1)}-y_{u}\right)^{2}+\left(z_{s}^{(1)}-z_{u}\right)^{2}} \\
\rho_{2} & =\sqrt{\left(x_{s}^{(2)}-x_{u}\right)^{2}+\left(y_{s}^{(2)}-y_{u}\right)^{2}+\left(z_{s}^{(2)}-z_{u}\right)^{2}} \\
\rho_{3} & =\sqrt{\left(x_{s}^{(3)}-x_{u}\right)^{2}+\left(y_{s}^{(3)}-y_{u}\right)^{2}+\left(z_{s}^{(3)}-z_{u}\right)^{2}} \\
\rho_{4} & =\sqrt{\left(x_{s}^{(4)}-x_{u}\right)^{2}+\left(y_{s}^{(4)}-y_{u}\right)^{2}+\left(z_{s}^{(4)}-z_{u}\right)^{2}}
\end{aligned}
$$

donde $\left(x_{s}^{(i)}, y_{s}^{(i)}, z_{s}^{(i)}\right)$ son las coordenadas del i-ésimo punto de referencia, y $\rho_{i}$ es el rango entre el usuario y dicho punto.

Este análisis extremadamente simplificado ya pone de manifiesto las características más importantes de la navegación GNSS. A saber:

- El cálculo se realiza básicamente por multilateración en tres dimensiones.

- Los satélites no participan del proceso de cálculo de la solución de navegación, salvo como faros anunciando su posición y hora.

- La presencia de la Hora del Sistema codificada en la modulación es clave para calcular la "distancia" a los puntos de referencia.

- Es necesaria una cantidad mínima de mediciones de rango independientes para poder despejar todas las incógnitas en la solución de navegación.

- Es crítica la correcta sincronización de todos los relojes involucrados.

Este último ítem puede haber pasado inadvertido en el análisis anterior, y es sin embargo el principal problema que presenta una implementación práctica del sistema simplificado presentado. Para que sea más claro, si un receptor intenta determinar la posición del

\footnotetext{
${ }^{10}$ Siempre que no hayan tres referencias colineales ni cuatro coplanares.
} 
un usuario a partir de las señales transmitidas por cuatro satélites diferentes, existen cinco sistemas espacialmente separados unos de otros, con referencias de tiempo (relojes) independientes. Los tiempos de propagación se obtuvieron a partir de medir la diferencia entre $t_{r}$ y $t_{t}^{(i)}$, pero dichas medidas fueron realizadas tomando diferentes relojes como referencia. Si dichos patrones de referencia no están correctamente sincronizados, cada microsegundo de error significan 300m de error en el rango correspondiente.

Una de las tareas del Segmento de Control es la de encargarse de garantizar el sincronismo entre todos los relojes de a bordo de la constelación, dentro de un margen adecuado. Ello se logra monitoreando permanentemente los parámetros de funcionamiento y las señales transmitidas por los satélites, y comparando estos valores con el patrón de referencia central del sistema. A partir de este análisis se formula un modelo del avance de cada uno de los relojes atómicos de a bordo que permite establecer la relación entre la hora anunciada por estos y la Hora de Sistema real con error despreciable.

Por otro lado, el patrón de tiempo utilizado en el receptor está totalmente fuera de la órbita de control del sistema. Más aún, los receptores suelen contar con referencias de tiempo poco sofisticadas generadas a partir de relojes de baja calidad (comparados con un patrón atómico), frecuentemente resonadores de cuarzo. Incluso si el usuario contara con la posibilidad de sincronizar esporádicamente el reloj del receptor con la Hora del Sistema este sincronismo se perdería rápidamente debido a la propia inestabilidad de su oscilador, que está afectada por la temperatura, las vibraciones y otros factores ambientales.

Para resolver este problema los receptores GNSS relajan la expectativas de sincronización entre el reloj del receptor y la hora central del sistema, y permiten que el reloj del receptor pueda estar desplazado por una cantidad $b$ (por bias, en inglés) respecto de esta última. Admitiendo esto, la hora de arribo de la señal al receptor medida en la base de tiempo de este último será $\tilde{t_{r}}$,

$$
\tilde{t_{r}}=t_{r}+b
$$

donde $t_{r}$ es la hora de arribo verdadera (medida en la base de tiempo del sistema). Al término $b$ se lo llama sesgo, bias u offset, y es una incógnita que en este punto no se puede determinar (o de otra forma se podría sincronizar el receptor con el sistema).

Dado que la hora de arribo verdadera medida en la base de tiempo del sistema no es conocida, tampoco podemos conocer exactamente el tiempo de propagación $t_{p}^{(i)}$. En su lugar tenemos la cantidad $\tilde{t}_{p}^{(i)}$, que se puede verificar fácilmente que difiere del tiempo de propagación verdadero por el término $b$ :

$$
\tilde{t}_{p}^{(i)}=t_{p}^{(i)}+b
$$


Se define una cantidad semejante a la de la ecuación 2.23, denominada pseudorango, que depende por un lado del rango geométrico verdadero y por otro del sesgo del reloj del receptor:

$$
\tilde{\rho}_{i}=\tilde{t}_{p}^{(i)} c
$$

Se puede plantear entonces la siguiente ecuación no lineal que relaciona cuatro incógnitas, $x_{u}, y_{u}, z_{u}$ y $b$ :

$$
\begin{aligned}
\tilde{\rho}_{i} & =\rho_{i}+b c \\
\tilde{\rho}_{i} & =\sqrt{\left(x_{s}^{(i)}-x_{u}\right)^{2}+\left(y_{s}^{(i)}-y_{u}\right)^{2}+\left(z_{s}^{(i)}-z_{u}\right)^{2}}+b c .
\end{aligned}
$$

Se puede probar que con cuatro o más de estas ecuaciones (es decir $M \geq 4$ ) se puede plantear un sistema de ecuaciones que permite resolver simultáneamente las tres coordenadas de la posición geométrica, y el bias del reloj del receptor:

$$
\begin{aligned}
\tilde{\rho}_{i} & =\sqrt{\left(x_{s}^{(1)}-x_{u}\right)^{2}+\left(y_{s}^{(1)}-y_{u}\right)^{2}+\left(z_{s}^{(1)}-z_{u}\right)^{2}}+b c \\
\tilde{\rho}_{i} & =\sqrt{\left(x_{s}^{(2)}-x_{u}\right)^{2}+\left(y_{s}^{(2)}-y_{u}\right)^{2}+\left(z_{s}^{(2)}-z_{u}\right)^{2}}+b c \\
\tilde{\rho}_{i} & =\sqrt{\left(x_{s}^{(3)}-x_{u}\right)^{2}+\left(y_{s}^{(3)}-y_{u}\right)^{2}+\left(z_{s}^{(3)}-z_{u}\right)^{2}}+b c \\
\ldots & \cdots \cdots \\
\tilde{\rho}_{M} & =\sqrt{\left(x_{s}^{(M)}-x_{u}\right)^{2}+\left(y_{s}^{(M)}-y_{u}\right)^{2}+\left(z_{s}^{(M)}-z_{u}\right)^{2}}+b c
\end{aligned}
$$

La restricción $M \geq 4$ para poder resolver el sistema es la razón por la que las constelaciones del Segmento Espacial se diseñan para garantizar al menos cuatro satélites en todo momento en condición de línea de vista con el receptor.

Aunque no se mostrará aquí en detalle, de una forma similar es posible plantear un sistema de ecuaciones que permite resolver la velocidad del usuario. En este caso las entradas al sistema de ecuaciones son las desviaciones aparentes de la frecuencia portadora de cada satélite respecto de su frecuencia nominal; estas desviaciones son proporcionales a la derivada del pseudorango. A partir de cuatro o más ecuaciones se puede resolver el vector velocidad del usuario $\left(v_{x}, v_{y}\right.$ y $\left.v_{z}\right)$ y la desviación en frecuencia de su reloj de referencia del receptor respecto de su valor nominal (la llamada deriva o drift del reloj).

Por razones de extensión se detendrá aquí la exposición sobre el funcionamiento del cálculo de navegación los sistemas GNSS como GPS y GLONASS. El modelo simplificado presentado anteriormente es suficiente para comprender las condiciones de contorno que deben satisfacer los algoritmos de adquisición, sincronización y seguimiento que serán presentados en las secciones y capítulos siguientes. El lector interesado puede encontrar una exposición mucho más completa en las referencias [3] y [4] acerca del proceso de cálculo de soluciones de navegación, incluyendo el acondicionamiento previo 
de las mediciones (compensación de la desviación del reloj del satélite, cálculo de los efectos relativistas debidos a la dinámica del transmisor, compensación de los retardos de propagación debidos a las capas de la atmósfera, etc.).

\subsubsection{Aplicaciones}

La finalidad clásica de los receptores GNSS es la determinación de la localización del usuario. Se entiende por localización la determinación de la posición y opcionalmente la velocidad del receptor GNSS, y por extensión del usuario que lo utiliza o de vehículo donde está montado. Esta información de navegación puede utilizarse a su vez con diferentes fines, que van desde la localización de usuarios en regiones agrestes hasta el seguimiento de trayectoria de vehículos de alta velocidad.

Se puede clasificar como "convencional" a cualquier receptor GNSS para aplicaciones civiles cuyo diseño no esté especialmente sintonizado con una aplicación particular. Es el tipo de receptor GNSS más frecuentemente encontrado en la práctica, y pueden tomar la forma de dispositivos de mano autónomos, o como módulo integrante de dispositivos más complejos (teléfonos celulares, tablets, cámaras de fotos). En la Figura 2.16 se pueden ver varios ejemplos de factores forma en los que pueden aparecer los receptores GNSS dependiendo de la aplicación de que se trate.

Los receptores convencionales típicamente se utilizan exclusivamente con fines de navegación, ya sea como instrumento estático o cuasi-estático (como instrumento de mano, por ejemplo), o bien a bordo de vehículos de baja velocidad. Un criterio para establecer los límites del conjunto de aplicaciones que pueden denominarse de baja velocidad podría ser el siguiente: se consideran de baja velocidad todas aquellas aplicaciones donde el efecto de la dinámica de los vehículos es despreciable comparado con los efectos debidos a otras fuentes (por ejemplo, debido a la variación de velocidad del satélite transmisor, y las inestabilidades propias del oscilador utilizado en el receptor). En términos generales se pueden considerar como vehículos de baja velocidad a automóviles, buses, trenes, barcos, etc., e incluso a pequeños aviones civiles y comerciales.

Dependiendo de la aplicación específica el receptor puede realizar procesamientos adicionales, cambios de representación, filtrado, etc. con el fin de hacer la información más comprensible para el usuario. Un receptor GNSS portátil, por ejemplo, típicamente convierte las coordenadas de posición a coordenadas LLA (Latitud, Longitud y Altura), ubica esas coordenadas en un mapa de los alrededores previamente almacenado en la memoria del receptor, y puede utilizarlas para proponer al usuario el camino más conveniente para alcanzar un dado destino. 
Por supuesto que la utilización de los receptores GNSS como instrumentos de navegación está lejos de ser la única aplicación posible del sistema. Una lista exhaustiva es imposible, pero se pueden nombrar varios ejemplos con el fin de mostrar la diversidad de aplicaciones de este tipo de sistemas.

Los sistemas GNSS puede ser utilizados como sistemas de transferencia de tiempo de alcance global, que permiten la sincronización precisa de la hora en relojes separados por grandes distancias. Con este fin se utilizan receptores de laboratorio que procesan las señales recibidas desde los satélites GNSS y calculan la soluciones de navegación a intervalos definidos (típicamente de un segundo). Utilizando la información de tiempo de sistema presente en esta solución cada receptor generará una secuencia de pulsos cuyos flancos se encuentran alineados con los segundos del sistema GNSS, lo cual recibe el nombre de señal PPS (de Pulso Por Segundo o Pulse-Per-Second). Esta señal PPS es entonces utilizada como referencia de tiempo para otros instrumentos.
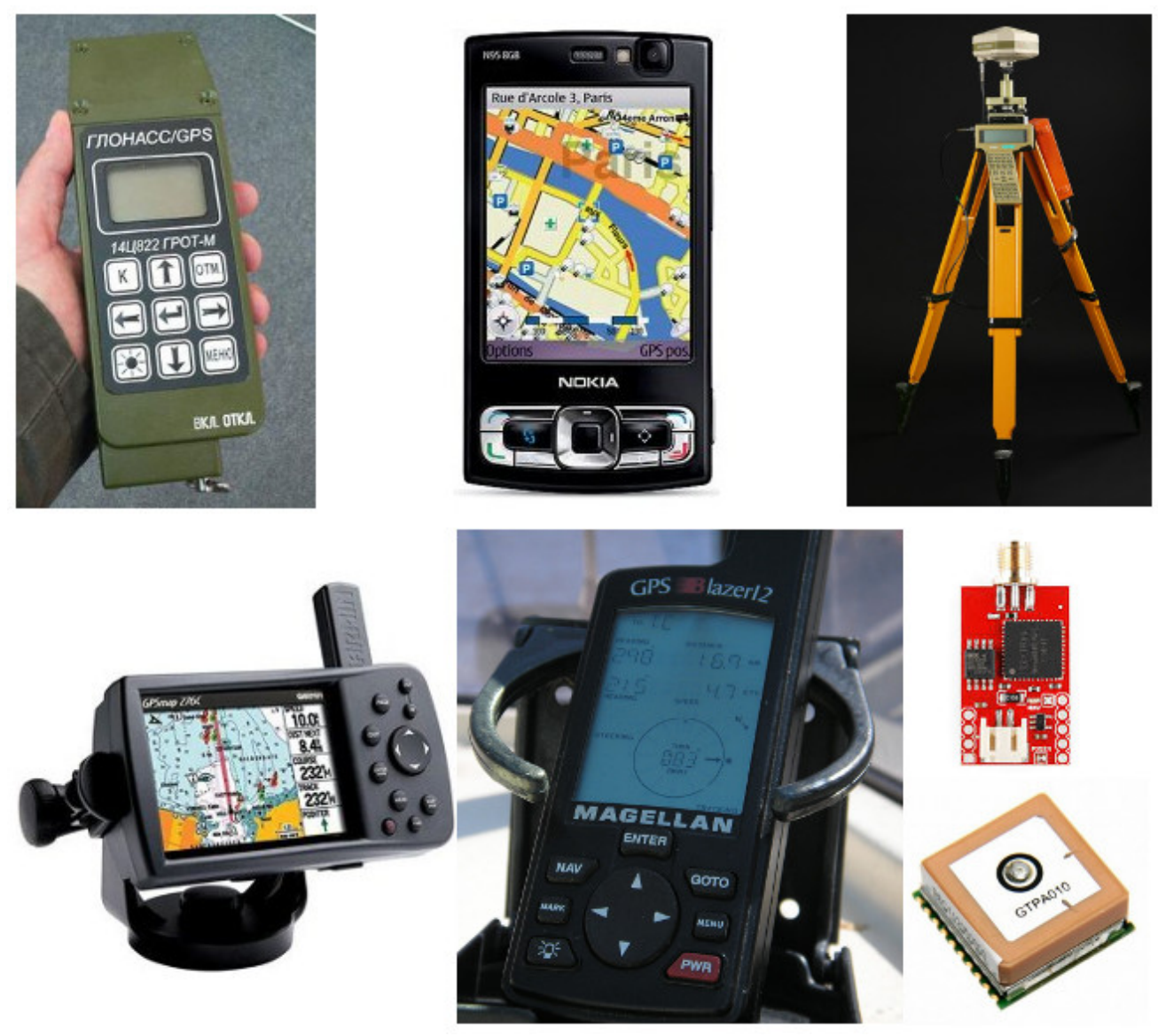

Figura 2.16: Algunos ejemplos de los formatos en que vienen los receptores GNSS según la aplicación. De izquierda a derecha y de arriba hacia abajo: Un receptor GLONASS/GPS de mano pretérito, teléfono celular con navegación GPS incorporada, receptor GPS de precisión para agrimensura, receptor GPS para automóvil, receptor GPS marítimo, dos micro módulos GPS para aplicaciones embebidas. 
Utilizando sistemas semejantes al anterior en múltiples locaciones separadas geográficamente, los instrumentos de todas ellas quedarán sincronizados entre sí a través de la Hora del Sistema que es común a todos. El error de sincronización estará determinado por la precisión de las soluciones de navegación de los receptores, que típicamente es del orden de algunos nanosegundos. Es fácil ver que este tipo de sistema permite no sólo la sincronización de los instantes de toma de muestra, sino también la transferencia de frecuencias de referencia, calibración de instrumentos, sincronización de redes, etc.

Como se mencionó anteriormente, las señales transmitidas por los satélites GNSS se ven afectadas por un retardo al atravesar la ionosfera cuyo valor depende de las condiciones de esta capa atmosférica durante el intervalo de propagación de la señal. El estado de la ionosfera es muy volátil, variando rápidamente a lo largo del día en función de una larga serie de factores que incluyen la orientación relativa al sol de la región bajo estudio, las tormentas geomagnéticas, las eyecciones solares, etc.

La distorsión provocada por la ionosfera en los tiempos de propagación de las señales de radiofrecuencia sigue una ley bien conocida que depende fundamentalmente del estado de dicha capa atmosférica (cuantificado por el parámetro TEC, Total Electron Count) y la frecuencia central de la señal incidente. Mediante la utilización de receptores de laboratorio de doble banda es posible medir las diferencias de retardo en una y otra banda y por intermedio de esa medida caracterizar la condición atmosférica reinante, en tiempo real, y sin la necesidad de equipos extremadamente onerosos ni campañas complejas (lanzamiento de globos, etc.).

Cerrando esta enumeración de casos de uso particulares, si se colocan múltiples antenas en un arreglo fijo en el que se conocen de forma precisa la ubicaciones relativas de unas antenas respecto de las otras es posible determinar la orientación del arreglo mediante el procesamiento de las diferencias en las fases de portadora con la que arriban varias señales GNSS a cada una de las antenas del conjunto. Si el arreglo se encuentra fijo a un vehículo esto permite determinar la orientación del mismo, complementando las mediciones de orientación obtenidas mediante otros dispositivos y así mejorando la calidad de la información disponible para realizar la navegación del mismo. [13].

\subsection{Resumen de capítulo}

Los sistemas de navegación por satélite de tipo GNSS han adquirido un enorme relevancia en años recientes debido al gran abanico de posibles aplicaciones de los mismos en todas las actividades tanto comerciales como científicas y militares. La historia de estos sistemas, sin embargo, se remonta hasta varias décadas atrás, cuando se realizaron los 
primeros ensayos de utilización de constelaciones de satélites especialmente dedicadas a transmitir señales que permitieran a vehículos marítimos y terrestres la determinación de su posición en el globo terrestre. No fue hasta la entrada en escena de los sistemas GPS y GLONASS a principios de la década del ochenta que el concepto alcanzó finalmente su forma más madura, moldeando en el proceso la mayor parte de las tecnologías que son utilizadas hasta el día de hoy por las versiones más modernas de estos sistemas.

El auge actual de la utilización de los sistemas GNSS y el interés comercial por su explotación auguran una gran aceleración en su desarrollo en los años próximos, con la incorporación de nuevas constelaciones y la modernización de las existentes para sumar nuevas capacidades y mejorar las características de los servicios de navegación actuales.

En el presente el escenario tecnológico de la navegación por satélite está dominado por dos actores principales, que son los sistemas GPS (perteneciente a los Estados Unidos) y GLONASS (controlador por Rusia). Si bien ambos sistemas han seguido históricamente caminos de desarrollo independientes, las tecnologías subyacentes a ambos son fundamentalmente las mismas, por lo que existe un alto nivel de simetría entre los sistemas desarrollados alrededor de uno y otro sistema.

Los receptores GNSS capaces de recibir y procesar las señales más de un sistema GNSS diferente presentan una serie de ventajas en términos de redundancia, disponibilidad de servicios y de calidad de las soluciones de navegación que se pueden obtener comparados con los receptores convencionales monosistema, por lo que existe una tendencia muy fuerte orientada hacia el desarrollo de este tipo de receptores multisistema. 


\section{Capítulo 3}

\section{Receptores GNSS convencionales}

\subsection{Introducción}

En este capítulo se presentará la estructura y los algoritmos principales que regulan el funcionamiento de un receptor GNSS convencional. Esta información servirá de punto de partida para comprender el impacto que tienen en el diseño del receptor las características particulares de la utilización de receptores GNSS a bordo de vehículos cohete que serán examinadas en el Capítulo 4.

Por razones de brevedad se concentrará la descripción en aquellos conceptos más generales que se aplican a una amplia variedad de receptores, dejando los detalles para la bibliografía específica del tema. Una descripción más acabada puede encontrarse en [3] y [4] para el caso de los receptores del sistema GPS, aunque las mismas ideas son de fácil extrapolación al caso de receptores GLONASS.

\subsection{Etapas de un receptor convencional}

Si bien existe un amplia variedad de receptores GNSS con diseño y propósitos diferentes, la amplia mayoría de ellos sigue una arquitectura de procesamiento que puede ser representada tal como se ve en la Figura 3.1. Dicha figura representa al receptor dividido en una serie de etapas de procesamiento que operan sobre las señales de entrada hasta alcanzar la solución de navegación PVT (Position, Velocity, Time).

En las secciones siguientes se expondrán las características principales de cada una de estas etapas y se presentarán modelos analíticos de algunas de ellas. 


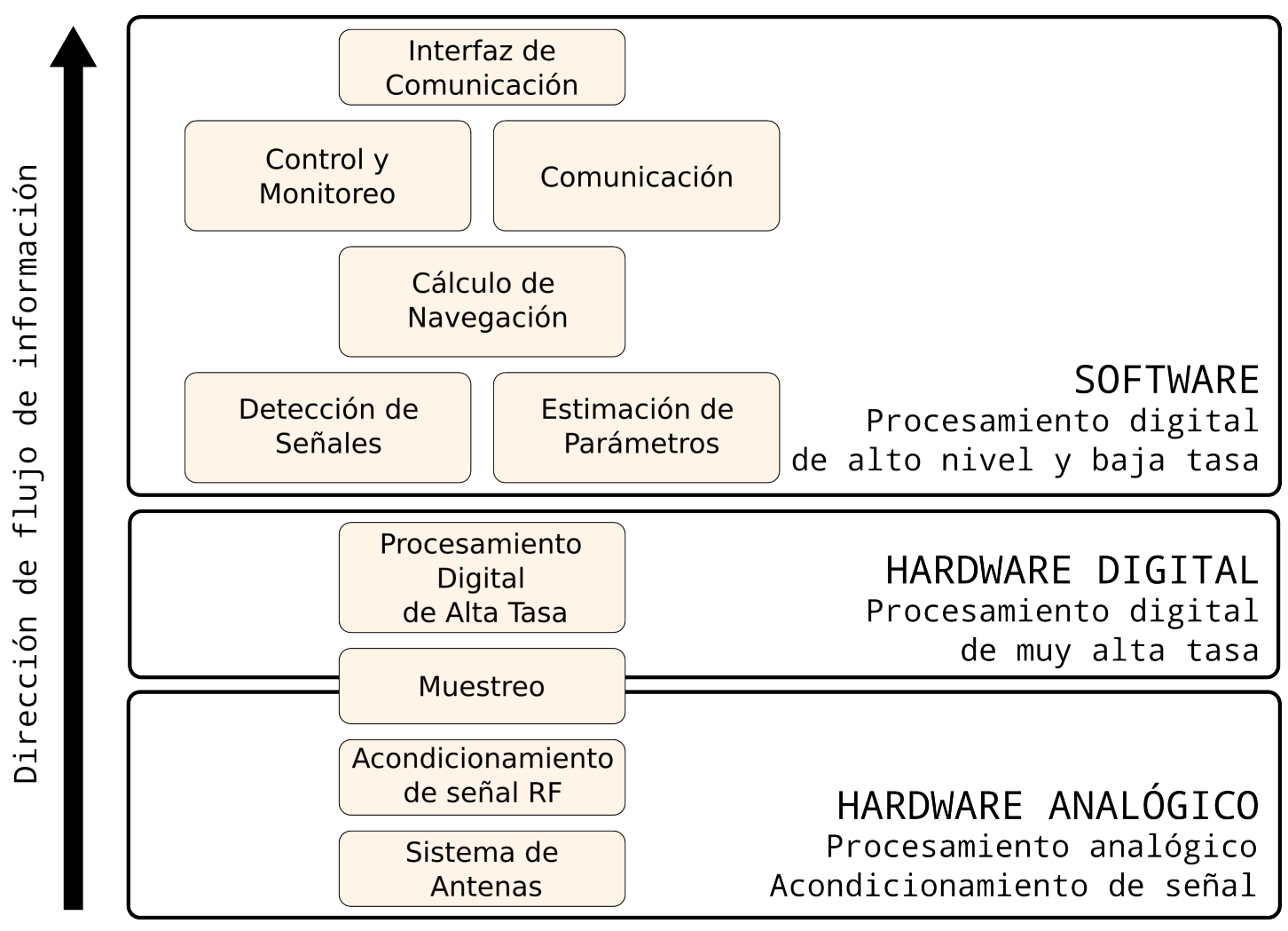

FiguRA 3.1: Etapas de procesamiento en un receptor GNSS convencional.

\subsection{Sistema de antenas}

La antena es la primera etapa que debe atravesar la señal en un receptor. Es el elemento encargado de convertir la señal de radiofrecuencia que se propaga por el espacio libre en una señal eléctrica confinada que pueda ser procesada por los circuitos del receptor. Sus características son sumamente importantes, debido a que la eficiencia de la antena para realizar la conversión anterior es uno de los factores determinantes de la sensibilidad que pueda lograrse en el receptor.

En los receptores convencionales generalmente existe una única antena de entrada. La utilización de múltiples antenas se reserva para casos de aplicación específicos donde es necesaria redundancia espacial (como por ejemplo en el caso de cálculo de orientación mediante señales GNSS), o donde una única antena no permite lograr una cobertura adecuada del conjunto de direcciones de arribo posibles.

\subsubsection{Características}

Algunas de las características más importantes de las antenas de RF utilizadas en GNSS son las siguientes: 
- La bandas o bandas de RF a las es sensible.

- El patrón de radiación.

- El tipo de polarización.

- El carácter activo o pasivo de la antena.

\subsubsection{Bandas sensibles}

Las bandas de radiofrecuencia utilizadas en aplicaciones GNSS dependen de subconjunto de señales GNSS que se quieran procesar. Tal como se vio en capítulos anteriores cada sistema de posicionamiento transmite múltiples señales que pueden ser utilizadas por los receptores del segmento terrestre. Cada tipo de señal presenta sus propias particularidades en términos de la modulación utilizada, ancho de banda, valor nominal de la frecuencia portadora, etc.

En la actualidad los receptores de uso convencional existentes en el mercado se limitan mayormente a procesar las señales civiles de los sistemas GPS y en algunos casos también GLONASS, las cuales se transmiten sobre diferentes sub-bandas de la banda L1 del espectro radioeléctrico. Para recibir la señal GPS C/A el rango de frecuencias de interés es la sub-banda centrada en $1575,42 \mathrm{MHz}$ (valor nominal) y que tiene un ancho de banda mínimo de entre $2 \mathrm{MHz}$ y $20 \mathrm{MHz}$ dependiendo de la aplicación particular. Una antena apta para ser utilizada con un receptor GLONASS, en cambio, debe estar sintonizada para poder como mínimo recibir señales en el segmento espectral que va aproximadamente de $1596 \mathrm{MHz}$ a $1608 \mathrm{MHz}$ que es el rango que cubre la totalidad de los canales FDMA utilizados por la señal. La relativa cercanía de los espectros de uno y otro sistema en en la banda L1 permite la construcción de antenas de doble sistema que pueden ser utilizadas con receptores duales GPS/GLONASS.

\subsubsection{Patrón de radiación}

En los receptores convencionales se suelen utilizar antenas con patrón de radiación hemisférico, que concentran la ganancia de la antena en la dirección de cénit de la misma y rechazan las señales que arriban en la dirección opuesta. En ángulo de apertura entre puntos de $-3 \mathrm{dBi}$ (ganancia relativa respecto de una antena isotrópica) es típicamente de $140^{\circ}$, y la ganancia máxima de aproximadamente $6 \mathrm{dBi}$ en la dirección del cénit de la antena. 


\subsubsection{Polarización}

De todas las variantes de polarización que puede tener una antena, las polarizaciones de tipo circular (a derecha o a izquierda) son particularmente útiles en los sistemas de comunicación satelital. Esto es así por su característica de ser insensibles al ángulo de rotación relativa de la antena receptora respecto de la transmisora alrededor de la línea que las une, lo cual hace que no sea necesario garantizar una orientación relativa de una respecto a la otra para lograr establecer un enlace de comunicación eficiente.

Además, la utilización de polarización circular tiene la ventaja añadida de que permite lograr un mejor nivel de rechazo en condiciones de multicamino. Este último es el nombre que reciben los escenarios en los que además de la señal recibida en la dirección de la recta que une las antenas transmisora y receptora, en esta última inciden además frentes de onda adicionales debidos a reflexiones de la misma señal en objetos en su vecindad. Muchos tipos de reflexiones provocan la inversión de la polarización circular de la señal (esto es, una señal con polarización derecha se refleja como de polarización izquierda, y viceversa), por lo que la señales reflejadas dejan de tener una polarización compatible con la antena receptora y por lo tanto su influencia se atenúa enormemente.

Debido a estas ventajas la totalidad de los satélites transmisores de todos los sistemas GNSS y también la amplia mayoría de los receptores utilizan antenas con polarización circular en su diseño. En el caso de los sistemas GPS y GLONASS, el diseño de ambos sistemas es tal que se requiere de la utilización de antenas con polarización circular a derecha en el receptor para lograr un nivel de eficiencia óptimo del canal y maximizar la potencia de señal recuperada.

Debe notarse, sin embargo, que también posible la utilización de antenas con polarización lineal para recibir las señales de estos sistemas, pero en este caso se produce una pérdida de $3 \mathrm{~dB}$ respecto de lo que se lograría utilizando una antena con polarización circular a derecha. Existen casos donde este este compromiso es necesario en función de cumplir con otros requerimientos (como por ejemplo, el perfil aerodinámico de la antena).

\subsubsection{Alimentación}

Respecto de sus requerimientos de alimentación, las antenas pueden dividirse en pasivas y activas. Las primeras se encuentran formadas solamente por el elemento radiante, generalmente formado por uno o varios elementos conductores cuyas dimensiones le otorgan características receptoras en la frecuencia de diseño de la antena. Las antenas pasivas se encuentran totalmente desprovistas de todo tipo de electrónica activa (amplificadores, por ejemplo), por lo que no requieren de ningún tipo de alimentación externa para 
su funcionamiento. Este tipo de antena es perfectamente adecuada cuando la antena está conectada de forma directa al receptor o unida a éste a través de un cable muy corto, pero la ausencia de amplificación en la antena hace que la figura de ruido del receptor crezca rápidamente a medida que la longitud de dicho cable aumenta. Por esto último no es conveniente la utilización de antenas pasivas cuando el receptor y la antena se encuentran separados, como suele ser el caso de receptores montados en vehículos.

Las antenas activas se encuentran formadas por la combinación de una antena pasiva con una etapa activa formada por un amplificador de bajo ruido (LNA, Low Noise Amplifier). Para evitar la saturación del amplificador generalmente también se incorpora a la antena un filtro pasabanda que limita la recepción de señales fuera de su banda de diseño. El agregado de la etapa de ganancia inmediatamente a continuación de la antena pasiva limita el impacto que tiene la atenuación del cable de conexión en la figura de ruido del sistema, por lo que este tipo de antena se utiliza cuando es necesario separar físicamente la antena del resto del receptor. La alimentación requerida para el amplificador generalmente se provee desde el receptor a través del mismo cable RF.

\subsubsection{Modelo de señal}

En cualquier instante dado en la antena se encuentran presentes y superpuestas las señales transmitidas por todos los satélites que están en situación de línea de vista con la antena receptora. Limitando el análisis a las señales civiles de banda L1 y suponiendo despreciable cualquier reflexión debida a multicamino se puede modelar la señal de salida de la antena usando la siguiente expresión:

$$
s^{\text {ant }}(t)=n^{\text {ant }}(t)+\sum_{i=1}^{M} A_{i}^{a n t} c_{i}(t+\tau) d_{i}(t) \cos \left(2 \pi\left(f_{i}^{a n t}+\Delta_{i}\right) t+\phi_{i}^{a n t}\right)
$$

donde cada término de la sumatoria representa una señal GPS C/A o GLONASS L1OF independiente que arriba a la antena, $A_{i}^{\text {ant }}$ es la amplitud de dicha señal en el conector de salida de la antena, $c_{i}(t)$ la función de expansión de código, $d_{i}(t)$ el mensaje de navegación modulado, $f_{i}^{a n t}$ la frecuencia nominal de portadora, $\Delta_{i}$ es la desviación Doppler de la frecuencia portadora, y $\phi_{i}$ la fase de portadora en $t=0$. El término $n^{\text {ant }}(t)$ representa el ruido presente en la antena, que generalmente es modelado como AWGN (Additive White Gaussian Noise).

Debido a los niveles extremadamente bajos de potencia con que arriban las señales al receptor la práctica totalidad de la potencia de la señal $s^{a n t}(t)$ es debida al término de ruido $n^{a n t}(t)$. Es sólo mediante procesamiento y filtrado posterior que la relación SNR 
de las señales recibidas puede ser elevada por encima del ruido lo suficiente como para permitir su procesamiento y demodulación.

\subsection{Acondicionamiento y amplificación}

Es la primera etapa de procesamiento de la señal ya dentro del receptor.

Es una etapa analógica donde la señal recibida desde la antena es amplificada, filtrada, y desplazada en frecuencia para limitarla en ancho de banda a la banda de interés, transportar la señal a una banda de frecuencia intermedia, y aumentar los niveles de señal para que ésta pueda ser digitalizada en las etapas siguientes.

El funcionamiento de esta etapa es similar al de las primeras etapas de cualquier tipo de receptor de radiofrecuencia, consistiendo en general de una o más etapas de conversión de frecuencia conectadas en cascada. Cada una de estas puede a su vez dividirse conceptualmente en amplificación, filtrado y mezcla con un oscilador local.

A medida que se reduce progresivamente la frecuencia central de la señal a través de las sucesivas etapas de frecuencia intermedia (FI) se puede aumentar cada vez más la selectividad de los filtros pasabanda para eliminar potencia de ruido fuera de la banda de interés. Esto persigue el doble propósito de por un lado reducir la mínima frecuencia que muestreo será necesario aplicar posteriormente y también eliminar la mayor cantidad de potencia de ruido que sea posible sin distorsionar la señal.

El modelo de la señal a la salida de la etapa de acondicionamiento y amplificación es similar al de la etapa anterior,

$$
s^{i f}(t)=n^{i f}(t)+\sum_{i=1}^{M} A_{i}^{i f} c_{i}(t+\tau) d_{i}(t) \cos \left(2 \pi\left(f_{i}^{i f}+\Delta_{i}\right) t+\phi_{i}^{i f}\right),
$$

sin embargo debe notarse que las amplitudes en esta etapa se ven modificadas, lo cual queda representado por la nueva amplitud de las señales $A_{i}^{i f}$, y lo mismo ocurre con las frecuencias y las fases iniciales que se ven alteradas por el batido con el oscilador local. Si el receptor tiene una etapa de radiofrecuencia de una única etapa de conversión, como la representada en la Figura 3.2, la relación entre la frecuencia intermedia $f_{i}^{i f}$ y la frecuencia portadora nominal a la entrada $f_{i}^{a n t}$ está dada por la frecuencia del oscilador local utilizado en el batido, $f_{l o}$ :

$$
f_{i}^{i f}=f_{i}^{a n t}-f_{l o}
$$




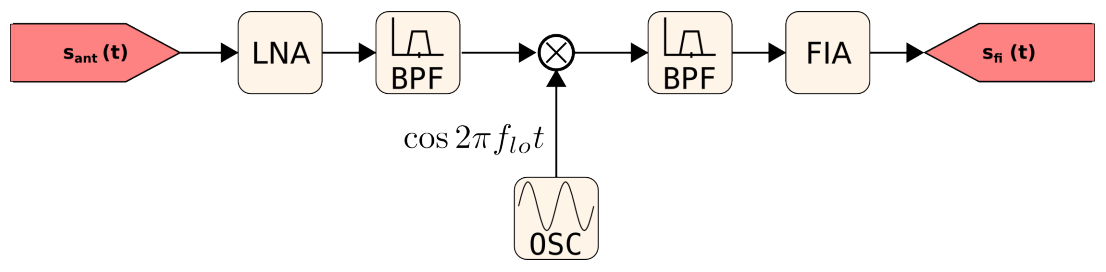

FigurA 3.2: Etapa de radiofrecuencia típica con una única etapa de conversión.

El ruido presente a la salida de esta etapa no es una versión amplificada del ruido $n^{\text {ant }}(t)$ de la etapa anterior. Las diferencia se debe por un lado a que parte de la potencia de ruido original es eliminada gracias al filtrado mucho más selectivo que se hace en esta etapa comparado con el ancho de banda de señal que proviene de la antena. Este filtrado elimina la mayor parte de la potencia superflua que no pertenece a la banda de interés, y por lo tanto tiende a mejorar sustancialmente la relación SNR de la señal cuando se considera el ancho de banda total ocupado por la señal a la entrada.

Por otro lado, la electrónica activa formada por los circuitos amplificadores y conversores de frecuencia introduce potencia de ruido adicional dentro de la banda de interés. La cantidad de potencia agregada es función de la figura de ruido (NF, Noise Figure) de la etapa. Como consecuencia de este incremento del ruido en banda, la relación SNR tenderá a decrementarse al atravesar la etapa si la relación se mide sobre el ancho de banda de interés.

Esta dependencia de la relación SNR con el ancho de banda considerado es la razón por la que generalmente se utiliza un índice alternativo de medición de relación señal a ruido, llamado la relación potencia de portadora a densidad espectral de ruido, o $C / N_{o}$. Este índice es el cociente entre la potencia de señal y el valor de la densidad espectral de ruido a la frecuencia portadora de la señal. Numéricamente equivale a considerar toda la potencia de señal concentrada en una portadora pura y calcular la relación señal a ruido sobre un ancho de banda de $1 \mathrm{~Hz}$ alrededor de dicha portadora.

El índice $C / N_{o}$ es independiente de cualquier suposición respecto del ancho de banda, por lo que resulta particularmente útil en el caso de receptores de sistemas DS-SS, como GPS y GLONASS, donde el ancho de banda ocupado por la señal se modifica durante el procesamiento por efecto de la función de expansión de espectro. El $C / N_{o}$ puede ser convertido a una relación SNR convencional para un dado ancho de banda $B W$ mediante el cociente

$$
S N R_{B W}=\frac{C / N_{o}}{B W}
$$

si se asume que la densidad espectral de ruido unilateral $N_{o}$ es constante en todo el ancho de banda $B W$. 


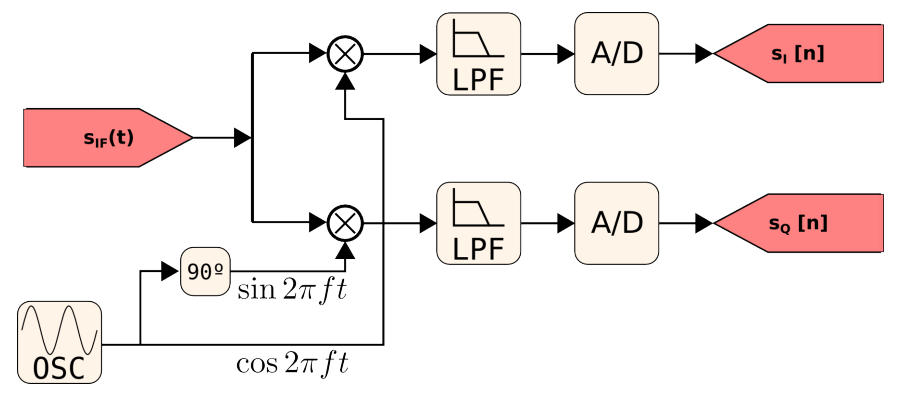

Figura 3.3: Conversión A/D fase/cuadratura con dos conversores.

\subsection{Muestreo}

Esta etapa consiste en uno o más convertidores A/D que toman la señal de frecuencia intermedia generada a la salida de la etapa anterior y la digitalizan para obtener las muestras que serán procesadas en las etapas subsiguientes.

Existen muchas variantes en el tipo de muestreo que se realiza en esta etapa. Lo más frecuente es la obtención de muestras de la señal en fase y cuadratura respecto de una frecuencia dada, lo cual puede realizarse con un conversor de dos canales como el representado en la Figura 3.3. Este diseño requiere de dos canales de conversión independientes, cada uno con sendos conversores $\mathrm{A} / \mathrm{D}$, uno para la componente en fase y otro para la componente en cuadratura. Este esquema es conceptualmente muy sencillo pero su implementación requiere que los dos canales de conversión estén perfectamente balanceados, lo que dificulta su construcción a partir de componentes discretos.

Existen esquemas alternativos que sólo requieren un único canal conversor, al costo de realizar la conversión A/D al doble de la tasa. Un esquema como este es llamado de pseudomuestreo $I Q$ que se puede ver representado en la Figura 3.4. Se puede probar que si frecuencia de muestreo es lo suficientemente alta comparado con la frecuencia de portadora de la señal, entonces el pseudomuestreo genera muestras de las componentes en fase y en cuadratura de la envolvente modulada con una portadora compleja. La frecuencia de esta portadora compleja es función de la frecuencia de la portadora original y de la frecuencia de muestreo utilizada. La tasa de muestreo de la salida es la mitad de la frecuencia de muestreo del conversor. [3]

Ambos esquemas de muestreo admiten el mismo modelo de la salida. Si consideramos por el momento una única señal $s^{i f}(i)(t)$ libre de ruido a la entrada de la etapa, la salida puede modelarse como dos secuencias $s_{i}^{d I}[n]$ (fase) y $s_{i}^{d Q}[n]$ (cuadratura) que tienen la 


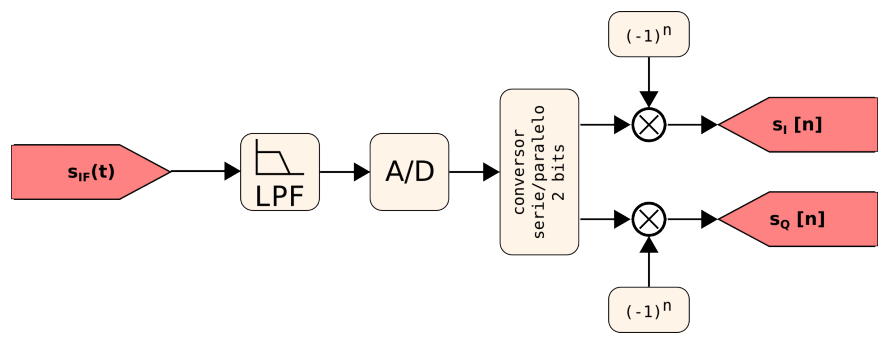

Figura 3.4: Conversión A/D con pseudomuestreo.

forma:

$$
\begin{aligned}
s_{i}^{d I}[n] & =A_{i}^{d} c_{i}\left(n T_{s}+\tau\right) d_{i}\left(n T_{s}\right) \cos \left(2 \pi\left(f_{i}^{d} \pm \Delta_{i}\right) T_{s} n+\phi_{i}^{d}\right), \\
s_{i}^{d Q}[n] & =A_{i}^{d} c_{i}\left(n T_{s}+\tau\right) d_{i}\left(n T_{s}\right) \sin \left(2 \pi\left(f_{i}^{d} \pm \Delta_{i}\right) T_{s} n+\phi_{i}^{d}\right) .
\end{aligned}
$$

Estas expresiones son las partes real e imaginaria de una señal modulada con una portadora compleja cuya expresión es:

$$
s_{i}^{d}[n]=A_{i}^{d} c_{i}\left(n T_{s}+\tau\right) d_{i}\left(n T_{s}\right) \exp \left(j\left(2 \pi\left(f_{i}^{d} \pm \Delta_{i}\right) T_{s} n+\phi_{i}^{d}\right)\right) .
$$

En esta etapa se produce una traslación de la frecuencia de portadora. La relación entre la frecuencia portadora original y la frecuencia portadora a la salida de esta etapa depende del tipo de muestreo IQ realizado. También es importante notar que si bien la desviación Doppler $\Delta_{i}$ no cambia de magnitud, puede cambiar de signo. Nuevamente, esto depende de las características del muestreo IQ utilizado.

El modelo completo, considerando múltiples señales y ruido, de las muestras a la salida de esta etapa puede entonces ser resumido en:

$$
s^{d}[n]=n^{d}[n]+\sum_{i=1}^{M} A_{i}^{d} c_{i}\left(n T_{s}+\tau\right) d_{i}\left(n T_{s}\right) \exp \left(j\left(2 \pi\left(f_{i}^{d} \pm \Delta_{i}\right) T_{s} n+\phi_{i}^{d}\right)\right) .
$$

\subsection{Procesamiento digital de alta tasa}

Luego de abandonar la etapa anterior, las muestras de señal en fase y cuadratura se bifurcan en una multitud de vías de procesamiento paralelas, llamados canales de correlación o simplemente canales. Un canal de correlación está formado por un conjunto de los recursos de hardware que necesarios para realizar el procesamiento por correlación de la señal GNSS de un único satélite. Un receptor necesita tantos canales de correlación como señales deba procesar simultáneamente. 


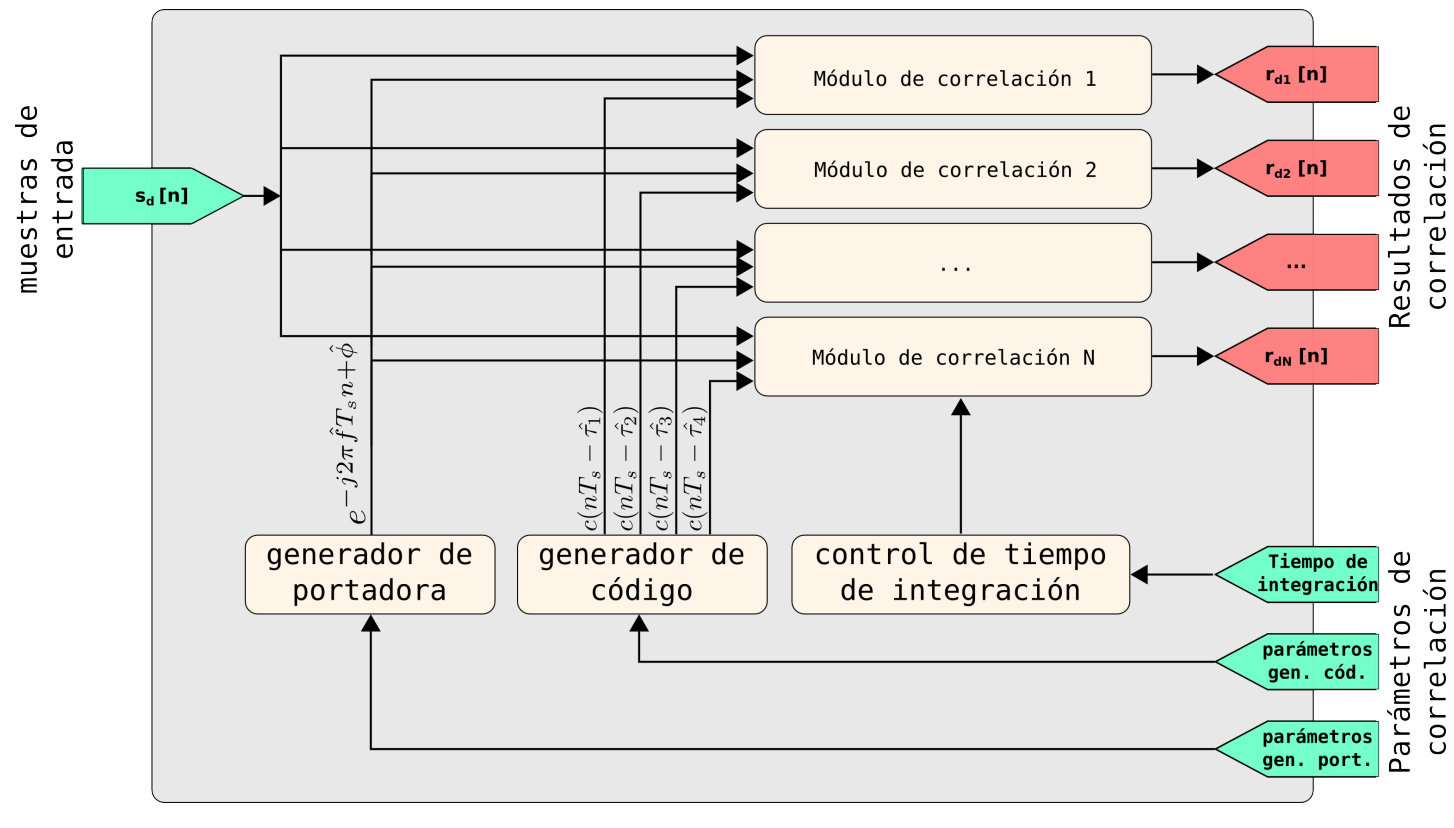

FigurA 3.5: Esquema de las partes principales de un canal de correlación.

El procesamiento por correlación de una señal GNSS consiste en su traslación a banda base mediante la eliminación de la portadora compleja, la recompresión del espectro de la señal por eliminación de la función de código, y la maximización de la relación SNR mediante integración y diezmado en un proceso similar a la utilización de un receptor óptimo en una comunicación digital clásica. En el caso de señales CDMA -como la señal civil C/A GPS- el procesamiento por correlación también efectúa la selección de la señal del satélite deseado de entre todas las señales presentes en las muestras de entrada, por obra de la ortogonalidad entre las funciones de código de diferentes satélites.

En la Figura 3.5 puede verse una representación esquemática de un canal de correlación típico, compuesto por los siguientes elementos principales:

- Un generador de réplica local de portadora compleja.

- Un generador de réplicas locales de función de código.

- Control de tiempo de integración.

- Uno o más módulos de correlación.

A su vez, la operación de cada uno de los módulos de correlación individuales puede verse en la Figura 3.6.

Debe notarse que si bien por cada canal de correlación se genera una única réplica local de portadora para todos los módulos de correlación, el generador de código sintetiza una 


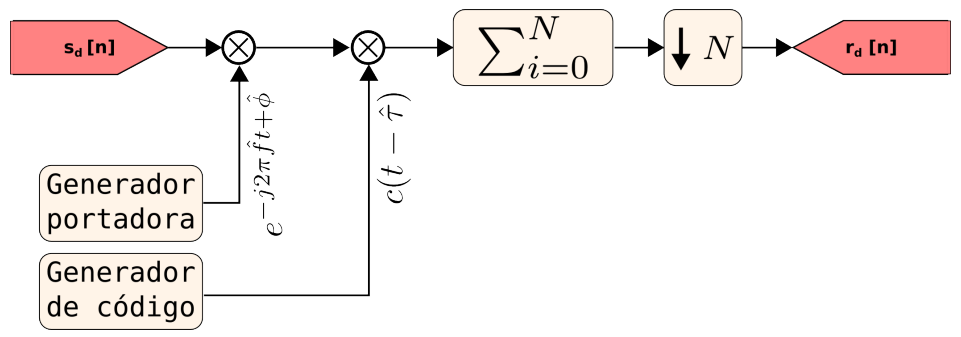

FiguRA 3.6: Esquema de la operación de correlación.

réplica de la función de código diferente para cada uno de ellos. Estas réplicas difieren entre sí por el retardo $\hat{\tau}_{i}$ de la función de código sintetizada, difiriendo unos de otros generalmente por intervalos de alguna fracción de chip.

La cantidad de módulos de correlación presentes en un canal depende del diseño particular y de la misión específica del mismo. En términos generales, un canal de correlación utilizado para el seguimiento de señales requiere típicamente de tres módulos de correlación, llamados correladores Early, Punctual y Late por razones que serán explicados más adelante.

Sin embargo, en el caso de canales destinados a la búsqueda y adquisición de señales de satélite la cantidad de módulos de correlación suele ser mucho mayor, para así reducir el tiempo de búsqueda de la señal. En estos casos el número de módulos de correlación suele ser del orden de 20 o más módulos individuales.

\subsubsection{Correlación de una señal GNSS aislada}

En la Figura 3.6 puede verse la representación esquemática de un módulo de correlación implementado digitalmente. Con el fin de analizar su funcionamiento se incluyen en la figura los generadores de código y portadora, pero tal como se mencionó al hablar de la Figura 3.5 estos generadores en realidad son elementos comunes a todos los módulos de correlación de un mismo canal.

Con el fin de simplificar el análisis de la operación del módulo de correlación discreto se lo suele sustituir por un modelo analógico equivalente como el que se puede ver en la Figura 3.7. La equivalencia entre los modelos discreto y analógico es válida en la medida en la que la frecuencia de muestreo $f_{s}$ sea varias veces más alta que las componentes de frecuencia más alta presentes en la entrada.

$\mathrm{Al}$ intervalo de tiempo $T_{I}=N T_{s}$ se le llama tiempo de integración o tiempo de correlación, y es un parámetro sumamente importante de todos los algoritmos de procesamiento de señal GNSS. 


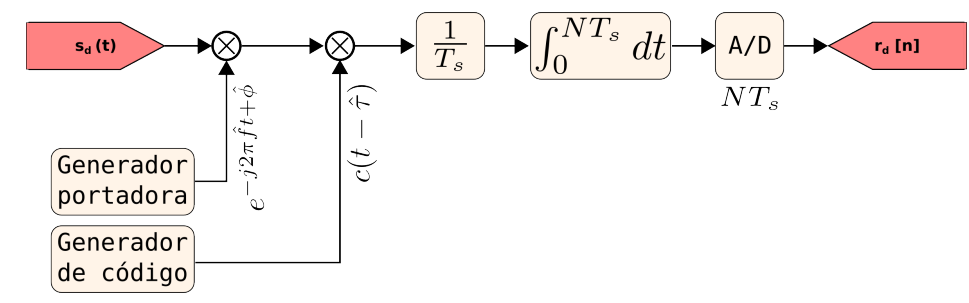

FigurA 3.7: Modelo analógico aproximado de la operación de correlación, válido si la frecuencia de muestreo es lo suficientemente alta.

Utilizando el modelo analógico del correlador, considerando que la entrada al mismo es una única señal compleja $s_{i}^{d}(t)$ dada por

$$
s_{i}^{d}(t)=A_{i}^{d} c_{i}(t+\tau) d_{i}(t) \exp \left(j\left(2 \pi\left(f_{i}^{d} \pm \Delta_{i}\right) t+\phi_{i}^{d}\right)\right)
$$

que es la reconstrucción continua de la señal discreta $s_{d}(i)[n]$ de la expresión (3.7), y suponiendo que el factor $d_{i}(t)$ debido al mensaje de navegación permanece constante e igual a un valor $d_{i}$ durante todo el intervalo de integración, entonces se puede probar que las partes real $r_{I}[m]$ e imaginaria $r_{Q}[m]$ del resultado de correlación tienen la siguiente expresión [3][4]:

$$
\begin{aligned}
r_{(i, j)}^{I}[m]= & A_{i}^{d} T_{I} d_{i} r_{c c(i, j)}(\tau-\hat{\tau}) \operatorname{sinc}\left(T_{I}\left(f_{i}^{d} \pm \Delta_{i}-\hat{f}\right)\right) \\
& \cos \left(\pi T_{I}\left(f_{i}^{d} \pm \Delta_{i}-\hat{f}\right)+\left(\phi_{i}^{d}-\hat{\phi}\right)\right) \\
r_{(i, j)}^{Q}[m]= & A_{i}^{d} T_{I} d_{i} r_{c c(i, j)}(\tau-\hat{\tau}) \operatorname{sinc}\left(T_{I}\left(f_{i}^{d} \pm \Delta_{i}-\hat{f}\right)\right) \\
& \sin \left(\pi T_{I}\left(f_{i}^{d} \pm \Delta_{i}-\hat{f}\right)+\left(\phi_{i}^{d}-\hat{\phi}\right)\right),
\end{aligned}
$$

donde $r_{c c(i, j)}$ es la función de correlación entre las funciones de código correspondientes al i-esimo y j-ésimo satélite.

Definiendo el error en la estimación de frecuencia $\Delta f_{i}=f_{i}^{d} \pm \Delta_{i}-\hat{f}$, el error en la estimación de fase promedio durante el intervalo de integración $\Delta \phi=\pi T_{I}\left(f_{i}^{d} \pm \Delta_{i}-\right.$ $\hat{f})+\left(\phi_{i}^{d}-\hat{\phi}\right)$, el error en la estimación de retardo $\Delta \tau=\tau-\hat{\tau}$, y expresando el resultado de correlación como un único número complejo se obtiene la siguiente expresión del resultado de correlación:

$$
\begin{aligned}
r_{(i, j)}^{C}[m] & =r_{(i, j)}^{I}[m]+j r_{(i, j)}^{Q}[m] \\
& =A d_{i} r_{c c(i, j)}(\Delta \tau) \operatorname{sinc}\left(T_{I} \Delta f_{i}\right) \exp (j \Delta \phi)
\end{aligned}
$$

En esta ecuación se pueden señalar tres factores que son clave por su impacto en la amplitud de las muestras de correlación:

- La intercorrelación $r_{c c(i, j)}()$ entre las i-esima y j-esima funciones de código. 
- El error en la estimación del retardo de la función de código $\Delta \tau$.

- El error en la estimación de la frecuencia portadora $\Delta f_{i}$.

Los primeros dos factores están relacionados íntimamente con las cualidades de auto e intercorrelación de la familia de códigos empleados como funciones de expansión de espectro en los sistemas GNSS. Las señales civiles de GPS C/A y GLONASS L1OF utilizan funciones de código basadas en secuencias que tienen características de auto e intercorrelación muy semejantes a las de las secuencias pseudoaleatorias. Esto significa que su función de autocorrelación $r_{c c i}(\Delta \tau)$ (equivalente a $r_{c c(i, j)}()$ cuando $i=j$ ) puede modelarse aproximadamente como la siguiente función triangular de $\Delta \tau$ (en chips):

$$
r_{c c i}(\Delta \tau)=\left\{\begin{array}{lll}
0 & \text { si } & -\infty \leq \Delta \tau \leq-1 \\
1+\Delta \tau & \text { si } & -1 \leq \Delta \tau \leq 0 \\
1-\Delta \tau & \text { si } & 0 \leq \Delta \tau \leq 1 \\
0 & \text { si } & 1 \leq \Delta \tau \leq \infty
\end{array}\right.
$$

Mientras que la función de intercorrelación $r_{c c(i, j)}()$ cuando $i \neq j$ se puede considerar idénticamente cero para todo valor de $\Delta \tau$ (ortogonalidad de las secuencias).

En GPS tasa de chips de la función de código es 1,023 MHz y por lo tanto 1 chip equivale aproximadamente a 1 us. GLONASS en cambio tiene una tasa de código $511 \mathrm{kHz}$ así que 1 chip es aproximadamente igual a 2 us.

Se debe señalar que lo anterior es sólo una visión idealizada de las funciones de autocorrelación e intercorrelación verdaderas. Las secuencias de código de largo finito y repetición periódica utilizadas en GPS y GLONASS tienen valores de autocorrelación para $|\Delta \tau| \geq 1$ que aunque son pequeños por comparación al máximo central no valen cero. De la misma forma, la función de intercorrelación real entre dos funciones de código diferentes no es nula para todos los valores de $\Delta \tau$. Por último, ambas funciones presentan la misma periodicidad que las funciones de código que les dan origen (1023 chips en GPS, y 511 en GLONASS).

El tercero de los factores de la expresión (3.12) es una dependencia del módulo con frecuencia $\Delta f$. La forma que toma esta dependencia se puede ver en la Figura 3.8, donde se puede ver que $\operatorname{sinc}\left(T_{I} \Delta f_{i}\right)$ toma su valor máximo cuando $\Delta f_{i}$ es cero, y a partir de allí decrece en módulo tendiendo a cero en infinito y con cruces por cero para cuando $\Delta f=k / T_{I}$ para todo $k$ entero. El ancho del lóbulo central es una función inversa del tiempo de correlación utilizado, lo que será importante al analizar los algoritmos de adquisición de señal más adelante.

De lo anterior se pueden extraer las siguientes conclusiones: 


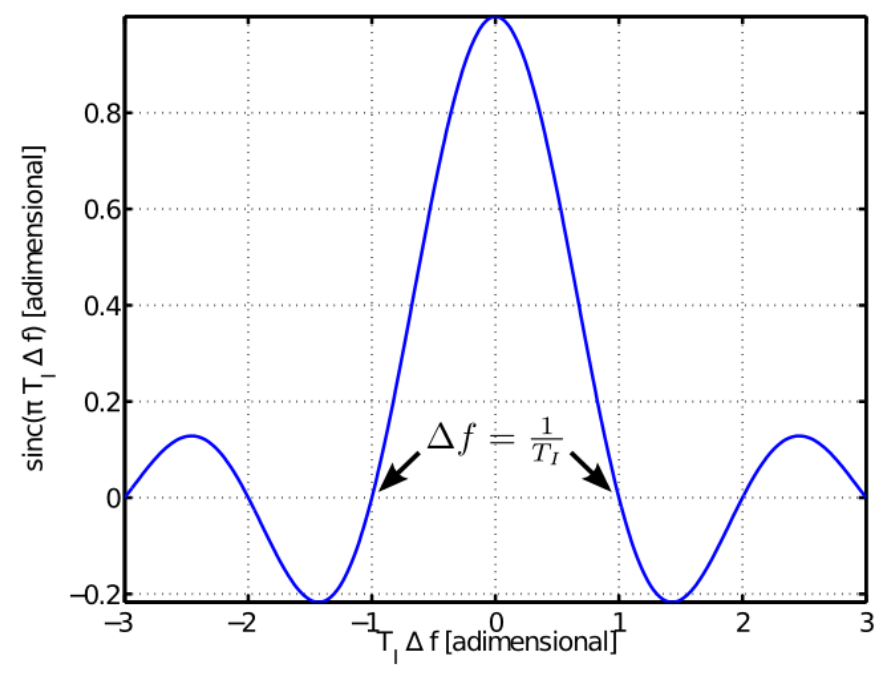

Figura 3.8: Perfil de la dependencia en frecuencia de la función de correlación, en función de $T_{I} \Delta f$.

- La amplitud de la correlación de una señal contra la función de código incorrecta es aproximadamente nula para todo $\Delta f_{i}$ y $\Delta \tau_{i}$.

- La amplitud de la correlación de una señal contra la función de código correcta:

- Es máxima cuando $\Delta f_{i}$ y $\Delta \tau_{i}$ son ambos cero.

- Decrece linealmente con el módulo de $\Delta \tau$ si $|\Delta \tau| \leq 1$.

- Es aproximadamente cero si $|\Delta \tau| \geq 1$.

- Decrece con $\operatorname{sinc}\left(T_{I} \Delta f_{i}\right)$ en función de $\Delta f_{i}$.

- Es cero si el error de frecuencia $\Delta f$ es un múltiplo de $1 / T_{I}$

\subsubsection{Correlación con múltiples señales GNSS y ruido}

El modelo de la expresión (3.12) está basado en suponer una única señal a la entrada del correlador y ausencia de ruido. Dado que la correlación es una operación lineal es fácil ver que si consideramos el caso más general donde la señal de entrada es la superposición de las señales de múltiples satélites y además se encuentra perturbada por ruido aditivo, entonces las muestras de correlación a la salida serán

$$
r_{j}^{C}[m]=n^{C}[m]+\sum_{i=1}^{M} r_{(i, j)}^{C}[m]
$$

donde la única novedad es el término $n^{C}[m]$, que es el resultado de la correlación del ruido $n^{d}[n]$. Dado que este último es un proceso independiente, idénticamente distribuido, de ruido Gaussiano con media nula, se puede probar que el término $n^{C}[m]$ también 
corresponde a muestras de un proceso Gaussiano de media nula, y potencia dada por el ancho de banda de ruido equivalente del correlador. [39]

Los demás términos de la ecuación (3.14) corresponden a las correlaciones de cada una de las señales GNSS presentes en las muestras a la entrada con las réplicas locales de portadora y código. Tanto en GPS (que usa CDMA) como en GLONASS (que usa FDMA), si una señal con función de código y frecuencia portadoras que se corresponden la función de código y la frecuencia de portadora de las réplicas forma parte del conjunto de señales presentes en la entrada, entonces el término correspondiente dominará el resultado de correlación. En ese caso la expresión (3.14) se puede aproximar con

$$
\begin{aligned}
r_{j}^{C}[m] & \approx n^{C}[m]+r_{(i, j)}^{C}[m] \\
& \approx n^{C}[m]+A d_{i} r_{c c(i, j)}(\Delta \tau) \operatorname{sinc}\left(T_{I} \Delta f_{i}\right) \exp (j \Delta \phi) .
\end{aligned}
$$

La forma en que ocurre este proceso de selección es diferente según sea la señal deseada una señal GPS o una señal GLONASS.

En el caso de señales GPS, todos aquellos términos que correspondan a señales cuya función de expansión de espectro es diferente de la generada localmente resultan eliminadas debido a la ortogonalidad entre las funciones de código. Sólo si se encuentra presente una señal cuya función de código coincide con la generada localmente y tal que $\left(\Delta f_{i}, \Delta \tau_{i}\right) \approx(0,0)$ será que el término correspondiente de la expresión (3.14) dominará el resultado de correlación y superará el piso de ruido.

GLONASS utiliza la misma función de código para expandir el espectro de las señales de todos los satélites pero asigna diferentes rangos de frecuencias posibles a unos y otros. El receptor en este caso puede seleccionar la señal de un satélite dado a partir de conocer el rango de valores posibles que puede tomar la frecuencia portadora del mismo. Debido a que la separación entre canales FDMA GLONASS es mucho mayor que el inverso del tiempo de los integración $T_{I}$ prácticos, el factor $\operatorname{sinc}\left(\pi T_{I} \Delta f_{i}\right)$ de la expresión de correlación hará despreciable el aporte de cualquier satélite que no sea el deseado independientemente del valor de $\Delta \tau_{i}$. Al igual que ocurre en GPS si las réplicas de portadora y de código tienen parámetros de frecuencia portadora y retardo cercanos a los valores de la señal presente entonces el término correspondiente dominará el resultado de correlación superando el piso de ruido.

Si la señal a la entrada es una superposición de señales GLONASS y GPS, la correlación cruzada de las señales de un sistema con las réplicas de código y portadora del otro siempre será despreciable, debido a la naturaleza diferente de los códigos de expansión (en tipo y en tasa de chips) y a la separación de los rangos de frecuencia ocupados por uno y otro. 


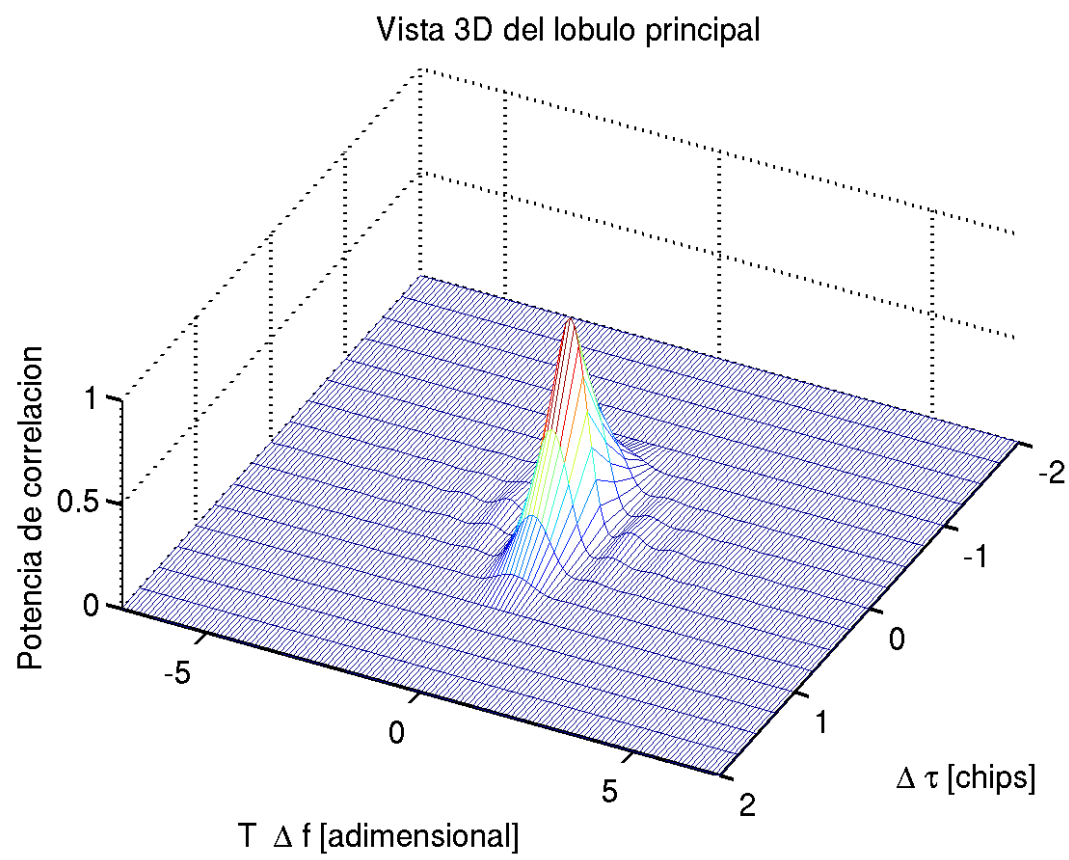

Figura 3.9: Potencia de correlación del lóbulo principal. El eje de la frecuencia está graficado en términos del producto $T_{I} \Delta f$ para independizar la gráfica de la elección del tiempo de integración $T_{I}$.

En la Figura 3.9 se puede ver la potencia de correlación (módulo al cuadrado) normalizada, graficada en función de $T_{I} \Delta f$ y $\Delta \tau$ en una región alrededor del pico de correlación. La utilización de $T_{I} \Delta f$ (frecuencia normalizada) en lugar de $\Delta f$ para el eje de la frecuencia permite describir la forma de la función en forma independiente del valor de tiempo de integración $T_{I}$ utilizado. En la figura se puede identificar claramente la existencia de un lóbulo central donde la potencia de correlación es máxima cuando los errores de retardo y frecuencia son simultáneamente nulos, y una disminución gradual de la misma a medida que los errores aumentan. Fuera del rango $-0,5 \leq \Delta \tau \leq 0,5$ (en chips) la relación potencia de correlación es cero (en nuestro modelo simplificado de la autocorrelación de la secuencia pseudoaleatoria). Ver corte del lóbulo en la Figura 3.10. En la dimensión de la frecuencia la potencia tiene ceros periódicos para errores de frecuencia múltiplos del inverso del tiempo de integración $T_{I}$, y la envolvente decrece aproximadamente con el cuadrado de inverso del error de frecuencia. Ver corte del lóbulo en la Figura 3.11.

\subsection{Estimación de parámetros de señal}

A partir del análisis anterior se deduce que con el fin de poder procesar señales GNSS es necesario conocer con buena aproximación los valores de la frecuencia portadora y del retardo de la función de código que la modulan. En caso contrario el ruido aditivo que 


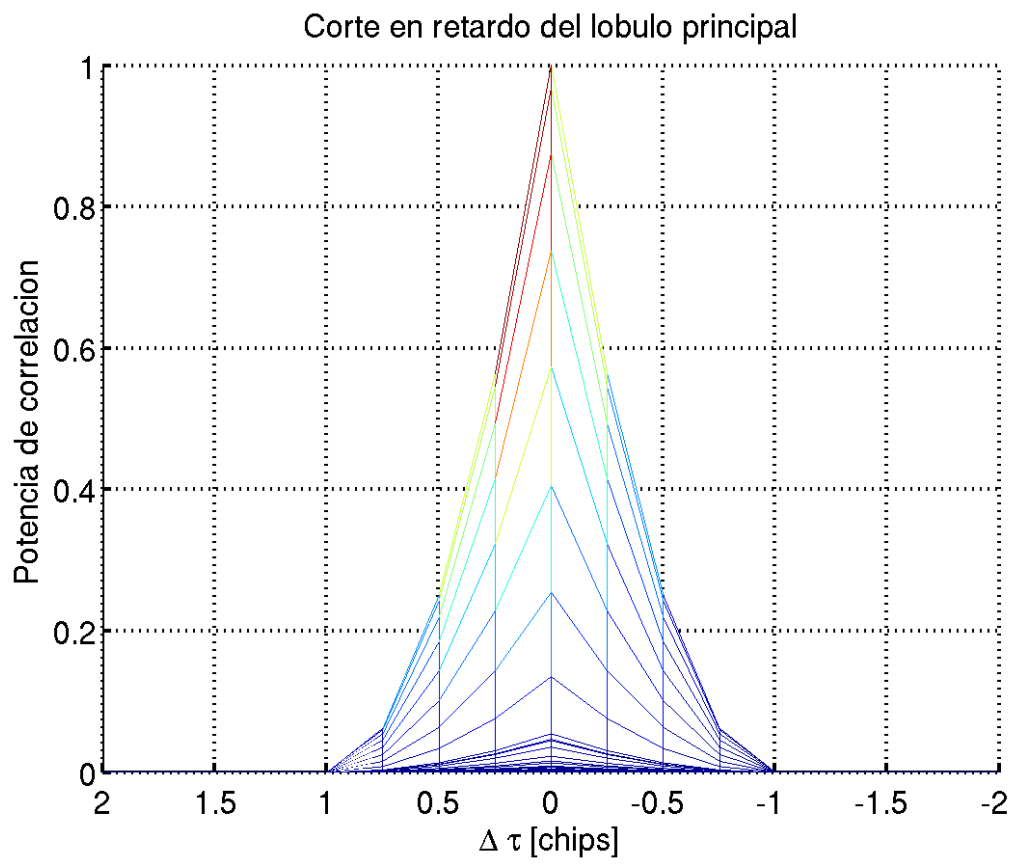

Figura 3.10: Potencia de correlación del lóbulo principal; corte a lo largo del eje $\Delta \tau$.

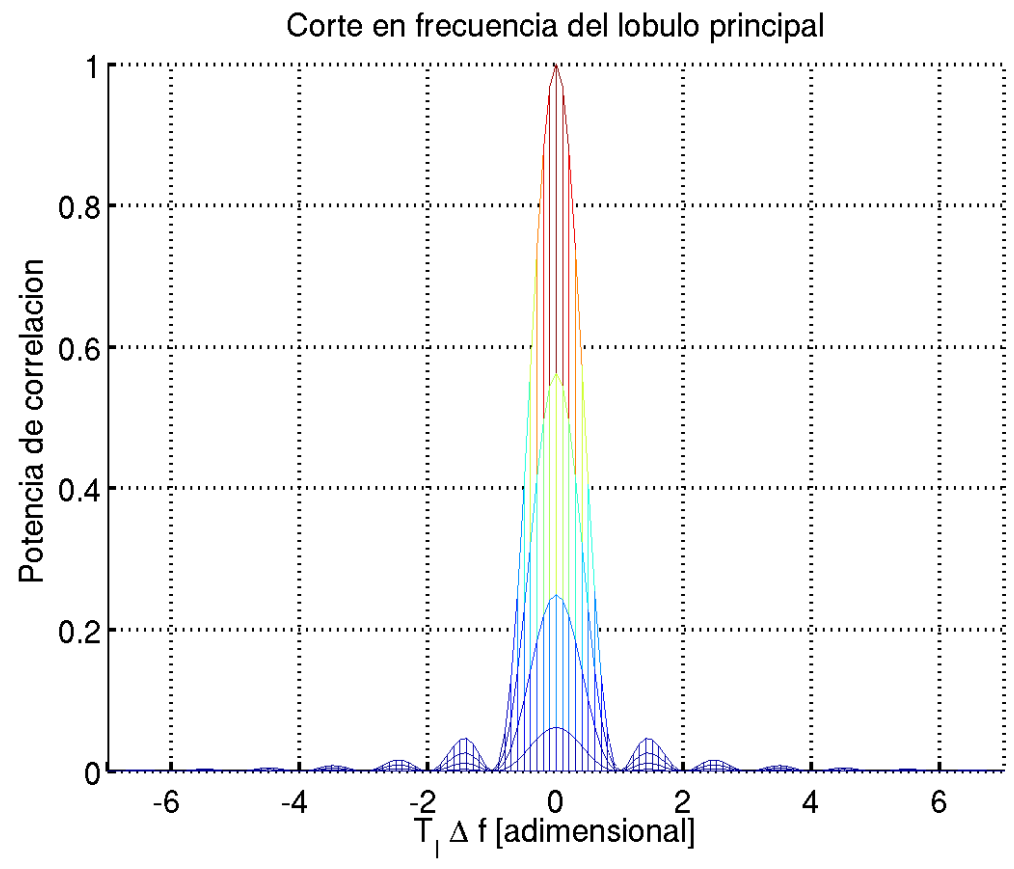

Figura 3.11: Potencia de correlación del lóbulo principal; corte a lo largo del eje $T_{I} \Delta f$. 


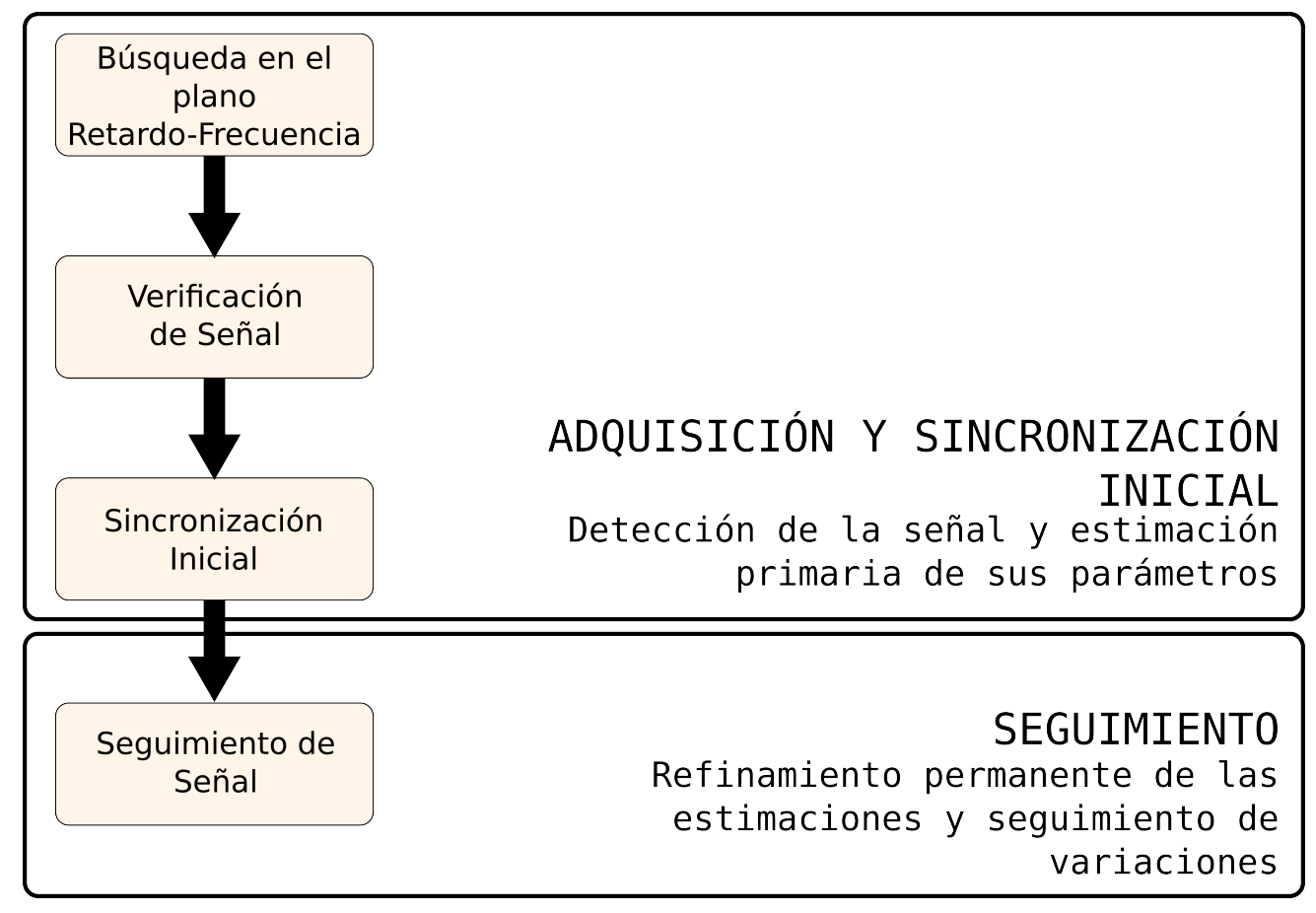

FiguRA 3.12: Etapas de procesamiento de una señal GNSS.

siempre está presente en la señal enmascarará su presencia e imposibilitará su detección y procesamiento.

En condiciones reales la frecuencia y el retardo de una señal GNSS no son constantes sino que se encuentran en permanente situación de cambio, sujetos a las variaciones en la posición y velocidad tanto del receptor como de los satélites transmisores, modificaciones en las condiciones atmosféricas, inestabilidades en los relojes involucrados, etc. Claro que dichas variaciones no son arbitrarias, y sus rangos pueden ser acotados a partir del conocimiento de las causas que las provocan.

Se puede anticipar entonces que la tarea del receptor no es tan simple como activar un dado canal de comunicación y comenzar a demodular la señal. Es necesario un proceso previo de búsqueda de los valores de frecuencia y retardo de la señal para lograr una estimación inicial de dichos parámetros, y posteriormente se debe realizar un seguimiento de sus variaciones para permitir su demodulación sin pérdida de continuidad a medida que estos cambian.

En efecto, el procesamiento de una señal GNSS por parte del receptor típicamente puede dividirse en dos fases principales:

- Adquisición de señal.

- Seguimiento de variaciones. 
Estas fases se corresponden adecuadamente a nuestras expectativas de los párrafos anteriores. En las secciones siguientes se presentará un resumen de la función y el procesamiento realizado en cada una de estas etapas.

\subsubsection{Adquisición}

Es el nombre de la primera fase de procesamiento de una dada señal GNSS, durante el cual se realiza la detección de la señal y la determinación de sus parámetros de frecuencia y retardo de código.

Esta fase puede a su vez dividirse en varias subetapas:

- Búsqueda de señal.

- Verificación.

- Sincronización inicial.

\subsubsection{Búsqueda de señal}

Al comienzo del proceso de adquisición de una señal GNSS el receptor generalmente no cuenta con información lo suficientemente precisa como determinar de antemano los valores de frecuencia de portadora y retardo de la señal, por lo que es necesario llevar adelante un proceso de búsqueda que permita determinarlos.

Este proceso de búsqueda debe abarcar todas las posibles combinaciones de frecuencia portadora y retardo de código que puede asumir la señal que se pretende adquirir, ya que solamente cuando los errores de código y frecuencia tienden simultáneamente a cero la potencia de correlación se puede detectar por encima del piso de ruido.

Pese a la incertidumbre inicial es posible acotar los rangos de variación posibles para los dos parámetros a determinar. En la dimensión de la frecuencia el rango de valores $R_{f}$ que puede tomar la frecuencia portadora se puede establecer a priori que será una banda alrededor del valor nominal de la frecuencia portadora,

$$
R_{f} \in\left(f_{c n}-\Delta f_{\max }, f_{c n}+\Delta f_{\max }\right)
$$

donde $f_{c n}$ es el valor nominal de la frecuencia portadora, y $\Delta f_{\max }$ es la máxima desviación de frecuencia respecto del valor nominal, la cual se verá a continuación que puede ser acotada a partir del conocimiento de sus fuentes. 
La máxima desviación $\Delta f_{\max }$ tiene dos componentes dominantes: la máxima desviación de frecuencia portadora por efecto Doppler, y la desviación del oscilador de referencia del receptor respecto de su valor nominal. Se puede acotar el peor caso posible de desviación a partir de las cotas de cada una de sus causas.

$$
\left|\Delta f_{\max }\right| \leq\left|\Delta f_{\text {dop }}\right|+\left|\Delta f_{\text {osc }}\right|
$$

donde $\Delta f_{\text {dop }}$ y $\Delta f_{\text {osc }}$ son las máximas desviaciones Dopper y de reloj respectivamente. La cota de la desviación Doppler $\Delta f_{\text {dop }}$ puede ser determinada mediante la utilización de un modelo simple de la dinámica relativa entre el receptor y los satélites de la constelación para una caso de aplicación típico. En el caso más común es el de un receptor estático o cuasi-estático (baja velocidad comparada con la velocidad de los satélites GNSS, $3,9 \mathrm{~km} / \mathrm{s}$ ) ubicado en algún punto de la superficie terrestre. La máxima proyección de la velocidad relativa del receptor y el satélite a lo largo del vector línea de vista que los une es de aproximadamente $800 \mathrm{~m} / \mathrm{s}$, correspondiente a una desviación $\Delta f_{\text {dop }}$ de $4 \mathrm{kHz}$ en la portadora de L1. [4]

La cota de la desviación debida a la referencia de tiempo del receptor $\Delta f_{\text {osc }}$ se encuentra determinada por la tolerancia del oscilador utilizado para generarla. El valor aparente de la frecuencia portadora L1 sufrirá una desviación de aproximadamente $1,5 \mathrm{kHz}$ por cada 1 ppm de apartamiento respecto de su valor nominal. Una referencia de tiempo típica de tipo TCXO (Temperature Compensated Crystal Oscillator) puede tener tolerancias de entre 1 ppm y 2 ppm, resultando en una desviación de entre $1,5 \mathrm{kHz}$ y $3 \mathrm{kHz}$.

En la Figura 3.13 se puede ver un registro de la desviación de frecuencia $\Delta f$ para todos los satélites observados por un receptor GPS estático a lo largo de un intervalo de 20 horas. Cada una de las curvas individuales presentes en la gráfica sigue las variaciones de la frecuencia portadora de un dado satélite transmisor, desde el momento de su adquisición hasta el desenganche del mismo. Se ven en las curvas dos efectos bien diferenciados.

Por un lado, la forma de las curvas similar a una "S" espejada es característica de la evolución de la frecuencia portadora por efecto Doppler: positiva cuando el satélite aparece en el horizonte y su dirección de movimiento es tal que se está acercando al receptor, cero cuando su elevación es máxima y la velocidad del satélite es ortogonal al vector línea de vista, y luego negativa mientras el satélite se aleja hasta esconderse detrás del horizonte.

Por otro lado se observa una desviación respecto del cero del valor medio de las frecuencias de todos los satélites calculada sobre todos los horarios. Esta desviación de la media es ocasionada por la desviación de la referencia de tiempo del receptor respecto de su 


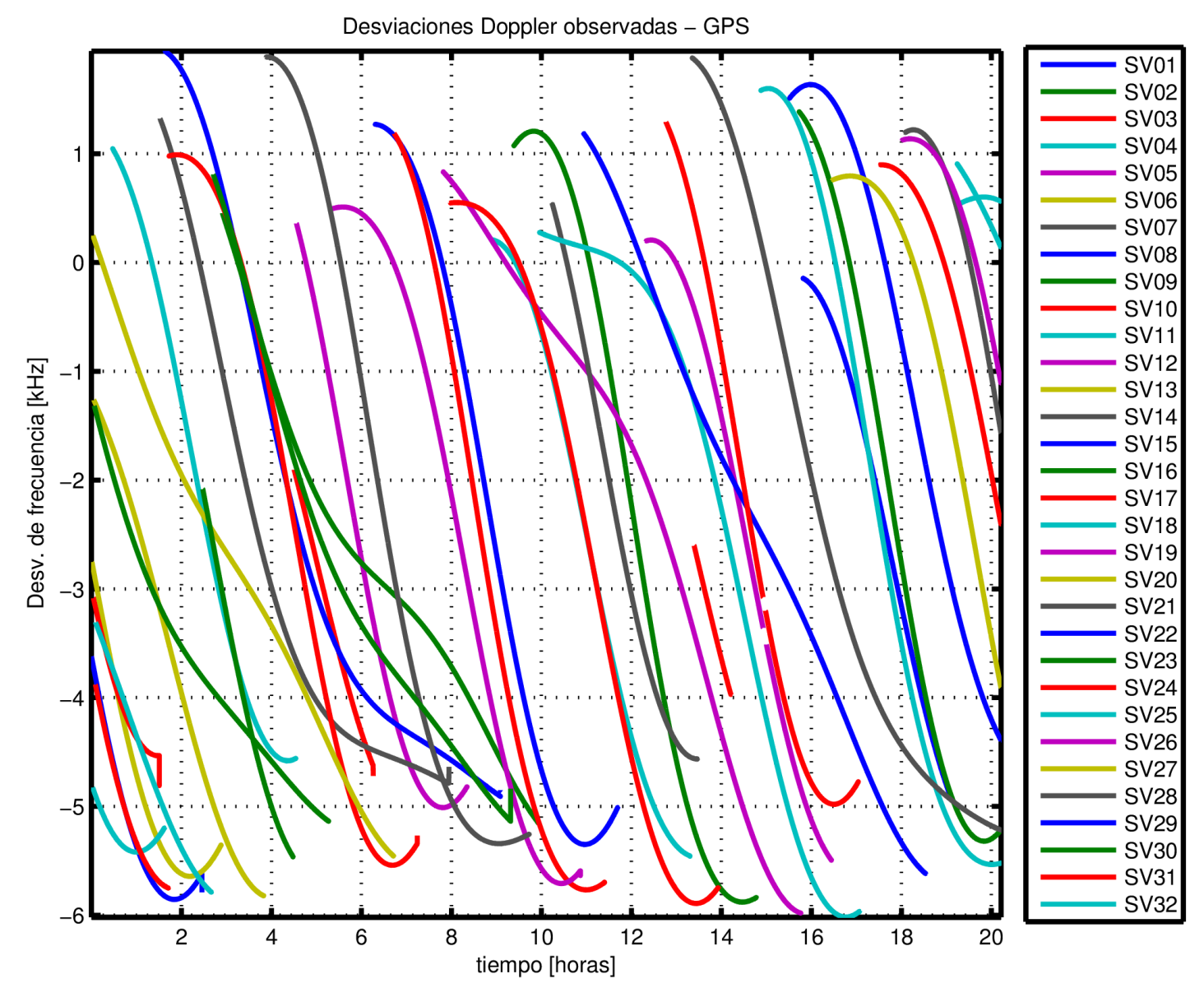

FigurA 3.13: Desviación de la frecuencia portadora respecto de su valor nominal, para cada uno de los satélites GPS observados por el receptor GNSS desarrollado en este trabajo a lo largo de un intervalo de 20 hs.

valor nominal, la cual está mayormente determinada desde el momento de fabricación del cristal utilizado.

En la dimensión del retardo la periodicidad de la función de código acota naturalmente el rango de valores posibles $R_{r}$ al intervalo de no ambigüedad de la secuencia pseudoaleatoria. En el caso de la señal C/A del sistema GPS la secuencia pseudoaleatoria utilizada tiene una longitud de 1023 chips, por lo que el rango de valores posibles de retardo está restringido al rango $R_{r}^{(\mathrm{gps})} \in[0,1022]$. GLONASS L1OF en cambio utiliza una secuencia de largo 511 chips, por lo que el rango de búsqueda será $R_{r}^{(\text {glo })} \in[0,510]$.

Dado que los dos parámetros a buscar están desacoplados entre sí todas las combinaciones de valores de frecuencia portadora $f_{c}$ con retardo $\tau$ son posibles. El espacio de búsqueda que el receptor necesita examinar entonces es el conjunto producto $R_{f} \times R_{r}$. Este espacio es frecuentemente representado mediante el llamado plano retardo-frecuencia, que consiste en dos ejes ortogonales que representan el espacio de búsqueda en retardo y en frecuencia respectivamente. Ver Figura 3.14. 


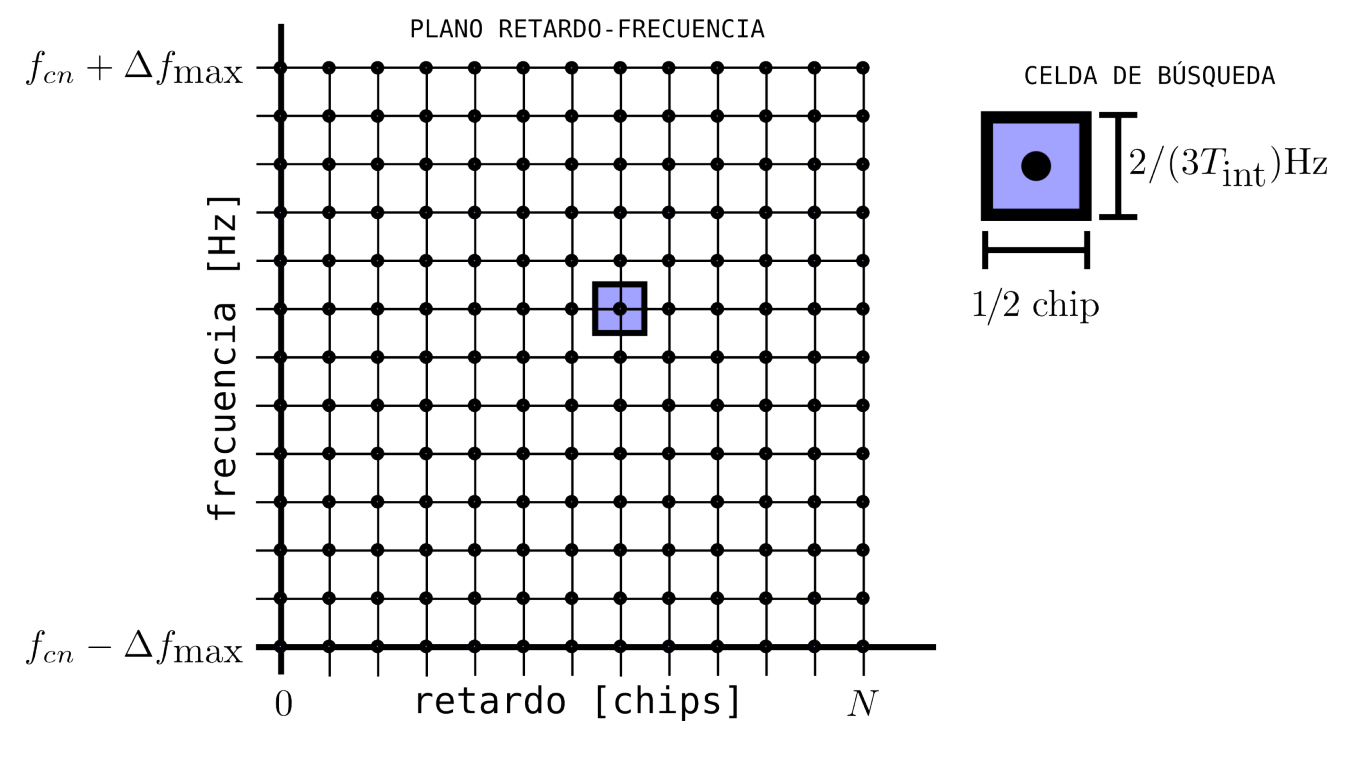

FigurA 3.14: Plano retardo-frecuencia utilizado para representar el espacio de búsqueda del receptor, indicando la relación entre las coordenadas de prueba (puntos negros) y las celdas que representan. Arriba a la derecha se indican las dimensiones típicas de una celda de búsqueda.

El proceso de búsqueda de una señal GNSS consiste en el recorrido exhaustivo de todas las combinaciones posibles de pares retardo-frecuencia $(\hat{f}, \hat{\tau})$. Por cada combinación el receptor realiza una correlación y calcula la potencia de correlación resultante (potencia de la muestra de correlación). Si la potencia de correlación medida supera un umbral mínimo el receptor declara la posible existencia de una señal en esas coordenadas del plano retardo-frecuencia. El valor del umbral de detección se calcula a partir de la potencia del piso de ruido presente, con algún criterio tal que permita lograr un balance adecuado entre tasa de falsa alarma y probabilidad de detección.

Por supuesto, la cantidad de pares $\left(\hat{f}_{i}, \hat{\tau}\right)$ en el conjunto producto $R_{f} \times R_{r}$ es infinita. Para mantener el tiempo de búsqueda acotado es necesario dividir el plano en una grilla con una cantidad finita de celdas. Por cada celda el receptor examina solamente un único par retardo-frecuencia en representación de toda la celda. Este representante está indicado en la Figura 3.14 mediante los puntos centrales de cada celda.

Tal como se vio al discutir el modelo de correlación (expresión (3.15)) la potencia de correlación recuperada alrededor de los valores de retardo y frecuencia verdaderos de una señal decae gradualmente a medida que aumentan los errores de $\Delta \tau$ y $\Delta f$, formando lo que llamamos el lóbulo principal de la correlación de la señal (Figura 3.9). Las dimensiones de este lóbulo permiten establecer un tamaño adecuado para las celdas de forma tal de minimizar el tiempo de búsqueda sin sacrificar probabilidad de detección.

En el corte del lóbulo principal paralelo al eje del retardo (Figura 3.10) se observa que el lóbulo tiene un ancho máximo de dos chips en la base, correspondiente a la forma 
de la función de autocorrelación idealizada de la función de código. En la dimensión de la frecuencia (Figura 3.11) se suele tomar como ancho del lóbulo principal la distancia entre los primeros ceros de la función de correlación, que es $2 / T_{I}$.

Con el fin de no afectar excesivamente la probabilidad de detección la práctica más frecuente es dimensionar las celdas del plano de búsqueda de forma tal que siempre sean más pequeñas que el soporte del lóbulo principal. Es una práctica común la utilización de planos de búsqueda formados por celdas $1 / 2$ chip de largo por $2 /\left(3 T_{I}\right)$ en la dimensión de la frecuencia. Esta elección da un balance adecuado entre tamaño de celdas y tiempo que toma el proceso de búsqueda: las celdas son lo suficientemente pequeñas como para que ensayar el punto central sea representativo del resto de los puntos de la misma celda, pero también lo suficientemente grandes como para que el proceso de búsqueda pueda ser finalizado en un tiempo razonable.

El receptor inspecciona de esta forma todas las celdas que forman el plano retardofrecuencia. Si una vez finalizado el recorrido del plano no se han encontrado señales válidas, el satélite buscado es declarado ausente. Si en cambio durante la búsqueda se encuentra un par de coordenadas $\left(\hat{f}_{i}, \hat{\tau}\right)$ que superan un umbral de detección preestablecido se declara la presencia de un candidato.

\subsubsection{Verificación de candidatos}

Para minimizar la probabilidad de falsas alarmas dicho candidato es verificado utilizando algoritmos que permiten decidir con baja probabilidad de falsa alarma la presencia o ausencia de una señal en las coordenadas del candidato. En [4] se puede ver la descripción de los algoritmos Tong y M-de-N, que son utilizados para verificar la señal.

Si luego de la verificación los ensayos arrojan un resultado consistente con una falsa alarma, el receptor retoma el proceso de búsqueda en las coordenadas del candidato. Si en cambio la verificación es consistente con la presencia de una señal GNSS el receptor pasa a la siguiente etapa de procesamiento, la sincronización inicial.

Adicionalmente es posible llevar a cabo un proceso de refinamiento de las coordenadas $\left(\hat{f}_{i}, \hat{\tau}\right)$ antes de iniciar el proceso de verificación. Esto tiene por objetivo reducir el grado de incerteza en la estimación de las coordenadas para minimizar la pérdida de potencia asociada a la misma, y así maximizar la probabilidad de que una señal verdadera supere la verificación. El proceso de refinado generalmente consiste en realizar un proceso de búsqueda local alrededor de las coordenadas de la detección utilizando una grilla con mejor resolución que la del plano general. 


\subsubsection{Sincronización inicial}

La etapa de sincronización inicial lleva a cabo la eliminación del error residual en los valores de frecuencia y retardo obtenidos en las etapas anteriores. Los errores en las estimaciones $(\hat{f}, \hat{\tau})$ que posee el receptor al entrar en esta etapa son aproximadamente del orden de las dimensiones de una celda de búsqueda (original o refinada), los cuales deben ser mejorados antes de comenzar la demodulación de la señal. Además en esta etapa el receptor también realiza una estimación de la fase instantánea de la portadora $\hat{\phi}$ como paso necesario para poder iniciar el proceso de detección del mensaje de navegación transmitido en la señal con un esquema BPSK.

El refinamiento de las estimaciones de frecuencia y retardo, y la estimación de la fase instantánea de la portadora son realizadas utilizando lazos de seguimiento de fase de portadora y de código similares a los que son utilizados en la etapa de Seguimiento. La descripción de su funcionamiento se posterga hasta la Sección 3.7.2.

La tercera función de esta etapa es la de determinación del alineamiento de los pulsos del mensaje de navegación que modulan la señal. Esta pieza de información es fundamental por dos razones. Por un lado, la posición de los flancos de los bits de datos forma parte de la información de temporización que se encuentra codificada en la señal, la cual es imprescindible para generar las mediciones de tiempo de transmisión (y pseudorango) utilizadas para el cálculo de posición.

Por otro lado, para mejorar la relación SNR de las muestras de correlación en la fase de seguimiento posterior se suele utilizar tiempos de integración "largos": para evitar que las inversiones de fase debidas al mensaje de navegación afecten la potencia recuperada con estas correlaciones largas se utilizan tiempos de integración de 5 ms o 10 ms (valores que dividen de forma entera la duración de un tiempo de bit, $20 \mathrm{~ms}$ ), y se alinean los intervalos de integración de forma tal que las inversiones de fase ocurran en el instante entre dos integraciones. Así se garantiza el cumplimiento de la hipótesis de que el factor $d_{i}(t)$ es constante durante el intervalo de integración, y por lo tanto la potencia de correlación es siempre máxima.

Tal como se describió en el capítulo anterior, los bits de datos del mensaje de navegación son sincrónicos con los períodos de $1 \mathrm{~ms}$ de la función de código; esto es cierto tanto en GLONASS como en GPS. Esto significa que una vez determinados los parámetros de avance de la función de código (relacionados con el retardo estimado previamente) el receptor solamente necesita eliminar la ambigüedad determinando el alineamiento correcto de entre las 20 posibilidades que existen. 
El algoritmo más difundido para realizar esta tarea se denomina Método del Histograma, y consiste en realizar integraciones de $1 \mathrm{~ms}$ que estén alineadas con los períodos de la función de código, y buscar las inversiones de fase de valores de correlación que delatan cambios de signo en el factor $d_{i}(t)$ [3][40]. Otro método, presentado en [41], logra probabilidades de error en condiciones de baja relación $C / N_{o}$ mucho menores que el anterior. Este utiliza una aproximación de búsqueda basada en el criterio de Máxima Verosimilitud, y funciona buscando el alineamiento que maximiza la energía de bit recuperada. Al igual que el primero, este método toma como entrada una serie de resultados de correlación de $1 \mathrm{~ms}$ alineados con la función de código.

De forma auxiliar a la presente tesis se desarrolló un nuevo método, también de máxima verosimilitud, que puede encontrarse publicado en las referencias [14] y [15]. Este último tiene la ventaja de no imponer una duración de tiempo de integración específica, permitiendo al diseñador diferentes tipos de compromiso entre la probabilidad de error y el tiempo de integración utilizado. Para el caso particular en que se utilizan tiempos de integración de $1 \mathrm{~ms}$, este nuevo método se comporta de forma equivalente al de maximización de la energía de bit en términos de la probabilidad de error. Se pueden encontrar más detalles sobre este método en el Apéndice C.

La etapa de Sincronización Inicial culmina cuando el receptor determina una terna de valores instantáneos estimados $\left(\hat{f}\left(t_{o}\right), \hat{\phi}\left(t_{o}\right), \hat{\tau}\left(t_{o}\right)\right)$ que caracterizan completamente a la portadora y a la función de código en un instante de referencia $t_{o}$, y también posee información del alineamiento de los bits de datos que le sirve para alinear las integraciones de la etapa de Seguimiento y para comenzar a demodular el mensaje de navegación.

\subsubsection{Seguimiento}

Una vez finalizado el proceso de Adquisición, el receptor cuenta con una estimación de los valores aproximados de los parámetros $\left(\hat{f}\left(t_{o}\right), \hat{\phi}\left(t_{o}\right), \hat{\tau}\left(t_{o}\right)\right)$ de la señal, así como el alineamiento relativo de los bits de datos del mensaje de navegación en la señal. De forma implícita queda también perfectamente determinada la tasa de avance de la función de código, ya que como se vio en un capítulo anterior ésta presenta una relación fija con la frecuencia de portadora de la señal.

Si las estimaciones de los valores de estos parámetros fuesen perfectas, el receptor podría utilizarlas para extrapolar el progreso de la fase de portadora, de la función de código y de los instantes de muestreo de los bits de datos para todo tiempo futuro, pudiendo a partir de esta información demodular completamente la señal. 
Sin embargo esto no es posible en la práctica, porque por más precisas que sean las estimaciones obtenidas en la fase de adquisición, las mismas se encuentran inevitablemente afectadas por errores de estimación y ruido. Además, las variaciones en la velocidad relativa de los satélites respecto del receptor, las inestabilidades en la frecuencia de los osciladores utilizados, y las variación de las condiciones atmosféricas son todos elementos que provocarán variabilidad en el tiempo de los parámetros de la señal tal como son percibidos por el receptor. Todas estas perturbaciones provocan que cualquier pronóstico acerca del estado de la señal para cualquier instante futuro tienda rápidamente a diverger respecto del estado real de la misma.

Con el fin de eliminar cualquier error residual en la estimación previa y de seguir las variaciones en el tiempo de los parámetros de la señal es que los receptores típicamente utilizan estimadores que funcionan como sistemas a lazo cerrado, midiendo el error entre los parámetros estimados y sus valores reales y utilizando esta medida de error para ajustar los valores estimados.

Con este fin el receptor generalmente implementa dos lazos de seguimiento por cada señal de satélite que se está monitoreando:

- Un lazo de seguimiento de portadora, para la estimación de parámetros de la portadora: frecuencia portadora y fase instantánea.

- Un lazo de seguimiento de código, para la estimación de los parámetros de la función de código: tasa y retardo de código.

En ambos casos el esquema de funcionamiento simplificado es el que puede verse en la Figura 3.15, que puede reconocerse rápidamente como un sistema de control clásico con realimentación unitaria. Allí una referencia de entrada $\Omega$ es comparada con la estimación local $\hat{\Omega}$ de su valor, y el error $\Delta \Omega$ (diferencia entre el valor real y el estimado) atraviesa una función de transferencia $H(s) / s$ que da lugar al estimador local. Se sabe a través de la teoría del control automático clásico que si los polos del sistema realimentado son estables entonces el valor del estimador $\hat{\Omega}$ tenderá al valor de la variable real $\Omega$.

En la representación de la Figura 3.15 se separa explícitamente la función de transferencia de lazo abierto $H(s) / s$ en dos partes, un filtro de transferencia $H(s)$ y un polo integrador $1 / s$. Esta representación es típica de los lazos de seguimiento de fase de señales utilizados en GNSS porque permite aislar la estimación de la tasa de variación $\hat{\dot{\Omega}}$. En los lazos de seguimiento de portadora y código esto permite obtener información de la frecuencia portadora instantánea y de la tasa de avance de la función de código, respectivamente. La extracción de este polo siempre es posible debido a que por razones que se detallarán 


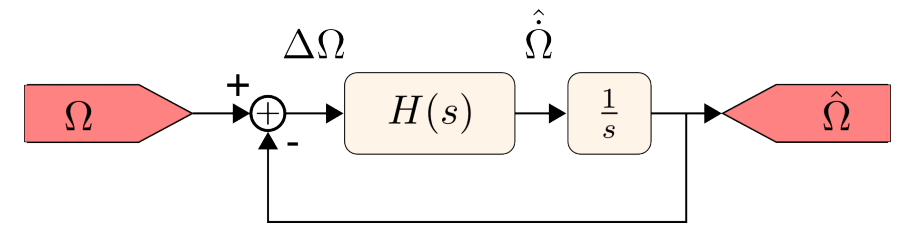

FiguRA 3.15: Estructura general de los lazos realimentados utilizados para estimar los parámetros de la señal.

en la Sección 3.7.2.4 los lazos utilizados en GNSS siempre cuentan con uno o más polos integradores en la función de transferencia de lazo abierto.

\subsubsection{Lazo de seguimiento de portadora}

El esquema anterior aplicado a la estimación de la fase de la portadora es el clásico lazo de enganche de fase PLL (Phase-Locked Loop) que es uno de los pilares de los sistemas de comunicación digitales y analógicos con demodulación coherente. La referencia del lazo es en este caso la fase instantánea de portadora, y el lazo provee estimaciones de la frecuencia y fase instantáneas de portadora.

Algunos diseños reemplazan el lazo PLL por uno de tipo FLL (Frequency-Locked Loop) para el seguimiento de portadora, pero debido a que los FLL no realizan una estimación de la fase instantánea, este tipo de diseño requiere de provisiones especiales para poder demodular el mensaje de navegación presente en la señal.

\subsubsection{Lazo de seguimiento de código}

Para el seguimiento de la función de código de la señal se utiliza un lazo de tipo DLL (Delay-Locked Loop) con discriminador de tipo Early-Late. La referencia del lazo de seguimiento de código es el retardo de la función de código.

Si bien del lazo de seguimiento de código también se puede obtener una estimación de la tasa de avance de la función de código, esta estimación es redundante porque la misma variable puede ser estimada indirectamente a través del valor frecuencia que se extrae del lazo de seguimiento de portadora. Esto es así porque como se explicó anteriormente ambas frecuencias, código y portadora, se generan guardando una relación fija entre ellas en el satélite transmisor. Más aún, debido a la elevada sensibilidad al ruido del lazo de seguimiento de código, a todos los fines prácticos es preferible la utilización del valor obtenido a partir de la lazo de seguimiento de portadora, que da lugar a una estimación de mucho mejor calidad. 


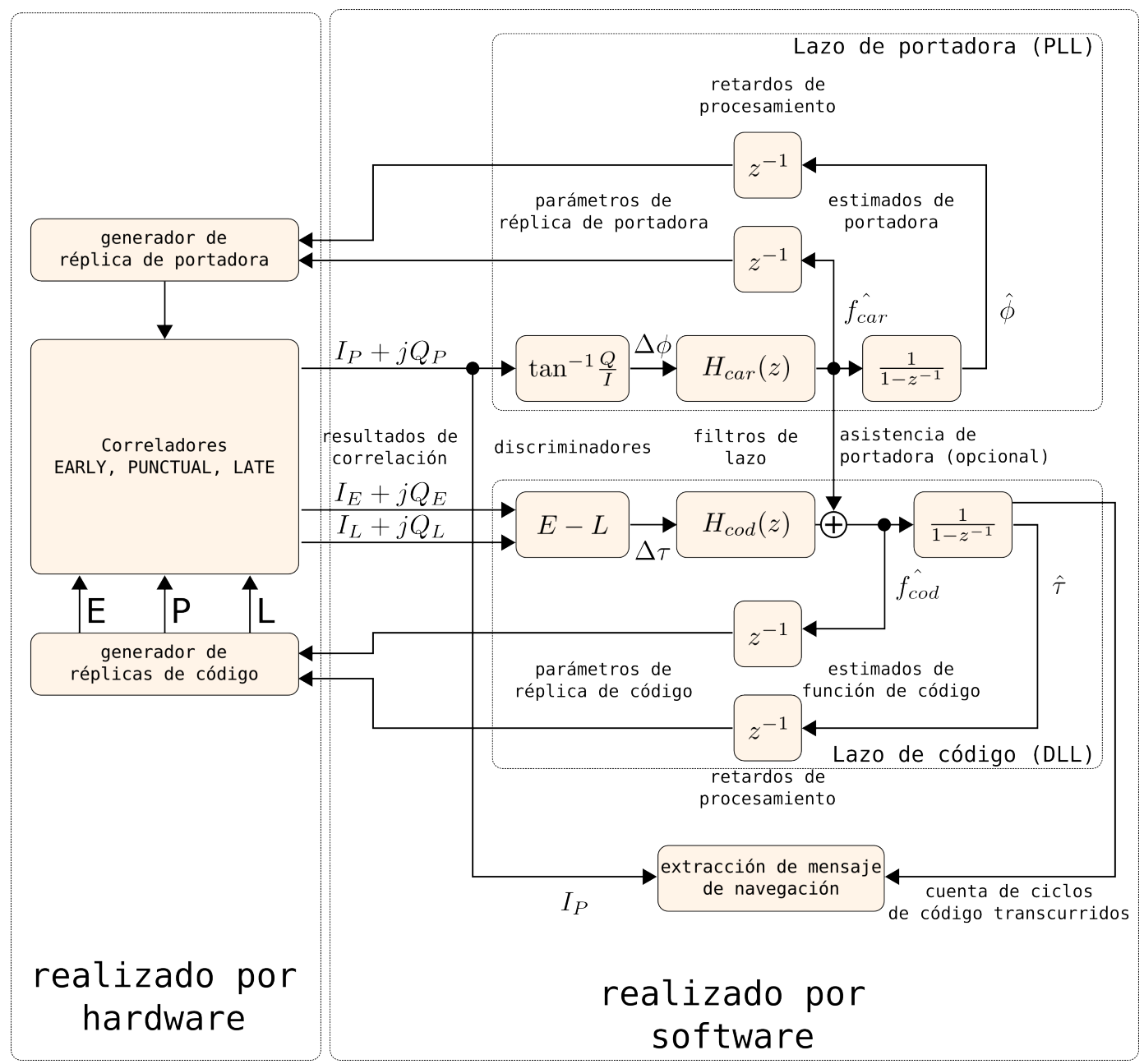

FigurA 3.16: Versión más completa del funcionamiento conjunto de los lazos de portadora y de código durante la fase de seguimiento de señal.

\subsubsection{Implementación discreta de los lazos}

Si bien la representación abstracta de la Figura 3.15 permite razonar la forma de funcionamiento de los lazos de seguimiento a partir del modelo abstracto de un lazo genérico, la implementación práctica de los mismos es más semejante a lo que se puede ver en la Figura 3.16.

La primera diferencia de importancia es la naturaleza discreta de la implementación. Los lazos de seguimiento procesan los resultados de correlación generados periódicamente por un canal de correlación presente en el hardware de procesamiento de alta tasa. El intervalo de muestreo es igual al tiempo de integración utilizado en las correlaciones. Este tiempo de integración puede tomar diferentes valores; valores típicos son de $1 \mathrm{~ms}$ para los lazos de seguimiento utilizados durante la sincronización en la fase de adquisición, mientras que en la fase de seguimiento se utilizan integraciones de $10 \mathrm{~ms}$ alineadas con los flancos de del mensaje de navegación. 
Las referencias de fase $\phi$ y retardo $\tau$ no son observables de forma directa en la señal. La comparación de los errores de lazo se realiza utilizando un discriminador de fase y otro de código en los lazos de seguimiento correspondientes. Los discriminadores son algoritmos que a partir de los resultados de correlación pueden generar un valor directamente proporcional al error de una variable de interés (fase o retardo).

Generalmente se utilizan tres correladores, conocidos como Early, Punctual y Late. Tal como se vio en la Sección 3.6 el hardware genera una única réplica local de portadora que es utilizada por todos los correladores, pero existen múltiples réplicas de la función de código que difieren entre sí por el retardo. El retardo utilizado en la réplica Punctual se corresponde exactamente con el valor del parámetro retardo $\hat{\tau}$ configurado en el generador de la réplica de la función de código al comienzo de la correlación. Las réplicas Early y Late se encuentran adelantada y atrasada respectivamente por una cantidad de tiempo $\Delta / 2$ respecto de Punctual. El tiempo $\Delta / 2$ generalmente se toma de longitud equivalente a $1 / 2$ chip de la función de código, pero intervalos más angostos son posibles y de hecho se utilizan para reducir la sensibilidad del lazo de código al ruido en la referencia.

El discriminador de fase procesa los resultados de correlación para obtener a su salida un valor proporcional al error $\Delta \phi$ entre la fase de la portadora $\phi$ y la de la réplica local, $\hat{\phi}$. Existe múltiples formas de implementar el discriminador, las cuales son examinadas en detalle en [4]; en términos generales todas las variantes calculan el argumento de la correlación Punctual, la cual como se puede ver en la expresión (3.15) es justamente la diferencia $\Delta \phi$ entre la fase $\phi(t)$ de portadora de la señal y la fase $\hat{\phi}(t)$ de la réplica de portadora.

El discriminador de fase óptimo según el criterio de máxima verosimilitud y también el que tiene la mayor región de operación lineal es la función arco tangente,

$$
\Delta \phi=\arctan \frac{Q_{P}}{I_{P}}
$$

En los sistemas modernos esta variante del discriminador puede ser calculada de forma simple mediante tablas de look-up, que es una metodología relativamente económica en términos de cómputo y recursos de memoria, por lo que no existen razones de peso para utilizar discriminadores diferentes.

El rango de valores del error de fase $\Delta \phi$ donde el discriminador se comporta linealmente está limitado a un intervalo de validez alrededor de cero que depende del discriminador utilizado, pero también de la presencia del mensaje de navegación modulado. Debido a la modulación BPSK de los bits del mensaje de navegación es necesario insensibilizar el discriminador ante variaciones de $180^{\circ}$ en la fase de la señal, lo cual se logra utilizando 

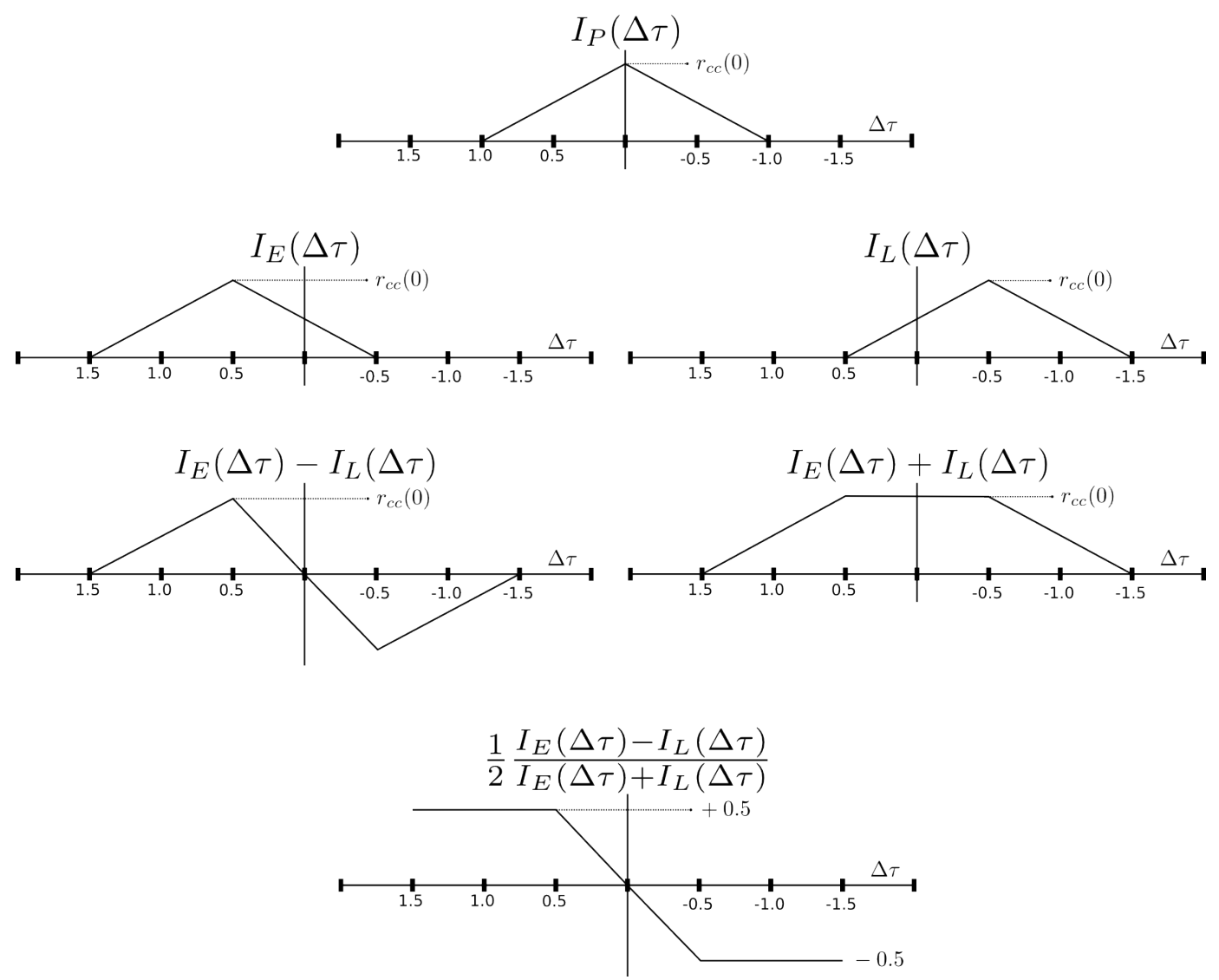

Figura 3.17: Funcionamiento del discriminador coherente de la expresión (3.16).

discriminadores que devuelvan el argumento del número complejo como un ángulo de los cuadrantes 1ro o 4to solamente, como por ejemplo la función arco tangente de dos cuadrantes. Esto limita el máximo rango lineal de operación de cualquier discriminador simple al intervalo $[-\pi / 2,+\pi / 2]$. Existe un discriminador de fase aumentado con memoria para lazos de seguimiento PLL llamado UFA (Unambiguous Frequency Aided) que extiende este rango de operación lineal a la totalidad de los reales en el caso en que se cumplan ciertas condiciones respecto del máximo error de frecuencia. Se volverá sobre este discriminador en la Sección 6.3.1.2 del Capítulo 6.

El discriminador de código que calcula el error $\Delta \tau$ funciona aprovechando las características de la función de autocorrelación de la función de código, en un esquema de tipo Early-Late. Un ejemplo de discriminador de código coherente (es decir, que asume que el error de fase de portadora es despreciable) es

$$
\Delta \tau=\frac{1}{2} \frac{\left(I_{E}-I_{L}\right)}{\left(I_{E}+I_{L}\right)}
$$

donde $I_{E}$ y $I_{L}$ son las componentes en fase de las correlaciones Early y Late respectivamente. Las unidades del resultado del cálculo anterior es el error de retardo en chips. 
El funcionamiento de dicho discriminador puede verse en la Figura 3.16, donde también puede apreciarse que el rango de funcionamiento lineal del mismo se restringe al intervalo que va de $-0,5$ a $+0,5$ chips de error. Si el espaciado entre réplicas Early-Punctual-Late $\Delta / 2$ es menor que 0,5 chips entonces la región lineal de funcionamiento del discriminador decrece de forma acorde al rango $[-\Delta / 2,+\Delta / 2]$.

Si bien el modelo simplificado de discriminador presentado en la expresión (3.16) es útil para exponer el funcionamiento de los discriminadores de código de forma muy simple, debe tenerse en cuenta que esta forma de discriminador es particularmente sensible al ruido que inevitablemente afecta a los valores de $I_{E}$ y de $I_{L}$ debido a la presencia de estos últimos en el denominador de la expresión (3.16). Dado que el objeto del denominador de dicha expresión es solamente normalizar la amplitud de la señal, las implementaciones prácticas reales reemplazan el denominador por una estimación de dicha amplitud:

$$
\Delta \tau=\frac{1}{2} \frac{\left(I_{E}-I_{L}\right)}{\tilde{A}}
$$

donde $\tilde{A}$ se calcula mediante un promedio muestral del valor de $I_{E}+I_{L}$ durante un intervalo de muestras de longitud adecuada.

Existen muchas otras estructuras de discriminador de código además de las dos anteriores. Si bien conceptualmente el funcionamiento de todas es idéntico, se diferencian unas de otras por la capacidad de procesar señales que no se encuentran perfectamente en fase (es decir, que tienen la potencia de señal repartida entre las componentes $I$ y $Q$ ) y por el nivel de sensibilidad al ruido. Para más detalles se puede consultar la referencia $[4]$.

Los retardos de procesamiento que se pueden ver en la Figura 3.16 aparecen como consecuencia de que el procesamiento de una tanda de resultados de correlación toma una cantidad de tiempo finita durante la cual el hardware ya se encuentra realizando la correlación siguiente. El retardo de la figura modela matemáticamente este efecto. Existe un segundo conjunto de retardos de procesamiento, ocultos en la figura dentro del correlador, que modelan el tiempo que toma ejecutar una correlación: una vez que los parámetros de una dada correlación entran en efecto, el resultado de dicha correlación afectará el estado de los lazos recién un tiempo de correlación después cuando el resultado de la correlación esté disponible. Los retardos de procesamiento recién mencionados deben ser tenidos en cuenta en la fase de diseño de los filtros de lazo para que la respuesta del sistema implementado se corresponda con la intención del diseñador. 


\subsubsection{Respuesta dinámica de los lazos}

Las características de la transferencia de lazo abierto $H(s) / s$ determinan el tipo de respuesta dinámica que presentará el mismo ante diferentes clases de variaciones de la referencia. Esto repercute directamente en la capacidad del receptor de adaptarse a diferentes tipos de perturbaciones en las señales que tengan origen en la dinámica física del vehículo donde se encuentra el receptor, como por ejemplo variaciones en la velocidad, aceleraciones repentinas, etc.

De la teoría de control automático se sabe que la cantidad de polos integradores $\left(s_{0}=0\right.$ en el dominio continuo y $z_{0}=1$ en el discreto) que tenga la transferencia de lazo abierto de un sistema de seguimiento con realimentación unitaria determina el error de estado estacionario que tendrá dicho lazo para una serie de tipos de variación en su entrada: escalón, rampa, parábola. etc. A la cantidad de polos integradores se la define como el tipo del lazo, mientras que a la cantidad de polos totales de la transferencia se la denomina el orden del lazo. Por supuesto, el tipo siempre será menor o igual que el orden de un mismo lazo.

Las características de la respuesta del lazo para diferentes clases de variación de la referencia se resumen a continuación para los primeros tres tipos.

Tipo I Presenta error estacionario nulo ante un escalón en la referencia, y alcanza un estado estacionario de error constante ante una rampa. Diverge con dinámicas parabólicas o superiores.

Tipo II Presenta error estacionario nulo ante un escalón o rampa en la referencia, y alcanza un estado estacionario de error constante ante una parábola. Diverge con dinámicas cúbicas o superiores.

Tipo III Presenta error estacionario nulo ante un escalón, rampa, o parábola de la referencia, y alcanza un estado estacionario de error constante ante una variación cúbica. Diverge con dinámicas de orden cuarto o superior.

Si bien las características de seguimiento en régimen estable mejoran con el tipo del lazo, también lo hace la dificultad para garantizar la estabilidad del sistema a lazo cerrado. Por esta razón no es frecuente la utilización de lazos de órdenes más elevados que lo necesario para cumplir con los requerimientos dinámicos de la aplicación.

La existencia de desviaciones en las frecuencias de portadora y código respecto de sus valores nominales significan que el requerimiento operativo base para los lazos de seguimiento utilizados en receptores GNSS es el de poder seguir rampas de fase/retardo 
(que son equivalentes a desviaciones de la frecuencia de portadora/código respectivamente) con error estacionario nulo. Si bien las desviaciones de frecuencia son a su vez variantes en el tiempo (ver Figura 3.13) para el caso de receptores estacionarios o cuasiestacionarios generalmente se puede asumir que el error debido la tasa de variación de la desviación es despreciable y por lo tanto los lazos de seguimiento se diseñan utilizando lazos Tipo II. Se deja la utilización de lazos Tipo III para aquellos casos donde la tasa de variación de la desviación de frecuencia es tal que no se puede despreciar el error de estado estacionario que esto genera. Este es generalmente el caso de receptores GNSS que funcionan a bordo de vehículos capaces de mantener grandes valores de aceleración de forma sostenida en el tiempo (cohetes, aviones militares, etc.).

El error de estado estacionario no es el único criterio de diseño. Debido a que los discriminadores de fase y retardo tienen rangos de operación lineal acotados, el diseño del filtro de lazo también debe garantizar máximo error de seguimiento no salga de la región de funcionamiento lineal para ninguna condición operativa especificada. Esto está relacionado con la duración de los transitorios de ajuste, que depende no sólo del tipo y orden del diseño del lazo, sino también de la ubicación de los polos y ceros en el lugar de raíces.

En términos informales puede relacionarse la velocidad de respuesta del lazo con el ancho de ruido equivalente $B_{n}$ del mismo, definido en sistemas de tiempo continuo como

$$
B_{n}=\frac{1}{2 \pi G^{2}(0)} \int_{-\infty}^{\infty}|G(j \omega)|^{2} d \omega
$$

donde $G(s)$ es la transferencia a lazo cerrado del sistema. La definición discreta es análoga a la anterior pero la integral se realiza alrededor del círculo unitario. A mayor ancho de banda equivalente, mayor velocidad de extinción de transitorios, y menor error máximo. Esto debe tomarse como una regla general solamente, ya que la relación entre unos valores y otros dependerán no sólo del ancho de banda, sino del diseño concreto (cantidad y distribución de polos y ceros del lazo realimentado) y deberán obtenerse para un cada diseño particular ya sea de forma analítica o mediante simulación.

La estrategia más común para el diseño de los filtros de los lazos consiste en plantear el modelo de tiempo continuo de la Figura 3.15 y diseñar una transferencia $H(s) / s$ que tenga las características que sean requeridas por la aplicación. En [4] se proveen plantillas para diseñar filtros óptimos (en sentido de mínima energía de error con un escalón en la referencia) de Tipo I, II y III, las cuales son repetidas en la Figura 3.18 por conveniencia; utilizando estas plantillas el diseñador sólo necesita calcular los coeficientes de la transferencia a partir del ancho de banda de ruido $B_{n}$ deseado. Por supuesto que estas plantillas no son más que una solución enlatada que da una solución óptima ante una 


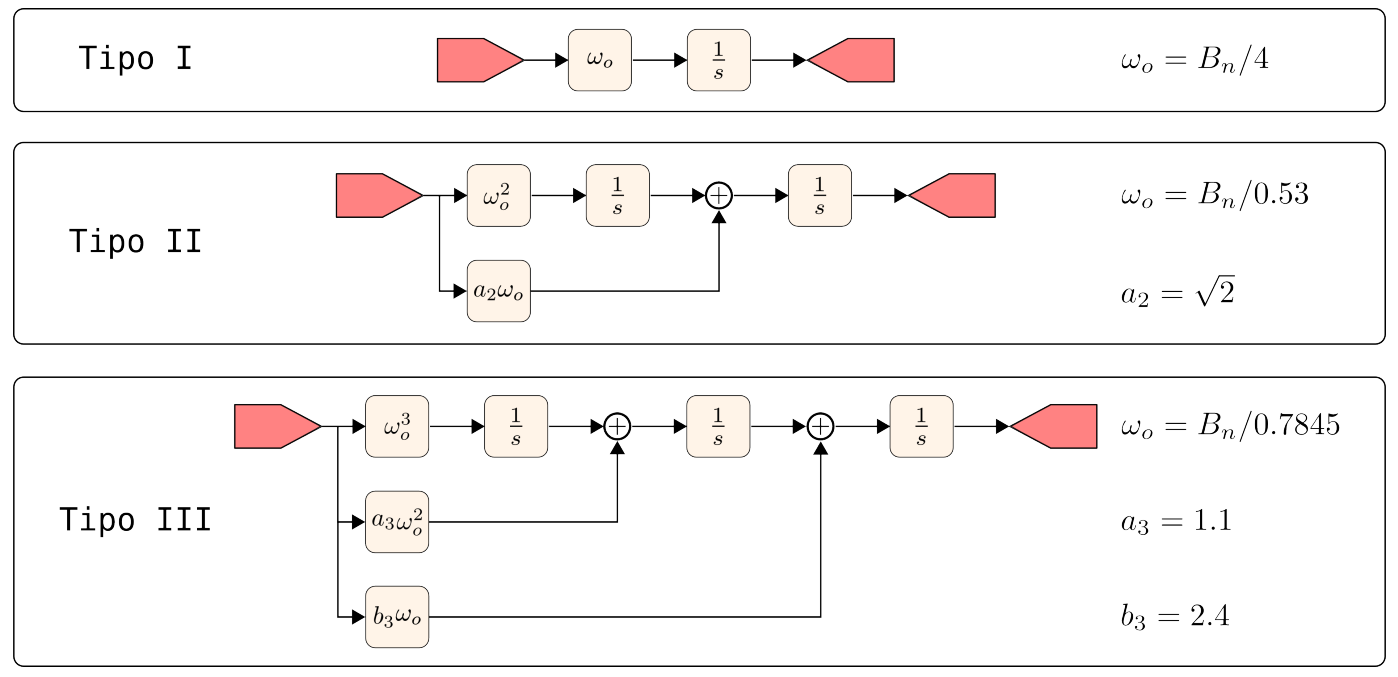

FigurA 3.18: Plantillas para el diseño de los filtros de lazos analógicos propuestos en [4]. $B_{n}$ es el ancho de banda de ruido equivalente deseado para el lazo.

determinada clase de entrada, pero el diseñador puede optar por diseñar la transferencia utilizando cualquier otro criterio de diseño que aplique para un caso particular.

Una vez que se ha diseñado el filtro en el dominio continuo se procede a convertir la transferencia continua al dominio discreto utilizando para ello alguna de las aproximaciones habituales (rectangulares hacia adelante, hacia atrás, o trapezoidal), obteniendo así una transferencia $H(z)$ equivalente que se puede implementar en el receptor utilizando aritmética de punto fijo o flotante.

La técnica de diseño analógico seguido de una aproximación discreta del filtro de lazo arroja buenos resultados en la medida en la que la transferencia de lazo cerrado tenga un ancho de banda de ruido que sea inferior a $\frac{1}{10}$ de la frecuencia de muestreo discreta (el inverso del tiempo de correlación utilizado). Este límite es una guía general y no debe ser tomado como una regla estricta, pero se fundamenta en el hecho de que si la frecuencia de corte es superior a dicho límite entonces las constantes de tiempo del diseño se vuelven comparables con el intervalo de muestreo utilizado. Debe señalarse también que esta técnica de diseño desprecia la existencia los retardos de procesamiento que fueron mencionados en 3.7.2.3, lo cual sólo tiene sentido si las constantes de tiempo del filtro de lazo son mucho mayores que el tiempo de muestreo.

Existe una estrategia alternativa de diseño que consiste en desarrollar el filtro de lazo directamente en el dominio discreto. Esta estrategia no goza de la misma popularidad que la aproximación discreta de filtros continuos por la simple razón de que las técnicas de diseño en el dominio discreto no cuentan ni con la misma variedad ni con la misma difusión que las técnicas de diseño en el dominio continuo. Más aún, el diseño discreto no ofrece ventajas significativas frente a la metodología clásica cuando la frecuencia de 
corte del lazo es lo suficientemente baja comparada con la frecuencia de muestreo del sistema, lo cual abarca la amplia mayoría de los casos de aplicación posibles.

El diseño discreto se muestra ventajoso cuando la dinámica que deben tolerar los lazos de seguimiento demanda anchos de banda $B_{n}$ que no cumplen con la regla de 1/10 de la frecuencia de muestreo, en cuyo caso la utilización de filtros continuos discretizados dará lugar a filtros discretos cuyo comportamiento no es el deseado. Cuando eso ocurre, la solución más frecuente consiste en incrementar la frecuencia de muestreo mediante una reducción de los tiempos de correlación utilizados (por ejemplo $5 \mathrm{~ms}$ en lugar de $10 \mathrm{~ms}$ ) pero esto incrementa la carga de cómputo del procesador del sistema.

Una alternativa mejor puede ser la de utilizar guías de diseño como las provistas en [1] para diseñar filtros discretos de lazo de portadora óptimos. Esta aproximación será la utilizada en el Capítulo 6 cuando se trate del diseño de los lazos de seguimiento del receptor GNSS desarrollados como parte de este trabajo de tesis.

\subsubsection{Condición de enganche}

El funcionamiento de ambos lazos, código y portadora, permite maximizar la potencia de señal recuperada por correlación, ya que hace que los errores $(\Delta f, \Delta \tau)$ de la expresión $(3.15)$ tiendan a $(0,0)$. En efecto, ambos lazos garantizan que las estimaciones $(\hat{f}, \hat{\tau})$ sigan los desplazamientos del centro del lóbulo de correlación por el plano retardo-frecuencia. En el caso de que se utilice un PLL para el seguimiento de portadora, entonces este último tiende a concentrar toda la potencia de señal sobre la componente en fase, $r_{(i, j)}^{I}[m]$. En este caso el mensaje de navegación de la señal puede ser demodulado simplemente decodificando los pulsos que son observables en dicha dicha componente.

La condición de operación anterior, donde los estimadores siguen fielmente las variaciones de los parámetros de la señal, es lo que generalmente se denomina una condición de enganche de los lazos con la señal.

Por el contrario, si la estimación de la frecuencia portadora hecha por el lazo PLL, o del retardo determinada por el lazo DLL toman valores demasiado alejados del máximo de correlación, entonces se producirá una caída en la relación SNR de las muestras de correlación. Cuanto más profunda sea esta caída, más difícil es recuperar la convergencia de los estimadores hacia los valores de los parámetros, por lo que es posible que eventualmente los estimadores diverjan tanto que terminen saliendo completamente del lóbulo de correlación. Si esto ocurre la relación SNR pasa a ser será esencialmente cero y la recuperación un estado de enganche es prácticamente imposible. En esta condición se habla de un desenganche de los lazos de seguimiento, que no es ni más ni menos que la pérdida de la condición de sincronismo con la señal. 


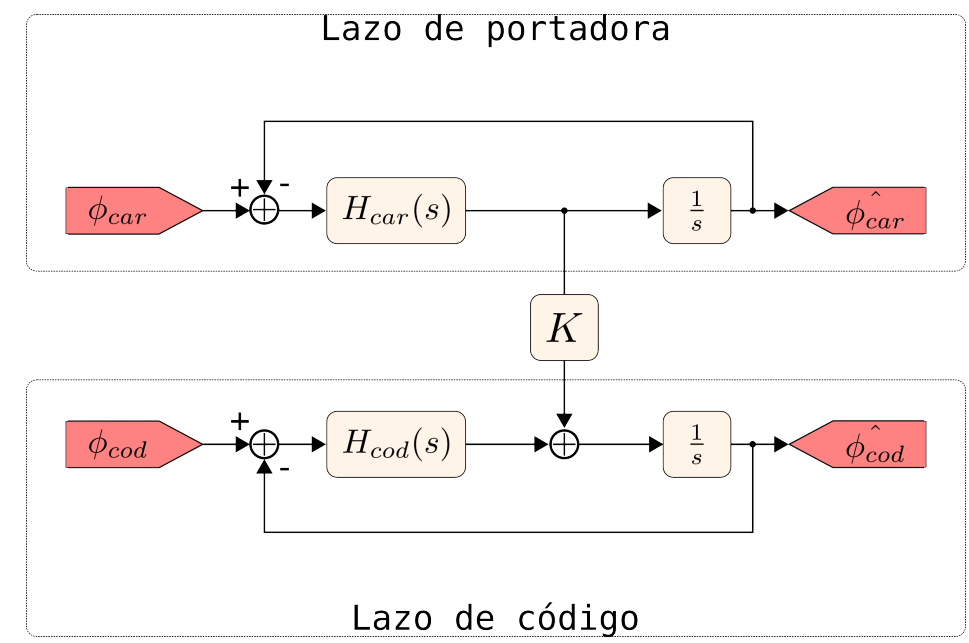

Figura 3.19: Esquema de asistencia de lazos.

El desenganche puede puede ocurrir por varios motivos, siendo el más frecuente simplemente la pérdida de relación $C / N_{o}$ cuando el satélite transmisor desaparece detrás del horizonte. Para receptores convencionales el mínimo valor de $C / N_{o}$ necesario para que los lazos de seguimiento permanezcan enganchados con la señal suele considerarse del orden de $29 \mathrm{~dB}-\mathrm{Hz}$, porque en las proximidades de dicho valor el estado de enganche de los lazos de portadora y de código es precario en el mejor de los casos, y cualquier perturbación (por dinámica o por ruido) puede provocar el desenganche de ambos.

La desincronización puede también ocurrir si la dinámica del vehículo sufre alguna modificación súbita que provoca que los errores $(\Delta f, \Delta \tau)$ crezcan por fuera del lóbulo de correlación antes de que los lazos puedan compensar la perturbación. Evitar esta circunstancia requiere de un diseño apropiado de la función de transferencia de los lazos, teniendo en cuenta las dinámicas máximas que pueden encontrarse en cada aplicación particular.

\subsubsection{Asistencia de lazo de portadora}

Si bien en principio los lazos de portadora y de código pueden funcionar independientemente uno de otro, es frecuente la utilización de una técnica llamada asistencia de portadora que inyecta la estimación de frecuencia del PLL escalada en magnitud en la estimación de tasa de avance del código del lazo DLL. En la Figura 3.19 puede verse un diagrama del funcionamiento de esta técnica. El valor del factor de escala $K$ es el cociente entre la frecuencia de código nominal y la frecuencia de portadora nominal, cociente que como se comentó en el capítulo anterior es una constante bien definida para cada sistema GNSS. Para señales GPS C/A el valor de $K$ es $\frac{1}{1540}$, mientras que para 
GLONASS L1OF el cociente depende del número $k$ de canal FDMA que tiene asignado cada satélite transmisor.

El esquema de asistencia permite que el lazo de seguimiento DLL se beneficie de la relativamente alta inmunidad al ruido de entrada que tienen los lazos PLL. En este caso el PLL se diseña para compensar rápidamente las perturbaciones en la frecuencia portadora de la señal debidas a la dinámica del vehículo por efecto Doppler, mientras que el diseño del DLL se relaja acentuando sus características pasabajo para filtrar la mayor cantidad de ruido posible y así mejorar la calidad de la estimación del retardo, que beneficia de forma directa a la calidad de la solución de posición que calcula el receptor. Dado que el lazo de portadora se encarga de rastrear las variaciones debidas a la dinámica del vehículo, el lazo de código puede limitarse a un lazo de Tipo I sin que se produzcan problemas de divergencia en presencia de dinámica.

\subsubsection{Extracción del mensaje de navegación}

Utilizando un lazo PLL para hacer el seguimiento de fase y suponiendo que tanto este último como el DLL están operando en condiciones operativas normales, entonces los valores de los errores de fase $\Delta \phi$, frecuencia portadora $\Delta f$ y retardo $\Delta \tau$ pueden considerarse despreciables. La expresión (3.15) aplicada al correlador Punctual entonces se reduce a

$$
{ }^{C}[m] \approx n^{C}[m]+A d[m]
$$

donde $n^{C}$ es el ruido complejo de correlación de la m-ésima muestra de correlación, y $d[m]$ es el valor del símbolo de datos del mensaje de navegación $(+1 \mathrm{o}-1)$ correspondiente a dicha muestra. Se había asumido en la extracción de la expresión (3.15) que el valor de $d[m]$ permanece constante durante la integración. Para garantizar el cumplimiento de esta hipótesis en la etapa de seguimiento se utilizan tiempos de correlación que son divisores exactos de la duración del tiempo de bit y se los sincroniza con los flancos de bit para que el comienzo de un nuevo bit siempre coincida con el comienzo de un intervalo de integración. Esto es posible gracias a la información sobre la posición de los flancos de bit que se obtiene en la última etapa de la fase de Adquisición y Sincronización Inicial, tal como se describió en 3.7.1.3.

A partir de la información de alineamiento de los flancos de bit el receptor puede agrupar las integraciones de acuerdo al intervalo de bit que ocupan. Por ejemplo, utilizando tiempos de integración de $10 \mathrm{~ms}$ y suponiendo que el comienzo de la correlación con $m=0$ coincide con el comienzo del bit con $n=0$, entonces dado que los bits de la señal C/A del sistema GPS tienen una duración de 20 ms es fácil ver que la m-ésima 
correlación forma parte del n-ésimo bit con $n=\lfloor m / 2\rfloor$. Conviene notar que dado que se supusieron nulos de los errores de fase, frecuencia y retardo, entonces los valores de correlación $I_{P}[m]$ son efectivamente la integral de los pulsos NRZ bipolares que quedaron en banda base al eliminar la portadora y la función de código de la señal GNSS (ver la codificación de la señal GPS C/A en 2.2.5). Sumando todos los segmentos de un mismo bit obtenemos la integral del pulso correspondiente a un bit individual

$$
b^{g p s}[n]=I_{P}[2 n]+I_{P}[2 n+1] .
$$

Si se compara el area $b[n]$ de cada bit contra cero se puede determinar el valor del n-ésimo bit $d[n]$. Notar que este esquema es justamente el receptor óptimo para señales NRZ:

$$
d[n]= \begin{cases}+1 & b[n] \geq 0 \\ -1 & b[n]<0\end{cases}
$$

Para la señal L1OF de GLONASS el esquema general es exactamente el mismo, excepto por el hecho de que la forma de los pulsos utilizados para modular el mensaje de navegación en GLONASS es Manchester (ver Sección 2.3.5). En este caso para que el esquema de decisión sea óptimo y utilice toda la energía de bit el área del bit debe calcularse como

$$
b^{g l o}[n]=I_{P}[2 n]-I_{P}[2 n+1]
$$

para que el valor $b^{g l o}$ sea equivalente a la correlación del pulso recibido con el pulso Manchester.

Se había dicho antes que con el fin de no verse afectados por la modulación de datos, el lazo de seguimiento de portadora es insensible a cambios de $180^{\circ}$. Una consecuencia muy importante de esto es que el lazo de portadora puede engancharse con iguales probabilidades en fase o en contrafase respecto de la fase original utilizada para modular el mensaje de navegación, y por lo tanto la secuencia de bits demodulada tiene $50 \%$ de probabilidades de estar invertida respecto de la transmitida por el satélite.

Tanto GPS como GLONASS contemplan mecanismos de resolución de esta ambigüedad en el diseño de su mensaje de navegación. En el caso de GPS C/A el receptor puede determinar la polaridad correcta como parte del proceso de cálculo de la paridad de las palabras de 30 bits en que se divide el mensaje de navegación, gracias a la presencia de bits de valor fijo en posiciones conocidas de secuencia. La señal L1OF de GLONASS, en cambio, resuelve el problema de la polaridad utilizando codificación diferencial de los bits del mensaje de navegación.

Por supuesto que la recuperación de la secuencia de bits sólo es el primer paso del proceso de demodulación del mensaje de navegación. Como se explicó en las secciones 2.2.5 y 
2.3.5, las señales GNSS GPS C/A y GLONASS L1OF cuentan con niveles adicionales de estructura con los que el receptor debe sincronizarse. La sincronización en estos niveles es un proceso que comienza junto con la demodulación de la secuencia de bits, y que debe encargarse de las siguientes tareas:

- Detección de las marcas de sincronización

- Palabra de telemetría de la señal C/A.

- Marca de temporización de L1OF.

- Detección de la polaridad del mensaje.

- Validación del sincronismo:

- Verificaciones de paridad.

- Verificación de campos invariantes.

- Detección de inconsistencias entre repeticiones.

- Detección de actualizaciones de la información transmitida.

- Extracción de información de reloj, información orbital y de constelación.

Sobre el funcionamiento de los algoritmos encargados de realizar estas taras no se dirá nada aquí por escapar del alcance de este trabajo. Detalles para el caso de la señal GPS C/A pueden hallarse en [3], mientras que para GLONASS L1OF deberán ser extraídos con paciencia del documento del sistema, referencia [33].

\subsection{Cálculo de Navegación}

El receptor utiliza las mediciones de tiempo de transmisión y de frecuencia portadora de las señales recibidas para determinar una solución de navegación consistente en información de la posición, la velocidad, y la hora local, lo que también recibe el nombre de fix de navegación.

En la Sección 2.4.1 del capítulo anterior ya se presentó una introducción al modelo de cálculo de navegación utilizado en los sistemas GNSS GPS y GLONASS, por lo que dicha información no será repetida aquí. Las secciones siguientes se concentrarán en las cuestiones operativas relacionadas con la generación de soluciones de navegación. 


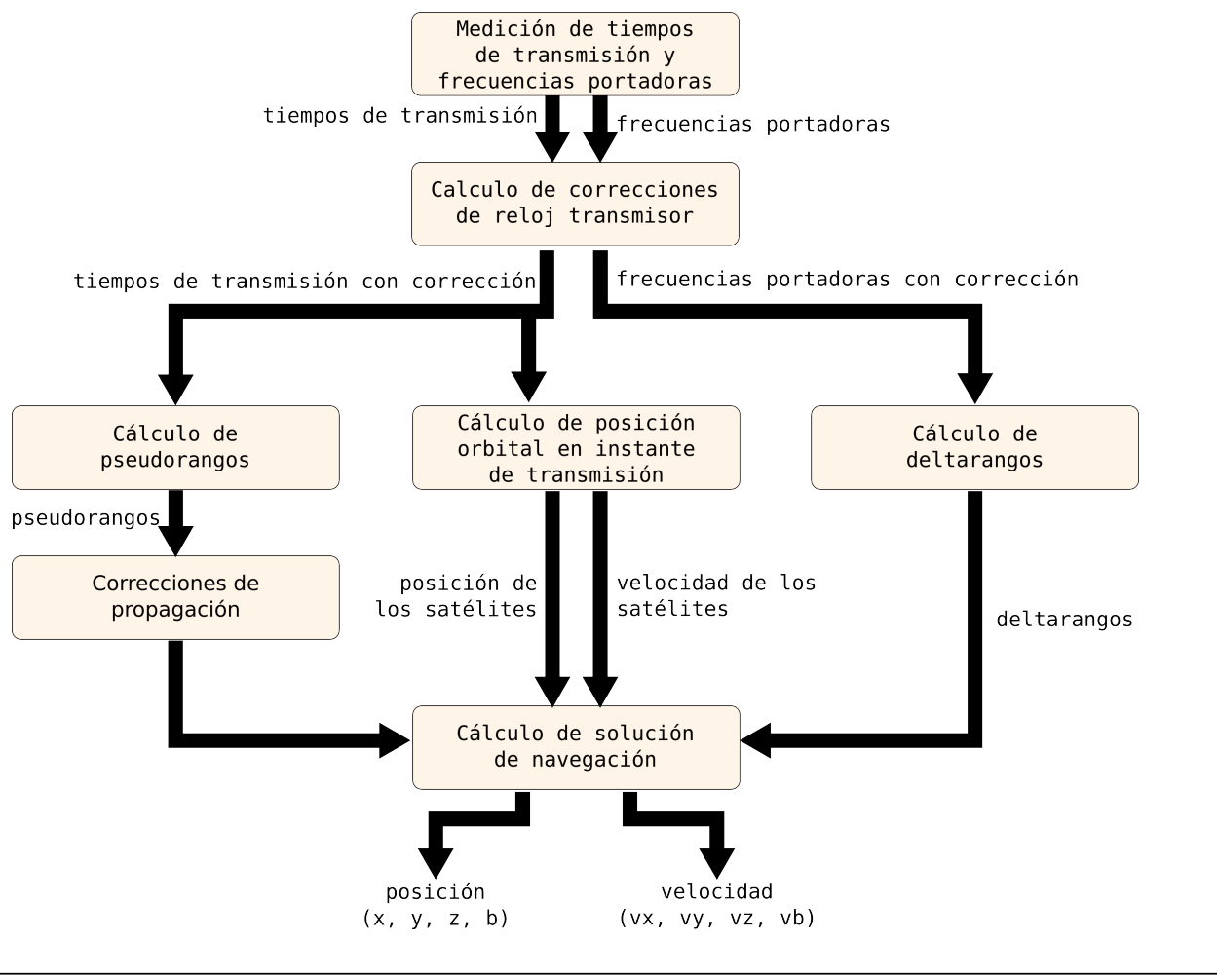

Figura 3.20: Pasos de la resolución de la solución de navegación.

\subsubsection{Obtención de mediciones}

El tiempo de transmisión $t_{t t}(t)$ se determina a partir de la unión de varias fuentes de información relacionadas con el sincronismo con la señal a diferentes niveles. Como se explicó en 2.2.5.3 y en 2.3.5.3, la medición de tiempo de transmisión puede dividirse en dos términos principales,

$$
t_{t t}(t)=t_{t t c}(t)+t_{t t f}(t)
$$

donde el tiempo $t_{t t c}(t)$ es el tiempo grueso, mientras que $t_{t t f}(t)$ es el tiempo fino. El tiempo grueso mide el tiempo de transmisión en unidades de período de bit (20ms) y su valor es calculado por las rutinas de demodulación del mensaje de navegación. El tiempo fino provee la fracción de tiempo que está por debajo de la resolución del tiempo grueso, y su valor se deriva del estado de lazo de seguimiento de código de la señal.

La desviación de frecuencia portadora utilizada para el cálculo de la velocidad del vehículo se puede obtener de forma directa a partir de la estimación de la frecuencia portadora del lazo de seguimiento correspondiente. 


\subsubsection{Algoritmos de navegación}

La secuencia de pasos fundamentales que realiza el receptor para obtener el fix de navegación puede verse en la Figura 3.20.

El proceso comienza con un evento de generación de mediciones. En presencia de este evento el receptor genera una imagen simultánea del estado de todos los lazos de seguimiento y de los sistemas encargados de la demodulación de datos de señales activas. Con estos datos se arman las muestras de tiempo de transmisión de la señal recibida de cada uno de los satélites en el instante de toma de mediciones.

Los tiempos de transmisión medidos son los que vienen estampados en la codificación de las señales recibidas, pero la hora anunciada por los satélites está afectada de un corrimiento debido a la tolerancia de la referencia de tiempo de a bordo. Este error debe ser corregido para determinar la hora de emisión verdadera (eso es, medida según la referencia de la Hora de Sistema). Tanto GPS como GLONASS proveen de la información necesaria para realizar esta corrección en la forma de un modelo polinómico de la variación del error en el tiempo, cuyos coeficientes son transmitidos como parte del mensaje de navegación. De forma similar se puede corregir en las mediciones de desviación de la frecuencia portadora la diferencia debida al apartamiento en emisión de la portadora respecto de su valor nominal.

Una vez conocidos los tiempos de transmisión y las desviaciones de frecuencias medidos relativos todos al patrón de tiempo central del sistema, los tiempos de transmisión son convertidos en pseudorangos y las desviaciones de frecuencia en deltarangos. Los tiempos de transmisión además se utilizan para calcular la posición y velocidad de cada uno de los satélites transmisores en el momento de emisión de sus respectivas señales para poder plantear los sistemas de ecuaciones vistos en 2.4.1.

Los pseudorangos requieren de correcciones adicionales debidos a distorsiones ocurridas durante el tránsito de la señal. Las correcciones más importantes son la compensación de la disminución de la velocidad de propagación de las ondas electromagnéticas dentro de la atmósfera (ionósfera y tropósfera) y la compensación del efecto relativista Sagnac que se debe al desplazamiento del receptor en el marco de referencia inercial donde los relojes de los satélites transmisores se encuentran sincronizados.

Finalmente, el receptor utiliza la información de posición y velocidad de los satélites transmisores, los pseudorangos y los deltarangos para construir los sistemas de ecuaciones que una vez resueltos arrojan la solución de posición

$$
(x, y, z, b)
$$


donde $x, y, \mathrm{y} z$ son las coordenadas del receptor y $b$ es el sesgo del reloj del receptor respecto de la Hora del Sistema, y la solución de velocidad

$$
\left(v_{x}, v_{y}, v_{z}, v_{b}\right)
$$

compuesta de las tres coordenadas espaciales de la velocidad $v_{x}, v_{y}$ y $v_{z}$, y de la derivada del sesgo $v_{b}$.

\subsubsection{Tasa de generación de soluciones}

En aplicaciones de baja dinámica es normalmente más que suficiente con una tasa de obtención de soluciones de navegación de una vez por segundo. Tasas mayores que esta son posibles si el sistema cuenta con la capacidad de cómputo suficiente para resolver los sistemas de ecuaciones, pero en este caso debe considerarse que los beneficios de resolver más veces por segundo pueden ser limitados.

En particular, la respuesta dinámica de los lazos de seguimiento provocará una alta correlación entre conjuntos de mediciones sucesivas si el intervalo entre mediciones es del orden de las constantes de tiempo de los mismos. Si bien las constantes de tiempo de los lazos pueden ser reducidas (aumentando el ancho de banda de ruido de los mismos), esto típicamente provocará un deterioro en el ruido de medición.

La tasa de generación de soluciones por lo tanto no es una variable libre sino que debe considerarse como un compromiso entre los requerimientos dinámicos de la aplicación y las cotas de error en la solución deseadas.

\subsubsection{Pulso por segundo}

Es frecuente en los receptores GNSS la existencia de una salida de pulso-por-segundo (PPS, o pulse-per-second) a través de la cual el receptor genera una marca de tiempo periódica de frecuencia $1 \mathrm{~Hz}$ coincidente con el comienzo de los los segundos de la Hora del Sistema (GPS o GLONASS). La marca consiste en alguno de los flancos de un pulso eléctrico, y la tolerancia de dicha señal es del orden de algunas decenas de nanosegundos. Esta señal es utilizada en aplicaciones donde es necesario sincronizar múltiples estaciones remotas entre sí, al sincronizar todas ellas contra la referencia común de la hora de un sistema GNSS.

Para generar la señal PPS el receptor calcula la Hora del Sistema correspondiente al instante de toma de mediciones de un fix de navegación a partir de la hora del receptor 
y el sesgo $b$ de la solución, y con esta información se programa la generación de un pulso de la señal PPS coincidente con el próximo segundo entero de la Hora del Sistema.

Generalmente los receptores con salida PPS también sincronizan la generación de soluciones de navegación para que coincidan con los pulsos PPS. En este caso, la primera vez que el receptor calcula un fix esta solución se utiliza para ajustar los instantes de generación posteriores y para inicializar el generador de pulsos PPS. A partir de ese momento el receptor generará pulsos y soluciones de navegación, ambos alineados con los segundos del sistema.

\subsection{Control y monitoreo}

Bajo el título de Control y Monitoreo se encuentran abarcadas todas aquellas tareas adicionales que no se encuentran relacionadas con la función específica de un receptor GNSS sino con proveer soporte a las funciones vitales, administrando recursos, proveyendo comunicación interna entre los módulos del software y hardware, etc.

Los tipos de procesamiento realizados por el receptor son de naturaleza absolutamente concurrente, por lo que la utilización de un sistema operativo multitarea que dé soporte a la sincronización interna entre los diversos módulos es casi obligatoria. Será el sistema operativo entonces el encargado de resolver los problemas de gestión del recursos de cómputo y memoria, proveer interfaces de sincronización, exclusión en el acceso a secciones críticas, y regular el acceso al hardware, entre otras funciones varias.

Por supuesto que también es posible la implementación de soluciones de tipo bare-metal donde la aplicación se ejecuta directamente sobre el hardware sin sustento de un sistema operativo explícito, lo cual permite cierta economía en la utilización de memoria. Sin embargo este tipo de diseño traslada a la aplicación todas las responsabilidades de interacción con el hardware y administración de la multitarea, sincronización, etc., dificultando su desarrollo e impactando negativamente en la portabilidad de la aplicación. Estos problemas limitan la utilización de la aproximación bare-metal a proyectos pequeños donde la economía de recursos sea prioritaria.

El software del receptor puede representarse dividido en tres grandes módulos, como se ve en la Figura 3.21: un sistema operativo, la aplicación en sí misma, y eventualmente un conjunto de librerías. Estos módulos interaccionan entre sí y con el hardware por intermedio de interfaces bien definidas. Este tipo de estructura no es exclusiva de los receptores GNSS sino que es propia de la mayor parte de los sistemas embebidos de mediana complejidad. 


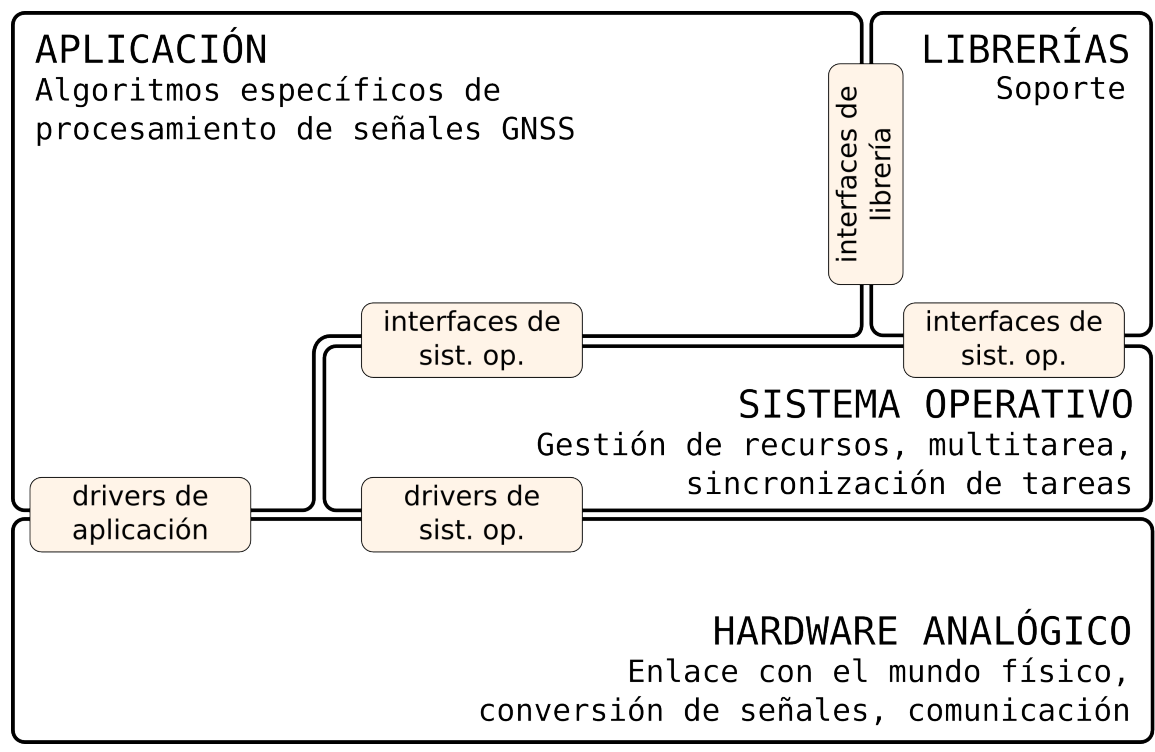

Figura 3.21: Relación entre el hardware, el sistema operativo y la aplicación.

Se ha visto en las secciones anteriores que la mayor parte de los algoritmos del receptor funcionan a base de procesar las muestras de correlación generadas por el hardware de forma periódica. Cada nuevo conjunto de muestras de correlación produce la activación de las tareas encargadas de realizar el procesamiento y generar los parámetros de configuración para las correlaciones siguientes. Este procesamiento tiene características de tiempo real duro ya que todo el procesamiento debe ser realizado dentro del intervalo de tiempo de un tiempo de correlación, antes de que se produzca la activación del conjunto siguiente. Debe sumarse a esto la superposición en las ejecuciones de actividades de diversos tipos, con diferentes periodicidades. Por ejemplo, un receptor puede tener múltiples canales de hardware ocupados en realizar seguimiento de señales activas (procesando correlaciones de $10 \mathrm{~ms}$ ) mientras realiza adquisiciones con otro canal de correladores (tiempo de integración de $4 \mathrm{~ms}$ ) y sincronización en otro (tiempo de integración $1 \mathrm{~ms}$ ). Todas estas actividades deben poder completar con sus respectivas cotas de tiempo de ejecución sin interferencia mutua.

Parte de la solución del problema de la ejecución en tiempo parte de la utilización de un sistema operativo adecuado, de los conocidos normalmente como sistemas operativos de tiempo real (RTOS, Real-Time Operating System). Esta categoría de sistemas operativos no se distinguen tanto por las interfaces que proveen comparadas con las de un sistema operativo convencional, sino más bien por las implementación de la funcionalidad detrás de las mismas: donde un sistema operativo convencional generalmente optimiza todos sus algoritmos para el caso más frecuente con el fin de minimizar los tiempos medios de ejecución, un RTOS minimizará el tiempo de peor caso para acotar la ejecución máxima. 
El sistema operativo es solamente parte de la solución. El cumplimiento de las cotas de ejecución de tiempo real requiere de un diseño apropiado del mismo software de aplicación, en este caso del receptor. El análisis planificabilidad (capacidad de cumplir con todas las cotas de ejecución) de un sistema es -en términos generales- un problema abierto que no conoce solución analítica, pero existen hace décadas resultados muy importantes para casos especiales. Algunos de los resultados más importantes en este sentido están dados en [42] para el análisis de la planificabilidad de conjuntos de tareas estrictamente periódicas. Se propone allí una técnica de planificación estática de tareas conocida como Rate Monotonic Scheduling, junto con un criterio analítico que permite probar la planificabilidad de un conjunto de tareas. Si bien el modelo utilizado para derivar las garantías de RMS es sumamente ideal, es posible mediante algunas simplificaciones adecuadas utilizar RMS para estructurar las actividades de un receptor de forma tal de que el sistema cumpla con las cotas de tiempo real de todas sus partes.

\subsection{Comunicación}

El módulo de comunicación es el encargado de realizar el intercambio de información, configuración y comandos entre el receptor y los sistemas externos al mismo. Este módulo se encarga del acondicionamiento, segmentación y formateado de la información a transferir. Los canales de comunicación a utilizar pueden ser únicos o múltiples, al igual que los protocolos utilizados.

La naturaleza de la información generada por el receptor incluye las soluciones de navegación pero no se limita a ellas, sino que generalmente abarca la casi totalidad de los productos intermedios utilizados para realizar el cálculo de dicha solución permitiendo a los sistemas externos realizar diferentes tipos de post-procesamiento de las mediciones del receptor.

Las piezas de información generadas por el receptor típicamente incluyen:

- Conjunto de datos asociados a una solución de navegación:

- Solución de posición.

- Solución de velocidad.

- Lista de satélites utilizada en la solución.

- Observables correspondientes a la solución:

- Mediciones de tiempo de transmisión y/o pseudorangos.

- Mediciones de frecuencia y/o deltarangos. 
- Información demodulada de las señales de satélite:

- Mensaje de navegación en bruto.

- Correcciones de reloj por satélite.

- Efemérides por satélite.

- Almanaque de la constelación.

- Anuncios de sistema.

- Información de estado del receptor:

- Eventos de procesamiento relevantes:

- Adquisición de nuevas señales.

- Desenganche de señales.

- Errores de operación.

- Condiciones anómalas.

- Información de las señales en seguimiento:

- Identificador de satélite

- Relación $C / N_{o}$

- Elevación del satélite respecto al horizonte.

Los protocolos de comunicación utilizados pueden dividirse en protocolos propietarios y protocolos estandarizados. Los primeros son los más frecuentes y corresponden al diseño que cada fabricante o diseñador de receptores utiliza para los productos de su catálogo. Suelen ser protocolos binarios, basados en mensajes, diseñados para ser transmitidos a través de canales de comunicación serie.

Existen también protocolos estandarizados que ofrecen compatibilidad entre los equipos de diferentes fabricantes. El estándar por excelencia para receptores GNSS es el NMEA 0183, originalmente utilizado para integrar e intercambiar datos entre diversos tipos de sensores de aplicación náutica. Este es un protocolo basado en la transmisión de líneas de texto formadas por caracteres con codificación ASCII de 7 bits. Cada línea sigue un formato bien definido compuesto por campos separados por comas, los cuales identifican el tipo de información contenida en la línea y los valores de los datos transmitidos. Debido a su codificación no binaria, el protocolo NMEA tiene la cualidad de que la información transmitida es legible de forma prácticamente inmediata para cualquier usuario que tenga acceso a la consola de comunicación. Sin embargo esto también provoca una muy baja eficiencia de la utilización del canal de comunicación comparado con los protocolos binarios, y además los tipos de información contemplados en el estándar NMEA 
representan sólo un subconjunto de aquellos que pueden ser transportados utilizando la mayoría de los protocolos propietarios.

Otro protocolo estandarizado, pero que tiene un propósito totalmente diferente es el RTCM SC-104. Mientras que NMEA 0183 está enfocado en la utilización de un receptor como instrumento de navegación autónomo, RTCM está diseñado específicamente para aplicaciones de GNSS diferencial. El protocolo permite el intercambio de mediciones de código y portadora entre un receptor fijo de posición conocida y otro receptor móvil. Para más información de este tipo de aplicaciones se puede consultar en la referencia bibliográfica [4].

El enlace físico utilizado por la mayor parte de los receptores GNSS para sus protocolos de comunicaciones es generalmente alguna forma de canal serie. Casi con exclusividad se utilizan canales de tipo RS-232 o RS-422, por su ubicuidad y robustez. NMEA 0183 define el enlace físico como un canal RS-422 con el fin de permitir conectar múltiples dispositivos sobre un canal común.

\subsection{Resumen de capítulo}

Previo a la introducción de los conceptos específicos al desarrollo de los algoritmos de procesamiento GNSS multiantena que son objeto del presente trabajo de tesis, es necesario contar con una base sólida de conocimiento sobre el funcionamiento de los receptores utilizados en aplicaciones más convencionales, como son los receptores portátiles para uso personal, seguimiento de cargas, transporte, etc. Introducir esta información ha sido el objeto de este capítulo.

En las páginas anteriores se llevó adelante la descripción de la arquitectura que se encuentra más frecuentemente implementada como base para la amplia mayoría de los receptores GNSS mono y multisistema. Esta arquitectura puede analizarse como una cadena de procesamiento compuesta por etapas de procesamiento analógico de la señal, muestreo, procesamiento digital de alta tasa y diezmado, y finalmente el procesamiento de alto nivel llevado a cabo por un sistema de cómputo programable.

Esta última etapa puede a su vez descomponerse en una multitud de procesos que se ejecutan de forma concurrente para realizar tareas de adquisición de señales, seguimiento de sus variaciones, demodulación de los mensajes transmitidos en las mismas, resolución de los sistemas de ecuaciones de posición y velocidad, comunicación con los sistemas externos, etc. 
Se verá más adelante que el desarrollo de los algoritmos para receptor multiantena construye sobre esta misma arquitectura base, extendiendo los algoritmos de adquisición y seguimiento para permitir la utilización de múltiples entradas de señal a la vez que se enmascara esta naturaleza múltiple de los algoritmos más abstractos (navegación, demodulación, etc.). 


\section{Capítulo 4}

\section{Contexto de aplicación del receptor}

\subsection{Introducción}

El objetivo del presente capítulo es la descripción del entorno operativo en el que deben funcionar los algoritmos desarrollados como parte de este trabajo de tesis. Este entorno está compuesto por un lado por el perfil de la misión a la que el receptor está destinado, pero también por las características del hardware subyacente, ya que desde el punto de vista del programador éste se presenta como una condición de contorno más.

En la primera parte del capítulo se realiza una breve descripción de las características más relevantes del contexto de utilización del receptor, tipo de vehículo, dinámicas esperables, etc. Tomando dicha información como punto de partida se presenta la arquitectura general del receptor que ha sido propuesto como solución para dicha misión.

La arquitectura así presentada está compuesta por una parte de hardware y otra de software. Los algoritmos que son el objeto de la presente tesis forman parte del software del receptor, mientras que el hardware del mismo fue desarrollado anteriormente de forma separada e independiente. Sin embargo, dado que las características de este último tienen el potencial de afectar las decisiones de diseño de los algoritmos, se dedicará la segunda parte del este capítulo a exponer sus características más relevantes.

\subsection{Perfil de misión}

Los desarrollos presentados en los capítulos subsiguientes se encuentran enmarcados en el diseño de un receptor GNSS destinado a ser utilizado como instrumento de a bordo de 


\begin{tabular}{|c|c|c|c|}
\hline Vehículo & Origen & Proveedor & Carga \\
\hline Minotaur I & $\overline{\text { EEUU }}$ & Orbital Sciences & $580 \mathrm{~kg}$ a LEO \\
\hline Falcon 1 & EEUU & SpaceX & $650 \mathrm{~kg}$ a LEO \\
\hline Ariane I & Europa & Aérospatiale & $1400 \mathrm{~kg}$ a LEO \\
\hline Vega & Europa & $\mathrm{ESA} / \mathrm{ASI}$ & $1430 \mathrm{~kg}$ a polar \\
\hline Delta II 7320 & EEUU & United Launch Alliance & $2865 \mathrm{~kg}$ a LEO \\
\hline Long March 2D & China & $\begin{array}{c}\text { China Academy of } \\
\text { Launch Vehicle Technology }\end{array}$ & $3500 \mathrm{~kg}$ a LEO \\
\hline Soyuz-FG & Rusia & TsSKB-Progress & $6790-7130 \mathrm{~kg}$ a LEO \\
\hline Delta IV-M+(5,2) & EEUU & United Launch Alliance & $11470 \mathrm{~kg}$ a LEO \\
\hline Long March 3B/E & China & $\begin{array}{c}\text { China Academy of } \\
\text { Launch Vehicle Technology }\end{array}$ & $11500 \mathrm{~kg}$ a LEO \\
\hline Falcon 9 v1.1 & EEUU & SpaceX & $13150 \mathrm{~kg}$ a LEO \\
\hline Ariane 5ME & Europa & EADS Astrium & $25200 \mathrm{~kg}$ a LEO \\
\hline Saturn V & EEUU & $\begin{array}{c}\text { Boeing, } \\
\text { North American, Douglas } \\
\end{array}$ & $118000 \mathrm{~kg}$ a LEO \\
\hline
\end{tabular}

CuAdro 4.1: Algunos ejemplos de vehículos lanzadores de cargas satelitales, ordenados por su capacidad de carga máxima a órbitas LEO o similares.

vehículos lanzadores de cargas satelitales livianas hacia órbitas LEO (Low-Earth Orbit).

La función del receptor en ese contexto es la de proveer información de navegación en tiempo real a los sistemas de Navegación, Guiado y Control (NGC) del vehículo. Como función adicional, la telemetría generada servirá para realizar un seguimiento en tiempo real desde tierra de la trayectoria, generar un registro de la misma para su análisis posterior, y complementar los mecanismos de seguridad de vuelo. Adicionalmente, en vehículos de múltiples etapas la utilización de receptores asociados a las etapas descartadas puede permitir su seguimiento y la determinación del punto de impacto de las mismas luego de finalizada la misión.

\subsubsection{Características de los vehículos}

En la actualidad la inyección de cargas satelitales se lleva a cabo de forma exclusiva mediante la utilización de vehículos lanzadores no reutilizables de tipo cohete, siendo la única excepción a esta regla el venerable y ya retirado Space Shuttle.

Existen múltiples diseños de vehículos inyectores, provistos por diversas fuentes tanto gubernamentales como -en los últimos años- privadas. En una primera aproximación estos pueden ser agrupados en categorías basándose en el peso y volumen de las cargas útiles que son capaces de transportar. Una lista muy breve de algunos de los vehículos de este tipo puede verse en el Cuadro 4.1. 


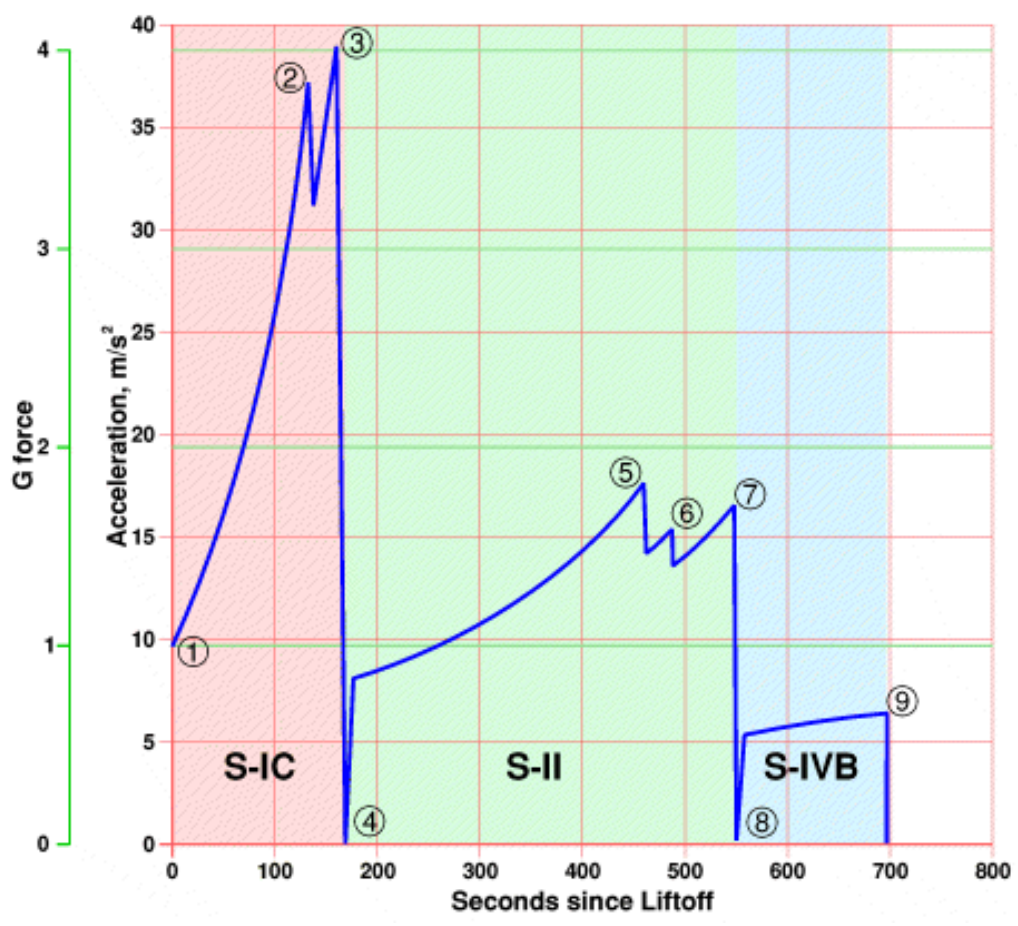

Figura 4.1: Perfil de aceleración de vehículo Saturn V utilizado en la misión Apollo 15. Extraído de [44], imagen de dominio público. Puntos de interés: (1) Encendido de motores del S-IC (primera etapa propulsora). El progresivo incremento en aceleración se debe a un incremento en la eficiencia de los motores con la altura y a la reducción en el peso del vehículo. (2) Apagado del motor central del S-IC. (3) Apagado programado de los motores periféricos S-IC al alcanzar $4 \mathrm{~g}$. (4) Ignición de los motores de la segunda etapa del vehículo (S-II). La pendiente reducida se debe a la menor fuerza impulsora de esta etapa comparado a la anterior. (5) Apagado del motor central de S-II. (6) Modificación de la mezcla de combustible. (7) apagado de los motores laterales al alcanzar 1,8 g. (8) Encendido del motor de la tercera etapa, S-IVB. (9) Apagado del motor de S-IVB. El vehículo se encuentra en órbita con cero aceleración.

La configuración típica de los vehículos consiste en un cuerpo segmentado, dividido en etapas que son descartadas progresivamente durante el vuelo a medida que agotan el combustible que contienen. Esta estrategia permite mantener una relación de empuje a masa beneficiosa durante todas las fases del vuelo y así reducir la exigencia sobre los sistemas de propulsión. Cada vez que ocurre una separación de etapas, la etapa descartada se separa dejando al descubierto los motores de la etapa siguiente. Los motores de las etapas superiores, expuestos en esta maniobra, se encienden entonces para impulsar su vuelo, mientras que la etapa descartada se precipita a tierra. Es posible probar que no existen beneficios apreciables en construir vehículos de más de tres o cuatro etapas, por lo que la mayoría de los diseños en existencia tienen configuraciones de esa cantidad de segmentos [43].

Con el fin de alcanzar los valores de velocidad final necesarios para una inyección orbital exitosa, los vehículos mantienen una dinámica acelerada sostenida durante todas las fases 
del vuelo. La magnitud de dicha aceleración depende de las características del vehículo (su tamaño, su peso, su propósito, la etapa de vuelo, etc.), pero el rango de valores habituales oscila entre $1 \mathrm{~g}$ y $5 \mathrm{~g}$, donde g es la aceleración gravitatoria terrestre a nivel del mar.

En el caso de vehículos de múltiples etapas el vuelo consistirá de tantas fases de vuelo propulsado como la cantidad de segmentos que conforman el cuerpo del vehículo, separadas por breves intervalos de vuelo balístico mientras se realiza la separación y el encendido de motores. Algunas misiones de inyección en órbitas MEO o superiores tienen además una etapa de coasting durante la última fase de vuelo, en la cual los motores permanecen apagados mientras el vehículo se desplaza a lo largo de una orbita transitoria hasta una posición propicia para encender los motores y completar el proceso de inyección en la órbita definitiva.

A manera de ejemplo se puede ver en la Figura 4.1 el perfil de aceleración correspondiente a la misión Apollo 15. Dicha misión utilizó un vehículo tipo Saturn V, el cual es un vehículo de tres etapas utilizado entre los años 1968 y 1976. Cada etapa de vuelo comienza con el encendido de los motores correspondientes. El repentino impulso ocasiona un súbito incremento de la aceleración en dirección del eje del vehículo. La magnitud de la aceleración no permanece constante durante el vuelo, sino que tiende a incrementarse a medida que se consume el combustible (debido a la pérdida de masa) y a que aumenta la altura (reduciendo la densidad atmosférica). El apagado de los motores también provoca un súbito cambio en el valor de aceleración, siendo su magnitud todavía superior al escalón de aceleración durante su encendido.

El vehículo Vega, un vehículo de inyección de cargas livianas mucho más moderno y pequeño que el Saturn V, presenta un perfil de aceleración durante el vuelo como el que se puede ver en la Figura 4.2. Se puede ver allí que a pesar de las diferencias en misión y tamaño, el perfil general de uno y otro vehículo se presentan como comparables en términos de aceleración máxima y evolución general de los valores de aceleración por etapa.

Debe mencionarse que también existe una categoría más pequeña de vehículos, frecuentemente llamados Sounding Rockets, cuya aplicación principal es la investigación científica atmosférica y servir de modelo de ensayo de los sistemas los sistemas de propulsión y guiado de cohetes de mayor envergadura. Este tipo de vehículos tienen envergaduras mucho menores que los vehículos inyectores, su vuelo no supera los $120 \mathrm{~km}$ de altura y generalmente se encuentran compuestos de una única etapa. Sus sistemas de propulsión pueden o no ser controlados, y pueden funcionar a partir de combustibles líquidos a sólidos. Si bien en el extremo superior de esta categoría los vehículos son básicamente versiones a escala de los lanzadores multietapa, los vehículos más pequeños tienen más 


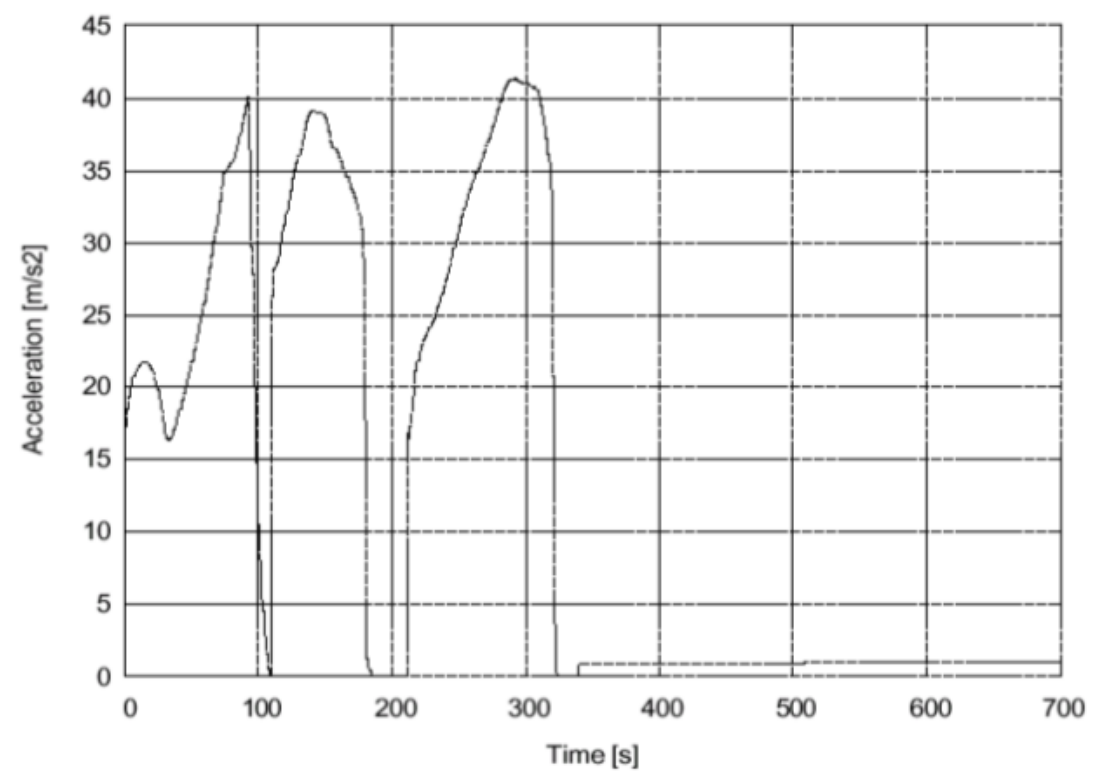

Figura 4.2: Perfil de aceleración típico para un vehículo Vega, extraído del manual de usuario del vehículo. Ver referencia [45].

parentesco con los misiles y pueden tener dinámicas considerablemente más ágiles que los vehículos inyectores, alcanzando en algunos casos aceleraciones de hasta $30 \mathrm{~g}$ [46].

Existe otra dinámica de vuelo que es de interés a los fines del diseño del receptor, que consiste en el giro del vehículo alrededor del su eje principal. El caso más extremo de este tipo de dinámica se da en cohetes sonda pequeños con motores de altos valores de empuje y sin control a lazo cerrado de la trayectoria, donde este tipo de movimiento de giro se genera intencionalmente con el fin de estabilizar el vuelo por rigidez giroscópica y minimizar el efecto de cualquier asimetría en el sistema de propulsión[43].

Es totalmente diferente el caso de vehículos lanzadores, donde la relación de empuje a masa es mucho más moderada y existen sistemas de control a lazo cerrado de la trayectoria. Estos vehículos cuentan con sistemas de estabilización de giro para garantizar que la velocidad angular se encuentre dentro de márgenes que aseguren la integridad estructural de la aeronave. Los sistemas de control del cohete Vega pueden operar en modos de orientación fija o imprimir una tasa de giro constante para uniformar la temperatura de la cápsula que contiene la carga útil, aunque la guía de usuario [45] no cita una cifra para dicha tasa. En la guía de planificación de carga útil del Delta II [47] se da como rango de valores típicos el que va de $1 \mathrm{deg} / \mathrm{seg}$ a $3 \mathrm{deg} / \mathrm{seg}(0,16 \mathrm{rpm}$ a $0,5 \mathrm{rpm})$. Una vez en órbita, la última etapa de estos vehículos puede dar un spin adicional de hasta algunas decenas de rpm a la carga útil antes de la liberación definitiva, pero esto se hace ya fuera del vuelo controlado. 


\subsubsection{Problemática de la aplicación}

\subsubsection{Sistema de antenas}

A diferencia de lo que ocurre con otras aplicaciones más convencionales donde los receptores GNSS utilizados tienen una única antena ubicada en la parte más alta y descubierta del vehículo para garantizar una buena visibilidad de cielo abierto, en vehículos de tipo cohete esta elección presenta una serie de problemas que demandan la utilización de soluciones alternativas.

En su posición de despegue la parte más alta del vehículo es la llamada cofia del vehículo. Consiste en una estructura aerodinámica de forma aproximadamente cónica que durante el vuelo atmosférico se encarga de reducir la sección eficaz que presenta el vehículo a la resistencia del aire. En su interior generalmente existe una cavidad donde se alberga la carga útil del vehículo. En el caso de vehículos inyectores esta carga consistirá en el o los satélites que han de ser transportados a la órbita destino, mientras que en el caso de cohetes sonda la carga útil consiste típicamente en el instrumental de medición que forma la carga científica de la misión.

Una antena ubicada en el extremo superior de la cofia tiene una visibilidad excelente de cielo abierto durante el lanzamiento y las primeras fases de vuelo. Sin embargo, la trayectoria de vuelo de los vehículos lanzadores no es vertical, sino que la orientación se modifica progresivamente para alcanzar el punto de inyección de la carga con velocidad tangencial a la órbita designada, potencialmente reduciendo la visibilidad de la antena GNSS durante el vuelo.

Por otro lado, dado que la carga útil se encuentra ubicada dentro de la misma cofia, esta última debe abrirse para exponer la carga útil antes de alcanzar el punto de inyección. Esto se lleva a cabo durante la última etapa de vuelo propulsado expulsando la cobertura de la misma, lo que por supuesto invalida la utilización de cualquier tipo de instrumental de apoyo en su superficie, incluyendo antenas.

Para salvar estos problemas los receptores GNSS utilizados bordo de vehículos cohete no ubican sus antenas en la parte superior de la aeronave. En lugar es eso se utilizan sistemas de antenas más complejos, formados por arreglos de múltiples antenas individuales distribuidas en la periferia del cuerpo del vehículo. Con una distribución adecuada se puede garantizar que la visibilidad tenga una cobertura total del cielo abierto durante todas las fases del vuelo de la aeronave. Estos arreglos de antenas se pueden dividir en dos tipos principales: arreglos Modo Suma y arreglos Modo Diversidad [11]. 


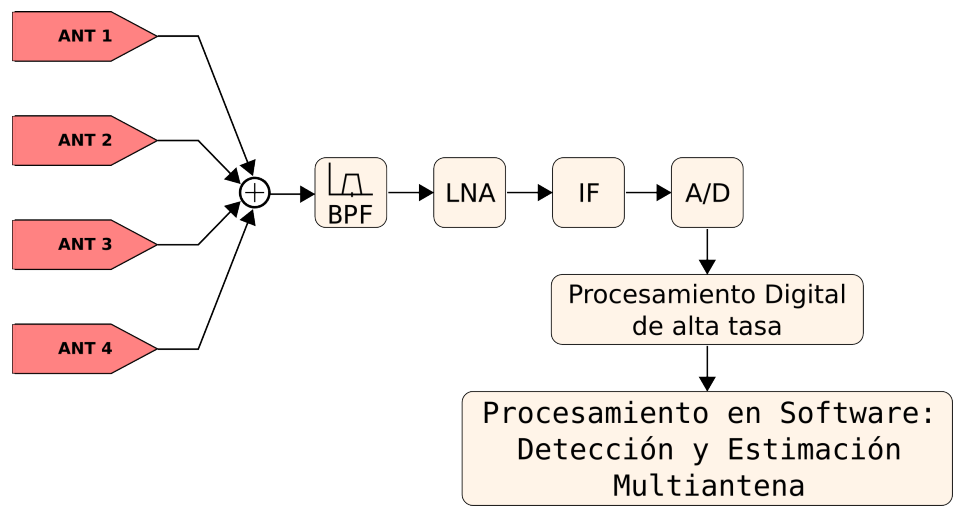

Figura 4.3: Arreglo de cuatro antenas en modo suma.

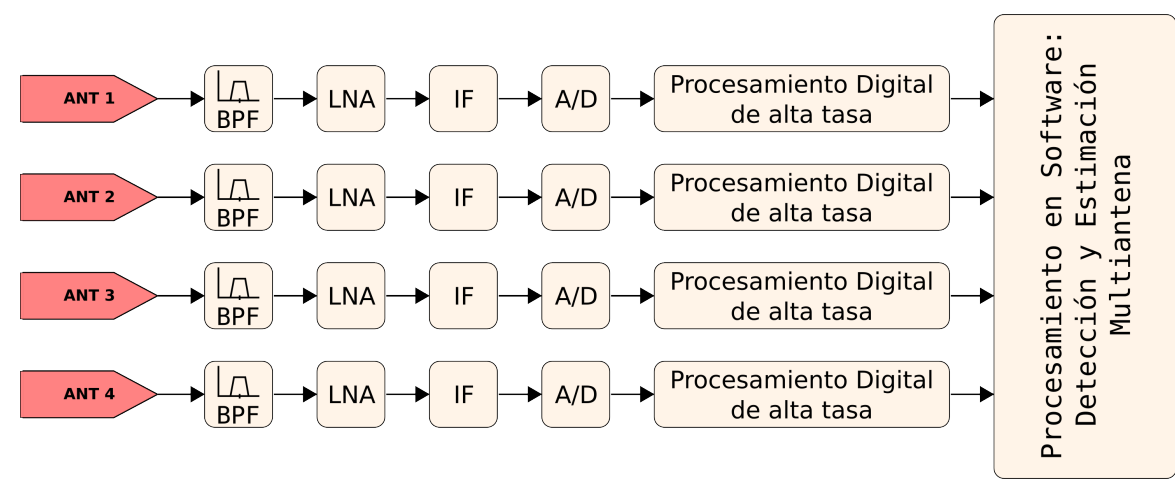

Figura 4.4: Arreglo de cuatro antenas en modo diversidad.

En los arreglos de tipo Modo Suma la entrada de las diversas antenas son combinadas utilizando un power combiner que suma las señales provenientes de las distintas antenas y produce una salida única que puede ser procesada por el receptor. Vease Figura 4.3. El arreglo entero puede ser visto como una única antena equivalente, con su patrón de radiación que resulta de la combinación de aportes de las antenas individuales.

Este tipo de configuración presenta problemas para los sistemas GNSS porque las dimensiones físicas de los vehículos (y por lo tanto de la separación entre antenas) no son despreciables frente a la longitud de onda de las frecuencias portadoras utilizadas (aproximadamente $20 \mathrm{~cm}$ en banda L1): debido a las diferencias en las fases de portadora con la que una señal arriba a las diferentes antenas se generan una serie de direcciones de arribo particulares (relativas al arreglo de antenas) tales que las señales de las antenas individuales pueden sumarse destructivamente en el combinador, produciendo una cancelación parcial o incluso total de la señal. Estas cancelaciones se manifiestan en el patrón de radiación equivalente como direcciones de muy baja ganancia de señal, resultando en puntos ciegos en la capacidad de recepción del receptor GNSS [6][8].

Para evitar este problema se puede utilizar un esquema de tipo Modo Diversidad. En 
este esquema se asigna a cada antena su propia cadena de entrada separada, encargada de realizar por etapas el filtrado, la amplificación, la bajada a FI, el muestreo y el procesamiento digital de alta tasa para la señal de la antena correspondiente. Ver Figura 4.4. Dado que las señales nunca se combinan analógicamente se elimina el problema de la combinación destructiva, y se conservan los patrones de visibilidad de las antenas individuales. Es el software del receptor el que debe relacionar las señales provenientes de unas y otras antenas para lograr un procesamiento coherente de las señales de los satélites.

\subsubsection{Dinámica acelerada}

Como se mencionó anteriormente los vehículos cohete se encuentran sometidos durante el vuelo a intensos valores de aceleración a lo largo del eje principal del vehículo. La variación en la velocidad del vehículo asociada a estos altos valores de aceleración afecta la recepción de señales de radiofrecuencia por efecto Doppler, según el cual la longitud de onda aparente (y por lo tanto la frecuencia percibida) de una señal sufre una variación que es función de las velocidades del transmisor y el receptor en la dirección de movimiento de la onda.

El efecto Doppler en las señales GNSS no afecta únicamente la frecuencia portadora sino más bien genera un escalamiento de la totalidad de la señal, provocando por ende también corrimientos en la tasa de chips de la función de código que expande el espectro, y en la tasa de bits de la modulación de datos.

Cuando las velocidades del transmisor y el receptor son mucho menores que la velocidad de propagación de la onda (en este caso, la velocidad de la luz $c$ ) la variación de frecuencia $\Delta f(t)$ de una señal de frecuencia instantánea $f(t)$ debido al efecto Doppler se puede calcular mediante la siguiente expresión

$$
\Delta f(t)=f(t) \frac{\overrightarrow{v_{r}}(t) \cdot \vec{l}(t)}{c}
$$

donde $\overrightarrow{v_{r}}(t)$ es el vector de velocidad relativa entre transmisor y receptor y $\vec{l}(t)$ es el llamado vector vector línea de vista. El vector línea de vista es un vector normal cuya dirección apunta del receptor al transmisor. Sean $\overrightarrow{p_{s}}(t)$ y $\overrightarrow{v_{s}}(t)$ la posición y la velocidad del satélite, $\overrightarrow{p_{v}}(t)$ y $\overrightarrow{v_{v}}(t)$ la posición y la velocidad del vehículo, el vector de línea de vista se define como

$$
\vec{l}(t)=\frac{\overrightarrow{p_{s}}(t)-p_{v}(t)}{\left|\overrightarrow{p_{s}}(t)-p_{v} \overrightarrow{(t)}\right|}
$$


y el de velocidad relativa como

$$
\overrightarrow{v_{r}}(t)=\overrightarrow{v_{s}}(t)-\overrightarrow{v_{v}}(t)
$$

En el caso particular de vehículos cohete y señales GNSS, las frecuencias transmitidas son invariantes en el tiempo, y la gran distancia a la que se encuentran los satélites de la superficie permite despreciar la variación en el tiempo del vector línea de vista. La velocidad instantánea de los satélites es de módulo prácticamente constante y su dirección varía lentamente, por lo que puede ser supuesta aproximadamente constante para el análisis que sigue. Hechas estas simplificaciones la expresión (4.1) se convierte en

$$
\Delta f(t)=f \frac{\left(\overrightarrow{v_{s}}-\overrightarrow{v_{v}}(t)\right) \cdot \vec{l}}{c}
$$

Es de interés definir a partir de esto la tasa de variación de la frecuencia percibida, ya que este parámetro repercute de forma directa en la capacidad del receptor de permanecer sincronizado con la señal de los satélites. Derivando la expresión (4.4) resulta la siguiente expresión

$$
\Delta \dot{f}(t)=-\frac{f\left(\overrightarrow{a_{v}}(t) \cdot \vec{l}\right)}{c}
$$

donde se puede ver que la tasa de variación es proporcional a la proyección del vector de aceleración del vehículo sobre el vector línea de vista. El peor caso posible ocurre cuando ambos vectores son colineales, por lo que se puede determinar la máxima tasa de variación de frecuencia como

$$
\left|\Delta \dot{f_{\max }}\right|=\frac{f\left|\overrightarrow{a_{v}}\right|_{\max }}{c}
$$

Tomando como ejemplo el caso de la frecuencia portadora de la señal GPS C/A, el valor nominal de la frecuencia $f$ transmitida es $1545,75 \mathrm{MHz}$. En este caso la máxima tasa de variación de la frecuencia debido al efecto Doppler es de $5,25 \mathrm{~Hz} / \mathrm{seg}$ por cada g de aceleración adicional en el valor de $\left|\overrightarrow{a_{v}}\right|_{\text {max }}$. Las consecuencias de este tipo de distorsión en la frecuencia de la señal requieren de un diseño adecuado de los lazos de seguimiento utilizados en el receptor.

Tal como se discutió al discutir estos últimos en la Sección 3.7.2 los lazos de seguimiento de portadora para receptores GNSS utilizados a bordo de vehículos acelerados deben ser de Tipo III o superior para poder permanecer sincronizados y sin error estacionario en presencia de una variación lineal en el valor de la frecuencia instantánea de portadora como la prevista por la expresión (4.6).

La utilización de diseños con asistencia de frecuencia (ver 3.7.2.6) permite garantizar 
que si se resuelve el problema del seguimiento de las variaciones de frecuencia portadora en presencia de dinámica acelerada, entonces el mismo problema queda también automáticamente resuelto para el lazo de seguimiento de retardo, y por ende también para la tasa de bits del mensaje de navegación (cuyo progreso el receptor contabiliza mediante la cantidad de ciclos de la función de código trascurridos).

Si bien un lazo de seguimiento de portadora de Tipo III garantiza la capacidad de seguimiento en condiciones de dinámica uniformemente acelerada, se ve claramente en la Figura 4.1 que existen una serie de discontinuidades en los valores de aceleración del vehículo producidos por los sucesivos encendidos y apagados de los motores de las etapas del vehículo. Cada discontinuidad afectará de forma inmediata la frecuencia instantánea de la portadoras de las señales seguidas por el receptor. Estas discontinuidades provocarán a su vez la aparición de transitorios de ajuste en los lazos de seguimiento de portadora de las señales. Dado que la implementación de los lazos de seguimiento sufre de una serie de alinealidades debidas por un lado a su naturaleza discreta, pero también a limitaciones de los discriminadores, es responsabilidad del diseñador garantizar que la magnitud de los transitorios no supere el rango de operación lineal del diseño para evitar problemas con la capacidad de seguimiento.

\subsubsection{Otras problemáticas}

Por supuesto, existe toda una clase mucho más grande de problemas asociados con este tipo de aplicación. Son particularmente críticos los problemas de aseguramiento de calidad (Quality Assurance) y de tolerancia a fallos (Fault Tolerance).

El aseguramiento de calidad busca garantizar la aptitud de un sistema para el cumplimiento de la misión que tiene asignada. Dado que en general ningún sistema salvo los más triviales puede ser verificado de forma realmente exhaustiva, la aproximación habitual al problema del aseguramiento de la calidad de los mismos pasa por establecer un conjunto de requisitos mínimos que deben cumplir los procesos utilizados para generarlos. El nivel de exigencia es mayor cuanto mayor es el nivel de criticidad del sistema en cuestión. Ejemplos de esto en el dominio aeronáutico son las normativas de la Radio Technical Commission for Aeronautics (RTCA) conocidas como DO-178 (para software) y DO-254 (para hardware).

Mientras que el aseguramiento de calidad está relacionada con minimizar la probabilidad de que se ocurran fallas durante la operación futura del sistema (Fault Avoidance), la tolerancia a fallas hará más robusto al sistema durante su operación compartimentándolo en unidades de contención que limitan la propagación de los efectos de cualquier avería de un componente durante la misión. En su forma más general, la tolerancia se logra 
mediante la utilización de diferentes formas de redundancia (espacial, de información, de tiempo, etc.) para poder detectar e incluso enmascarar la ocurrencia de fallas durante la operación del sistema.

El presente trabajo no aborda estas problemáticas debido que la implementación de los procesos y las técnicas necesarios no pueden ser llevada a cabo a nivel individual, sino que demanda de un esfuerzo concertado de todos los niveles de decisión involucrados en el diseño del receptor y de sus proyectos marco.

\subsection{Requerimientos mínimos}

Se establecieron como requerimientos más relevantes para el desarrollo que ocupa este trabajo de tesis los siguientes:

- Procesamiento en tiempo real.

- Sistemas GNSS con los que debe operar el receptor.

- Estructura del sistema de antenas utilizado.

- Valores extremos de la dinámica del vehículo.

\subsubsection{Procesamiento en tiempo real}

El propósito final del proyecto es desarrollar un receptor GNSS de a bordo para vehículos cohete como los utilizados en vehículos inyectores satelitales. Su objetivo primordial es el cálculo de soluciones de navegación PVT, las cuales serán transmitidas a los sistemas de Navegación, Guiado y Control del vehículo. Estos últimos procesarán esta información, junto con la proveniente de otros sensores (como acelerómetros y giróscopos) para determinar las acciones de control que es necesario aplicar para mantener el vehículo dentro de una trayectoria controlada.

La naturaleza inmediata de los servicios provistos por el receptor a los sistemas de navegación hace que sea necesario llevar a cabo el procesamiento de todas las señales en tiempo real, generando mediciones pseudorango/deltarango y fixes de navegación durante el transcurso de la misión a medida que progresa la misma, y con latencias compatibles con los requerimientos del sistema de NGC del vehículo. 


\subsubsection{Sistemas GNSS operables}

Con el fin de reducir el nivel de dependencia un único sistema GNSS se estableció que el receptor debe poder operar con los dos sistemas GNSS dominantes en la actualidad, GPS y GLONASS, pudiendo procesar simultáneamente señales de uno y otro.

En ambos casos las señales utilizadas son las señales civiles de banda L1: la señal C/A del sistema GPS, y la L1OF de GLONASS.

\subsubsection{Sistema de antenas}

Debido a la inaccesibilidad de la cofia como lugar para ubicar la antena del receptor, el receptor debe procesar la señal proveniente de un conjunto de antenas situadas en los laterales del vehículo, el cual tiene forma cilíndrica con $3 \mathrm{~m}$ de diámetro máximo.

\subsubsection{Dinámica esperada}

Los límites de operación más relevantes para el presente trabajo son el máximo escalón de aceleración y la máxima tasa de giro.

El máximo escalón de aceleración determina la magnitud de la perturbación a los lazos de seguimiento que ocurrirá en el evento del encendido o apagado de motores, por lo que afecta el diseño de los mismos. Su valor se estableció en $10 \mathrm{~g}$.

La tasa máxima de giro del cuerpo del vehículo esperable se estableció en $4 \mathrm{rpm}$. Este parámetro es relevante para estudiar el efecto que tiene la rotación del vehículo sobre la recepción de señales a través del sistema de antenas de entrada al receptor.

\subsection{Diseño propuesto}

Con el fin de cumplir con las condiciones de operación anteriores se propuso un diseño basado en un receptor multiantena de tipo diversidad como el presentado anteriormente en la Figura 4.4. El arreglo de antenas está compuesto por cuatro elementos independientes, cada uno de los cuales cuenta con su propia cadena de procesamiento individual: radiofrecuencia, muestreo y procesamiento digital.

Tanto el software como la etapa de procesamiento digital de alta tasa pueden realizar el procesamiento de las señales civiles de los sistemas GNSS GPS y GLONASS. Debido a las simetrías en las definiciones a bajo nivel de la estructura de la señal de ambos 


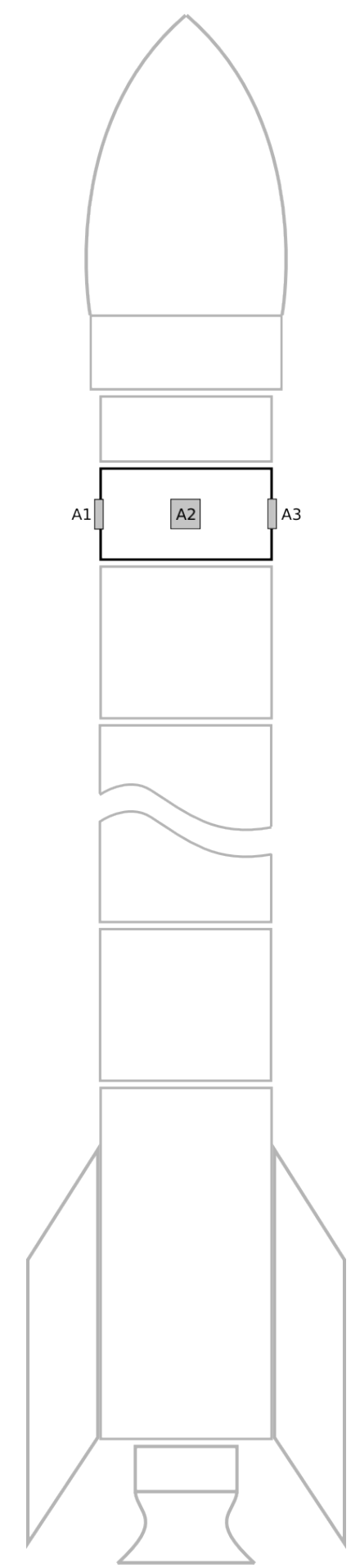

Figura 4.5: Representación esquemática de la ubicación de las antenas en el cuerpo del vehículo. 


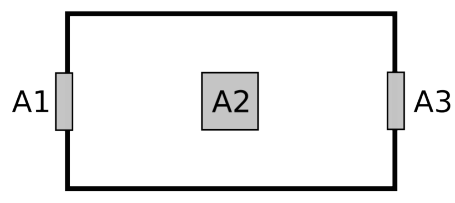

vista frontal

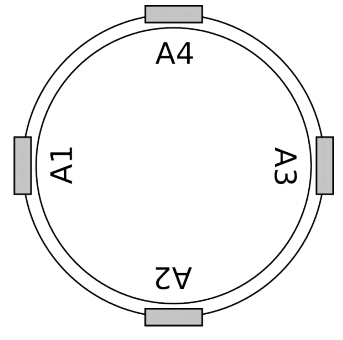

vista superior

FigurA 4.6: Detalle de la distribución de las antenas en la periferia del cuerpo del vehículo.

sistemas, esto puede realizarse mediante la implementación en hardware de generadores de código configurables que generen la función de código de uno u otro sistema, y utilizando frecuencias de muestreo suficientemente altas para acomodar los espectros de ambas señales.

Estando presentes las características anteriores en el hardware, los algoritmos de software necesarios para realizar la adquisición de señales, la sincronización y su seguimiento son prácticamente idénticos para los dos sistemas GNSS; las diferencias son mayormente en los valores de las frecuencias nominales de portadora y código de cada tipo de señal, en la configuración del generador de código de hardware de correlación, y en la forma de contabilización del avance de la fase de código en los lazos de seguimiento.

Por otro lado la demodulación del mensaje de navegación debe realizarse necesariamente de forma individual para cada sistema, ya que los formatos utilizados por GPS y GLONASS son totalmente diferentes. Esto, sin embargo, es una tarea de interpretación de datos de baja tasa y complejidad acotada.

\subsubsection{Arreglo de antenas}

Para el arreglo se utilizan cuatro antenas individuales con patrones de radiación hemisféricos distribuidos a intervalos regulares en la periferia del vehículo. La orientación de las antenas es tal que el cénit de cada una de ellas (dirección de máxima ganancia) es normal a la superficie del vehículo. En la Figura 4.5 se puede ver una representación esquemática de la posición del arreglo de antenas en el cuerpo de un vehículo genérico, mientras que la Figura 4.6 muestra un detalle de la distribución de las antenas individuales.

Un ejemplo del tipo de patrón de ganancia típico de las antenas utilizadas puede verse en la Figura 4.7. Allí se puede ver que la apertura de la antena, medida como se hace habitualmente entre los puntos de $-3 \mathrm{dBi}$ de ganancia, es de aproximadamente de $150^{\circ}$. 


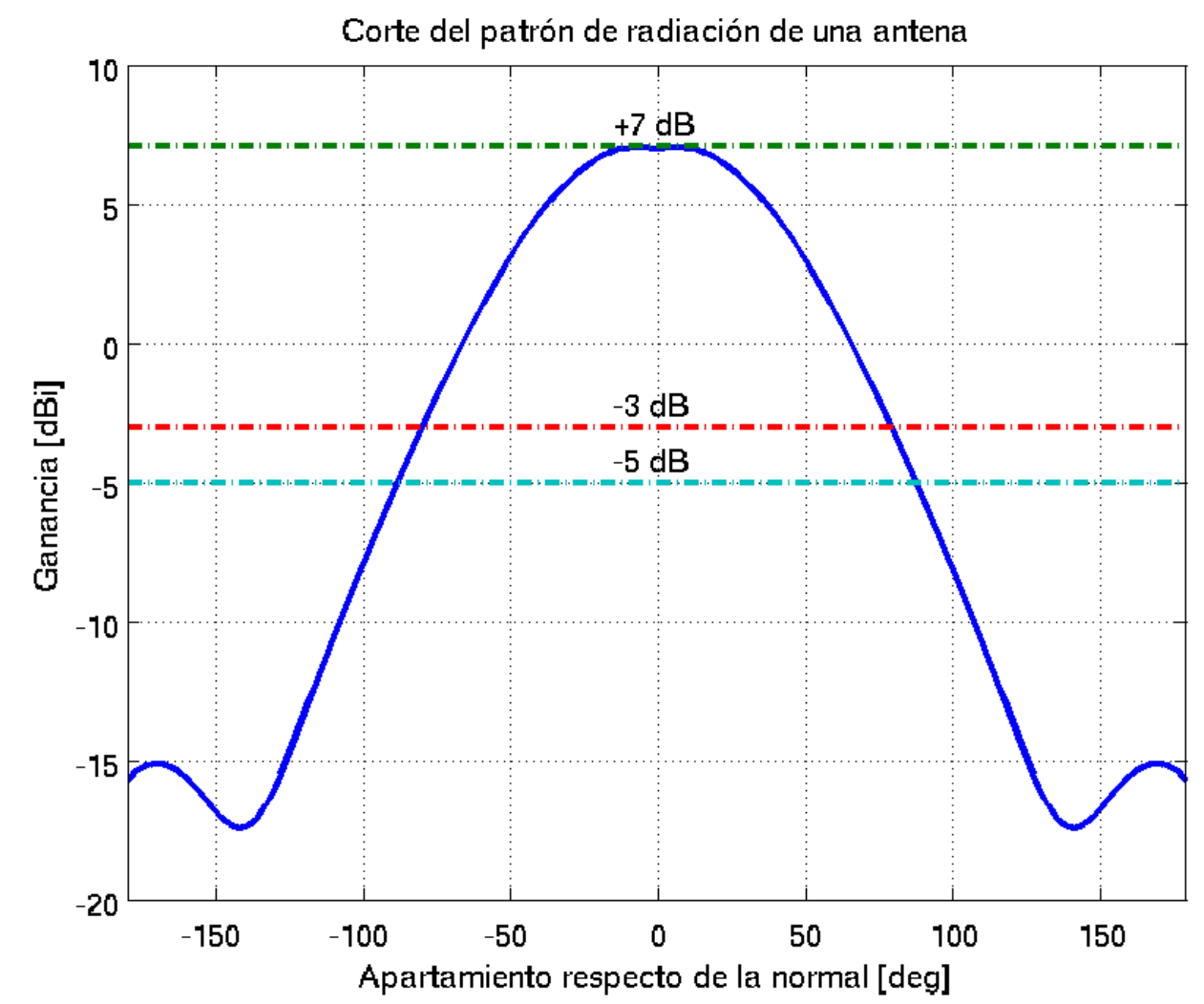

FigurA 4.7: Patrón de radiación típico de una antena parche. El eje horizontal son ángulos medidos desde la dirección normal a la antena.

Por otro lado, la cobertura de la antena puede considerarse todavía mayor: tomando $35 \mathrm{~dB}-\mathrm{Hz}$ como el nivel mínimo de relación $C / N_{o}$ deseado, el nivel de ganancia de antena bajo el cual se logra dicha relación en condiciones operativas nominales (niveles de potencia mínimos garantizados por los sistemas GPS y GLONASS, y valores típicos de temperatura de ruido de la antena y figura de ruido del receptor, etc.) es de $-5 \mathrm{dBi}$, lo que da una cobertura útil de la antena de la Figura 4.7 de aproximadamente $160^{\circ}$.

En un arreglo de tipo diversidad las salidas de las antenas no se combinan analógicamente sino que cada elemento es procesado de forma independiente por el receptor. La visibilidad del receptor basado en este tipo de arreglo queda entonces definida por la cobertura conjunta de la totalidad de las antenas.

El tipo de cobertura conjunta que se logra de esta forma puede apreciarse en la Figura 4.8, donde se pueden ver las ganancias que tendrán cada una de las cuatro antenas del arreglo para una señal con dirección de arribo perpendicular al cuerpo del vehículo. En dicha figura se puede ver lo que es una característica esencial de este tipo de arreglo para los fines de la presente tesis, que es el solapamiento entre las regiones de cobertura de las diferentes antenas. Este solapamiento permite la recepción de señales a través de 


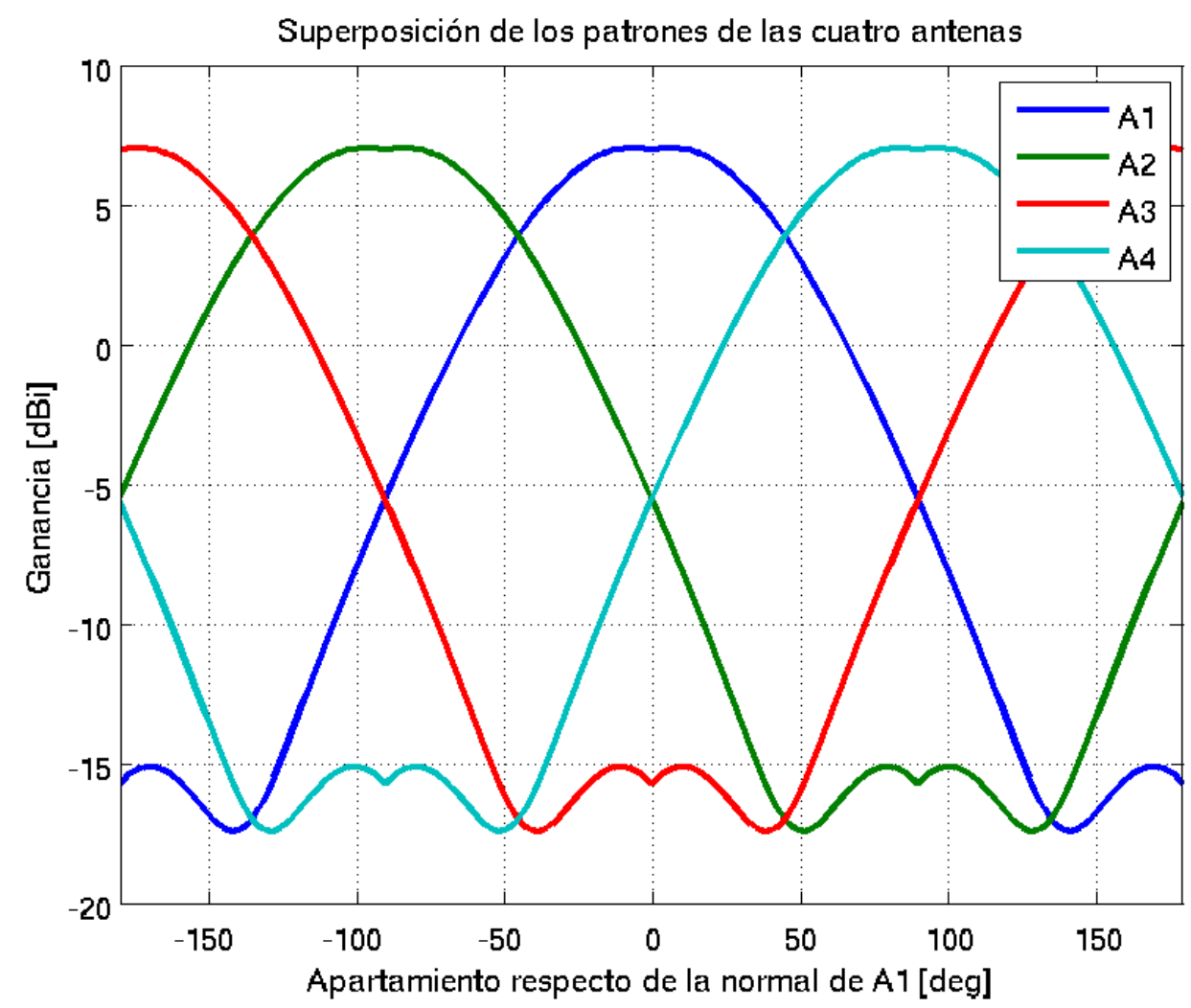

FigurA 4.8: Cobertura angular del conjunto de antenas en modo diversidad. El eje horizontal está medido en términos del ángulo desde la dirección normal a la antena A1.

más de un elemento del arreglo al mismo tiempo, lo que nos lleva a definir los siguientes tipos de cobertura:

Cobertura de una antena El cono de direcciones de arribo con ganancia de antena mayor que $-5 \mathrm{dBi}$. Para el diagrama de radiación típico visto anteriormente, esto abarca todas las direcciones de arribo que forman un ángulo menor que $80^{\circ}$ con la perpendicular a la antena.

Cobertura del arreglo El conjunto de las direcciones de arribo de señal tales que se encuentran dentro del cono de cobertura de al menos una de las cuatro antenas.

A partir de estas definiciones se representan las coberturas de cada una de las cuatro antenas individuales en la Figura 4.9. Se ve allí que cada antena tiene una región $20^{\circ}$ de apertura donde la cobertura es exclusiva, mientras que $70^{\circ}$ a cada lado de esa región la cobertura es simultánea con alguna de las antenas adyacentes. Este solapamiento será oportunamente explotado para poder conmutar la recepción de la señal de un dado satélite de una antena a otra sin perjuicio de la demodulación de la misma. 


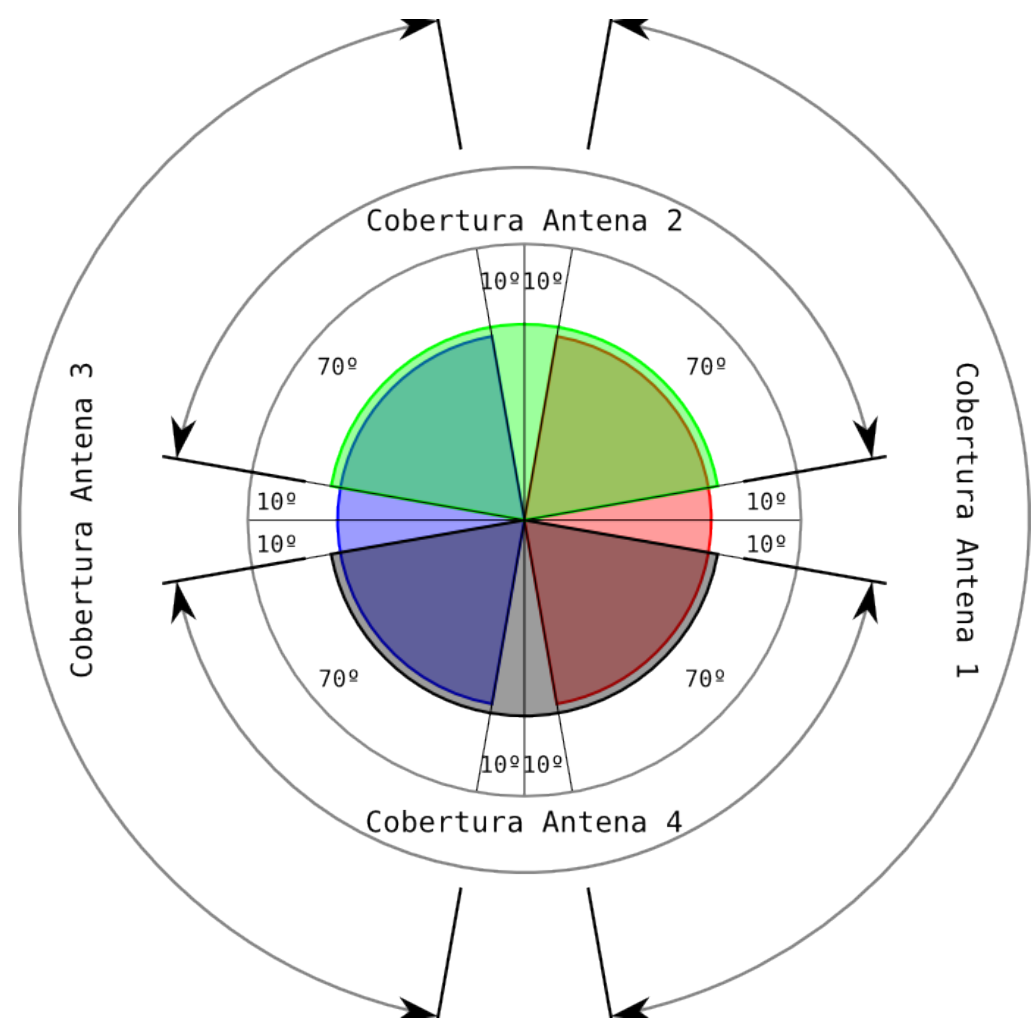

FigurA 4.9: Cobertura angular del conjunto de antenas en modo diversidad.

Como se indicó anteriormente la representación de la Figura 4.8 corresponde al caso simplificado del cortar los patrones de radiación con un plano perpendicular al eje del vehículo. Este caso es optimista, ya que para direcciones de arribo que tengan inclinaciones diferentes la situación se degrada debido a la forma hemisférica de los patrones de radiación en tres dimensiones. No obstante se verá a continuación que dicha degradación es progresiva y todavía permite elevados niveles de superposición entre antenas adyacentes para inclinaciones elevadas.

En la Figura 4.10 se muestra una gráfica de niveles donde está representada la cantidad de antenas que tienen cobertura para todas las direcciones de arribo posibles. La cobertura total de arreglo está representada por la combinación de las regiones donde una o más antenas tienen cobertura. En la gráfica las direcciones de arribo están identificadas por una dupla de ángulos $(\alpha, \beta)$. Sea $X$ un eje que pasa por el centro del arreglo y cuya dirección positiva pasa por la Antena 1, el eje $Y$ definido similarmente por el centro del arreglo y la Antena 2, y el eje $Z$ definido por la regla de mano derecha, entonces

$\alpha$ Es el ángulo de elevación del vector línea de vista respecto del plano $X Y$ que incluye las cuatro antenas.

$\beta$ Es el ángulo que forma respecto del eje $X$ la proyección del vector línea de vista sobre el plano $X Y$. 


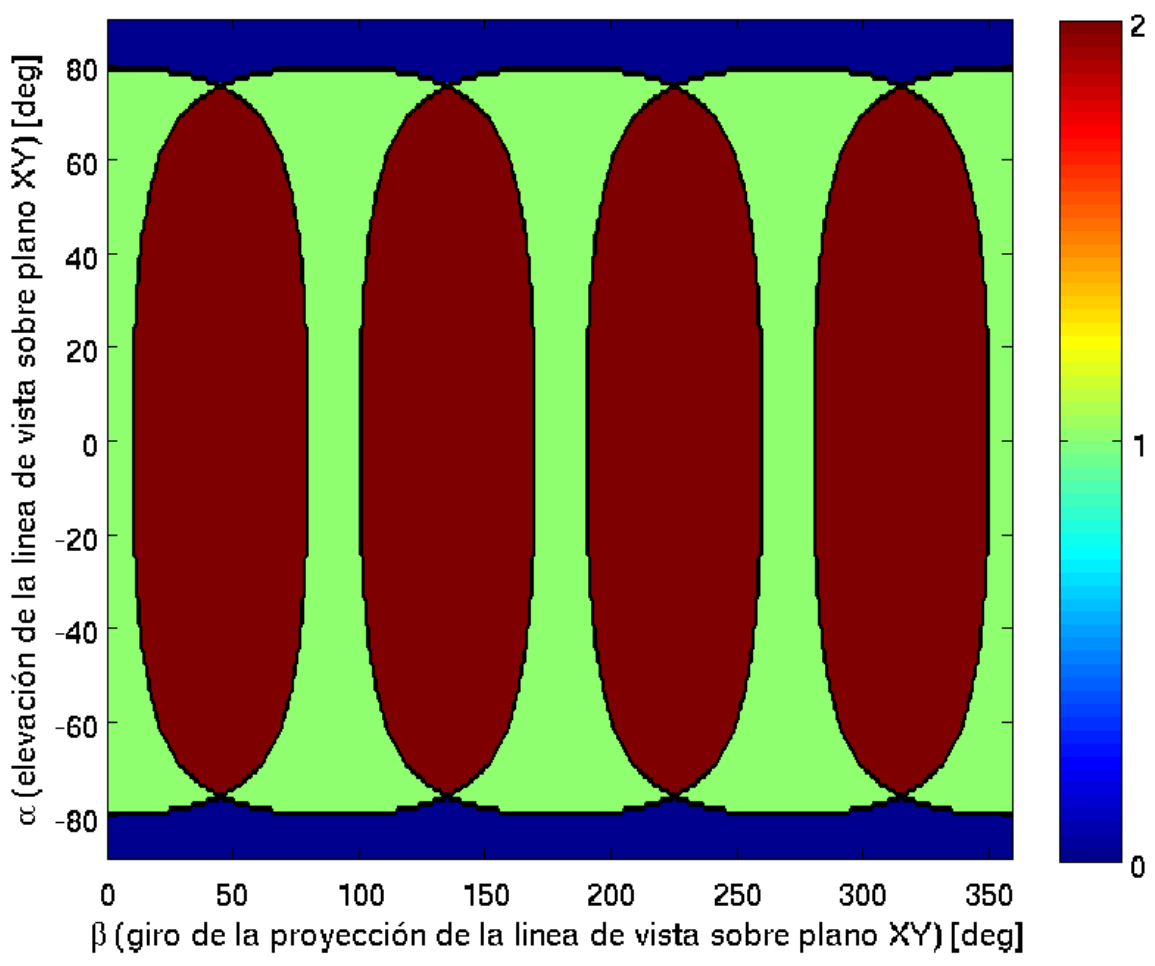

FigurA 4.10: Cobertura del arreglo de antenas de modo diversidad. El color de cada punto indica la cantidad de antenas que tienen cobertura para una dirección dada por las coordenadas $(\alpha, \beta)$ del punto, donde $\alpha$ es el ángulo de elevación del vector línea de vista respecto del plano $X Y$ que incluye las cuatro antenas, y $\beta$ es el ángulo que forma la proyección de dicho vector sobre $X Y$ respecto del eje $X$. La figura asume que las antenas están ubicadas con direcciones de cénit coincidentes con los vectores de línea de vista dados por los pares de ángulos $\left(0^{\circ}, 0^{\circ}\right),\left(0^{\circ}, 90^{\circ}\right),\left(0^{\circ}, 180^{\circ}\right)$ y $\left(0^{\circ}, 270^{\circ}\right)$.

Siguiendo las convenciones recién enunciadas, en la figura las cuatro antenas del arreglo tienen direcciones de cénit coincidentes con los vectores de línea de vista dados por los pares $(\alpha, \beta)$ que son iguales a $\left(0^{\circ}, 0^{\circ}\right),\left(0^{\circ}, 90^{\circ}\right),\left(0^{\circ}, 180^{\circ}\right)$ y $\left(0^{\circ}, 270^{\circ}\right)$.

Se puede ver en la Figura 4.10 que el grado de solapamiento entre antenas adyacentes permanece aproximadamente invariante hasta ángulos de incidencia superiores a $60^{\circ}$ respecto del plano horizontal. Con ángulos incidencia tales que $|\alpha|>80^{\circ}$ (es decir, direcciones casi paralelas al eje del vehículo) no hay cobertura por parte de ninguno de los miembros del arreglo.

Debe notarse que las regiones sin cobertura se encuentran sobre-representadas en la figura anterior debido a la proyección plana utilizada en la misma; una evaluación más realista puede verse en la representación 3D de la Figura 4.11, donde cada punto de la esfera representa a un vector línea de vista normal a la esfera y que pasa por dicho punto. 


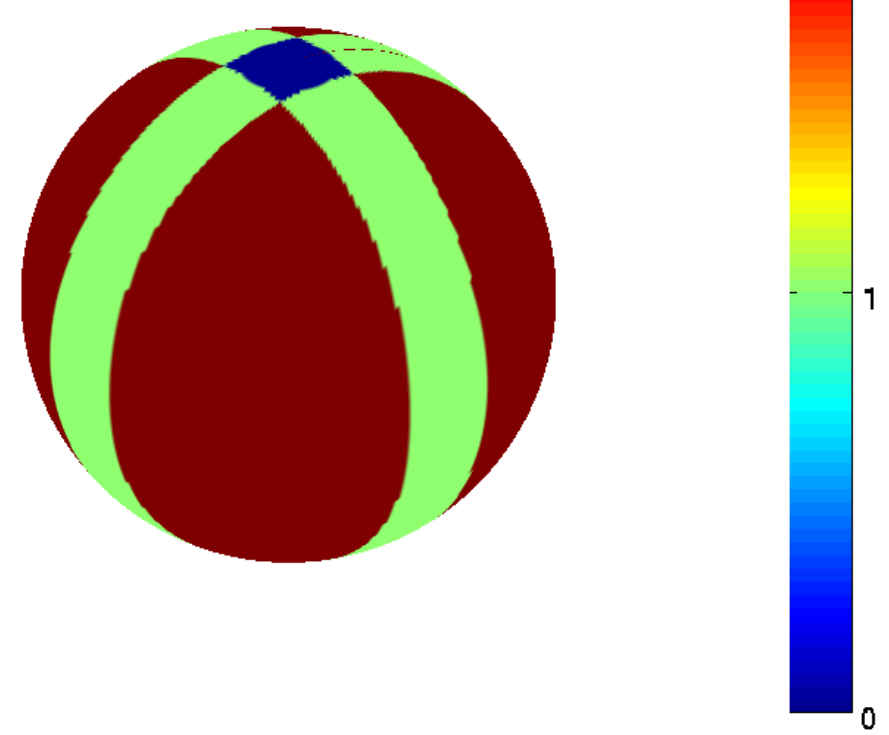

Figura 4.11: Representación 3D de la cobertura del arreglo de antenas de modo diversidad, correspondiente a los mismos datos que la Figura 4.10. El color de cada punto indica la cantidad de antenas que tienen cobertura para una dirección de arribo dada por el vector línea de vista que es normal a la esfera y que pasa por dicho punto.

\subsubsection{Mediciones de rango/deltarango}

Debido a la distancia física entre los miembros del arreglo, existen pequeñas diferencias en los observables de pseudorango/deltarango calculados para cada señal que dependen de la antena utilizada para la recepción de la misma.

La distancia entre los miembros del arreglo no permite definir un único punto físico donde se produce la recepción (el centro de fase de la antena), lo cual es crítico para la definición del rango entre el receptor y cada uno de los satélites. En un receptor multiantena en modo diversidad cada antena tiene su propio centro de fase para las señales, y por ende la definición de rango entre el receptor y el satélite depende de la antena considerada. Dependiendo de las dimensiones del arreglo y del ángulo de arribo de la señal las diferencias en los rangos según se midan con una antena u otra pueden ir desde algunos centímetros hasta algunos metros.

Claramente esto introduce una incertidumbre en los observables, ya que las mediciones de pseudorango obtenidas a partir de señales recibidas a través de antenas diferentes serán inconsistentes entre sí al no esta referidas a un mismo punto. Si bien en general 
esta inconsistencia no inhibe la capacidad del receptor de determinar la posición del vehículo, las cotas de error de la solución obtenida serán superiores que las que se podrían anticipar a partir de consideraciones puramente estadísticas basadas en el ruido de los observables.

Los vehículos inyectores de cargas livianas suelen tener diámetros que dependiendo de la etapa pueden ser de entre $1,5 \mathrm{~m}$ y $3 \mathrm{~m}$. Dado que los errores propios de la medida de pseudorango (debidos al ruido, retardos atmosféricos, residual del reloj, etc.) de un receptor GNSS monobanda se encuentran típicamente en el orden de los $12 \mathrm{~m}(1 \sigma)$ se puede argumentar que el incremento en el error de la solución de navegación en este caso será más bien moderado.

Por otro lado, en el caso de receptores doble banda L1/L2 o utilizados a bordo de vehículos de dimensiones mayores el problema no podrá ser despreciado. En estos casos una solución puede hallarse para referenciar todas las mediciones respecto aun mismo punto si se cuenta con información adicional. Utilizando una solución de navegación aproximada junto con información de la orientación del vehículo (obtenida externamente) es posible determinar la orientación del arreglo en relación con cada una de las señales incidentes. Con esa información es trivial aplicar una corrección a las mediciones de pseudorango para referirlas todas a punto común (el centro del arreglo, por ejemplo) antes de realizar el cálculo de navegación definitivo.

Problemas semejantes aparecen también en las mediciones de deltarango en presencia de rotación del vehículo alrededor de su eje. Dado un diámetro $D_{v}$, la velocidad tangencial de una antena cuando el vehículo tiene está girando con $n_{v}$ revoluciones por minuto es

$$
v_{t}=\frac{2 \pi}{60} \frac{D_{v} n_{v}}{2} .
$$

Para un vehículo de $D_{v}=3 \mathrm{~m}$ y girando con $n_{v}=4 \mathrm{rpm}$ eso significa una velocidad tangencial de $1,5 \mathrm{~m} / \mathrm{s}$. La velocidad relativa de unas antenas respecto a otras será en el peor caso del doble de esta cifra para el caso de dos antenas antipodales, lo que puede afectar marcadamente las mediciones de deltarango utilizadas para calcular la velocidad del vehículo.

\subsubsection{Algoritmos}

Los algoritmos de procesamiento a bajo nivel del receptor no cambian fundamentalmente respecto de sus versiones en receptores convencionales. El receptor multiantena todavía debe cumplir con todas las etapas del procesamiento de una señal de satélite: adquisición, verificación, sincronización, y seguimiento. 


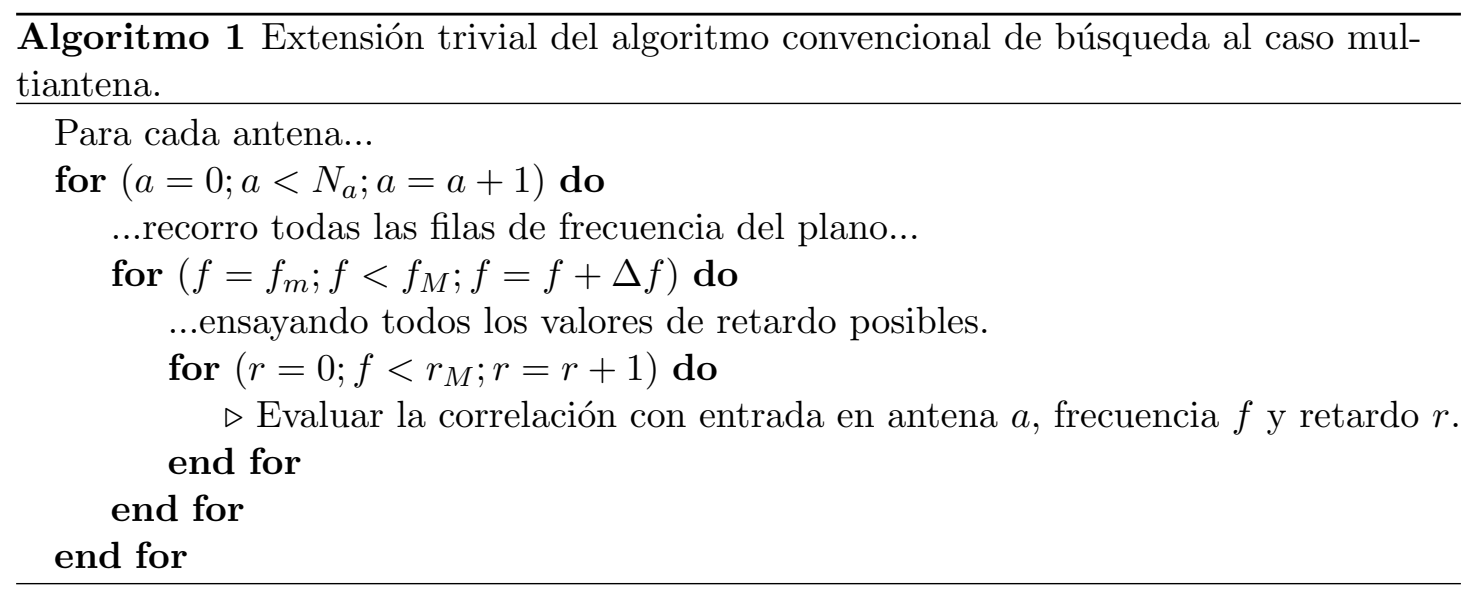

Sin embargo el diseño propuesto del arreglo de antenas de entrada distribuye la visibilidad del conjunto total de señales disponibles. La dinámica del vehículo y de los mismos satélites provocarán cambios en la distribución de este conjunto de señales sobre los miembros del arreglo, por lo que el receptor deberá poder adaptarse dinámicamente a estos cambios a la vez que se mantiene la continuidad en la decodificación de la señal y la generación de soluciones de navegación. Esta capacidad requerirá de extender las ideas base detrás de los algoritmos convencionales.

\subsubsection{Adquisición}

Como se explicó oportunamente, en un receptor convencional el proceso de búsqueda de la señal consiste en realizar un barrido de todas las celdas del plano retardo-frecuencia en búsqueda de un evento de detección de señal.

En el caso del receptor multiantena la señal de un satélite en línea de vista podrá ser detectada solamente en aquellas antenas cuya orientación favorezca la recepción de dicha señal. Dado que en principio el receptor no tiene información previa respecto de las direcciones de arribo ni de la orientación del vehículo, el receptor deberá por lo tanto repetir el proceso de búsqueda de la señal en cada una de las antenas de entrada antes de poder dictaminar la ausencia de la misma.

La forma más trivial de realizar esto es repetir secuencialmente procesos de búsqueda convencionales en cada una de las antenas. Para cada antena individual se realiza el barrido del plano retardo-frecuencia completo, y solamente una vez concluido éste se comienza el barrido en la antena siguiente. Una representación básica en forma de pseudocódigo puede encontrarse en el Algoritmo 1.

Si bien este algoritmo es simple, es incompatible con la velocidad de giro máxima del vehículo durante el vuelo que fue especificada en la Sección 4.3.4. El barrido de un 
plano-retardo frecuencia en condiciones típicas (sin información previa de la ubicación de la señal) toma un tiempo del orden de una docena de segundos. Por otro lado, en el peor caso de velocidad de giro del cuerpo del vehículo ( $4 \mathrm{rpm})$ cada antena dará un giro completo cada 15 segundos. Es fácil ver por lo tanto que los tiempos de un proceso y otro no permiten garantizar el proceso de búsqueda cubra todas las posibles combinaciones de celdas del plano retardo-frecuencia y direcciones de arribo posibles.

Una alternativa mejor es la de modificar el orden de recorrido de las dimensiones de la forma que se ve en el Algoritmo 2. Al igual que en un receptor convencional, el receptor barre una única vez el plano retardo-frecuencia, pero cada celda es inspeccionada repetidas veces iterando cada vez la antena tomada como entrada de señal. Dado que el tiempo que toma realizar el examen de una única celda es del orden de milisegundos (es el tiempo de integración total utilizado: tiempo coherente por repeticiones no coherentes por cantidad de antenas), queda garantizado que todas las direcciones de arribo posibles sean examinadas durante el proceso de búsqueda.

En los dos casos anteriores el tiempo total que toma realizar el proceso de búsqueda de la señal se incrementa respecto del método convencional en tantas veces como antenas de entrada existan. Es posible reducir este incremento explotando la superposición entre las regiones de cobertura de las antenas del arreglo.

Se vio en secciones anteriores que la cobertura del arreglo es en buena medida redundante, por lo que es posible utilizar solamente dos de las cuatro antenas del arreglo para realizar la búsqueda si estas se eligen antipodales entre sí. De esta forma el proceso de búsqueda todavía cubre la práctica totalidad de las direcciones de arribo, mientras que el tiempo que toma realizarlo se incrementa solamente por un factor de dos respecto del que le tomaría a un receptor convencional.

La última alternativa que se mencionará aquí consiste en realizar el recorrido de las celdas para todas las antenas del arreglo simultáneamente utilizando correladores adicionales.

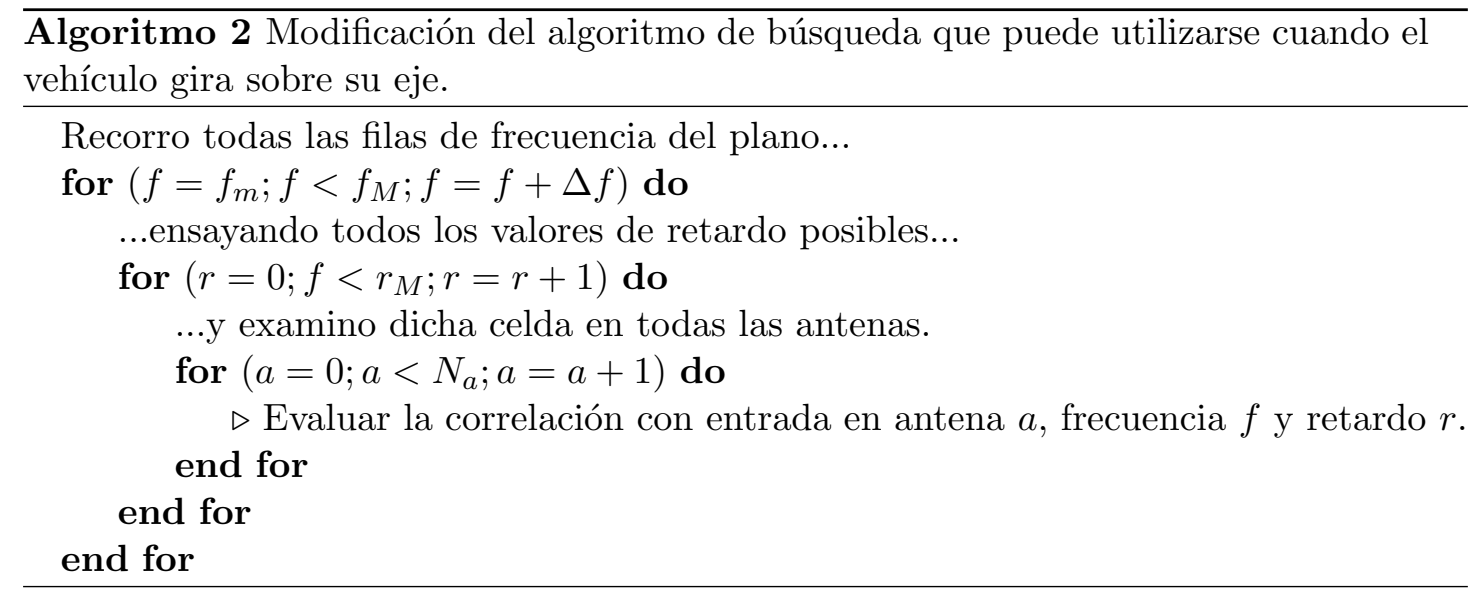


La principal ventaja que tiene este método es el de no requerir tiempo adicional para realizar la búsqueda de señal, ya que todas las antenas son inspeccionadas en paralelo. Existe también un costo, por supuesto, que está dado por el incremento en la cantidad de recursos de hardware que son necesarios para implementar los correladores adicionales y en la cantidad de muestras de correlación que deberá procesar el software por cada tiempo de integración.

\subsubsection{Seguimiento}

En la Sección 4.4.2 se comentó el efecto de la distancia física entre las antenas del arreglo en las mediciones de rango/deltarango. Dicho análisis está hecho desde el punto de vista del impacto de procesar conjuntamente señales de satélites diferentes y que están siendo recibidas a través de antenas físicamente separadas entre sí. En esta sección se introducirán otra serie de problemas ocasionados por la separación física entre las antenas, esta vez relacionados con las diferencias en los parámetros de una misma señal cuando es recibida por antenas diferentes.

En la Sección 3.7.2 se discutió el funcionamiento de los algoritmos de seguimiento de señal, mencionando su función como actualizadores permanentes de los parámetros de la señal (frecuencia y fase de portadora, y retardo de la función de código) asociados tanto a la obtención de mediciones rango/deltarango como a la demodulación del mensaje de navegación.

La utilización de un arreglo de antenas de entrada agrega un nuevo nivel de dificultad a la tarea de los algoritmos de seguimiento debido a que la dinámica del vehículo y de los propios satélites transmisores generará variaciones en la orientación relativa de las señales recibidas respecto del arreglo de entrada. Para mantener la sincronización con la señal el receptor debe permanentemente monitorear las condiciones de recepción de cada señal a través de todos los miembros del arreglo para determinar cuál es la antena que se encuentra mejores condiciones de recepción para cada señal individual.

Este proceso de selección de la antena se realiza mediante el procesamiento simultáneo de todas las antenas del arreglo. Se extiende el canal de correlación en hardware que tiene asignado cada señal de forma tal de contar correladores Early, Puntual y Late para cada una de las cuatro antenas de entrada. Cada ciclo de correlación se generan doce muestras de correlación, correspondientes a los tres correladores de cada una de las cuatro antenas. Se mide la potencia de señal recuperada a través de cada una de las antenas, seleccionando la que tiene el nivel más alto para ser utilizada como entrada para los algoritmos de demodulación de datos. 
Cuando ocurre una modificación en la situación de recepción tal que las potencias de señal recibidas por cada antena cambian y esto provoca un cambio en la antena con mayor potencia, el receptor debe migrar la demodulación de la señal a la nueva antena. Estas migraciones pueden ocurrir con una frecuencia elevada: con el vehículo rotando sobre su eje a $4 \mathrm{rpm}$ la antena mejor orientada para recibir una dada señal de satélite cambia en promedio cada

$$
\frac{60 \mathrm{seg}}{1 \mathrm{~min}} \frac{1 \mathrm{~min}}{4 \mathrm{rev} / \mathrm{min}} \frac{1}{4 \text { antenas }}=3,25 \mathrm{seg} .
$$

En general los parámetros de la señal de un mismo satélite tal como son recibidos por dos antenas diferentes serán de valores cercanos pero lo suficientemente diferentes como para no poder ignorar la diferencia. Esta diferencia nuevamente se debe a la separación física entre las antenas del arreglo, que dota a cada antena de un rango y una velocidad relativa propia respecto del satélite transmisor.

La longitud de onda de las señales transmitidas en el rango de frecuencias correspondientes las señales GPS C/A y GLONASS L1OF es de aproximadamente $20 \mathrm{~cm}$, lo cual es varias veces menor que la diferencia en la distancia recorrida por la señal entre el satélite y dos antenas diferentes. De esto se desprende que la fase de portadora instantánea con la que arriba la señal a diferentes antenas será totalmente diferente, pudiendo diferir por cualquier valor en el rango $[0,2 \pi)$.

Menos drástica es la diferencia en la fase de arribo de la función de código. Dado que un chip de la función de código de GPS equivale aproximadamente a 293,25 m a la velocidad de la luz, y que la longitud correspondiente del chip GLONASS es aún mayor, $587,08 \mathrm{~m}$, la diferencia entre las fases de la función de código con las que la señal arriba a dos antenas diferentes es generalmente una fracción de chip despreciable frente al mismo ruido de medición.

Cuando se considera el movimiento de rotación del vehículo, aparecen también variaciones importantes en la desviación Doppler de la señal según es percibida por unas u otras antenas. La máxima diferencia entre las frecuencias instantáneas en dos antenas ubicadas en oposición una de la misma ocurre cuando la velocidad tangencial de las mismas es colineal con el vector linea de vista. En ese caso, la diferencia entre ellas será

$$
\left|f_{1}-f_{2}\right| \leq \frac{f_{c}}{c} \frac{2 \pi D_{v} n_{v}}{60}
$$

donde $f_{c}$ es el valor de la frecuencia portadora, $c$ es la velocidad de la luz en el vacío, $D_{v}$ es el diámetro del vehículo y $n_{v}$ es la velocidad de giro del mismo. Tanto para GPS como para GLONASS la diferencia máxima de frecuencia portadora para dos antenas en condición máxima es del orden de $6,7 \mathrm{~Hz}$ cuando $n_{v}=4 \mathrm{rpm}$ y $D_{v}=3 \mathrm{~m}$. 
Para lograr conmutar las señales de antena en antena con la frecuencia indicada anteriormente sin introducir problemas en la demodulación de los datos e incluso en el enganche de la señal se requiere que durante las migraciones el receptor cuente con buenos estimados de los juegos de parámetros de portadora de la señal correspondientes tanto a la antena de origen como a la de destino, lo cual puede lograrse con lazos de seguimiento adicionales asociados a cada antena individual.

\subsection{Resumen de capítulo}

La arquitectura de los receptores GNSS para uso a bordo de vehículos de tipo cohete requiere de una serie de características especiales que le permitan hacer frente al conjunto de exigencias que plantea este contexto de operación del sistema.

Son problemas muy específicos de esta aplicación los rangos de operación dinámica que debe enfrentar el receptor, especialmente las altas velocidades y aceleraciones súbitas que pueden afectar la conservación del sincronismo de las señales. Por otro lado, la estructura misma de los vehículos también plantea una serie de dificultades a la hora de diseñar el sistema de antenas, ya que existen restricciones tanto de tipo estructural como funcional que limitan su diseño, ubicación y la cobertura que puede lograrse. Sumado a esto, en el caso de los objetivos del trabajo actual existe también el requerimiento adicional de poder procesar señales de los sistemas GPS y GLONASS simultáneamente con el objetivo de tener diversidad de sistemas.

A partir del establecimiento del conjunto de requerimientos que se plantean como meta para este trabajo de tesis, y de los juegos de compromisos que se pueden anticipar entre la arquitectura general de los algoritmos de procesamiento de un receptor GNSS y los escenarios de uso conformados por los requerimientos anteriores, es que se propusieron una serie de diseños básicos que serán la plataforma para el desarrollo de las ideas que se extenderán en los capítulos subsiguientes.

Estas propuestas establecen las características del sistema de antenas de entrada, conformado por un arreglo cuádruple de antenas en modo diversidad, y de los algoritmos básicos de adquisición y seguimiento que deberán implementarse para procesar las señales recibidas por este arreglo. 



\section{Capítulo 5}

\section{Hardware del prototipo}

\subsection{Introducción}

Este capítulo presenta una introducción al prototipo del hardware del receptor multiantena GPS/GLONASS que se tomó como base para el desarrollo del software que implementa los algoritmos que se presentan en los capítulos siguientes, ya que su diseño introduce una serie de condiciones de contorno que limitan las posibilidades de desarrollo y por lo tanto impactan en el diseño de los algoritmos presentados.

El capítulo se encuentra dividido en tres secciones principales, que corresponden a las tres etapas de procesamiento más importantes en que se divide el hardware del receptor. La relación entre estas etapas puede verse en la Figura 5.1

Etapa de acondicionamiento y muestreo Abarca todo el procesamiento analógico y de muestreo necesario para producir muestras complejas de señal: amplificación, filtrado, bajada a frecuencia intermedia y conversión A/D.

Etapa de procesamiento de alta tasa Consiste en el banco de canales de correlación GPS/GLONASS multiantena desarrollado para este prototipo. Realiza el procesamiento digital de las muestras de la señal a la tasa de muestreo de entrada y genera a su salida las muestras de correlación a tasas mucho menores que pueden ser procesadas por la computadora del receptor.

Etapa de cómputo Es la computadora que forma el corazón del receptor, encargada de realizar el procesamiento de más alto nivel de la señal: adquisición, verificación, sincronización y seguimiento de señales, cálculo de soluciones de navegación, comunicaciones, etc. 


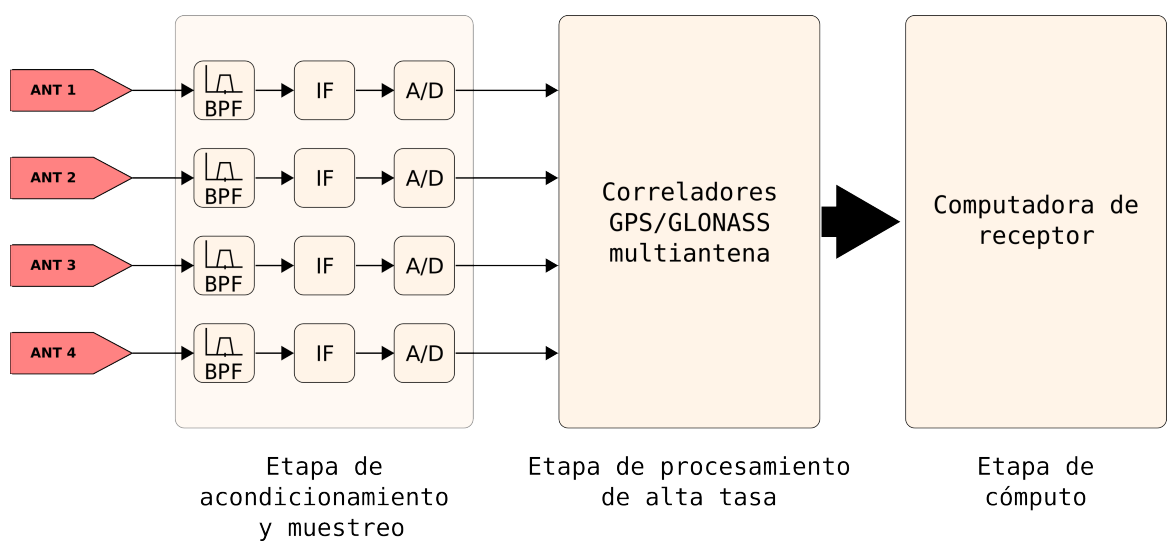

Figura 5.1: Bloques principales de hardware del prototipo del receptor GPS/GLONASS multiantena.

Dada la elevada complejidad de los detalles de cada una de las etapas se intentará mantener la exposición acotada a aquellos temas que son especialmente relevantes para el desarrollo posterior.

\subsection{Etapa de acondicionamiento de señal y muestreo}

La etapa de acondicionamiento y muestreo se encuentra compuesta de cuatro cadenas de procesamiento de señal de radiofrecuencia paralelas, una por cada una de las cuatro antenas de entrada del receptor.

Todas las cadenas utilizan la misma referencia de frecuencia para generar todas las señales periódicas necesarias, garantizando así una relación fija de frecuencia y fase entre ellas. Esto garantiza, entre otras cosas, que la frecuencia del oscilador local utilizado para realizar la bajada a frecuencia intermedia sea exactamente la misma en las cuatro cadenas, y que la operación de muestreo ocurra sincrónicamente en todos los conversores A/D.

\subsubsection{Filtrado y amplificación}

Las primeras etapas de cada una de las cadenas de procesamiento RF consiste en una etapa de acondicionamiento de señal que se encarga fundamentalmente del filtrado y de la amplificación de la misma.

El filtrado se realiza utilizando una combinación de filtros pasa-banda centrados en la banda de GPS y GLONASS de L1. El filtrado de esta etapa tiene por funciones por un lado limitar la potencia total de ruido que se deja pasar a los amplificadores de bajo 
ruido posteriores de forma de evitar su saturación, y además llevar a cabo la eliminación de la frecuencia imagen antes de realizar la bajada a FI.

Debido a lo elevado del valor de la frecuencia central de la señal de entrada (ubicada todavía en banda L1), la selectividad de los filtros pasa-banda de entrada no es suficiente para realizar un filtrado estrecho alrededor de las bandas ocupadas por GPS C/A y GLONASS L1OF. La tarea de filtrado será completada posteriormente una vez que la señal haya sido trasladada a frecuencia intermedia.

La amplificación tiene etapas de ganancia fija y otras de ganancia variable. Las etapas de ganancia variable se utilizan como parte de un sistema realimentado que ajusta la amplitud de la señal para garantizar un nivel de amplificación tal que asegure una amplitud óptima de señal a la entrada de los conversores A/D. Este sistema realimentado de regulación de amplitudo forma un sistema de Control Automático de Ganancia, o AGC (Automatic Gain Control).

\subsubsection{Bajada a frecuencia intermedia}

Las señal amplificada y filtrada se mezcla con un oscilador local de frecuencia $f_{l o}$ para llevar la señal a una frecuencia intermedia mucho más baja que la banda original. En esta etapa también se realiza una segunda ronda de filtrado, que reduce la potencia de ruido que contamina la señal y acota el ancho de banda para satisfacer el teorema de muestreo antes de la conversión A/D.

El mezclado de la señal de entrada con el oscilador local provoca una modificación de las frecuencias centrales de cada una de las señales GPS y GLONASS presentes. El esquema de bajada es de tipo Low Side Tuning (LST), que significa que la frecuencia del oscilador local es menor que las frecuencias de todas las señales GPS y GLONASS de la entrada. La nueva frecuencia nominal de cada señal en FI $f_{I 1(n)}$ se calcula a partir de la expresión

$$
f_{I 1(n)}=f_{l 1(n)}-f_{l o}
$$

donde $f_{l 1(n)}$ es la frecuencia central nominal y $f_{l o}$ es la frecuencia de oscilador local utilizada en el prototipo de hardware, $1545 \mathrm{MHz}$.

La utilización de un esquema de bajada de tipo LST implica que en esta etapa no se produzca modificación del signo de las desviaciones de frecuencia por efecto Doppler. Por razones que se explicarán en la Sección 5.2.3.1 esto es un dato de interés para el software del receptor. 


\begin{tabular}{|r|c|c|}
\hline Señal & Canal & Frecuencia \\
\hline GPS & & $30,4200 \mathrm{MHz}$ \\
\hline GLONASS & -7 & $53,0625 \mathrm{MHz}$ \\
GLONASS & -6 & $53,6250 \mathrm{MHz}$ \\
GLONASS & -5 & $54,1875 \mathrm{MHz}$ \\
GLONASS & -4 & $54,7500 \mathrm{MHz}$ \\
GLONASS & -3 & $55,3125 \mathrm{MHz}$ \\
GLONASS & -2 & $55,8750 \mathrm{MHz}$ \\
GLONASS & -1 & $56,4375 \mathrm{MHz}$ \\
GLONASS & 0 & $57,0000 \mathrm{MHz}$ \\
GLONASS & 1 & $57,5625 \mathrm{MHz}$ \\
GLONASS & 2 & $58,1250 \mathrm{MHz}$ \\
GLONASS & 3 & $58,6875 \mathrm{MHz}$ \\
GLONASS & 4 & $59,2500 \mathrm{MHz}$ \\
GLONASS & 5 & $59,8125 \mathrm{MHz}$ \\
GLONASS & 6 & $60,3750 \mathrm{MHz}$ \\
\hline
\end{tabular}

CuAdro 5.1: Valores de las frecuencias portadoras nominales luego de realizada la conversión a FI.

\subsubsection{Plan de frecuencias en frecuencia intermedia}

En el Cuadro 5.1 se pueden encontrar los valores nominales de las frecuencias portadoras luego de la etapa de conversión a FI, tanto para la señal GPS C/A como para cada uno de los canales FDMA GLONASS de la señal L1OF.

\subsubsection{Conversión $\mathrm{A} / \mathrm{D}$}

Cada una de las cuatro cadenas de entrada tiene su propio conversor A/D que se encarga de discretizar tanto en tiempo como en amplitud las señales de frecuencia intermedia para su procesamiento posterior en la etapa de correlación.

En el procesamiento de señales GNSS es típica la utilización de pocos niveles de cuantización en la amplitud de la señal; codificaciones de dos y tres bits (cuatro y ocho niveles de cuantización diferentes, respectivamente) son típicas. Eso es así debido a que se puede probar que en condiciones habituales de operación, si los umbrales entre niveles de cuantización se eligen adecuadamente, entonces la pérdida de relación SNR efectiva causada por la cuantización es prácticamente despreciable. Por ejemplo, utilizando solamente dos bits para codificar signo y amplitud la degradación es de aproximadamente 0,6 dB respecto del cuantizador ideal (con infinitos niveles de cuantización). Se puede consultar esto en mayor profundidad en la referencia [3]. 
En el prototipo de receptor se utilizan conversores A/D de 8 bits, pero un circuito de reducción convierte la cantidad de niveles de cuantización a solamente cuatro, convirtiendo las muestras a una representación de dos bits (uno de signo y otro de módulo). La relación de costo/beneficio de esta decisión de diseño es que la pérdida de aproximadamente $0,6 \mathrm{~dB}$ se ve más que compensada por el ahorro de recursos lógicos necesarios para implementar la etapa de correlación multiantena, la cual como se verá posteriormente se encuentra implementada en un dispositivo lógico programable de tipo FPGA (Field Programmable Gate Array).

Para lograr mantener los umbrales de los conversores A/D en sus valores óptimos, cada una de las cuatro cadenas de entrada regula los niveles de sus respectivas ganancias variables realimentando información que obtiene monitoreando la distribución de probabilidades de las muestras de dos bits a la salida.

Observando los valores de las frecuencias intermedias de cada una de las señales individuales en el Cuadro 5.1 se puede ver que la frecuencia máxima del espectro a muestrear es de aproximadamente $63 \mathrm{MHz}$, por lo que una conversión A/D directa requiere al menos el doble de esa frecuencia como frecuencia de muestreo. Sin embargo la ocupación de este ancho de banda es baja:

- La banda GPS se encuentra alrededor de $30 \mathrm{MHz}$ con un ancho de banda principal de $2 \mathrm{MHz}$

- La banda GLONASS se halla entre $53 \mathrm{MHz}$ y $60 \mathrm{MHz}$, con un ancho aproximado de $8 \mathrm{MHz}$.

Se puede ver que en total menos de $10 \mathrm{MHz}$ de los $63 \mathrm{MHz}$ se encuentran efectivamente ocupados por señal.

Para evitar las altas frecuencias de muestreo necesarias para realizar muestreo directo del espectro anterior, en el diseño del hardware del prototipo se optó por la utilización de la técnica de muestreo pasa-banda. Esta última utiliza una frecuencia de muestreo $f_{m p}$ menor que la frecuencia máxima de la señal a muestrear, pero mayor o igual que el ancho de banda ocupado. En este caso no es tan relevante la frecuencia máxima de la señal (que solamente condiciona el ancho de banda de entrada del conversor A/D utilizado) sino la diferencia entre las frecuencias ocupadas máxima y mínima y el alineamiento de la región que delimitan respecto de los múltiplos de la frecuencia de muestreo.

Las sub-bandas GPS y GLONASS no se encuentran adyacentes en frecuencia intermedia porque eso hubiera requerido la utilización de osciladores locales diferenciados durante la etapa de bajada a frecuencia intermedia. Por esta razón la distancia entre las frecuencias 
máxima y mínima del rango utilizado por las señales (aproximadamente $33 \mathrm{MHz}$ ) sigue siendo relativamente alta comparado con el ancho de banda efectivamente ocupado.

Además, la ubicación del rango ocupado en el espectro no se presta para la utilización de la frecuencia de muestreo pasa-banda mínima (igual al ancho de banda ocupado por la señal), por lo que para evitar el solapamiento del espectro muestreado se requiere la utilización de una frecuencia más alta que dicho mínimo.

Las restricciones anteriores limitan las ventajas de realizar muestreo pasa-banda en lugar de muestreo pasa-bajos. Estas circunstancias podrían ser atenuadas parcialmente mediante la utilización de muestreo en fase y cuadratura (ya sea pasa-bajos o pasabanda), pero esto incrementaría la cantidad de conversores A/D necesarios al doble y complejizaría la interfaz entre ellos y la etapa de correlación posterior duplicando la cantidad de canales de transmisión de muestras.

A la luz de estos problemas se optó por realizar un compromiso fuerte en el diseño del prototipo. Se optó por la utilización de muestreo real, con solamente cuatro conversores A/D, y la frecuencia de muestreo $f_{m p}$ se estableció en $20 \mathrm{MHz}$ con el criterio de limitar la tasa de procesamiento de la etapa de correlación posterior. Debido a que esta frecuencia de muestreo es menor que la frecuencia máxima presente en el espectro a muestrear genera un efecto de replicado que trasladará las frecuencias portadoras a nuevos valores en el rango de frecuencias representables en el espectro discreto $\left[0, f_{m p}\right]$.

Debido a la distribución de las frecuencias en FI (Cuadro 5.1) el efecto de replicado del espectro al ser muestreado con $f_{m p}=20 \mathrm{MHz}$ produce una superposición parcial de los espectros de diferentes señales en el espectro discreto. Esto puede verse claramente en la Figura 5.2. La superposición provoca una reducción de aproximadamente $3 \mathrm{~dB}$ en la relación SNR de algunas de las señales debido al incremento en el piso de ruido en las proximidades de su portadora. Esta degradación afecta a los canales GLONASS $k=5$ y $k=6$ y a la frecuencia central de las señales GPS.

\subsubsection{Doppler negativo y positivo}

La naturaleza real de la señal que ha sido muestreada permite interpretar la ubicación frecuencial de cada una de las señales GPS/GLONASS individuales en el espectro discreto de dos formas alternativas.

La primera es identificar como valor de la frecuencia portadora a la posición de su componente compleja que está ubicada dentro del intervalo $\left[0, f_{m p} / 2\right]$, mientras que la componente presente en el intervalo complementario se asocia al espectro conjugado de 


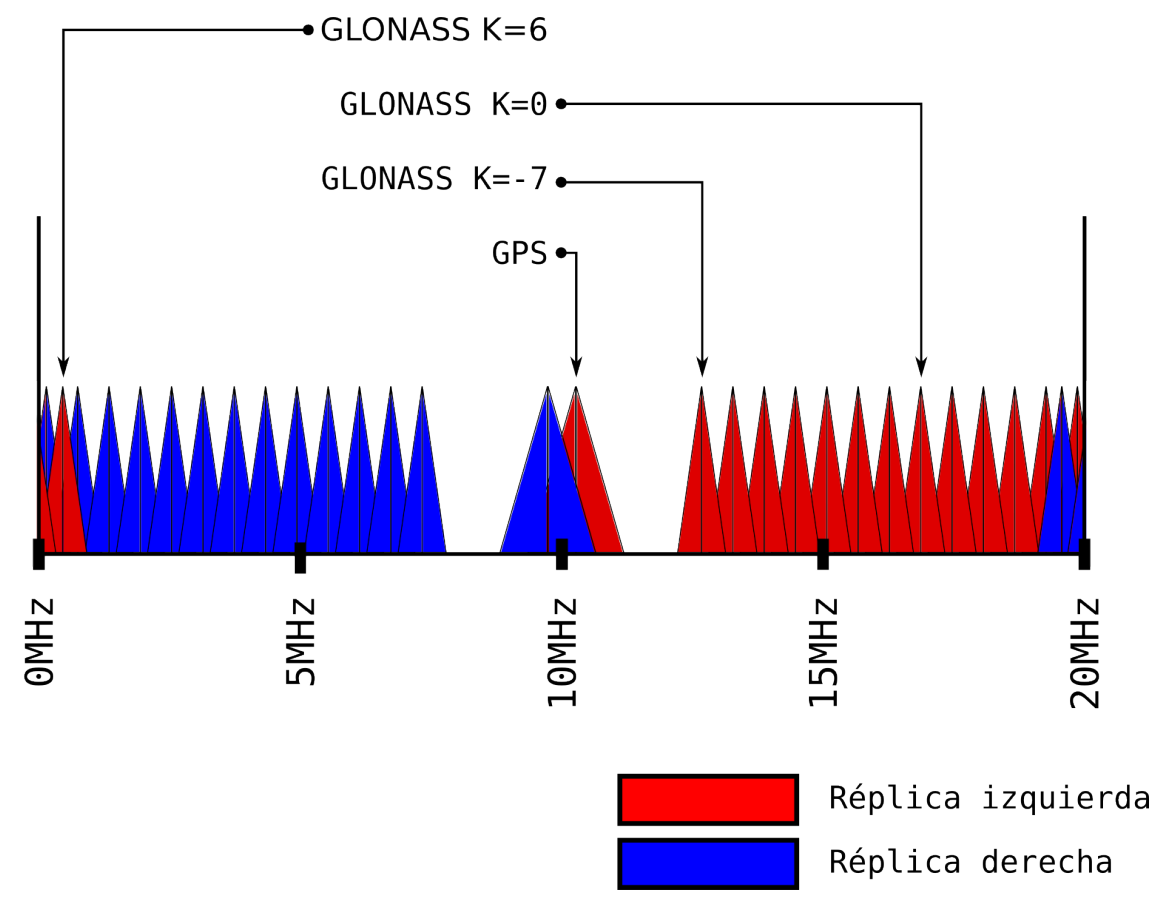

Figura 5.2: Representación del solapamiento entre réplicas que ocurre durante el muestreo de la señal en frecuencia intermedia. Puede verse que existe superposición entre los canales superiores de GLONASS de una y otra réplica, así como también en la sub-banda de GPS. Estas superposiciones provocan un incremento del piso de ruido de las señales, y por lo tanto una reducción de la relación SNR.

la anterior. Según esta interpretación el espectro de la señal muestreada que se ve en la Figura 5.3 correspondería a una señal con frecuencia central ubicada en $5 \mathrm{MHz}$.

La interpretación alternativa consiste en asignar la frecuencia portadora de acuerdo con la posición de la componente compleja que se encuentra en el intervalo $\left[f_{m p} / 2, f_{m p}\right]$, mientras que componente en el intervalo $\left[0, f_{m p} / 2\right]$ toma el rol de conjugada. Volviendo al ejemplo de la Figura 5.3, este criterio asignaría a la señal muestreada allí representada una frecuencia portadora de $15 \mathrm{MHz}$.

Por supuesto, existen infinidad de otras elecciones posibles. Cualquier frecuencia que difiera por una cantidad entera de múltiplos de la frecuencia de muestreo de alguna de las dos elecciones anteriores será equivalente a ella. A los efectos de la discusión que sigue basta con limitarnos a las dos alternativas que existen dentro del rango de frecuencias no ambiguo del espectro discreto $\left[0, f_{m p}\right]$.

En la mayoría de los sistemas de comunicaciones convencionales la diferenciación anterior es insustancial, y generalmente se optará por la primera interpretación por ser más natural. En los sistemas GNSS, en cambio, la diferencia se vuelve relevante debido a que el signo de los desplazamientos de la frecuencia portadora es tan relevante como su módulo. 

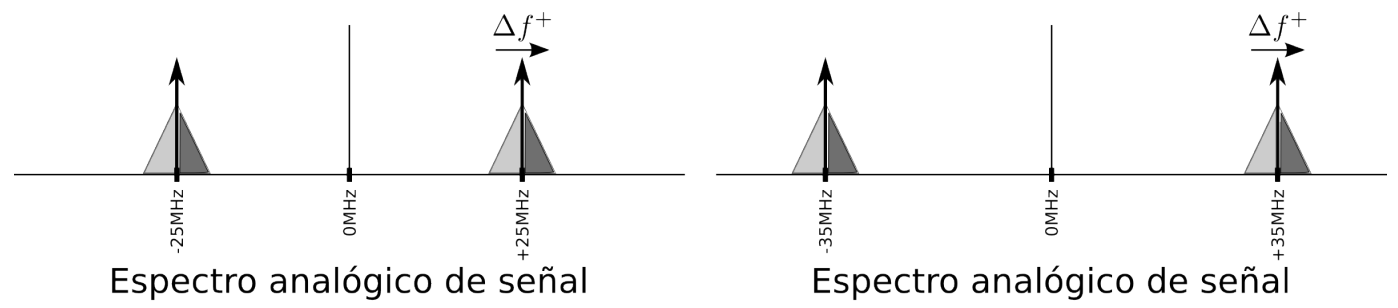

Espectro analógico de señal
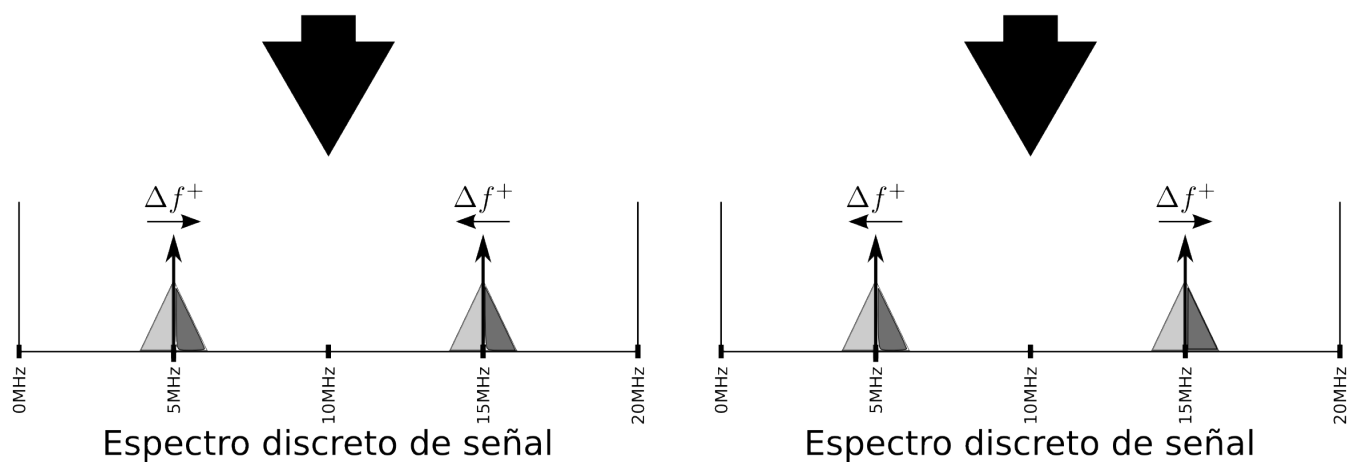

FigurA 5.3: Efecto del muestreo pasabanda de $20 \mathrm{MHz}$ sobre dos señales de $25 \mathrm{MHz}$ y $35 \mathrm{MHz}$. Se indica también en la figura la dirección en que se moverán los espectros con un desplazamiento Doppler positivo en la señal analógica original.

Como se vio en capítulos anteriores, el valor del desplazamiento Doppler convertido en deltarango es el observable utilizado para determinar la velocidad del vehículo. El signo del desplazamiento es indicador de la dirección de velocidad relativa entre receptor y transmisor, y si no es considerado correctamente el sistema de ecuaciones de velocidad arrojará una solución incorrecta. Igualmente crítico es el conocimiento de la dirección del desplazamiento de frecuencia al realizar asistencia en frecuencia del lazo de portadora al lazo de código, ya que si el signo de la desviación de frecuencia es el incorrecto la asistencia deja de cooperar con el funcionamiento del lazo de código para pasar a convertirse en una potente perturbación al mismo.

Volviendo a la Figura 5.3, se puede ver que dependiendo de cual de las dos interpretaciones se utilice, el signo de los desplazamientos Doppler resultará o no invertido dependiendo de cual fuera la relación entre el valor de la frecuencia portadora en frecuencia intermedia y la frecuencia de muestreo. Se puede comprender ahora también la relevancia de indicar en la Sección 5.2.2 que el signo de los desplazamientos en frecuencia intermedia coincide con el de la señal en su banda de transmisión original.

Definimos entonces una portadora discreta de Doppler positivo como aquella tal que el signo de los desplazamientos por efecto Doppler respecto del valor nominal coincide con el signo del desplazamiento de la señal analógica original en banda L1. Si en cambio los signos difieren se define a la portadora discreta como de Doppler negativo. 


\begin{tabular}{|r|c|c|c|}
\hline Señal & Canal & $\begin{array}{c}\text { Portadora } \\
\text { Doppler Positivo }\end{array}$ & $\begin{array}{c}\text { Portadora } \\
\text { Doppler Negativo }\end{array}$ \\
\hline GPS & & $10,4200 \mathrm{MHz}$ & $9,5800 \mathrm{MHz}$ \\
\hline GLONASS & -7 & $13,0625 \mathrm{MHz}$ & $6,9375 \mathrm{MHz}$ \\
GLONASS & -6 & $13,6250 \mathrm{MHz}$ & $6,3750 \mathrm{MHz}$ \\
GLONASS & -5 & $14,1875 \mathrm{MHz}$ & $5,8125 \mathrm{MHz}$ \\
GLONASS & -4 & $14,7500 \mathrm{MHz}$ & $5,2500 \mathrm{MHz}$ \\
GLONASS & -3 & $15,3125 \mathrm{MHz}$ & $4,6875 \mathrm{MHz}$ \\
GLONASS & -2 & $15,8750 \mathrm{MHz}$ & $4,1250 \mathrm{MHz}$ \\
GLONASS & -1 & $16,4375 \mathrm{MHz}$ & $3,5625 \mathrm{MHz}$ \\
GLONASS & 0 & $17,0000 \mathrm{MHz}$ & $3,0000 \mathrm{MHz}$ \\
GLONASS & 1 & $17,5625 \mathrm{MHz}$ & $2,4375 \mathrm{MHz}$ \\
GLONASS & 2 & $18,1250 \mathrm{MHz}$ & $1,8750 \mathrm{MHz}$ \\
GLONASS & 3 & $18,6875 \mathrm{MHz}$ & $1,3125 \mathrm{MHz}$ \\
GLONASS & 4 & $19,2500 \mathrm{MHz}$ & $0,7500 \mathrm{MHz}$ \\
GLONASS & 5 & $19,8125 \mathrm{MHz}$ & $0,1875 \mathrm{MHz}$ \\
GLONASS & 6 & $0,3750 \mathrm{MHz}$ & $19,6250 \mathrm{MHz}$ \\
\hline
\end{tabular}

CUADRo 5.2: Ocupación de frecuencias luego del muestreo pasa-banda real.

Resta decir que el receptor puede funcionar con igual eficacia independientemente de la interpretación realizada respecto de la frecuencia portadora. La única salvedad es que en el caso de asignar como valor de frecuencia portadora aquella correspondiente a los desplazamientos de Doppler negativo, entonces las estimaciones de la desviación de frecuencia realizadas por los lazos de seguimiento de portadora deberán ser invertidos de signo antes de ser utilizados por otros subsistemas del receptor, ya sea como observables de navegación o como asistencia de frecuencia al lazo de código.

\subsubsection{Plan de frecuencias discreto}

El plan de frecuencias resultante de este muestreo pasa-banda puede encontrarse en el Cuadro 5.2. Allí se indican tanto los valores de frecuencia portadora con desplazamiento Doppler negativo como con desplazamiento Doppler positivo para cada una de las frecuencias centrales GPS y GLONASS relevantes.

\subsection{Etapa de correlación multiantena}

La etapa de correlación multiantena es semejante a lo ya descripto en la Sección 3.6 para el caso monoantena. Se encuentra formada por un dispositivo implementado en lógica programable y sintetizado en una FPGA. Este dispositivo contiene un conjunto de canales de correlación configurables encargados de procesar las muestras de entrada 


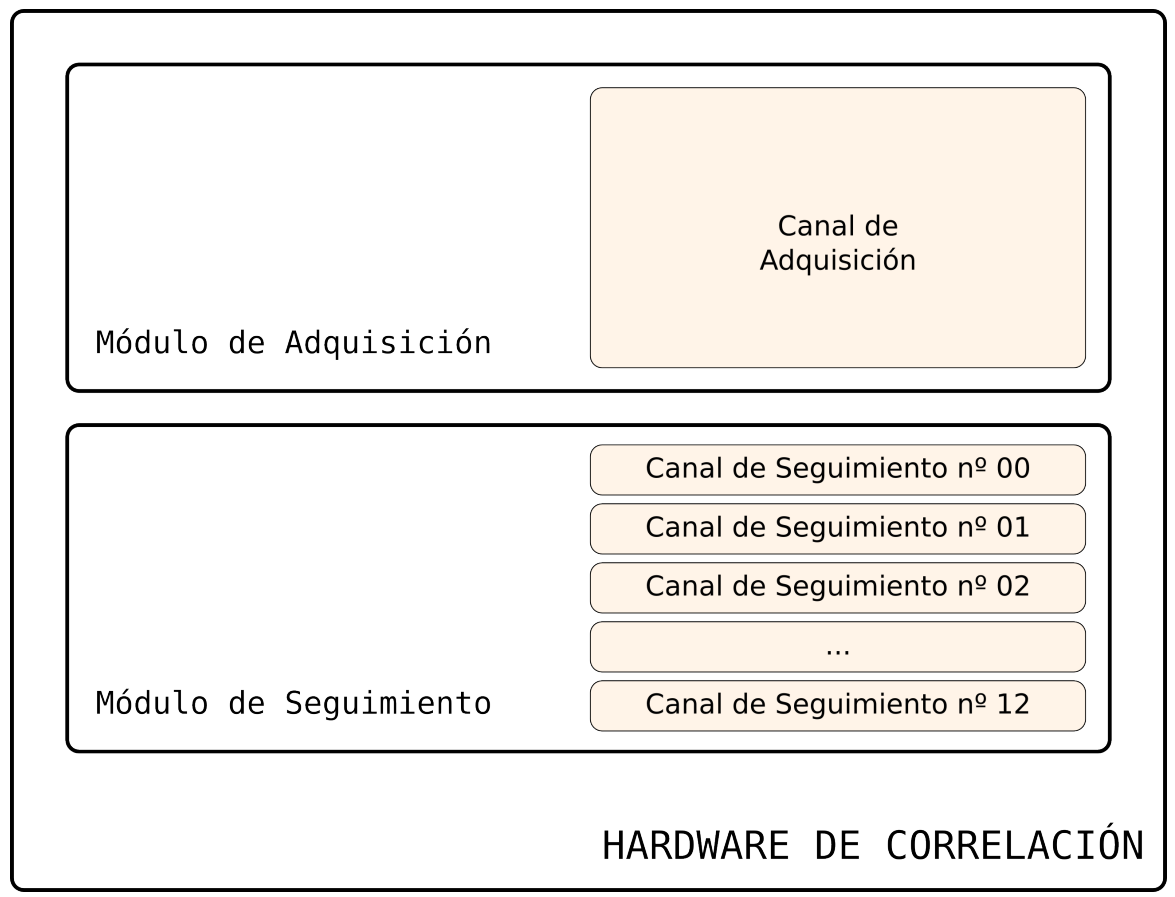

FIGURA 5.4: Organización interna del hardware de correlación del prototipo de receptor multiantena.

que provienen de la sección de conversión A/D de cada una de las antenas y generar las muestras de correlación que deben ser procesadas por la etapa de cómputo.

La implementación de las operaciones de generación de réplicas y cálculo de correlaciones mediante lógica especialmente dedicada a esta función permite reducir considerablemente la carga del procesador de la etapa de cómputo, el cual de esta forma solamente necesita operar en tiempo real sobre las muestras de correlación que se generan con tasas de entre $100 \mathrm{~Hz}$ y $1000 \mathrm{~Hz}$, en lugar de tener que hacerlo directamente sobre las muestras de señal que provienen de la etapa de conversión A/D a $20 \mathrm{MHz}$.

El hardware de correlación se encuentra dividido en dos grandes módulos de funcionalidad especializada, destinados específicamente a las tareas de adquisición de señal y de seguimiento. Ver Figura 5.4. El diseño fundamental en ambos casos es similar, estando ambos formado por canales de correlación como los vistos en la Sección 3.6. Las diferencias entre ambos módulos se encuentran en el balance de recursos asignados internamente a diferentes operaciones, ya que en cada caso los módulos han sido adecuados a las diferentes necesidades de los procesos respectivos. 


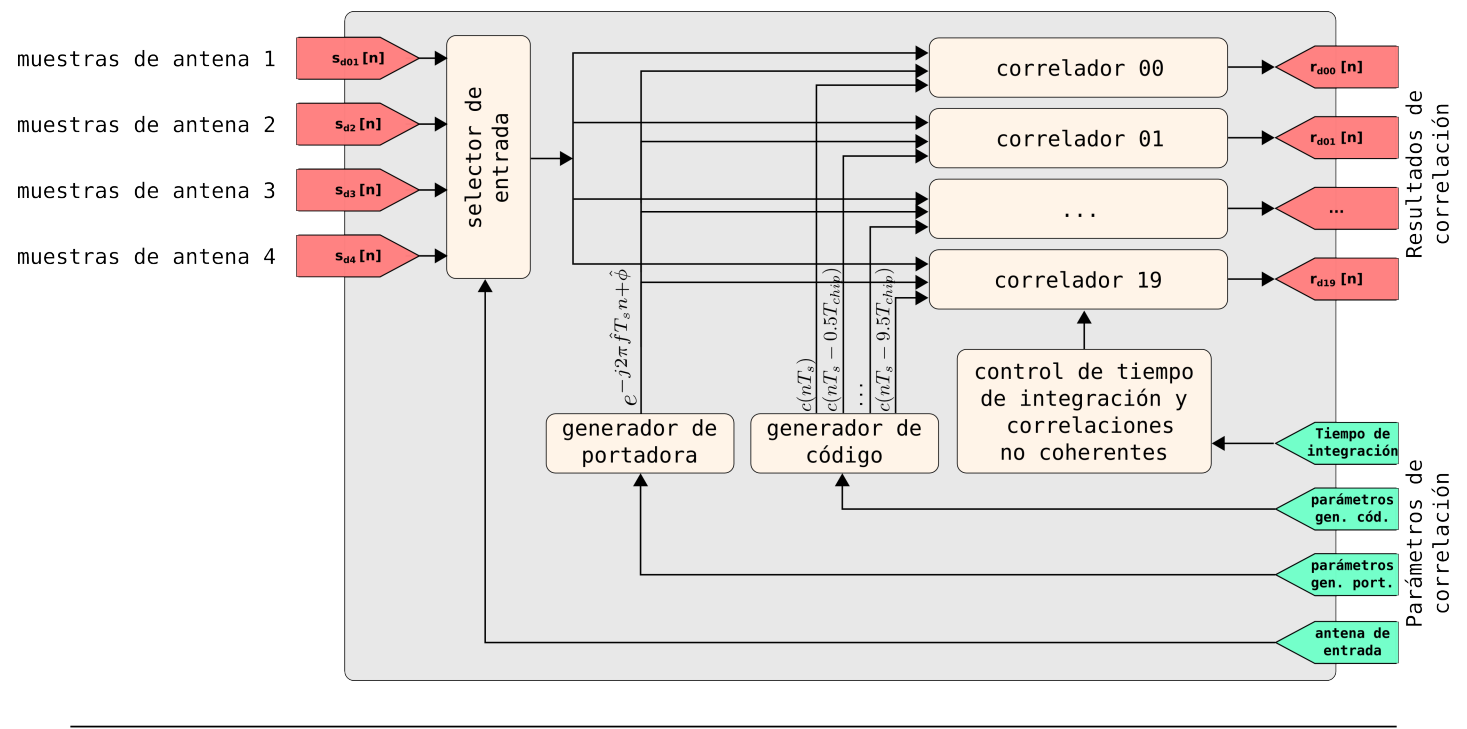

FigurA 5.5: Canal de adquisición multiantena.

\subsubsection{Módulo de adquisición}

El módulo de adquisición se encuentra formado por un único canal de adquisición. Este canal está formado por un conjunto de 20 módulos de correlación, un generador de réplica de código, un generador de réplica de portadora y un selector de antena de entrada. Un diagrama simplificado de la organización interna del canal de adquisición puede verse en la Figura 5.5. Esta configuración permite ejecutar el proceso de adquisición de una única señal por vez, por lo que la adquisición de múltiples señales debe realizarse necesariamente de forma secuencial.

El generador de código sintetiza réplicas de la función de código para todos los módulos de correlación, espaciadas entre ellas a intervalos de medio tiempo de chip. La utilización de veinte correladores en paralelo permite acelerar el proceso de recorrido del plano retardo-frecuencia, al examinar múltiples celdas del mismo de forma simultánea. Para ello se agrupan las celdas en grupos de veinte, todas de un mismo valor de frecuencia portadora y todas con valores de retardo de código consecutivos entre si a intervalos de medio chip.

El generador de código es capaz de sintetizar las funciones de código GPS o GLONASS de forma configurable. Las secuencias son generadas de forma discreta utilizando un NCO (Numerically Controlled Oscilator) conectado en cascada con un generador de secuencias configurable. El NCO puede configurarse para generar una señal de avance de chips de tasa y fase inicial configurables, la cual a su vez se utiliza para hacer avanzar el generador de funciones de código. Este último es un sistema configurable capaz de funcionar ya sea como el generador de código utilizado en el sistema GPS (ver Figura 2.7) o como el de GLONASS (ver Figura 2.10). 
La réplica de portadora compleja se genera utilizado un segundo generador, formado a su vez por otro NCO y por un par de tablas de look-up. La tasa de avance del NCO se configura para que su acumulador haga roll-over con la frecuencia de la portadora que se quiere generar, mientras que el valor inicial del acumulador establece la fase inicial (al comienzo de un tiempo de integración) de esta última. Una vez puesto en funcionamiento el valor instantáneo del acumulador del NCO es proporcional a la fase instantánea de la portadora. A medida que el NCO avanza, el valor del acumulador se utiliza para entrar en dos tablas de look-up que convierten este valor en la amplitud de una sinusoide discretizada; una de las tablas corresponde a una función coseno mientras que la otra mapea una función seno. Estas salidas se utilizan para formar las partes real e imaginaria de la exponencial compleja discreta sintetizada, $\exp ^{-j 2 \pi f \hat{f} T_{s} n+\phi}$.

El módulo de adquisición no cuenta con la posibilidad de procesar de forma simultánea las cuatro antenas de entrada. En lugar de ello el canal de adquisición tiene un multiplexor a su entrada que permite seleccionar una de las cuatro antenas para su procesamiento. Esta restricción intrínseca al diseño impone la necesidad de utilizar alguna de las dos técnicas de búsqueda multiantena, secuencial o entrelazada, que fueron comentadas en la Sección 4.4.3.1.

La lógica de control del canal de adquisición permite dos modos de operación alternativos, correspondientes a la realización de correlaciones convencionales (coherentes) y correlaciones no coherentes. Cuando el dispositivo se encuentra en modo de realización de correlaciones coherentes el tiempo de integración se especifica mediante un único número (el tiempo de integración utilizado), y los resultados de correlación se encuentran expresados en forma de valor complejo con partes real e imaginaria.

El modo no coherente consiste en la acumulación de los módulos al cuadrado (energía) de los resultados de varias correlaciones coherentes consecutivas. El tiempo de integración entonces debe especificarse por dos parámetros: el intervalo de integración coherente, y la cantidad de repeticiones no coherentes. La utilización de correlaciones no coherentes tiene el beneficio de brindar al resultado de cierto grado de inmunidad frente a la modulación de datos presente en la señal, aunque al costo de una pequeña degradación de la relación SNR en la capacidad de detección [24]. En este modo de operación el resultado está dado como el valor acumulado total de las energías de las correlaciones coherentes realizadas, un valor estrictamente real y sin ninguna información de fase.

La ejecución de una correlación comienza con la configuración de sus parámetros desde la computadora central del receptor. Los parámetros necesarios pueden resumirse en

- Sistema a operar: GPS o GLONASS. 


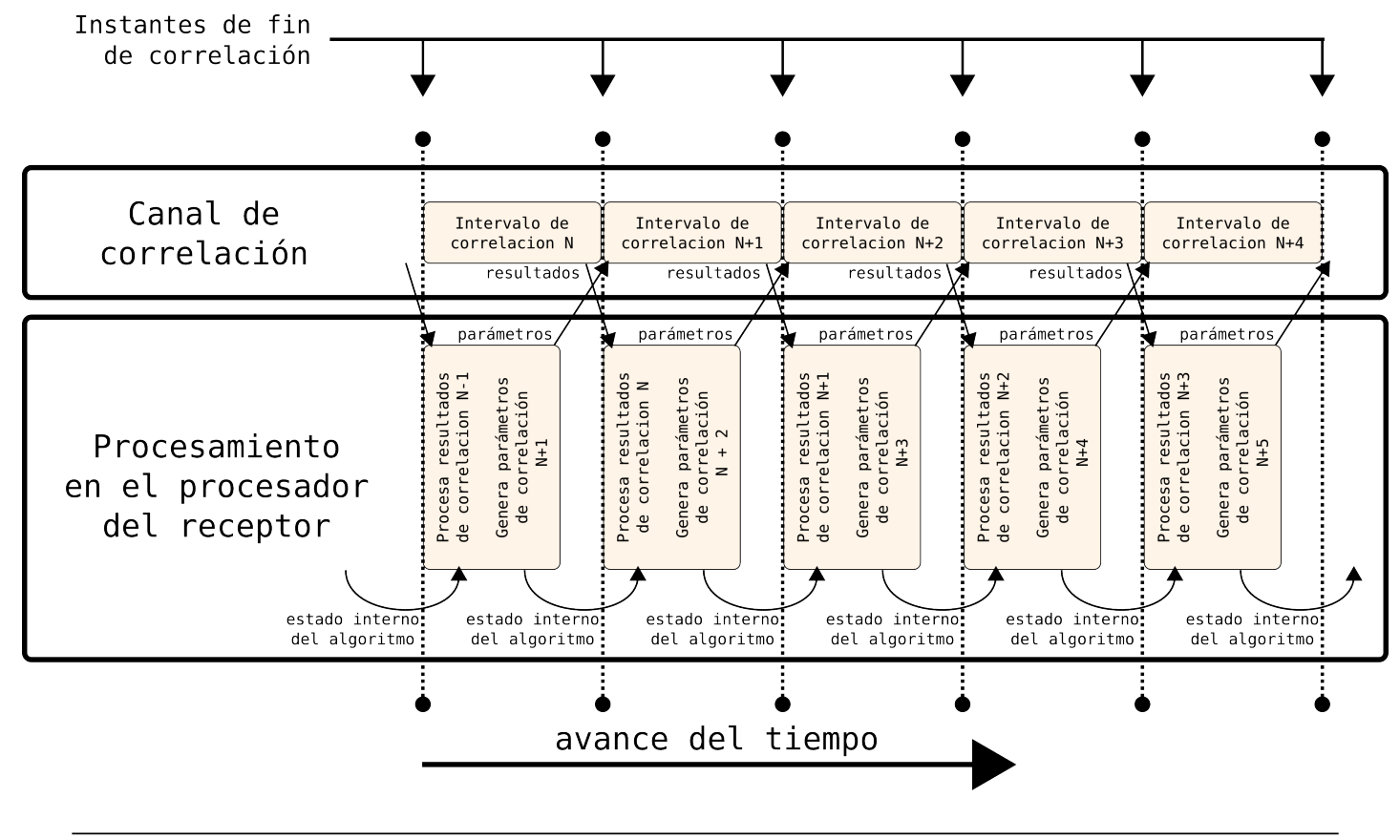

Figura 5.6: Entrelazado entre intervalos de correlación y de procesamiento.

- Parámetros de portadora

- Frecuencia de la réplica de portadora.

- Fase inicial de la réplica de portadora.

- Parámetros de función de código

- Tasa de chips de la réplica de código.

- Estado inicial del generador de código (GPS o GLONASS) y fracción sub-chip de la fase.

- Tiempo de integración

- Modo de operación del correlador: coherente o no coherente.

- Tiempo de integración coherente.

- Cantidad de repeticiones no coherentes.

- Antena de entrada.

Dado que el procesamiento de una tanda de resultados de correlación es una operación que toma una cantidad finita de tiempo de cómputo, este procesamiento se realiza en paralelo con el cálculo de la tanda de correlaciones siguientes. De esta forma el canal de adquisición se encuentra en operación permanente. El costo de esta eficiencia se encuentra en el software, cuya complejidad se ve incrementada debido a que en efecto en todo momento existen tres correlaciones en juego: 
- La correlación cuyos parámetros están siendo generados, para ser procesada dentro de dos intervalos de correlación.

- La correlación que está siendo calculada en hardware.

- Los resultados de la correlación cuyos parámetros se generaron dos intervalos de correlación atrás.

En la Figura 5.6 se representó esquemáticamente esta forma de procesamiento. Esto no es exclusivo de los correladores del módulo de adquisición, sino que también es una cualidad de los correladores de seguimiento, aunque su impacto es más visible en los primeros que en los segundos. Se verá el impacto de esta naturaleza entrelazada de las ejecuciones de las integraciones con los ciclos de procesamiento de las mismas en el Capítulo 7 al discutir los algoritmos de adquisición del receptor multiantena.

\subsubsection{Módulo de seguimiento}

El módulo de seguimiento se encuentra compuesto por doce canales de correlación independientes. Cada uno de estos canales cuenta con todos los recursos necesarios para realizar el procesamiento por correlación de una señal GNSS independiente: doce módulos de correlación, un generador de réplica de código y un generador de réplica de portadora.

A diferencia de lo que ocurre con el canal de adquisición visto anteriormente, cada canal de seguimiento cuenta con cuatro grupos de tres correladores, cada uno asociado a una antena de entrada del receptor. Ver Figura 5.7. Cada grupo de tres está formado por un correlador Early, un correlador Punctual y un correlador Late. La separación entre los mismos es configurable, permitiendo de esa forma la implementación de esquemas de seguimiento de tipo Narrow Correlator [3].

Los receptores convencionales sincronizan los intervalos de integración de cada canal activo de forma tal que los flancos de la modulación de datos de la señal coincidan siempre con los instantes de final/comienzo de correlación del canal que la procesa. Esto tiene la finalidad de evitar la degradación en la relación SNR de la muestra que sería ocasionada por una inversión de la fase de señal durante el intervalo integrado en la correlación. Este tipo de alineamiento forzado restringe los tiempos de correlación que pueden ser utilizados en seguimiento a valores que dividan de forma entera el intervalo entre flancos de la modulación presente (20 ms en GPS y 10 ms en GLONASS). Además, debido a que los alineamientos de los mensajes de bits de diferentes satélites transmisores son diferentes (dependen de la distancia del satélite hasta el receptor), esta modalidad de trabajo implica que las integraciones de unos y otros canales de seguimiento comiencen y terminen de forma asíncrona unas de otras. 


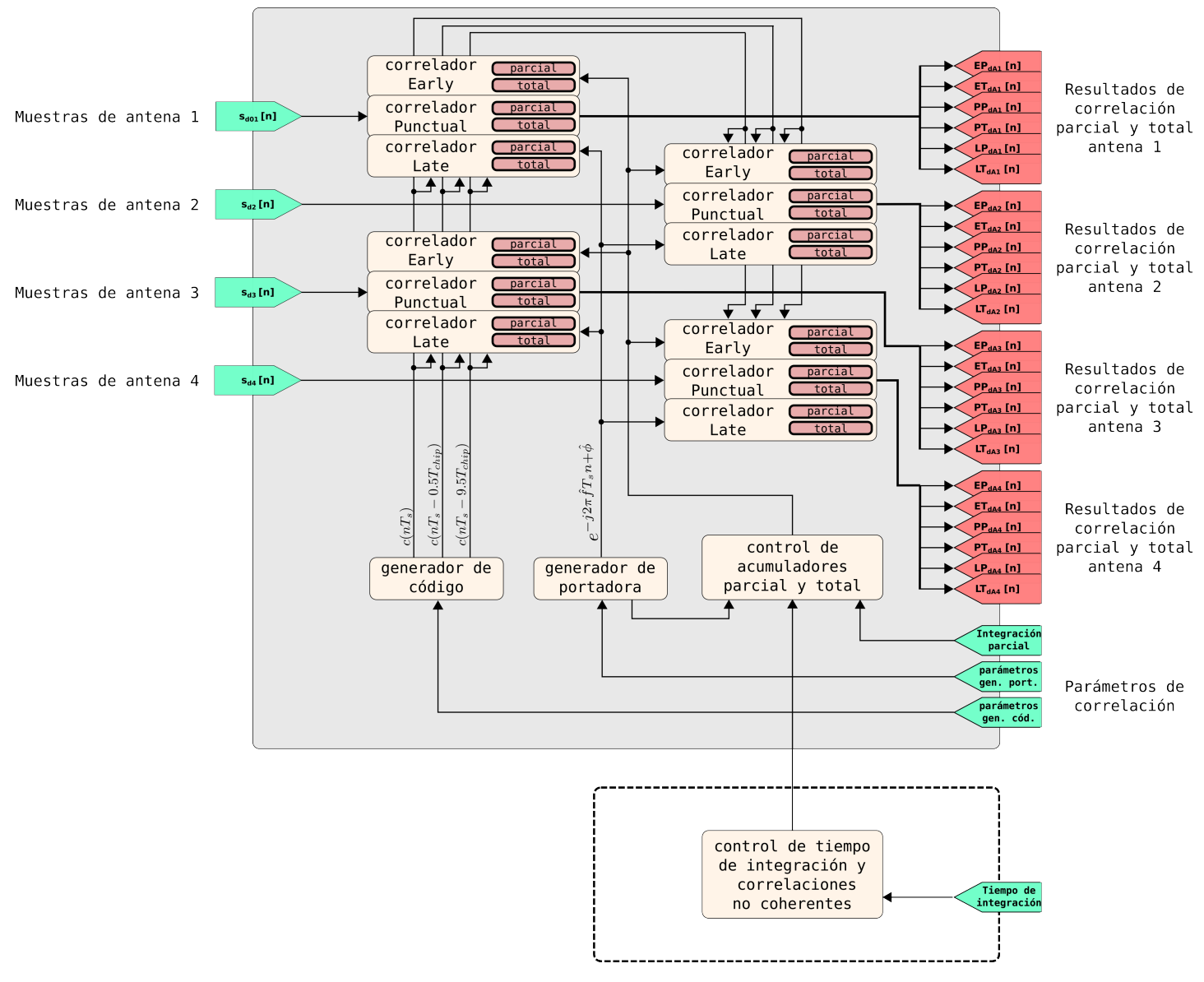

FigurA 5.7: Canal de seguimiento multiantena.

La etapa de correlación multiantena utiliza una filosofía diferente en el prototipo que se está discutiendo: todos los canales de correlación intervalos de integración sincrónicos, de forma tal que los intervalos de correlación de todos ellos comienzan y terminan siempre juntos. La configuración del tiempo de correlación es por lo tanto un parámetro común a todos los canales, tal como se ve en la Figura 5.7.

Por supuesto, esta sincronicidad no permite en principio la alineación de los intervalos de integración de los canales activos con los pulsos del mensaje de navegación modulado en las señales que tienen asignadas. En lugar de esto se utiliza un mecanismo denominado de bit partido donde cada uno de los doce módulos de correlación por canal genera dos valores de correlación complejos (cada uno con partes reales e imaginaria): un valor de correlación parcial y otro de correlación total. [48]

El valor de correlación denominado total es equivalente al valor complejo generado por un módulo de correlación convencional, igual al valor de la correlación integrada durante la totalidad del intervalo de largo $T_{I}$. 

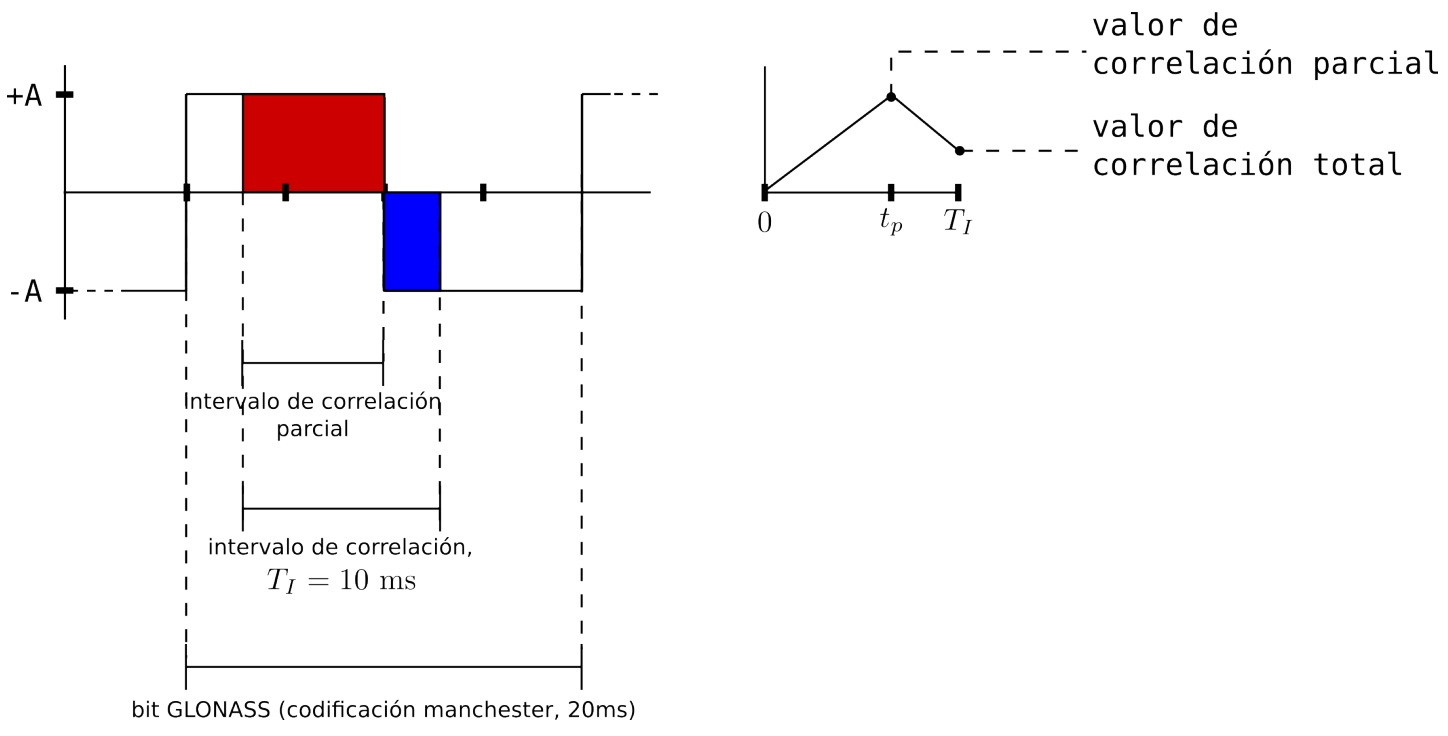

FiguRA 5.8: Diagrama de demostración de la obtención de correlaciones parcial y total para minimizar el impacto de las transiciones de fase del mensaje de navegación en el valor integrado. A los fines de la demostración, en la figura se muestra el caso de la integración de una señal real, pero se puede extrapolar trivialmente al caso complejo.

El valor de correlación parcial, por otro lado, corresponde al valor de la integral en algún instante intermedio $t_{p}$ durante el intervalo de correlación (es decir, $t_{p}<T_{I}$ ). El instante $t_{p}$ se configura junto con los demás parámetros de la correlación a partir del conocimiento que tiene el receptor del alineamiento relativo entre los intervalos de correlación y de los pulsos que forman el mensaje de navegación.

La relación entre los valores de correlación parcial y total pueden verse más claramente en la Figura 5.8. Allí se ejemplifica un caso típico con un mensaje de navegación de formato GLONASS (codificación Manchester, con tasa de bits de 50 bps), y la realización de una integración de 10 ms no alineada con los flancos del mensaje de navegación. Esto modela exactamente lo que ocurriría en la rama real (en fase) de un correlador cuando el error en las estimaciones de fase y frecuencia de portadora y de retardo de función de código son despreciables. La extensión del ejemplo a un caso más general es trivial.

En la figura anterior se puede ver que la presencia de una inversión de signo debida a los pulsos de la codificación del mensaje de navegación ocasiona una cancelación parcial de la energía de señal en el valor de la correlación debido al cambio de signo de la señal integrada durante el intervalo de correlación. En presencia de ruido esto provoca una caída en la relación SNR resultante, con un peor caso que ocurre cuando el cambio de signo es equidistante de ambos extremos del intervalo de integración y por lo tanto la cancelación de energía es completa. 
Puede ocurrir que en la posición de un dado flanco de bit del mensaje de navegación no ocurran inversiones de fase de la señal, porque la secuencia de bits transmitidos por el satélite se asume aleatoria, con bits independientes y equiprobables, y por lo tanto cualquier bit tiene un $50 \%$ de probabilidades de tomar el mismo valor que el bit anterior. En el caso de la modulación Manchester en el flanco que ocurre en mitad de un tiempo de bit siempre ocurrirá una inversión del signo de la señal de datos debido a la forma del pulso utilizado, pero en los flancos que se encuentran entre dos bits diferentes esta inversión sólo tendrá una probabilidad de ocurrencia del $50 \%$.

La utilización de la técnica del bit partido permite al receptor contar con datos suficientes para reconstruir los valores de las áreas anterior y posterior al flanco de bit (respectivamente roja y azul en la figura). La primera es idénticamente igual al valor de la correlación parcial. La segunda en cambio se calcula restando al valor de correlación total la correlación parcial. El receptor puede entonces rectificar ambas áreas y sumarlas coherentemente, eliminando así el efecto del mensaje de navegación ${ }^{1}$

Los parámetros de las correlaciones de seguimiento son semejantes a los utilizados para el correlador de adquisición:

- Sistema a operar: GPS o GLONASS.

- Parámetros de portadora

- Frecuencia de réplica de portadora.

- Fase inicial de réplica de portadora.

- Parámetros de función de código

- Tasa de chips de réplica de código.

- Estado inicial del generador de código (GPS o GLONASS) y fracción sub-chip de la fase.

- Separación entre señales Early, Punctual y Late.

- Tiempo de integración.

- Duración del tiempo de correlación total. Como se mencionó anteriormente este parámetro es común a todos los canales de seguimiento.

- Duración de la correlación parcial.

\footnotetext{
${ }^{1}$ Vale mencionar en este punto que la elección de utilizar correlaciones parciales y totales en lugar de generar directamente en el correlador los valores pre y post flanco fue de pura conveniencia. La generación directa de las correlaciones pre y post en el hardware del correlador hubiera requerido una operación de salvado del valor del acumulador y una reinicialización del mismo en $t_{p}$, mientras que las correlaciones parciales y totales sólo requieren el salvado, por lo que reduce la cantidad de casos esquina que es necesario contemplar en el diseño lógico del correlador discreto.
} 
Un conjunto de parámetros como el anterior debe ser configurado por cada canal de seguimiento activo.

Por último, puede comentarse que tal como ya fue discutido al hablar del módulo de adquisición, para los canales del módulo de seguimiento existe también una relación diferida entre las correlaciones y los intervalos de procesamiento como la de la Figura 5.6 .

\subsection{Etapa de cómputo}

La etapa de cómputo del receptor está formada por una computadora, memoria y dispositivos de entrada/salida.

El procesador del sistema es un procesador LEON 3. Éste es una implementación de la arquitectura Sparc V8 especialmente pensada para su utilización en sistemas críticos. El procesador en sí mismo es un soft-core, es decir un procesador definido en un lenguaje de descripción de hardware. El LEON 3 forma parte de una librería de módulos IP (del inglés Intellectual Property, denominación de módulos lógicos complejos pre-diseñados) llamada GRLIB.

La librería GRLIB se encuentra orientada al diseño de Systems-On-Chip (SoC) sintetizables en dispositivos lógicos reprogramables (FPGAs, CPLDs, etc). La gama que dispositivos incluidos en la librería incluye, sin agotar la lista, dispositivos de comunicaciones (UARTs, I2C, Firewire, Ethernet), controladores de memoria SRAM y DRAM, controladores de memorias Flash, controladores de interrupciones, módulos de interfaz de propósito general, módulos de depuración del sistema, y muchos otros módulos prediseñados.

A partir de estos módulos fundamentales el diseñador puede sintetizar un SoC a medida de sus necesidades, pudiendo no solamente seleccionar los módulos IP que formarán parte del mismo sino también configurar los parámetros de funcionamiento de los mismos. El mismo procesador LEON 3 cuenta con una multitud de configuraciones posibles que permiten ajustar sus características en función de la tarea y de los recursos lógicos disponibles: tamaño de caches de datos y programa, política de renovación de las caches, implementación de multiplicación por hardware, implementación de instrucciones MAC (Multiply/ACcumulate) en el repertorio, cantidad de ventanas de registros, cantidad de ciclos que toma una carga de memoria, presencia y modalidad del predictor de saltos, etc. 
La versión comercial de la GRLIB agrega la posibilidad de utilizar versiones tolerantes a fallas de algunos módulos clave, como el procesador LEON 3 y los controladores de memoria. Estas versiones tolerantes se diferencian por contar con detección y corrección de errores en memoria y en bancos densos de registros. La implementación de un sistema basado en estos módulos sobre un dispositivo lógico programable que sea tolerante a altas dosis de radiación resulta en sistemas con un alto nivel de confiabilidad que pueden ser utilizados en misiones de tipo aeroespacial o terrestre nuclear. Sistemas completos como estos, formados por un SoC sintetizado en una FPGA tolerante a radiación, pueden ser diseñados a medida o adquiridos directamente de Aeroflex-Gaisler.

El sistema de procesamiento se desarrolló utilizando la versión no comercial de la librería GRLIB, instanciando un sistema basado en el procesador LEON 3, un controlador de memoria, una UART de comunicación, y los módulos de soporte y depuración necesarios para la puesta en marcha del sistema.

El dispositivo correlador descripto en la Sección 5.3 fue integrado mediante una interfaz directa con el bus $A M B A$ que que comunica todos los módulos entre sí. De esta forma se mapearon todos los registros de configuración y datos del correlador en un rango de direcciones del mapa de memoria del procesador.

El sistema resultante fue sintetizado y programado en la FPGA de un kit de desarrollo Altera DE2-110 de la firma Altera. Este kit provee módulos de memoria Flash, SRAM, DRAM y transceivers para los puertos de comunicación y depuración que completan el sistema. A través de los puertos de propósito general del kit de desarrollo se estableció la comunicación con la etapa de acondicionamiento y muestreo, implementada en una serie de placas dedicadas.

La computadora del sistema fue alimentada con un reloj de $40 \mathrm{MHz}$ derivado de la misma referencia temporal utilizada por las dos etapas de procesamiento anteriores: acondicionamiento y procesamiento de alta tasa.

\subsection{Sistema completo}

En la Figura 5.9 puede verse una imagen del prototipo del hardware de receptor multiantena completamente ensamblado.

En primer plano se puede ver el kit de desarrollo Altera que alberga la computadora del receptor junto con la etapa de correlación multiantena, así como todo el hardware auxiliar necesario para los canales de programación y comunicación entre el receptor y el exterior. 


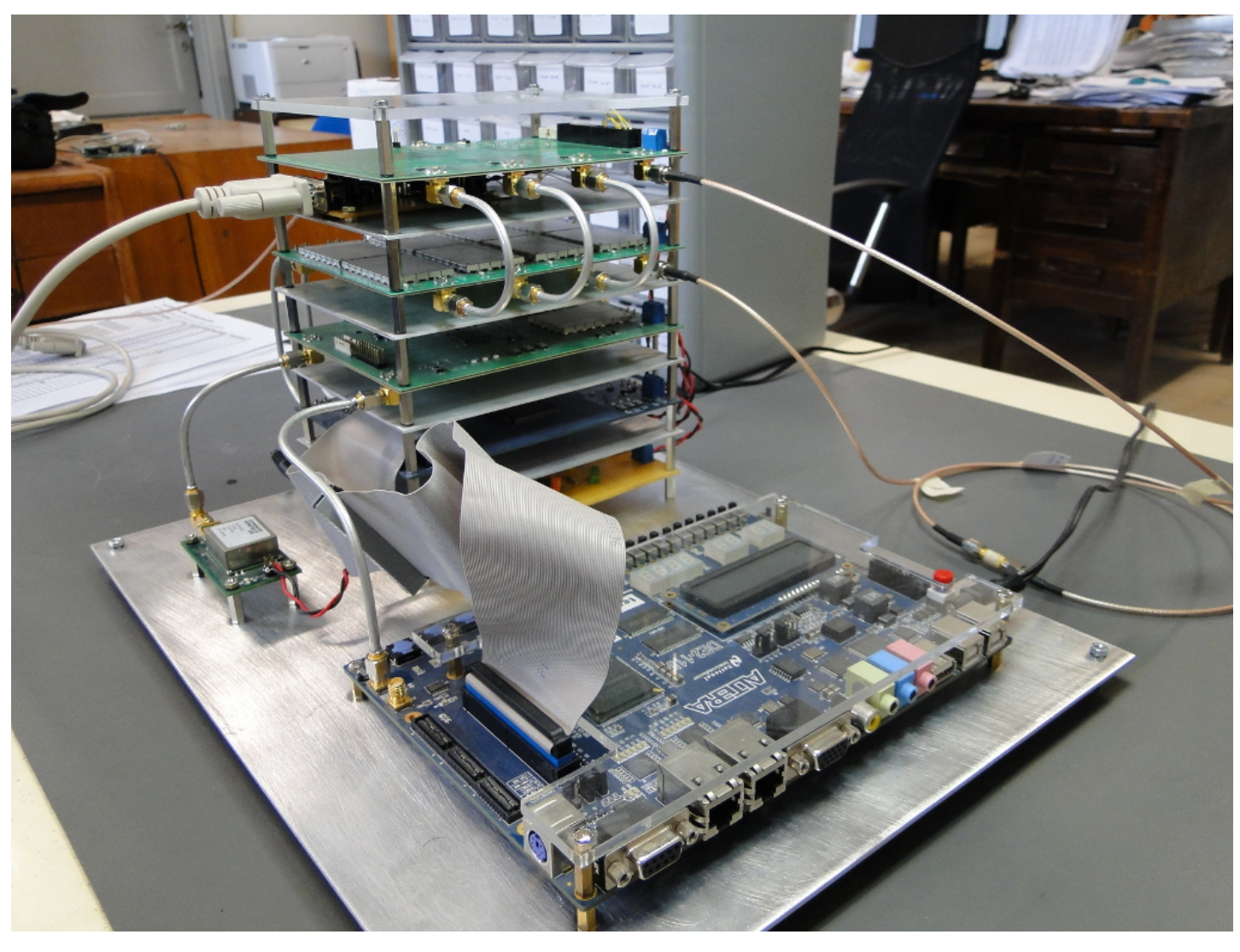

FiguRA 5.9: Foto del prototipo del hardware del receptor completamente ensamblado.

En segundo plano, y conectado al kit de desarrollo mediante un cable plano de cuarenta pines, se ve el conjunto de placas de circuito impreso que forma el sistema de acondicionamiento de señal y muestreo. Comenzando de abajo hacia arriba las placas visibles corresponden a:

1. Regulación de tensiones de alimentación (placa amarilla).

2. Conversión A/D (placa azul).

3. Síntesis de frecuencias (placa verde inferior).

4. Acondicionamiento y bajada a frecuencia intermedia (placa verde central).

5. Cuadruplexor de ganancias programables (placa verde superior).

Esta última placa no forma parte del prototipo en sí mismo, sino de los sistemas de depuración y soporte auxiliares, permitiendo la simulación de múltiples antenas de entrada a partir de una única entrada real.

Por último, abajo a la derecha de la imagen puede observarse el oscilador OCXO (OvenControlled Cristal Oscilator) de referencia de todas las frecuencias del sistema. 


\subsection{Resumen de capítulo}

A diferencia de lo que ocurre con otros tipos de sistemas de comunicación, la interpretación y utilización de señales GNSS tiene la característica de requerir que el receptor combine información de la señal correspondiente a una gran cantidad de niveles de estructura diferentes, desde la fase de sus señales componentes hasta los parámetros obtenidos por demodulación de su mensaje de datos.

Dado que por razones de eficiencia buena parte del procesamiento por correlación de la señal se realiza mediante la utilización de hardware específicamente dedicado a tal fin, las características de este último terminan determinando en buena medida las posibilidades y limitaciones de las capas de procesamiento superiores.

Este capítulo se concentró en la descripción de las características del hardware del prototipo de receptor GPS/GLONASS multiantena sobre el que se basará la implementación de los algoritmos presentados en los capítulos siguientes. Se presentaron las características de cada una de las capas de procesamiento, comenzando por las de procesamiento analógico de la señal, las características del muestreo digital, el sistema de correlación multiantena, y por último se presentó brevemente las características del sistema de cómputo que gobierna el receptor.

El conocimiento de esta información es imperativo para el desarrollo de estrategias de procesamiento de señal adecuadas, ya que las características del hardware son en definitiva también condiciones de contorno que deben reconocer todos algoritmos que forman parte del software del receptor. 



\section{Capítulo 6}

\section{Algoritmos de Seguimiento Multiantena}

\subsection{Introducción}

Este capítulo presenta los algoritmos relacionados con el seguimiento de señales GNSS desarrollados como parte de esta tesis. El capítulo siguiente se dedica a los algoritmos de adquisición de señales para el receptor multiantena.

Esta inversión en el orden natural de los temas obedece a la intención de minimizar la repetición de contenidos, ya que en las últimas etapas de la adquisición se lleva a cabo la tarea de sincronización, la cual funciona sobre la base de un esquema de seguimiento de señales con lazos de portadora y código similares a los utilizados en los algoritmos de seguimiento. Introduciendo los algoritmos de seguimiento antes que los de adquisición permite entonces profundizar ahora en el diseño de lazos, y llegado el capítulo de adquisición presentar solamente las características más relevantes de los lazos utilizados para sincronización.

Se dará inicio al capítulo con una presentación de la arquitectura general del sistema de seguimiento, su conformación en tareas, la distribución de funciones entre las mismas, y las definiciones fundamentales que serán utilizadas posteriormente. Seguirán a esto una descripción del diseño de los lazos de seguimiento utilizados, tanto de portadora como de código, y las relaciones entre ambos (asistencia y detección de falsos enganches de frecuencia). Se cerrará el capítulo con una breve descripción del funcionamiento de la tarea de seguimiento de bajo nivel. 


\subsection{Arquitectura general del sistema de seguimiento}

$\mathrm{Al}$ igual que ocurre con los receptores convencionales, el sistema de seguimiento se encuentra dividido en una serie de canales de procesamiento, los cuales se encuentran formados por una parte en software y otra en hardware. En hardware cada canal está formado por un canal de correlación de seguimiento de los ya descriptos en la Sección 5.3.2. En software está conformado por un conjunto de algoritmos y por el estado de los mismos. La información de estado asociada al seguimiento de cada señal particular consiste de la identidad de la señal, la estimación actual de frecuencia portadora, la estimación actual de fase de portadora y de código, el estado interno de los filtros de lazo, etc.

En el modelo actual del prototipo de receptor existen doce canales de seguimiento, uno por cada canal de correlación de seguimiento de los que dispone el hardware. Cada uno de estos canales puede encontrarse en dos estados:

Inactivo El canal no tiene ninguna señal de satélite asignada. Su estado es por lo tanto nulo y no requiere de tiempo de procesamiento.

Activo El canal tiene una señal asignada. Los algoritmos de seguimiento deben procesar las muestras de correlación generadas cada $10 \mathrm{~ms}$ para actualizar el estado del canal y generar los parámetros de la correlación siguiente.

El conjunto de algoritmos utilizados para seguimiento de señales se encuentra dividido fundamentalmente en dos tareas de ejecución periódica, que se distribuyen entre ellas las actividades necesarias para el seguimiento de todos los canales de seguimiento activos. La primera de estas tareas recibe el nombre Tarea de Seguimiento Superior (o TSS) mientras que la segunda es la Tarea de Seguimiento Inferior (TSI).

La denominación superior e inferior en este contexto hace referencia a la frecuencia relativa de ejecución de una y otra, que a su vez determina el nivel de prioridad de ejecución dentro del conjunto de tareas administradas por el sistema operativo que da sustento al software del receptor. La TSS tiene un nivel de prioridad de ejecución superior a la TSI, que tiene una frecuencia de ejecución mucho menor que la primera.

Un diagrama simplificado de la estructura del conjunto de algoritmos necesarios para llevar a cabo el seguimiento de señales GNSS multiantena puede verse en la Figura 6.1. La perspectiva de dicha figura es la de un único canal de seguimiento, pero en la realidad ambas tareas deben realizar cada una de las operaciones indicadas en la gráfica para cada uno de los canales que se encuentren activos en un momento dado. 
Tarea de Seguimiento Superior (ejecución cada 10ms)
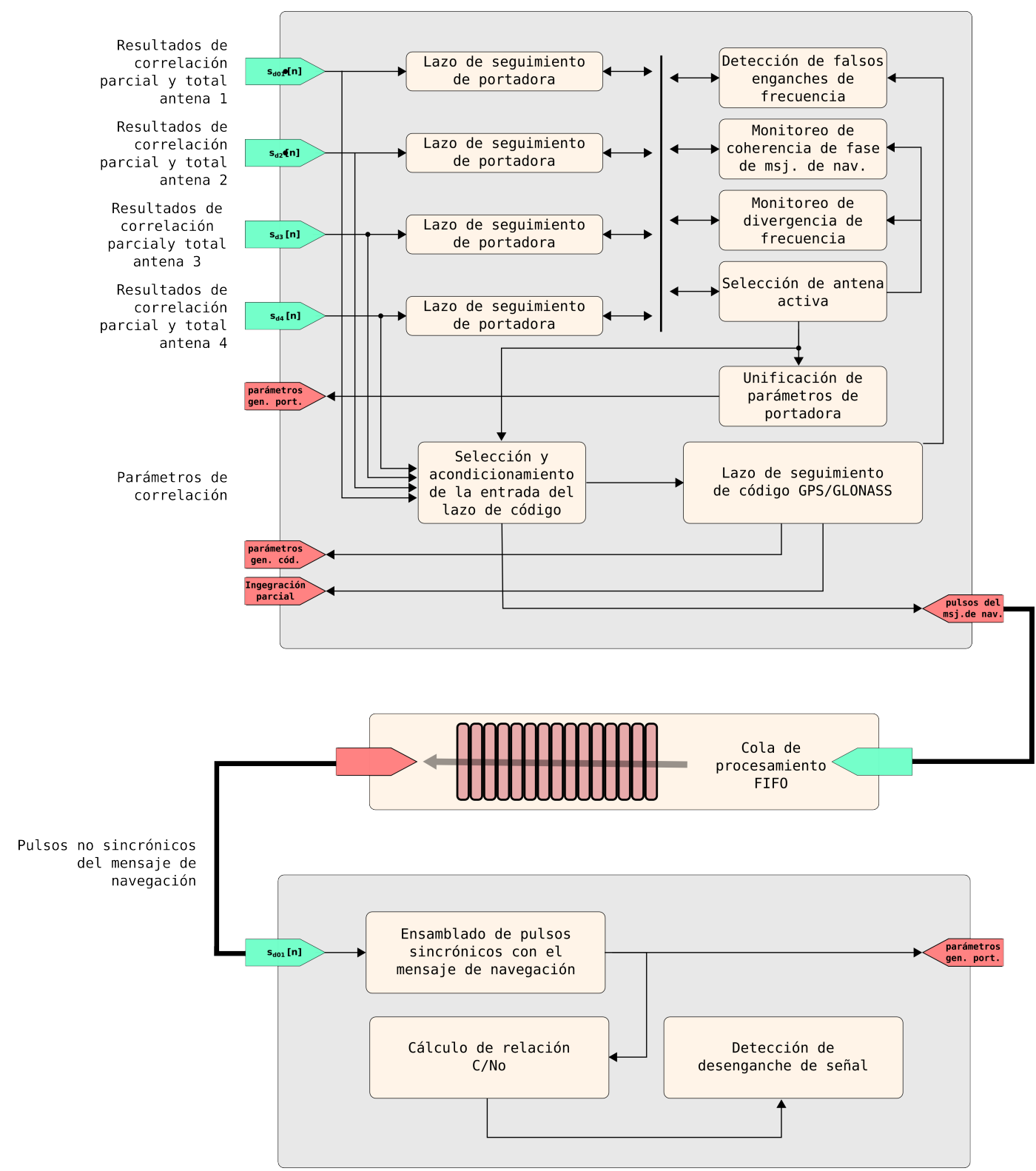

Tarea de Seguimiento Inferior (Ejecución cada 250ms)

Figura 6.1: Diagrama simplificado de la relación entre las tareas de seguimiento superior e inferior, y la arquitectura interna de ellas.

\subsubsection{Actividades de la TSS}

La TSS es activada periódicamente por la interrupción de fin de correlación generada por el hardware. Los tiempos de correlación utilizados actualmente son de $10 \mathrm{~ms}$, por lo que la TSS se ejecuta 100 veces por segundo. Durante cada activación la TSS ejecuta 
los algoritmos de seguimiento de cada uno de los canales que se encuentran activos, actualizando el estado de los lazos de seguimiento y las estimaciones de los parámetros de la señal, generando mediciones de navegación, y encolando un subconjunto de los resultados de correlación para su procesamiento posterior en la TSI.

\subsubsection{Seguimiento multiantena}

La principal característica que distingue a los algoritmos de seguimiento multiantena presentados como parte de esta tesis de los utilizados en los receptores más convencionales es la utilización de múltiples lazos de seguimiento de portadora, uno por cada una de las antenas de entrada.

Tal como ya se estableció en 4.4.3.2, existirán diferencias tanto en la fase como en la frecuencia instantánea de portadora percibida por cada una de las antenas. La utilización de múltiples lazos PLL de seguimiento de portadora permite establecer los parámetros de la señal en cada una de las antenas de forma individual.

El funcionamiento de cada uno de los lazos de portadora no está condicionado por la existencia de señal en la antena de entrada asociada al mismo, ya que no se realiza detección de la presencia de señal. En lugar de eso, los cuatro PLLs funcionan de forma incondicional siempre procesando las muestras que tienen a su entrada, ya sea que exista o no señal en las mismas. Como consecuencia de este modalidad de trabajo aquellos lazos asociados a antenas con línea de vista hacia el satélite transmisor se encontrarán efectivamente enganchados con la señal recibida, mientras que los lazos restantes evolucionarán aleatoriamente debido a que su entrada consiste fundamentalmente de ruido.

\subsubsection{Selección de antena activa}

El submódulo de selección de antena activa determina cuál de las cuatro antenas de entrada al receptor cuenta con la mayor potencia de correlación instantánea (correspondiente a la muestra actual). Esta antena recibe entonces el rol de Antena Activa, mientras que las restantes asumen el rol de Antenas Pasivas. La antena activa es utilizada como entrada para el lazo DLL de seguimiento de código y para la demodulación del mensaje de navegación. La designación de determinada antena en el rol de antena activa es solamente transitoria, repitiéndose el proceso de selección para en cada ciclo de activación de la TSS.

La utilización de módulos de AGC en cada una de las cadenas de las antenas de entrada tiene un efecto igualador de la potencia de ruido total de las muestras discretas en las cuatro antenas. Dado que la potencia de ruido y el ancho de banda equivalente de las 
señales muestreadas que ingresan desde los cuatro convertidores A/D son iguales, entonces una comparación en términos de la amplitud de señal equivale a una comparación de las relaciones $C / N_{o}$ de la señal. El criterio de seleccionar la antena con mayor potencia de correlación por lo tanto equivale a elegir la antena que recibe la señal con la relación $C / N_{o}$ más alta.

Este criterio de selección de la antena activa en virtud de su potencia de correlación instantánea y sin verificación objetiva de la presencia de una señal en dicha antena funciona bajo el supuesto de que siempre al menos una de las cuatro antenas de entrada está expuesta a la señal GNSS procesada. Dado que en condiciones de enganche de los lazos la probabilidad de que la potencia instantánea de una antena no expuesta supere a la potencia instantánea de una antena expuesta es despreciable, se garantiza entonces que la antena activa elegida con el criterio anterior siempre será una antena de entrada con señal procesable.

El sistema operando de esta forma es vulnerable a la situación de extinción de la señal del satélite cuando se produce la pérdida total de potencia de correlación en las cuatro antenas simultáneamente. El tratamiento de esta situación se encuentra cubierto por los mecanismos de detección de desenganche que se llevan a cabo en la TSI, la cual tiene entre sus funciones obtener una estimación promediada de la relación $C / N_{o}$ de la señal a través de cada una de las cuatro antenas y utilizarla para detectar la condición de desenganche si los niveles son insuficientes en todas las antenas simultáneamente.

\subsubsection{Monitoreo de divergencia de los estimadores de frecuencia}

Este submódulo se encarga de vigilar la evolución de los estimadores de las antenas auxiliares para acotar la dispersión máxima de sus estimaciones de frecuencia. Esto es necesario por dos razones.

La primera está relacionada con el discriminador de fase utilizado en los lazos de seguimiento PLL, el discriminador UFA (Unambiguous frequency Aided). Se posterga la discusión del discriminador hasta que se discuta el diseño de los lazos PLL en la sección 6.3.1.2, pero a los fines de la discusión presente puede adelantarse que este discriminador tiene un rango de operación lineal acotado en frecuencia. Para su correcto funcionamiento es necesario que se cumpla la condición:

$$
\left|f_{c}-\hat{f}_{c}\right|<\frac{1}{4 T_{I}}
$$


donde $T_{I}$ es el tiempo de correlación utilizado. En el caso presente, con $T_{I}=10 \mathrm{~ms}$, la cota máxima de error de la estimación de frecuencia para mantener el discriminador de fase dentro de su rango de operación es $\left|f_{c}-\hat{f}_{c}\right|<25 \mathrm{~Hz}$.

La segunda razón proviene de la necesidad de garantizar un transitorio de enganche rápido en las antenas desenganchadas. La condición de enganche o desenganche de los PLLs de las cuatro antenas de entrada es una circunstancia transitoria, que irá evolucionando con las alternativas de movimiento y cambios de orientación del vehículo respecto de la dirección de arribo de la señal. Una vez garantizada la linealidad del comportamiento de los lazos de seguimiento de fase mediante el cumplimiento de la condición de operación lineal del discriminador UFA, un lazo libre será capaz de alcanzar el enganche con la señal de interés tan pronto el nivel de SNR en la antena alcance el mínimo de operación. Esta transición ocurrirá gradualmente mediante un transitorio que hará converger los valores aleatorios de la estimación de frecuencia y fase de portadora del lazo desenganchado a los valores reales de estos parámetros en la señal recibida. Esta convergencia será más rápida cuanto menor sea el error inicial de la estimación de frecuencia portadora.

El submódulo de monitoreo de divergencia limita la divergencia de los estimadores de las antenas pasivas respecto de la antena activa. Para ello se establece un radio máximo alrededor del valor de la estimación de frecuencia portadora realizada por la antena activa donde deben encontrarse las estimaciones de toda las antenas pasivas. La magnitud de este radio se establece para acomodar la máxima diferencia de frecuencia entre dos antenas debida a la rotación del vehículo sobre su eje, a la vez que se respeta la cota máxima que establece la restricción crítica respecto del error de frecuencia máximo que garantiza el funcionamiento del discriminador UFA.

\subsubsection{Unificación de los parámetros de portadora}

La existencia de este módulo está relacionada con una limitación particular del hardware de correlación. En este último, el diseño del módulo de seguimiento provee un único generador de portadora que debe ser compartido por los correladores de las cuatro antenas de entrada. La consecuencia directa de esta decisión de diseño es que pese a que cada uno de los cuatro PLLs de seguimiento de portadora genera su propia estimación de los parámetros de fase y frecuencia, solamente un par podrá configurarse como parámetro a utilizar en las correlaciones de las cuatro antenas.

El submódulo de unificación de parámetros debe decidir a partir de los cuatro pares frecuencia/fase $\left(\hat{f}^{(1)}, \hat{\phi}^{(1)}\right),\left(\hat{f}^{(2)}, \hat{\phi}^{(2)}\right),\left(\hat{f}^{(3)}, \hat{\phi}^{(3)}\right)$ y $\left(\hat{f}^{(4)}, \hat{\phi}^{(4)}\right)$ estimados por cada uno de los PLLs en cada iteración del procesamiento, qué par de parámetros $\left(f_{U}, \phi_{U}\right)$ será el utilizado para configurar el generador de portadora para el ciclo de correlación siguiente, 
y debe corregir las consecuencias de este reemplazo para que los lazos de todas las antenas puedan operar normalmente como si tuvieran un generador de portadora a su completa disposición.

El modelo del resultado de correlación de una señal GNSS ya fue discutido anteriormente, resultando la expresión (3.15). A continuación se repite dicha expresión básica, pero con la notación modificada para reflejar la dependencia de los valores de frecuencia y fase reales de la señal $\left(f^{(k)}, \phi^{(k)}\right)$ y de los estimadores de esos mismos parámetros $\left(\hat{f}^{(k)}, \hat{\phi}^{(k)}\right)$ con la antena de entrada $k$ que se considere:

$$
\begin{aligned}
r^{(k) \approx} & n^{(k)} \\
& +A^{(k)} d r_{c c}(\Delta \tau) \operatorname{sinc}\left(T_{I}\left(f^{(k)}-\hat{f}^{(k)}\right)\right) \exp \left(j \pi T_{I}\left(f^{(k)}-\hat{f}^{(k)}\right)+\left(\phi^{(k)}-\hat{\phi}^{(k)}\right)\right)
\end{aligned}
$$

donde $n^{(k)}$ es un término de ruido de correlación complejo, Gaussiano y circularmente simétrico, $\Delta \tau$ es el error en la estimación del retardo de la función de código.

A los fines de la discusión que sigue podemos suponer que $r_{c c}(\Delta \tau)$ toma algún valor fijo $r_{c c}$, que dependerá del correlador (Early, Punctual, o Late) bajo consideración. Para simplificar las expresiones siguientes se absorberán todos los factores constantes del término de señal en un único factor de amplitud $R$ :

$$
R^{(k)}(\Delta \tau)=A^{(k)} d r_{c c}(\Delta \tau)
$$

La expresión (3.15) asume que los parámetros de fase y portadora con los que fue configurado el generador de portadora durante la correlación coinciden con los valores estimados por lazo de seguimiento de la $k$-ésima antena, $\left(\hat{f}^{(k)}, \hat{\phi}^{(k)}\right)$. Por las razones mencionadas anteriormente, en el prototipo de receptor las correlaciones se realizan utilizando un par de valores $f_{U}$ y $\phi_{U}$ común a todas las antenas de entrada. Las correlaciones correspondientes a la $k$-ésima antena se modelan entonces:

$$
r^{(k)} \approx n^{(k)}+R(\Delta \tau) \operatorname{sinc}\left(T_{I}\left(f^{(k)}-f_{U}\right)\right) \exp \left(j \pi T_{I}\left(f^{(k)}-f_{U}\right)+\left(\phi^{(k)}-\phi_{U}\right)\right)
$$

Se puede ver en esta expresión que:

- El parámetro de fase $\phi_{U}$ afecta la fase del término de señal de $r^{(k)}$.

- El parámetro de frecuencia $f_{U}$ afecta tanto la fase como la amplitud. Esto último lo hace por medio de la dependencia a través de la función $\operatorname{sinc}(x)$.

Estas distorsiones deben ser compensadas o minimizadas de alguna forma para permitir el normal funcionamiento de los lazos de seguimiento de portadora. 
En principio se puede asumir que $f^{(k)} \approx f_{U}$ para todas las antenas $k$, por lo que entonces $\operatorname{sinc}\left(T_{I}\left(f^{(k)}-f_{U}\right)\right) \approx 1$ y así lo tanto podemos ignorar la dependencia de la potencia de señal recuperada con la elección de $f_{U}$ :

$$
r^{(k)} \approx n^{(k)}+R(\Delta \tau) \exp \left(j \pi T_{I}\left(f^{(k)}-f_{U}\right)+\left(\phi^{(k)}-\phi_{U}\right)\right)
$$

Posteriormente se volverá sobre las consecuencias de esta suposición.

Así evadido el escollo de la distorsión en amplitud, la distorsión de fase puede ser corregida de mediante una simple rotación compleja. Para ello se utiliza un factor de módulo unitario y fase elegida para compensar la diferencia entre los valores estimados de frecuencia y fase $\left(\hat{f}^{(k)}, \hat{\phi}^{(k)}\right)$ y los valores utilizados durante la correlación $\left(f_{U}, \phi_{U}\right)$.

$$
r^{(k) *} \approx r^{(k)} \exp \left(j \pi T_{I}\left(f_{U}-\hat{f}\right)+\left(\phi_{U}-\hat{\phi}\right)\right.
$$

Esta rotación no afecta las características estadísticas del término de ruido, ya que como se mencionó anteriormente es complejo y circularmente simétrico, y la relación SNR de la muestra se conserva. La fase del término de señal del valor resultante $r^{(k) *}$ resulta ahora:

$$
\begin{aligned}
r^{(k) *} & \approx n^{(k) *}+R(\Delta \tau) \exp \left(j \pi T_{I}\left(f^{(k)}-f_{U}+f_{U}-\hat{f}^{(k)}\right)+\left(\phi^{(k)}-\phi_{U}+\phi_{U}-\hat{\phi}^{(k)}\right)\right) \\
& \approx n^{(k) *}+R(\Delta \tau) \exp \left(j \pi T_{I}\left(f^{(k)}-\hat{f}^{(k)}\right)+\left(\phi^{(k)}-\hat{\phi}^{(k)}\right)\right)
\end{aligned}
$$

Esta rotación se realiza en los resultados de correlación de las cuatro antenas, utilizando en cada caso el factor de corrección correspondiente a los estimadores de frecuencia y fase de dicha antena. Hecho esto, los resultados rotados $r^{(k) *}$ son equivalentes a que se hubieran utilizado generadores de portadora independientes para las cuatro antenas.

Respecto del criterio de selección de valores $\left(f_{U}, \phi_{U}\right)$, la elección del valor de fase $\phi_{U}$ es trivial. Debido a que todos los efectos del parámetro $\phi_{U}$ son cancelados totalmente luego de la rotación final existe libertad absoluta para elegir su valor, siendo simplemente convencional por lo tanto utilizar el valor $\phi_{U}=0$.

Más compleja es la elección de $f_{U}$. Si bien todos los efectos de este parámetro sobre la fase de la muestra son cancelados por la rotación, se vio anteriormente que la elección de $f_{U}$ también es determinante en la distorsión de amplitud del término de señal de $r^{(k)}$. Este efecto no puede ser compensado porque si bien es posible escalar el valor $r^{(k)}$ para compensar la pérdida de amplitud por el factor $\operatorname{sinc}\left(T_{I}\left(f^{(k)}-f_{U}\right)\right)$, esto escala en igual medida la señal y el ruido. La elección de $f_{U}$ debe entonces realizarse con el fin de minimizar el impacto de dicho factor. 
El cumplimiento de la suposición $\operatorname{sinc}\left(T_{I}\left(f^{(k)}-f_{U}\right)\right) \approx 1$ requiere que los valores de las estimaciones $\hat{f}^{(k)}$ tengan una dispersión reducida comparado con el ancho del lóbulo de la función $\operatorname{sinc}(x)$, que para $T_{I}=10 \mathrm{~ms}$ es de $\frac{2}{T_{I}}=200 \mathrm{~Hz}$. Esto se cumple con facilidad en el caso de los lazos de seguimiento de portadora que se encuentran enganchados con la señal, ya que la dispersión de valores de frecuencia debida a la máxima tasa de rotación axial del vehículo cabe cómodamente en ese rango. Las estimaciones de frecuencia de los lazos que se encuentran desenganchados por falta de línea de vista al satélite transmisor, en cambio, tomarán valores básicamente aleatorios dentro de las restricciones impuestas por los algoritmos correspondientes (ver Sección 6.2.1.3).

Bajo las condiciones de funcionamiento habituales, una elección simple y efectiva del valor $f_{U}$ consiste en utilizar la estimación de frecuencia del lazo de la antena activa. Esta elección combina las cualidades de optimizar la relación SNR en la antena que está siendo utilizada como entrada para el lazo de seguimiento de código y demodulación del mensaje de navegación, y de que bajo todas la condiciones operativas salvo la pérdida absoluta de la señal el lazo correspondiente a la antena activa siempre se encuentra en condición de enganche con la señal del satélite por lo que su estimación de frecuencia es válida.

\subsubsection{Monitoreo de coherencia de polaridad del mensaje de navegación}

Tal como se vio anteriormente, el mensaje de navegación de los sistemas GLONASS y GPS se encuentra formado por una secuencia de pulsos bipolares que modulan la señal. Su presencia en esta última condiciona el diseño de los lazos de seguimiento de fase, los cuales deben ser planificados de forma tal de ser insensibles a las inversiones de $180^{\circ}$ en la fase de la portadora.

Esta insensibilidad de los lazos a la modulación implica a su vez que la estimación de la fase de portadora realizada por los lazos PLL de seguimiento de fase del receptor es ambigua, existiendo un $50 \%$ de probabilidades de que estos se enganchen en fase coherente con la portadora recibida, y el $50 \%$ restante de que lo haga en la fase exactamente opuesta. Este fenómeno es semejante a lo que ocurre con los lazos de PLL analógicos de tipo Costas, utilizados para la recepción de señales moduladas con portadora suprimida.

Si bien la ambigüedad en la estimación no afecta la capacidad de seguimiento de la señal, en cambio efectivamente producirá ambigüedad en la polaridad de los pulsos del mensaje de navegación recuperados por el receptor: la secuencia de pulsos recibida (NRZ o Manchester) tiene tantas probabilidades de ser demodulada al derecho como al revés. 
El diseño de los mensajes de navegación de los sistemas GPS y GLONASS contemplan esta dificultad, e incluyen en su especificación características que permiten determinar la polaridad de la secuencia de pulsos recibida:

- En el caso de GPS (ver Sección 2.2.5.2) este proceso se lleva a cabo en paralelo con la detección de la palabra de telemetría TLM, y dependiendo de la polaridad con la que se detecte la secuencia buscada es la polaridad con la que se interpreta el resto del mensaje.

- GLONASS utiliza una aproximación diferente (ver Sección 2.3.5.2), donde la secuencia de bits se encuentra codificada utilizando codificación diferencial, donde los 1s del mensaje de navegación se codifican transmitiendo un pulso con polaridad inversa a la del pulso anterior, mientras que los 0s lo hacen conservando la misma polaridad. Este tipo de codificación es insensible a la polaridad absoluta la secuencia de pulsos codificados ya que la información se encuentra codificada en los cambios de la misma.

La detección de la polaridad del mensaje de navegación a partir de los indicios presentes en el mensaje mismo (GPS) o de su codificación (GLONASS) es suficiente para cualquier receptor convencional.

En el caso del receptor presentado en este trabajo se mostró anteriormente que el seguimiento de portadora no se lleva a cabo mediante la utilización de un lazo de seguimiento de fase de portadora único sino que existe un PLL por cada antena de entrada, y que la demodulación de los datos se realiza de forma oportunista utilizando en cada momento la antena con mayor potencia de señal. A partir de la discusión de los párrafos anteriores es fácil entender que, en ausencia de otros mecanismos externos, la probabilidad de que la polaridad del mensaje de navegación recuperado por dos antenas diferentes sea coincidente es de tan sólo del $50 \%$.

Este problema requiere ser tratado, ya que de no hacer nada se corre el riesgo de introducir errores de múltiples bits en la secuencia de bits demodulados, los cuales pueden no ser detectados por los mecanismos de detección de error previstos en el diseño del mensaje de navegación que asumen errores aleatorios y no correlacionados entre bits consecutivos. Incluso en el hipotético caso de que el error pudiera ser detectado, la frecuencia con la que ocurren los reemplazos de antena activa cuando la velocidad de rotación del vehículo sobre su eje es máxima (ver Sección 4.3.4) significarían que una perturbación considerable a la continuidad de la demodulación de datos.

Por las razones anteriores es preferible una solución que permita realizar los reemplazos de antena activa sin alterar la polaridad de la secuencia de pulsos demodulados, evitando 
de esa forma todo tipo de distorsión en el mensaje demodulado. Esto demanda que el receptor sea capaz de eliminar la ambigüedad relativa entre las fases de portadora estimadas de los cuatro lazos PLL: o todos se encuentran enganchados en fase, o todos en contrafase, por lo que la polaridad de la secuencia de pulsos demodulados por todas resulta unificada.

La implementación práctica de lo anterior es relativamente simple. Durante cada ciclo de procesamiento, luego de seleccionada la que será la antena activa se evalúan las polaridades de los resultados de correlación de las tres antenas pasivas contra los correspondientes a la antena activa. Si alguna de ellas se encuentra invertida respecto de la antena activa significa que el PLL correspondiente se encuentra enganchado a contrafase del PLL de la antena activa. En este caso el algoritmo corrige la situación modificando el estado del PLL de la antena pasiva invirtiendo su estimación de fase en $180^{\circ}$. Debe notarse que gracias a la insensibilidad a las inversiones de $180^{\circ}$ de los lazos de seguimiento, la metodología de corrección anterior no provoca ningún tipo de perturbación en la estimación de fase ni frecuencia de la antena pasiva que es corregida.

La implementación práctica del algoritmo anterior es apenas más compleja que lo descripto, debido a que para minimizar la posibilidad de realizar correcciones superfluas debido a falsas alarmas en la detección de inversiones de polaridad, la decisión de intervenir en el estado de un lazo se toma utilizando un criterio que evalúa no sólo la muestra de correlación presente sino también las anteriores inmediatas.

\subsubsection{Actividades de la TSI}

La TSI se ejecuta periódicamente cuatro veces por segundo. Durante cada ejecución se procesan en orden de llegada todas las muestras recibidas de la TSS a través de la cola de procesamiento, correspondientes a todos los canales de seguimiento activos en un momento dado.

El procesamiento realizado consiste de varias etapas. La primera de estas se encarga de sintetizar a partir de los resultados de correlación recibidos (que incluyen las partes parcial y total de la integración con bit partido, ver Sección 5.3.2) una secuencia de pseudo-correlaciones de 10 ms de duración, sincrónicas con los flancos de bit del mensaje de navegación. Esto se realiza a partir de analizar la cantidad de ciclos de la función de código transcurridos durante cada correlación para determinar como combinar las partes parcial y total del resultado de correlación de correlaciones consecutivas para conformar tiempos de integración que comiencen y terminen en múltiplos de $10 \mathrm{~ms}$ alineados con los pulsos del mensaje de navegación. 
La etapa de síntesis anterior sirve a dos propósitos separados. Por un lado es indispensable para generar una secuencia pulsos que pueda ser procesada por los algoritmos de extracción del mensaje de navegación sin sacrificio de energía de bit (minimizando así la probabilidad de error de bit del mensaje demodulado), y por otro es un requisito previo para poder eliminar la modulación de datos antes de realizar una estimación promediada del valor de $C / N_{o}$ de la señal en cada antena de entrada.

Estas son justamente las tareas de la segunda etapa de procesamiento, que está encargada de retransmitir las pseudo-correlaciones al módulo de extracción del mensaje de navegación y de realizar el cálculo de la relación $C / N_{o}$ de cada una de las señales recibidas a través de cada una de las antenas de entrada. Del módulo de extracción de mensaje de navegación no se dirá nada aquí por exceder los alcances de la presente tesis, pero es suficiente decir que es fundamentalmente idéntico al subsistema equivalente en un receptor convencional porque toda la complejidad del manejo de múltiples antenas de entrada queda enmascarada por el sistema de seguimiento que lo alimenta.

La estimación de la relación $C / N_{o}$ se hace para cada una de las antenas de entrada utilizando la técnica conocida como Narrow-Wide [3]. Esta última no es la única técnica posible (ver el artículo [49]) pero tiene la ventaja de no requerir de una estimación independiente de la varianza de ruido para llevar adelante el cálculo, algo que la generación actual de correladores multiantena no provee. La técnica requiere de coherencia de fase durante todo el intervalo promediado en la estimación $(250 \mathrm{~ms}$, en el caso del receptor aquí descripto) por lo que la estimación es incorrecta si el sistema de seguimiento de portadora no se encuentra operando con error de seguimiento nulo. Se verá posteriormente que esta situación solamente ocurre, y de forma transitoria, frente a eventos de cambio repentino de la aceleración del vehículo.

La tercera y última etapa de procesamiento llevada a cabo en la TSI examina para cada señal los valores de $C / N_{o}$ con que es recibida a través de cada una de las cuatro antenas de entrada y determina a partir de los valores observados si la señal se encuentra en condición de enganche o si se ha perdido sincronismo con ella.

El criterio aplicado para determinar el enganche de la señal es pedir que la relación $C / N_{o}$ de la señal a través de al menos una de las cuatro antenas de entrada debe ser superior que un valor umbral mínimo. Este umbral se toma en $27 \mathrm{~dB}$. La violación de este criterio para una señal durante una dada ronda de procesamiento inicia un contador asociado a la señal que se incrementa con cada nueva violación y se decrementa si el criterio de enganche se cumple. Si el contador alcanza el valor cuatro (equivalente a un segundo consecutivo con relación $C / N_{o}$ baja) se declara el desenganche de la señal asociada y se liberan los recursos de software y hardware asociados a ella (canal de correlación 
de seguimiento, canal de seguimiento en la TSS, registros de datos en el módulo de extracción del mensaje de navegación, etc.).

La tolerancia de un segundo antes de declarar el desenganche permite evitar la generación de falsos positivos en el detector de desenganche cuando ocurren perturbaciones de tipo dinámico (un despegue, por ejemplo). Estas últimas afectan la estimación de la relación $C / N_{o}$ debido al transitorio que introducen en los lazos de seguimiento de fase de la señal, pero se verá más adelante que la duración de estos transitorios de rechazo es del orden de algunas décimas de segundo y por lo tanto no es posible que provoquen la falla de cuatro verificaciones de desenganche consecutivas. La tolerancia de un segundo también permite reducir la probabilidad de declarar en desenganche señales fronterizas (señales enganchadas pero con baja relación $C / N_{o}$ ) cuya estimación $C / N_{o}$ pueda hacer excursiones por encima y por debajo del umbral.

\subsection{Diseño de los lazos de seguimiento}

En términos generales el diseño de los lazos de seguimiento utilizados en el receptor multiantena es muy similar al de un receptor convencional de alta dinámica.

Cada canal de seguimiento cuenta con cinco lazos de seguimiento de señal con el fin de estimar los parámetros de la señal que tiene asignada. Cuatro de esos lazos son los lazos de seguimiento de fase de portadora de tipo PLL que se encargan de la estimación de los parámetros de fase $\hat{\phi}$ y frecuencia $\hat{f}$ de la señal en cada una de las cuatro antenas de entrada, mientras que el quinto lazo es un lazo de seguimiento de código de tipo DLL Early-Late.

Todos los lazos de seguimiento de fase son diseñados con un ancho de banda de ruido $B_{n}$ elevado, para garantizar de esa forma una velocidad adecuada de respuesta ante la dinámica de la señal, la cual a su vez se encuentra condicionada por la dinámica de movimiento del vehículo. Esto disminuye la duración de los transitorios de enganche y de recuperación ante perturbaciones en los parámetros de la señal, como por ejemplo la súbita modificación de la tasa de variación de la frecuencia que ocurre durante el encendido y el apagado de los motores de las etapas del vehículo.

El lazo de seguimiento de código, por otro lado, se diseña con un ancho de banda de ruido angosto, a fin de minimizar la sensibilidad del estimador de retardo $\hat{\tau}$ a la potencia de ruido superpuesta a la señal, lo cual es un factor crítico en la calidad de la estimación de tiempo de transmisión que se extrae del lazo para realizar los cálculos de navegación. 
Como se discutió en el Capítulo 3, el estrechamiento del ancho de banda de ruido del lazo de código requiere de la utilización de asistencia de frecuencia desde el lazo de seguimiento de portadora. Ver Sección 3.7.2.6. En el caso del receptor multiantena la asistencia se hace siempre utilizando la estimación de frecuencia de portadora del PLL correspondiente a la antena activa.

\subsubsection{Lazos de seguimiento de portadora}

Se estableció a partir de los requerimientos del receptor que la dinámica acelerada del vehículo demanda la utilización de lazos de Tipo III, capaces de sostener error de estado estacionario nulo en condiciones de aceleración permanente.

Por otro lado, eventos como los enganches de lazo ocurridos cuando el nivel de potencia de señal en una antena auxiliar se hace perceptible y las discontinuidades en la aceleración del vehículo que ocurren durante el encendido y apagado de los motores introducen perturbaciones en la capacidad de los lazos de estimar los parámetros de la portadora. Los transitorios resultantes de estas perturbaciones serán de duración y magnitud mayores cuanto menor sea la capacidad de los lazos de seguimiento para rechazarlas. Esta capacidad de rechazo está dada por el ancho de banda de ruido $B_{n}$ de los mismos, por lo que se optó por la utilización de diseños de filtros de lazo que admiten anchos de banda superiores a los utilizados en receptores convencionales.

Incluso utilizando anchos de banda extendidos los transitorios de ajuste pueden provocar errores en la estimación de fase de magnitud muy por encima del rango de operación lineal de los discriminadores de fase convencionales. Para incrementar el rango de operación lineal de los lazos se utilizó un tipo especial de discriminador de fase denominado UFA (Unambiguous Frequency-Aided) que elimina las limitaciones de rango del discriminador de fase $\operatorname{tg}^{-1}($ ) bajo ciertos supuestos respecto del error de frecuencia máximo. $[1]$

En las secciones siguientes se describirá el diseño de los filtros utilizados en los lazos PLL de seguimiento de portadora, seguido de una presentación del funcionamiento del discriminador UFA. Una vez comprendidas las limitaciones impuestas por este último al diseño del primero se presentará el diseño definitivo utilizado, fundamentando el ancho de banda seleccionado mediante simulaciones.

\subsubsection{Filtro de lazo}

Ya se mencionó en la Sección 3.7.2.4 que la técnica de diseño más habitual del filtro del lazo consiste en su diseño en el dominio continuo, seguida de una conversión al 


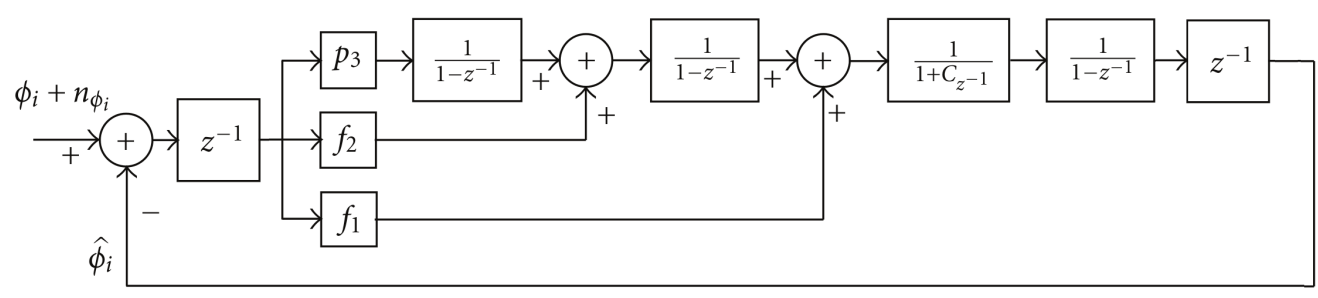

Figura 6.2: Lazo PLL Tipo III propuesto en [1]. En la figura se ve la estructura del lazo completo, incluyendo los retardos que modelan el comportamiento del hardware de correlación (retardos unitarios $z^{-1}$ al principio y al final de la cadena).

dominio discreto a través de la aproximación de su transferencia $H(s)$ con una $H(z)$ implementable en el receptor.

Se mencionó también que la debilidad de esta metodología radica justamente en el paso de aproximar de forma discreta la transferencia, ya que la transferencia obtenida es fiel a la original solamente si el ancho de banda del filtro es mucho menor que la frecuencia de muestreo utilizada por el sistema discreto que lo aproxima. Con los tiempos de integración $T_{I}$ de 10 ms utilizados en seguimiento, y utilizando la regla del dedo"mencionada en la Sección 3.7.2.4, el límite superior para el ancho de banda de ruido $B_{n}$ de los lazos realizables por este método es de $10 \mathrm{~Hz}$, que es un valor insuficiente para cumplir con los requerimientos demandados por las características de la misión del receptor multiantena.

Con el fin de incrementar el ancho de banda $B_{n}$ que es posible lograr sin recurrir a modificar el tiempo de integración $T_{I}$, para este trabajo se optó por utilizar una técnica de diseño de los filtros que se encuentra publicada en la referencia [1], la cual permite generar un filtro óptimo directamente en el dominio discreto. Al igual que ocurría con los filtros continuos propuestos en 3.7.2.4 (Figura 3.18), la optimalidad del diseño discreto consiste en lograr el filtro de lazo que para un dado ancho de banda de ruido minimiza la energía del error ante una clase de perturbaciones a en su entrada (en este caso una parábola en la referencia, o escalón de aceleración).

En el artículo de la referencia [1] se deriva la estructura de filtro PLL discreto que permite lograr un filtro discreto óptimo apto para ser utilizado a bordo de vehículos sometidos a aceleraciones constantes de altos valores. El filtro propuesto es un filtro de Tipo III, lo que garantiza error de estado estacionario nulo incluso en condiciones de aceleración constante.

La estructura del lazo propuesto puede verse en la Figura 6.2. Dicha figura representa el modelo analítico del lazo cerrado completo, incluyendo el filtro, los dos bloques $z^{-1}$ que modelan los retardos en el hardware, y la realimentación. 


\begin{tabular}{|c|c|c|c|c|}
\hline $\begin{array}{c}\text { Ancho de banda } \\
\text { de ruido } B_{n}\end{array}$ & $\begin{array}{c}\text { Coeficiente } \\
\text { de cálculo } v\end{array}$ & $\begin{array}{c}\text { Coeficiente } \\
f_{1}\end{array}$ & $\begin{array}{c}\text { Coeficiente } \\
f_{2}\end{array}$ & $\begin{array}{c}\text { Coeficiente } \\
p_{3}\end{array}$ \\
\hline $10.0 \mathrm{~Hz}$ & $7.592 \mathrm{e}-07$ & $1.909 \mathrm{e}-01$ & $1.700 \mathrm{e}-02$ & $7.919 \mathrm{e}-04$ \\
$12.0 \mathrm{~Hz}$ & $1.829 \mathrm{e}-06$ & $2.210 \mathrm{e}-01$ & $2.254 \mathrm{e}-02$ & $1.211 \mathrm{e}-03$ \\
$14.0 \mathrm{~Hz}$ & $3.772 \mathrm{e}-06$ & $2.493 \mathrm{e}-01$ & $2.839 \mathrm{e}-02$ & $1.714 \mathrm{e}-03$ \\
$16.0 \mathrm{~Hz}$ & $6.952 \mathrm{e}-06$ & $2.760 \mathrm{e}-01$ & $3.447 \mathrm{e}-02$ & $2.296 \mathrm{e}-03$ \\
$18.0 \mathrm{~Hz}$ & $1.178 \mathrm{e}-05$ & $3.013 \mathrm{e}-01$ & $4.072 \mathrm{e}-02$ & $2.951 \mathrm{e}-03$ \\
$20.0 \mathrm{~Hz}$ & $1.870 \mathrm{e}-05$ & $3.253 \mathrm{e}-01$ & $4.709 \mathrm{e}-02$ & $3.674 \mathrm{e}-03$ \\
$22.0 \mathrm{~Hz}$ & $2.817 \mathrm{e}-05$ & $3.482 \mathrm{e}-01$ & $5.353 \mathrm{e}-02$ & $4.458 \mathrm{e}-03$ \\
$24.0 \mathrm{~Hz}$ & $4.068 \mathrm{e}-05$ & $3.701 \mathrm{e}-01$ & $6.003 \mathrm{e}-02$ & $5.298 \mathrm{e}-03$ \\
$26.0 \mathrm{~Hz}$ & $5.673 \mathrm{e}-05$ & $3.911 \mathrm{e}-01$ & $6.656 \mathrm{e}-02$ & $6.190 \mathrm{e}-03$ \\
$28.0 \mathrm{~Hz}$ & $7.680 \mathrm{e}-05$ & $4.112 \mathrm{e}-01$ & $7.309 \mathrm{e}-02$ & $7.130 \mathrm{e}-03$ \\
$30.0 \mathrm{~Hz}$ & $1.014 \mathrm{e}-04$ & $4.306 \mathrm{e}-01$ & $7.963 \mathrm{e}-02$ & $8.112 \mathrm{e}-03$ \\
$32.0 \mathrm{~Hz}$ & $1.310 \mathrm{e}-04$ & $4.493 \mathrm{e}-01$ & $8.615 \mathrm{e}-02$ & $9.135 \mathrm{e}-03$ \\
$34.0 \mathrm{~Hz}$ & $1.662 \mathrm{e}-04$ & $4.673 \mathrm{e}-01$ & $9.264 \mathrm{e}-02$ & $1.019 \mathrm{e}-02$ \\
$36.0 \mathrm{~Hz}$ & $2.073 \mathrm{e}-04$ & $4.847 \mathrm{e}-01$ & $9.911 \mathrm{e}-02$ & $1.128 \mathrm{e}-02$ \\
$38.0 \mathrm{~Hz}$ & $2.549 \mathrm{e}-04$ & $5.016 \mathrm{e}-01$ & $1.055 \mathrm{e}-01$ & $1.241 \mathrm{e}-02$ \\
$40.0 \mathrm{~Hz}$ & $3.094 \mathrm{e}-04$ & $5.179 \mathrm{e}-01$ & $1.119 \mathrm{e}-01$ & $1.356 \mathrm{e}-02$ \\
\hline
\end{tabular}

Cuadro 6.1: Cálculo de los coeficientes $v, f_{1}, f_{2}$ y $p_{3}$ en función del ancho de banda $B_{n}$, cuando el tiempo de integración es $T_{I}=10 \mathrm{~ms}$.

Los coeficientes $f_{1}, f_{2}$ y $p_{3}$ se calculan a partir de un coeficiente de cálculo $v$ que está tabulado en función del ancho de banda $B_{n}$ que se desea lograr y del tiempo de integración $T_{I}$ utilizado. En el cuadro 6.1 se listan los valores de los coeficientes del filtro como función del ancho de banda de ruido, calculados numéricamente para $T_{I}=10 \mathrm{~ms}$.

La totalidad de la implementación de los filtros se llevó a cabo utilizando operaciones de punto fijo, debido a que el procesador del prototipo de receptor multiantena actualmente no soporta operaciones en punto flotante de forma nativa.

\subsubsection{Discriminador de fase UFA}

Los discriminadores de fase convencionales son sistemas sin memoria que determinan el error de la estimación de fase a partir de determinar el argumento de los resultados del correlador Punctual. El discriminador óptimo (según un criterio de máxima verosimilitud) es la función arcotangente, que también tiene la virtud de ser el discriminador sin memoria que mayor rango de operación lineal permite: $[-\pi,+\pi)$. Con el fin de insensibilizar el lazo de seguimiento de fase a la modulación BPSK del mensaje de navegación se reduce deliberadamente el rango de operación a $\left[-\frac{\pi}{2},+\frac{\pi}{2}\right)$ mediante la utilización de un arco tangente de dos cuadrantes en lugar de uno de cuatro. Esta limitación en el rango de operación del discriminador limita la máxima excursión del error de lazo antes de que este último deje de comportarse de forma lineal. 
El discriminador UFA es una extensión sobre el discriminador $\arctan ($ ) de dos cuadrantes convencional que extiende su rango de operación lineal a todo el intervalo $(-\infty,+\infty)$ a cambio de imponer una restricción en la magnitud máxima del error en la estimación de frecuencia del lazo. El funcionamiento de este discriminador se puede encontrar publicado en la referencia [1] pero en beneficio del lector a continuación se presenta una elaboración alternativa.

Conceptualmente el funcionamiento del discriminador UFA es muy sencillo. Para comprender su funcionamiento es conveniente primero reexaminar el discriminador arcotangente convencional. Éste puede dividirse en dos operaciones diferentes:

1. Cálculo del argumento de la muestra de correlación.

2. Mapeo de dicho argumento al error de fase.

Debido a la naturaleza misma de la función arco tangente de dos cuadrantes, la primera operación introduce ambigüedad en la determinación del error de fase. Para resolver esta ambigüedad el discriminador convencional asume que el error de fase se encuentra siempre en el rango $\left[-\frac{\pi}{2},+\frac{\pi}{2}\right)$ y bajo esta suposición mapea el error de fase al argumento del resultado de correlación con una relación 1 a 1 .

El discriminador UFA realiza la primera operación de forma idéntica al discriminador convencional, pero en la segunda parte, en lugar asumir un rango fijo de valores posibles para el error de fase, mapea el resultado de la función arco tangente a un intervalo centrado el último valor conocido del error de fase $e_{U}[n]$. Esto es el intervalo:

$$
e_{U}[n] \in\left[e_{U}[n-1]-\frac{\pi}{2}, e_{U}[n-1]+\frac{\pi}{2}\right) .
$$

Como consecuencia el discriminador UFA no limita la máxima magnitud del error de fase, el cual podría tomar valores arbitrariamente grandes, pero si su máxima tasa de variación: el módulo de la diferencia entre dos valores consecutivos del error de fase debe necesariamente ser menor que $\frac{\pi}{2}$ para que el mapeo sea correcto. En la Sección 6.3.1.3 se volverá sobre esta restricción y sus consecuencias.

La implementación del algoritmo del discriminador UFA es trivial. En [1] se propone una posibilidad, pero aquí se propone otra variante que admite una implementación más eficiente.

Una representación conceptual del discriminador UFA puede encontrarse en la Figura 6.3. Allí puede verse que el discriminador consiste en un bloque que calcula el argumento $e_{p}[n]$ de la muestra de correlación Punctual, seguido de un bloque que corrige en dicho argumento para obtener el error de fase del discriminador UFA, $e_{U}[n]$. La corrección de 


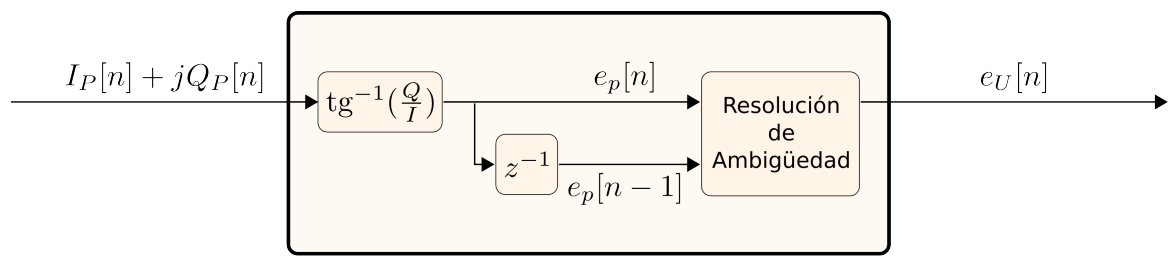

Discriminador UFA

FiguRA 6.3: Representación conceptual del discriminador UFA.

la ambigüedad consiste en la adición de un múltiplo entero de intervalos de ambigüedad, de la siguiente forma

$$
e_{U}[n]=k[n] \pi+e_{p}[n]
$$

donde $e_{p}[n]$ es el argumento de la muestra de correlación a la salida de la función arco tangente de dos cuadrantes, $k[n]$ es la cantidad de intervalos de ambigüedad que es necesario adicionar (número entero), y $e_{U}$ es el error de fase estimado calculado por el UFA. La complejidad radica en determinar $k[n]$.

Por simplicidad es conveniente definir una función auxiliar, la función $I_{\pi}(x)$. Esta última es similar a la función redondeo pero en lugar de devolver el número entero más cercano (hacia arriba o hacia abajo) al argumento $x$ de la función, devuelve el múltiplo de $\pi$ más próximo. Utilizando la función $I_{\pi}(x)$ se puede escribir la restricción sobre la máxima variación del error de fase entre muestras consecutivas como

$$
0=I_{\pi}\left(e_{U}[n]-e_{U}[n-1]\right)
$$

Reemplazando la expresión (6.1) en la expresión anterior y teniendo en cuenta la propiedad

$$
I_{\pi}(x+l \pi)=I_{\pi}(x)+l \pi
$$

resulta una expresión recursiva para el cálculo de $k[n]$ :

$$
k[n]=k[n-1]-\frac{I_{\pi}\left(e_{p}[n]-e_{p}[n-1]\right)}{\pi}
$$

El cálculo de la expresión anterior todavía requiere del cálculo de la función $I_{\pi}($ ), además de un cociente en punto flotante, pero es posible ver que el rango de valores posibles del argumento de $I_{\pi}($ ) se encuentra acotado al rango $[-\pi, \pi)$ (la máxima diferencia entre dos muestras de $e_{p}$ ). Más aún, el segundo término sólo puede tomar los valores $+1,0$ o -1 . Es fácil ver entonces que la expresión anterior puede ser implementada mediante el Algoritmo 3.

En resumen, el discriminador UFA funciona actualizando para cada nueva muestra de correlación el contador de semiciclos de ambigüedad $k[n]$ utilizando la expresión (6.3), 


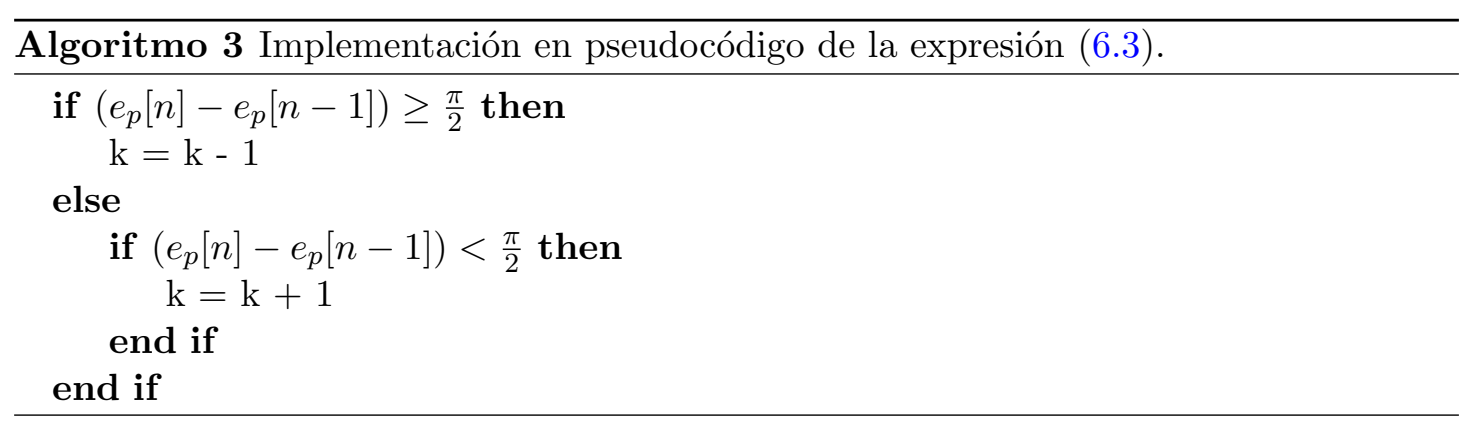

y usando dicho valor para calcular el error de fase $e_{U}[n]$ mediante la expresión (6.1).

\subsubsection{Falsos enganches de frecuencia}

La restricción en la máxima diferencia entre dos muestras de fase consecutivas (expresión (6.4)) impone una restricción en el máximo error en la estimación de frecuencia del lazo donde opera el discriminador. Es fácil ver que

$$
\begin{aligned}
\left|2 \pi \Delta f_{\max } T_{I}\right| & \leq \frac{\pi}{2} \\
|\Delta f| & \leq \frac{1}{4 T_{I}}
\end{aligned}
$$

de donde resulta la restricción que ya fue comentada en la sección 6.2.1.3.

Si por cualquier razón el lazo de seguimiento alcanza un estado tal que la restricción de la expresión (6.4) no se cumple, entonces el lazo entrará en la región de atracción de un nuevo punto de operación estable en el cual el error de fase es cero pero la estimación de frecuencia del lazo se encuentra desplazada en $\pm \frac{1}{2 T_{I}}$ Hertz respecto de la frecuencia portadora real. A esta condición patológica de operación se la denomina generalmente falso enganche porque es indistinguible de la condición de enganche real a partir de la simple observación de la evolución del estado del lazo.

Un lazo operando en condición de falso enganche es un situación particularmente peligrosa. En esta condición las estimaciones de frecuencia portadora (y por ende los observables de deltarango) se encuentran falseados, por lo que el problema se propaga de forma directa al sistema de navegación afectando la solución de velocidad (y si se utiliza un estimador acoplado, como un filtro Kalman por ejemplo, también la de posición).

En los casos donde existe asistencia de frecuencia del lazo de portadora al de código el error en la estimación de frecuencia del primero imprimirá una perturbación en el segundo. En el caso de utilizar un lazo de código Tipo I (típico en los esquemas de lazo asistido) el error en la estimación de frecuencia del lazo de portadora provocará un error de estado estacionario en la estimación de retardo que afectará el observable de 
pseudorango. Si el lazo de código tiene una ganancia de lazo cerrado lo suficientemente pequeña, esta perturbación puede incluso sacar el lazo de su región de operación lineal y provocar la pérdida de enganche de la señal.

Si bien el error en la estimación de frecuencia provoca una reducción en la potencia de correlación recuperada, el error de frecuencia de $\pm \frac{1}{2 T_{I}}$ hace que la frecuencia estimada se encuentre cómodamente ubicada dentro del lóbulo principal de la función sinc( ) con apenas $3,92 \mathrm{~dB}$ de degradación en la relación $C / N_{o}$ respecto del óptimo. Esta caída generalmente no es suficiente para provocar el desenganche del lazo afectado por lo que la condición de falso enganche frecuentemente se eternizará a menos que la condición sea detectada y terminada externamente.

Las medidas contra los falsos enganches pueden ser de dos tipos: preventivas y paliativas. Las primeras consisten en realizar un diseño cuidadoso de los lazos de seguimiento para garantizar que bajo todas las condiciones operativas esperables el error de frecuencia del lazo permanezca acotado. En las secciones siguientes se verá que esto se hace seleccionando adecuadamente el ancho de banda $B_{n}$ del lazo. La prevención por diseño es por lejos la mejor medida de protección contra los falsos enganches.

Los paliativos se encargan de la detección y rectificación de la situación una vez que ya se ha manifestado. Debido a que no existen mecanismos instantáneos de detección de una condición de falso enganche, siempre existirá un intervalo de tiempo entre la entrada en esta situación y su detección durante el cual la calidad de los observables de navegación y posiblemente la solución de navegación misma se verán comprometidos en mayor o menor medida.

Una primera forma de detección de la condición de falso enganche es mediante el monitoreo de la coherencia del mensaje de navegación demodulado de la señal, debido a que la condición de falso enganche con $T_{I}=10 \mathrm{~ms}$ imposibilita la recuperación del mensaje de navegación. Esto es así porque el error de frecuencia provoca la existencia de inversiones en la fase del mensaje demodulado cada $10 \mathrm{~ms}$, las cuales causan la casi total cancelación de la energía de los bits de 20 ms del mensaje de navegación. Los módulos encargados de la demodulación del mensaje de navegación pueden detectar la degradación mediante la verificación de los códigos de detección de errores y la validación de los campos invariantes, pero esta metodología puede ser relativamente lenta, imprecisa y sensible a errores de demodulación provocados por otras causas (transitorios de los lazos de seguimiento de fase, por ejemplo).

En el caso de señales GPS otro detector simple consiste en comparar las fases de la primera y la segunda correlación de $10 \mathrm{~ms}$ de cada bit del mensaje de navegación. Si existen inversiones de fase frecuentes entre las dos es un síntoma fuerte de que existe 
una situación de falso enganche en progreso. Este mecanismo es mucho más rápido que el anterior, pero desgraciadamente no es práctico para el sistema GLONASS porque las características de la estructura del mensaje de navegación de este sistema requerirían de la utilización de tiempos de integración de 5 ms para poder hacer una comprobación semejante.

Un tercer método, que será profundizado en la Sección 6.3.2.1, consiste en utilizar la estimación de frecuencia del lazo de código para evaluar la estimación de frecuencia del lazo de portadora. Este método de detección es más lento que los anteriores (su velocidad es función del ancho de banda del lazo de código), pero puede ser implementado dentro de los mismos algoritmos de seguimiento sin intervención de módulos externos y además funciona de forma universal tanto en GPS como en GLONASS. Su discusión se postergará hasta que se haya introducido el lazo de seguimiento de código, con el que está íntimamente ligado.

\subsubsection{Diseño del filtro de lazo}

A partir de los parámetros dinámicos presentados en la Sección 4.3.4 se estableció que el valor más apropiado de ancho de banda de ruido $B_{n}$ necesario para los lazos de seguimiento es de $21 \mathrm{~Hz}$. A esta elección se llegó mediante la simulación del modelo de la Figura 6.2 para examinar su respuesta frente a una serie de eventos típicos que ocurren durante la operación habitual de los lazos de seguimiento:

- Escalón de fase.

- Escalón de frecuencia.

- Escalón de aceleración.

Los escalones de fase y frecuencia modelan la incertidumbre en el valor inicial de la estimación de fase/frecuencia de portadora durante los momentos inmediatamente posteriores al enganche del lazo con la señal de un satélite. Esto ocurre tanto durante el enganche inicial post-adquisición, como durante el proceso de enganche que ocurre cuando la señal de un satélite entra en el cono de cobertura de una antena auxiliar.

Si bien los enganches del lazo suelen involucrar el efecto combinado de errores tanto en fase como en frecuencia, en los siguientes párrafos se modelarán ambos tipos de perturbación por separado por simplicidad. De esa forma se pueden analizar sus características individuales. Mediante la utilización de márgenes de seguridad apropiados en el diseño se puede salvaguardar los efectos combinados de ambos tipos de perturbación. 
El escalón de aceleración modela el efecto de los instantes de encendido y apagado de motores en los vehículos cohete. Como se mencionó oportunamente, esta súbita aceleración provoca una discontinuidad en la tasa de variación de la frecuencia por efecto Doppler. Los lazos de seguimiento deben ser capaces de rechazar esta perturbación rápidamente y con un mínimo de perjuicio para el resto del sistema.

Para seleccionar un valor de ancho de banda de ruido del lazo es necesario alcanzar un compromiso razonable entre la velocidad de respuesta de este último ante las diferentes clases de perturbación que pueden aparecer a su entrada, y al mismo tiempo mantener todos sus parámetros operativos dentro de su zona de funcionamiento.

En una sección anterior se describió el funcionamiento del discriminador de fase UFA, el cual confiere al lazo la posibilidad de extender su región de operación lineal al admitir valores de error de fase arbitrariamente grandes. Esto relaja los compromisos de diseño, ya que ahora este último puede admitir posibilidades en las que el error de la estimación de fase toma valores de error de fase arbitrariamente grandes sin salir de la región de operación lineal de operación.

Sin embargo no debe olvidarse que la región de operación lineal del discriminador UFA está acotada en frecuencia, por lo que la respuesta del lazo de seguimiento ante cualquier tipo de perturbación de la entrada debe ser tal que se respete que el máximo error de frecuencia sea menor al límite que establece la expresión (6.4).

Dado que el sobrepaso en el error de frecuencia del lazo tienden a crecer cuanto mayor es el ancho de banda de ruido del mismo esta limitación se convierte en un criterio fundamental para aceptar o rechazar una dada posibilidad de diseño.

De lo anterior surge que el compromiso a alcanzar es aquel que permita maximizar el ancho de banda de ruido para reducir la duración de los transitorios, mientras simultáneamente se mantiene acotado el máximo error de frecuencia.

A continuación se presentan las simulaciones del lazo de seguimiento de portadora configurado con el ancho de banda seleccionado $(B n=21 \mathrm{~Hz})$. Todas la figuras presentadas corresponden a la simulación de la evolución del lazo discreto durante un intervalo de tiempo de 1 segundo. En todos los casos la perturbación se aplica 0,2 segundos luego de iniciada la simulación. El tiempo de muestreo asumido corresponde al tiempo de integración utilizado, $T_{I}=10 \mathrm{~ms}$.

En la Figura 6.4 se pueden ver la evolución de los errores de fase y de frecuencia del lazo ante un escalón de fase en la referencia de entrada. El escalón aplicado en este caso es de $180^{\circ}$ en adelanto, lo cual es el peor caso posible cuando el discriminador de fase utilizado 

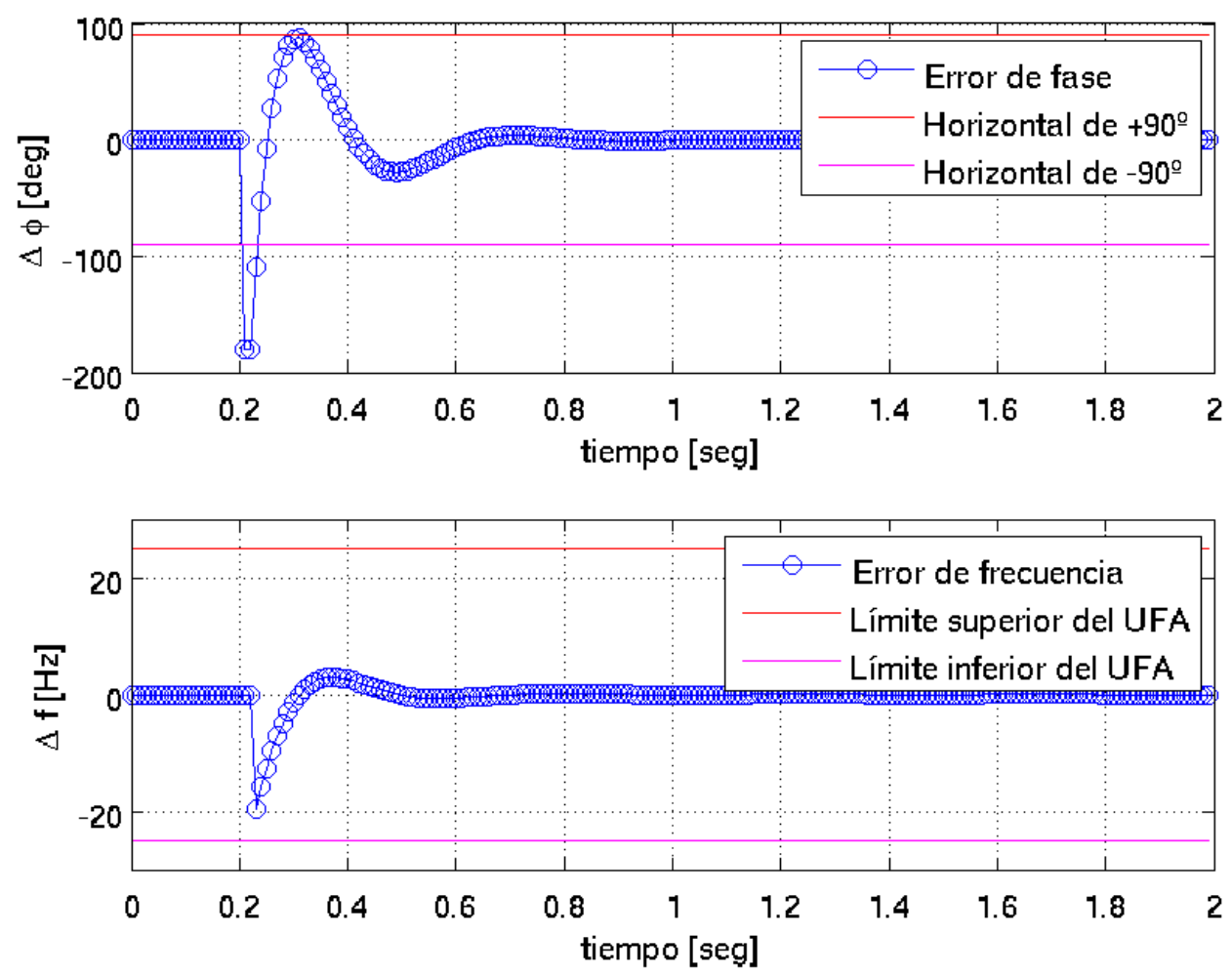

Figura 6.4: Simulación del comportamiento del lazo de seguimiento de portadora ante un escalón de fase $180^{\circ}$ en la referencia. (arriba) Error de fase del lazo. (abajo) Error de frecuencia del lazo.

es el UFA. Este límite proviene de analizar los diferentes casos que pueden darse en el Algoritmo 3 en presencia de un escalón de fase a la entrada.

En el error de fase (parte superior de la figura) puede verse que posteriormente a la inserción del escalón en la referencia existe un intervalo de dos muestras durante las cuales la estimación de fase del lazo no se modifica (el error permanece constante). Esto ocurre debido al efecto de los dos retardos puros $z^{-1}$ (ver Figura 6.2), que limitan la capacidad de respuesta del lazo. La evolución posterior del error de fase consiste en un transitorio de aproximadamente $400 \mathrm{~ms}$ de duración con un sobrepaso máximo de aproximadamente el $50 \%$ del error inicial.

La mitad inferior de la Figura 6.4 muestra simultáneamente el error de frecuencia, que es la diferencia entre la estimación de frecuencia del lazo y la frecuencia real de portadora. Dado que la perturbación de la entrada es una modificación súbita de la fase sin modificación de la frecuencia la frecuencia de portadora es constante durante toda la simulación. El transitorio que se puede apreciar en el error de frecuencia es debido exclusivamente a la estimación de frecuencia del lazo, la cual es ajustada durante 

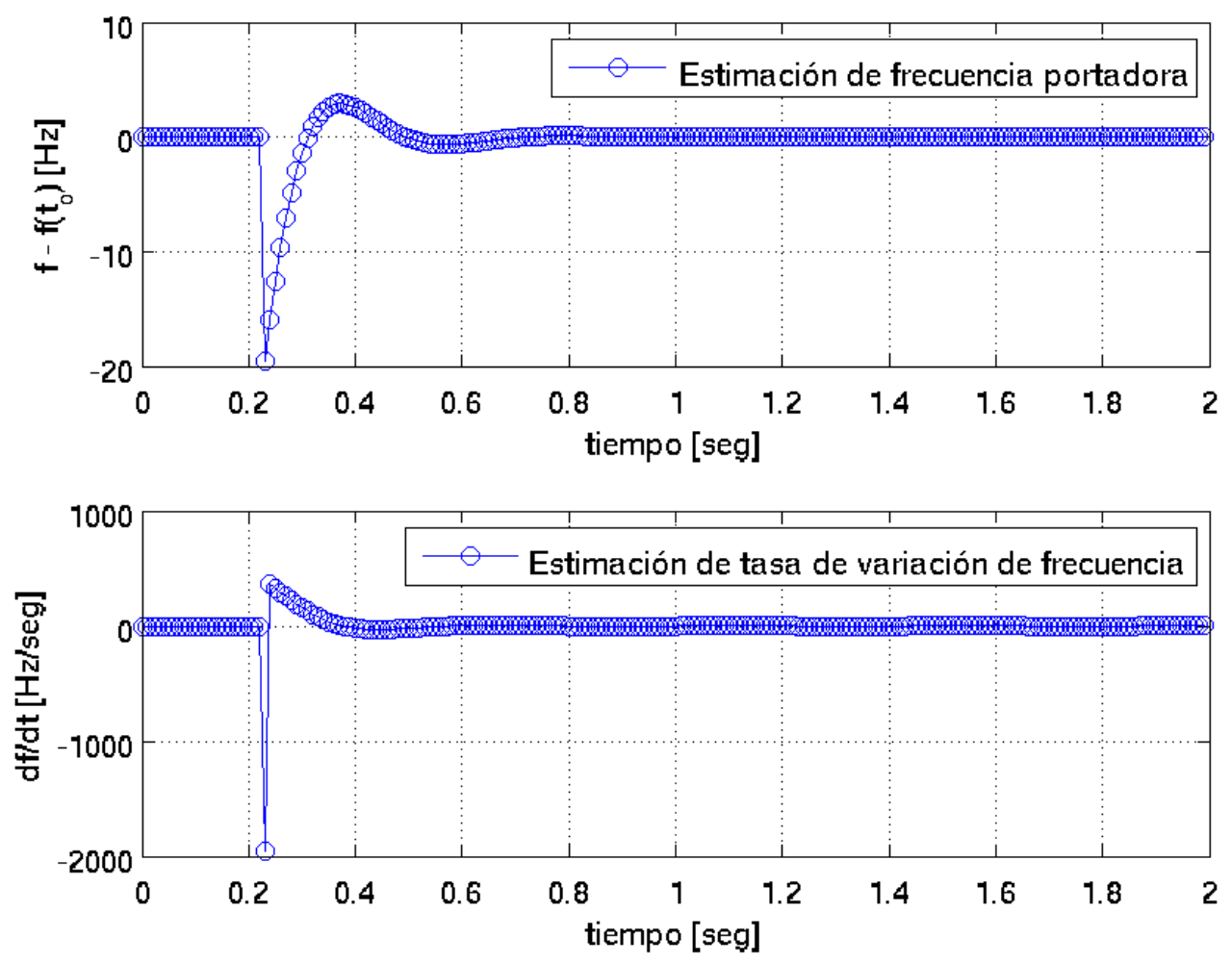

Figura 6.5: Simulación del comportamiento del lazo de seguimiento de portadora ante un escalón de fase $180^{\circ}$ en la referencia. (arriba) Estimación del lazo del valor de frecuencia portadora, relativo a su valor al comienzo de la simulación. (abajo) Estimación del lazo de la tasa de variación de la frecuencia, proporcional a la aceleración.

el transitorio de ajuste para lograr adelantar la estimación de fase hasta emparejar la estimación de fase a la referencia para rechazar la perturbación.

En la gráfica anterior se encuentran señalados los límites de la región de operación del discriminador UFA en la forma de líneas horizontales en $\pm 25 \mathrm{~Hz}$ (valor límite correspondiente al valor de tiempo de integración $T_{I}$ utilizado). Puede verse que con el ancho de banda seleccionado el error de frecuencia máxima permanece dentro de la banda de operación lineal del lazo, teniendo todavía un margen de seguridad de aproximadamente el $20 \%$.

La Figura 6.5 muestra la evolución de las estimaciones de frecuencia portadora y de aceleración para la misma perturbación (escalón de fase). La estimación de frecuencia se encuentra graficada de forma relativa a su valor inicial para examinar como modifica su valor a lo largo de la simulación. Aquí también se puede ver que la estimación de frecuencia sufre un transitorio como consecuencia del proceso de ajuste de la estimación de fase del lazo, pero que una vez rechazada la perturbación la estimación de frecuencia del lazo vuelve a su valor inicial pre-excitación. 

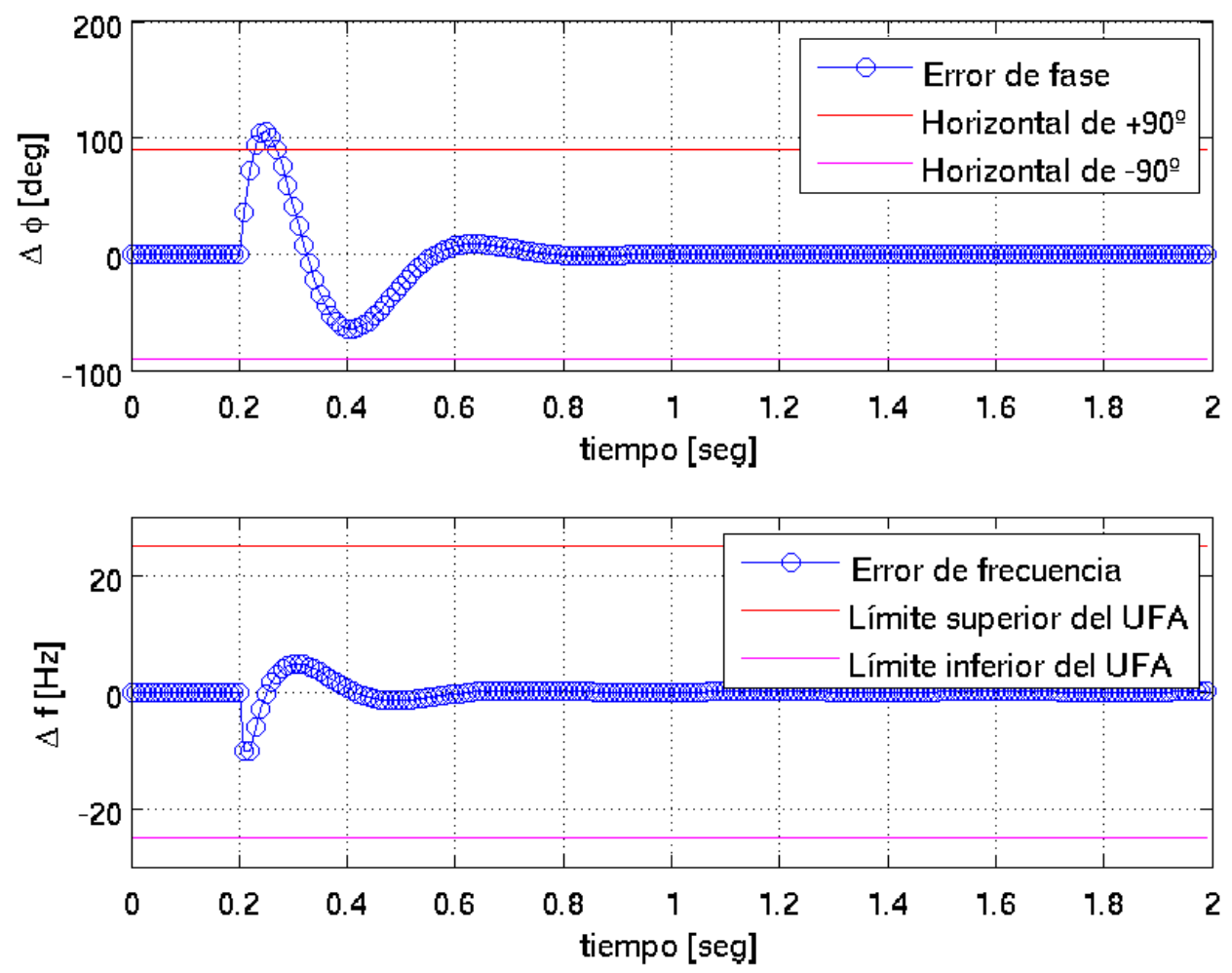

Figura 6.6: Simulación del comportamiento del lazo de seguimiento de portadora ante un escalón de frecuencia de $10 \mathrm{~Hz}$ en la referencia. (arriba) Error de fase del lazo. (abajo)

Error de frecuencia del lazo.

La aceleración estimada por el lazo presenta un pico inicial de aproximadamente $2000 \mathrm{~Hz} / \mathrm{s}$, seguido de un transitorio de extinción que devuelve la estimación a su valor inicial. Nótese que el pico inicial es solamente un artefacto resultante de la diferenciación de los valores consecutivos del error de fase y no presenta ningún problema para el funcionamiento del lazo de seguimiento.

Las Figuras 6.6 y 6.7 presentan las respuestas del error de fase, el error de frecuencia, la estimación de frecuencia y la estimación de aceleración del lazo de seguimiento de portadora en presencia de una pertubación de la entrada de tipo escalón de frecuencia (rampa de fase). Es escalón de frecuencia aplicado en este caso es de $10 \mathrm{~Hz}$, que es un valor superior al máximo esperable según lo ya discutido en la sección 4.4.3.2 respecto de la máxima diferencia entre las frecuencias portadoras observadas por dos antenas del arreglo de entrada.

Puede verse en la mitad superior de la Figura 6.6 que la modificación brusca de la frecuencia de portadora provoca un adelantamiento gradual de la fase de la referencia respecto de la estimación del lazo, incrementando en la dirección de los reales positivos el error de fase del lazo. Puede notarse aquí la ventaja de contar con un discriminador 

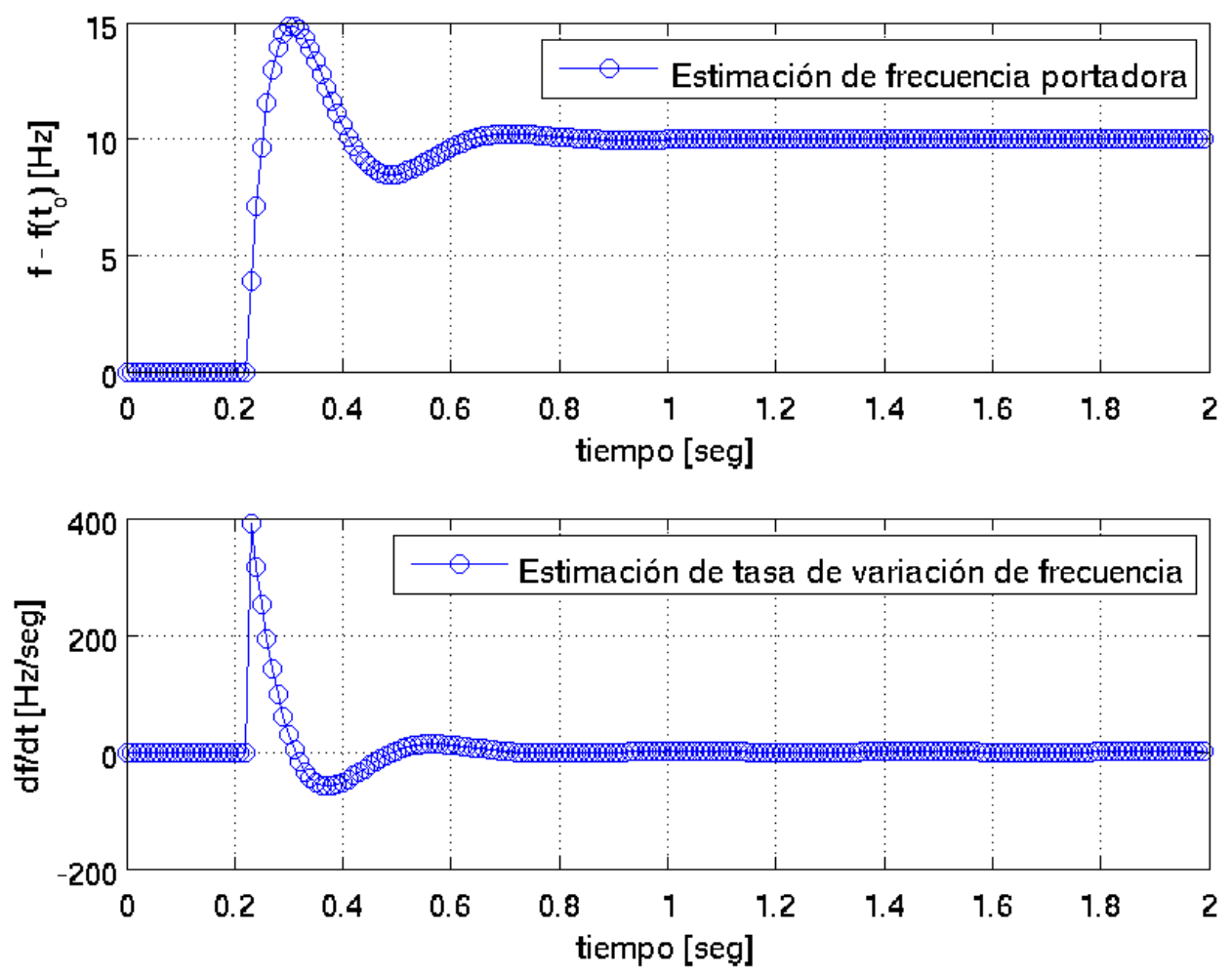

Figura 6.7: Simulación del comportamiento del lazo de seguimiento de portadora ante un escalón de frecuencia de $10 \mathrm{~Hz}$ en la referencia. (arriba) Estimación del lazo del valor de frecuencia portadora, relativo a su valor al comienzo de la simulación. (abajo) Estimación del lazo de la tasa de variación de la frecuencia, proporcional a la aceleración.

de fase de rango extendido como el UFA: el máximo error de fase ocurrido durante el transitorio de rechazo es mayor que $90^{\circ}$, lo que queda por fuera de la región de operación lineal de un discriminador arco tangente convencional.

El máximo error de frecuencia del lazo durante todo el transitorio cabe cómodamente dentro de la región de operación lineal del discriminador UFA, con un error pico de menos de la mitad del valor límite.

En la Figura 6.7 se ve que una vez finalizado el transitorio de rechazo de la perturbación, la estimación de frecuencia del lazo de portadora alcanza un valor final de coincidente con el escalón de frecuencia de $10 \mathrm{~Hz}$ ocurrido a la entrada.

Por último, las Figuras 6.8 y 6.9 corresponden a la evolución del lazo de seguimiento de portadora en presencia de una perturbación de tipo escalón de aceleración en la referencia. Para estas simulaciones la perturbación introducida en la entrada es la del peor caso posible: vector de aceleración colineal con el vector línea de vista entre el receptor y el satélite transmisor y de $10 \mathrm{~g}$ de magnitud. 

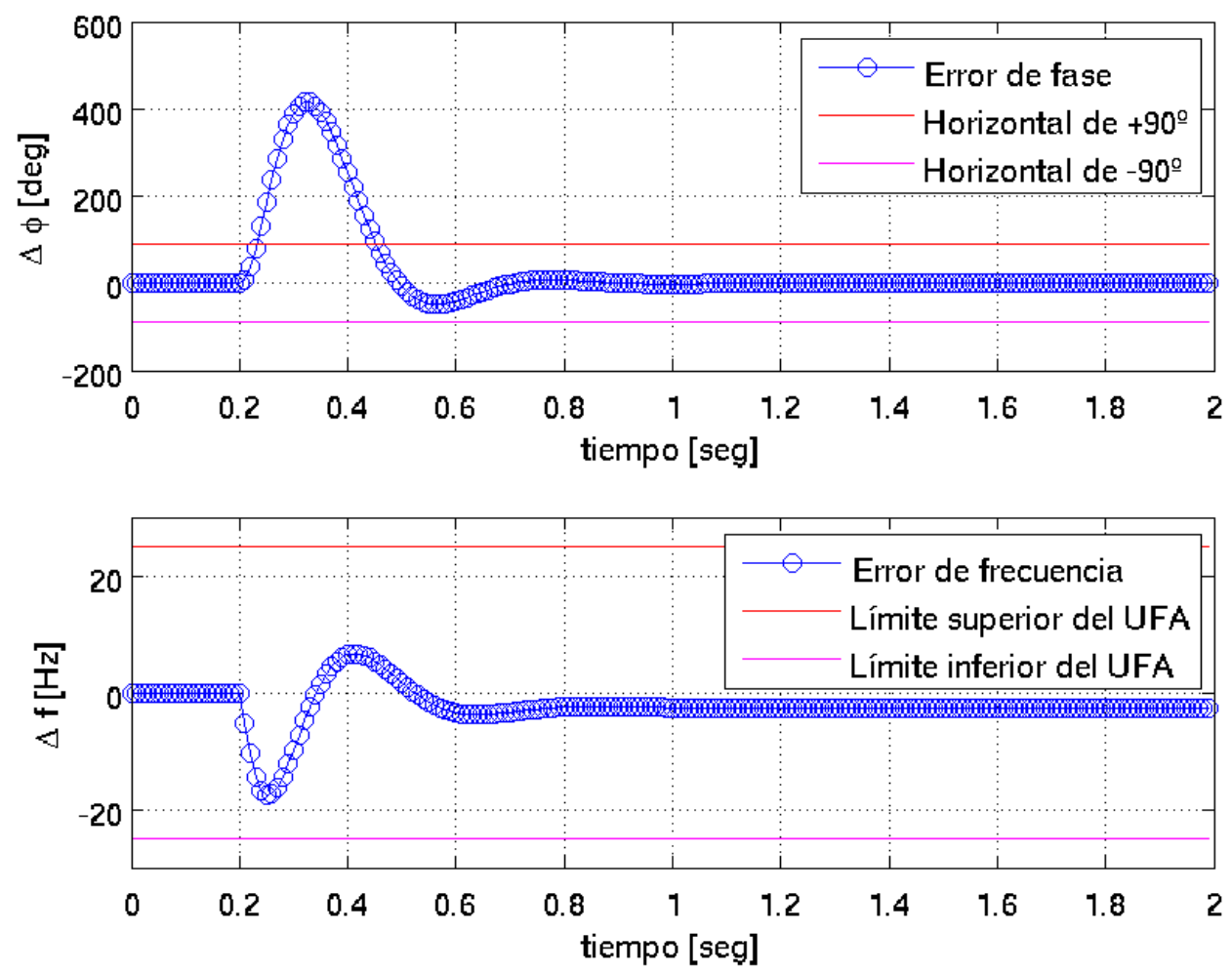

FigurA 6.8: Simulación del comportamiento del lazo de seguimiento de portadora ante un escalón de aceleración de $10 \mathrm{~g}$ en la referencia. (arriba) Error de fase del lazo. (abajo)

Error de frecuencia del lazo.

Aquí también puede verse la ventaja del discriminador UFA. En la gráfica del error de fase del lazo (mitad superior de la Figura 6.8) se observa que como consecuencia de la discontinuidad en la tasa de variación de la frecuencia, existe un transitorio en el error de fase del lazo que alcanza un valor pico superior a $400^{\circ}$ antes de comenzar a extinguirse, superando ampliamente el rango de operación de los discriminadores convencionales.

El error máximo de frecuencia nuevamente se encuentra cerca de la mitad de su rango máximo, lo que deja un margen de seguridad razonable para garantizar que una aceleración súbita no provocará la entrada de los lazos de seguimiento de portadora en una situación de falso enganche.

Debe notarse que una vez que se ha extinguido el transitorio de fase el lazo alcanza un estado estable donde el error de frecuencia no es cero (ver en Figura 6.8, extremo derecho de la gráfica del error de frecuencia). Esto se debe a que la estimación de frecuencia de un lazo discreto de seguimiento de fase no corresponde a la frecuencia instantánea en los instantes de muestreo, sino a un instante medio tiempo de muestreo antes. Esto no afecta el funcionamiento de los lazos, ya que como se puede ver incluso en las condiciones más extremas de aceleración la diferencia es pequeña, pero debe ser compensado al generar 

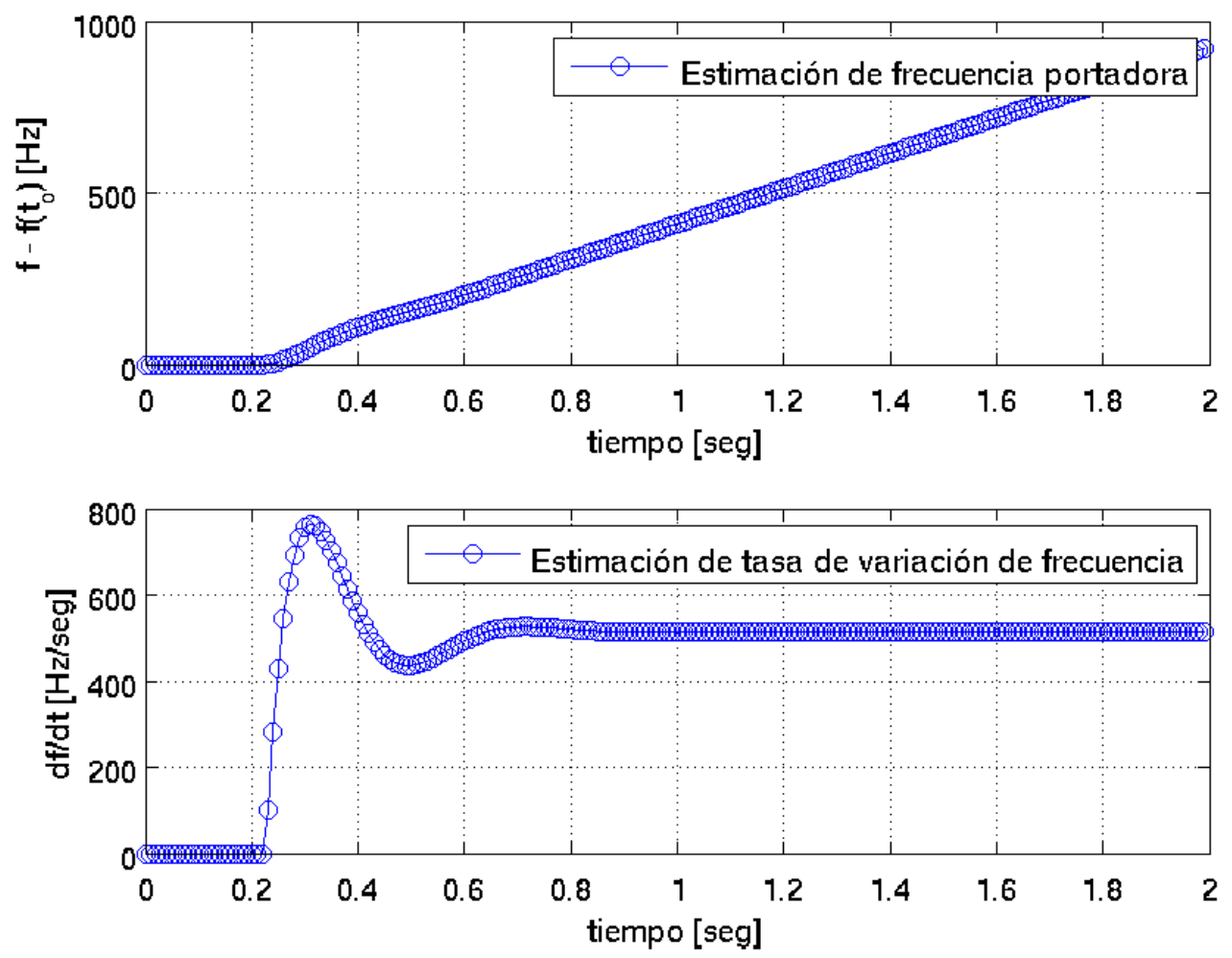

Figura 6.9: Simulación del comportamiento del lazo de seguimiento de portadora ante un escalón de aceleración de $10 \mathrm{~g}$ en la referencia. (arriba) Estimación del lazo del valor de frecuencia portadora, relativo a su valor al comienzo de la simulación. (abajo) Estimación del lazo de la tasa de variación de la frecuencia, proporcional a la aceleración.

observables para navegación o de lo contrario las mediciones resultarán sesgadas. La compensación es trivial utilizando la estimación de aceleración del lazo.

La estimación de la frecuencia portadora (Figura 6.9, arriba) muestra el tipo de evolución esperable en una condición de aceleración constante, en la que la frecuencia se incrementa de forma lineal a partir del momento de introducción de la perturbación. La tasa de variación es proporcional a la magnitud de la aceleración, según la expresión

$$
\frac{d f}{d t}=\frac{1}{\lambda_{c}} \frac{d v(t)}{d t}
$$

donde $\lambda_{c}$ es la longitud de onda de la portadora, que para GPS y GLONASS es de aproximadamente $19 \mathrm{~cm}$. Para la aceleración de $10 \mathrm{~g}$ simulada en este caso la derivada de la frecuencia es de aproximadamente $500 \mathrm{~Hz} / \mathrm{s}$. Este último valor puede observarse en la estimación interna de la aceleración que genera el lazo, visible en la mitad inferior de la Figura 6.9. 
Finalizando, puede verse a partir de las simulaciones que la utilización de un ancho de banda de ruido $B_{n}$ de $21 \mathrm{~Hz}$ alcanza un balance apropiado entre velocidad de respuesta ante diferentes tipos de perturbación de la entrada a la vez que se garantiza la operación del lazo en su región lineal. Contrario a lo que puede suponerse inicialmente, en las simulaciones anteriores se puede ver que la mayor exigencia para el lazo la presentan las perturbaciones de tipo escalón de fase, que pueden llevar el error de frecuencia hasta un valor pico del $80 \%$ de la cota de operación; los escalones de frecuencia y aceleración provocan errores máximos más cercanos al $50 \%$.

\subsubsection{Lazo de seguimiento de código}

A diferencia de la arquitectura del sistema de seguimiento de portadora, formado por los múltiples lazos de seguimiento de fase asociados a cada antena, el seguimiento del retardo de la función de código de cada señal GNSS se lleva a cabo utilizando un único lazo DLL de seguimiento de código, de forma muy similar a lo utilizado en receptores convencionales.

La asistencia de código relaja los requerimientos dinámicos de los lazos de código porque se utiliza la estimación de desviación de frecuencia Doppler de los lazos de portadora para ajustar la tasa de avance del lazo de código. Una interpretación posible es entonces que el lazo de código funciona deslizándose por encima de la dinámica rápida que resuelve la asistencia, ajustando solamente las variaciones lentas en el retardo de código debidas a dinámicas no relacionadas a la variación Doppler (como por ejemplo variaciones en el retardo de grupo atmosférico).

En ausencia de condiciones dinámicas apremiantes el factor determinante a la hora de elegir el ancho de banda de ruido $B_{n}$ del lazo DLL es entonces la sensibilidad al ruido de la estimación de retardo del lazo, la cual afecta de forma directa a la calidad de los observables de pseudorango que serán alimentados a los módulos de navegación. La estimación de retardo del lazo tendrá una componente de ruido de estimación esencialmente Gaussiano, de media cero, y de varianza $\sigma_{n}$ que será mayor cuanto mayor sea el ancho de banda de ruido $B_{n}$ del lazo: a mayor ancho de banda, menor es la calidad de la estimación. Esto sugiere una necesidad de minimizar el ancho de banda $B_{n}$ del lazo.

Debe notarse que la minimización de $B_{n}$ tiene otras consecuencias prácticas. La reducción del ancho de banda acarrea un incremento en la capacidad de promediado del lazo, que tiene como contracaras:

- Un empeoramiento de su tiempo de respuesta.

- El ensanchamiento de la función de autocorrelación de la estimación de retardo. 


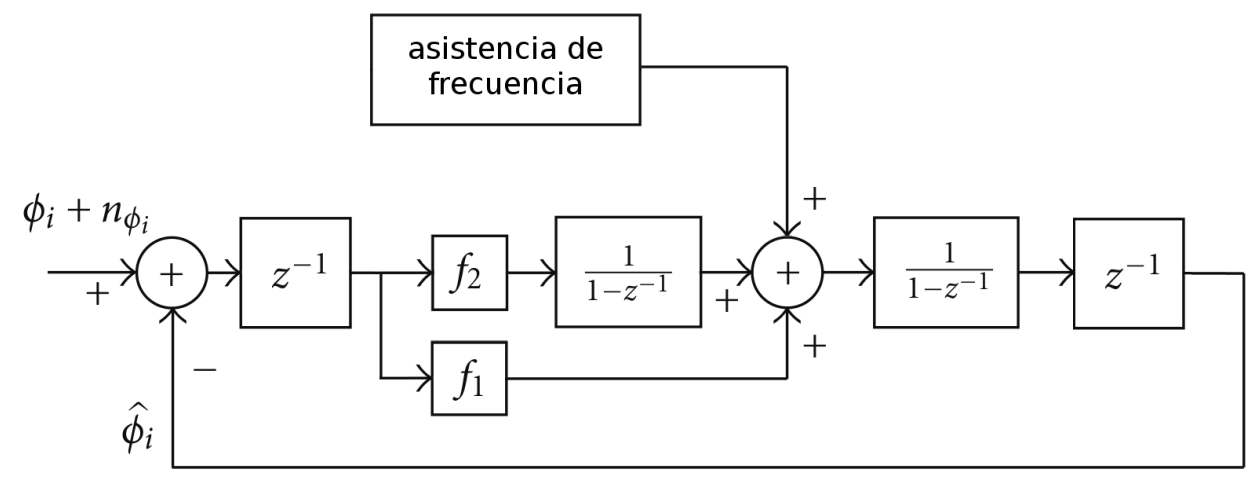

Figura 6.10: Modelo analítico del lazo discreto Tipo II de seguimiento de código. Se incluye en la figura la entrada de asistencia de frecuencia que proviene de los lazos de seguimiento de portadora.

El incremento en el tiempo de respuesta no es particularmente problemático en la práctica debido a lo reducido de la dinámica resultante una vez que los efectos Doppler han sido eliminados mediante asistencia. De hecho, el principal inconveniente de una constante de tiempo larga en el lazo de código no son las variaciones en los parámetros de la señal, sino la duración del transitorio inicial que ocurre cuando se inicia el seguimiento de una señal debido al error residual en la estimación del retardo resultante del proceso de adquisición.

Por otro lado, el ensanchamiento de la función de autocorrelación pone en riesgo la independencia entre los valores de retardo estimados a la salida del lazo. Típicamente la estimación del lazo de código será muestreada a intervalos regulares de aproximadamente un segundo para generar las mediciones que a su vez serán utilizadas para calcular soluciones de navegación con esa misma cadencia. Si la independencia entre muestras consecutivas es importante, como es el caso de sistemas de cálculo de navegación basados en filtrado Kalman, el ancho de banda de los lazos deberá ser consensuado con las necesidades de los algoritmos de navegación.

Dicho todo lo anterior, los valores típicos utilizados para el ancho de banda $B_{n}$ de los lazos de código están en el rango que va de $0,1 \mathrm{~Hz}$ a $1 \mathrm{~Hz}$, que permiten un buen compromiso entre calidad de las señales y la constante de tiempo del transitorio de rechazo a perturbaciones.

Dado lo reducido de los valores de anchos de banda de ruido necesarios, típicamente el diseño de los filtros de lazo de código se realiza mediante la utilización de la técnica de aproximación discreta de un filtro analógico, sin perjuicio alguno de la optimalidad del lazo resultante. 


\subsubsection{Detector de falsos enganches}

Tal como se discutió en la Sección 6.3.1.3, los lazos de seguimiento de portadora tienen un talón de Aquiles en el discriminador de fase, el cual es insensible a errores de frecuencia de $\pm \frac{1}{2 T_{I}}$ en la estimación de la frecuencia portadora.

Si bien como se vio en la Sección 6.3.1.4 un diseño cuidadoso de los lazos de seguimiento de portadora permite evitar la entrada en una condición de falso enganche debido a perturbaciones dinámicas en la señal de referencia, existen otras circunstancias que también pueden provocar la manifestación de este tipo de problema por lo que su existencia no puede ser completamente ignorada. Una estimación inicial deficiente del valor de frecuencia de portadora durante el proceso de adquisición, por ejemplo, puede desencadenar la inicialización de los algoritmos de seguimiento de la señal en condición de falso enganche desde su misma activación.

En pos de incrementar la robustez del diseño del receptor es conveniente contar con un mecanismo de detección del fenómeno de falso enganche para permitir la recuperación de un estado operativo saludable. En la Sección 6.3.1.3 se mencionaron varios esquemas de detección posibles, con sus ventajas y desventajas.

De los tres métodos presentados sólo el primero y el tercero son relevantes para el receptor aquí presentado. El segundo método carece de aplicabilidad debido al requerimiento de operar con señales de los sistemas GPS y GLONASS, que requiere de soluciones aplicables a ambos sistemas.

El primer método está basado en el monitoreo de la coherencia del mensaje de navegación demodulado, lo cual forma parte integral del proceso de decodificación del mismo. Este método no será tratado aquí por exceder el alcance de la presente tesis, pero basta decir que su implementación (prácticamente trivial) consiste en imponer una cota máxima al tiempo necesario lograr/recuperar la sincronización con las estructuras de datos que forman el mensaje de navegación (subtramas GPS, y lineas GLONASS). Esta condición de sincronismo puede verificarse mediante la comprobación de los códigos de detección y corrección de errores presentes en el mensaje de navegación, confirmación del valor de campos invariantes en el mensaje y de aquellos cuyos valores pueden ser anticipados (contadores, indicadores de tiempo, etc). Superado ese tiempo se declara la existencia de una anomalía y se procede a terminar el seguimiento de la señal generadora de los datos. Este método permite detectar, entre otros problemas, la presencia de falsos enganches de frecuencia. El tiempo medio hasta la detección dependerá de la elección particular de umbrales que haya sido utilizada, pero típicamente será del orden de algunos segundos para evitar falsos positivos. 
El método restante es el que será detallado aquí, debido a que se encuentra íntimamente relacionado con el diseño del lazo de seguimiento de código. La técnica explota la cualidad del lazo DLL de seguimiento de código de poder contar con una estimación no ambigua de la frecuencia de la señal seguida.

Se sabe que las desviaciones Doppler de portadora y código guardan una relación bien definida, por lo que la estimación de frecuencia del lazo de código permite contar con una estimación de la frecuencia portadora independiente de la realizada por el PLL de seguimiento de portadora. No obstante, la alta sensibilidad al ruido del lazo de seguimiento de código hace que la estimación de frecuencia de este lazo sea de una calidad muy inferior a la del lazo de portadora, razón por la que esta última se prefiere para la generación de observables de desviación de frecuencia.

Sin embargo, una ventaja de la estimación de frecuencia del lazo de código por encima de la de los lazos de portadora es la de estar totalmente libre de problemas de falso enganche, lo que abre la puerta para su para conformar un detector de falsos enganches del lazo de portadora.

En una condición operativa saludable, las estimaciones de frecuencia de uno y otro lazo deben guardar la misma relación $K$ que guardan la frecuencia nominal de portadora y la frecuencia nominal de código transmitidas por cada satélite.

$$
\Delta f_{\text {cod }}=K \Delta f_{\text {car }}
$$

Para la señal GPS C/A el valor de $K$ es siempre 1/1540. Para GLONASS L1OF, en cambio, el valor de $K$ depende del canal $k \in[-7, \ldots, 6]$ utilizado por cada satélite para transmitir su señal; en el caso del canal GLONASS L1OF central (el de $k=0$ ) $K \approx$ 1/3135, y para los demás canales toma valores semejantes.

En una condición de falso enganche se producirá un error en la estimación de frecuencia del lazo de portadora mientras que la estimación del lazo de código será correcta, por lo que el receptor podrá utilizar el incumplimiento de la relación anterior para detectar la situación anómala.

Por supuesto esta técnica requiere de la existencia de una estimación de frecuencia explícita en el lazo de seguimiento de código. Conviene en este sentido la utilización de lazos de Tipo II o superior, cuya implementación puede hacerse de forma tal de exponer una estimación de la tasa de código de forma explícita.

Generalmente el receptor utilizará asistencia de frecuencia desde el lazo de portadora para reducir los requerimientos dinámicos del lazo de código, como en el esquema mostrado 
en la Figura 6.10. En este caso la estimación de frecuencia del lazo de código normalmente será nula ya que en este caso toda la información que necesita de las variaciones de frecuencia llega a través de la asistencia.

En presencia de una condición de falso enganche en el lazo de portadora se producirá un error en la estimación de la tasa de avance de código que se alimenta a través de la asistencia al lazo de código. Este error será percibido como una perturbación que será compensada por el lazo ajustando su estimación interna de la tasa de avance de código. Esta estimación de frecuencia no nula en el lazo de código es el indicador de que existe un falso enganche de frecuencia.

Dado que un falso enganche de frecuencia produce un error de $\pm \frac{1}{2 T_{I}} \mathrm{~Hz}$ en la estimación de frecuencia del PLL, la magnitud de la perturbación percibida por el DLL asistido será entonces

$$
\Delta f_{\text {cod }}= \pm K \frac{1}{2 T_{I}}
$$

El detector de falsos enganches puede implementarse como un detector de cero: mientras la estimación de frecuencia del lazo de código es aproximadamente nula, el estado de operación del lazo de portadora es saludable. El umbral de detección se toma a mitad de camino del valor anterior, que coincide con el límite del rango de frecuencias aceptable con el UFA. Un posible falso enganche se detecta entonces si se cumple que

$$
\frac{\left|\Delta f_{\text {cod }}\right|}{K}>\frac{1}{4 T_{I}}
$$

Esta técnica se encuentra con un problema práctico debido a la sensibilidad al ruido del lazo DLL. Una caracterización estadística del detector se puede encontrar en el Apéndice A. Se prueba allí que la estimación de frecuencia del lazo de código asistido puede modelarse como una variable aleatoria Gaussiana de media nula y varianza que es función de la relación $C / N_{o}$ de la señal, de la separación entre los correladores Early y Late, de la tasa de chips del código $T_{c h i p}$, y del ancho de banda $B_{n}$ con el que haya sido diseñado el lazo. La expresión de la varianza se puede encontrar en la expresión (A.24).

A partir de lo anterior se puede deducir con facilidad que la estimación del error de frecuencia del lazo de portadora que se puede obtener utilizando el esquema propuesto es, en ausencia de falso enganche, una variable aleatoria Gaussiana, de media cero, y con desviación estandar:

$$
\sigma_{f}=K \sqrt{\frac{16}{27} \frac{B_{n}^{3}}{\frac{C}{N_{o}}} \frac{\Delta}{T_{c h i p}}} .
$$

En la expresión anterior la varianza está en unidades de $[\mathrm{Hz}]$. 


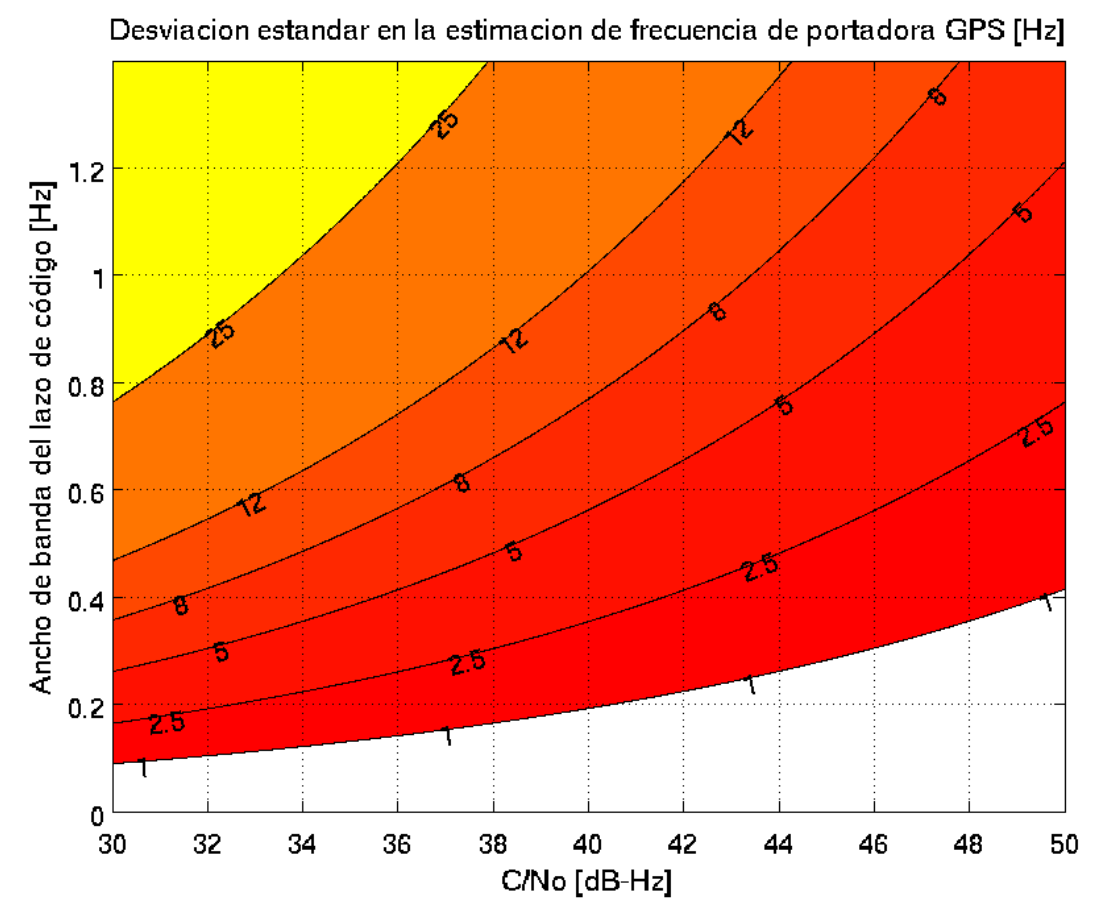

Figura 6.11: Desviación estándar de la estimación de error de frecuencia de portadora en función del ancho de banda $B_{n}$ del lazo de código y de la relación $C / N_{o}$ de la señal, y para el caso de GPS.

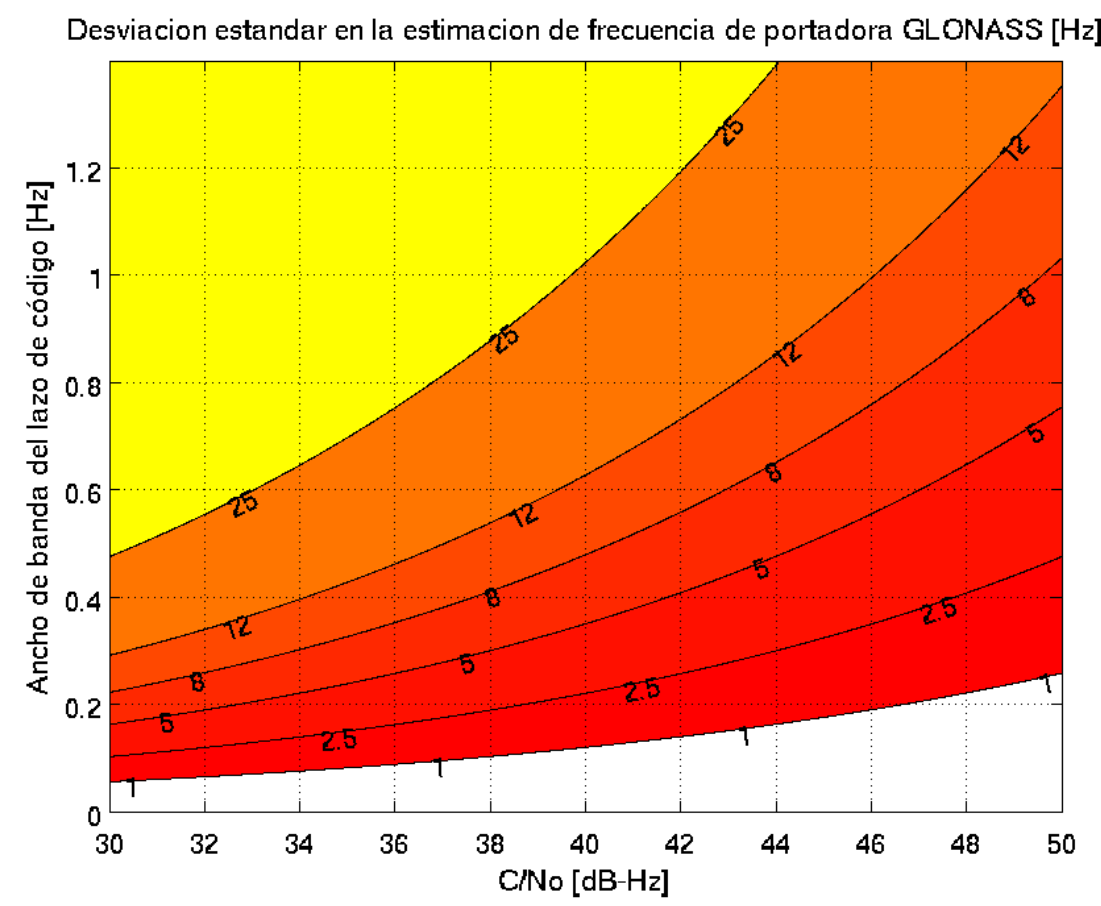

FiguRa 6.12: Desviación estándar de la estimación de error de frecuencia de portadora en función del ancho de banda $B_{n}$ del lazo de código y de la relación $C / N_{o}$ de la señal, y para el caso de GLONASS (canal $k=0$ ). 
El efecto de la expresión anterior puede verse en la Figura 6.11 y la Figura 6.12, donde se ve representada la desviación estándar $\sigma_{f}$ como función del ancho de banda $B_{n}$ y la relación $C / N_{o}$, para GPS y GLONASS (canal $k=0$ ) respectivamente. Se asume una separación entre correladores $\Delta$ igual a $1 T_{\text {chip }}$ por ser lo más clásico, en el entendimiento de que valores más pequeños permitirán mejoras en el desempeño del detector. La diferencia entre las curvas de uno y otro sistema se deben exclusivamente a la diferencia en el valor de $K$ en un caso y en otro, ya que el cociente $\Delta / T_{\text {chip }}$ es el mismo para ambos sistemas.

Para el valor del tiempo de integración $T_{I}$ de $10 \mathrm{~ms}$ el umbral de detección de un falso enganche está en $25 \mathrm{~Hz}$. En la Figura 6.13 pueden verse las curvas de nivel correspondientes a la probabilidad de falsa alarma del detector para una señal GPS en función del ancho de banda de ruido $B_{n}$ y de la relación $C / N_{o}$. En la Figura 6.14 se ve lo mismo para el caso GLONASS $k=0$. Nuevamente, la diferencia entre unas y otras curvas se debe a la diferencia en el valor de la constante $K$.

Puede verse en las figuras anteriores que la probabilidad de falsa alarma crece rápidamente al aumentar el ancho de banda de ruido $B_{n}$ de diseño del lazo. En caso de que los requerimientos desde el sistema de navegación exijan valores $B_{n}$ incompatibles con el valor de probabilidad de falsa alarma deseado el algoritmo del detector puede ser modificado para no declarar un falso enganche hasta que varios ensayos independientes así lo indiquen.

Tal como se deduce hacia el final del Apéndice A, la latencia entre la aparición de un falso enganche y la detección del mismo es aproximadamente igual a una constante de tiempo $\tau_{s}$, calculada como

$$
\tau_{s}=\frac{3}{4 B_{n}} .
$$

Para valores útiles del ancho de banda del lazo de código, este tiempo es de entre algunos segundos y una decena de segundos, aproximadamente el mismo retardo que tiene la detección de falsos enganches mediante detección de problemas en la demodulación del mensaje de navegación.

\subsubsection{Diseño del filtro de lazo}

La arquitectura del sistema de seguimiento de código está compuesta por un único lazo de seguimiento de código que procesa las muestras de la antena activa, recibiendo asistencia de frecuencia desde el lazo de seguimiento de portadora de dicha antena.

Si bien en arquitecturas de lazo de código asistido suele limitarse la complejidad de este último a un lazo simple de Tipo I, con el fin de implementar el detector de falsos 


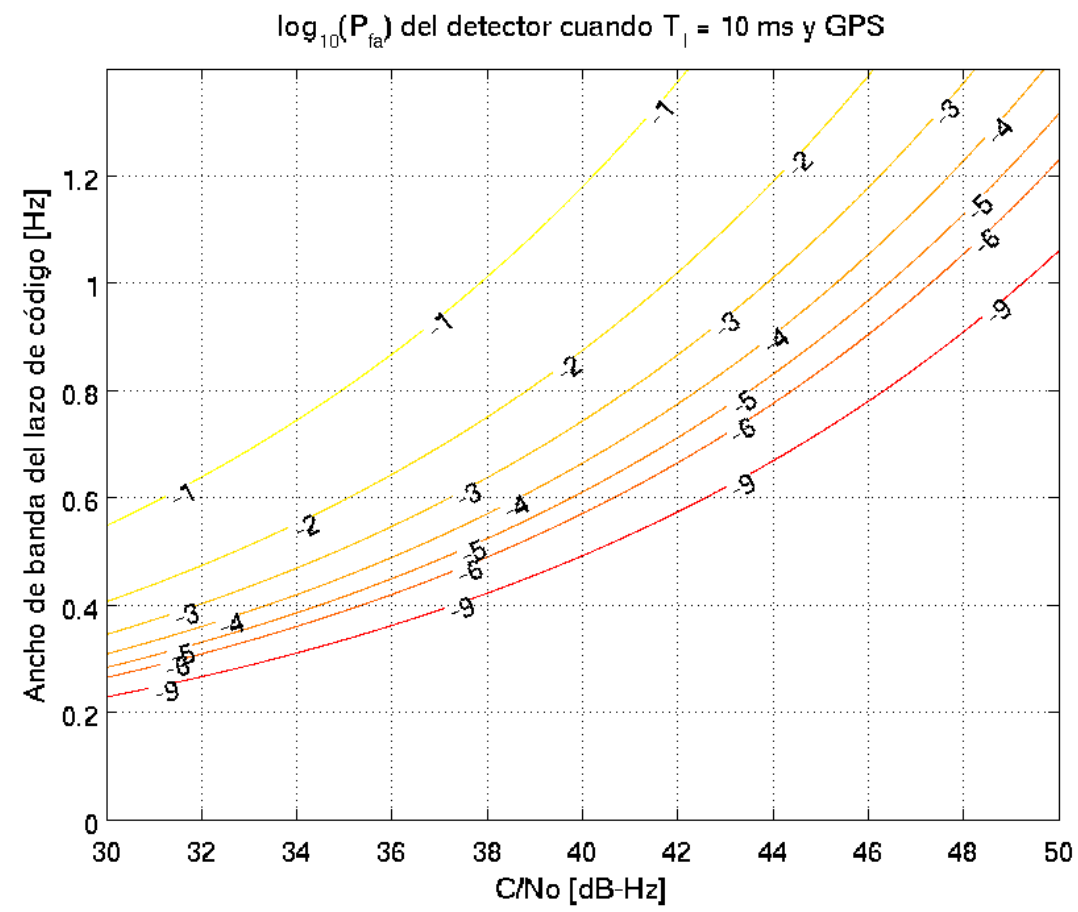

Figura 6.13: Probabilidad de falsa alarma del detector de falsos enganches en función del ancho de banda $B_{n}$ del lazo de código y de la relación $C / N_{o}$ de la señal, para el caso de GPS.

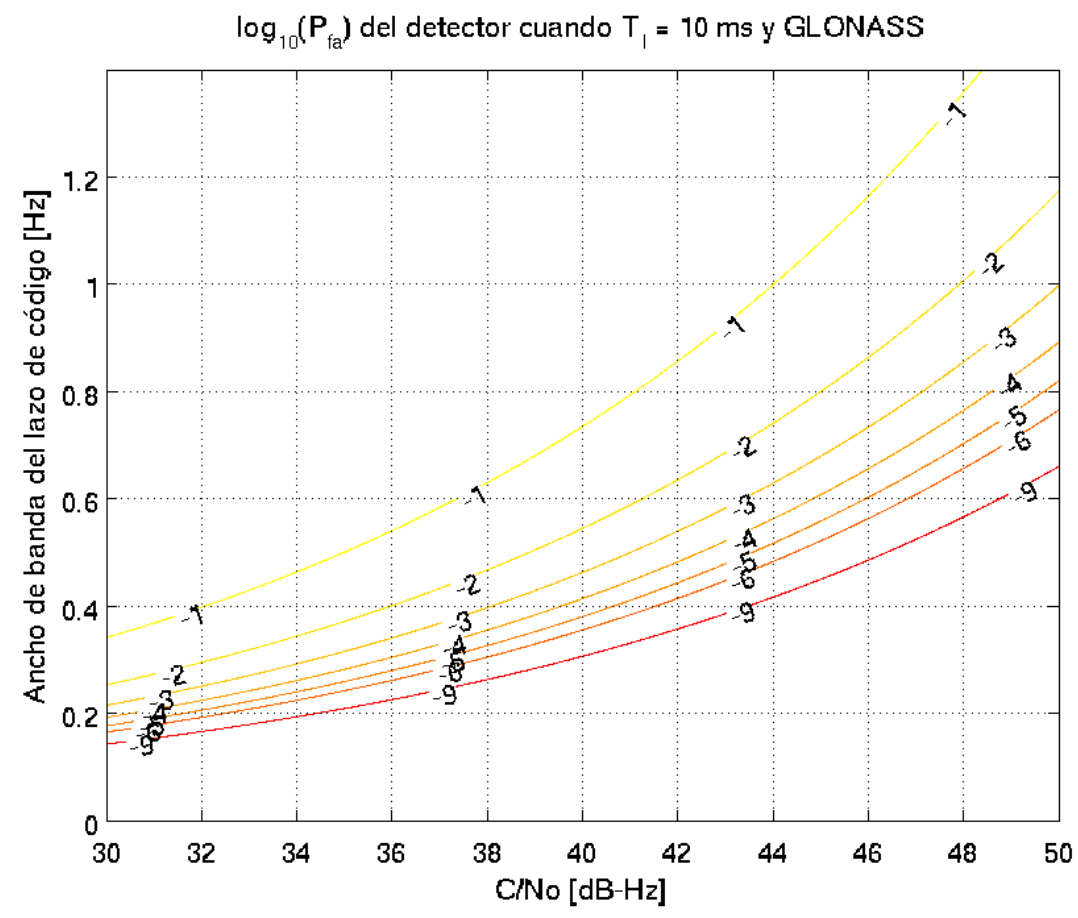

FiguRA 6.14: Probabilidad de falsa alarma del detector de falsos enganches en función del ancho de banda $B_{n}$ del lazo de código y de la relación $C / N_{o}$ de la señal, para el caso de GLONASS (canal $k=0$ ). 


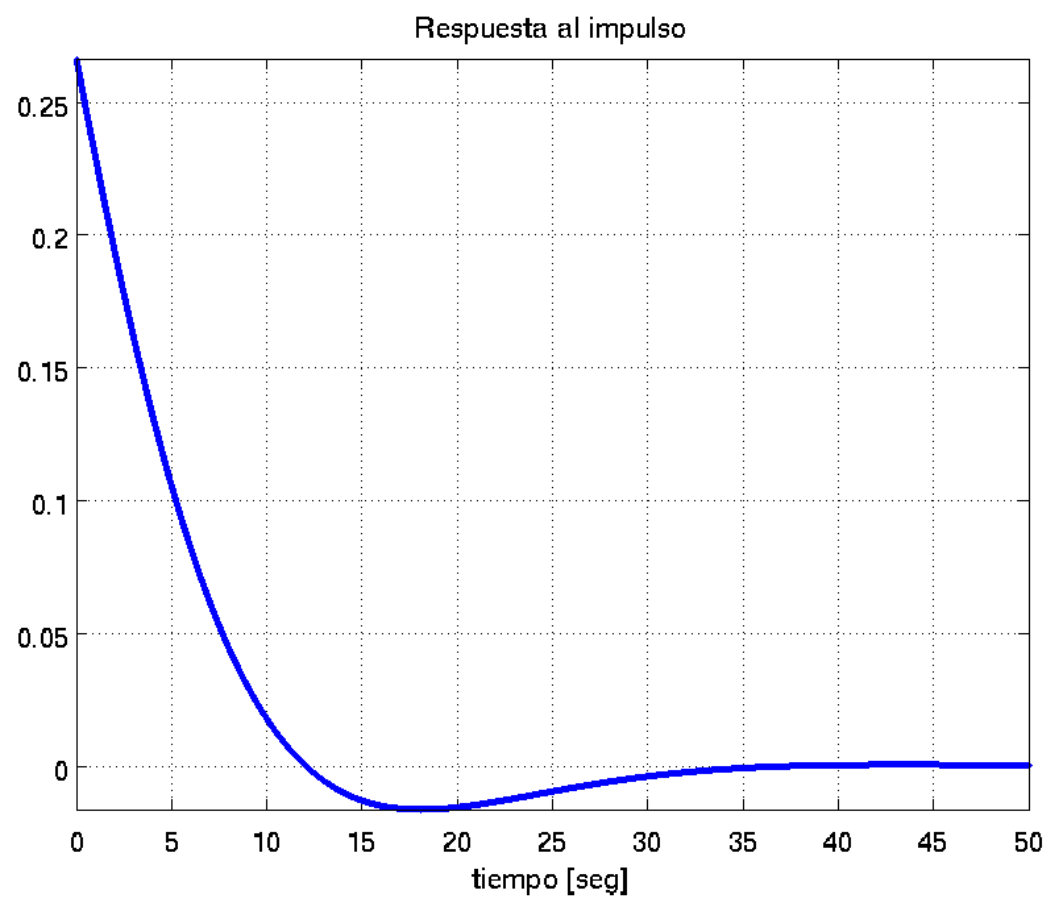

Figura 6.15: Respuesta al impulso del lazo de seguimiento de código simulado.

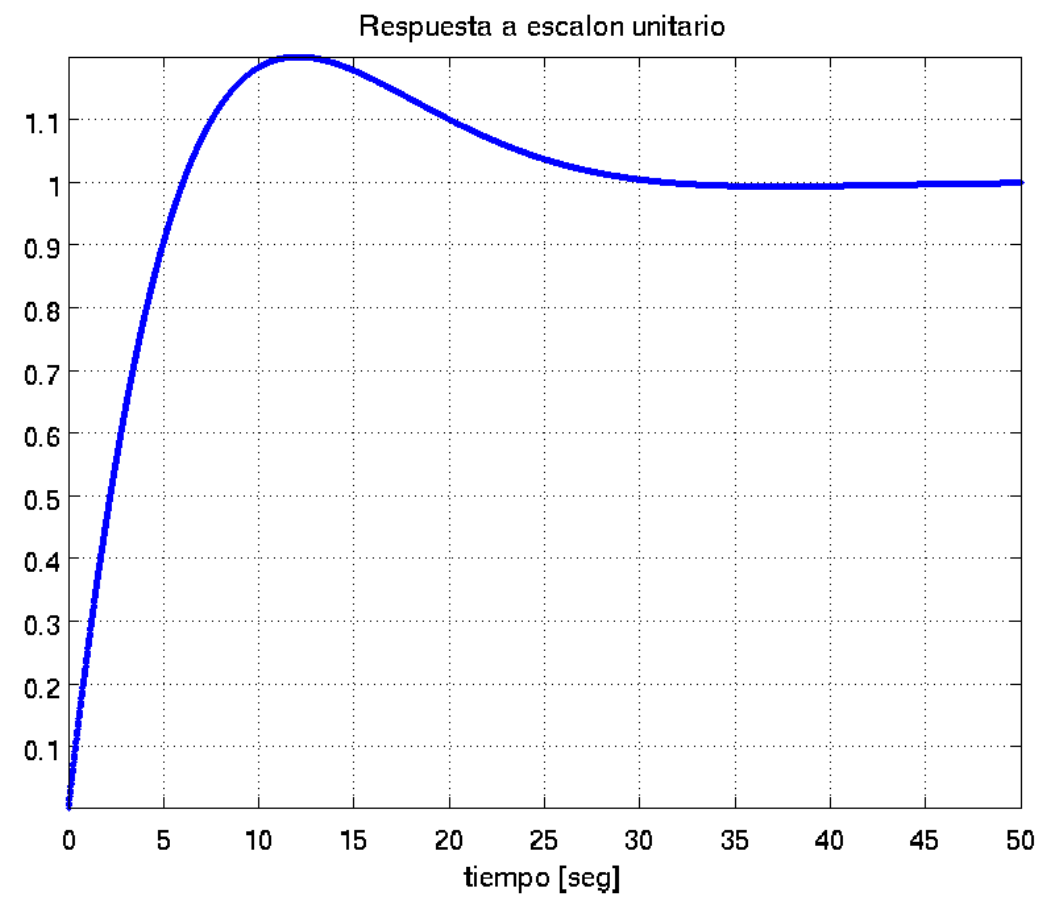

Figura 6.16: Respuesta al escalón del lazo de seguimiento de código simulado. 
enganches de frecuencia discutido en la Sección 6.3.2.1 el diseño actual utiliza un diseño de Tipo II óptimo como el mostrado en la Figura 3.18. El sistema discreto equivalente, en el que han incluido la asistencia de frecuencia desde el sistema de seguimiento de portadora y los ineludibles retardos introducidos por el hardware de correlación se puede ver en la Figura 6.10.

El ancho de banda de ruido $B_{n}$ se seleccionó en un valor típico para lazos de este tipo, $0,1 \mathrm{~Hz}$, que además tiene la ventaja de presentar una muy baja probabilidad de falsa alarma en el detector de falsos enganches de frecuencia. Esta decisión se vio facilitada por el hecho de que en la actualidad no existe ningún tipo de requisito concreto respecto de la independencia en el ruido que afecta a los observables de tiempo de transmisión que usa el módulo de navegación del receptor.

En la Figura 6.15 puede verse la repuesta al impulso de la transferencia del lazo de seguimiento de código, mientras que en la Figura 6.15 se ve la repuesta ante un escalón de fase en la entrada. Esta última figura presenta el tipo de transitorio que sufrirá inicialmente inmediatamente después de su activación el lazo de código, como consecuencia del error residual en la estimación de la fase de código que resulta del proceso de adquisición.

En ambas figuras puede verse lo lento de la dinámica del lazo como consecuencia de la elección del valor de $B_{n}$. Debido a la naturaleza asistida del lazo de código esto no presenta problemas mayores para todas aquellas dinámicas comunes entre portadora y código.

La latencia $\tau_{s}$ del detector de falsos enganches en este caso es de aproximadamente 7,5 seg entre evento y detección. La verificación se hace cuatro veces por segundo, y la probabilidad de falsa alarma es inferior a $10^{-9}$, por lo que el tiempo medio entre falsas alarmas es del orden de 69000 horas. .

\subsection{Resumen de capítulo}

Este capítulo se dedicó enteramente a la discusión del conjunto de algoritmos propuestos para llevar adelante el seguimiento de señales GNSS en el receptor multiantena. La introducción de este tema de forma previa a la discusión de los algoritmos de adquisición en el Capítulo 7 obedece a la intención de minimizar el solapamiento de temas, ya que una forma reducida de lazos de seguimiento se utiliza también durante las últimas etapas del proceso de adquisición.

Se presentó la arquitectura de seguimiento basada en la división de trabajo entre dos tareas de ejecución periódica, la TSS y la TSI. Estas están a su vez formadas por una 
colección de algoritmos encargados no solamente de actualizar los lazos de estimación de señal que son la base de cualquier sistema de comunicación digital, sino también los mecanismos de selección y conmutación de antenas, monitoreo de estado de señales, control de divergencia de estimadores, detección de desenganche, monitoreo de coherencia de mensaje modulado, etc.

Se dedicó un apartado especial al diseño de los lazos de seguimiento, tanto de portadora como de código, por ser éste un tema fundamental para permitir su operación en condiciones dinámicas con el nivel de exigencia que demandan los requerimientos planteados en el Capítulo 4. En este sentido se discutieron las técnicas de diseño de los filtros de lazo digitales utilizados para cada tipo de lazo (portadora y código), el funcionamiento del discriminador de fase de alcance extendido UFA, la problemática de los falsos enganches, y se realizaron simulaciones para lograr una relación adecuada de compromiso entre la capacidad de dinámica de los lazos para rechazar perturbaciones y los límites operativos de funcionamiento de los mismos.

Se posterga la presentación de los ensayos realizados sobre la implementación de los algoritmos de seguimiento en el software del receptor hasta el Capítulo 8, donde se presentarán resultados de ensayos dinámicos con dinámica acelerada y conmutación de antenas. 



\section{Capítulo 7}

\section{Algoritmos de adquisición multiantena}

\subsection{Introducción}

Al igual que ocurre con los algoritmos convencionales, el proceso de adquisición está compuesto de tres etapas principales que pueden verse en la Figura 7.1. La primera de estas etapas divide el espacio de búsqueda en una grilla formada por una cantidad finita de celdas, y recorre dicha grilla ensayando un único representante por celda en busca de potencia de señal.

Debido a que inevitablemente existe determinada cantidad de potencia de ruido presente en los resultados de correlación de todas las celdas, es necesario establecer un umbral mínimo de detección que permita distinguir señal de ruido. La elección de este umbral de detección es un balance entre la probabilidad de detección (que determina la sensibilidad del receptor) y la probabilidad de falsa alarma (que afecta el tiempo de adquisición).

La etapa de verificación tiene por objetivo reducir la cantidad de detecciones espurias, sometiendo la celda candidata a una serie de ensayos estadísticos que reduzcan la probabilidad de aceptación de una celda sin señal. Son solamente las celdas que superan esta segunda etapa las que entran en la etapa de sincronización, relativamente costosa en tiempo, que se encarga de obtener una estimación mucho más precisa de los parámetros de frecuencia portadora y retardo de la función de código, además de determinar el alineamiento de los pulsos del mensaje de navegación en la señal recibida.

Las principales diferencias entre el algoritmo para receptor multiantena y los algoritmos más convencionales tienen que ver fundamentalmente con la extensión del espacio de 


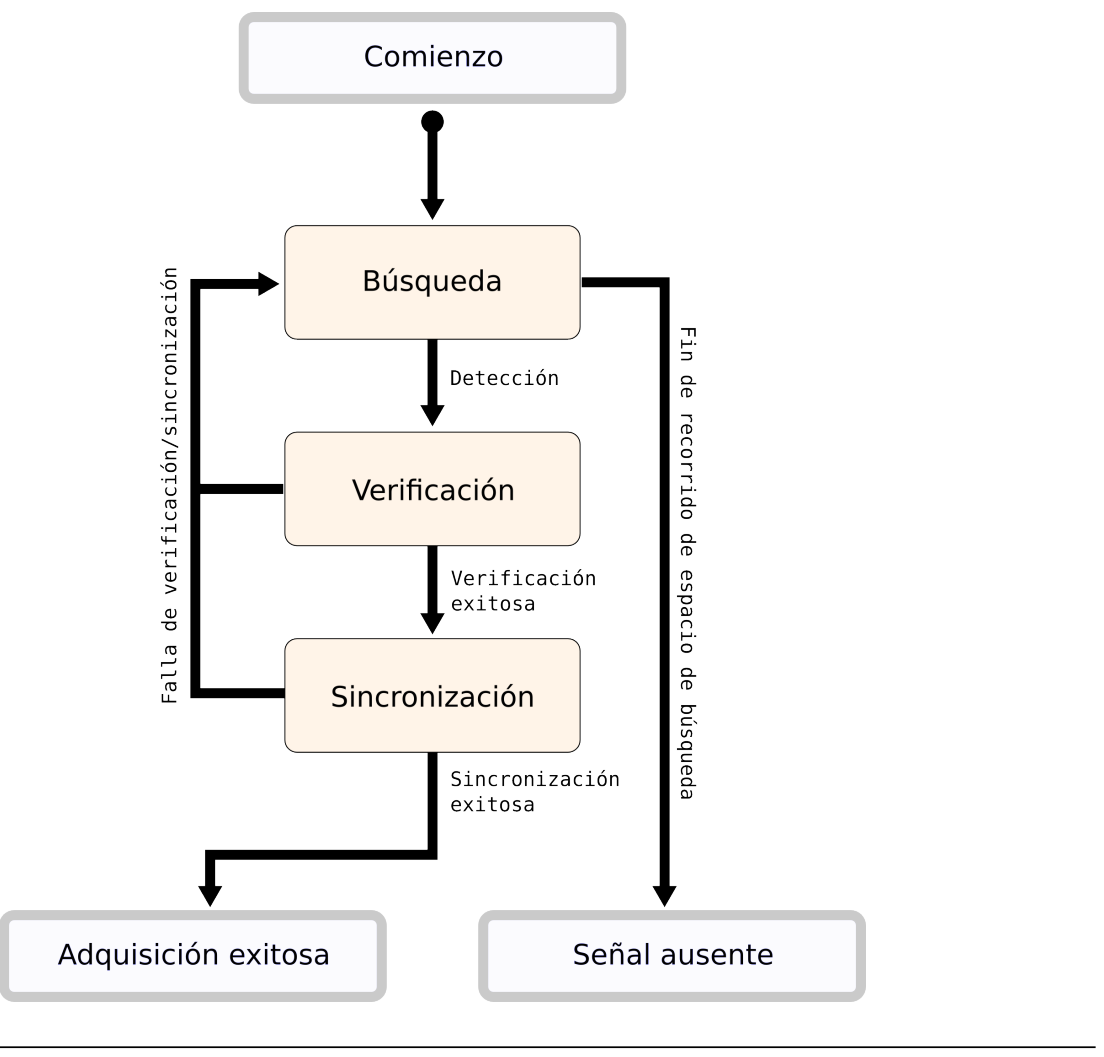

FigurA 7.1: Etapas principales en que se divide el proceso de adquisición.

búsqueda bidimensional clásico (el plano retardo-frecuencia) con una dimensión adicional, y con algunas restricciones adicionales causadas por la dinámica que debe ser capaz de tolerar el receptor. Por esta razón es que en este capítulo se intentará en la medida de lo posible no repetir aquellos conceptos que ya fueron vertidos en el Capítulo 3, poniendo énfasis en las características más propias de la implementación utilizada.

\subsection{Características de la adquisición multiantena}

Cada adquisición comienza con el establecimiento de los parámetros de la misma, que pueden verse resumidos en el Cuadro 7.1. Los dos primeros parámetros allí nombrados son de configuración del sistema, ya que establecen el tipo de función de expansión de espectro que se utilizará durante el proceso de búsqueda. En conjunto, ambos parámetros identifican de forma única una señal GNSS.

El concepto de señal durante la adquisición es el de un conjunto de parámetros que permiten demodular la transmisión de un satélite para su procesamiento. En el caso de GPS esto consiste en el número de secuencia pseudo-aleatoria (PRN) utilizada para expandir el espectro, que guarda una relación uno a uno con el identificador de satélite 


\begin{tabular}{|r|l|}
\hline Parámetro & Descripción \\
\hline System ID & Sistema. GPS o GLONASS. \\
Signal ID & Identificador de la señal a buscar. PRN GPS, o $k$-channel GLONASS. \\
$f_{c}$ & Frecuencia central del rango de búsqueda. \\
$f_{r}$ & Radio de búsqueda en frecuencia desde $f_{c}$. \\
$T_{c o h}$ & Tiempo de integración coherente. \\
$N_{c o h}$ & Repeticiones no coherentes. \\
$\Delta f$ & Repeticiones no coherentes. \\
$a_{m a s k}$ & Antenas habilitadas para la búsqueda. \\
\hline
\end{tabular}

CUADRo 7.1: Parámetros más relevantes del proceso de adquisición de una señal GNSS GPS/GLONASS en el receptor multiantena.

(SVID) por lo que la detección de una señal modulada usando un dado PRN identifica inmediatamente al satélite transmisor.

La situación es diferente para GLONASS debido a que este sistema utiliza una única secuencia de expansión de espectro para todos los satélites transmisores, diferenciándose unos de otros solamente por el canal FDMA utilizada por cada uno. Existen 14 señales GLONASS diferentes correspondientes a los canales FDMA existentes (ver Sección 2.3.4). Para acomodar los 24 vehículos activos de la constelación del sistema en estos 14 canales disponibles, múltiples satélites ubicados en posiciones orbitales antipodales entre sí se asignan al mismo canal. Como consecuencia de esta compartición de señales entre transmisores la sola adquisición de una señal GLONASS no permite por sí misma identificar al vehículo transmisor sin información adicional. Esta información identificatoria adicional se encuentra presente en el mensaje de navegación, cuya demodulación es un proceso posterior.

Los dos parámetros $f_{c}$ y $f_{r}$ establecen el rango de valores de frecuencia portadora que es necesario barrer en búsqueda de una dada señal. La elección de estos valores depende fundamentalmente de la cantidad de información con la que cuente el receptor antes de comenzar el proceso de adquisición. Una búsqueda ciega (sin información previa) por ejemplo, deberá barrer todo el espectro de valores de portadora posibles alrededor de la frecuencia portadora nominal. La incertidumbre en este caso está condicionada por la calidad del oscilador utilizado como referencia local en el receptor, y por el máximo desplazamiento Doppler esperable en las condiciones dinámicas de operación. Una búsqueda asistida con información externa, en cambio, puede acotar el rango de búsqueda utilizando la información orbital del satélite y de la posición y velocidad aproximada del receptor.

Con el fin de hacer más robusto el proceso de búsqueda frente a los efectos de la modulación de datos en las señales de los satélites, durante la búsqueda de señal se utilizan 
integraciones no coherentes. En este modo de operación el módulo de adquisición del hardware realiza $N_{c o h}$ integraciones convencionales de duración $T_{c o h}$ y devuelve una potencia total acumulada $R_{n c}$ que es la suma de las potencias de señal de todas ellas:

$$
R_{n c}=\sum_{i=1}^{N_{c o h}} I^{2}[i]+Q^{2}[i]
$$

donde $I^{2}[i]$ y $Q^{2}[i]$ son las componentes en fase y cuadratura de la i-ésimo período coherente de la correlación no coherente. La duración de la correlación en este caso es $T_{I}=N_{c o h} T_{c o h}$.

El paso de frecuencia utilizado $\Delta f$ determina el ancho en frecuencia de las celdas del plano de búsqueda. Si bien es un parámetro ajustable, su valor siempre debe mantener una relación adecuada con el ancho en frecuencia del lóbulo principal de correlación, que en el caso de correlaciones no coherentes está determinado por el tiempo de integración coherente $T_{c o h}$. Si bien es una convención habitual la utilización de la regla $\Delta f=\frac{2 / 3}{T_{c o h}}$, para este proyecto se prefirió una elección más conservadora de $\Delta f=\frac{1 / 2}{T_{c o h}}$ que mejora la sensibilidad de la adquisición a expensas de incrementar el tiempo que tomar recorrer el espacio de búsqueda.

No aparece en el Cuadro 7.1 ningún parámetro relativo a la fase de la función de código. El rango de búsqueda se toma siempre el rango completo de valores de fase posibles (1023 chips para GPS y 511 para GLONASS), dado que son contados los casos donde el receptor cuenta con información suficiente para acotar la adquisición en esta dimensión de forma exitosa. Por otro lado la dimensión de las celdas en la dimensión del retardo está establecido de forma rígida por el espaciado de los correladores en el módulo de adquisición del hardware, en $1 / 2$ chip.

Por último, el parámetro $a_{m a s k}$ es una lista de las antenas habilitadas para la búsqueda. Este parámetro permite limitar el proceso de adquisición a un subconjunto de las antenas de entrada para acotar la penalización en tiempo que significa ejecutar el proceso de búsqueda en todas las antenas del arreglo. Si bien al excluir antenas del proceso de adquisición se reduce la cobertura de direcciones de arribo posibles, un compromiso aceptable consiste en limitar el proceso de adquisición a pares de antenas antipodales (por ejemplo los pares $A 1$ y $A 3$ o $A 2$ y $A 4$ en el esquema de la Figura 4.6), notando que en esta configuración la apertura de los patrones de radiación de las antenas todavía permiten alcanzar un alto grado de cobertura mientras que el tiempo que toma recorrer el espacio de búsqueda se reduce aproximadamente a la mitad. 


\subsubsection{Entrelazado de planos de búsqueda entre antenas}

Tal como se vio en la Sección 5.3.1 el módulo de adquisición del hardware de correlación está compuesto por un generador de réplica de código, un generador de réplica de portadora y veinte módulos de correlación. Las fases de las réplicas de la función de código recibidas por cada uno de estos módulos de correlación están espaciadas entre sí por intervalos de 1/2 chip. Esta estructura permite al receptor agilizar los procesos de búsqueda de la señal en el plano retardo-frecuencia examinando hasta diez chips de la fase de la función de código de forma simultánea.

A diferencia de lo que ocurre con el módulo de seguimiento, el módulo de adquisición solamente puede calcular la correlación de las réplicas con la señal proveniente de una única antena de entrada por ciclo de operación, la cual es seleccionada de entre las cuatro entradas disponibles mediante uno de los parámetros de configuración de la correlación. Es por lo tanto responsabilidad de los algoritmos de adquisición iterar entre todas las antenas para detectar la presencia de la señal buscada.

Esta aproximación es económica en recursos de hardware pero tiene un costo muy importante en tiempo, ya que el tiempo total que toma recorrer el espacio de búsqueda se ve multiplicado por tantas veces como antenas de entrada sean examinadas, comparado con el tiempo que tomaría en un receptor monoantena convencional en igualdad de todos los demás parámetros de la adquisición (dimensiones del plano, tamaño de las celdas, tiempo de correlación, etc.).

Existen por supuesto múltiples formas de serializar los procesos de búsqueda en todas las antenas. Trivialmente, puede tomarse al menos dos variantes principales

Seriado Para cada antena, barrer la totalidad del plano de búsqueda correspondiente antes de pasar a la antena siguiente.

Entrelazado Para cada celda del plano de búsqueda barrer todas las antenas de entrada, entrelazando en el tiempo los procesos de búsqueda en diferentes antenas.

La primera opción es naturalmente la extensión más simple de los algoritmos monoantena del Capítulo 3. No es obvio a primera vista que este método tenga desventajas adicionales frente a la variante entrelazada, y de hecho ciertamente no tiene ninguna en un escenario de operación estático (vehículo quieto).

Rápidamente aparecen problemas, sin embargo, en un escenario dinámico. El tiempo que toma recorrer un plano completo puede calcularse mediante la expresión

$$
t_{p}=T_{I} \frac{\Delta f}{f_{s}} \frac{N_{\text {chips }}}{\left(\frac{1}{2} N_{\text {corr }}\right)}
$$


donde $T_{I}$ es el tiempo de integración, $\Delta f$ es el ancho de la banda de frecuencias a examinar, $f_{s}$ es el paso en frecuencia de la grilla de búsqueda, $N_{c o r r}$ es la cantidad de correladores simultáneos en el hardware y $N_{\text {chips }}$ es la cantidad de chips de la función de código del sistema (1023 para GPS y 511 para GLONASS). La expresión asume una separación de 0,5 chips entre correladores del hardware. El tiempo total $t_{t}$ que toma completar el proceso de búsqueda en todas las antenas de peor caso es

$$
t_{t}=N_{\text {ant }} t_{p}
$$

donde $N_{a n t} \leq 4$ es la cantidad de antenas involucradas en el proceso de adquisición.

Dando valores típicos para una búsqueda ciega a las variables anteriores $(\Delta f=10 \mathrm{kHz}$, $f_{s}=250 \mathrm{~Hz}, N_{\text {corr }}=20$ y $T_{I}=4 \mathrm{~ms}$ ) se puede verificar que los tiempos que toma recorrer el plano de búsqueda son de aproximadamente 16 seg para GPS y 8 seg para GLONASS. Comparando esto con la velocidad de giro máxima del vehículo donde está montado el arreglo de antenas (4 rpm) es fácil ver que no es posible garantizar que el proceso de adquisición, aún recorriendo todas las antenas, examine todas las direcciones de arribo posibles.

Un recorrido del espacio de búsqueda en forma entrelazada examina cada celda del plano de búsqueda en todas las antenas de entrada antes de pasar a la celda siguiente. De esta forma cada combinación de frecuencia portadora con retardo de la grilla se examina para todas las direcciones de arribo posibles en un tiempo igual a $N_{\text {ant }} T_{I}$. Dado que para valores prácticos de la cantidad de antenas y del tiempo de integración $N_{a n t} T_{I}$ es mucho menor que el tiempo que un ciclo de rotación del vehículo, se garantiza que independientemente de los cambios que sufra la orientación del arreglo de antenas durante el tiempo que toma el barrido del espacio de búsqueda, todas las celdas del plano serán examinadas en todas las direcciones de arribo posibles. El tiempo de peor caso sigue siendo el que indica la expresión (7.3).

\subsubsection{Recorrido del plano de búsqueda}

La forma de recorrido de las celdas del plano retardo-frecuencia en el receptor es similar a lo utilizado en un receptor convencional. La dimensión de la frecuencia es recorrida en sentido radial, comenzando a la frecuencia central $f_{c}$ y alejándose de ella hacia ambos bordes simultáneamente hasta cubrir toda la región de búsqueda. Esto minimiza el tiempo medio de adquisición en el caso de señales presentes, mientras que no modifica el tiempo de peor caso (señal ausente). 
La dimensión del retardo se recorre en sentido de retardo creciente. Esto es contrario al sentido intuitivo (deben recorrerse las fases de código en sentido decreciente en lugar de creciente), pero es una medida que otorga robustez al receptor cuando este se enfrenta a casos de multicamino intenso. Esto es así porque este sentido de recorrido garantiza que el receptor siempre encuentra primero la señal de rayo directo antes que cualquier versión con retardo adicional causada por rebotes de la señal en el entorno alrededor de las antenas.

\subsubsection{Verificación inmediata de candidatos}

El algoritmo de adquisición es un algoritmo ávido, ya que la verificación de una celda candidata que supera el umbral de detección se realiza de forma inmediata tan pronto como es detectada. Si la verificación y sincronización posteriores son exitosas, se declara la señal presente en las coordenadas de la detección. Si en cambio la verificación o la sincronización posteriores tienen problemas para recuperar una señal consistente se declara la celda candidata como una falsa alarma y se retoma el proceso de búsqueda en el punto del plano de búsqueda donde se abandonó anteriormente.

Este tipo de estrategia minimiza el tiempo medio de adquisición de señales presentes, comparado con otros algoritmos que esperan a haber recorrido todo el espacio de búsqueda antes de verificar un único candidato (el punto con mayor potencia de correlación de todo el espacio recorrido, generalmente), algo que como se vio anteriormente puede tomar una cantidad considerable de tiempo.

Una aproximación ávida a la verificación de celdas candidatas también reduce la posibilidad de no poder verificar detecciones exitosas debido a que la señal se desplazó de posición en el espacio de búsqueda durante el intervalo de tiempo que transcurre entre la detección y una verificación diferida. Esto puede ocurrir si el vehículo se encuentra rotando (provoca un cambio en la antena expuesta a la señal) o en condición acelerada (cambio de la desviación Doppler de la portadora y la tasa de avance de la función de código).

Por otro lado, la estrategia de verificación ávida es particularmente sensible a la elección del umbral de detección. Si la probabilidad de falsa alarma es demasiado elevada el avance del proceso de búsqueda por el espacio de posibilidades de búsqueda será frecuentemente interrumpido por los procesos de verificación de las falsas detecciones. Dado que la verificación es una operación relativamente costosa en tiempo, esto prolongará el tiempo total que toma hacer una adquisición. 


\subsubsection{Umbral de detección}

En el Apéndice B se establece que la probabilidad de que una celda libre de señal supere un umbral $U$ es

$$
P_{f a}(u)=e^{-N_{c o h} u} \sum_{n=0}^{N_{c o h}-1} \frac{1}{n !}\left(N_{c o h} u\right)^{n}
$$

donde $u=\frac{U}{\mu_{r}}$ es el umbral expresado de forma relativa a la potencia media de correlación de ruido. El desarrollo asume que el ruido que afecta cada una de las integraciones coherentes que suman en potencia para generar el resultado de la correlación no coherente es independiente, Gaussiano y circularmente simétrico, lo cual es cierto cuando el ruido que afecta a la señal a la entrada de la antena es AWGN.

Con el fin de mantener una dada probabilidad de falsa alarma $P_{f a}$ se selecciona el umbral relativo $u$ a partir de la expresión anterior (por ejemplo utilizando las curvas de la Figura B.1 del Apéndice B), y se realiza una estimación de la potencia media muestral del piso de ruido:

$$
\hat{u_{r}}=\frac{1}{N} \sum_{i}^{N} R_{n c}[i] .
$$

El umbral de detección estimado se calcula entonces simplemente como

$$
\hat{U}=\hat{u_{r}} u
$$

\subsubsection{Procesamiento segmentado}

La mecánica de funcionamiento del módulo de correlación está marcada por el ciclo característico de uso, formado por tres etapas bien definidas: configuración de los parámetros de la correlación, cálculo de la correlación en el hardware y procesamiento de los resultados de la misma. Esto fue discutido oportunamente en la Sección 5.3.1, y representado gráficamente en la Figura 5.6.

Esta característica es importante para el diseño de los algoritmos de adquisición, los cuales para minimizar el tiempo de ejecución de todas sus tareas deben solapar en el tiempo el procesamiento de cada uno de los cálculos de correlación individuales necesarios. En cada ciclo de procesamiento el software debe procesar los resultados de la última correlación completada y configurar los parámetros de la correlación a procesar dos ciclos en el futuro. Simultáneamente con la ejecución del software, el módulo de correlación efectúa el cálculo de la correlación que fue configurada en el ciclo anterior. 


\begin{tabular}{|c|c|c|c|}
\hline & CONFIGURACIÓN & CORRELACIÓN & PROCESAMIENTO \\
\hline $\begin{array}{l}\text { Etapa A } \\
\text { ciclo m }\end{array}$ & $\begin{array}{l}\text { Etapa A } \\
\text { correlación m }\end{array}$ & $\begin{array}{l}\text { Etapa A } \\
\text { correlación m-1 }\end{array}$ & $\begin{array}{l}\text { Etapa A } \\
\text { correlación m-2 }\end{array}$ \\
\hline $\begin{array}{r}\text { Etapa A } \\
\text { ciclo } m+1\end{array}$ & $\begin{array}{c}\text { Etapa A } \\
\text { correlación } \mathrm{m+1}\end{array}$ & $\begin{array}{c}\text { Etapa A } \\
\text { correlación m }\end{array}$ & $\begin{array}{c}\text { Etapa A } \\
\text { correlación m-1 }\end{array}$ \\
\hline $\begin{array}{r}\text { Etapa A } \\
\text { ciclo } m+2\end{array}$ & $\begin{array}{l}\text { Etapa A } \\
\text { correlación } \mathrm{m}+2\end{array}$ & $\begin{array}{l}\text { Etapa A } \\
\text { correlación } \mathrm{m}+1\end{array}$ & $\begin{array}{l}\text { Etapa A } \\
\text { correlación m }\end{array}$ \\
\hline $\begin{array}{r}\text { Etapa A } \\
\text { ciclo } m+3\end{array}$ & $\begin{array}{c}\text { Etapa A } \\
\text { correlación m+3 }\end{array}$ & $\begin{array}{l}\text { Etapa A } \\
\text { correlación } m+2\end{array}$ & $\begin{array}{l}\text { Etapa A correlación m+1 } \\
\text { (CUMPLE CONDICIÓN DE } \\
\text { CAMBIO DE ETAPA) }\end{array}$ \\
\hline $\begin{array}{r}\text { Etapa } \mathrm{B} \\
\text { ciclo } 1\end{array}$ & $\begin{array}{c}\text { Etapa B } \\
\text { correlación } 1\end{array}$ & (anulada) & (vacante) \\
\hline $\begin{array}{r}\text { Etapa B } \\
\text { ciclo } 2\end{array}$ & $\begin{array}{c}\text { Etapa B } \\
\text { correlación } 2\end{array}$ & $\begin{array}{l}\text { Etapa B } \\
\text { correlación } 1\end{array}$ & (vacante) \\
\hline $\begin{array}{r}\text { Etapa B } \\
\text { ciclo } 3\end{array}$ & $\begin{array}{c}\text { Etapa B } \\
\text { correlación } 3\end{array}$ & $\begin{array}{c}\text { Etapa B } \\
\text { correlación } 2\end{array}$ & $\begin{array}{c}\text { Etapa B } \\
\text { correlación } 1\end{array}$ \\
\hline $\begin{array}{r}\text { Etapa B } \\
\text { ciclo } 4\end{array}$ & $\begin{array}{c}\text { Etapa B } \\
\text { correlación } 4\end{array}$ & $\begin{array}{c}\text { Etapa B } \\
\text { correlación } 3\end{array}$ & $\begin{array}{c}\text { Etapa B } \\
\text { correlación } 2\end{array}$ \\
\hline$(\ldots)$ & $(\ldots)$ & $(\ldots)$ & $(\ldots)$ \\
\hline & $\begin{array}{l}\text { REALIZADO EN } \\
\text { SOFTWARE }\end{array}$ & $\begin{array}{l}\text { REALIZADO EN } \\
\text { HARDWARE }\end{array}$ & $\begin{array}{l}\text { REALIZADO EN } \\
\text { SOFTWARE }\end{array}$ \\
\hline
\end{tabular}

Figura 7.2: Representación en forma de diagrama de ocupación de un pipeline del procesamiento de las muestras de correlación. Se puede ver que las correlaciones cuyos parámetros de configuran en el $i$-ésimo ciclo se realiza en el ciclo $i+1$, y sus resultados se procesan en el $i+2$. Un cambio de régimen (debido a un cambio de etapa de procesamiento, por ejemplo) provoca la inserción de burbujas en el pipeline que deben ser purgadas antes de operar en el nuevo régimen.

Una forma sencilla de comprender este tipo funcionamiento es asimilarlo a un pipeline de tres etapas: configuración, correlación y procesamiento. Una representación de este tipo puede verse en la Figura 7.2.

En la figura puede verse la coexistencia en cada ciclo de operación de la ejecución de tres correlaciones diferentes, cada una en una etapa distinta. Dos de las etapas (configuración y procesamiento) se ejecutan en el software de adquisición, mientras que la tercera (correlación) corresponde al módulo de adquisición de hardware de correlación. 
Se puede ver en la misma imagen el efecto que tiene un cambio de etapa de procesamiento de la señal, que como se verá más adelante ocurre por ejemplo cuando se detecta una señal durante el proceso de búsqueda, o cuando se confirma la presencia de una señal en la verificación de una celda. Estos cambios de etapa requieren de un reemplazo de los algoritmos de procesamiento, y en muchos casos la reconfiguración del modo de operación de los correladores.

La imposibilidad de modificar de forma retroactiva los parámetros de la correlación en curso en los correladores del módulo de adquisición introducen necesariamente al menos un ciclo de espera hasta que dicha correlación salga del pipeline.

Un segundo ciclo de espera es necesario para purgar la correlación configurada en el mismo ciclo. Debe notarse que esto último no es estrictamente necesario, ya que las etapas de configuración y procesamiento se realizan ambas secuencialmente por una misma pieza de código, pero simplifica la lógica de los algoritmos tratarlas como etapas independientes y favorece la legibilidad del código.

Por lo anterior, cada vez que se produce un cambio de etapa, la etapa entrante requiere de dos ciclos de inicialización dedicados a llenar el pipeline configurando las primeras dos correlaciones que serán procesadas, mientras simultáneamente se purgan los dos vacíos introducidos por el cambio de etapa. Recién en el tercer ciclo de operación los algoritmos alcanzan régimen estable con ocupación plena de todas las etapas del pipeline.

\subsection{Arquitectura del sistema de adquisición}

Los algoritmos de adquisición en el prototipo de receptor multiantena se encuentran implementados mediante una máquina de estados en software que lleva a cabo las secuencias de operaciones necesarias: estimación del piso de ruido, detección de celdas candidatas en el espacio de búsqueda, verificación de celdas candidatas, y sincronización de portadora, código y mensaje de navegación.

Los statecharts son un tipo de diagrama para máquinas de estados que incorpora extensiones que lo dotan de una gran potencia para representar sistemas reactivos complejos sin que ocurra la rápida escalada de complejidad que caracteriza los diagramas convencionales cuando la cantidad de estados y transiciones a representar crece. Sus características más sobresalientes son la capacidad de representar de máquinas de estados anidadas, máquinas de estados concurrentes, la declaración explícita de acciones de estado y de transición, y la existencia de diferentes tipos de transiciones (condicionales, múltiples, propias e impropias, y otras múltiples posibilidades). Versiones normalizadas de estos diagramas forman parte de los estándares de modelado para sistemas de 


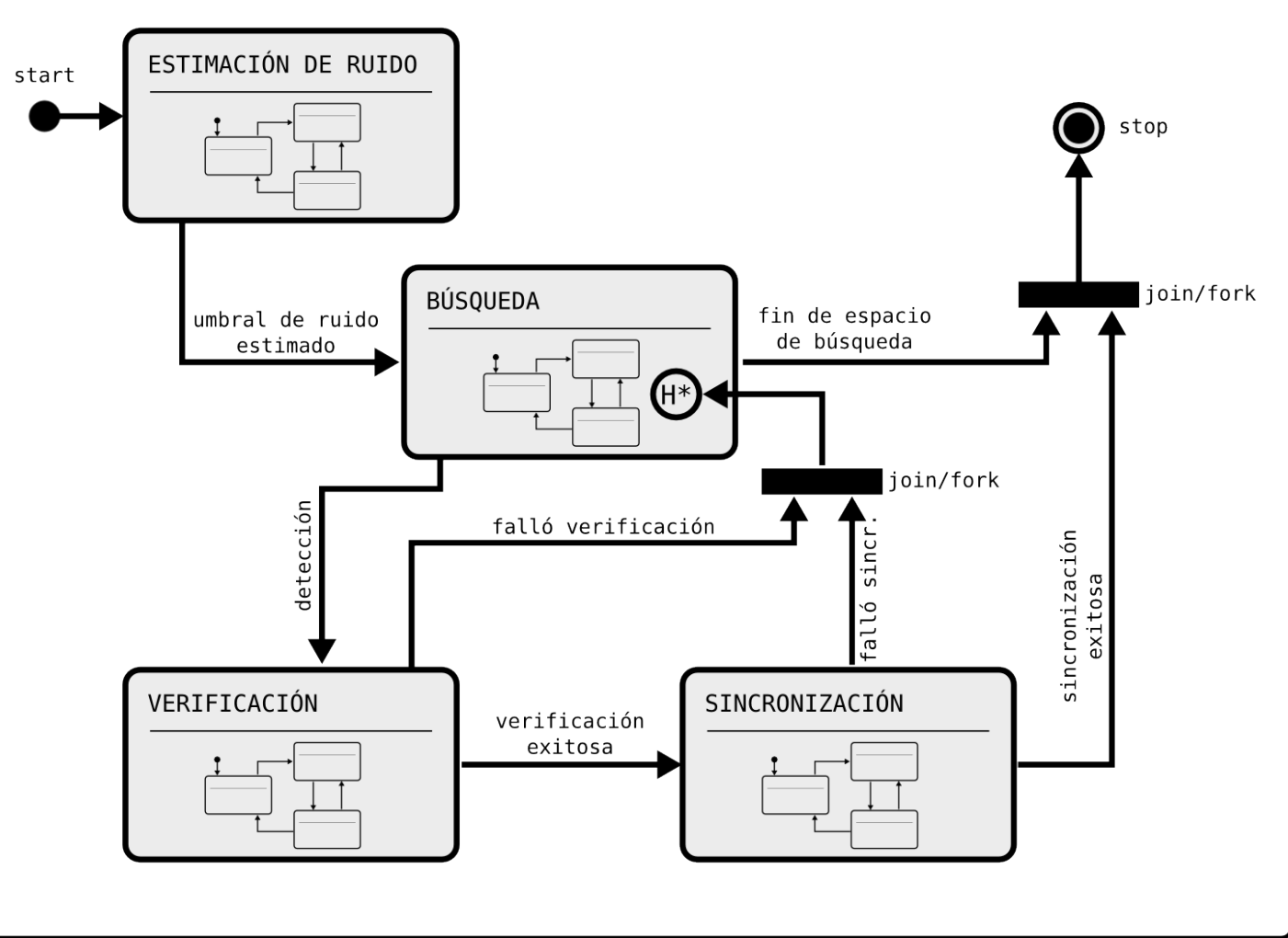

Figura 7.3: Diagrama statechart que representa el funcionamiento en alto nivel de algoritmo de adquisición implementado en el prototipo de receptor.

software UML (Universal Modeling Language) y su extensión para sistemas generales SysML (Systems Modeling Langage). No es la intención de este texto llevar adelante una descripción acabada de los statecharts, ni es necesario para los diagramas relativamente informales utilizados en esta tesis. El lector interesado puede encontrar más información sobre esta representación en [50].

El statechart que describe los algoritmos de adquisición en su nivel más general puede verse en la Figura 7.3, donde la máquina se divide en cuatro macro-estados principales:

- ESTIMACIÓN DE RUIDO

- BÚSQUEDA

- VERIFICACIÓN

- SINCRONIZACIÓN 
Tres de estos se corresponden directamente con las etapas de procesamiento que dividen la adquisición de señales, y cumplen con la tarea de sus etapas homónimas. El macroestado de estimación de ruido se encarga de la estimación de la potencia media del piso de ruido para determinar el umbral de detección que será utilizado posteriormente.

Cada uno de los macro-estados (de ahora en más estados a secas, salvo que la distinción sea necesaria) representa en realidad una secuencia de pasos de procesamiento que son a su vez representados por otras máquinas de estados. Esto es un ejemplo del anidamiento de máquinas de estados que permiten los statecharts.

El punto de entrada en la máquina de estado está dado por el círculo sólido de color negro que entra al estado de ESTIMACIÓN DE RUIDO, mientras que la finalización de la tarea está simbolizada por el círculo encerrado. Ambos símbolos son ejemplos de pseudo-estados, nombre que reciben porque el sistema no puede reposar en ellos (no son estados) aunque aparezcan en el diagrama como elementos terminales de los arcos de transición; los pseudo-estados representan transiciones condicionadas, modificaciones del régimen de la máquina, u otras operaciones especiales, y son uno de los elementos que proveen a los statecharts de una gran expresividad.

Otro ejemplo de pseudo-estado puede verse dentro del estado BÚSQUEDA: la expresión $\mathrm{H}^{*}$ encerrada en un círculo es un pseudo-estado conocido como deep-history; simboliza que toda transición que entra en BÚSQUEDA por dicho punto lo hace restaurando la totalidad de los estados internos (variables, máquinas anidadas, etc.) de dicho estado tal cual estaban la última vez que se abandonó el estado BÚSQUEDA. En este diagrama esto representa el hecho de que una verificación/sincronización fallida retoma el recorrido del espacio de búsqueda en la posición siguiente a la celda que provocó la verificación.

La secuencia de estados comienza por la ejecución de la estimación del piso de ruido. Este estado tiene un único punto de salida, que es una transición que lleva al estado BÚSQUEDA. El algoritmo permanece en este estado durante todo el tiempo que toma recorrer el espacio de búsqueda especificado en los parámetros de la adquisición. Estos parámetros no se encuentran explícitamente señalados en el diagrama por razones de espacio y claridad.

El estado BÚSQUEDA tiene dos salidas posibles. Una de estas salidas, saliente por su lateral derecho, es una transición que ocurre ante el evento de finalización del recorrido del espacio de búsqueda, y termina en el pseudo-estado terminal stop. Alternativamente, la transición saliente por el lateral inferior ocurre con el evento de detección de potencia de correlación por encima del umbral. Este evento desata la ejecución de los algoritmos asociados a la verificación, en el estado homónimo. 
VERIFICACIÓN a su vez tiene dos transiciones salientes; una verificación fallida (cuando no se puede comprobar estadísticamente la presencia de señal en las coordenadas de la detección) provoca un retorno a BÚSQUEDA a través del pseudo-estado deep history, retomando el recorrido del espacio de búsqueda en el punto donde se había abandonado anteriormente. Una verificación exitosa, por otro lado, provoca el avance de la máquina hacia el estado SINCRONIZACIÓN.

De forma similar al estado de verificación, el estado SINCRONIZACIÓN tiene dos arcos salientes, correspondientes a los eventos de sincronización fallida y exitosa. En el primer caso se anulan los efectos de la detección inicial y se retoma la búsqueda por el punto del espacio donde se abandonó, y en el segundo se finaliza la ejecución de la máquina de estado a través del arco que termina en stop.

Se puede ver fácilmente en el diagrama que el proceso de búsqueda finaliza tempranamente solamente en el evento de una detección de señal que es exitosamente verificada y sincronizada. En cualquier otro caso se completará el recorrido del espacio de búsqueda completo antes de declarar la ausencia de la señal buscada.

El algoritmo descripto por la Figura 7.3 implementa fielmente el procesamiento de adquisición presentado en la Figura 7.1, con la única adición de una etapa adicional para la estimación del umbral de detección. En las secciones siguientes se desarrollará el funcionamiento interno de cada una de los cuatro macro-estados de la máquina de adquisición.

\subsubsection{Etapa de estimación de ruido}

En la Figura 7.4 se puede ver una descripción de la máquina de estados anidada dentro del estado ESTIMACIÓN DE RUIDO del statechart de la Figura 7.3.

Esta etapa del proceso de adquisición lleva a cabo una estimación de la potencia media del piso de ruido $\hat{u}_{r}$ realizando una media muestral como la indicada en la expresión (7.5). Para ello se releva la potencia de ruido presente en la región de frecuencias de interés para la adquisición a realizar, y en cada una de las antenas habilitadas para la misma. El resultado de este proceso es una estimación $\hat{u}_{r}$ por cada una de las antenas habilitadas.

A partir del valor $\hat{u_{r}}$ obtenido para cada antena se determinan los umbrales de detección necesarios para lograr una dada probabilidad de $p_{f a}$, mediante la expresión (7.6). Este umbral se calcula individualmente para cada antena habilitada, y será utilizado tanto por las etapas de búsqueda como de verificación posteriores.

Para obtener un umbral significativo para los procesos de búsqueda y verificación, el relevamiento del piso de ruido debe realizarse utilizando la misma configuración de 


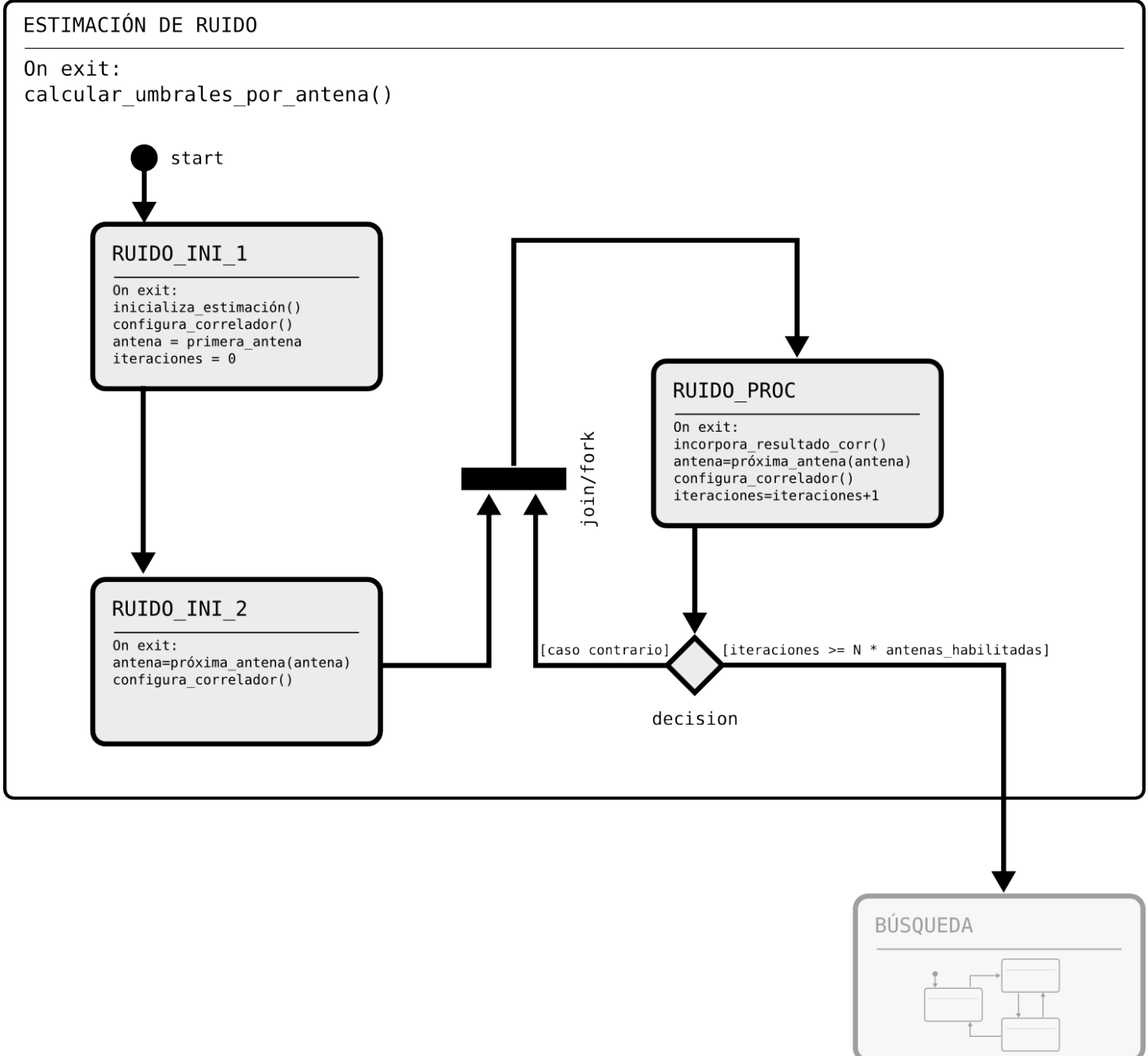

Figura 7.4: Diagrama statechart de la máquina de estado anidada dentro del estado compuesto ESTIMACIÓN DE RUIDO de la Figura 7.3.

tiempos de integración utilizados para dichas etapas. Esto significa utilizar la misma configuración de tiempo de integración coherente, y la misma cantidad de repeticiones no coherentes.

La configuración de la lista de antenas habilitadas para la adquisición, $a_{m a s k}$, determina cuales antenas deben ser examinadas. Aquellas antenas que no se encuentran habilitadas por esta configuración no requieren de una estimación de umbral de detección ya que el proceso de búsqueda no las examinará en busca de señal, y por lo tanto pueden ser excluidas también del proceso de relevamiento del piso de ruido.

La potencia de ruido no es uniforme en el espectro. Existen variaciones en el valor absoluto de la potencia de ruido observable en diferentes rangos de frecuencias, ocasionados por diferencias en el filtrado de procesamiento de algunas etapas así como también por el solapamiento de espectros GLONASS y GPS discutido en la Sección 5.2.3.2. 
Para obtener una evaluación del piso de ruido representativa de la condición que se encontrará durante el proceso de adquisición, este piso se evalúa examinando el espectro de ruido a la frecuencia central de la región de búsqueda. La medición del ruido en este rango de frecuencias requiere de configurar el generador de portadora local a la frecuencia central, de forma tal de llevar dicho rango del espectro a banda base, donde será integrado por los correladores.

Para eliminar toda posibilidad de sesgar la evaluación del umbral de detección contaminando las muestras con potencia de señal GNSS es que el generador local de función de código presente en los correladores es desactivado durante estas mediciones. Esto no modifica las características del ruido, pero impide la recompresión de las señales GNSS presentes y de esa forma inhibe que una cantidad apreciable de potencia de éstas contamine la media muestral de la potencia de ruido.

Como se puede ver en el statechart de la Figura 7.4, la etapa de estimación del piso de ruido se encuentra compuesta a su vez de tres estados. De estos, los dos primeros tienen la función de configurar las dos primeras correlaciones a procesar, configurando los generadores locales de código y portadora, los tiempos de integración y el punto en la frecuencia a analizar. También se inicializan todas las variables auxiliares a utilizar durante el proceso de cálculo de la media muestral, y se determinan cuántas y cuáles de las antenas de entrada deben ser examinadas (parámetro $a_{\text {mask }}$ de la adquisición).

El tercer estado realiza el procesamiento principal, ya una vez que el pipeline de configuración, cálculo y procesamiento de correlaciones se encuentra operando en régimen permanente. En este estado cada evento de fin de correlación inicia un ciclo de procesamiento donde se incorporan las nuevas mediciones a la estimación de las medias muestrales de cada antena, y se configuran los parámetros de la correlación siguiente para alternar de forma adecuada las antenas de entrada.

Esta etapa tiene una única salida posible, que es la transición hacia la etapa de búsqueda (estado BÚSQUEDA), que ocurre una vez que se recolectaron suficientes muestras para obtener un promediado aceptable. Durante el proceso de salida se calculan los valores de los umbrales de detección de cada antena.

\subsubsection{Etapa de búsqueda}

En la Figura 7.5 se puede ver el detalle interno del estado BÚSQUEDA del statechart de la Figura 7.3.

Esta etapa del proceso de adquisición se encarga de realizar el recorrido del espacio de búsqueda formado por los planos retardo-frecuencia de todas las antenas de entrada 


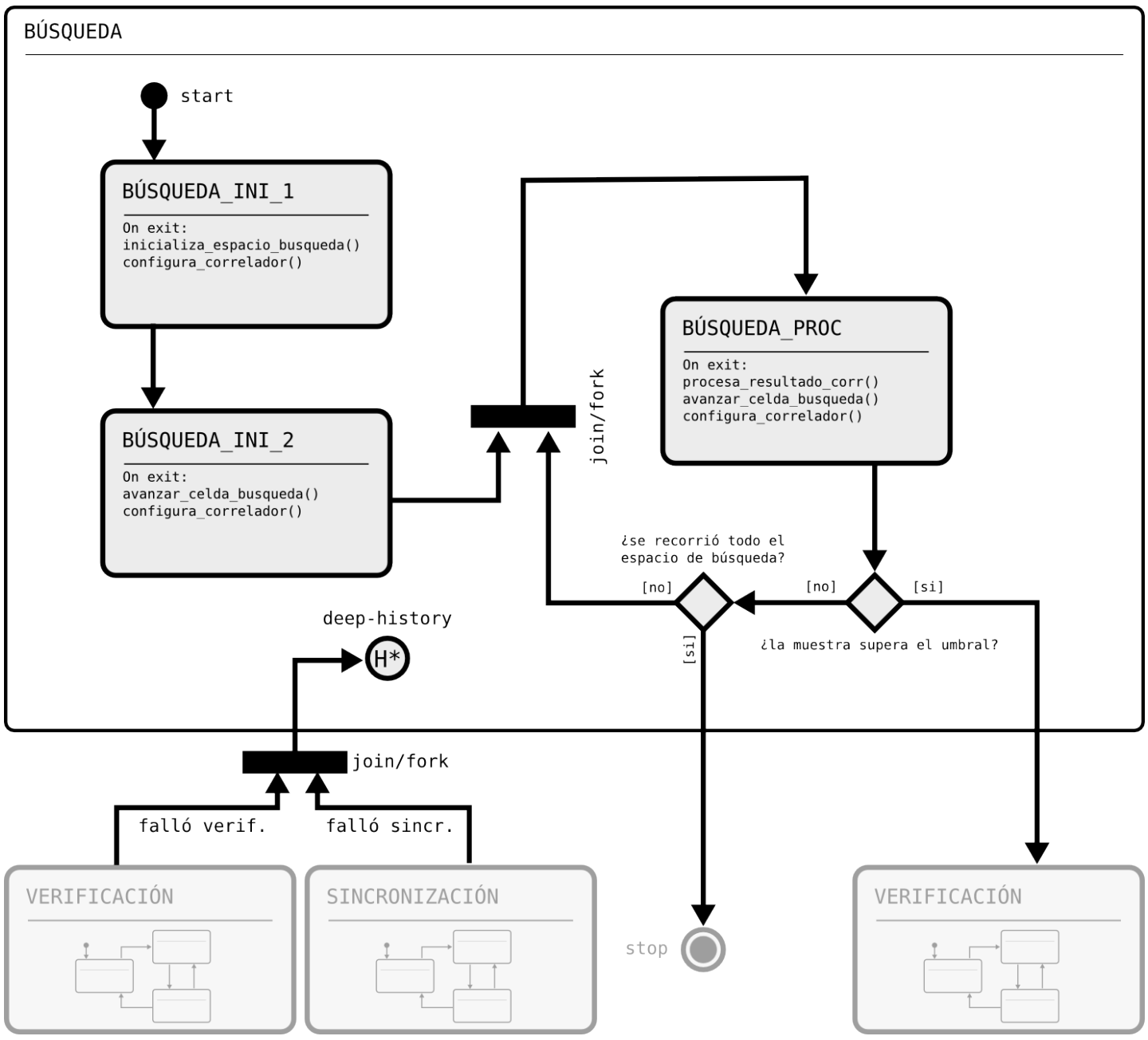

FiguRA 7.5: Diagrama statechart de la máquina de estado anidada dentro del estado compuesto BÚSQUEDA de la Figura 7.3.

habilitadas para la adquisición. Este espacio de búsqueda está delimitado por el rango de frecuencias a examinar (dado por los parámetros de frecuencia central y radio de búsqueda), la cantidad de retardos de código (1023 para GPS y 511 para GLONASS), y la cantidad de antenas habilitadas (parámetro $a_{m a s k}$ de la adquisición).

Durante el recorrido se realizan correlaciones en cada una de las celdas del espacio de búsqueda, utilizando los parámetros de tiempo de integración coherente y repeticiones no coherentes deseados. La potencia de correlación no coherente así obtenida para cada celda se compara contra el umbral de detección calculado en la etapa anterior (estado ESTIMACIÓN DE RUIDO). El tipo de recorrido del espacio de búsqueda es del tipo entrelazado discutido en la Sección 7.2.1.

El paso de frecuencia $\Delta f$ se calcula utilizando la regla discutida en la Sección 7.2. En la dimensión del retardo, la disponibilidad de un juego de 20 correladores separados a intervalos de $1 / 2$ chip en el módulo de adquisición permite acelerar el proceso de 
búsqueda. De esta forma cada ciclo de correlación puede cubrir una ventana de 20 celdas consecutivas en retardo, equivalente a 10 chips de la función de código.

Como se puede ver en la Figura 7.5, la implementación de esta etapa consiste en una máquina de tres estados que sigue el mismo patrón visto anteriormente de dos estados de inicialización y uno de procesamiento principal, siendo los primeros dos necesarios para configurar las primeras dos correlaciones, mientras que el tercero realiza el procesamiento con el pipeline en régimen permanente.

Además de los tres estados explícitamente indicados subyace también una cierta cantidad de información de estado adicional implícito, generalmente denominado el estado extendido de la máquina, que contiene principalmente información acerca de la posición actual del espacio de búsqueda que está siendo examinado.

Existen dos puntos de salida de la máquina de estado que son el origen de las transiciones salientes que ya se anticipaban en la Figura 7.3. Estas transiciones salientes corresponden a la bifurcación hacia la etapa de verificación (estado VERIFICACIÓN en la Figura 7.3), y al pseudo-estado de parada stop.

La transición hacia el estado VERIFICACIÓN se activa al detectar que el nivel de potencia de correlación no coherente de alguna de las celdas supera el umbral de detección correspondiente a la antena de entrada de dicha correlación. Este evento provoca la anulación de los dos ciclos de correlación posteriores (que se encuentran en las etapas de configuración y correlación del pipeline) y la recuperación de los parámetros de configuración de la correlación donde se realizó la detección: frecuencia portadora, retardo de código, antena de entrada.

La transición hacia el pseudo-estado stop ocurre si se completa el recorrido de la totalidad del espacio de búsqueda sin que haya sido positivamente verificada la presencia de señal buscada en ninguna celda del mismo. En este caso se declara la ausencia de la señal y se finaliza el proceso de adquisición.

Externamente el estado BÚSQUEDA puede ser accedido desde los estados VERIFICACIÓN y SINCRONIZACIÓN a través del pseudo-estado deep-history, además de a través de la vía convencional (su estado por defecto, señalado por el pseudo-estado start). Dicho punto de entrada representa la capacidad del algoritmo de búsqueda de recordar la posición de la última celda examinada antes de la última transición a VERIFICACIÓN, y de retomar la búsqueda en dicha celda si se produce un problema en alguna de las etapas posteriores a la detección. 


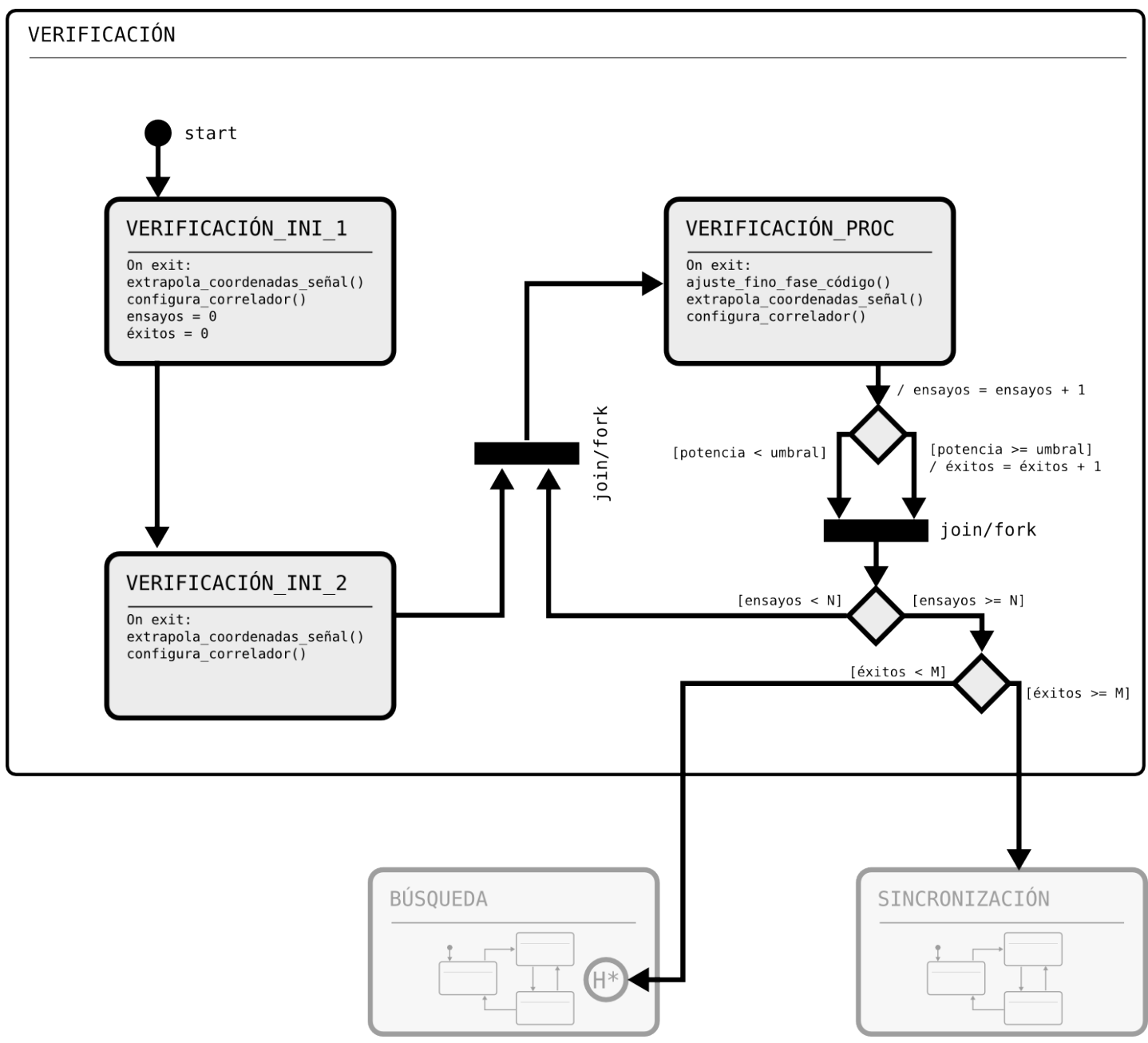

Figura 7.6: Diagrama statechart de la máquina de estado anidada dentro del estado compuesto VERIFICACIÓN de la Figura 7.3.

\subsubsection{Etapa de verificación}

En la Figura 7.6 se puede ver el detalle interno del estado VERIFICACIÓN del statechart de la Figura 7.3.

En esta etapa se somete la celda donde se produjo una detección a una serie de ensayos adicionales para filtrar la mayor parte de las falsas alarmas que se producen durante el recorrido del espacio de búsqueda en la etapa anterior.

Los ensayos consiste en la realización de $N$ mediciones de potencia de correlación consecutivas sobre la misma celda, utilizando los mismos parámetros de correlación (tiempo de integración coherente y repeticiones no coherentes) utilizados durante la búsqueda. Para superar la verificación, la celda debe superar el umbral de detección en al menos $M$ de los $N$ ensayos, una técnica muy apropiadamente conocida como $M-o f-N$ en la bibliografía. Los valores de estos parámetros son $M=5$ y $N=8$, que permiten la mejor 
probabilidad de detección de verificación de señal para una dada probabilidad de falsa alarma de la verificación [4].

Debido al espaciado en retardo de las celdas que dividen los planos retardo-frecuencia, se entra a la etapa de verificación con una incertidumbre del orden de $\pm 1 / 4$ de chip. Esta incertidumbre puede significar una reducción en la potencia de la señal de hasta $6 \mathrm{~dB}$ en el punto de ensayo de la celda comparado con la que tendría en las coordenadas reales de la señal.

Para reducir esta pérdida de potencia de señal, en esta etapa se lleva a cabo un refinamiento a lazo abierto de la estimación del retardo de la función de código. Para esto se utilizan tres de los correladores del módulo de adquisición: el correlador de verificación y dos correladores laterales. El primero se configura siempre utilizando la mejor estimación disponible del retardo de la función de código, mientras que los dos correladores laterales se encuentran desplazados en $1 / 2$ chip respecto al primero, uno en adelanto y otro en atraso.

En cada ciclo de operación se comparan las potencias de correlación recuperadas por los dos correladores laterales. Si la estimación del retardo de código coincidiera exactamente con el retardo de la función de código de la señal, las potencias medidas en ambos debieran ser aproximadamente iguales (siendo la diferencia debida al ruido aditivo presente). Ver Figura 3.10. Si existe diferencia, el correlador con mayor potencia indica el signo del error en la estimación.

El algoritmo de corrección a lazo abierto compara las potencias de los correladores laterales, y corrige la estimación del retardo por una cantidad fija en la dirección del correlador lateral de mayor potencia. La corrección aplicada es de 1/16 de chip, que es una cantidad lo suficientemente pequeña para no provocar errores si el ruido provoca una corrección de signo equivocado y lo suficientemente grande para eliminar la mayor parte de la incertidumbre inicial luego de $N=8$ ensayos. Debe notarse que en ausencia de señal, esta estrategia de modificación de la estimación del retardo no modifica la probabilidad de falsa alarma de la etapa de verificación.

En la Figura 7.6 se plasman aquellas partes más relevantes del funcionamiento de la etapa de verificación. Se ven allí las dos etapas de inicialización, para establecer las condiciones de operación del algoritmo de verificación, y un tercer estado que contabiliza la cantidad de ensayos realizados y exitosos.

Si luego de $N$ ensayos la cantidad de detecciones es igual o superior a $M$, la verificación de la señal se considera exitosa y se procede avanzar la adquisición a la etapa de sincronización. En caso contrario se declara la detección inicial como una falsa alarma, y se 
retorna a la etapa de búsqueda retomando el recorrido del espacio de posibilidades en el punto donde se produjo la falsa alarma.

\subsubsection{Etapa de sincronización}

La etapa de sincronización se encarga de la eliminación de los rangos residuales de incertidumbre en los estimados de retardo de la función de código, y frecuencia de la portadora. Adicionalmente, se obtiene información de fase de la portadora, así como también sobre la posición de los flancos de los pulsos del mensaje de navegación en la señal.

La etapa, representada en la Figura 7.3 por el estado SINCRONIZACIÓN, está implementada en tres estados. Cada uno de estos es un estado compuesto, formado internamente por una máquina de estados anidada. Ver la Figura 7.6.

El estado CENTRAR_LÓBULO se encarga de reducir la incertidumbre en la estimación de la frecuencia portadora hasta un valor aceptable para los lazos de seguimiento que funcionan en SEGUIMIENTO.

La función de CAPTURA_LÓBULO es la de generar un barrido del la potencia de correlación de la señal, en función del retardo y la frecuencia, en las proximidades de la coordenadas retardo-frecuencia de la señal estimadas por las etapas anteriores. Su función es primordialmente la de registrar la situación de detección de la señal a la entrada del estado SEGUIMIENTO, cuyos algoritmos son sumamente sensibles a errores en la estimación de las etapas anteriores, y evaluar anomalías en la señal de los satélites adquiridos; esta información, si bien no es imprescindible para el funcionamiento autónomo del receptor, es útil desde el punto de vista de la verificación de su funcionamiento.

En las secciones siguientes se profundizará el funcionamiento interno de cada uno de los sub-estados que componen el estado compuesto SINCRONIZACIÓN.

\subsubsection{Centrado de lóbulo}

Esta etapa se encarga de reducir el nivel de incertidumbre en el conocimiento de la estimación de la frecuencia portadora antes de poner en marcha los lazos de seguimiento de la etapa SEGUIMIENTO. La necesidad de esto proviene de que en esta instancia la incertidumbre de frecuencia está fundamentalmente dada por el paso de frecuencia utilizado para recorrer los plano retardo-frecuencia del espacio de búsqueda de la señal. La utilización de una estrategia ávida de verificación de candidatos también genera la posibilidad de que se produzcan detecciones de señal en las coordenada de los lóbulos 


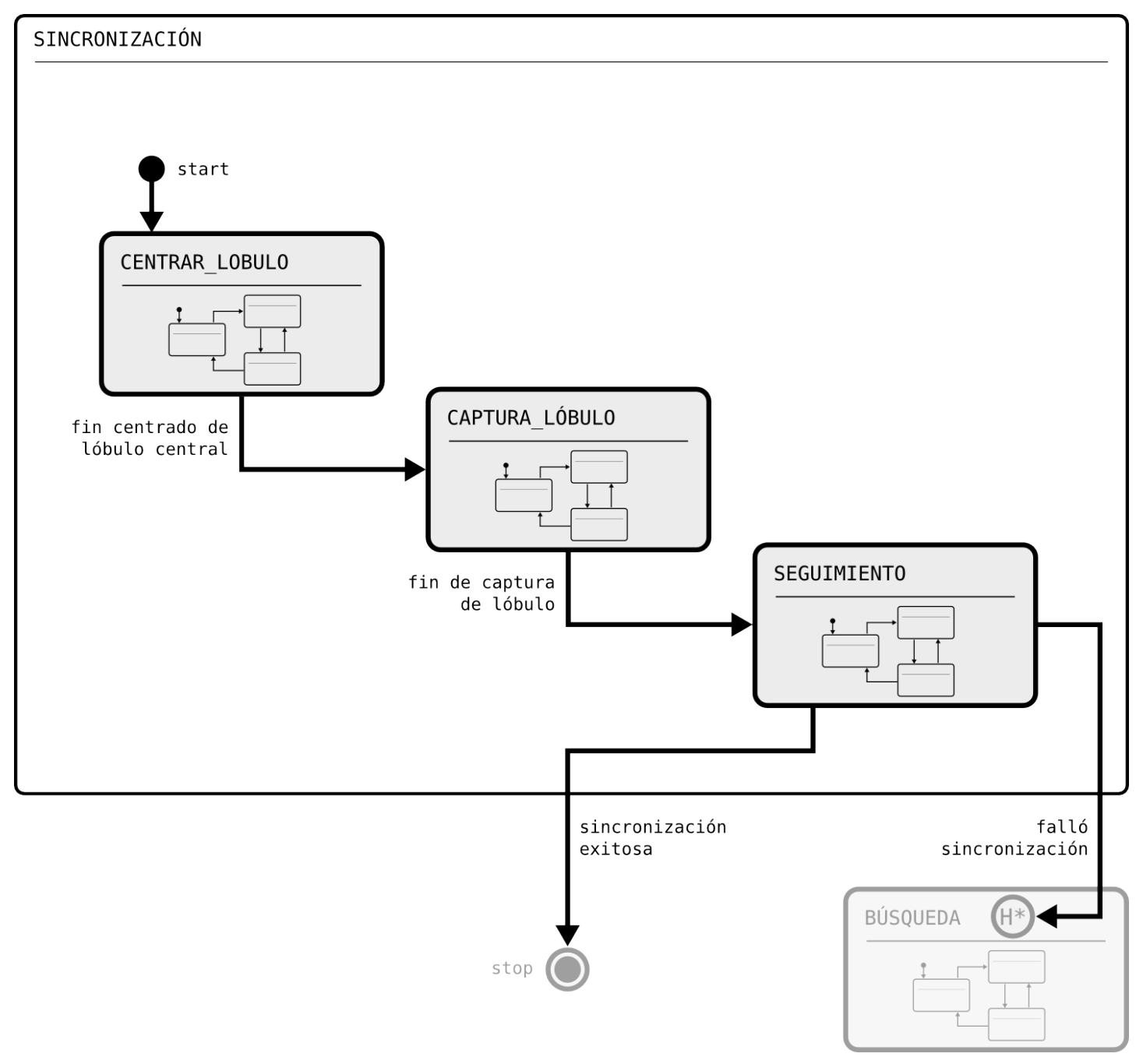

Figura 7.7: Diagrama statechart de la máquina de estado anidada dentro del estado compuesto SINCRONIZACIÓN de la Figura 7.3.

secundarios del pico de correlación de la señal, lo que puede incrementar el error en la estimación inicial de la frecuencia por más de un múltiplo del ancho del lóbulo principal (inverso del tiempo de integración coherente).

Se verá posteriormente que la última parte del proceso de sincronización requiere del funcionamiento de un lazo de seguimiento de portadora (entre otras cosas) para lograr enganche de fase y frecuencia con la señal. Este lazo es un lazo de tipo PLL con discriminador de fase UFA-PLL fundamentalmente idéntico a los vistos en el Capítulo 6, excepto por la circunstancia de que funciona procesando muestras de correlación de $3 \mathrm{~ms}$ de tiempo de integración. De acuerdo con lo visto en la Sección 6.3.1.3 este tiempo de integración significa que el máximo error en la estimación de frecuencia para evitar el falso enganche es de $83 \mathrm{~Hz}$.

Típicamente, para limitar el impacto de la modulación de datos en el proceso de detección 


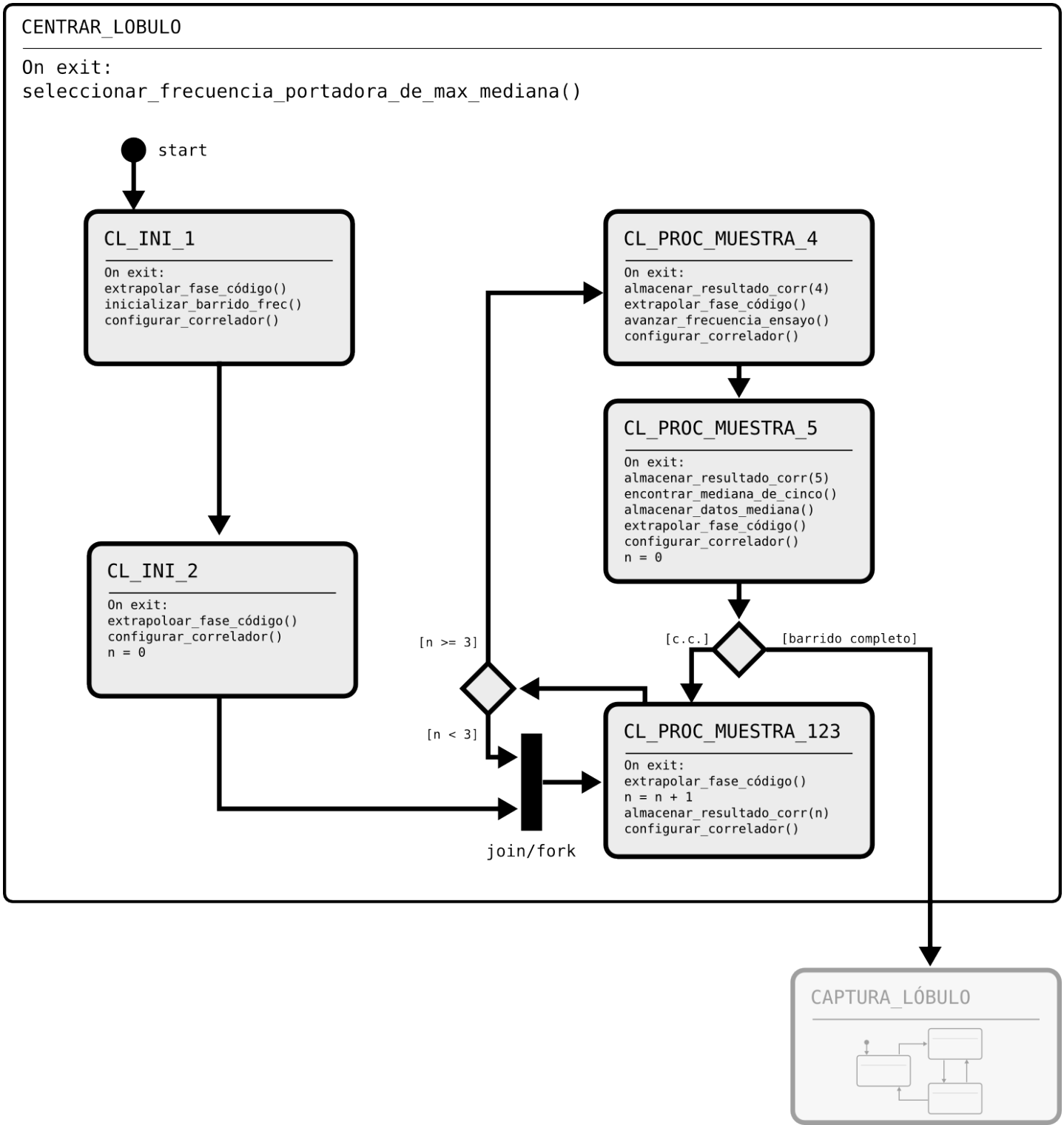

FiguRA 7.8: Diagrama statechart de la máquina de estado anidada dentro del estado compuesto CENTRAR_LÓBULO de la Figura 7.7.

de señal el parámetro de tiempo de integración coherente toma los valores de 1 ms o 2 ms, que corresponde a pasos de frecuencia de $500 \mathrm{~Hz}$ o $250 \mathrm{~Hz}$ respectivamente (ver Sección 7.2). Sumado a la posibilidad de detectar y verificar la señal en un lóbulo secundario, es fácil ver que el error en frecuencia a la entrada de la etapa de sincronización puede ser varias veces superior a la cota de funcionamiento del lazo de seguimiento de portadora.

Para evitar que estas situaciones provoquen un falso enganche en el lazo de seguimiento de portadora que funciona en el estado SEGUIMIENTO, es necesario reducir la incertidumbre a un valor por debajo de los límites de operación del lazo.

La reducción de la incertidumbre se logra realizando un barrido en frecuencia de las 
adyacencias de las coordenadas retardo-frecuencia de la señal detectada buscando aquella frecuencia que maximiza la potencia de correlación recuperada. La reducción en el error de frecuencia se logra por un lado utilizando un tiempo de integración coherente más largo que el utilizado durante la búsqueda inicial ( $8 \mathrm{~ms}$ sin repeticiones no coherentes), y un paso de frecuencia correspondientemente más pequeño. Este barrido cubre un rango de frecuencias de $3 \mathrm{kHz}$ centrados en la estimación de la frecuencia portadora de la señal verificada, que le permite encontrar el lóbulo principal incluso si la detección se produjo en un lóbulo secundario.

El tiempo de integración coherente de 8 ms estrecha el ancho y eleva el máximo de lóbulo principal de correlación, mejorando la precisión con la que se puede ubicar el valor de portadora. El paso de frecuencia correspondiente es de $62,5 \mathrm{~Hz}$, que significa que en el peor caso el barrido examinará al menos un punto a menos de $31,25 \mathrm{~Hz}$ del máximo real.

La utilización de tiempo de integración coherentes más largos provoca una sensibilidad muy aumentada a la presencia del mensaje de navegación en la señal. El efecto de las transiciones de $180^{\circ}$ en la fase debidas a la modulación de datos es el de falsear la medición de potencia, incrementando la potencia de correlación para valores de error de frecuencia que hicieran que la potencia recuperada fuera baja, y reduciéndola fuertemente cuando debiera ser alta. Para evitar que este efecto afecte la capacidad del algoritmo de centrado de identificar el máximo de correlación, cada valor de frecuencia del barrido es examinado cinco veces. De estos cinco ensayos se selecciona la mediana y se descartan los cuatro resultados restantes. Este es el valor de potencia que es utilizado para buscar el máximo de potencia de correlación. Se ve entonces que estrictamente el algoritmo encuentra la frecuencia más próxima a la portadora real buscando la máxima mediana de cinco de las potencias de correlación en las frecuencias barridas.

La utilización de la mediana para seleccionar permite descartar aquellas integraciones que hayan sido afectadas por transiciones del mensaje de navegación, ya que estas tenderán a tener valores muy por encima o muy por debajo del valor real. Si la mitad más uno de las integraciones no se encuentra afectada por transiciones de datos, entonces la mediana de las potencias de correlación es un estimador adecuado del valor de potencia de correlación en función estrictamente del error de frecuencia.

De hecho, para GPS se puede probar que haciendo la mediana de cinco utilizando tiempos coherentes de $8 \mathrm{~ms}$, en los $40 \mathrm{~ms}$ consecutivos que toma el ensayo pueden ocurrir un máximo de dos transiciones de bit y por lo tanto solamente dos o menos de las cinco correlaciones pueden verse afectadas por dichas transiciones. En el caso de GLONASS el problema es más difícil, porque su mensaje de navegación tiene flancos más frecuentes y podrían bajo determinadas condiciones haber más correlaciones afectadas, pero incluso 
entonces la mediana de cinco permite minimizar los problemas si las potencias de correlación de las integraciones afectadas no son todas mayores ni todas menores que la potencia real.

La implementación del algoritmo de centrado de lóbulo consiste en cinco estados, de los cuales los dos primeros son los de inicialización de las correlaciones, y los tres restantes se encargan del cálculo de la mediana de cinco. Ver Figura 7.8. CL_PROC_MUESTRA_123 se encarga del procesamiento de las tres primeras muestras de correlación de las cinco utilizadas para calcular la mediana. Lo que separa este estado de los dos siguientes es que la correlación siguiente a configurar en los correladores pertenece a la misma celda (mismo valor de frecuencia portadora).

Los dos estados restantes, CL_PROC_MUESTRA_4 y CL_PROC_MUESTRA_5, procesan la cuarta y quinta muestra que serán utilizadas en la mediana de la celda actual, pero configuran en los correladores los parámetros correspondientes a la siguiente celda a examinar. CL_PROC_MUESTRA_5 además calcula efectivamente la mediana, y si su valor supera el máximo valor de mediana observado hasta este punto se registra la frecuencia portadora examinada como la nueva mejor estimación de la frecuencia portadora de la señal.

Esta etapa no finaliza hasta que no se haya recorrido todo el rango de frecuencias de $3 \mathrm{kHz}$ alrededor de la estimación de frecuencia de la señal verificada en la etapa anterior. Cuando eso ocurre, se avanza incondicionalmente a la siguiente sub-etapa de la sincronización, el estado CAPTURA.

\subsubsection{Captura de lóbulo}

Como se adelantó, la etapa de captura de lóbulo genera un registro bidimensional de la potencia de correlación en las inmediaciones de las coordenadas de la señal detectada. Este registro sirve para monitorear la calidad de los datos resultante de las etapas de detección, verificación y refinamiento anteriores, que es crítica para una correcta puesta en marcha de la última sub-etapa de la sincronización.

En esta etapa se realiza un barrido en frecuencia utilizando tiempos de correlación de $3 \mathrm{~ms}$ coherentes, sin repeticiones no coherentes. El recorrido abarca todo el lóbulo central, $333 \mathrm{~Hz}$ a cada lado de la frecuencia portadora, a pasos de $33 \mathrm{~Hz}$. Gracias a los múltiples correladores que contiene el módulo de adquisición no es necesario realizar un barrido en retardo, sino que se utilizan cinco de los veinte correladores disponibles para registrar la potencia de correlación en un rango $[-1,+1]$ chip alrededor de la señal, a intervalos de 0,5 chips. 


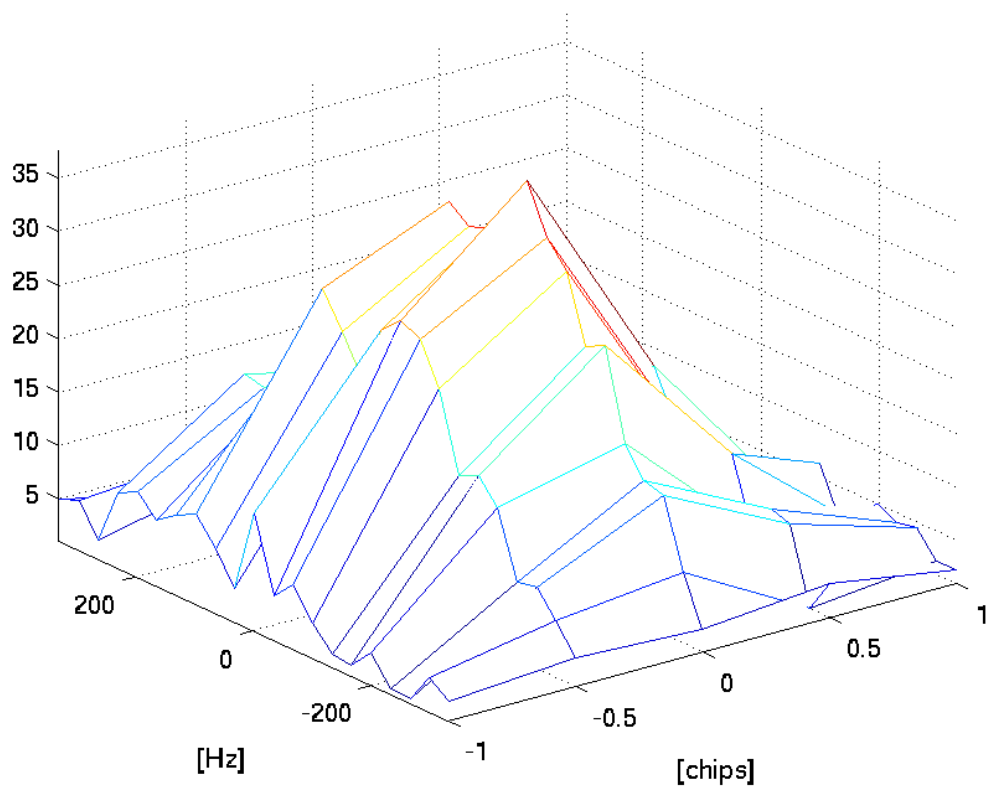

Figura 7.9: Captura de envolvente del lóbulo de correlación obtenida con tiempos de integración de $3 \mathrm{~ms}$ y paso de frecuencia de $33 \mathrm{~Hz}$.

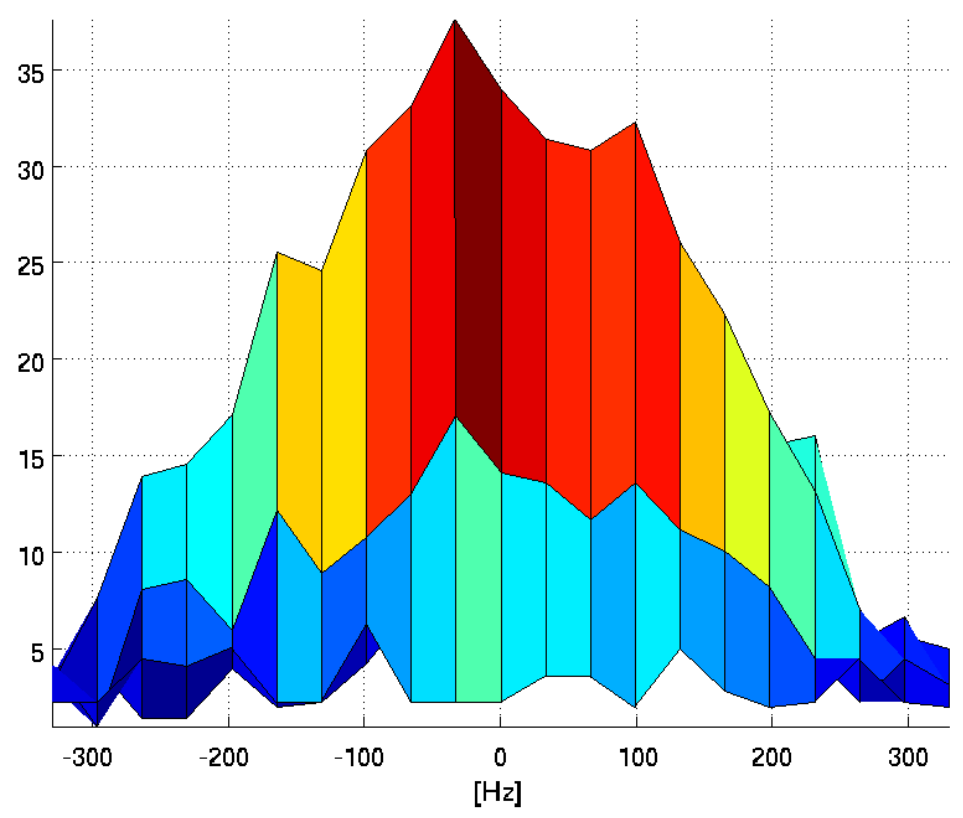

Figura 7.10: Vista en frecuencia del mismo lóbulo que se ve la Figura 7.9. 


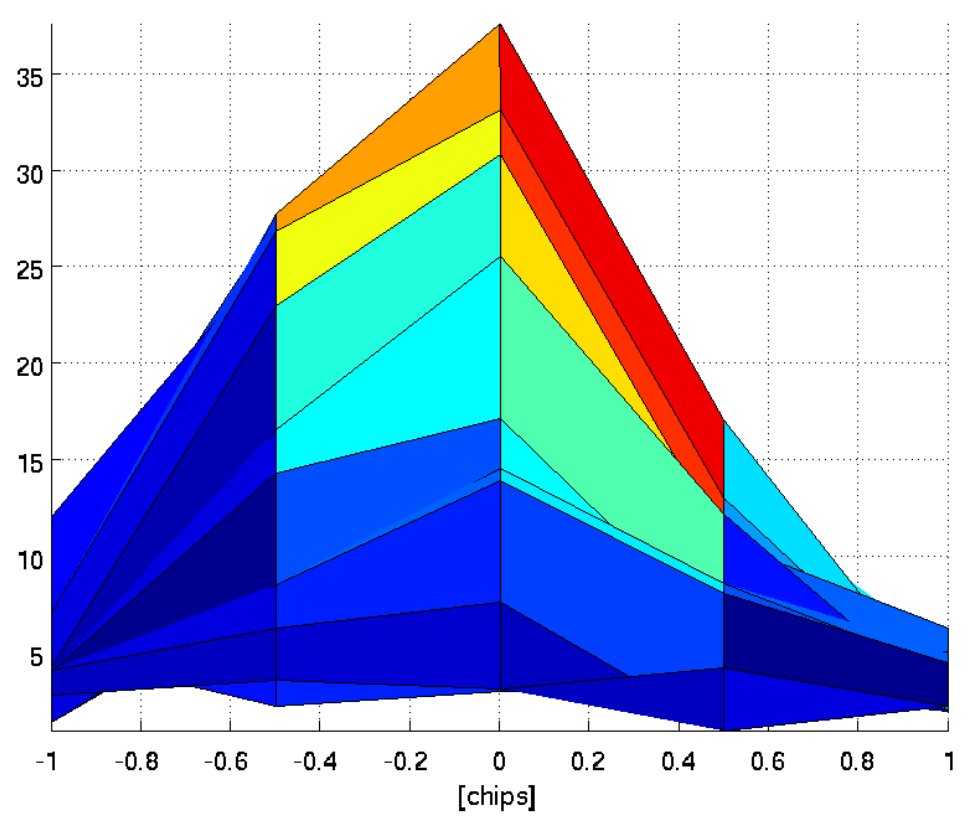

Figura 7.11: Vista en retardo del mismo lóbulo que se ve en la Figura 7.9.

Los datos registrados por esta etapa pueden se representados gráficamente. Esto es lo que se ha hecho en la Figura 7.9. La Figura 7.10 muestra el mismo pico de señal con una vista perpendicular al eje de la frecuencia, y en la Figura 7.11 lo mismo pero respecto del eje del retardo.

En estas figuras puede apreciarse que la estimación de los parámetros retardo-frecuencia de la señal que fueron logrados por las etapas anteriores de la adquisición de la señal son muy próximas a los valores reales de las mismas que pueden ser aproximados gráficamente a partir de la forma del lóbulo principal.

Esta etapa utiliza una estrategia similar a la anterior para evitar las distorsiones debidas a los mensajes de navegación. En este caso, la utilización de tiempos coherentes de $3 \mathrm{~ms}$ hace que sea suficiente con la utilización de una mediana de tres para poder eliminar las correlaciones afectadas por transiciones en el mensaje de navegación. Más aún, con esta elección de tiempo de integración se puede probar que de cada tres correlaciones consecutivas de $3 \mathrm{~ms}$ bajo ninguna condición puede haber más de una de ellas afectada por una transición de bit, tanto en el sistema GPS como en GLONASS. Por esta razón la muestra seleccionada por mediana nunca estará afectada por la modulación de datos de la señal.

La estructura interna del estado CAPTURAR_LÓBULO es un muy similar a la del estado anterior. Ver Figura 7.12. La única diferencia consiste en que al ser la mediana solamente de tres, ninguno de los estados repite su ejecución (como ocurría con 


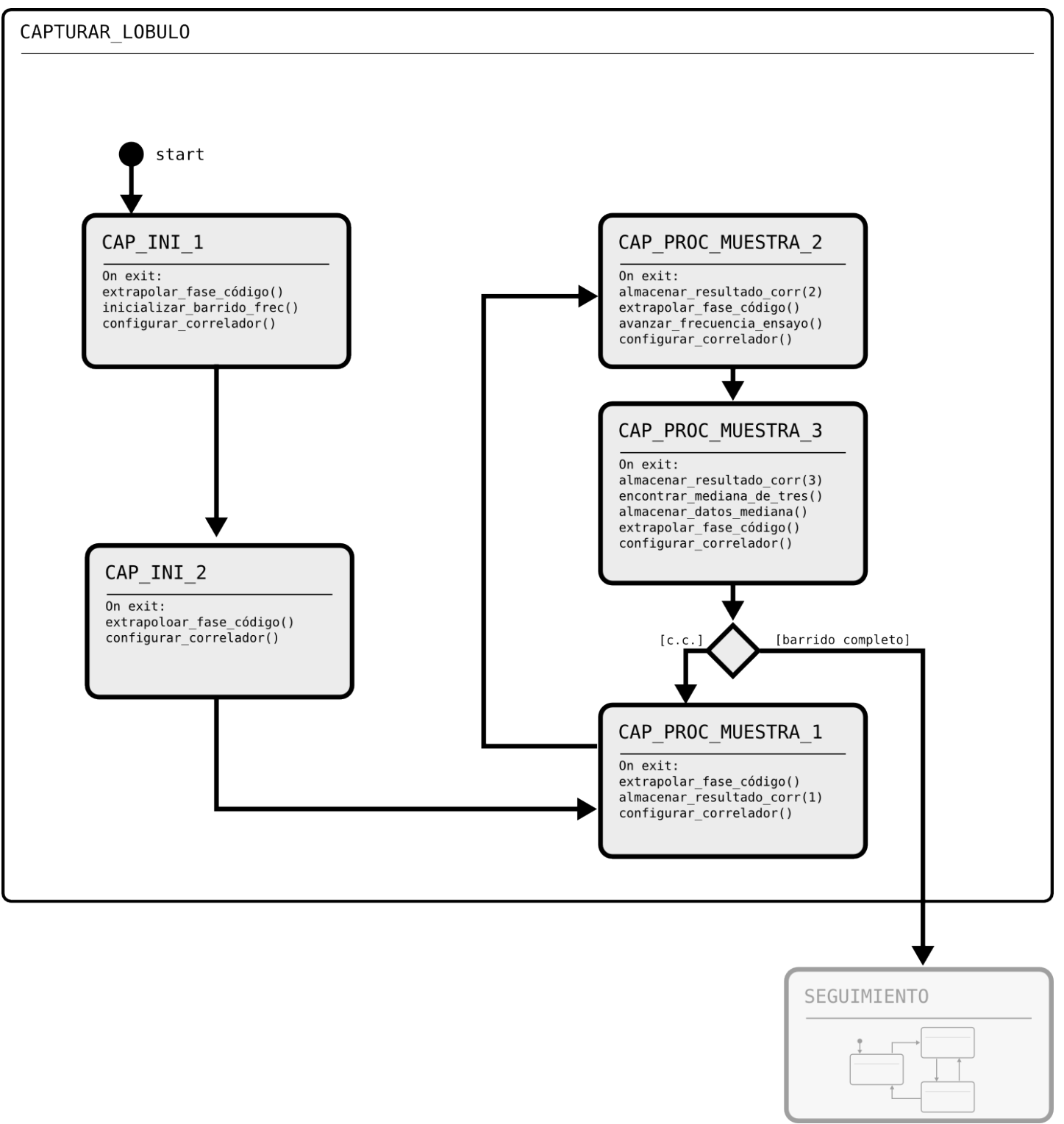

FiguRA 7.12: Diagrama statechart de la máquina de estado anidada dentro del estado compuesto CAPTURA de la Figura 7.7.

\section{CL_PROC_MUESTRA_123 en CENTRAR_LÓBULO).}

Cuando se completa el barrido de frecuencia registrando la potencia de correlación en las proximidades de las coordenadas de retardo-frecuencia estimadas, la adquisición avanza incondicionalmente a la última y más importante de las etapas de la sincronización, implementada en el estado SEGUIMIENTO de la Figura 7.7. 


\subsubsection{Seguimiento y detección de flancos}

Esta es la última etapa de la adquisición de señales GNSS. En ella se realiza la estimación definitiva de los valores de la frecuencia portadora y del valor del retardo de la función de código, eliminando el error residual de las etapas anteriores hasta limitar el error de estimación al efecto del ruido en la estimación. Adicionalmente esta etapa también realiza una estimación del progreso de la fase de la portadora en el tiempo que permita posteriormente la demodulación del mensaje de navegación. Por último, y de forma totalmente fundamental para el procesamiento posterior de la señal, esta etapa realiza la detección de la posición de los flancos de los pulsos del mensaje de navegación en la señal.

La representación en statechart de la etapa es en su nivel externo muy similar a las anteriores etapas. Existen, como en casos anteriores, dos estados de preparación de los correladores (SEG_INI_1, SEG_INI_2), encargados de configurar los tiempos de integración adecuados. Ver Figura 7.13.

El estado SEG_INI_1 tiene una función adicional muy importante que es la de alinear los intervalos de integración con los ciclos de la función de código de la señal. Se verá posteriormente que este alineamiento es una pre-condición necesaria para el correcto funcionamiento de los algoritmos de detección de flancos implementados. El alineamiento se logra en SEG_INI_1 mediante el ajuste de la duración de la correlación siguiente, extendiéndola el tiempo necesario para que su finalización coincida con la finalización de un ciclo de la función de código.

El estado principal de la etapa, SEG_ACTUALIZACION_Y_DETECCION, recibe su nombre de las dos tareas principales que ocurren dentro en esta etapa del procesamiento: la actualización de lazos de seguimiento de fase y portadora y la detección de los flancos de los pulsos del mensaje de navegación.

La operación de los algoritmos que operan en SEG_ACTUALIZACION_Y_DETECCION puede ser representada como formada por dos máquinas de estados que se ejecutan concurrentemente. La primera de ellas, ACTUALIZACION_LAZOS, representa la ejecución de los algoritmos de actualización de lazos de seguimiento, mientras que TRANSITORIO_ENGANCHE y DETECCIÓN forman parte del sistema de detección de flancos.

Los algoritmos de seguimiento de portadora y código utilizados son muy similares a los ya presentados en el Capítulo 6. Existe un único lazo de seguimiento de portadora debido a que el módulo de adquisición del hardware de correlación no tiene capacidad de correlación multiantena en paralelo, y por lo tanto los algoritmos presentados en el 


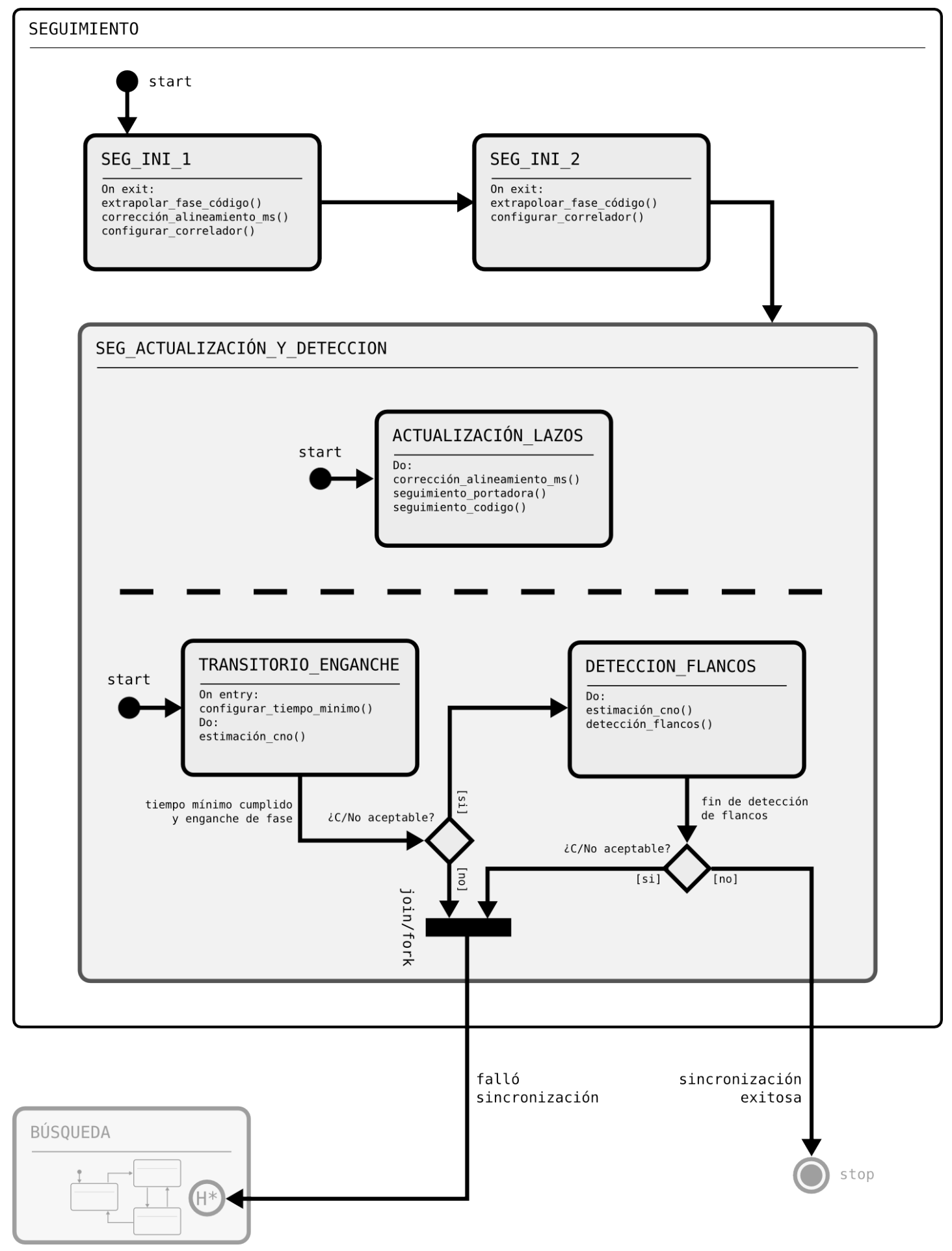

FigURA 7.13: Diagrama statechart de la máquina de estado anidada dentro del estado compuesto SEGUIMIENTO de la Figura 7.7. 
Capítulo 6 no son aplicables. En su lugar se realiza seguimiento monoantena convencional, utilizando como entrada aquella en la que se produjo la detección y verificación de la señal en las etapas de adquisición previas. Esto no provoca inconvenientes serios debido a que los lazos de seguimiento de esta etapa sólo necesitan permanecer en funcionamiento durante entre 2 y 2,5 segundos mientras se realiza la detección de flancos.

Los lazos de portadora y código comparten el mismo diseño básico que los descriptos en la Sección 6.3 .1 (portadora) y en la Sección 6.3.2 (código). Al igual que en ese caso, el esquema utilizado es un lazo con asistencia de fase del lazo de portadora al lazo de código, un lazo de portadora PLL de alta dinámica $(B n \approx 66 \mathrm{~Hz})$ con discriminador de fase UFA-PLL, lazo de código de orden reducido y ancho de banda acotado ( $B n=3 \mathrm{~Hz}$ ).

La detección de los flancos que se lleva a cabo en DETECCIÓN requiere que se haya estabilizado previamente la estimación de fase y frecuencia del lazo de seguimiento de portadora para poder aislar la modulación de los pulsos del mensaje de navegación. La espera hasta el cumplimiento de esta condición se produce en el estado TRANSITORIO_ENGANCHE.

La condición que provoca la transición de TRANSITORIO_ENGANCHE a DETECCIÓN es el cumplimiento de un tiempo mínimo (aproximadamente 0,3 seg, calculado por simulación de la duración del transitorio de respuesta del lazo de portadora a un error de fase/frecuencia) y que se haya logrado una estimación de la relación $C / N_{o}$ de la señal. Cumplidas estas condiciones se verifica que el nivel de $C / N_{o}$ de la señal se encuentre en el rango de aceptabilidad para una señal en seguimiento estable, y si no se alcanza el nivel mínimo de dicho rango se aborta la adquisición y se retorna el proceso de adquisición al estado BÚSQUEDA. Esta verificación permite detectar problemas en la fase de centrado de lóbulo, que pueden provocar falsos enganches en el lazo de seguimiento de portadora.

Una vez en el estado DETECCIÓN se activan los algoritmos de detección de flancos del mensaje de navegación. Estos algoritmos se encargan de eliminar la ambigüedad en la posición de los flancos de los pulsos de mensaje de navegación en relación a los ciclos de la función de código de la señal, que como se vio anteriormente guardan una relación de sincronismo entre sí.

En un receptor GPS típico el proceso de eliminación de la ambigüedad debe determinar qué relación de fase guardan los pulsos del mensaje de navegación respecto de la función de código de entre los 20 alineamientos posibles que pueden tener entre ellos, proveyendo entonces información completa sobre la posición de los pulsos en la señal. En el receptor GPS/GLONASS aquí presentado la presencia de señales GLONASS modifica 
este esquema debido a la presencia de la marca de tiempo transmitida a 100 bps en esta última.

Para resolver el problema de la detección de los pulsos de navegación GPS/GLONASS de forma unificada, en esta implementación se optó por separarlo en dos partes. Como parte del proceso de adquisición se lleva adelante la determinación de la ambigüedad de la posición de los flancos módulo $10 \mathrm{~ms}$ (dicho de otra forma, de cada 10 ciclos de código consecutivos, determinar en qué comienzo de código podría ocurrir un flanco de pulso). Esto es equivalente a tratar la señal de entrada como si fuera una modulación NRZ de tasa 100 bps. Esto tiene las ventajas de poder hacerse de forma común a GPS y GLONASS, proveer suficiente información para habilitar el seguimiento posterior de la señal (Capítulo 6) y de además ser inmune a los cambios de tasa de datos de la señal GLONASS. Sin embargo, esta información parcial del alineamiento no es suficiente para comenzar la demodulación del mensaje de navegación.

Es responsabilidad del módulo de demodulación del mensaje eliminar la ambigüedad residual, lo cual puede hacerse trivialmente mediante un detector de cambios de signo en el caso de señales GPS (histograma de dos celdas), y mediante la detección de la marca de tiempo en GLONASS. Sobre esto no se entrará en detalles por exceder los alcances de la presente tesis.

El algoritmo inmediato para la detección de la posición de los flancos módulo 10 ms es el método del histograma, descripto en [3]. Este método tiene la desventaja de requerir que el tiempo de integración utilizado en esta etapa sea de $1 \mathrm{~ms}$ y que en consecuencia los lazos de seguimiento sean actualizados a una tasa de $1 \mathrm{kHz}$. Esta alta tasa de actualización de los lazos de seguimiento es la razón por la que generalmente la ejecución esta etapa de la adquisición se convierte en un cuello de botella del procesamiento.

Por las razones anteriores, para la implementación de los algoritmos de adquisición del prototipo de receptor se llevó adelante el desarrollo de una nueva técnica de detección de flancos apta para ser utilizada en lugar del método del histograma, y que tiene la característica de imponer menos restricciones sobre la tasa de las muestras de entrada del algoritmo. El resultado es una técnica de detección de alineamiento de flancos basada en el criterio de máxima verosimilitud y adaptable a diversas duraciones de tiempo de integración sin perjuicio excesivo de la probabilidad de error del resultado. Este método fue publicado en [15], y sus detalles pueden encontrarse también en el Apéndice $\mathrm{C}$ de esta tesis.

Para este receptor se hizo una implementación del detector de alineamiento de máxima verosimilitud basado en correlaciones de $3 \mathrm{~ms}$. La cantidad de flancos $F$ que se utilizan para tomar una decisión respecto del alineamiento se adapta en función de la estimación 
que se hace de la relación $C / N_{o}$ en el estado TRANSITORIO_ENGANCHE para lograr una probabilidad de error inferior a $10^{-6}$ :

- Entre $30 \mathrm{~dB}-\mathrm{Hz}$ y $35 \mathrm{~dB}-\mathrm{Hz}, F=40$.

- Entre $35 \mathrm{~dB}-\mathrm{Hz}$ y $40 \mathrm{~dB}-\mathrm{Hz}, F=20$.

- Arriba de $40 \mathrm{~dB}-\mathrm{Hz}, F=10$.

La elección de la cantidad $F$ de flancos necesarios para tomar una decisión del alineamiento afecta el tiempo que toma el proceso de sincronización, y es también función del sistema GNSS. El mensaje de navegación de GPS tiene en promedio 25 flancos de bit por segundo, mientras que el promedio para GLONASS se encuentra en la cercanías de 75 ; por esto el proceso de detección del alineamiento tendrá una duración promedio menor para señales GLONASS que para GPS.

El estado detección DETECCIÓN concluye cuando se observa la cantidad mínima de flancos $F$. Cuando eso ocurre se realiza una nueva estimación del valor $C / N_{o}$ de la señal, volviendo a verificar que su valor se encuentre en un rango aceptable de valores. Si el valor de $C / N_{o}$ es aceptable se da por terminado el proceso de adquisición, tomando el arco de salida que termina en el pseudo-estado stop. En caso contrario si el valor de $C / N_{o}$ no indica la existencia de una condición de enganche sólida se aborta el proceso de adquisición, retornando al estado compuesto BÚSQUEDA.

\subsection{Resumen de capítulo}

El proceso de adquisicón de las señales GPS C/A y GLONASS L1OF es un proceso complejo formado por una serie de etapas que a partir de un conocimiento limitado o nulo de los parámetros de la señal buscada deben lograr una estimación de los mismos con márgenes de error lo suficientemente acotados como para permitir la entrada exitosa de la señal en la etapa de seguimiento.

En este capítulo se llevó a cabo una descripción de los algoritmos utilizados para realizar el proceso de adquisición. La principal diferencia entre estos y sus contrapartes utilizadas en receptores convencionales radica en el recorrido secuencial del conjunto de antenas para garantizar que el proceso de búsqueda cubre la totalidad de las direcciones de arribo de señal posibles. Este recorrido secuencial debe ser tal que se entrelacen en el tiempo los procesos de búsqueda en los planos de retardo-frecuencia de todas la antenas de entrada que están siendo examinadas, para evitar el riesgo de aparición de situaciones 
patológicas como consecuencia de la combinación de la duración del proceso de búsqueda en cada antena con la velocidad de rotación del vehículo.

Para simplificar el análisis de los algoritmos utilizados para llevar adelante el proceso de adquisición, se utilizó una representación basada en máquinas de estados anidadas (statecharts), lo que permitió una representación muy fiel de la relación entre las diferentes etapas intermedias del proceso. Se puso énfasis en el impacto que tiene la naturaleza diferida del procesamiento en tiempo real de correlaciones sobre los algoritmos, que obliga al software a solapar el procesamiento de múltiples intervalos de correlación en el tiempo, con el correspondiente incremento en la complejidad de los algoritmos.

Un desarrollo lateral importante de la implementación de los algoritmos de adquisición en el receptor embebido fue el desarrollo de una nueva metodología de detección de flancos del mensaje de navegación, la cual es una de las tareas fundamentales de las últimas etapas del proceso de adquisición de una señal GNSS. Por razones de brevedad este capítulo no entra en detalles acerca de este desarrollo, limitándose a mencionarlo y utilizar sus resultados prácticos, pero una discusión más profunda de esta técnica de detección puede hallarse en el Apéndice $\mathrm{C}$ de este trabajo de tesis. 



\section{Capítulo 8}

\section{Ensayos de funcionamiento}

\subsection{Introducción}

En este capítulo se muestran los resultados de algunos de los ensayos realizados sobre la implementación de los algoritmos descriptos en los capítulos anteriores como parte del software de un prototipo de receptor GPS/GLONASS multiantena.

Los resultados presentados corresponden a una serie de ensayos funcionales realizados para verificar el correcto funcionamiento de distintos algoritmos del software del receptor. Estos incluyen ensayos estáticos realizados con señal real proveniente de antenas fijas y señal de satélites reales de los sistemas GPS y GLONASS, y otros realizados con la ayuda de un simulador de señales GNSS. Este último es un dispositivo capaz de sintetizar las señales de los satélites de múltiples sistemas (GPS, GLONASS, Galileo) en condiciones dinámicas configurables y para un número y distribución de antenas programable.

No se pretende aquí realizar una verificación exhaustiva del software implementado, sino tan sólo mostrar algunos resultados particularmente relevantes. Se comienza describiendo la interfaz de comunicación utilizada para recuperar la información transmitida por el receptor, y a través de una serie de capturas observar una condición de trabajo típica consistente en el seguimiento de señales de una combinación de satélites de los sistemas GPS y GLONASS de forma simultánea.

Luego se muestran los registros de variación de la frecuencia portadora de las señales GPS y GLONASS observadas por el receptor a lo largo de un intervalo de 24 horas, mostrando con ello no sólo la evolución en el tiempo de las señales presentadas sino también la estabilidad y autonomía de los algoritmos encargados de la adquisición y puesta en seguimiento de dichas señales a lo largo de la totalidad del intervalo registrado. 
En tercer término se presentan los resultados de dos ensayos dinámicos realizados con auxilio de un simulador GNSS para verificar el funcionamiento de los algoritmos de conmutación de antenas y seguimiento en condiciones de alta dinámica. Este ensayo confirma que el comportamiento de los algoritmos es el previsto por diseño, y verifica las respuesta de los mismos en presencia de escenarios que se aproximan a las condiciones que enfrentaría el receptor a bordo de un vehículo cohete.

Por último se cierra el capítulo exponiendo los resultados de una comparación de las probabilidades de adquisición estimadas de forma experimental con ayuda del simulador GNSS contra la curva de probabilidad teórica esperada para el tipo de algoritmo utilizado.

\subsection{Interfaz de comunicación con el receptor}

El prototipo de receptor se comunica con el mundo exterior a través de un canal de comunicación serie de tipo RS-232 que puede ser recibido utilizando una computadora personal convencional.

El protocolo utilizado para encapsular los mensajes es un protocolo de tipo binario compuesto por mensajes estructurados. Estos últimos transportan información sobre el estado, los eventos ocurridos, las acciones emprendidas por el receptor y los resultados más relevantes generados durante la operación del receptor, transmitidos en tiempo real.

Este protocolo es decodificado por un software que corre en la computadora personal, el cual selecciona de entre todos los mensajes enviados por el receptor aquellos que contienen la información deseada y la preparan para su presentación en pantalla en tiempo real. En el caso de las mediciones de observables y de resultados de navegación también es posible el almacenamiento de los valores en disco para su procesamiento posterior mediante un software de cálculo convencional.

En la Figura 8.1 se puede ver una captura de pantalla de una condición de trabajo típica del receptor en funcionamiento. En ella se pueden ver múltiples terminales, cada una corriendo una instancia independiente del software cliente del receptor. Las ventanas presentes en la captura son:

Consola Ventana inferior izquierda, detalle en la Figura 8.2.

Navegación Ventana superior izquierda, detalle en la Figura 8.3.

Canales Ventana superior derecha, detalle en la Figura 8.4. 


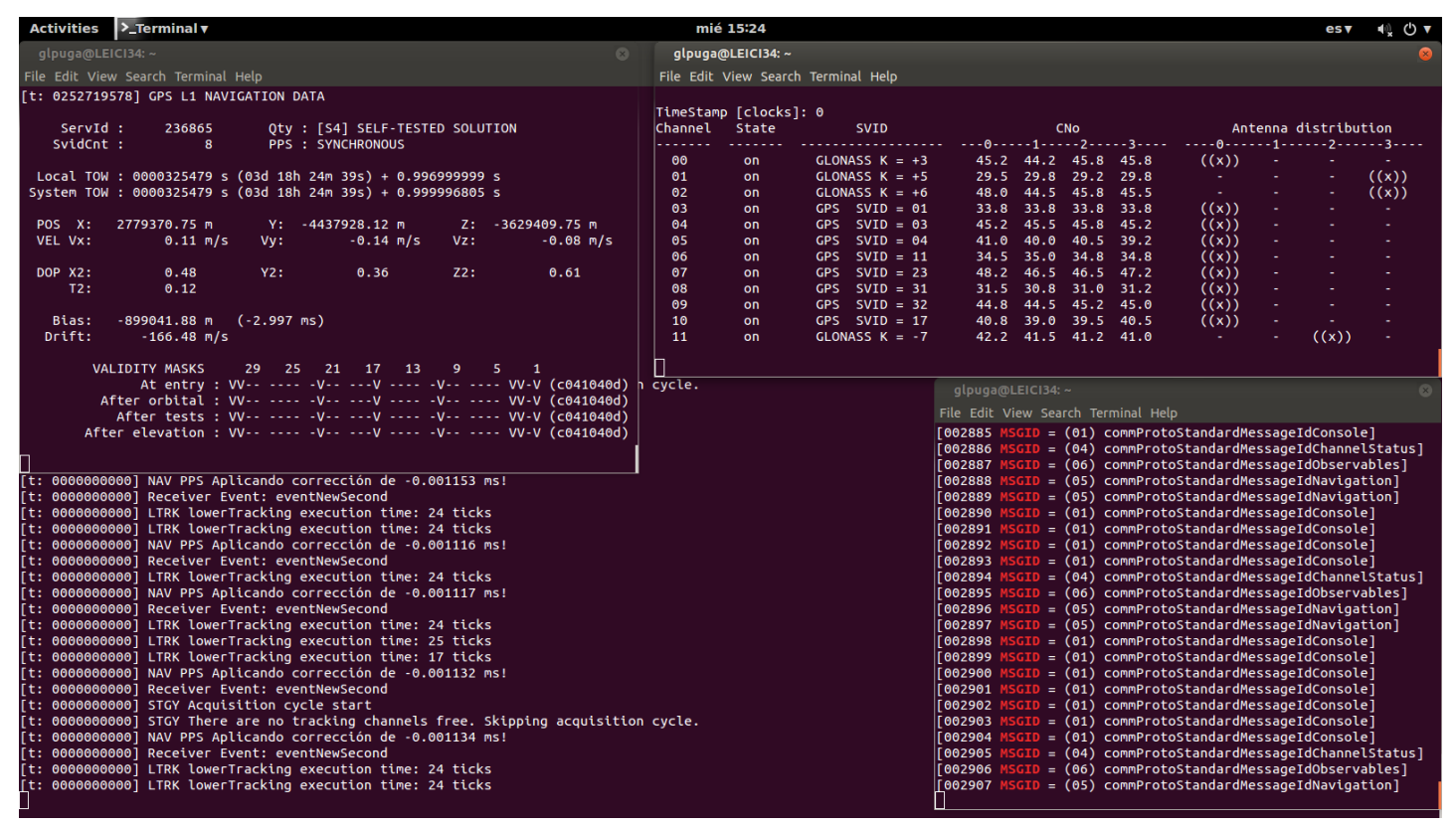

Figura 8.1: Captura de pantalla mostrando una condición de trabajo típica del prototipo de receptor multiantenna GPS/GLONASS. Las Figuras 8.2, 8.3, 8.4 y 8.5 muestran versiones ampliadas de las terminales individuales que se ven aquí.

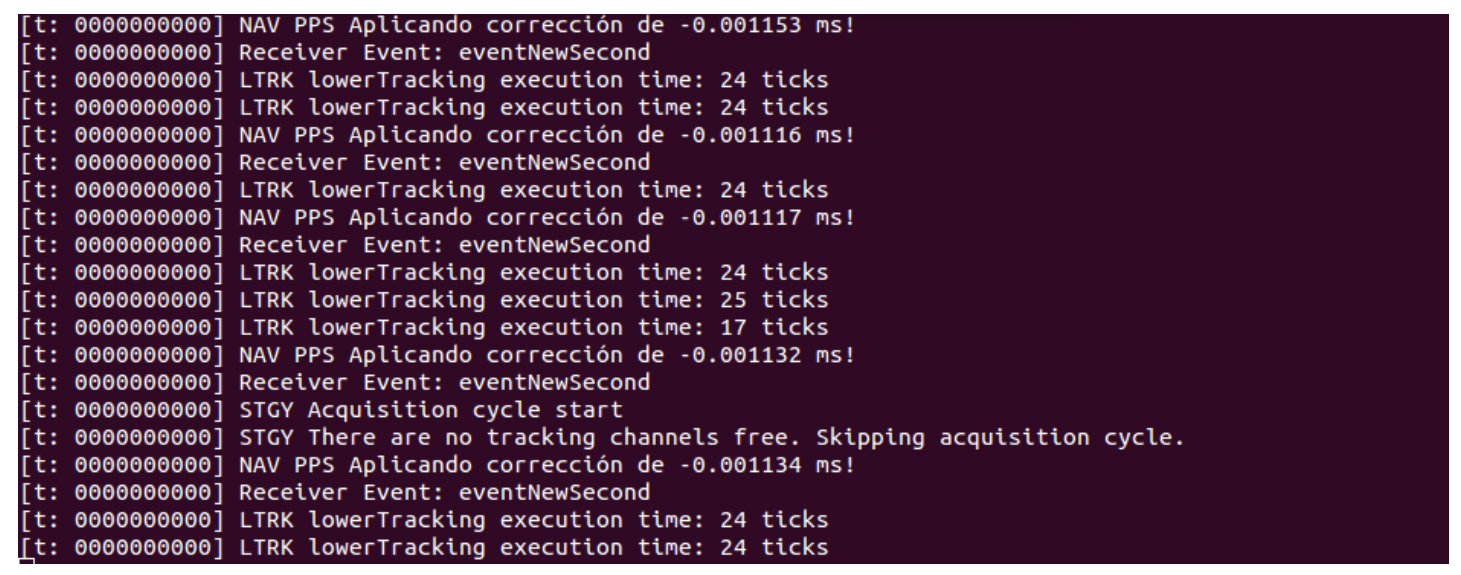

Figura 8.2: Vista en detalle de la terminal donde se presenta la información de consola transmitida por el receptor.

Comunicación Ventana inferior derecha, detalle en la Figura 8.5.

La consola es un tipo de mensajes que se utiliza para transmitir información no estructurada de propósito general en formato texto. Es una herramienta muy flexible que se utiliza para comunicar la ocurrencia de eventos, el comienzo y la finalización de procesos, la aparición de condiciones de alarma, y otra información útil para la depuración del receptor. 


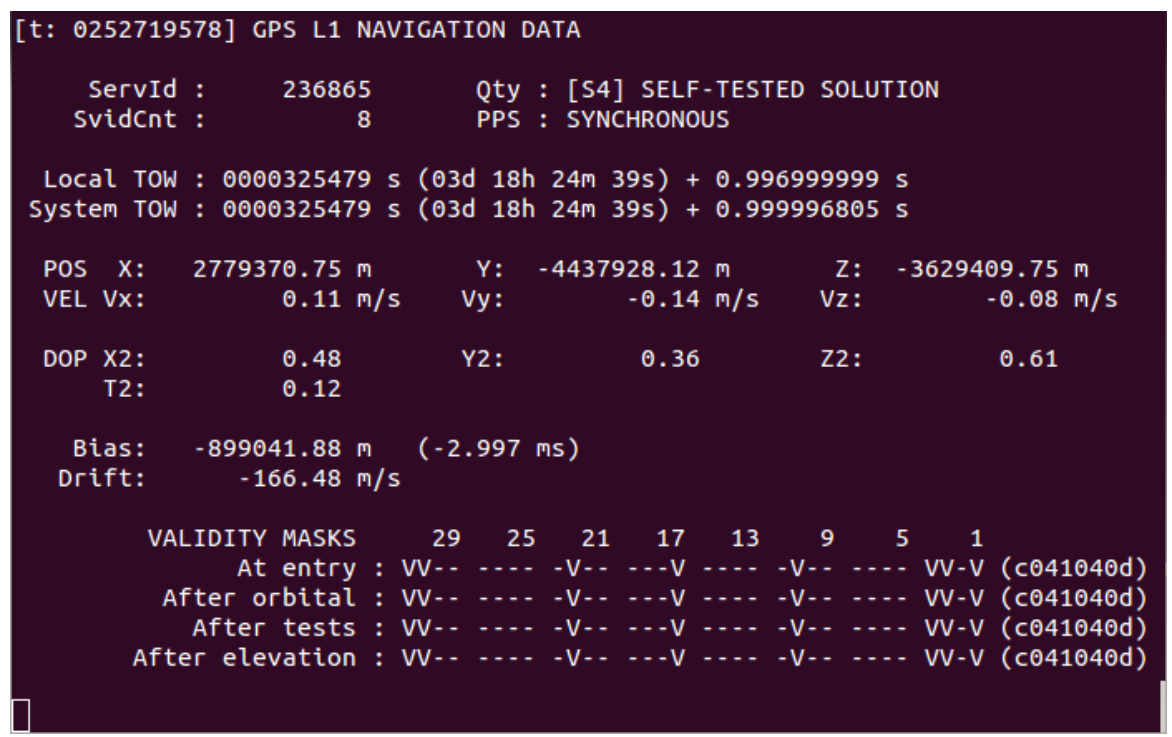

FigurA 8.3: Vista en detalle de la terminal donde se presenta la información de navegación GPS transmitida por el receptor. Una terminal semejante muestra la información de navegación GLONASS transmitida por el receptor de forma separada.

La información de navegación, visible en la Figura 8.3, muestra los resultados del cálculo de una solución de navegación a partir de señales GPS realizado por el receptor en tiempo real. Por brevedad no se incluye, pero una ventana semejante permitiría ver el contenido de los mensajes que transportan las soluciones de navegación GLONASS.

Si bien una descripción de los algoritmos de navegación escapa a los alcances de la presente tesis, puede asegurarse que su correcto funcionamiento es una prueba de validación importante de los algoritmos de adquisición y seguimiento presentados en los capítulos anteriores, ya que la calidad de la solución depende de forma directa de los observables generados por dichos algoritmos.

El estado de los canales que se ve en la Figura 8.4 presenta una síntesis del estado de funcionamiento de los canales de seguimiento del receptor. Esta información incluye las asignaciones de satélites a canales, los canales vacantes (no asignados), los niveles de relación $C / N_{o}$ de cada una de las señales recibidas discriminados por antena de entrada, y cuál de las antenas de entrada es la antena activa para cada una de las señales en seguimiento.

En la Figura 8.4 se puede ver que el receptor tiene la totalidad de los canales de seguimiento disponibles (doce) ocupados con una combinación de señales GPS (ocho canales) y GLONASS (los cuatro restantes). La captura de pantalla se llevó a cabo con un arreglo experimental donde una única antena alimenta a través de un cuadruplexor las cuatro entradas del receptor por lo que los niveles de relación $C / N_{o}$ de todas las antenas son 


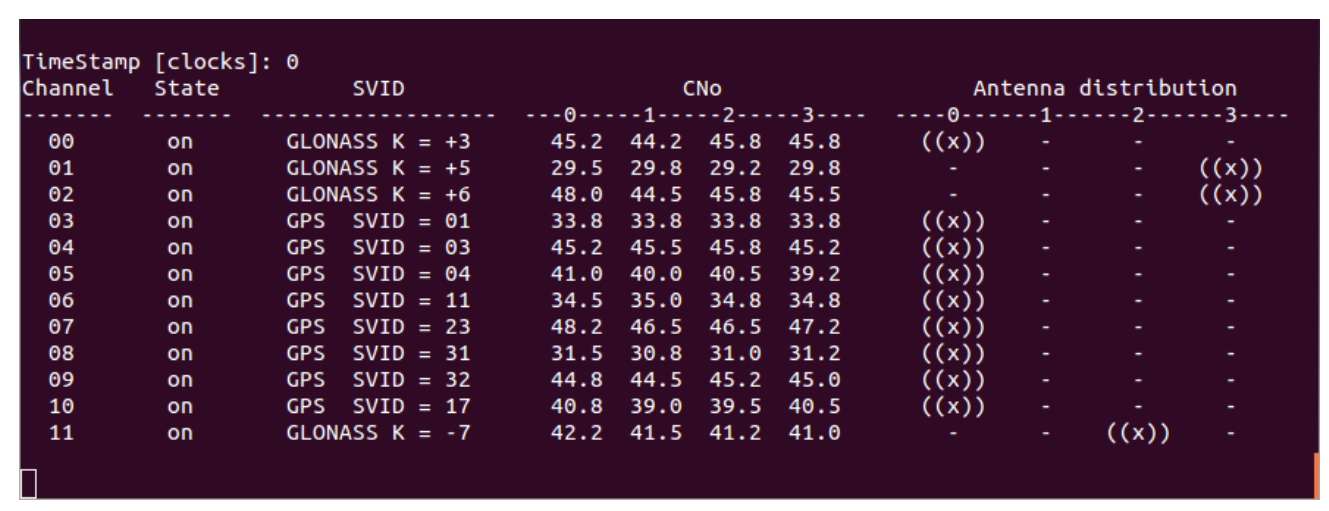

FigurA 8.4: Vista en detalle de la terminal donde se presenta la información de estado de canales transmitida por el receptor. Se puede ver que los doce canales del receptor están ocupados por una combinación de señales GPS (ocho canales) y GLONASS (cuatro canales). Los niveles de relación $C / N_{o}$ de cada señal a través de cada una de las cuatro antenas se pueden ver en las cuatro columnas centrales, mientras que la elección de antena activa está indicada con las cuatro columnas que se encuentran en el extremo derecho.

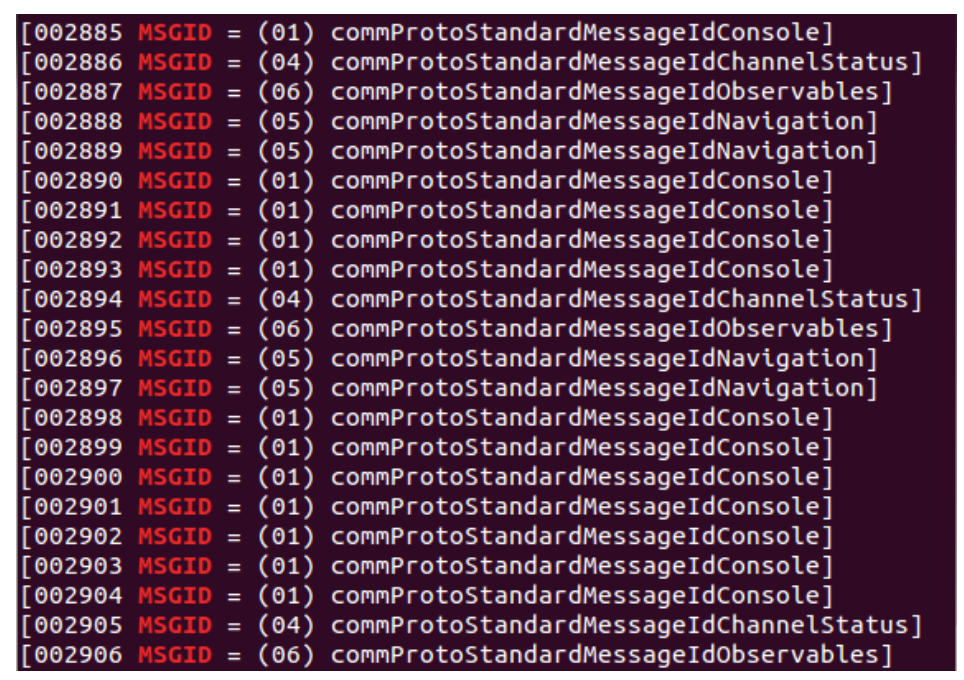

FigurA 8.5: Vista en detalle de la terminal donde se muestra un volcado de los mensajes transmitidos por el receptor a través de su protocolo de comunicación binario.

semejantes. Todos los satélites tienen relaciones $C / N_{o}$ en el rango normal de operación que va de $30 \mathrm{~dB}$ a los $45 \mathrm{~dB}$.

Por último, en la Figura 8.5 se puede ver un volcado de los mensajes transmitidos por el receptor en los instantes previos a la toma de la captura de pantalla.

No se presentan aquí, pero también existen mensajes para transmitir los observables para su procesamiento posterior fuera del receptor, registros de funcionamiento de los lazos de seguimiento para su depuración, y parte de los mensajes de navegación transmitidos por los satélites recibidos, entre otras posibilidades. 


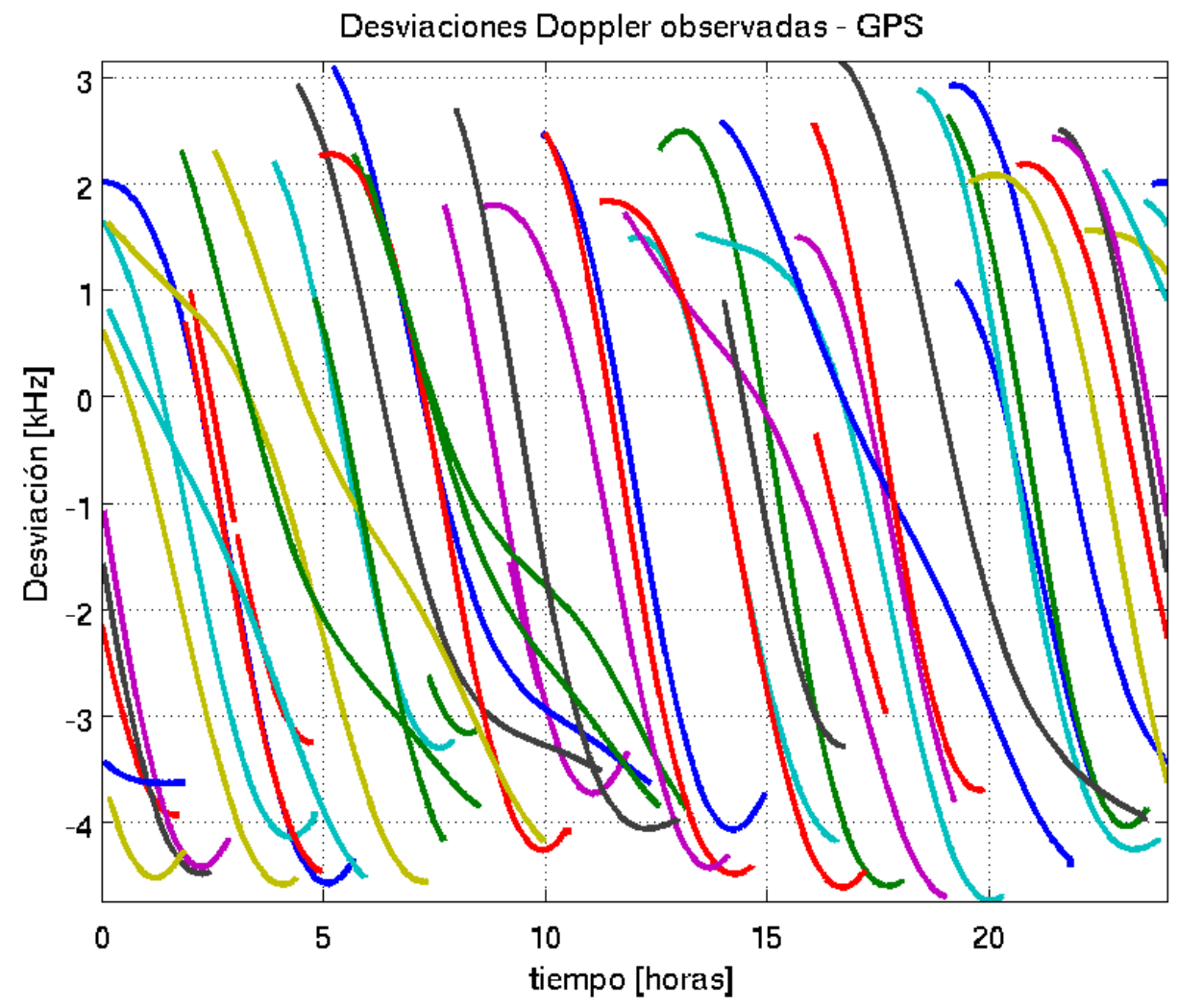

FigurA 8.6: Desviación de frecuencia respecto del valor nominal de portadora para todos los satélites GPS observados por el receptor durante un intervalo de funcionamiento continuo de 24 horas. Cada curva representa la evolución en el tiempo de la frecuencia portadora de un mismo satélite, desde el momento de su adquisición hasta la pérdida de su enganche.

\subsection{Seguimiento de señales con antena estática}

Las Figuras 8.6 y 8.7 muestran un registro de las desviación de la frecuencia portadora de cada uno de los satélites adquiridos y puestos en seguimiento por el prototipo de receptor durante un intervalo de tiempo de 24 horas de funcionamiento continuo. La primera de estas figuras presenta el caso se señales GPS exclusivamente, mientras que la segunda corresponde a señales GLONASS.

En ambos casos se utilizó el receptor conectado a una única antena hemisférica estática en posición normal (cénit hacia el cielo). Las señales de los satélites son señales reales, transmitidas por satélites pertenecientes a los segmentos espaciales de los sistemas GPS y GLONASS.

Una figura semejante a esta fue adelantada en el Capítulo 3, Figura 3.13. Tal como se explicó en ese momento, cada una de las curvas presentes en el registro indica la variación en la desviación de la frecuencia portadora de un dado satélite respecto de 


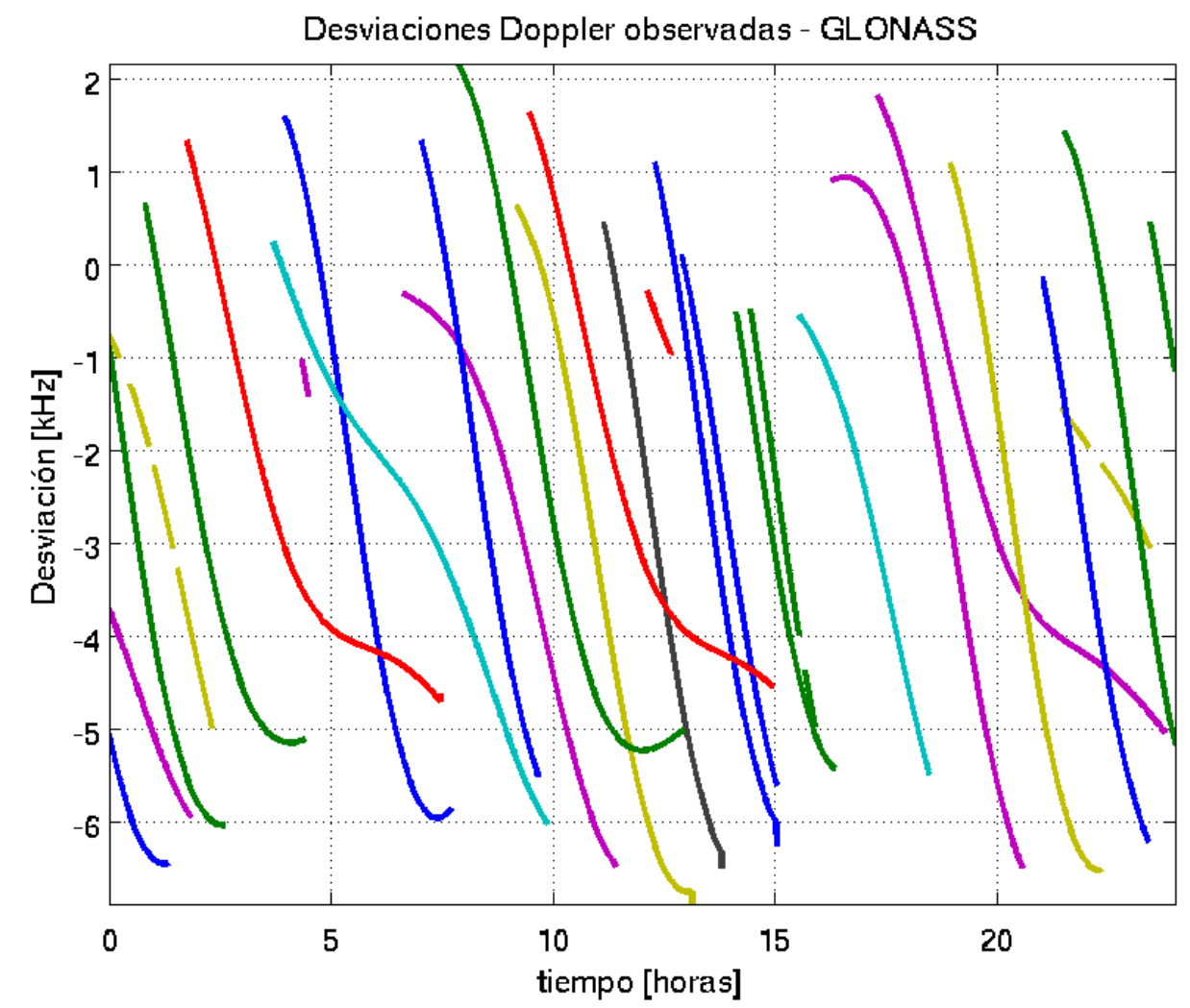

Figura 8.7: Desviación de frecuencia respecto del valor nominal de portadora para todos los satélites GLONASS observados por el receptor durante un intervalo de funcionamiento continuo de 24 horas. Cada curva representa la evolución en el tiempo de la frecuencia portadora de un mismo satélite, desde el momento de su adquisición hasta la pérdida de su enganche.

su valor nominal. Esta diferencia tiene dos fuentes principales: la variación por efecto Doppler, debido al cambio en el vector velocidad relativa del satélite respecto de la antena receptora, y las imperfecciones en la referencia de tiempo del receptor.

El comienzo de cada curva corresponde al instante de adquisición de la señal. El proceso de seguimiento de la misma ocupa todo el intervalo posterior, y se puede medir observando la duración de la proyección del trazo sobre el eje horizontal.

\subsection{Ensayos dinámicos con señal simulada}

Los apartados siguientes muestran los registros de funcionamiento de los lazos de seguimiento en dos condiciones de operación extremas correspondientes a los límites de requerimientos dinámicos presentados en el Capítulo 4: vehículo girando a $4 \mathrm{rpm}$ alrededor de su eje y aceleración súbita de $10 \mathrm{~g}$ sobre el eje del vehículo. 


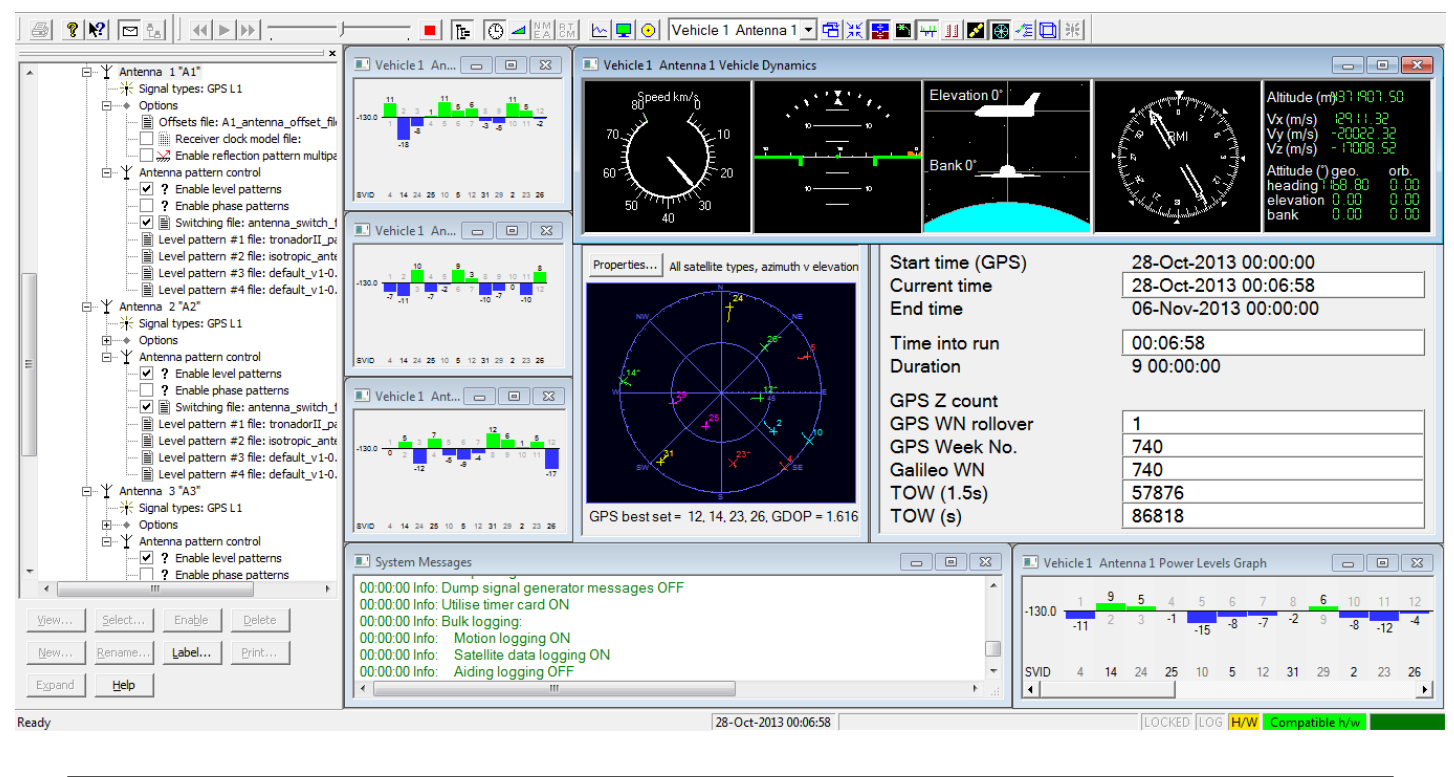

Figura 8.8: Captura de pantalla del software de control del simulador de señales GNSS utilizado para realizar las simulaciones dinámicas.

Para poder ejercitar los algoritmos de seguimiento en estas condiciones dinámicas se recurrió a un simulador de señales GNSS. Este tipo de equipo permite configurar escenarios de simulación casi completamente configurables, pudiendo controlarse la estructura del sistema de antenas, los patrones de radiación de las antenas individuales, los desplazamientos del vehículo (posición, velocidad y orientación), y la constelación de satélites presentes (GPS, GLONASS, Galileo). Este equipo permite la evaluación de comportamiento del prototipo de receptor en condiciones que de otra forma serían muy difíciles de sintetizar y efectuar los ensayos con un alto grado de repetibilidad. En la Figura 8.8 se puede ver una captura de pantalla del panel de control del software de control del simulador.

Una característica muy importante del simulador utilizado es la posibilidad de ejecutar escenarios de simulación multiantena con hasta cuatro antenas receptoras de señal GPS C/A. Esto es una capacidad invaluable para verificar el funcionamiento de los algoritmos presentados en esta tesis. Sin embargo el equipo disponible no permite la generación de escenarios GLONASS L1OF de más de una única antena, por lo que ensayos equivalentes a los que se presentarán a continuación no son posibles. No obstante ello, dado el alto nivel de independencia de los algoritmos respecto del sistema GPS o GLONASS al que pertenezca la señal es razonable asumir que el análisis siguiente vale por igual para las señales de ambos sistemas.

Utilizando este simulador se configuraron escenarios de simulación para verificar el funcionamiento del receptor en las condiciones de máxima exigencia esperadas en misión, las cuales fueron discutidas en el Capítulo 4 y por comodidad se resumen a continuación: 
- Vehículo cilíndrico de $3 \mathrm{~m}$ de diámetro.

- Arreglo cuádruple de antenas ubicadas sobre la periferia del vehículo a intervalos de $90^{\circ}$.

- Máxima velocidad de rotación del vehículo sobre su eje de 4 rpm.

- Máximo escalón de aceleración del vehículo de 10 g.

Las secciones siguientes muestran los registros de funcionamiento de los lazos de seguimiento en para dos escenarios diferentes:

- Conmutación de antenas con vehículo rotando a velocidad angular máxima.

- Escalón de aceleración con rotación.

Todos los registros tienen una duración de $7,5 \mathrm{~s}$, igual a la mitad del período de rotación del vehículo a su velocidad angular máxima.

\subsubsection{Conmutación de antenas con vehículo rotando a velocidad an- gular máxima}

Este ensayo tiene por propósito verificar la continuidad del proceso de seguimiento de una señal a través de múltiples conmutaciones de antena activa en las condiciones límite requeridas para la velocidad angular del vehículo $(4 \mathrm{rpm})$.

El escenario de simulación consiste en un arreglo de antenas como el descripto anteriormente rotando a $4 \mathrm{rpm}$ alrededor del centro del arreglo y sin desplazamiento de posición.

Este movimiento de giro provoca el cambio de la situación de visibilidad de cada una de las antenas del arreglo respecto de la constelación de satélites transmisores, obligando al receptor a adaptarse dinámicamente mediante la conmutación de antena activa de cada señal en función de los niveles de potencia con los que es recibida a través de cada antena del arreglo.

Las figuras siguientes corresponden a un único canal de seguimiento del receptor, el cual en el momento de toma de datos se encontraba asignado al seguimiento de la señal del satélite GPS de identificador SVID 04.

En la Figura 8.9 se pueden ver los niveles de amplitud de la envolvente de la señal recibida a través de cada una de las cuatro antenas del arreglo a lo largo del registro de 7,5 s de duración. El eje horizontal está indicado en ciclos de operación de los lazos de seguimiento, que equivalen a $10 \mathrm{~ms}$ cada uno. 


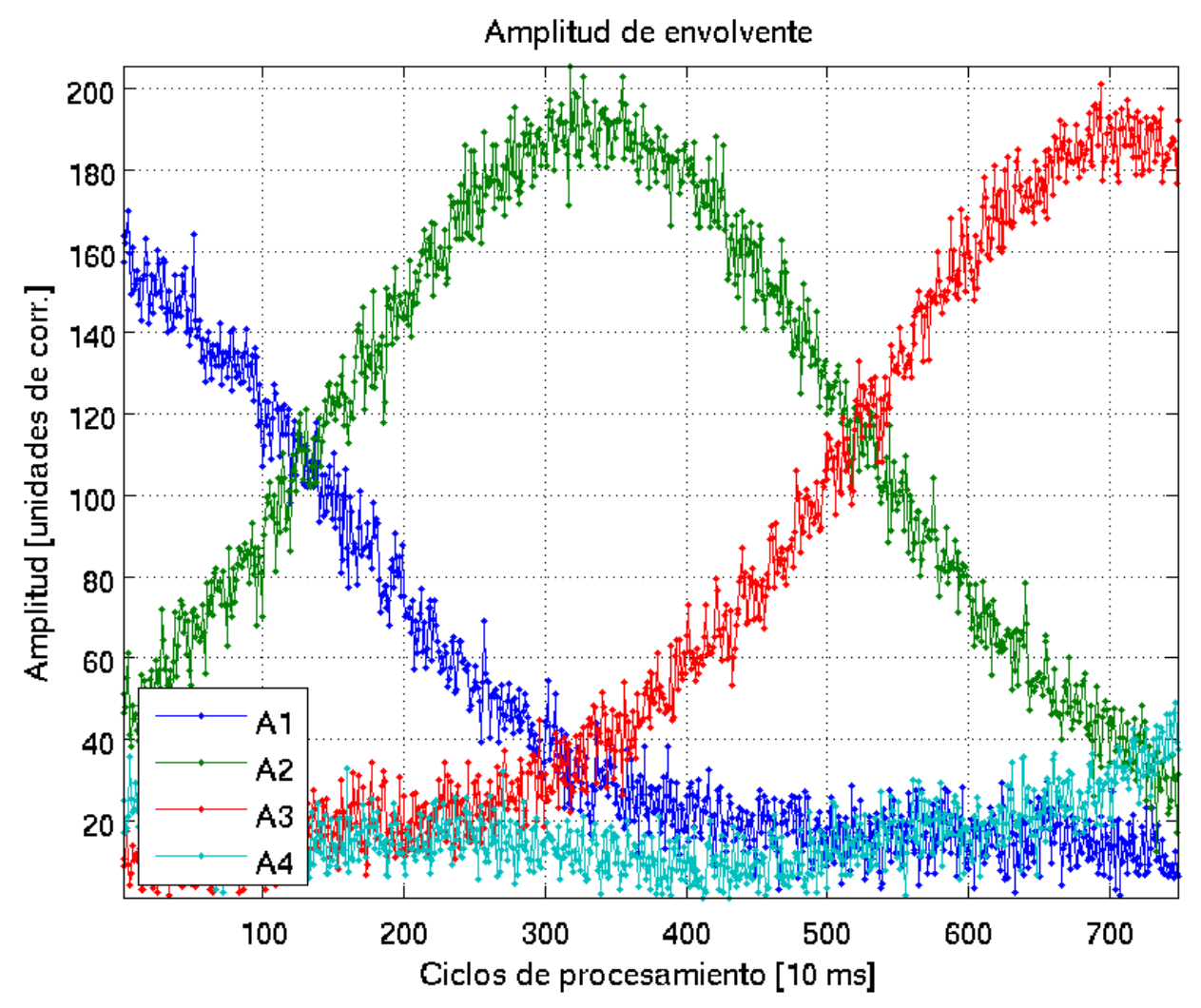

Figura 8.9: Amplitud de la envolvente de la señal recibida a través de cada una de las cuatro antenas de entrada durante el ensayo de conmutación de antenas con simulador GNSS.

En la figura se puede ver que los niveles de amplitud se encuentran modulados por el movimiento de giro del vehículo, debiéndose las variaciones al cambio de la dirección de arribo de la señal respecto del patrón de radiación de cada una de las antenas del arreglo.

La Figura 8.10 contiene el registro de asignación del rol de antena activa correspondiente al mismo intervalo de tiempo de la figura anterior. El rol de antena activa lo tiene inicialmente la antena A1 para luego seguirle en secuencia las antenas A2 y A3, correspondiente a un giro en sentido horario del arreglo de antenas (ver Figura 4.6).

Comparando las Figuras 8.9 y 8.10 se puede comprobar que efectivamente el receptor selecciona como antena activa aquella que tiene la potencia de señal más elevada de entre las cuatro antenas del arreglo.

En la proximidad de los puntos de conmutación, cuando las potencias recibidas a través de dos o más antenas son aproximadamente iguales, el rol de antena activa lo obtiene aleatoriamente cualquiera de ellas debido a la influencia del ruido que modifica las estimaciones de potencia instantánea de cada una. Como se mencionó oportunamente esto 


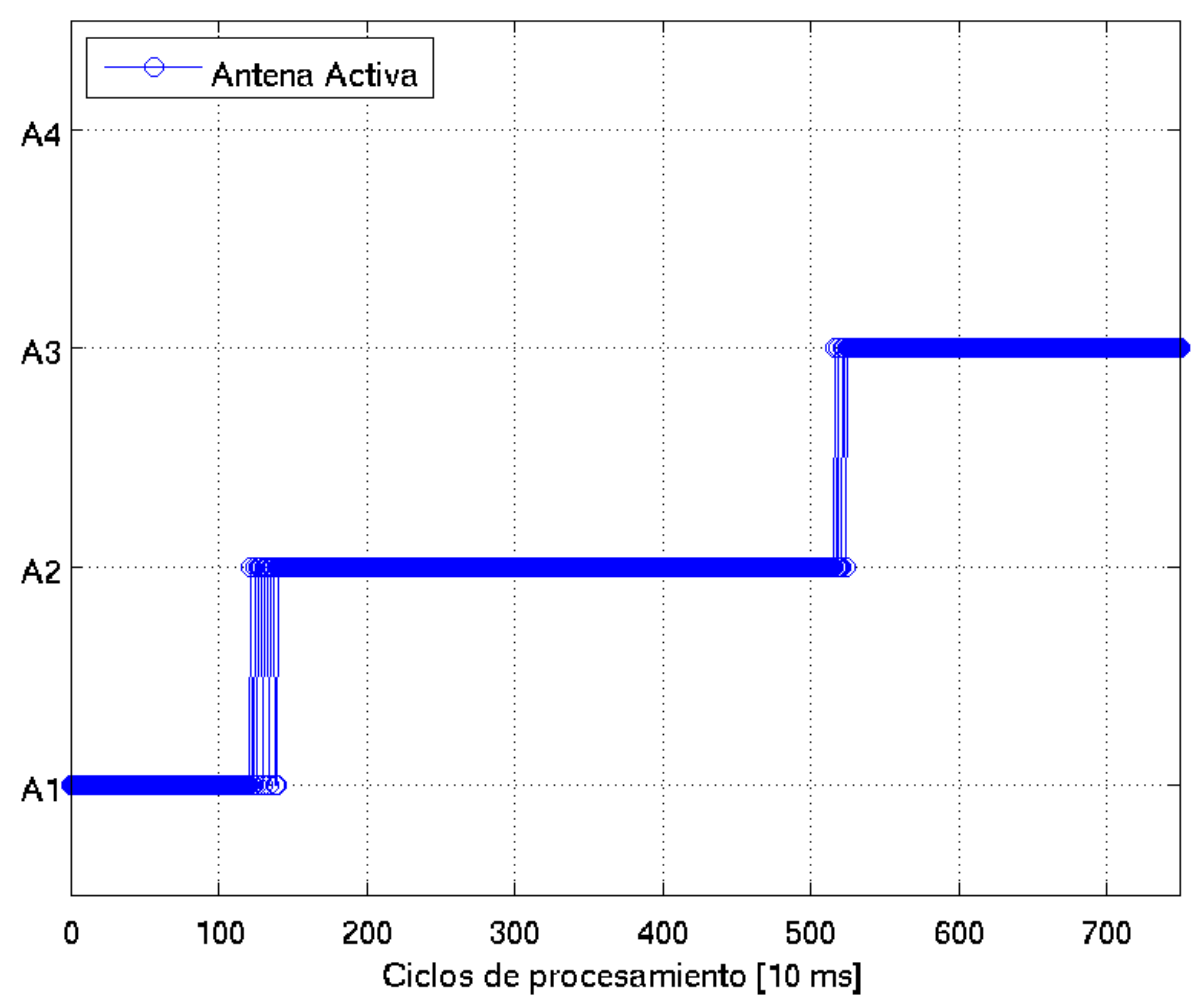

Figura 8.10: Asignación del rol de antena activa a lo largo del tiempo, durante el ensayo de conmutación de antenas con simulador GNSS.

no provoca ningún efecto perjudicial sobre la operación del receptor debido a que todas las antenas intervinientes se encuentran en condiciones similares de enganche.

Las señales recibidas a través de cada una de las cuatro antenas del arreglo ya llevadas a banda base se pueden ver en la Figura 8.11. Allí se muestra no sólo el efecto de la modulación en amplitud de cada una de las versiones de señal recibidas, sino la presencia de la modulación de datos del mensaje de navegación transmitido por el satélite durante el intervalo registrado. Se ve en la figura la coherencia en la polaridad de los mensajes de navegación recibidos a través de todas las antenas; tal como se discutió en la Sección 6.2.1.5 del Capítulo 6, lograr esta coherencia es una de las tareas de la TSS.

En la Figura 8.11 pueden verse tanto las componentes en fase como en cuadratura de las señales en banda base de cada una de las antenas receptoras. Es visible que en todas las antenas con una cantidad apreciable de potencia de señal, esta última se encuentra concentrada sobre la componente en fase. Esto permite verificar el correcto funcionamiento de la estimación de la fase instantánea de portadora, la cual es realizado de forma independiente por cada uno de los cuatro lazos de seguimiento PLL asignados a las antenas de entrada. 

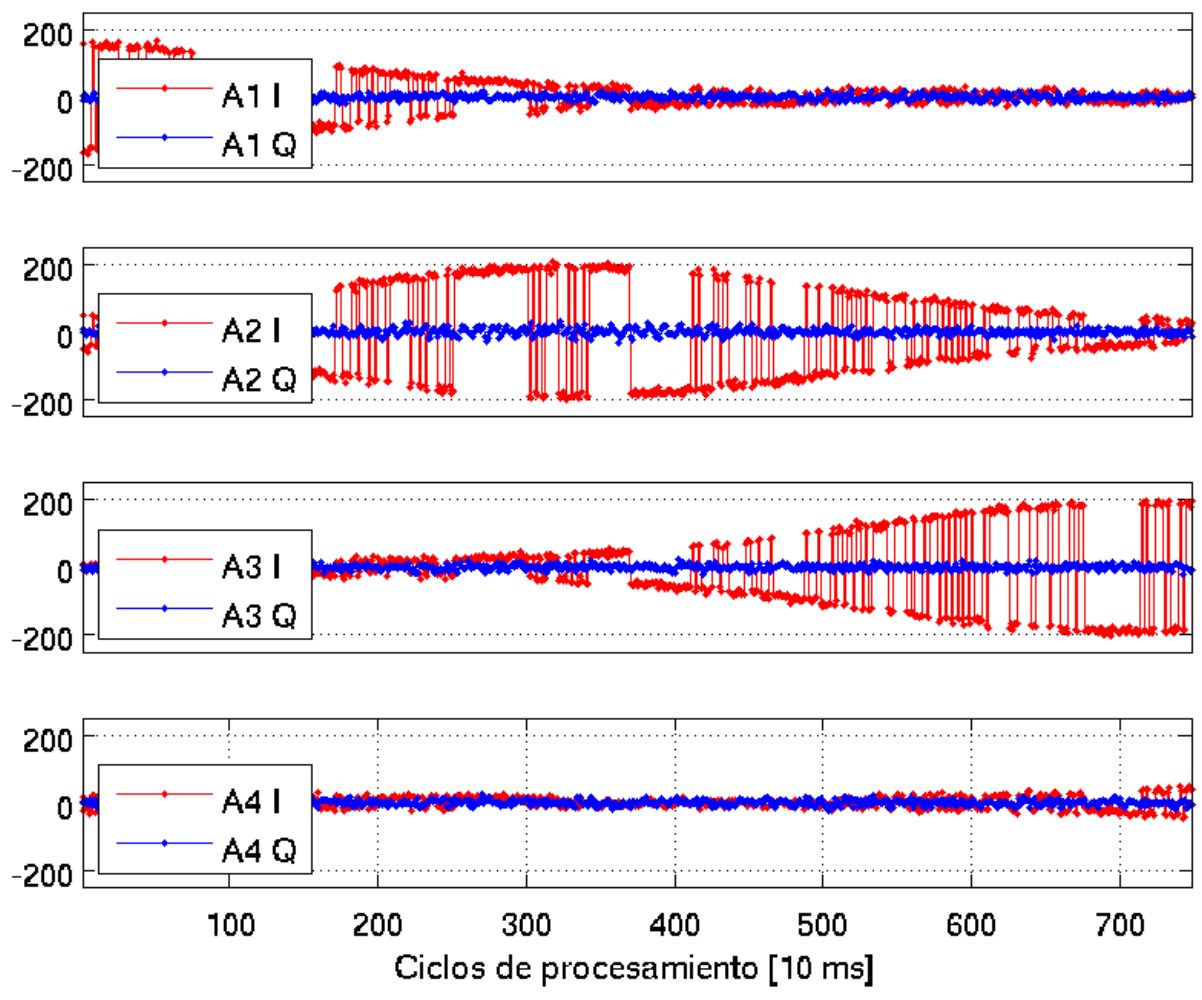

Figura 8.11: Señal en banda base recibida a través de cada una de las cuatro antenas de entrada, durante el ensayo de conmutación de antenas con simulador GNSS.

La consistencia en el enganche de cada uno de los PLLs de seguimiento de portadora puede verse también en la Figura 8.12, donde se encuentran representados los errores instantáneos de cada uno de los lazos de seguimiento de fase. Comparando con las figuras anteriores, es posible ver que tan pronto como una antena supera un nivel mínimo operativo de potencia instantánea de señal, su lazo de seguimiento de fase se engancha con la fase con la que arriba la portadora a dicha antena (segmentos donde el error de fase es aproximadamente cero). La desviación estándar del error de fase en condición de enganche es función de la relación $C / N_{o}$, reduciéndose la primera a medida que aumenta la segunda.

Por el contrario, cuando una antena no tiene suficiente potencia de señal, el error de su lazo de seguimiento asociado varía aleatoriamente de valor dentro de los márgenes de divergencia máxima que permite la TSS (ver Sección 6.2.1.3). Esto puede verse en la Figura 8.12 entre las muestras 300 y 550 aproximadamente para el lazo asociado a la antena A4, entre las muestras 0 y 120 para el lazo asociado a la antena A3, y de la muestra 600 en adelante para el lazo de la antena A1. Estos límites son sólo aproximados, porque en condiciones de muy baja relación $C / N_{o}$ un lazo PLL puede alternar entre el enganche y el desenganche en rápida sucesión. 

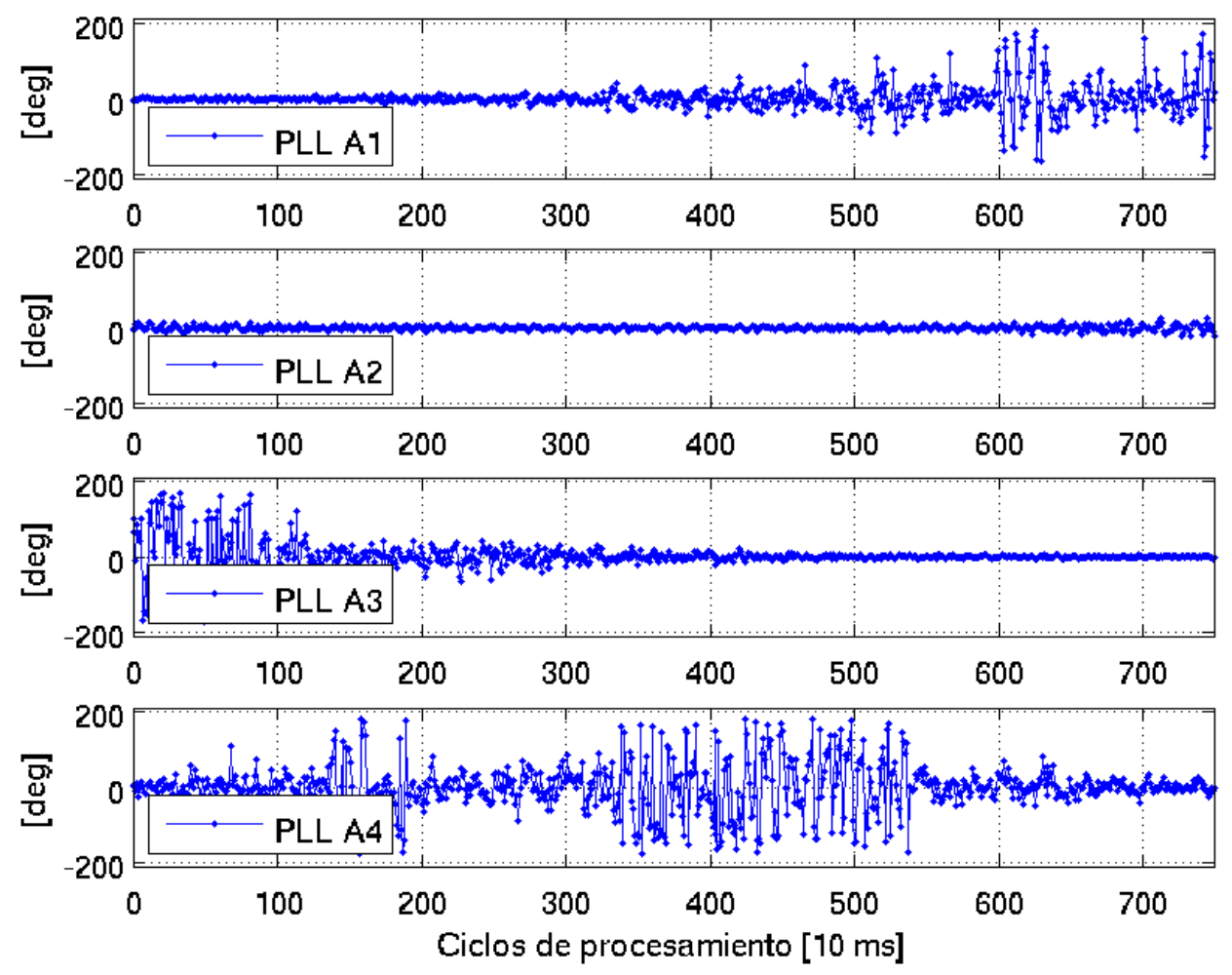

Figura 8.12: Error de fase de cada uno de los cuatros PLLs encargados del seguimiento de portadora de cada antena de entrada, durante el ensayo de conmutación de antenas con simulador GNSS. Cuando la relación $C / N_{o}$ de la señal a través de una antena baja demasiado el lazo correspondiente puede entrar en condición de desenganche, lo que queda evidenciado por el incremento en la varianza del error en esos intervalos.

Tomando la señal de banda base de la antena activa de cada ciclo de procesamiento, el receptor ensambla una versión unificada del mensaje de navegación demodulado. Una representación de este último es la que se puede ver en la Figura 8.13.

De forma similar, el error de alineamiento de fase del mensaje de navegación unificado anterior puede recuperarse uniendo los errores de fase de los lazos de seguimiento del PLL asociado a la antena activa en cada ciclo de operación. El resultado es el error de fase de antena activa que se ve en la Figura 8.14.

Por último, en la Figura 8.15 se puede ver el error de seguimiento del lazo DLL que se encarga de la estimación de la fase de la función de código que expande la señal. Este se mantiene uniformemente enganchado con la señal (error próximo a cero) durante todo el registro, con apenas una pequeña perturbación en los momentos de conmutación de una antena. Esta perturbación es ocasionada por la velocidad relativa de la antena respecto del vehículo en el momento de conmutación, la cual es causada por el movimiento de 


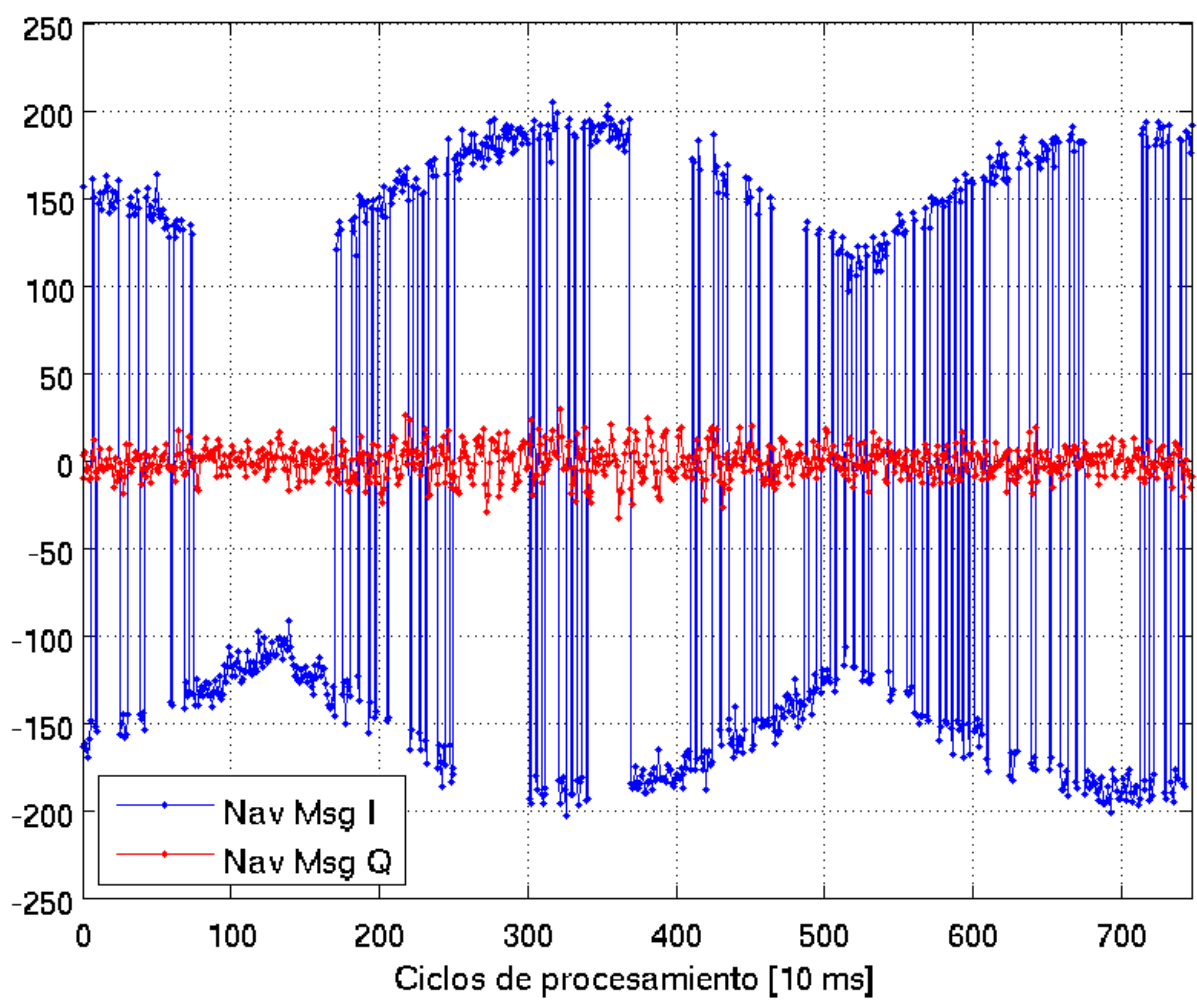

Figura 8.13: Mensaje de navegación demodulado durante el ensayo de conmutación de antenas con simulador GNSS. Esta señal es generada uniendo la secuencia de valores en banda base correspondientes de la antena que tiene el rol de antena activa en cada ciclo de operación.

rotación. Esta velocidad relativa se introduce en el lazo de código a través de la asistencia de frecuencia del lazo de portadora.

\subsubsection{Escalón de aceleración con rotación}

Este ensayo expone el receptor a una condición semejante a un cambio en el estado de funcionamiento (encendido o apagado) de los motores del vehículo. Los requerimientos establecidos en el Capítulo 4 demandan que los algoritmos de seguimiento sean capaces de soportar escalones de aceleración de hasta $10 \mathrm{~g}$ en la dinámica del vehículo.

El escenario de simulación propuesto para este ensayo comienza con el vehículo en condición estática (sin traslación ni rotación) durante un intervalo de dos minutos, tiempo suficiente para permitir la adquisición y la puesta en seguimiento de todos los satélites presentes en la constelación visible.

Una vez alcanzado este estado estable se aplica un escalón de aceleración de $10 \mathrm{~g}$ de magnitud, dirección perpendicular al plano que forman las antenas (o lo que es lo mismo, 


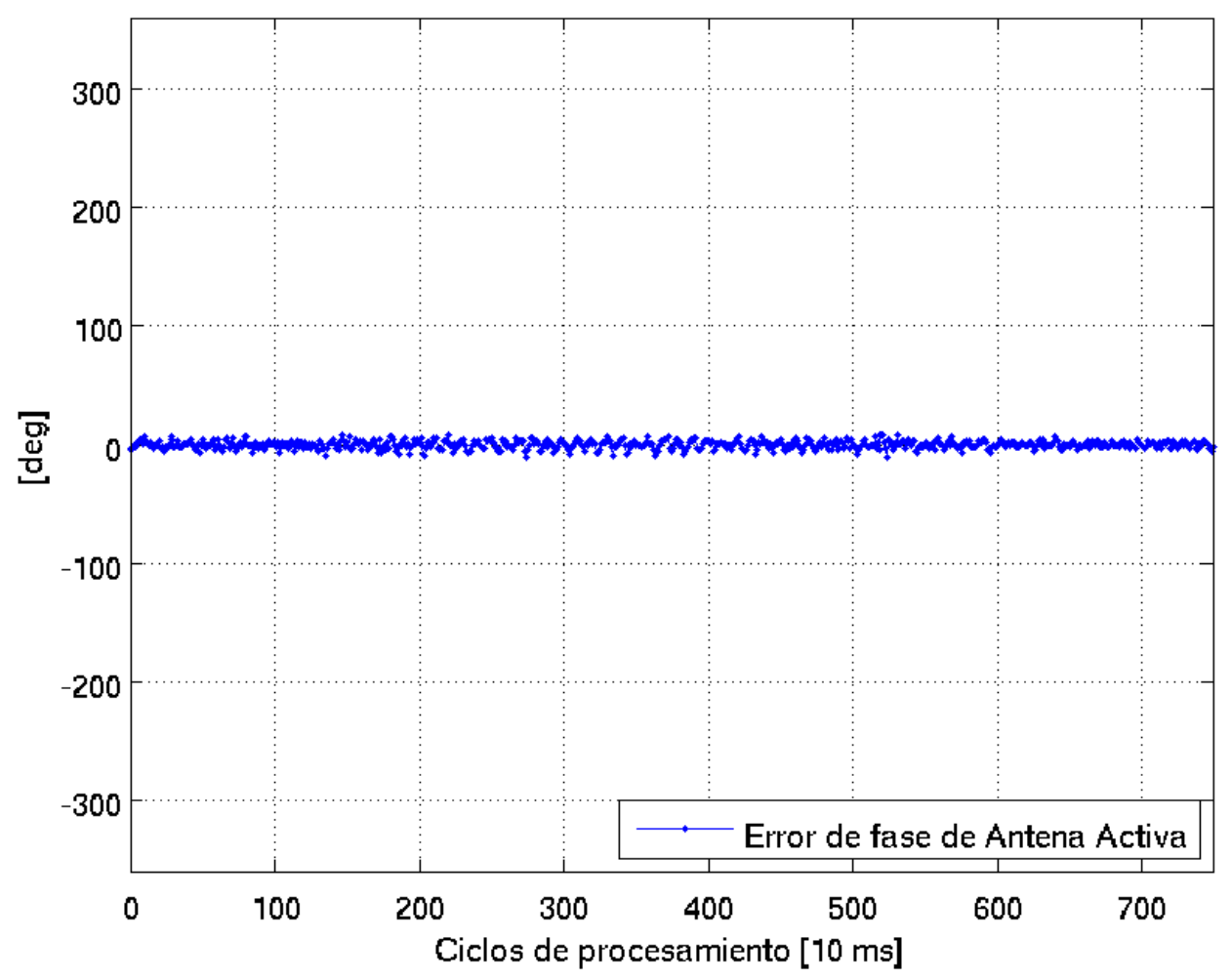

Figura 8.14: Error de fase de antena activa durante el ensayo de conmutación de antenas con simulador GNSS. Esta gráfica es generada uniendo la secuencia de los valores de error de fase del PLL correspondiente a la antena que tiene el rol de antena activa en cada ciclo de operación.

colineal con el eje de simetría del vehículo) y sentido ascendente. Simultáneamente con la aceleración se imprime al cuerpo del vehículo un escalón de velocidad angular que pone a rotar de forma instantánea el arreglo de antenas con la velocidad angular máxima requerida.

Debe notarse que este escenario no aplica $10 \mathrm{~g}$ de aceleración a lo largo del vector línea de vista de ningún satélite en particular, sino a lo largo del eje del vehículo. La perturbación efectiva que tenga esta dinámica sobre la señal del cada satélite será una función de la proyección del vector aceleración sobre el vector línea de vista del satélite. Así la perturbación será máxima para un satélite en el cénit (ambos vectores son colineales) y nula para uno en el horizonte (ambos vectores son ortogonales).

Las curvas que se mostrarán a continuación corresponden al registro de funcionamiento de un canal de seguimiento asignado a la señal del satélite GPS de identificador SVID 24. Este satélite tiene una elevación al momento del ensayo de aproximadamente $30^{\circ}$, por lo que los $10 \mathrm{~g}$ del vehículo se proyectan como aproximadamente $5 \mathrm{~g}$ en la dirección 


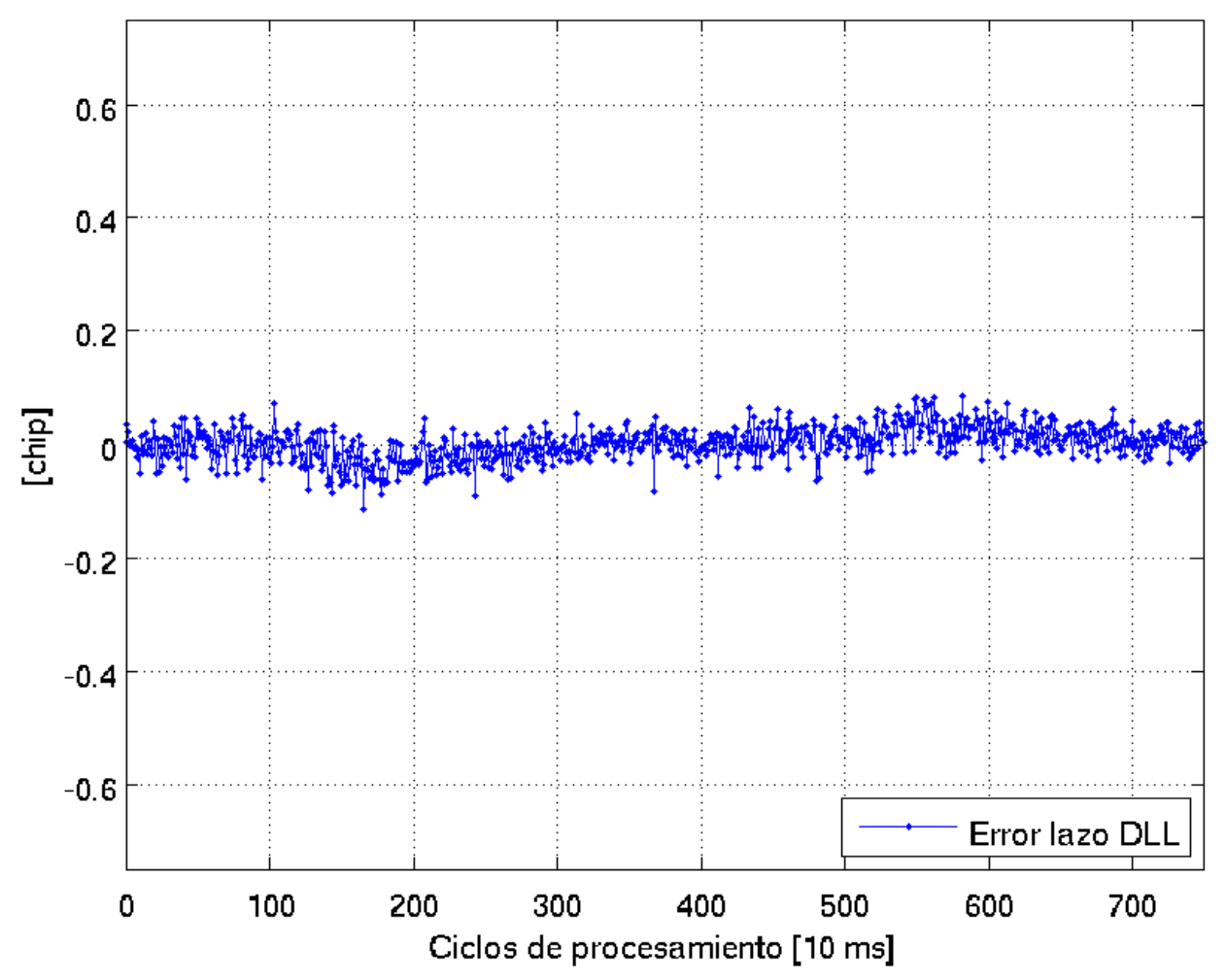

Figura 8.15: Error de lazo de código durante el ensayo de conmutación de antenas con simulador GNSS.

del vector línea de vista. El instante de aplicación del escalón de aceleración ocurre en la muestra 440 del registro.

En la Figura 8.16 se ve que las amplitudes de la envolvente de señal recibida a través de cada una de las antenas permanecen invariantes desde el comienzo del registro hasta el instante de aplicación del escalón de aceleración. A partir de dicho instante los valores de envolvente empiezan a variar como consecuencia de la rotación de 4 rpm que se imprime con el arranque. Esto provoca una conmutación de la antena activa desde la A1 activa inicialmente a la A2 cerca del final del registro. Ver Figura 8.17.

En las curvas de señal en banda base por antena, Figura 8.18, puede verse que la discontinuidad en la aceleración del vehículo produce un incremento de la potencia de señal en las ramas en cuadratura. Esto es especialmente visible en la antena A1.

Este fenómeno se debe a que la discontinuidad en la aceleración del vehículo introduce una perturbación de los lazos de seguimiento de fase de todas las antenas, lo que queda evidenciado por la aparición de un transitorio en todos los PLLs que se encuentran en condición de enganche en el momento de aplicación de la perturbación en la muestra 440 del registro. Ver curvas correspondientes al error de los PLLs de A1, A2 y A4 en 


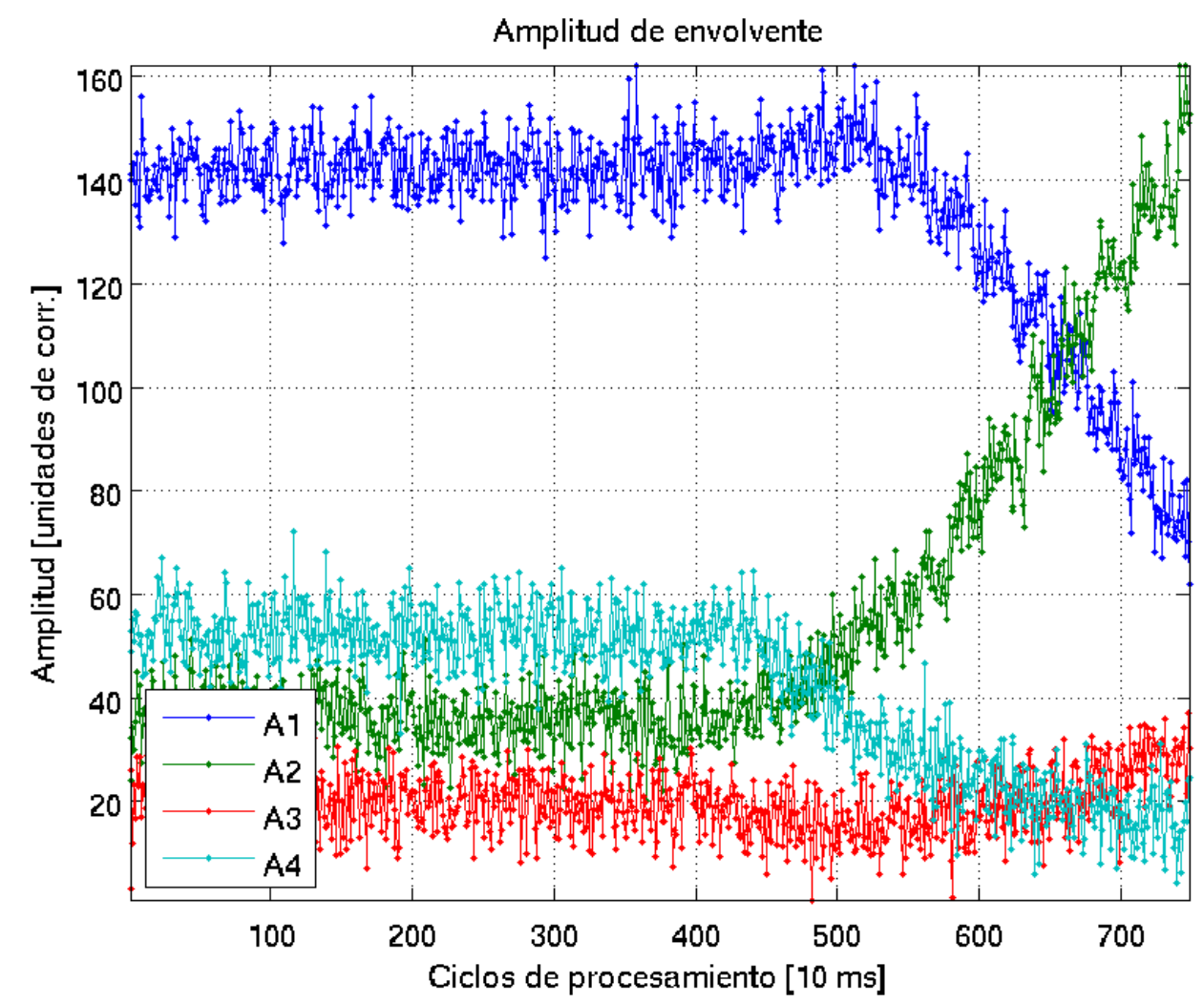

Figura 8.16: Amplitud de la envolvente de la señal recibida a través de cada una de las cuatro antenas de entrada durante el ensayo de escalón de aceleración con simulador GNSS.

la Figura 8.19. Notar que el registro de la antena A4 parecería mostrar un segundo transitorio cerca del fin de la gráfica (aproximadamente en la muestra 730), pero en realidad ese elemento es un artefacto visual ocasionado por el desenganche del PLL al caer la relación $C / N_{o}$ de la antena. Esto puede corroborarse en la Figura 8.16.

La forma del transitorio de error se puede apreciar más claramente en la gráfica de error de fase de antena activa, Figura 8.20. La forma de este transitorio puede compararse con la del transitorio en el error de fase de la simulación presentada en el Capítulo 6 para el caso de escalón de aceleración de $10 \mathrm{~g}$ (ver Figura 6.8). La diferencia en la amplitud del transitorio de la Figura 8.20 comparada con la del transitorio en la Figura 6.8 se debe a que los vectores de aceleración y de línea de vista al satélite no son colineales para el satélite que se presenta aquí.

La perturbación dinámica de los lazos de seguimiento de portadora ocurre simultáneamente en todos ellos, por lo que provoca necesariamente una distorsión en el mensaje de navegación demodulado. Ver Figura 8.21. 


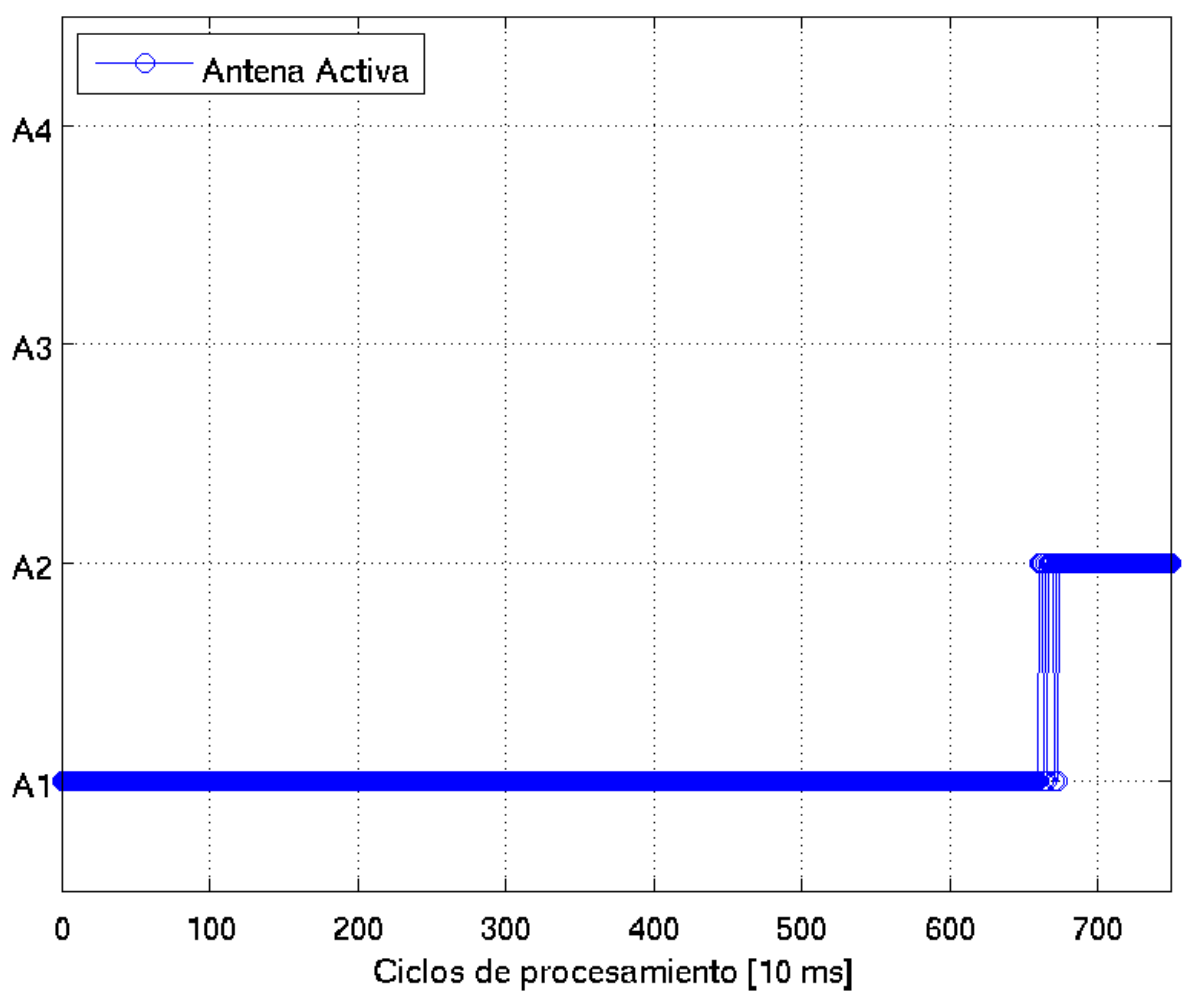

Figura 8.17: Asignación del rol de antena activa a lo largo del tiempo, durante el ensayo de escalón de aceleración con simulador GNSS.

Gracias al mecanismo de asistencia entre los lazos de seguimiento de portadora y de código, la rápida eliminación del transitorio por parte de los PLLs evita la introducción de una perturbación debida a la dinámica del vehículo en el lazo DLL de seguimiento de código. Esto se puede ver en la Figura 8.22, donde en el momento de aplicación del escalón de aceleración no se produce ninguna desviación perceptible en el error del lazo de código.

\subsection{Ensayo de adquisición con señal simulada}

Mediante la utilización del mismo simulador de señales GNSS utilizado para los ensayos dinámicos anteriores se relevó experimentalmente la curva de probabilidad de adquisición de señales GPS y GLONASS como función de la relación $C / N_{o}$ de la señal incidente.

Los resultados de este ensayo se encuentran resumidos en la Figura 8.23, donde se comparan las probabilidades de adquisición relevadas para los sistemas GPS y GLONASS contra la probabilidad teórica derivada de un modelo analítico simplificado de la probabilidad de adquisición. 

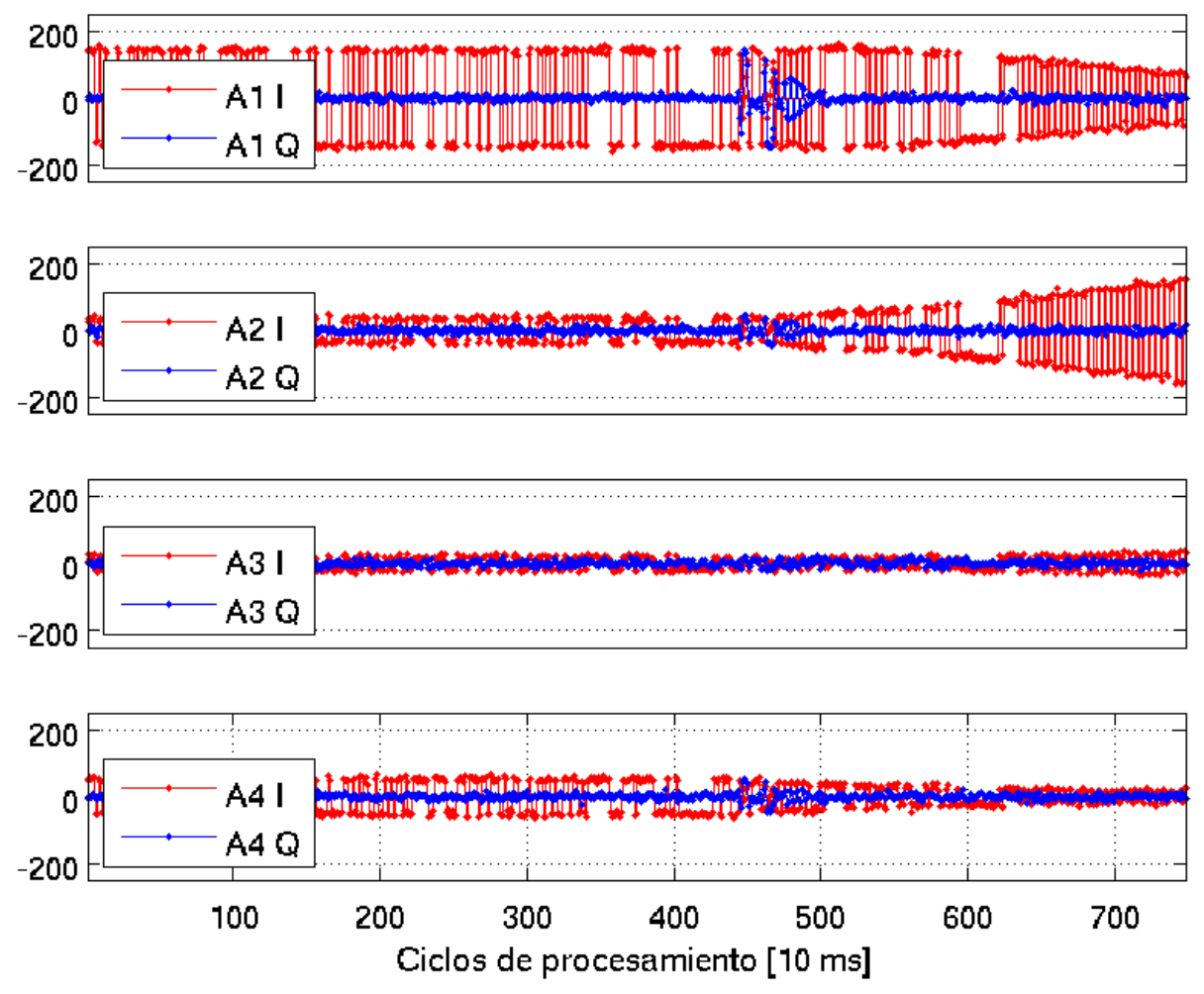

Figura 8.18: Señal en banda base recibida a través de cada una de las cuatro antenas de entrada, durante el ensayo de escalón de aceleración con simulador GNSS.

Puede verse que existe un alto nivel de correspondencia entre las curvas experimentales y la teórica, pudiendo atribuirse la diferencia al tamaño finito del espacio muestra utilizado para estimar las probabilidades empíricas (100 ensayos por punto, para mantener acotado el tiempo de ensayo), las simplificaciones del modelo analítico y sobre todo las dificultades de calibrar exactamente la relación $C / N_{o}$ de las señales de forma con precisión mejor que $1 \mathrm{~dB}$. Esta dificultad proviene del hecho que el simulador permite configurar de forma precisa la potencia de la señal en bornes de salida, pero el nivel de ruido es función de múltiples factores ambientales y experimentales: las temperaturas equivalentes y las ganancias de cada una de las etapas de la entrada, incluyendo la temperatura de ruido en bornes del simulador, temperatura equivalente y atenuación de los cables de conexión utilizados entre el simulador y el receptor, y la figura de ruido de entrada del receptor. 

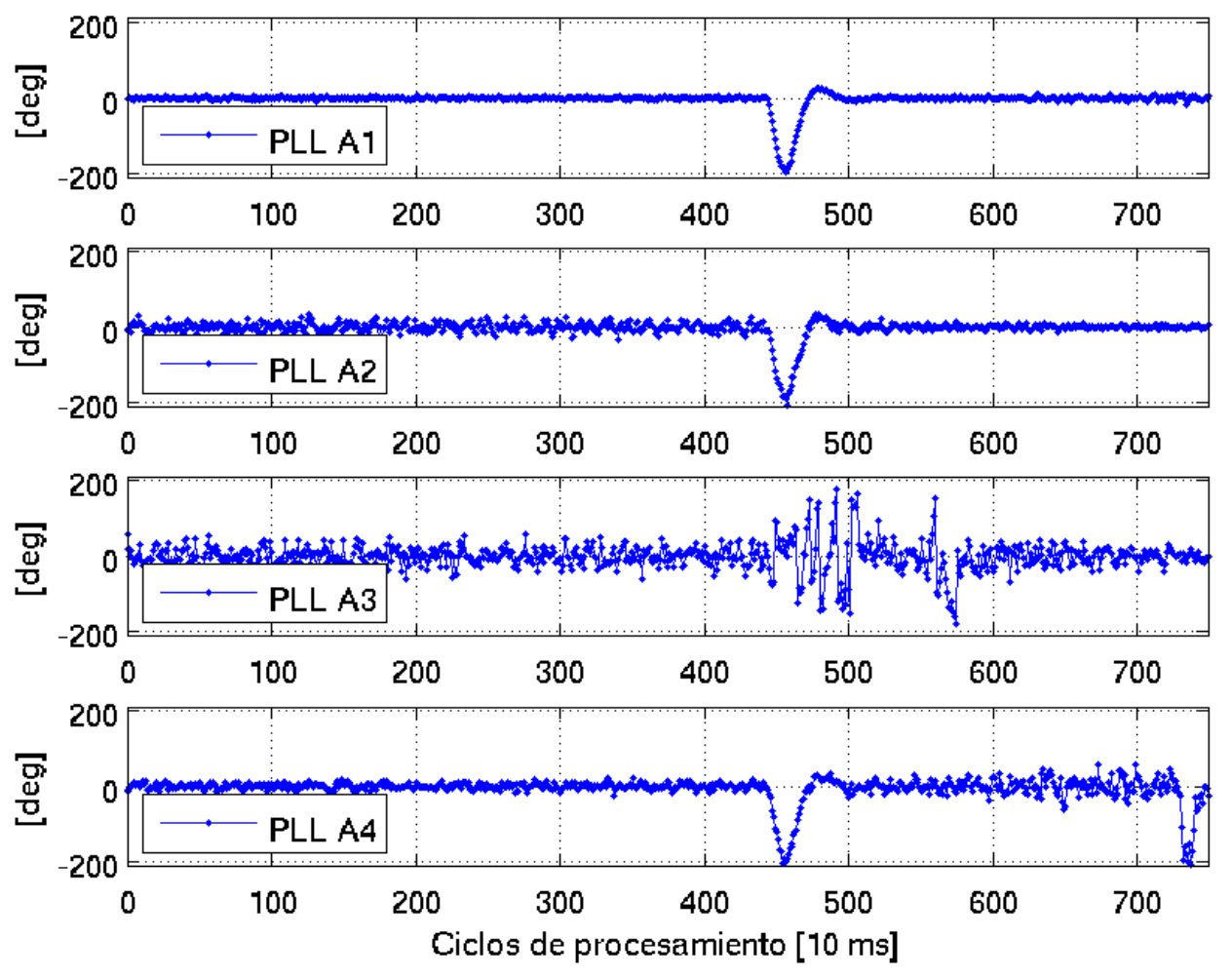

Figura 8.19: Error de fase de cada uno de los cuatros PLLs encargados del seguimiento de portadora de cada antena de entrada, durante el ensayo de escalón de aceleración con simulador GNSS. Cuando la relación $C / N_{o}$ de la señal a través de una antena baja demasiado el lazo correspondiente puede entrar en condición de desenganche, lo que queda evidenciado por el incremento en la varianza del error en esos intervalos. En esta gráfica se puede ver claramente que los lazos de seguimiento de portadora enganchados presentan un transitorio de rechazo de perturbación en el instante de aplicación de la dinámica acelerada (muestra 440).

\subsection{Resumen de capítulo}

Este capítulo cierra el trabajo de tesis presentando una serie de resultados de ensayo, realizados sobre los algoritmos introducidos en los capítulos anteriores, una vez implementados como parte del software que corre en el prototipo del receptor GPS/GLONASS multiantena. Por cuestiones de espacio esta presentación no puede ser exhaustiva, sino que se limita solamente a mostrar un subconjunto de los ensayos, seleccionados en función de su nivel de relevancia y pertinencia a los temas tratados.

Los resultados expuestos permiten observar al receptor operando con señales GPS y GLONASS de forma simultánea, la estabilidad y autonomía de los procesos de adquisición y seguimiento a través de los registros de 24 horas de variación de frecuencias portadoras de los satélites GPS y GLONASS, la capacidad de respuesta dinámica y 


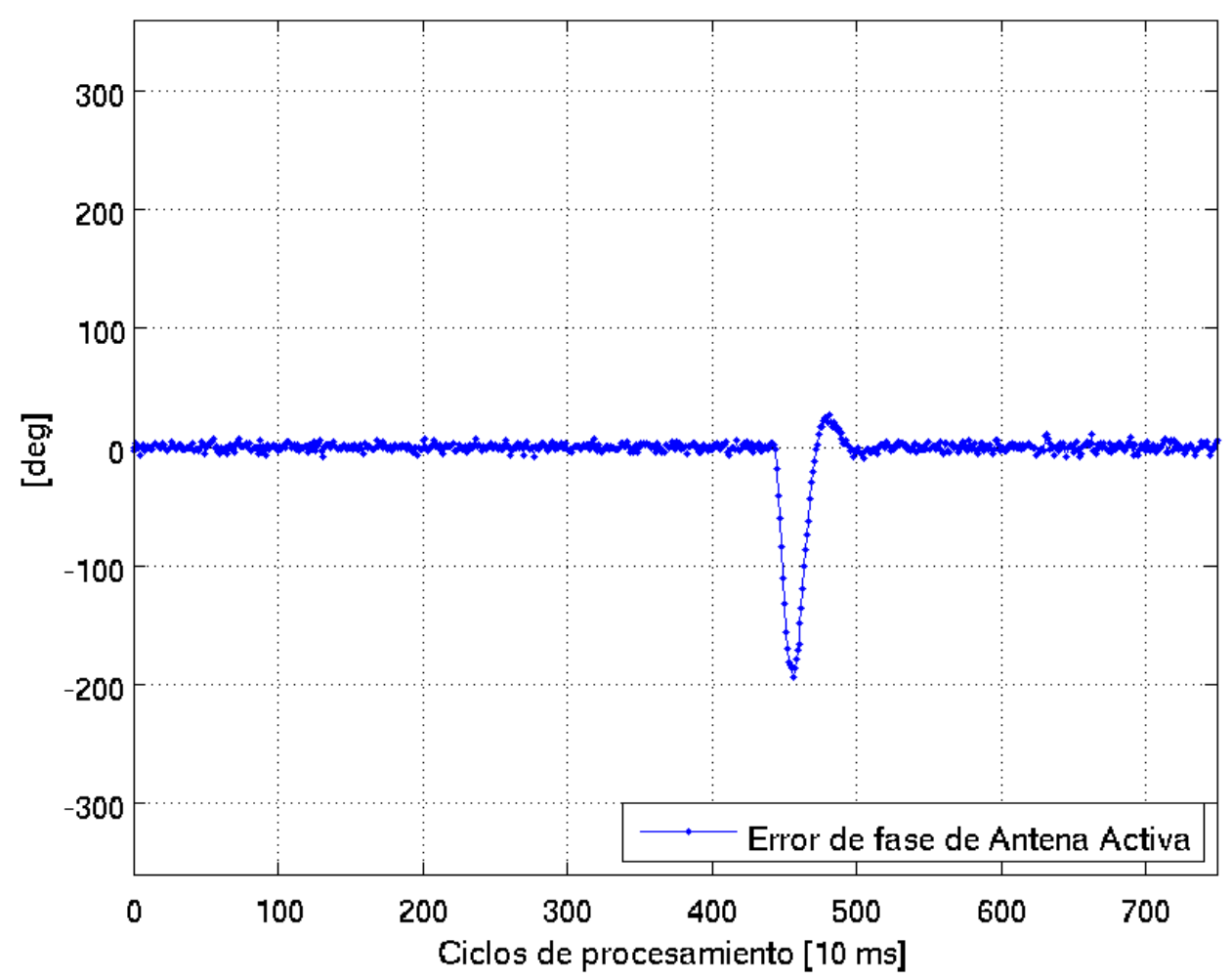

Figura 8.20: Error de fase de antena activa durante el ensayo de escalón de aceleración con simulador GNSS. Esta gráfica es generada uniendo la secuencia de valores de error de fase del PLL correspondiente a la antena que tiene el rol de antena activa en cada ciclo de operación.

de conmutación de antenas mediante ensayos con dinámica simulada, y por último la sensibilidad de los procesos de adquisición como función de la relación $C / N_{o}$.

Particularmente interesantes son los ensayos dinámicos y de conmutación de antenas. Estos fueron llevados a cabo mediante la utilización de un simulador de señales GNSS que permite la creación de escenarios de simulación totalmente controlados. En estos es posible configurar la trayectoria y orientación del vehículo en función del tiempo, la constelación de satélites presentes, la potencia de las señales incidentes, el patrón de radiación de las antenas receptoras, y muchos otros elementos. Este tipo de simulaciones permiten ensayar en laboratorio y de forma totalmente repetible el efecto que tiene la dinámica física del vehículo sobre el funcionamiento del receptor.

A través de este conjunto de ensayos se puede comprobar que los algoritmos de adquisición y seguimiento de señales que fueron el objeto de esta tesis son capaces de operar adecuadamente en las condiciones requeridas por la aplicación para la que fueron diseñados. 


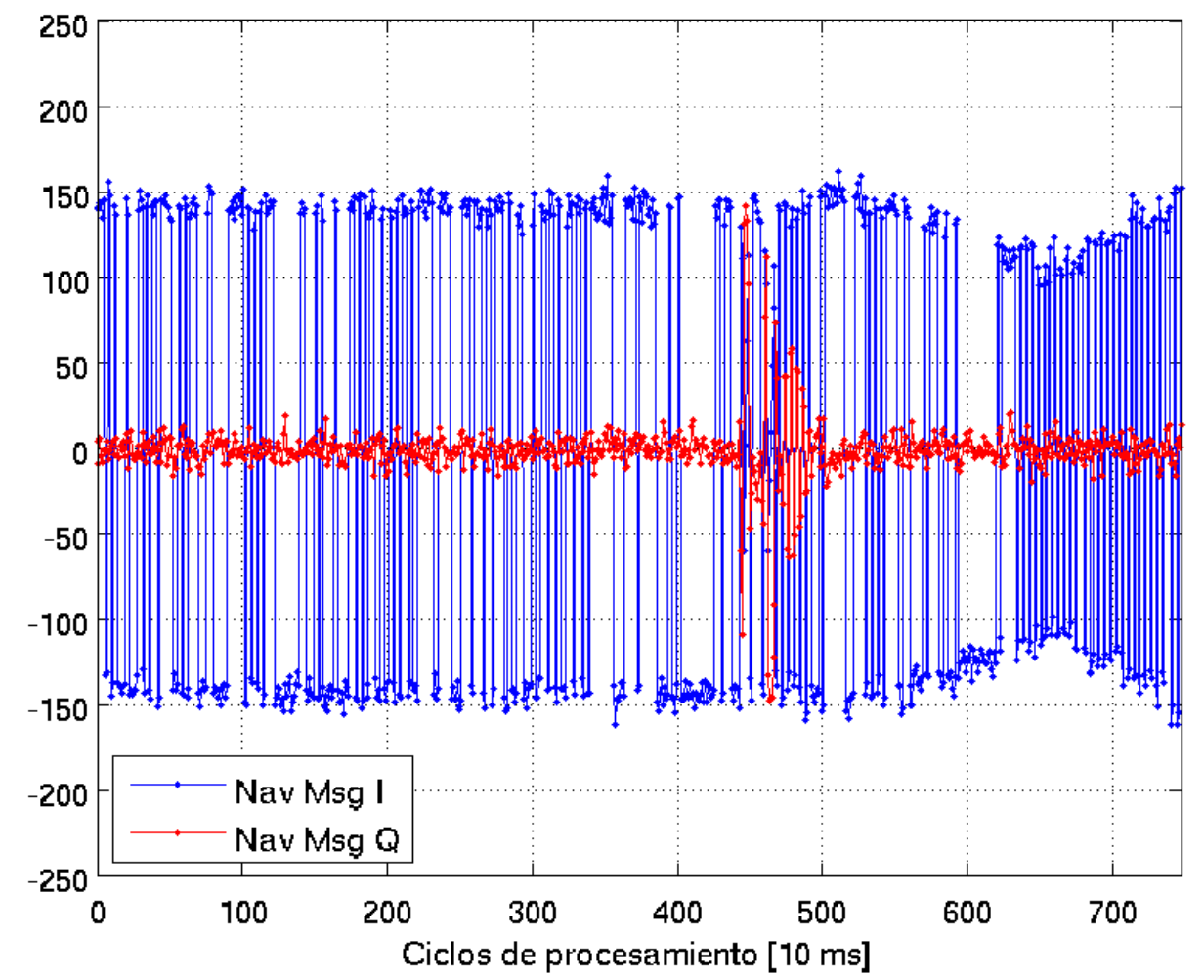

FiguRA 8.21: Mensaje de navegación unificado, durante el ensayo de escalón de aceleración con simulador GNSS. Esta señal es generada uniendo la secuencia de los valores en banda base correspondientes de la antena que tiene el rol de antena activa en cada ciclo de operación. 


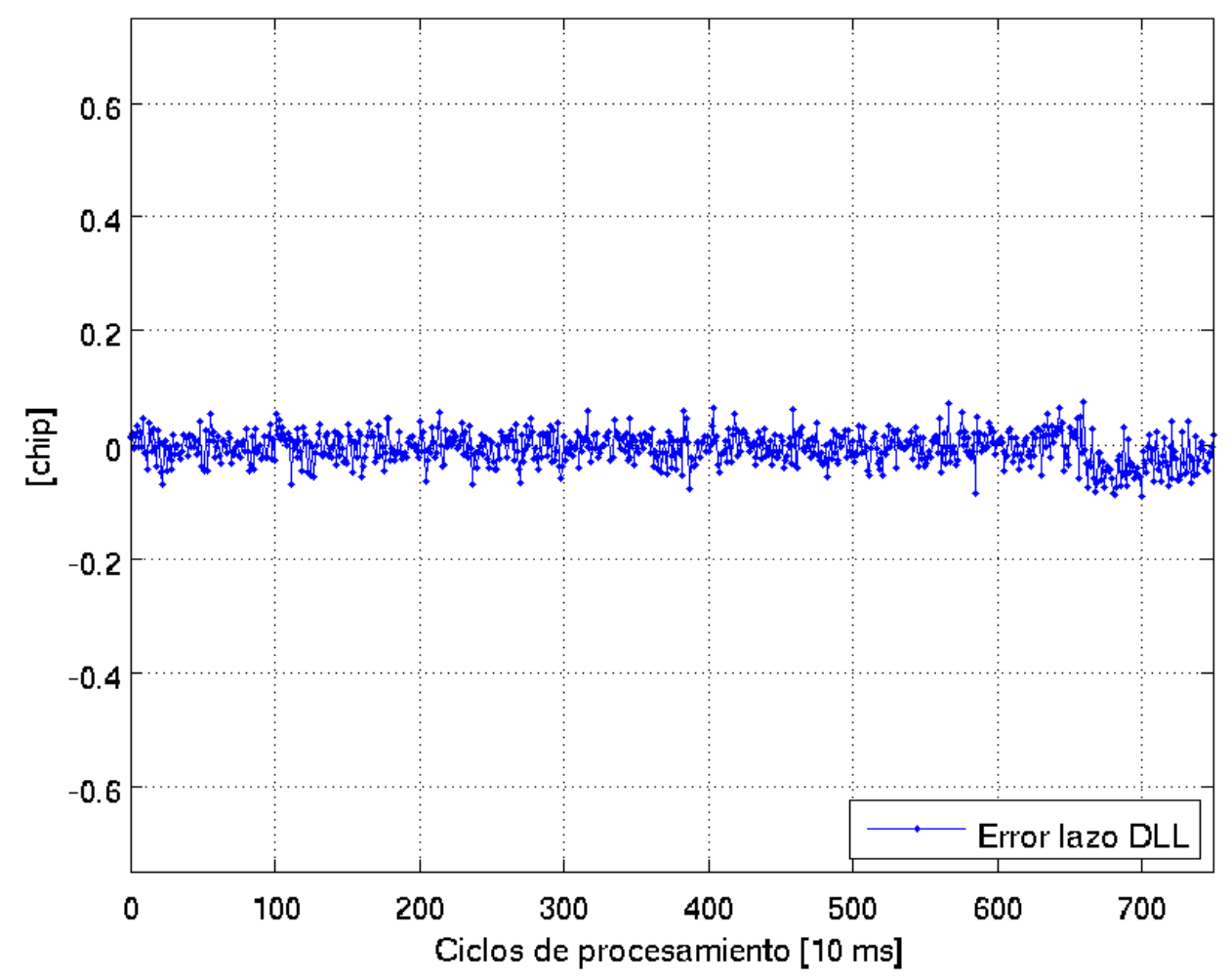

Figura 8.22: Error de lazo de código durante el ensayo de escalón de aceleración con simulador GNSS. 


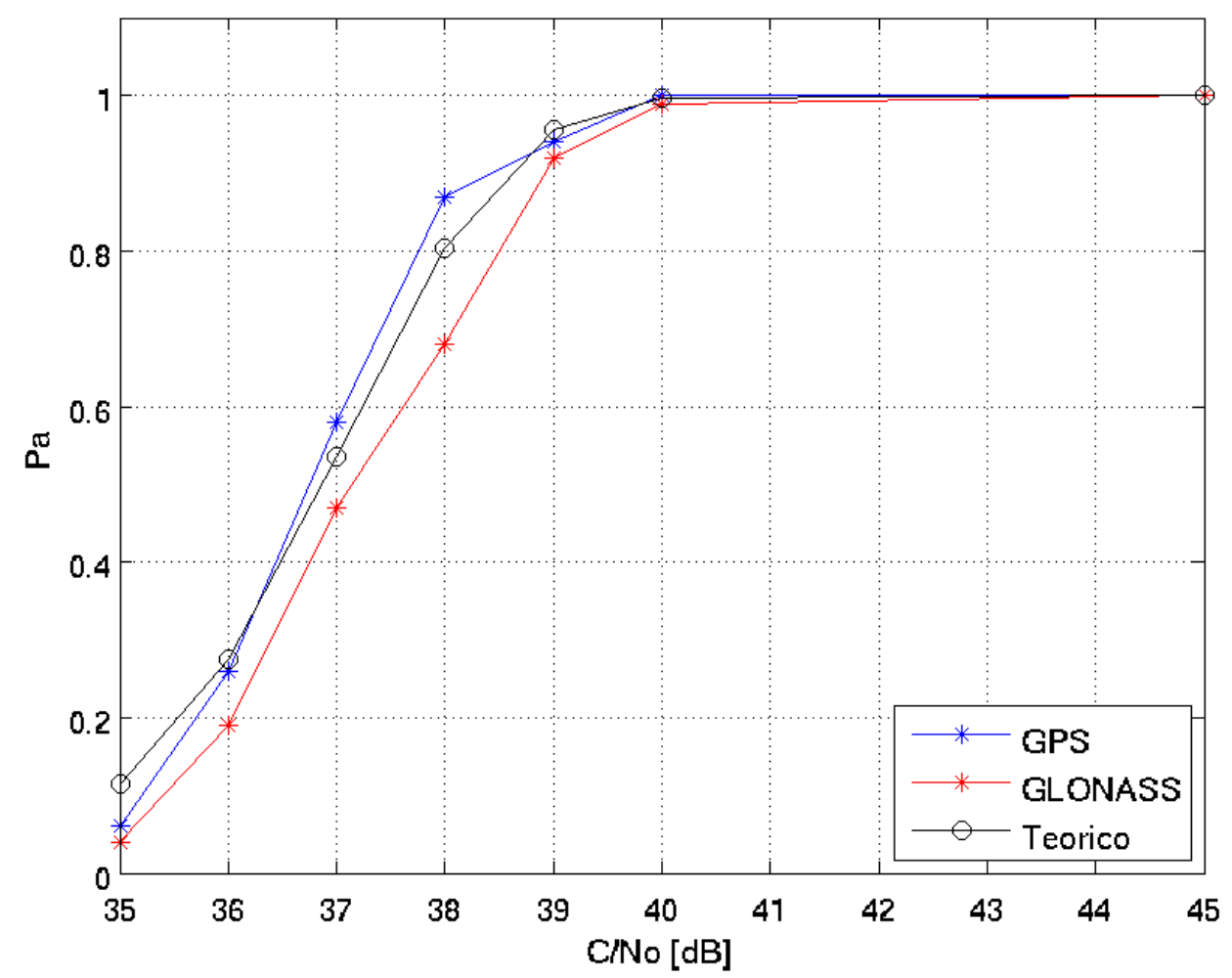

Figura 8.23: Comparación de las curvas de probabilidad de adquisición relevadas experimentalmente para señales GPS y GLONASS contra la curva teórica calculada utilizando un modelo matemático simplificado del proceso de adquisición. 


\section{Capítulo 9}

\section{Conclusión}

Los sistemas de navegación global por satélite -GNSS- han adquirido una relevancia cada vez más importante en las décadas recientes debido a sus múltiples aplicaciones a los sistemas de transporte, metrología, y distribución de tiempo, entre otras. Una de estas aplicaciones es el seguimiento de las trayectorias de vehículos de tipo cohete como los utilizados en la industria aeroespacial para realizar la puesta en órbita de cargas satelitales. En este campo los receptores GNSS proveen a los sistemas de Navegación, Guiado y Control (NGC) del vehículo de información precisa acerca de las coordenadas de posición y velocidad del mismo en un marco de referencia absoluto, complementando así la información provista por los instrumentos de navegación inerciales basados en la lectura de acelerómetros y giróscopos.

Este tipo de aplicación tiene una serie de características únicas que hacen inadecuada la utilización de receptores GNSS de arquitecturas convencionales. Los elevados valores de altura, velocidad y aceleración sostenida, los impulsos repentinos provocados por los sucesivos apagados y encendidos de los motores de las etapas del vehículo, y especialmente la naturaleza múltiple del sistema de antenas de entrada utilizado para lograr una recepción de señales adecuada durante todas las fases de la misión, son algunas de las diferencias más sobresalientes respecto de los receptores GNSS aplicados al seguimiento de vehículos terrestres.

Respecto del sistema de antenas de entrada utilizado, existen principalmente dos arquitecturas de receptor que se utilizan en la práctica como base para el diseño de este tipo de receptores: arquitecturas de Modo Suma y de Modo Diversidad. La primera de éstas es la de aparición más frecuente en los ejemplos que se encuentran en la literatura publicada sobre el tema, y tiene la ventaja de no requerir de estructuras de hardware muy diferentes de las utilizadas en receptores convencionales. Sin embargo la cobertura de direcciones de arribo que puede lograrse por esta vía depende fuertemente de la cantidad 
y distribución geométrica de las antenas que forman el arreglo de antenas de entrada, lo que dificulta el diseño y la reutilización del mismo, y no siempre permite llegar a un diseño totalmente satisfactorio.

Las arquitecturas basadas en sistemas de antenas de Modo Diversidad permiten lograr una cobertura elevada y simplifican el diseño del arreglo al desacoplar el procesamiento de las antenas individuales. El costo de esta aproximación se centra principalmente en la complejidad incrementada tanto del software como del hardware del receptor, los cuales requieren de un diseño especializado para permitir el procesamiento cohesivo de las señales que arriban a través de cada una de las antenas individuales del sistema de entrada.

El objetivo de esta tesis ha sido el desarrollo de los algoritmos de seguimiento y adquisición necesarios para operar el procesamiento de más bajo nivel de las señales GNSS en un receptor multiantena de modo diversidad de aplicación aeroespacial. Este escenario de aplicación determinó también una serie de requerimientos adicionales, relacionados con el tipo y la magnitud de las dinámicas que debía ser capaz de tolerar el diseño. Con el objetivo de lograr redundancia de sistema se estableció también que el receptor debía poder realizar el procesamiento de señales de cualquiera de los dos sistemas GNSS dominantes en la actualidad, GPS y GLONASS. Por último, el procesamiento debía poder ser realizado en tiempo real por un sistema embebido autónomo funcionando a bordo del vehículo.

El desarrollo del proyecto de tesis llevó a cabo no solamente el diseño de los algoritmos necesarios, sino también su implementación práctica. Esta implementación se hizo sobre la base de un prototipo del hardware del receptor GPS/GLONASS multiantena, el cual fue realizado de forma casi paralela como parte del mismo proyecto superior, que es el del desarrollo del receptor completo. La implementación de los algoritmos no se hizo de forma aislada ni experimental, sino que se llevó adelante de forma integral junto con la implementación del resto del software del receptor, el cual abarca también muchas otras áreas no discutidas en la presente tesis: interfaz hardware/software, comunicaciones, administración de sistema, gestión de recursos, navegación, demodulación del mensaje de navegación, etc.

La naturaleza acoplada y abarcadora de este tipo de implementación hizo que, con el fin de cumplir con las metas propuestas, fuera necesario tomar desvíos a lo largo del trabajo para atender a desarrollos auxiliares, como es el caso de los algoritmos de detección de falsos enganches (discutido en el Apéndice A) y del algoritmo de sincronización multimilisegundo (presentado en el Apéndice C). El primero resultó de la exploración de una idea sugerida en la bibliografía pero no profundizada en la misma, que atiende a 
la siempre presente necesidad de realizar detección de errores durante el funcionamiento del receptor aplicado a un sistema crítico. El segundo, en cambio, es un desarrollo novedoso surgido de la necesidad de alivianar la carga de procesamiento de la etapa de detección de flancos del mensaje de navegación, la cual es un cuello de botella importante en sistemas de bajos recursos de cómputo.

La implementación de los algoritmos fue ensayada en varias etapas. Inicialmente se realizaron pruebas en condiciones estáticas y utilizando una única antena de entrada para la puesta en marcha de los algoritmos de adquisición y seguimiento. Mediante pruebas de complejidad creciente se fueron agregando elementos al modelo de funcionamiento, para verificar la adquisición multiantena, el seguimiento, la conmutación de antenas, etc. Finalmente, la disponibilidad de un simulador de señales GNSS probó ser invaluable para validar el funcionamiento de los algoritmos en condiciones dinámicas similares a las del vehículo real, mediante la realización de simulaciones que incorporan los efectos de la dinámica (velocidad, aceleración, giro), patrones de antena realistas, antenas múltiples independientes y niveles de potencia semejantes a los esperados en condición de uso. Algunos de los resultados de estas simulaciones fueron presentados en el Capítulo 8.

Si bien los ensayos anteriores le dan el cierre adecuado al trabajo de tesis verificando el cumplimiento de las metas que se habían establecido para éste, el proyecto que dio marco al desarrollo aún se encuentra vigente y son múltiples las líneas de trabajo presentes y futuras dentro del mismo. Es necesario completar los sistemas auxiliares y de comunicación del receptor, para permitir un funcionamiento fluido y dependible, adecuado para su utilización en misión, y compatible con las necesidades de la computadora de navegación del vehículo. Es conveniente extender la cantidad y variedad de los canales comunicación que es posible administrar, adoptando en la medida de lo posible protocolos estándares de la industria como por ejemplo SpaceWire. Deben definirse criterios apropiados de validación independiente de los observables de navegación, así como también de las soluciones de posición y velocidad obtenidas a partir de los mismos, para así minimizar la probabilidad de propagación de errores a los sistemas clientes de los servicios del receptor. Por último pero no menos importante, es necesario avanzar sobre la formalización de los procesos de planificación, desarrollo y verificación del software para alinearlos con las prácticas recomendadas que se aplican en la industria aeroespacial.

Lejos de agotar las posibilidades, la enumeración anterior solamente resume algunas de las vías de trabajo futuras que será necesario encarar para llegar a un receptor GNSS plenamente funcional, apto para ser utilizado en vehículos de inyección de cargas satelitales livianas. Algunas de estas tareas se encuentran ya iniciadas con diferentes grados de avance, mientras que otras apenas están en fase de planificación. Algunas de ellas requieren de esfuerzos coordinados de diseño tanto de hardware como de software, y en 
algunos casos trascienden incluso las fronteras del receptor e incluyen a elementos del sistema vehículo (aviónica, navegación, etc.).

Es de naturaleza ardua y paciente el proceso de desarrollo del receptor de señales GNSS para vehículos inyectores en el que hemos venido trabajando como grupo durante estos años. Sus dificultades y principalmente su valor no residen solamente en la generación del objeto tecnológico en sí, sino también en la gestación de las de tecnologías asociadas, las herramientas, las técnicas, los procedimientos, y principalmente en la formación de los recursos humanos que son necesarios para llevar adelante un desarrollo de semejantes características.

Dado que como es en lo micro es también en lo macro, esta naturaleza intensa y de largo aliento de nuestro proyecto es compartida también por el proyecto que le da marco, motivación y sustento. Ese proyecto es el de construcción de una industria aeroespacial nacional, y se ha venido llevando adelante durante los últimos años en nuestro país gracias al fomento estatal, y a través de enormes esfuerzos realizados por los actores tanto públicos como privados del sistema científico y tecnológico argentino.

Sólo la continuidad del apoyo a este proyecto marco permitirán eventualmente capitalizar esos esfuerzos, poniendo finalmente en manos del país las herramientas para acceder y navegar ese otro dominio, el espacial, que también es de su patrimonio, y hacerlo por medio de una industria espacial nacional, soberana, autónoma y profesional. 


\section{Apéndice A}

\section{Detector de falsos enganches}

\section{A.1. Introducción}

En este apéndice se presentan las deducciones de una serie de relaciones útiles a la hora de evaluar los límites de funcionamiento del detector de falsos enganches basado en la estimación de frecuencia del lazo DLL de seguimiento de código, el cual se presenta en la Sección 6.3.2.1 del Capítulo 6.

\section{A.2. Modelo de lazo}

En la Figura A.1 se muestra el modelo de lazo de seguimiento de código que será empleado en las secciones siguientes.

Como se explica en la Sección 6.3.2, lo reducido de los anchos de banda de ruido típicamente utilizados para el lazo de código (comparado con la frecuencia de muestreo de su implementación discreta) permite analizar su comportamiento mediante un modelo analógico sin por ello incurrir en errores significativos.

El lazo representado de la Figura A.1 es una implementación de la plantilla de filtro óptimo para lazo de seguimiento Tipo II visto anteriormente en la Sección 3.7.2.4, Figura 3.18. Como se menciona allí la optimalidad del lazo se logra seleccionando los coeficientes con las expresiones

$$
\begin{aligned}
& A=\sqrt{2} w_{o} \\
& B=w_{o}^{2}
\end{aligned}
$$




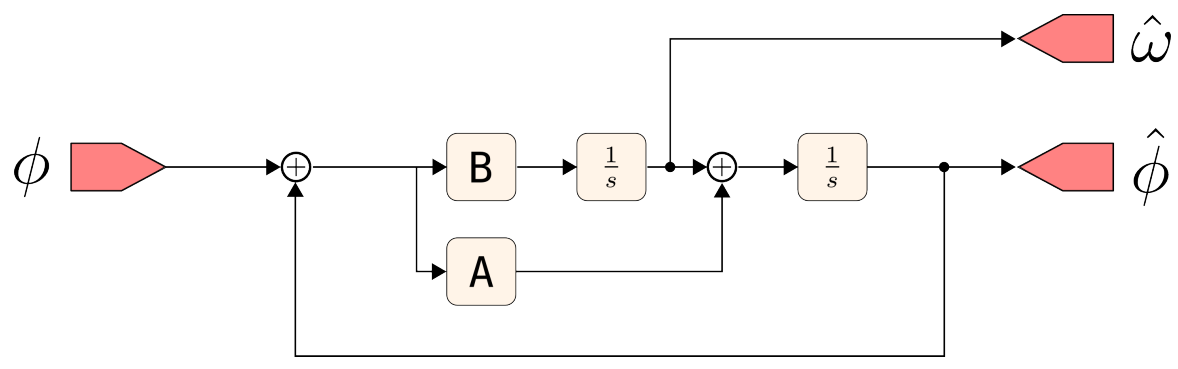

Figura A.1: Modelo analógico de un lazo de seguimiento Tipo II como el utilizado para el seguimiento de la fase de la función de código. En la figura se muestran las entradas y salidas a considerar.

donde el coeficiente $w_{o}$ es función del ancho de banda de ruido deseado,

$$
w_{o}=\left(\frac{8 B_{n}}{3 \sqrt{2}}\right)
$$

Esta elección particular de coeficientes cumple la desigualdad

$$
A^{2}<4 B
$$

que garantiza que los polos de lazo cerrado de la transferencia sean complejos conjugados. Esto será relevante más adelante.

\section{A.3. Transferencias de lazo}

Es necesario identificar primeramente dos transferencias en el lazo de la Figura A.1, las cuales servirán para relacionar la sensibilidad al ruido de la estimación de frecuencia del lazo con el ancho de banda de ruido de la estimación de fase $B_{n}$ del mismo lazo:

- Transferencia de estimación de fase $T_{\phi}(s)$.

- Transferencia de estimación de frecuencia $T_{\omega}(s)$.

La primera es la transferencia que caracteriza el ancho de banda de ruido del lazo, ya que determina la sensibilidad de la variable estimada con el ruido presente en la referencia.

$$
T_{\phi}(s)=\frac{\hat{\phi}(s)}{\phi(s)}
$$

donde $\phi(s)$ es la referencia del lazo y $\hat{\phi}(s)$ la estimación de fase del lazo. 
La segunda transferencia relaciona la estimación de la tasa de variación de la referencia que es un estado interno del lazo, $\hat{\omega}(s)$, con la referencia $\phi(s)$ :

$$
T_{\omega}(s)=\frac{\hat{\omega}(s)}{\phi(s)} .
$$

La transferencia de lazo abierto del lazo es

$$
G(s)=\left(A+\frac{B}{s}\right) \frac{1}{s}=\frac{s A+B}{s}=A \frac{s+\frac{B}{A}}{s^{2}}
$$

y el error de lazo

$$
E(s)=\frac{1}{1+G(s)} .
$$

A partir de lo cual la transferencia $T_{\phi}(s)$ se escribe

$$
\begin{aligned}
T_{\phi}(s) & =E(s) G(s) \\
& =\frac{A\left(s+w_{o}\right)}{s^{2}+A s+B} .
\end{aligned}
$$

donde $w_{o}=\frac{B}{A}$, y similarmente la transferencia $T_{\omega}(s)$ es

$$
\begin{aligned}
T_{\omega}(s) & =E(s) \frac{B}{s} \\
& =\frac{B s}{s^{2}+A s+B}
\end{aligned}
$$

\section{A.4. Ancho de banda de ruido}

Ambas transferencias definidas anteriormente tienen asociado a su vez un índice de ancho de banda de ruido equivalente que cuantifica potencia de ruido aditivo sumado a cada una de las estimaciones cuando la referencia se encuentra contaminada con ruido AWGN.

El ancho de banda de ruido de $T_{\phi}(s)$ no es ni más ni menos que el que convencionalmente se implica al hablar del ancho de banda de ruido del lazo $B_{n}$. Durante lo que resta de este apéndice se preferirá la denominación $B_{n \phi}$ para evitar confusiones con el ancho de banda de ruido de la transferencia de la estimación de frecuencia del lazo, $B_{n \omega}$.

El ancho de banda de ruido equivalente de la estimación de frecuencia $B_{n \omega}$ es de utilidad porque permitirá cuantificar la varianza de la estimación de frecuencia a partir de la relación SNR de la referencia. Más aún, a partir de relacionar $B_{n \omega}$ con $B_{n \phi}$ es posible determinar el compromiso que existe entre el $B_{n \phi}$, la relación SNR de la señal $C / N_{o}, \mathrm{y}$ la desviación estándar de la estimación de frecuencia $\sigma_{f}$. 


\section{A.4.1. Estimación de fase}

El ancho de banda de la transferencia $T_{\omega}(s)$ se calcula por definición como

$$
B_{n \omega}=\frac{1}{2 \pi H_{o \phi}^{2}} \int_{-\infty}^{\infty}\left|T_{\omega}(j a)\right|^{2} d a
$$

donde $H_{o \phi}$ es la altura del filtro ideal equivalente, que convencionalmente se toma igual a $T_{\phi}(0)$, por lo que resulta $H_{o \phi}=1$.

La dificultad de la expresión anterior reside en el cálculo de la integral anterior.

$$
I_{\phi}=\int_{-\infty}^{\infty}\left|T_{\phi}(j a)\right|^{2} d a
$$

En lo que sigue se desarrolla el cálculo de la integral utilizando teoría de residuos.

$$
\begin{aligned}
I_{\phi} & =\int_{-\infty}^{\infty}\left|T_{\phi}(j a)\right|^{2} d a \\
& =\int_{-\infty}^{\infty} T_{\phi}(j a) T_{\phi}^{*}(j a) d a \\
& =\int_{-\infty}^{\infty} T_{\phi}(j a) T_{\phi}(-j a) d a
\end{aligned}
$$

donde se explotó el hecho de que sobre el eje complejo se cumple que $T_{\phi}^{*}(j a)=T_{\phi}(-j a)$ por ser todos los coeficientes de la transferencia números reales. Mediante un cambio de variables $j w=s$ se puede convertir la integral convencional en una integral compleja sobre la curva abierta $C_{a}$ que recorre el eje $j w$ de $-\infty$ a $+\infty$.

$$
I_{\phi}=-j \int_{C_{a}} T_{\phi}(s) T_{\phi}(-s) d s
$$

Dado que la función integrada es una expresión racional cuyo denominador es de orden mayor en dos que el orden del numerador, entonces se puede probar que la integral de esta función a lo largo de una curva que encierra un semiplano izquierdo por infinito es cero. Esto permite igualar la integral anterior realizada sobre la curva $C_{a}$ a una integral realizada sobre una curva $C_{c}$ que incluye $C_{a}$ y se cierra por infinito encerrando el semiplano izquierdo. Ver Figura A.2.

$$
I_{\phi}=-j \int_{C_{c}} T_{\phi}(s) T_{\phi}(-s) d s
$$




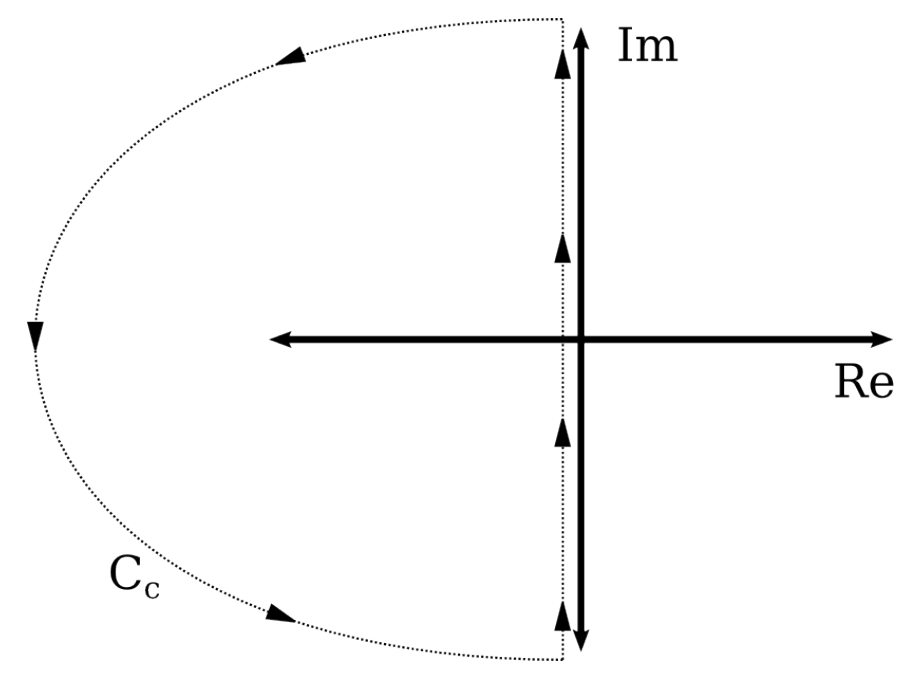

Figura A.2: Curva $C_{c}$ utilizada para rodear el semiplano izquierdo por infinito.

El problema ahora se reduce al cálculo de una integral compleja a lo largo de una curva cerrada con orientación positiva. Esta integral puede calcularse por residuos mediante

$$
\begin{aligned}
I_{\phi} & =-j\left(j 2 \pi \sum_{i} \operatorname{Res}_{i}\left\{T_{\phi}(s) T_{\phi}(-s)\right\}\right) \\
I_{\phi} & =2 \pi \sum_{i} \operatorname{Res}_{i}\left\{T_{\phi}(s) T_{\phi}(-s)\right\}
\end{aligned}
$$

donde existe un término por cada polo de la función $U_{\phi}(s)=T_{\phi}(s) T_{\phi}(-s)$ que está encerrado por la curva. En nuestro caso eso equivale a pedir que el polo se encuentre en el semiplano izquierdo.

$$
\begin{aligned}
U_{\phi}(s) & =T_{\phi}(s) T_{\phi}(-s) \\
& =\frac{A\left(s+w_{o}\right)}{\left(s^{2}+A s+B\right)} \frac{A\left(-s+w_{o}\right)}{\left(s^{2}-A s+B\right)} \\
& =\frac{A^{2}\left(-s^{2}+w_{o}^{2}\right)}{\left(s^{2}+A s+B\right)\left(s^{2}-A s+B\right)}
\end{aligned}
$$

Puede verse que existen cuatro polos complejos de los cuales sólo dos se encuentran en el semiplano izquierdo, mientras que los dos restantes se encuentran ubicados de forma simétrica a los anteriores en el semiplano derecho. Los polos del semiplano izquierdo son las soluciones de

$$
p_{1,2}=-\frac{A}{2} \pm j \frac{\sqrt{4 B-A^{2}}}{2}
$$

y los del semiplano derecho

$$
p_{3,4}=\frac{A}{2} \pm j \frac{\sqrt{4 B-A^{2}}}{2}
$$


Como se señaló en la Sección A.2 la utilización de un filtro analógico óptimo para el lazo de código implica el cumplimiento de la relación $A^{2}<4 B$, de lo que se desprende que los cuatro polos anteriores forman dos pares de polos conjugados. Es fácil ver entonces que por la simetría de la disposición que se cumple que:

$$
\begin{aligned}
& p_{2}=p_{1}^{*} \\
& p_{3}=-p_{1}^{*} \\
& p_{4}=-p_{1}
\end{aligned}
$$

Sólo los residuos de los polos en el plano encerrado son necesarios. El residuo asociado al polo $p_{1}$ se calcula como

$$
\begin{aligned}
\operatorname{Res}_{1}\left\{U_{\phi}(s)\right\} & =\lim _{s \rightarrow p_{1}}\left(s-p_{1}\right) \frac{A^{2}\left(-s^{2}+w_{o}^{2}\right)}{\left(s^{2}+A s+B\right)\left(s^{2}-A s+B\right)} \\
& =\lim _{s \rightarrow p_{1}}\left(s-p_{1}\right) \frac{A^{2}\left(-s^{2}+w_{o}^{2}\right)}{\left(s-p_{1}\right)\left(s-p_{2}\right)\left(s-p_{3}\right)\left(s-p_{4}\right)} \\
& =\frac{A^{2}\left(-p_{1}^{2}+w_{o}^{2}\right)}{\left(p_{1}-p_{2}\right)\left(p_{1}-p_{3}\right)\left(p_{1}-p_{4}\right)} \\
& =\frac{A^{2}\left(-p_{1}^{2}+w_{o}^{2}\right)}{\left(p_{1}-p_{1}^{*}\right)\left(p_{1}+p_{1}^{*}\right)\left(p_{1}+p_{1}\right)} \\
& =\frac{A^{2}\left(-p_{1}^{2}+w_{o}^{2}\right)}{\left(8 \operatorname{Im}\left\{p_{1}\right\} \operatorname{Re}\left\{p_{1}\right\} p_{1}\right)} .
\end{aligned}
$$

De forma similar el residuo del polo $p_{2}$ del mismo semiplano es

$$
\operatorname{Res}_{2}\left\{U_{\phi}(s)\right\}=\frac{-A^{2}\left(-p_{1}^{* 2}+w_{o}^{2}\right)}{\left(8 \operatorname{Im}\left\{p_{1}\right\} \operatorname{Re}\left\{p_{1}\right\} p_{1}^{*}\right)} .
$$

Ahora se puede empezar a desandar camino, reemplazando las expresiones logradas en las anteriores,

$$
\begin{aligned}
B_{n \phi} & =\frac{1}{4 \pi} I_{\phi} \\
& =\frac{1}{4 \pi} 2 \pi \sum_{i} \operatorname{Res}_{i}\left\{T_{\phi}(s) T_{\phi}(-s)\right\} \\
& =\frac{1}{2}\left(\operatorname{Res}_{1}\left\{U_{\phi}(s)\right\}+\operatorname{Res}_{2}\left\{U_{\phi}(s)\right)\right. \\
& =\frac{1}{2}\left(\frac{A^{2}\left(-p_{1}^{2}+w_{o}^{2}\right)}{\left(8 \operatorname{Im}\left\{p_{1}\right\} \operatorname{Re}\left\{p_{1}\right\} p_{1}\right)}+\frac{-A^{2}\left(-p_{1}^{* 2}+w_{o}^{2}\right)}{\left(8 \operatorname{Im}\left\{p_{1}\right\} \operatorname{Re}\left\{p_{1}\right\} p_{1}^{*}\right)}\right) \\
& =\frac{1}{2}\left(\frac{A^{2}\left(\left(-p_{1}^{2}+w_{o}^{2}\right) p_{1}^{*}-\left(-p_{1}^{* 2}+w_{o}^{2}\right) p_{1}\right)}{8 \operatorname{Im}\left\{p_{1}\right\} \operatorname{Re}\left\{p_{1}\right\}\left|p_{1}\right|^{2}}\right) \\
& =\left(\frac{A^{2} \operatorname{Im}\left\{\left(-p_{1}^{2}+w_{o}^{2}\right) p_{1}^{*}\right\}}{8 \operatorname{Im}\left\{p_{1}\right\} \operatorname{Re}\left\{p_{1}\right\}\left|p_{1}\right|^{2}}\right)
\end{aligned}
$$


e introducimos ahora los coeficientes del filtro de lazo,

$$
\begin{aligned}
B_{n \phi} & =\frac{\left(-B \sqrt{4 B-A^{2}}-(B / A)^{2} \sqrt{4 B-A^{2}}\right)}{\left(16\left(-\frac{A}{2}\right)\left(\frac{\sqrt{4 B-A^{2}}}{2}\right) B\right)} \\
& =\frac{\left(A^{2}+B\right)}{(4 A)}
\end{aligned}
$$

para finalmente llegar a la expresión buscada.

$$
B_{n \phi}=\frac{A}{4}+\frac{B}{4 A} .
$$

\section{A.4.2. Estimación de frecuencia}

Mediante un proceso fundamentalmente idéntico al anterior se puede probar la que $B_{n \omega}$ se puede calcular mediante la expresión:

$$
B_{n \omega}=\frac{B^{2}}{4 A}
$$

Cabe mencionarse que debido al cero que tiene la transferencia de $T_{\omega}(s)$ en $s=0$, la altura del filtro ideal $H_{o w}$ no puede seleccionarse utilizando el criterio habitual de elegir $H_{o \omega}=T_{\omega}(0)$. En lugar de ello para llegar a la expresión anterior se eligió arbitrariamente $H_{o \omega}=1$ con el fin de igualar las alturas del los filtros ideales asumidos para el cálculo de $B_{n \omega}$ y $B_{n \phi}$ y así hacer comparables las cifras de uno y otro. Este no es el único criterio posible, pero se vuelve irrelevante porque la elección particular de $H_{o \omega}$ no afecta el resultado final buscado. Esto es así porque la desviación estándar de la estimación de frecuencia depende del producto $B_{n \omega} H_{o \omega}$ (área del filtro ideal) que es una característica invariante de la transferencia analizada.

\section{A.5. Caracterización de ruido de referencia}

\section{A.5.1. Ruido en las muestras de correlación}

Para caracterizar el ruido equivalente de referencia del lazo de seguimiento de código se empleará el modelo extremadamente simplificado de la Figura A.3. Esta última representa las transformaciones que sufre la señal que son relevantes a la obtención de los resultados de correlación $I_{E}[n], I_{P}[n]$ y $I_{L}[n]$, correspondientes a las componentes en fase de las correlaciones Early, Punctual y Late respectivamente. 


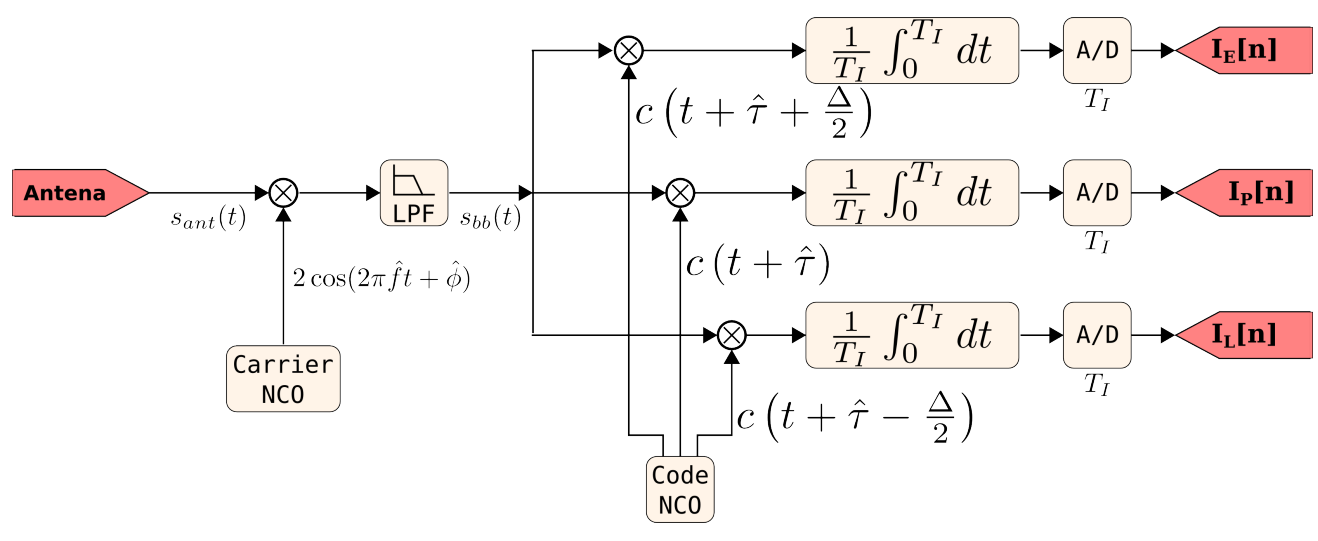

FigurA A.3: Modelo analógico aproximado de la operación de correlación, válido si la frecuencia de muestreo es lo suficientemente alta.

La Figura A.3 modela la recepción de la señal $s_{a n t}(t)$ a través de la antena del receptor. Esta se asume con una estructura muy simple,

$$
s_{\text {ant }}(t)=A c(t+\tau) \cos (2 \pi f t+\phi)+n(t)
$$

donde se modelan la amplitud de la señal, la función de código, la modulación de la portadora con frecuencia $f$ y fase $\phi$, y la presencia de ruido $n(t)$. El ruido es modelado como pasabanda, AWGN y circularmente simétrico, con densidad espectral de potencia de altura uniforme $N_{o} / 2$ centrada en la frecuencia portadora de la señal, y ancho de banda igual a esta última. La omisión de un factor que modele la presencia de modulación de datos $d(t)$ se debe a que una vez logrado el sincronismo de los intervalos de correlación con los pulsos de la modulación de datos puede asumirse que esta no tiene efectos sobre la relación SNR de las muestras de correlación.

La relación SNR de la señal a la entrada se caracteriza mediante su relación $C / N_{o}$, la cual en el modelo anterior puede escribirse como

$$
\frac{C}{N_{o}}=\frac{A^{2}}{2 N_{o}} .
$$

La señal es trasladada a banda base mediante multiplicación con una réplica local de la portadora, seguida de un filtrado pasabajo. En régimen estable, las estimaciones de frecuencia $\hat{f}$ y fase $\hat{\phi}$ del lazo de portadora serán tales que $\hat{f} \approx f$ y $\hat{\phi} \approx \phi$, por lo que para el análisis actual se puede asumir que se logra eliminación total de la portadora, siendo por lo tanto posible modelar la señal en banda base como

$$
s_{b b}(t)=A c(t+\tau)+n_{c}(t)
$$


donde $n_{c}(t)$ es la componente en fase del ruido $n(t)$. Puede probarse que $n_{c}(t)$ es también ruido Gaussiano, pasabajo y que su densidad espectral de potencia tiene altura uniforme $N_{o}$ dentro del rango de frecuencias ocupado por la señal.

El valor de la componente en fase de la correlación Early es.

$$
\begin{aligned}
I_{E}[n] & =\frac{1}{T_{I}} \int_{0}^{T_{I}} s_{b b}(t) c\left(t+\hat{\tau}+\frac{\Delta}{2}\right) d t \\
& \left.=\frac{1}{T_{I}} \int_{0}^{T_{I}} A c(t+\tau)+n_{c}(t)\right) c\left(t+\hat{\tau}+\frac{\Delta}{2}\right) d t \\
& =\frac{1}{T_{I}} \int_{0}^{T_{I}} A c(t+\tau) c\left(t+\hat{\tau}+\frac{\Delta}{2}\right) d t+\frac{1}{T_{I}} \int_{0}^{T_{I}} n_{c}(t) c\left(t+\hat{\tau}+\frac{\Delta}{2}\right) d t \\
& =\frac{1}{T_{I}} \int_{0}^{T_{I}} A c(t+\tau) c\left(t+\hat{\tau}+\frac{\Delta}{2}\right) d t+n\left(\hat{\tau}+\frac{\Delta}{2}\right) \\
& =A R_{c c}\left(\hat{\tau}-\tau+\frac{\Delta}{2}\right)+n\left(\hat{\tau}+\frac{\Delta}{2}\right) \\
& =A R_{c c}\left(\Delta \tau+\frac{\Delta}{2}\right)+n\left(\hat{\tau}+\frac{\Delta}{2}\right)
\end{aligned}
$$

Operando de la misma forma para los correladores Punctual y Late resultan:

$$
\begin{aligned}
& I_{E}[n]=A R_{c c}\left(\Delta \tau+\frac{\Delta}{2}\right)+n\left(\hat{\tau}+\frac{\Delta}{2}\right) \\
& I_{P}[n]=A R_{c c}(\Delta \tau)+n(\hat{\tau}) \\
& I_{L}[n]=A R_{c c}\left(\Delta \tau-\frac{\Delta}{2}\right)+n\left(\hat{\tau}-\frac{\Delta}{2}\right) .
\end{aligned}
$$

En todos los casos se puede ver que resultan dos términos, uno debido exclusivamente a la señal y otro exclusivamente al ruido. La dependencia del término de ruido con la elección de $\hat{\tau}$ y con el adelanto/retardo correspondiente al correlador $\left(I_{E}, I_{P}\right.$ o $\left.I_{L}\right)$ se ha dejado indicada de forma explícita porque será importante en breve.

\section{A.5.2. Ruido en el discriminador de código}

Se asume que la implementación del lazo de código utiliza un discriminador de código coherente como el demostrado en la expresión (3.17), que se repite a continuación por comodidad:

$$
\Delta \tau=\frac{1}{2} \frac{\left(I_{E}-I_{L}\right)}{\tilde{A}}
$$

donde la estimación $\tilde{A}$ de la amplitud de la señal se supone con error despreciable (es decir, $\tilde{A} \approx A$ ) y libre de ruido de estimación. Esto es una suposición razonable cuando $\tilde{A}$ se obtiene mediante un promediado lo suficientemente largo de las amplitudes de las muestras de correlación anteriores. 
Reemplazando (A.12) y (A.14) en la expresión del discriminador:

$$
\begin{aligned}
\tilde{\Delta \tau} & =\frac{1}{2} \frac{\left(A R_{c c}\left(\Delta \tau+\frac{\Delta}{2}\right)+n\left(\hat{\tau}+\frac{\Delta}{2}\right)-A R_{c c}\left(\Delta \tau-\frac{\Delta}{2}\right)+n\left(\hat{\tau}-\frac{\Delta}{2}\right)\right)}{\tilde{A}} \\
& =\frac{1}{2} \frac{\left(A R_{c c}\left(\Delta \tau+\frac{\Delta}{2}\right)-A R_{c c}\left(\Delta \tau-\frac{\Delta}{2}\right)\right.}{\tilde{A}}+\frac{1}{2} \frac{\left.n\left(\hat{\tau}+\frac{\Delta}{2}\right)-n\left(\hat{\tau}-\frac{\Delta}{2}\right)\right)}{\tilde{A}} \\
& =\Delta \tau+\frac{\left(n\left(\hat{\tau}+\frac{\Delta}{2}\right)-n\left(\hat{\tau}-\frac{\Delta}{2}\right)\right)}{2 \tilde{A}} \\
& =\Delta \tau+n_{\Delta}
\end{aligned}
$$

donde $n_{\Delta}$ es término aditivo debido al ruido que afecta a la estimación de error de retardo. Ese término es efectivamente el ruido de que afecta la referencia del lazo de código. Está compuesto por los aportes de ruido de $I_{E}$ y de $I_{L}$, pero como se verá a continuación, dichos aportes no son independientes:

$$
\begin{aligned}
n_{\Delta} & =\frac{\left(n\left(\hat{\tau}+\frac{\Delta}{2}\right)-n\left(\hat{\tau}-\frac{\Delta}{2}\right)\right)}{2 \tilde{A}} \\
& =\frac{\left(\frac{1}{T_{I}} \int_{0}^{T_{I}} n_{c}(t) c\left(t+\hat{\tau}+\frac{\Delta}{2}\right) d t-\frac{1}{T_{I}} \int_{0}^{T_{I}} n_{c}(t) c\left(t+\hat{\tau}-\frac{\Delta}{2}\right) d t\right)}{2 \tilde{A}} \\
& =\frac{\left(\int_{0}^{T_{I}} n_{c}(t)\left(c\left(t+\hat{\tau}+\frac{\Delta}{2}\right)-c\left(t+\hat{\tau}-\frac{\Delta}{2}\right)\right) d t\right)}{2 \tilde{A} T_{I}}
\end{aligned}
$$

En este paso se nota que si $\Delta<T_{\text {chip }}$ los chips correspondientes de las dos versiones desplazadas de la función de código se solapan parcialmente, tal como está representado en la Figura A.3.

En los intervalos de tiempo donde se restan chips del mismo valor en ambas versiones desplazadas de la función de código, la resta es idénticamente cero. Esto elimina el aporte de ruido de estos mismos intervalos al resultado final de la integral. Esto ocurre durante una fracción $1-\Delta / T_{\text {chip }}$ de cada tiempo de chip.

En los intervalos de tiempo donde se restan chips de valores independientes, valen las propiedades pseudoaleatorias de los códigos de expansión de espectro: la resta será una variable aleatoria $R$ que toma el valor 2 un $25 \%$ de las veces, -2 otro $25 \%$, y 0 el $\% 50$ restante. $R$ es independiente del ruido $n_{c}, \mathrm{y}$ su esperanza y varianza son:

$$
\begin{aligned}
& E\left\{R_{i}\right\}=0, \\
& E\left\{R_{i}^{2}\right\}=2 .
\end{aligned}
$$

Estos pulsos ocupan una fracción $\Delta / T_{\text {chip }}$ de cada tiempo de chip.

Si el tiempo de integración es lo suficientemente largo comparado con la duración de los chips individuales, se puede aproximar la expresión (A.17) mediante la expresión 


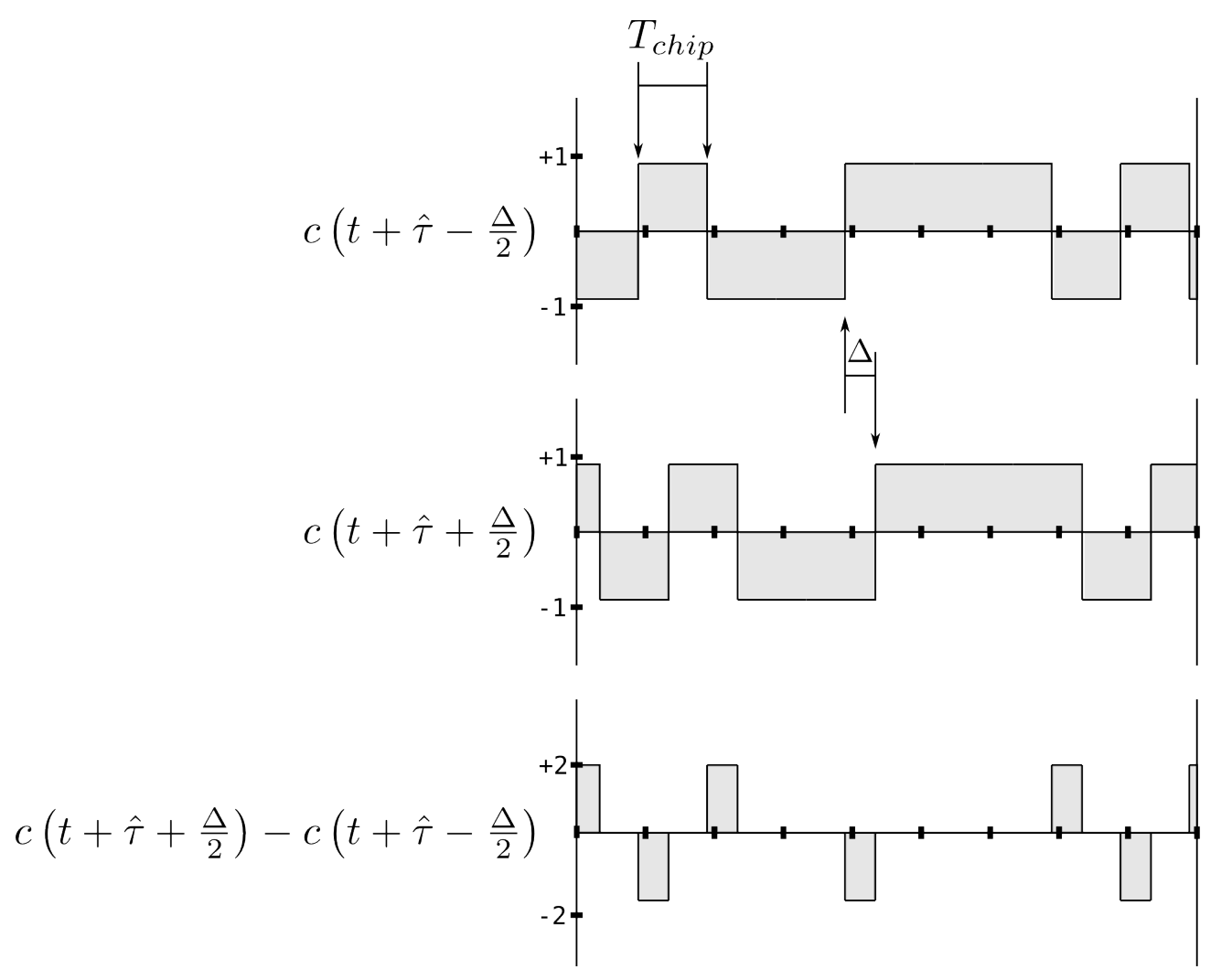

Figura A.4: Efecto de la superposición parcial de las funciones de código durante el tiempo de integración $T_{I}$ en la expresión (A.17) cuando $\Delta<T_{\text {chip }}$.

aproximada siguiente, la cual desprecia el efecto de los chips en los bordes del tiempo de integración,

$$
\begin{aligned}
n_{\Delta} & \approx \frac{1}{2 \tilde{A} T_{I}} \sum_{i=1}^{T_{I} / T_{\text {chip }}} R_{i} \int_{t_{o}+i T_{\text {chip }}}^{t_{o}+i T_{\text {chip }}+\Delta} n_{c}(u) d u \\
& \approx \frac{1}{2 \tilde{A} T_{I}} \sum_{i=1}^{T_{I} / T_{\text {chip }}} R_{i} n_{\Delta i}
\end{aligned}
$$

donde $\operatorname{los} n_{\Delta i}$ son variables aleatorias independientes que resultan de promediar durante intervalos disjuntos de duración $\Delta$ el ruido $n_{c}(t)$ de densidad espectral $N_{o}$. Se puede probar que

$$
\begin{aligned}
& E\left\{n_{\Delta i}\right\}=0, \\
& E\left\{n_{\Delta i}^{2}\right\}=N_{o} \Delta .
\end{aligned}
$$


Dada la independencia entre los $n_{\Delta i}$ y los $R_{i}$, y la suposición de que $T_{I} \gg T_{c h i p}$, por el Teorema del Límite Central $n_{\Delta}$ es una variable aleatoria Gaussiana con esperanza

$$
\begin{aligned}
E\left\{n_{\Delta}\right\} & =\frac{1}{2 \tilde{A} T_{I}} \sum_{i=1}^{T_{I} / T_{\text {chip }}} E\left\{R_{i}\right\} E\left\{n_{\Delta i}\right\} \\
& =0
\end{aligned}
$$

y varianza

$$
\begin{aligned}
E\left\{n_{\Delta}^{2}\right\} & =\left(\frac{1}{2 \tilde{A} T_{I}}\right)^{2} \sum_{i=1}^{T_{I} / T_{\text {chip }}} E\left\{R_{i}^{2}\right\} E\left\{n_{\Delta i}^{2}\right\} \\
& =\frac{1}{4 \tilde{A}^{2} T_{I}^{2}} \frac{T_{I}}{T_{\text {chip }}} 2 N_{o} \Delta \\
& =\frac{N_{o} \Delta}{2 \tilde{A}^{2} T_{I} T_{\text {chip }}}
\end{aligned}
$$

que es más útil reescribir como función de $C / N_{o}$ de la señal a la entrada:

$$
E\left\{n_{\Delta}^{2}\right\}=\frac{\Delta}{4 \frac{C}{N_{o}} T_{I} T_{\text {chip }}} .
$$

Debido a la independencia entre el ruido $n_{c}(t)$ de diferentes intervalos de integración se puede concluir que el ruido de la referencia del lazo $n_{\Delta}[n]$ forma un proceso discreto donde muestras diferentes son independientes entre sí. Si además asumimos que el $C / N_{o}$ de la señal no se modifica apreciablemente, el proceso es además idénticamente distribuido. En estas condiciones, la densidad espectral de potencia discreta de $n_{\Delta}^{2}$ se corresponde con la del ruido blanco discreto, con densidad espectral

$$
\begin{aligned}
\frac{N_{o}^{(d)}}{2} & =\frac{E\left\{n_{\Delta}^{2}\right\}}{\frac{1}{T_{I}}} \\
& =\frac{\Delta}{4 \frac{C}{N_{o}} T_{\text {chip }}} .
\end{aligned}
$$

No debe confundirse esta densidad espectral con la $\frac{N_{o}}{2}$ del ruido que afecta a la señal $s_{a}(t)$ a la entrada. La relación de la expresión (A.22) será utilizada en la sección siguiente para estimar la varianza de la estimación de frecuencia del lazo.

En la expresión (A.21) puede verse que la potencia de ruido que afecta a la medición de retardo de código decrece con la relación $C / N_{o}$ a la entrada, con el tiempo de integración $T_{I}$, y con la fracción $\Delta / T_{\text {chip }}$. Esto último es particularmente interesante, ya que habilita los esquemas de tipo narrow correlator que utilizan separaciones $\Delta<T_{\text {chip }}$ entre los correladores Early y Late para así incrementar la calidad del observable de tiempo de transmisión que se obtiene del lazo de seguimiento de código. 


\section{A.6. Ruido de la estimación de frecuencia}

Ha sido probado que el ruido de la referencia corresponde a un proceso de ruido discreto de tipo Gaussiano, de muestras independientes, de media cero, varianza dada por la expresión (A.21), y densidad espectral de potencia constante de altura dada por la expresión (A.22).

Anteriormente se dedujo también el ancho de banda de ruido de la estimación de frecuencia de un lazo de tiempo continuo que se utiliza como base para diseñar el lazo discreto correspondiente. Se mencionó también que en la medida en que el ancho de banda de ruido $B_{n}$ del lazo diseñado sea mucho menor que la frecuencia de muestreo del sistema discreto, puede asumirse que el lazo discreto obtenido por aproximación conservará las características del modelo continuo, incluyendo sus anchos de banda $B_{n w}$ y $B_{n \phi}$.

Establecido esto, es fácil probar que la estimación de frecuencia del lazo de seguimiento de código será una variable discreta de media cero, y por definición del ancho de banda equivalente de ruido su varianza será igual a

$$
\begin{aligned}
\sigma_{w}^{2} & =2 B_{n w} H_{o w} \frac{N_{o}^{d}}{2} \\
& =2 \frac{B^{2}}{4 A} \frac{\Delta}{4 \frac{C}{N_{o}} T_{\text {chip }}} \\
& =\frac{B^{2} \Delta}{8 A \frac{C}{N_{o}} T_{\text {chip }}}
\end{aligned}
$$

que tiene unidades de $\left[\mathrm{chip}^{2} \mathrm{seg}^{-2}\right]$, y donde $B$ y $A$ son los coeficientes del filtro de la Figura A.1.

Dado que el filtro además se diseña utilizando las plantillas de diseño de lazos de tiempo continuo óptimo, se puede reemplazar los coeficientes $A$ y $B$ por las expresiones (A.1) y (A.2) para obtener finalmente la varianza de la estimación de frecuencia del lazo de codigo, en unidades de $\left[\mathrm{chip}^{2} \mathrm{seg}^{-2}\right.$ ], en función del ancho de banda de fase $B_{n \phi}$ utilizado para diseñarlo:

$$
\sigma_{w}^{2}=\frac{16}{27} \frac{B_{n \phi}^{3}}{\frac{C}{N_{o}}} \frac{\Delta}{T_{\text {chip }}} .
$$

\section{A.7. Velocidad de respuesta del detector}

Nuevamente se utiliza el modelo de la Figura A.1 como sustituto aproximado del lazo de seguimiento de código discreto. 
Las transferencias del modelo fueron desarrolladas oportunamente al comienzo del presente apéndice, resultando en las expresiones (A.4) para la transferencia de lazo abierto, (A.3) para la transferencia del error de lazo, (A.5) para la transferencia de fase, y (A.6) para la transferencia de frecuencia.

El proceso de falso enganche del lazo de portadora es un proceso en el cual una vez que se produce una violación del rango de operación del discriminador UFA se produce un reemplazo del foco de atracción del lazo de portadora. A partir de este momento el lazo tiende al nuevo punto de operación con un transitorio cuya duración está determinada por las características dinámicas del filtro de lazo.

Una vez que el lazo de seguimiento de portadora se encuentra en situación de falso enganche el error en la estimación de frecuencia del PLL de portadora se traduce en un error en la asistencia de frecuencia al lazo de código, que a su vez es percibido por este último como una modificación en la tasa de avance de la función de código.

Debido a la dinámica mucho más rápida del lazo de seguimiento de portadora comparada con la del lazo de seguimiento de código todo el proceso de entrada en situación de falso enganche y de estabilización en este estado erróneo tiene una duración muy breve comparada con las constantes de tiempo del lazo de código. Esto permite modelar la perturbación desde el punto de vista del lazo de código como la aparición de un escalón de frecuencia en la referencia del mismo.

La forma de la respuesta de la estimación de frecuencia ante este tipo de perturbación permite examinar las características temporales de la respuesta.

\section{A.7.1. Respuesta al escalón de frecuencia}

Sea la respuesta $S(s)$ del lazo de la Figura A.1 ante un escalón de frecuencia unitario en la entrada. Un escalón de frecuencia se modela como una rampa en la referencia del lazo de seguimiento de retardo cuyo comienzo coincide con en el momento de aplicación de la perturbación.

$$
\begin{aligned}
S(s) & =\frac{1}{s^{2}} T_{\omega}(s) \\
& =\frac{1}{s^{2}} \frac{B s}{\left(s^{2}+A s+B\right)} \\
& =\frac{1}{s}-\left(\frac{\left(s+\frac{A}{2}\right)}{\left(s+\frac{A}{2}\right)^{2}+\left(B-\frac{A^{2}}{4}\right)}\right)-\left(\frac{\frac{A}{2}}{\sqrt{B-\frac{A^{2}}{4}}}\right)\left(\frac{\sqrt{B-\frac{A^{2}}{4}}}{\left(s+\frac{A}{2}\right)^{2}+\left(B-\frac{A^{2}}{4}\right)}\right) .
\end{aligned}
$$


En el dominio del tiempo, esto se convierte en una respuesta temporal de la forma

$$
s(t)=u(t)\left(1-e^{-a t}\left(\cos (b t)+\frac{a}{b} \sin (b t)\right)\right)
$$

donde las constantes $a$ y $b$ son

$$
\begin{aligned}
a & =\frac{A}{2}, \\
b & =\sqrt{B-\frac{A^{2}}{4}} .
\end{aligned}
$$

Reemplazando las expresiones de los coeficientes $A$ y $B$ del filtro óptimo (expresiones (A.1) y (A.2)) resulta

$$
\begin{aligned}
s(t) & =u(t)\left(1-e^{-\left(\frac{4 B_{n \phi} t}{3}\right)}\left(\cos \left(\frac{4 B_{n \phi} t}{3}\right)+\sin \left(\frac{4 B_{n \phi} t}{3}\right)\right)\right) \\
& =u(t)\left(1-e^{-\left(\frac{t}{\tau_{s}}\right)}\left(\cos \left(\frac{t}{\tau_{s}}\right)+\sin \left(\frac{t}{\tau_{s}}\right)\right)\right)
\end{aligned}
$$

donde se definió la constante de tiempo $\tau_{s}$ como

$$
\tau_{s}=\frac{3}{4 B_{n \phi}} .
$$

La constante de tiempo $\tau_{s}$ define completamente la forma de la respuesta en el tiempo $s(t)$, porque funciona como factor de escala de todas las apariciones de la variable $t$. Esto permite normalizar el eje del tiempo en función de la constante de tiempo, tal como se ha hecho en la Figura A.5.

La dependencia inversa de la constante de tiempo con el ancho de banda $B_{n \phi}$ implica que cuanto menor sea el ancho de banda del lazo de seguimiento, más lenta será la respuesta de la estimación de frecuencia del lazo ante una situación de falso enganche y más lenta por lo tanto la detección del evento.

Por último, es una circunstancia afortunada que $s\left(\tau_{s}\right)$ sea igual a 0,4917. Dado que el umbral de detección del falso enganche se pone justamente en mitad de la altura del escalón de frecuencia esperado en tal condición, eso significa que la detección del falso enganche tendrá una latencia aproximadamente igual a una constante de tiempo $\tau_{s}$ hasta su detección. 


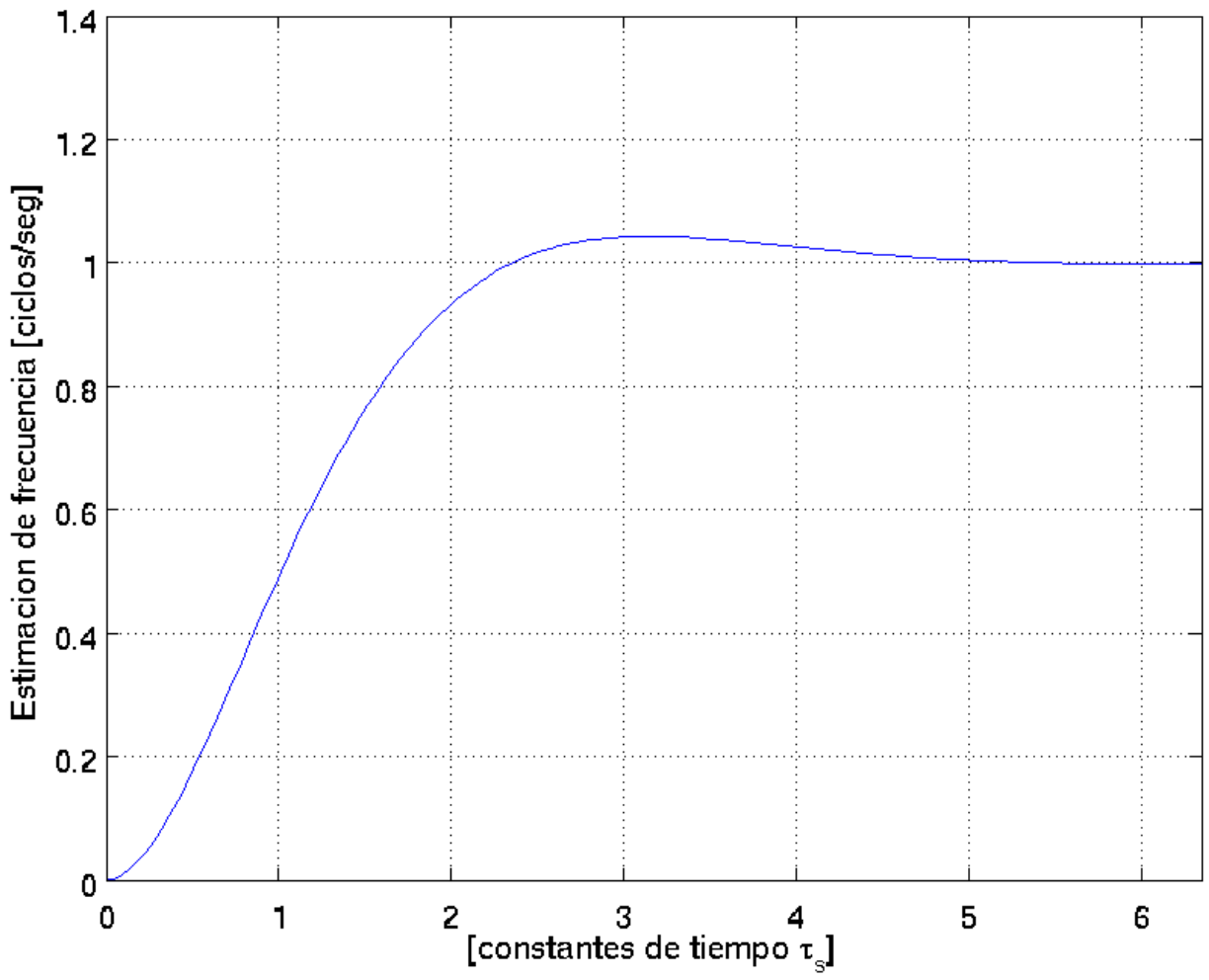

Figura A.5: Respuesta de la estimación de frecuencia del lazo de seguimiento de código a un escalón unitario de frecuencia. El eje horizontal es tiempo normalizado por la constante de tiempo $\tau_{s}$ de la exponencial y los períodos de las sinusoidales de la expresión (A.26). 


\section{Apéndice B}

\section{Probabilidad de falsa alarma de detección no coherente}

\section{B.1. Introducción}

Aquí se presenta la deducción de la expresión analítica de la probabilidad de falsa alarma $P_{f a}$ en función de los parámetros $T_{c o h}, N_{c o h}$ y el umbral normalizado $u$ utilizado por el detector de los algoritmos de adquisición con correlaciones no coherentes discutido en el Capítulo 7.

\section{B.2. Modelo estadístico de correlación no coherente sin señal}

Sea una variable aleatoria $r_{n c}$ resultado de una correlación no coherente formada por $N_{c o h}$ intervalos coherentes de duración $T_{c o h}$ cada uno. En ausencia de potencia de señal las componentes en fase $i[k]$ y en cuadratura $q[k]$ de las $k$-ésima correlación coherentes son variables aleatorias Gaussianas de varianza $\sigma^{2}$ :

$$
\begin{aligned}
i[k] & \sim \mathcal{N}\left(0, \sigma^{2}\right), \\
q[k] & \sim \mathcal{N}\left(0, \sigma^{2}\right) .
\end{aligned}
$$


El resultado de la correlación no coherente es la acumulación de las potencias de las integraciones coherentes individuales

$$
\begin{aligned}
r_{n c} & =\sum_{k=1}^{N_{c o h}} p[k] \\
& =\sum_{k=1}^{N_{c o h}}\left(i^{2}[k]+q^{2}[k]\right) .
\end{aligned}
$$

Se puede demostrar que la función de distribución de probabilidades de la potencia $p[k]$ de la correlaciones coherentes individuales tiene distribución de tipo exponencial de parámetro $\frac{1}{2 \sigma^{2}}$.

$$
p[k] \sim \mathcal{E}\left(0, \frac{1}{2 \sigma^{2}}\right) .
$$

La acumulación de $N_{c o h}$ variables aleatorias de distribución exponencial da lugar a una distribución Gamma, que permite determinar la función de densidad de probabilidad de la correlación no coherente $r_{n c}$ :

$$
r_{n c} \sim \Gamma\left(N_{c o h}, 2 \sigma^{2}\right) .
$$

La parametrización de la función asumida para la función Gamma es $\Gamma(s, \lambda)$, con $s$ el factor de forma (shape) y $\lambda$ el de escala (scale) de la distribución.

Una distribución Gamma con parámetro $k$ entero es equivalente una distribución de tipo Erlang,

$$
r_{n c} \sim \operatorname{Erlang}\left(N_{c o h}, \frac{1}{2 \sigma^{2}}\right)
$$

la cual posee una expresión analítica para su función de probabilidad acumulada:

$$
\begin{aligned}
F_{E}(p) & =1-\sum_{n=0}^{N_{c o h}-1} \frac{1}{n !} e^{\frac{p}{2 \sigma^{2}}}\left(\frac{p}{2 \sigma^{2}}\right)^{n} \\
& =1-e^{\frac{p}{2 \sigma^{2}}} \sum_{n=0}^{N_{c o h}-1} \frac{1}{n !}\left(\frac{p}{2 \sigma^{2}}\right)^{n} .
\end{aligned}
$$

La expresión anterior está parametrizada en función de la varianza $\sigma^{2}$ del ruido de las correlaciones coherentes. Dado que este valor no se puede estimar de forma directa desde los algoritmos de adquisición es conveniente parametrizar la función $F_{E}(p)$ según alguna magnitud de estimación más simple. 


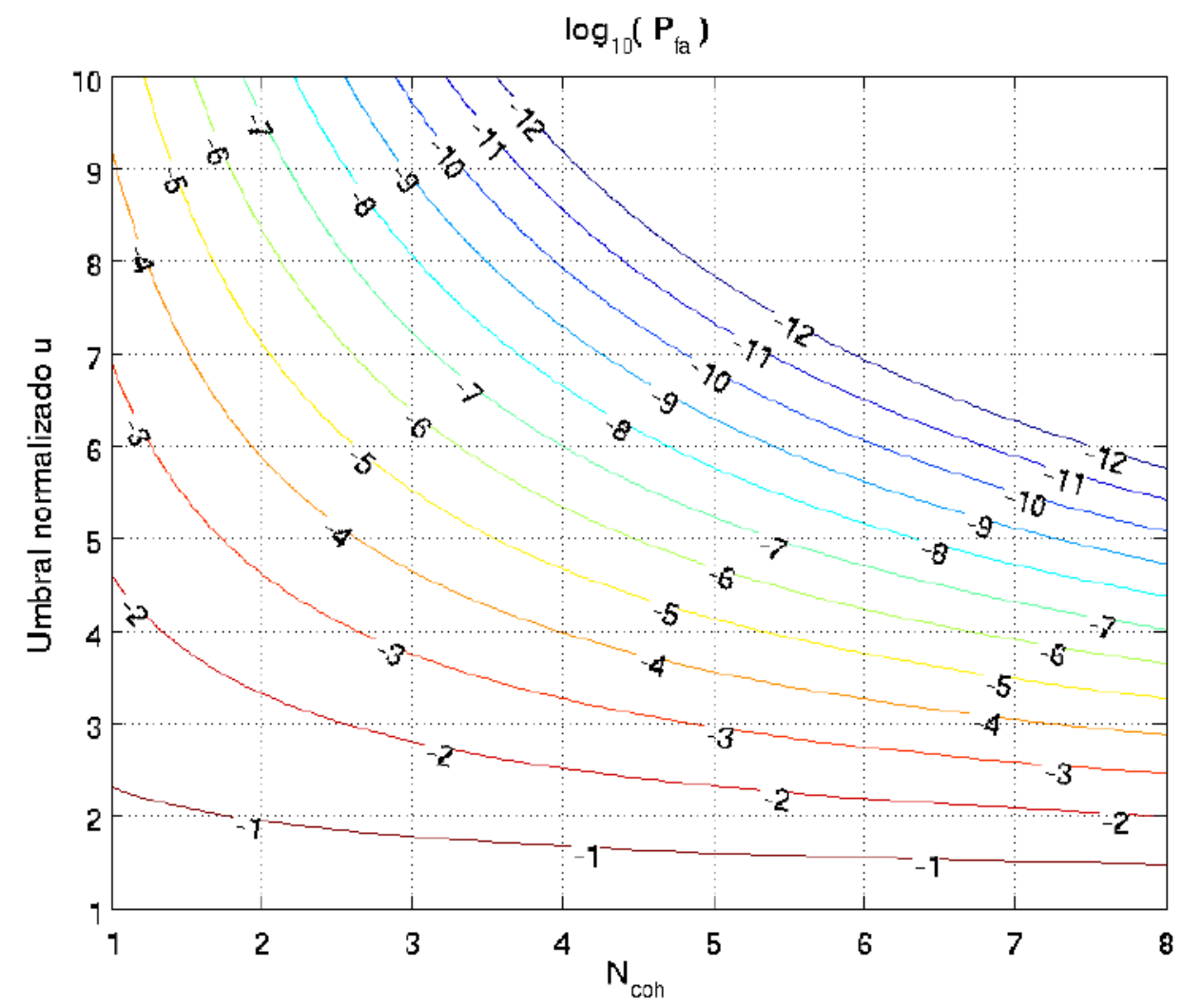

Figura B.1: Probabilidad de falsa alarma en una correlación no coherente, en función del umbral normalizado $u$ y de la cantidad de integraciones no coherentes sumadas, $N_{c o h}$.

Afortunadamente es trivial probar a partir de la expresión (B.1) que la media de la potencia de correlación no coherente sin señal $u_{r}$ guarda una relación lineal con $\sigma^{2}$, además de que su estimación es muy sencilla calculando una media muestral de un conjunto de valores de potencia de correlación no coherente sin señal:

$$
\begin{aligned}
\mu_{r} & =E\left\{r_{n c}\right\} \\
& =2 N_{c o h} \sigma^{2} .
\end{aligned}
$$

Reemplazando esta última expresión en la anterior resulta:

$$
F_{E}(p)=1-e^{\frac{N_{c o h} p}{\mu_{r}}} \sum_{n=0}^{N_{c o h}-1} \frac{1}{n !}\left(\frac{N_{c o h} p}{\mu_{r}}\right)^{n} .
$$

\section{B.3. Probabilidad de falsa alarma}

Definiendo el umbral de detección como función del umbral $u$ normalizado por la potencia media de correlación sin señal $U=\mu_{r} u$, entonces la probabilidad de falsa alarma $P_{f a}$ 
es

$$
P_{f a}(u)=1-F_{E}\left(\mu_{r} u\right)
$$

que resulta en la expresión final:

$$
P_{f a}(u)=e^{-N_{c o h} u} \sum_{n=0}^{N_{c o h}-1} \frac{1}{n !}\left(N_{c o h} u\right)^{n} .
$$

En la Figura B.1 puede verse la probabilidad de falsa alarma calculada para diversas combinaciones de valores de $N_{\text {coh }}$ y $u$. 


\section{Apéndice $\mathrm{C}$}

\section{Algoritmo de detección de flancos en señal GNSS}

\section{C.1. Introducción}

En este apéndice se presenta un algoritmo de detección del alineamiento de los pulsos NRZ de tasa 100 bps (duración $10 \mathrm{~ms}$ ) que utiliza integraciones de $N$ milisegundos de duración cuyo comienzo y final difieren de la posición del comienzo de cualquier pulso por una cantidad entera de milisegundos. Este es el algoritmo utilizado para determinar la posición módulo $10 \mathrm{~ms}$ de los flancos del mensaje de navegación en la última fase del proceso de adquisición de una señal GNSS GPS/GLONASS que se describe en el Capítulo 7.

El contenido del presente apéndice está basado en el material publicado oportunamente por el autor de la tesis en las referencias [14] y [15]. La primera de dichas publicaciones se basó en el desarrollo del método de detección de flancos para las señales GPS (codificación NRZ de 50 bps) y GLONASS (codificación Manchester de 50 bps) utilizando integraciones de $3 \mathrm{~ms}$. La segunda publicación generaliza la técnica para integraciones de $N$ milisegundos, y lo aplica a la detección de flancos en una codificación NRZ de 100 bps como la utilizada durante la adquisición del señal del receptor presentado en esta tesis. Esta última publicación además también presenta una expresión analítica que permite estimar la probabilidad de error de la técnica de detección de alineamiento expuesta.

Si bien todo el desarrollo presentado en este capítulo se concentra en la detección de flancos en una secuencia de pulsos NRZ de $100 \mathrm{bps}$, ni la forma del pulso ni la tasa son fundamentales al método y es trivial extender las mismas ideas para aplicar la misma técnica a pulsos de otras formas y tasas. 


\section{C.2. Modelo de señal}

Sea una secuencia de valores $I_{1}[i]$ resultantes de integrar la señal de entrada durante intervalos de 1 ms sincrónicos con los inicios y finales de los pulsos NRZ de 100 bps de la señal de datos en banda base.

$$
I_{1}[i]=B[\lfloor(i+m) / 10\rfloor]+n_{1}[i]
$$

donde $B[n]$ un proceso aleatorio que modela la secuencia aleatoria de bits transmitidos con amplitud normalizada $(B[n]= \pm 1), m$ es el alineamiento relativo de la primera integración respecto de los bordes de pulsos (inicialmente desconocido), $n_{1}[i]$ es una variable aleatoria Gaussiana, independiente para cada $i$, tal que $E\left\{n_{1}[i]\right\}=0$ y $\operatorname{Var}\left\{n_{1}[i]\right\}=\sigma_{1}^{2}$. La normalización de los valores para que se cumpla que $B[n]=1$ es fundamental para el funcionamiento del algoritmo aquí presentado. Mas adelante se volverá sobre este tema para ver como lograr esta normalización en una implementación práctica del algoritmo.

Este modelo asume que el comienzo de las integraciones de $N \mathrm{~ms}$ se encuentra alineado de forma tal que su comienzo difiere del comienzo del cualquier pulso de datos por una cantidad entera de milisegundos. Esta hipótesis no es especialmente restrictiva, ya que para un receptor GNSS este tipo de alineamiento puede conseguirse sincronizando el comienzo y final de las integraciones con los comienzos y finales de la función de código utilizada para expandir la señal, la fase de la cual es conocida para el receptor luego de las primeras fases de la adquisición.

A partir del modelo anterior de integraciones de $1 \mathrm{~ms}$ se puede modelar las muestras obtenidas utilizando integraciones de $\mathrm{N}$ milisegundos como

$$
I_{N}[j]=\sum_{a=0}^{N-1} I_{1}[N j+a] .
$$

Se puede reescribir lo anterior como

$$
I_{N}[j]=S[j]+n_{N}[j]
$$

donde

$$
n_{N}[j]=n_{1}[N j]+\ldots+n_{1}[N j+N-1]
$$

es la acumulación de los términos de ruido. De las características de $n_{1}[i]$ se deduce que el ruido acumulado sobre $N$ milisegundos es también Gaussiano, independiente $\forall j$, y tal que $E\left\{n_{N}[i]\right\}=0$ y $\operatorname{Var}\left\{n_{N}[i]\right\}=N \sigma_{1}^{2}$. 
El término $S[j]$ es la acumulación de los términos de señal durante todo el intervalo de $N$ milisegundos. Dependiendo de la presencia y posición de los cambios de signo en la modulación de datos este valor puede tomar valores $S[j]= \pm(N-2 k)$ donde $k \in[1, N]$ es la cantidad de milisegundos desde el comienzo de la integración antes de que ocurra un cambio de signo.

\section{C.3. Determinación del alineamiento}

Suponga por un momento una señal libre de ruido, tal que $I_{N}[i]=S[i]$; la secuencia de valores $I_{N}[i]$ obtenida inmediatamente identifica tanto la posición de los flancos de datos como la secuencia de bits transmitida durante ese intervalo. Por ejemplo, dada la siguiente secuencia de valores de integraciones de $3 \mathrm{~ms}$

$$
+3,+3,+1,-3,-3,-3,-3,-3,-3,+1,+3,+3,+3
$$

se puede fácilmente comprobar que hubo un cambio de signo $8 \mathrm{~ms}$ después del comienzo del intervalo observado y otro $20 \mathrm{~ms}$ después del primero. También se puede deducir la secuencia de bits transmitidos: $+1,-1,-1,+1$.

En general una dada secuencia de bits transmitidos y el alineamiento relativo de la primera integración respecto de los pulsos de datos definen completamente la secuencia de valores $S^{(n)}[i]$ que se obtendrá para determinada longitud $N$ de los intervalos de integración utilizados.

La igualdad vale en el sentido opuesto también, ya que la secuencia de valores $S[i]$ determina de forma única la secuencia de bits y la posición de los flancos en la secuencia. La excepción a esta relación inversa son las secuencias que no contienen transiciones de signo $(S[i]= \pm N \forall i)$ y por lo tanto no contienen información del alineamiento, pero estos casos patológicos pueden ser detectados de forma trivial.

Para determinar el alineamiento de los flancos relativo a una dada secuencia de largo $L$, se genera un diccionario de todas las secuencias posibles $S^{(n)}[i]$ del mismo largo, considerando para ello todas las combinaciones de alineamiento y secuencia de bits posibles. Este diccionario contiene todas las secuencias, y para cada una de ellas tiene almacenados los parámetros de alineamiento y de secuencia de bits que se usaron para generarla. Armados de esta herramienta sólo es necesario buscar la secuencia observada en el diccionario para determinar el alineamiento y opcionalmente también la secuencia de bits transmitidos. 
Por supuesto el algoritmo anterior es engañosamente simple: hay diez alineamientos iniciales posibles de la secuencia de integraciones respecto de los flancos de una señal de $100 \mathrm{bps}$, y si se tiene en cuenta que durante el intervalo de tiempo abarcado por la secuencia de longitud $L$ caben $B$ tiempos de bit (completos o incompletos) entonces hay al menos $2^{B}$ secuencias de bits posibles. En estas condiciones el tamaño del diccionario de búsqueda necesario es del orden de $10 \times 2^{B}$ entradas, de $L$ valores cada una. Incluso limitando los intervalos de observación a longitudes moderadas (medio segundo, por ejemplo), el tamaño del espacio de búsqueda es inmanejablemente extenso. Por esta razón el proceso de búsqueda necesita ser implementado de tal forma de reducir la cantidad de candidatos a examinar.

En la práctica además las muestras se encuentran afectadas por ruido, por lo que la comparación de la secuencia de entrada con las secuencias candidatas de debe hacerse de forma de minimizar la posibilidad de equivocar la elección como consecuencia de las perturbaciones aditivas presentes.

Estos dos problemas pueden ser resueltos mediante una combinación de un criterio de selección de máxima verosimilitud y una poda iterativa del espacio de búsqueda. Una solución a ambos problemas se verá a continuación.

\section{C.3.1. Criterio de selección}

Dada una secuencia de $L$ valores de integración de $N$ milisegundos, $I_{N}[i]$, es necesario un criterio de comparación de la misma contra los miembros del conjunto de candidatos posibles $\left\{S^{(n)}[i]\right\}$ para determinar cual de ellos es el de mayor parecido la secuencia buscada.

Utilizando el criterio de Máxima Verosimilitud es fácil probar que, bajo las hipótesis de Gaussianidad e independencia del ruido en los valores individuales de la secuencia de entrada, aquel candidato $S^{(n)}[i]$ que minimiza el índice de máxima verosimilitud

$$
J\left(I_{N}, S^{(n)}\right)=\sum_{i=1}^{L}\left(I_{N}[i]-S^{(n)}[i]\right)^{2}
$$

es el candidato más probable a corresponder a la secuencia observada. El criterio de búsqueda entonces consiste simplemente en encontrar el miembro del conjunto $\left\{S^{(n)}\right\}$ que minimiza el índice:

$$
\min _{n} J\left(I_{N}, S^{(n)}\right) .
$$

La estructura de la expresión (C.4) también sugiere un mecanismo muy sencillo de reducción del espacio de búsqueda, como se verá en la siguiente sección. 


\section{C.3.2. Recorrido del espacio de búsqueda}

Dado un candidato $S^{(n)}[i]$ el proceso de cálculo del índice $J\left(I_{p}, S^{(n)}\right)$ a partir de la expresión (C.4) puede ser planteado como un proceso iterativo donde a partir de un dado conjunto de parámetros de la señal candidata $S^{(n)}$ (alineamiento inicial y secuencia de bits) se inicializa una máquina de estados que genera la secuencia $S^{(n)}[i]$, la compara contra el valor observado $I_{N}[i]$, acumula el error cuadrático entre ambas, y avanza al estado siguiente para repetir el proceso con $i+1$. Luego de iterar este proceso $L$ veces (el largo de la secuencia observada), el error cuadrático acumulado total corresponde al valor del índice de máxima verosimilitud $J\left(I_{p}, S^{(n)}\right)$.

Para examinar el espacio de búsqueda completo el proceso anterior debe ser efectuado para cada miembro del conjunto $\left\{S^{(n)}[i]\right\}$, lo cual demanda un esfuerzo comparable al diccionario de candidatos planteado inicialmente. Sin embargo la estrategia del cálculo iterativo de los índices de verosimilitud permite una enorme economía de cálculo si se nota que:

1. El proceso de acumulación de dos secuencias $S^{\alpha}[i]$ y $S^{\beta}[i]$ cuyos primeros $j$ elementos son iguales puede hacerse una única vez para ambas hasta alcanzar el punto donde las secuencias se diferencian, a partir del cual se separa el proceso de cálculo de una y otra.

2. Si dos secuencias son iguales a partir del $j$-ésimo elemento, entonces a partir de ese punto ambas acumularán error en la misma medida. En consecuencia, aquella de estas dos que haya acumulado el mayor error cuadrático hasta este punto de unión puede ser descartada tempranamente porque ya se puede anticipar que existe otro candidato que al final del procesamiento tendrá un valor de error acumulado final menor al suyo.

Se propone a continuación un proceso de recorrido del espacio de búsqueda que saca provecho de las dos ideas anteriores para reducir la cantidad de procesamiento necesario para determinar el miembro de $\left\{S^{(n)}[i]\right\}$ que minimiza el índice $J\left(I_{p}, S^{(n)}\right)$.

Existen diez alineamientos iniciales posibles entre los intervalos de integración y los pulsos de datos, y dos posibles valores del pulso en el instante inicial $( \pm 1)$ de $S^{(n)}[0]$, resultando por lo tanto en veinte estados iniciales posibles para el generador de secuencias $S^{(n)}$. Se comienza el procesamiento inicializando veinte generadores, uno por cada una de las posibilidades iniciales. Cada uno de estos generadores de secuencia se utiliza para producir iterativamente una secuencia $S^{(n)}$ candidata, y calcular el error acumulado de la secuencia de valores observados $I_{N}[i]$ contra ellas. 
Cada vez que el generador alcanza un punto donde el valor del siguiente elemento de la secuencia a generar depende de que ocurra o no una transición de signo durante el intervalo de tiempo que representa dicho elemento, se crea una segunda copia del generador. Cada uno de estos dos generadores comparte la historia previa del original, y el error cuadrático acumulado hasta el punto de la división. Uno de los generadores continua la secuencia asumiendo que ocurre un cambio de signo, mientras que el otro hace la suposición contraria. De esta forma la cantidad generadores de secuencia activos es siempre la mínima indispensable para cubrir todas las variantes posibles que se hayan abierto a partir de los veinte casos iniciales posibles.

Mientras que esta aproximación reduce enormemente la cantidad de trabajo a realizar al evitar la repetición de cálculos que serían comunes a grandes cantidades de secuencias candidatas, la cantidad total de variantes luego de calcular $L$ muestras todavía puede ser un número extremadamente grande y por lo tanto insumirá enormes cantidades de memoria y tiempo de procesamiento.

Todavía es posible aplicar la segunda idea enumerada más arriba para reducir aún más la cantidad de trabajo. Para ello en cada paso se comparan los errores cuadráticos acumulados de todos aquellos generadores que tienen el mismo alineamiento inicial y signo del bit actual, pero difieren en la secuencia futura de bits de datos. Dado todas las instancias que se encuentran en la condición anterior tienen las mismas variantes de evolución futura posibles, sólo aquel que tenga el menor error acumulado hasta el momento tiene alguna posibilidad de eventualmente dar lugar a la secuencia que minimiza el índice de máxima verosimilitud, y por lo tanto todos los demás generadores pueden ser eliminados.

En todo momento existen solamente diez alineamientos iniciales y dos signos posibles, por lo que un proceso de poda como el anterior garantiza que en todo momento solamente veinte generadores (con sus estados asociados) sean necesarios para encontrar el mínimo global del índice de máxima verosimilitud en el espacio de posibilidades $\left\{S^{(n)}[i]\right\}$. Es fácil ver que esto reporta una economía muy grande de los recursos de procesamiento necesarios.

\section{C.4. Implementación}

Todo el proceso anterior puede ser implementado mediante un algoritmo de tipo Viterbi, para lo cual primero es necesario definir la máquina de estados que sirve para generar la secuencia de valores $S_{N}[n]$. 
Se define un estado por cada alineamiento del comienzo de un intervalo de integración de $N$ milisegundos respecto del intervalo de $10 \mathrm{~ms}$ del pulso de $100 \mathrm{bps}$, y por cada signo del bit de datos (dos posiblidades, \pm 1 ). Debido a la hipótesis inicial de que el principio de los intervalos de integración siempre difiere de la posición de cualquier flanco por una cantidad entera de milisegundos, entonces independientemente del valor que tome $N$ existen solamente diez alineamientos y dos signos posibles, o equivalentemente 20 estados.

Cada vez que la máquina de estados ejecuta una transición se emite un valor de secuencia $S_{N}[i]$ asociado a dicha transición. Existen $20+2 N$ transiciones posibles entre los 20 estados anteriores.

De esas, $2(10-N)$ corresponden a las transiciones entre dos integraciones sucesivas tales que los comienzos de ambas se encuentran dentro del mismo intervalo de bit. La integral abarcada por estas transiciones cabe completamente dentro de un mismo bit y por lo tanto nunca está afectada por cambios de signo, así que el valor de secuencia emitido es en todos los casos $S_{N}[i]= \pm N$.

Las restantes $4 N$ transiciones corresponden a $2 N$ estados asociados a integraciones cuyo comienzo ocurre en un intervalo de bit, pero su finalización en el siguiente. Estos estados tienen dos transiciones salientes, dadas por los casos de que haya o no haya cambio de signo entre el primer bit y el segundo. En el primer caso, el valor emitido depende de la posición del flanco dentro del intervalo de integración, que a su vez guarda una relación uno a uno con el alineamiento del comienzo de la integración. En el segundo caso, la ausencia de cambio de signo hace que el valor emitido por la transición sea $S_{N}[i]= \pm N$.

En los párrafos y secciones siguientes se utilizará el esquema que se ve en la Figura C.1 para identificar los estados. Mientras que el algoritmo aquí presentado no depende de ningún esquema de identificación de estados particular, el que se presenta en la figura tiene la ventaja de permitir una mecanización muy simple del proceso de generación del trellis de transición de estados para cualquier valor de $N$.

\section{C.4.1. Mecanización del Trellis}

Sea st el número identificador del estado según el esquema presentado en la Figura C.1. Cada estado tiene al menos una transición entrante que proviene del estado $s t_{s s}$

$$
s t_{s s}=\bmod (10+s t-N, 10)+10\lfloor s t / 10\rfloor,
$$

donde mod representa la operación resto de la división entera y $L$ es la operación truncado. Estas son las transiciones que o bien son internas a un mismo intervalo de bit 
Estados correspondientes a signo de datos positivo

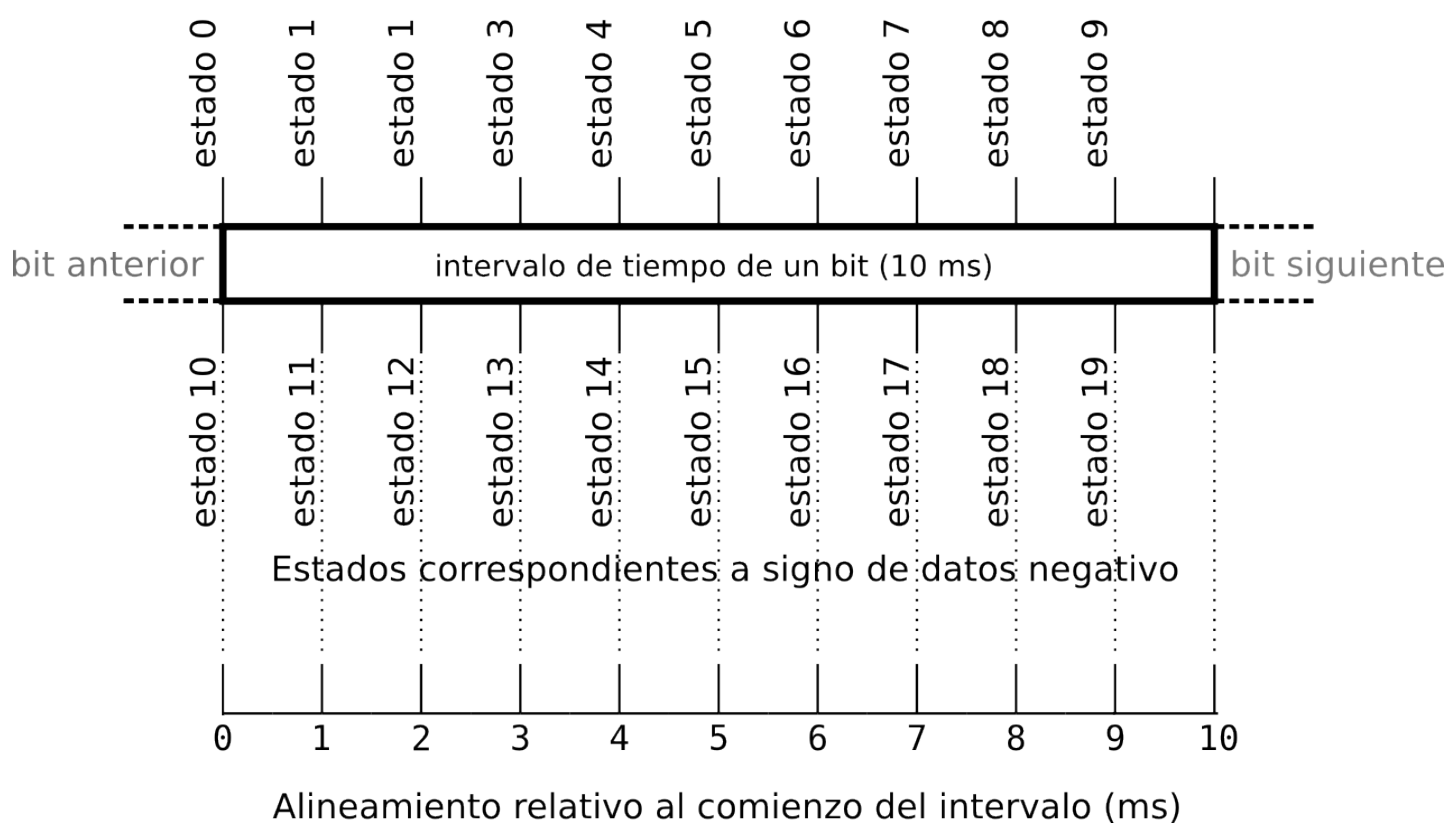

Figura C.1: Esquema de denominación de estados utilizado para la mecanización de la generación del trellis.

o bien atraviesan un flanco en el cual no hubo cambio de signo, por lo que en todos los casos el valor de la secuencia emitido es

$$
E_{s s}=(-1)^{\lfloor s t / 10\rfloor} N,
$$

donde el subíndice ss proviene de same sign.

Si $\bmod (s t, 10)<N$ entonces existe también una segunda transición entrante, proveniente del estado $s t_{d s}$

$$
s t_{d s}=\bmod \left(s t_{s s}+10,20\right) .
$$

Esta transición es la que modela el valor integrado cuando ocurre un cambio del signo de bit durante el intervalo de integración. Debido al cambio de signo las áreas integradas a ambos lados del flanco se cancelan parcial o totalmente y por lo tanto el valor emitido depende del alineamiento del estado de llegada de la transición respecto del flanco, según la expresión siguiente:

$$
E_{d s}=(2 \bmod (s t, 10)-N)(-1)^{\lfloor s t / 10\rfloor}
$$

donde el subíndice $d s$ proviene de different sign.

Un ejemplo de trellis generado con estas reglas puede verse en la Figura C.2 para el caso de $N=3 \mathrm{~ms}$. 


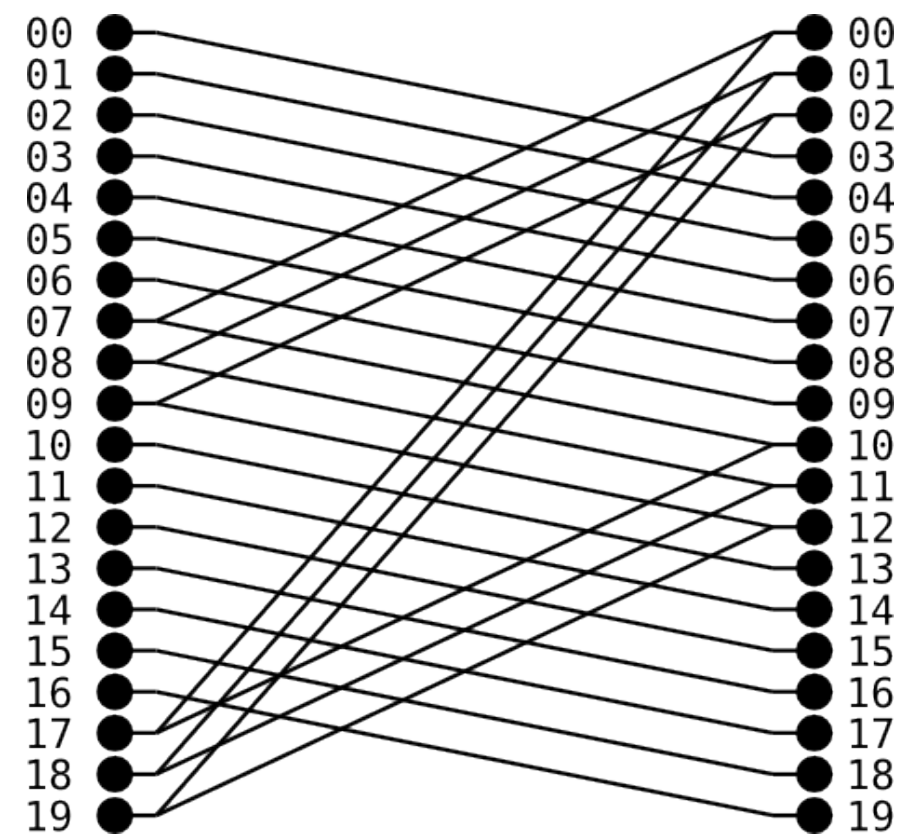

Figura C.2: Trellis de transición de estados para el caso de tiempos de integración de $3 \mathrm{~ms}(N=3)$. Por razones de espacio se omitieron los valores emitidos por el generador en cada transición.

\section{C.4.2. Algoritmo de procesamiento}

Inicialmente se crean 20 hipótesis posibles de alineamiento y signo. Cada hipótesis tiene asociada un alineamiento inicial, una máquina de estados para generar la secuencia de valores observados $S^{(n)}[i]$ y un acumulador de error cuadrático. Los acumuladores se inicializan todos en cero, mientras que las máquinas generadoras son inicializadas en el estado correspondiente al alineamiento y signo iniciales asociados a la hipótesis.

Dado que nunca habrá dos generadores en el mismo estado simultáneamente, decimos que cada una de las hipótesis ocupa el estado actual en que se encuentra su máquina de estados.

Una vez inicializadas las máquinas se comienza a procesar uno por uno los valores observados $I_{n}[0], I_{n}[1], I_{n}[2]$, etc. Para cada valor $I_{n}[i]$ se calculan los errores cuadráticos entre el valor observado y los valores emitidos por cada una de las transiciones presentes en el trellis.

Para cada transición presente en el trellis se procede a evaluar la evolución del conjunto de hipótesis según las dos reglas siguientes:

- Si el estado de destino de la transición tiene una única transición entrante, entonces se copia en ella la hipótesis que ocupa el estado origen luego de actualizar su acumulador sumando el error cuadrático del valor observado a través de la transición 
entre ambas.

- Si el estado destino tiene dos transiciones entrantes, eso significa que hay dos hipótesis cuyas máquinas pueden alcanzar el estado destino en el paso siguiente. En este caso se debe calcular el error actualizado (el acumulado más el error de la muestra observada) de ambas. Aquella hipótesis cuyo error cuadrático acumulado luego de la transición es el menor de los dos se copia al estado destino luego de actualizar su acumulador.

Estas reglas se encargan implícitamente de todo el proceso de bifurcación de generadores (en los estados que tienen dos transiciones salientes) y eliminación de generadores (estados destino con dos transiciones entrantes) que garantizan que con sólo 20 hipótesis en consideración en cada momento se pueda examinar el conjunto $\left\{S^{(n)}[i]\right\}$ completo.

Una vez procesados los $L$ valores observados de la secuencia de entrada se determina entre las 20 hipótesis sobrevivientes aquella que tiene el menor error cuadrático acumulado final. El alineamiento inicial de esta última es el alineamiento de los flancos de bits respecto de la primera integración de la secuencia según el criterio de máxima verosimilitud.

\section{C.5. Expresión analítica de probabilidad de error}

A título ilustrativo de la discusión siguiente, en la Figura C.3 se muestran los valores finales del error cuadrático acumulado para cada una de las 20 hipótesis sobrevivientes luego de procesar una señal con relación $C / N_{o}$ de $35 \mathrm{~dB}-\mathrm{Hz}$ utilizando integraciones de $5 \mathrm{~ms}(N=5)$. Esta curva se obtuvo por simulación del algoritmo presentado en las secciones anteriores.

Las hipótesis que ocupan los estados $s$ y $s+10$ están asociadas ambas al mismo alineamiento inicial, y debido al proceso de bifurcación y eliminación de candidatos resulta en la forma característica donde las hipótesis finales en los estados [00, 09] y [10, 19] toman formas similares. Se puede ver que en este caso la hipótesis con menor error cuadrático acumulado es aquella que ocupa el estado 06 una vez finalizado el procesamiento de la secuencia de entrada.

El panorama presentado por la Figura C.3 permite hacer una segunda observación: dentro del subconjunto de estados correspondientes a un mismo signo del bit de datos $([00,09]$ o $[10,19])$ el error acumulado de las hipótesis incorrectas tiende a aumentar a ambos lados de la hipótesis con el mínimo error. Cualitativamente esto se puede explicar haciendo notar que el error acumulado por las hipótesis sobrevivientes cercanas a la 


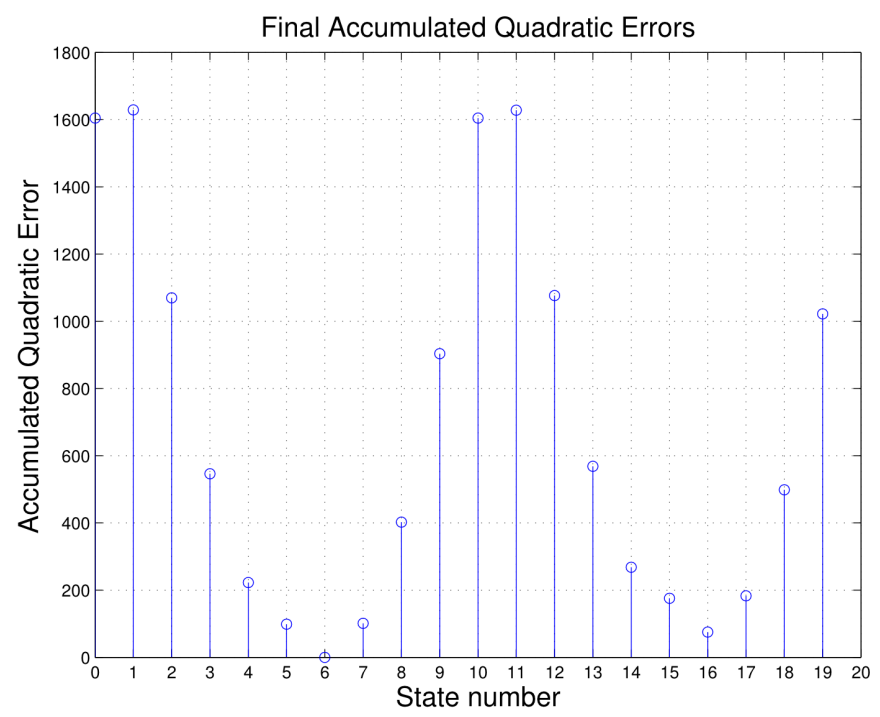

Figura C.3: Valores finales de los errores cuadráticos acumulados al final de una corrida de simulación con parámetros $N=5$ y $C / N_{o}=35 \mathrm{~dB}-\mathrm{Hz}$.

correcta tienden a corresponder hipótesis cuya secuencia de bits es la correcta, pero cuyo alineamiento está desplazado una cantidad entera de milisegundos respecto del alineamiento correcto. En esta condición, si la relación $C / N_{o}$ es lo suficientemente alta entonces se cumple que los errores acumulados finales de las hipótesis sobrevivientes se deben principalmente al error de alineamiento y no al ruido en las muestras de entrada. Por lo tanto, a mayor error de alineamiento mayor error acumulado final.

Esto último es particularmente cierto para las hipótesis inmediatamente adyacentes a la correcta, las cuales corresponden a secuencias idénticas a la correcta pero desalineadas de ésta por $\pm 1 \mathrm{~ms}$. Es esperable por lo tanto que estás dos hipótesis ocupen el segundo y tercer lugar en orden de error acumulado creciente.

Nuevamente en el ejemplo de la Figura C.3, las hipótesis que ocupan los estados 05 y 07 tienen los errores acumulados más bajos de todos excepto por la hipótesis correcta (la que ocupa el estado 06), y están asociados a alineamientos que difieren por $\pm 1 \mathrm{~ms}$ respecto del alineamiento de esta última.

Esta observación cualitativa permite fundamentar una aseveración que da pié para lograr una expresión analítica aproximada para la probabilidad de error del algoritmo: la probabilidad de identificar incorrectamente el alineamiento de la secuencia de bits corresponde esencialmente a la probabilidad de que el error acumulado de alguna de las dos hipótesis que difieren de la correcta por \pm 1 ms sea menor que el error acumulado de la hipótesis correcta.

Sea $S^{\alpha}$ el miembro del conjunto $\left\{S^{(n)}[i]\right\}$ que tiene la secuencia de bits y alineamiento inicial correctos. Sea $S^{\beta}$ un miembro de $\left\{S^{(n)}[i]\right\}$ que corresponde a la misma secuencia 
de bits que el anterior, pero cuyo alineamiento es incorrecto por $\pm 1 \mathrm{~ms}$. La probabilidad de que el algoritmo elija incorrectamente $S^{\beta}$ por sobre $S^{\alpha}$ es la probabilidad del evento

$$
\begin{aligned}
J\left(I_{N}, S^{\alpha}\right) & >J\left(I_{N}, S^{\beta}\right) \\
\sum_{a=0}^{L-1}\left(I_{N}[a]-S^{\alpha}[a]\right)^{2} & >\sum_{a=0}^{L-1}\left(I_{N}[a]-S^{\beta}[a]\right)^{2}
\end{aligned}
$$

Dado que las señales de datos que generaron $S^{\beta}$ y $S^{\alpha}$ difieren entre sí por un desplazamiento de $1 \mathrm{~ms}$, las secuencias $S^{\beta}$ y $S^{\alpha}$ son diferentes entre sí solamente en $F$ valores, donde $F$ es la cantidad de cambios de signo de los pulsos de datos ocurrido en todo el intervalo de $L$ valores observados. Dado que $N \leq 10 \mathrm{~ms}$ entonces a lo sumo puede haber una transición de signo por cada intervalo de integración. En consecuencia, muchos de los términos de la expresión anterior se cancelan entre sí, resultando

$$
\sum^{F}\left(I_{N}[a]-S^{\alpha}[a]\right)^{2}>\sum^{F}\left(I_{N}[a]-S^{\beta}[a]\right)^{2} .
$$

Para los términos restantes es fácil ver que la siguiente desigualdad vale como consecuencia del desplazamiento de $1 \mathrm{~ms}$ entre $S^{\beta}$ y $S^{\alpha}$ :

$$
S^{\alpha}[a]-S^{\beta}[a]= \pm 2
$$

y por lo tanto

$$
\sum^{F}\left(I_{N}[a]-S^{\alpha}[a]\right)^{2}>\sum^{F}\left(I_{N}[a]-S^{\alpha}[a] \mp 2\right)^{2} .
$$

Reemplazando $I_{N}[a]=S^{\alpha}[a]+n_{N}[a]$ :

$$
\begin{aligned}
\sum^{F}\left(n_{N}[a]\right)^{2} & >\sum_{F}^{F}\left(n_{N}[a] \mp 2\right)^{2} \\
0 & >\sum^{F}\left(\mp 4 n_{N}[a]+4\right) \\
\sum^{F} \pm n_{N}[a] & >F
\end{aligned}
$$

donde $n_{N}[a]$ es el ruido Gaussiano e independiente que afecta los valores integrados, y por lo tanto

$$
P\left\{\sum^{F} \pm n_{N}[a]>F\right\}=Q\left(\frac{\sqrt{F}}{\sigma_{N}}\right)
$$

siendo $Q(x)$ la función de probabilidad de que una variable aleatoria Gaussiana tenga un valor mayor que $x$ desviaciones estándar por encima de su media. 
Por último, dado que en $\left\{S^{(n)}[i]\right\}$ existen dos miembros que difieren por $\pm 1 \mathrm{~ms}$ de la secuencia correcta, y despreciando la probabilidad de que el error acumulado de la hipótesis correcta sea mayor que el de ambas hipótesis laterales, entonces la expresión final es

$$
P_{e} \approx 2 Q\left(\sqrt{\frac{2 F \frac{C}{N_{o}}}{1000 N}}\right)
$$

donde se ha reemplazado $\sigma_{N}^{2}=N \sigma_{1}^{2}$ por una expresión en función de la relación $C / N_{0}$ de la señal.

Se puede ver en la expresión (C.15) que los parámetros más relevantes a los fines de determinar la probabilidad de error son

- La cantidad de cambios de signo de bit en el intervalo observado, $F$.

- La duración de los tiempos de integración utilizados, $N$.

- La relación $C / N_{0}$ de la señal.

Mientras que la duración de las integraciones $N$ es un parámetro que generalmente se encuentra definido o al menos restringido por otros subsistemas del receptor (como por ejemplo, la tasa de actualización de los lazos de seguimiento de portadora y código deseada), y que la relación $C / N_{0}$ de la señal es un parámetro que se encuentra fuera del control del receptor, el diseñador tiene control sobre la probabilidad de error que puede alcanzar la detección de alineamiento mediante una adecuada elección del valor de $F$.

Más aún, dado que la expresión de la probabilidad de error no depende del largo $L$ de la secuencia de valores de integración observados, entonces no es necesario establecer el valor de este parámetro a priori. El algoritmo puede simplemente continuar procesando valores $I_{N}[i]$ durante todo el tiempo que sea necesario hasta que hayan ocurrido en la secuencia la cantidad $F$ de cambios de signo necesarios para obtener la probabilidad de error deseada. Es trivial determinar la cantidad $F$ de cambios de signo observados contando la cantidad de veces que cada hipótesis atraviesa una transición asociada a un cambio de signo entre dos bits consecutivos. Esta aproximación mantiene el tiempo necesario para detectar el alineamiento de la secuencia de datos en el mínimo necesario para una dada probabilidad de error. 


\section{C.6. Simulaciones}

Para verificar el funcionamiento del algoritmo de detección del alineamiento de los pulsos del mensaje de navegación se llevaron a cabo una serie de simulaciones para evaluar su probabilidad de error, compararlo contra otros métodos (histograma, energía de bit) y finalmente evaluar el comportamiento de una implementación práctica donde la normalización de las amplitudes no es ideal.

Las simulaciones se llevaron a cabo generando señales de datos de codificación NRZ y tasa $100 \mathrm{bps}$, con bits equiprobables de valores \pm 1 , independientes entre sí. Todas las secuencias $I_{N}[i]$ simuladas se generaron con la misma cantidad $F$ de cambios de signo en la secuencia de bits. Para conjugar la aleatoriedad de las secuencias de bits con la restricción en la cantidad de cambios de signo $F$ las secuencias generadas para la simulación tienen longitud $L$ variable.

Para mantener el tiempo de simulación acotado cada punto en las figuras es una probabilidad de error estimada sobre la base de simular hasta los primeros $10^{4}$ errores o los primeros $10^{6}$ ensayos, lo que ocurriese primero. Esto permite garantizar que la estimación de la probabilidad de error de todos los puntos se hizo sobre al menos $10^{2}$ errores si $P_{e}>10^{-4}, 10^{3}$ errores si $P_{e}>10^{-3}, 10^{4}$ errores si $P_{e}>10^{-2}$.

\section{C.6.1. Evaluación de la expresión analítica}

El primer juego de simulaciones evalúa el comportamiento de la probabilidad de error del método en función de sus parámetros relevantes $\left(F, N\right.$ y $\left.C / N_{0}\right)$ y lo compara con la expresión analítica aproximada de la probabilidad de error que fue presentada en la Sección C.5.

En las Figuras C.4, C.5 y C.6 se presentan en línea sólida las curvas resultantes de estimar por simulación la probabilidad de error del algoritmo de detección de flancos en función de la relación $C / N_{o}$ de la señal y del tiempo de integración $N$ de las muestras de correlación. Se ven allí curvas para todos los valores de $N$ entre 1 y 10 .

Superpuestos a las curvas anteriores se pueden ver (en línea de guiones) las curvas correspondientes al cálculo analítico de la probabilidad en función de $N$ y $C / N_{o}$ utilizando la expresión (C.15). Las tres figuras difieren unas de otras por el valor de la cantidad $F$ de flancos de bit presentes en las secuencias de entrada. En la Figura C.4 las secuencias simuladas tienen 50 transiciones $(F=50)$, en C.5 25 transiciones $(F=25)$ y en C.6 10 transiciones $(F=10)$. 


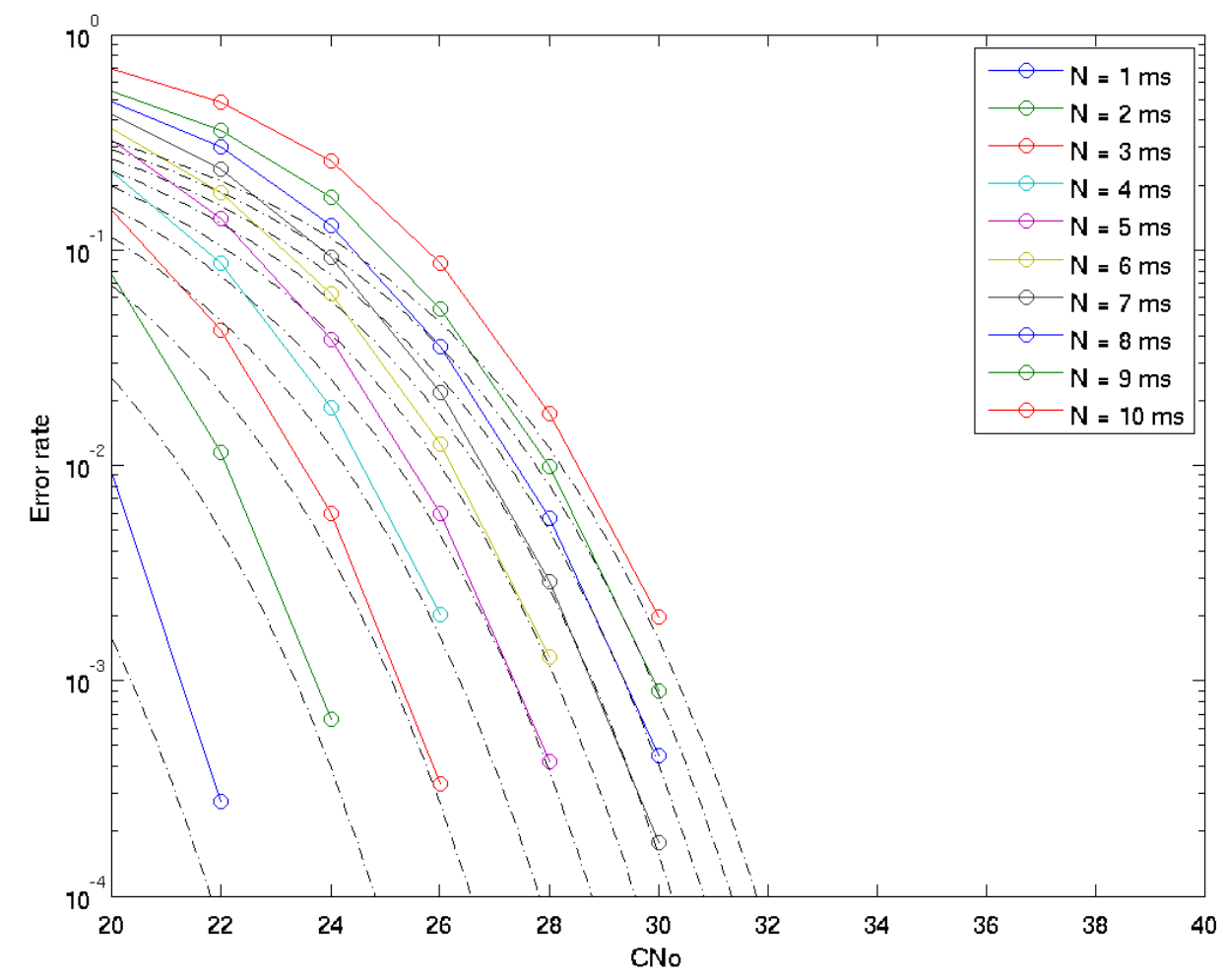

Figura C.4: Simulación de la probabilidad de error del método de detección de alineamiento presentado, con $F=50$ y para variantes con tiempos de integración $N=1$ a $N=10$ en función de la relación $C / N_{o}$. En línea de guiones se presentan las curvas correspondientes a la estimación de la probabilidad de error esperada según la expresión analítica (C.15).

Se puede ver en las figuras que los valores de probabilidad de error predichos por la expresión (C.15) concuerdan con mucha aproximación con las probabilidades de error estimadas por simulación cuando la relación $C / N_{o}$ es alta, y divergen una de otra cuando por el contrario la relación $C / N_{o}$ es pobre. El punto de quiebre entre una región y otra depende de $N$, pero puede ubicarse aproximadamente en $27 \mathrm{~dB}-\mathrm{Hz}$.

La razón para la divergencia entre las simulaciones y la curvas analíticas en la región de relación $C / N_{o}$ baja es debido a que en esa región deja de cumplirse suposición de que la probabilidad de detectar incorrectamente el alineamiento es aproximadamente igual a la probabilidad de equivocarse por $\pm 1 \mathrm{~ms}$.

En todos los casos, la probabilidad de error aumenta al disminuir la cantidad de flancos $F$ debido a que se reduce la cantidad de información de alineamiento presente en la entrada. La probabilidad aumenta también con el tiempo de integración en milisegundos utilizado, $N$, debido al empobrecimiento de la relación SNR de la información de alineamiento: la distancia entre los valores posibles que pueden tomar los elementos de la secuencia de entrada crece más lentamente que la desviación estándar del ruido presente en cada valor. 


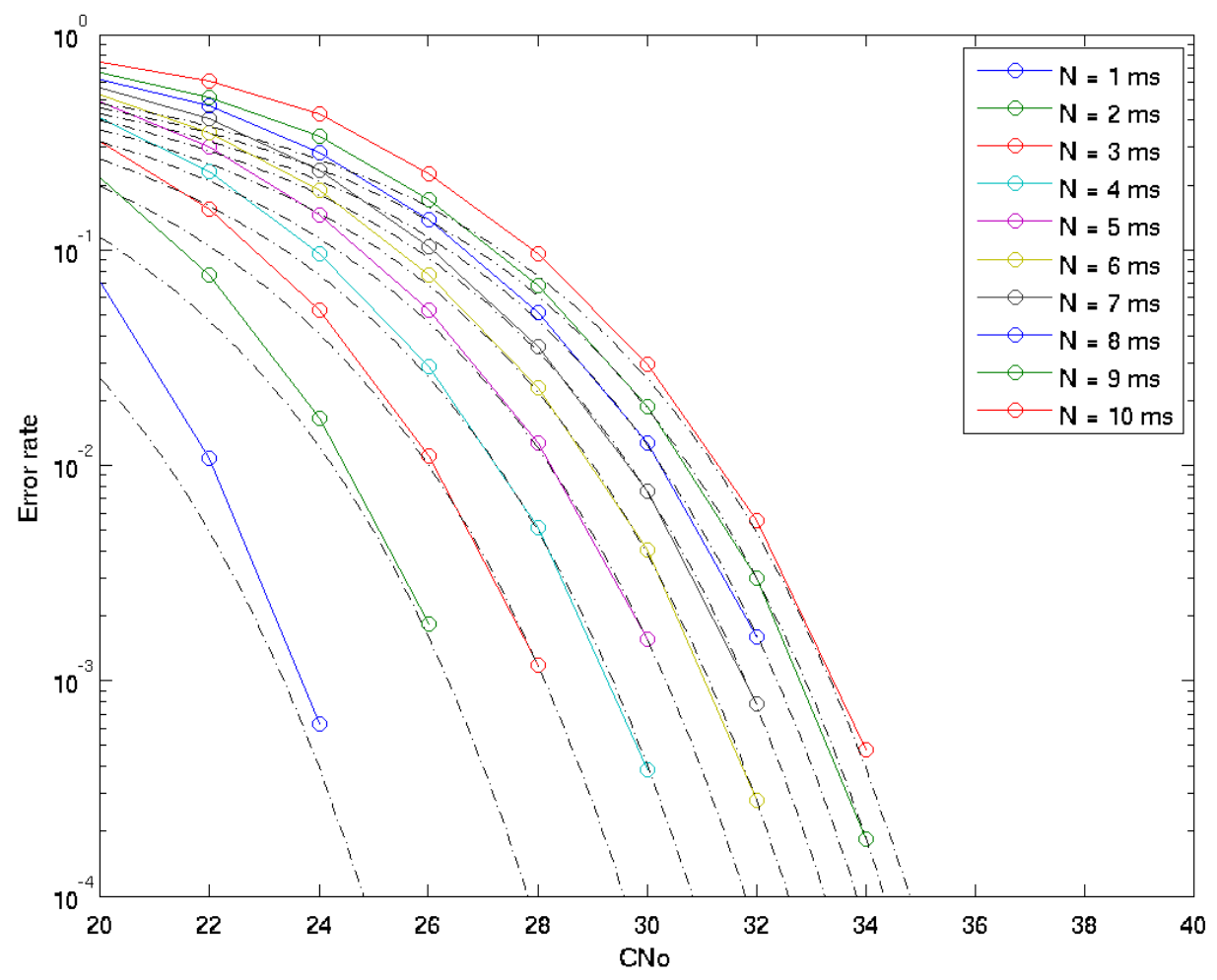

Figura C.5: Simulación de la probabilidad de error del método de detección de alineamiento presentado, con $F=25$ y para variantes con tiempos de integración $N=1$ a $N=10$ en función de la relación $C / N_{o}$. En línea de guiones se presentan las curvas correspondientes a la estimación de la probabilidad de error esperada según la expresión analítica (C.15).

Por último, la relación $C / N_{o}$ de la señal tiene un efecto positivo sobre la probabilidad de error independientemente de los valores de los otros dos parámetros.

\section{C.6.2. Comparación contra otros métodos}

Las Figuras C.7 (para $F=50$ ), C.8 (para $F=25$ ) y C.9 (para $F=10$ ) comparan la probabilidad de error del algoritmo de detección de alineamiento presentado en este apéndice contra otros dos algoritmos de sincronización de bit, el método del histograma y el de la energía de bit.

Se pueden ver cuatro curvas, correspondientes al método del histograma, el método de la energía de bit, y dos curvas correspondientes al método de detección de alineamiento de máxima verosimilitud presentado anteriormente. Estas últimas a su vez son simulaciones para los casos de tiempos de integración $N$ de $1 \mathrm{~ms}$ (demostrativa) y de $3 \mathrm{~ms}$ (implementada en el receptor). 


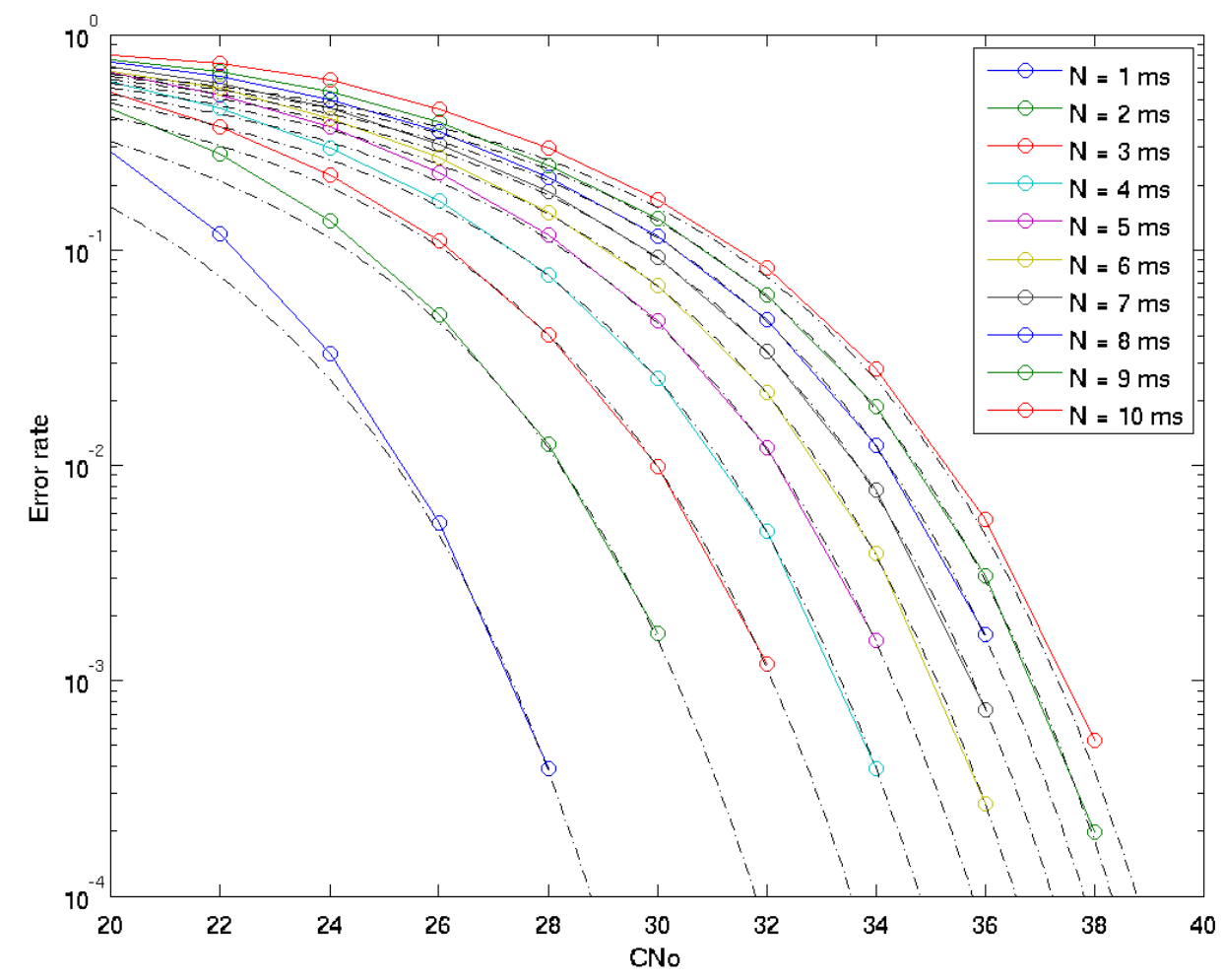

Figura C.6: Simulación de la probabilidad de error del método de detección de alineamiento presentado, con $F=10$ y para variantes con tiempos de integración $N=1$ a $N=10$ en función de la relación $C / N_{o}$. En línea de guiones se presentan las curvas correspondientes a la estimación de la probabilidad de error esperada según la expresión analítica (C.15).

Se puede ver que la probabilidad de error del método del histograma tiene la peor probabilidad de error de entre los tres métodos que utilizan integraciones de $1 \mathrm{~ms}$ (histograma, energía de bit y ML con $N=1 \mathrm{~ms}$ ). Inicialmente su probabilidad de error es también peor que la del método ML con $N=3 \mathrm{~ms}$ pero ésta esta tendencia luego se revierte al aumentar la relación $C / N_{o}$.

Se puede ver que en todos los casos las curvas de probabilidad de error de máxima energía de bit y ML con $N=1 \mathrm{~ms}$ se superponen. Esta equivalencia en la probabilidad de error de ambos proviene de que ambos métodos minimizan el error cuadrático total entre una secuencia de bits desconocida y la secuencia de valores de entrada. La diferencia en este caso es de aproximación, ya que el método de energía de bit realiza el cálculo fuera de línea adquiriendo la secuencia de entrada completa primero y luego agrupando sus valores de diferentes formas, mientras que el método presentado aquí funciona en vivo procesando los valores de la secuencia de entrada a medida que se van generando.

La curva de ML con $N=3 \mathrm{~ms}$ presenta una probabilidad de error superior a la del método de la energía de bit y ML con $N=1 \mathrm{~ms}$, e incluso eventualmente presenta una 


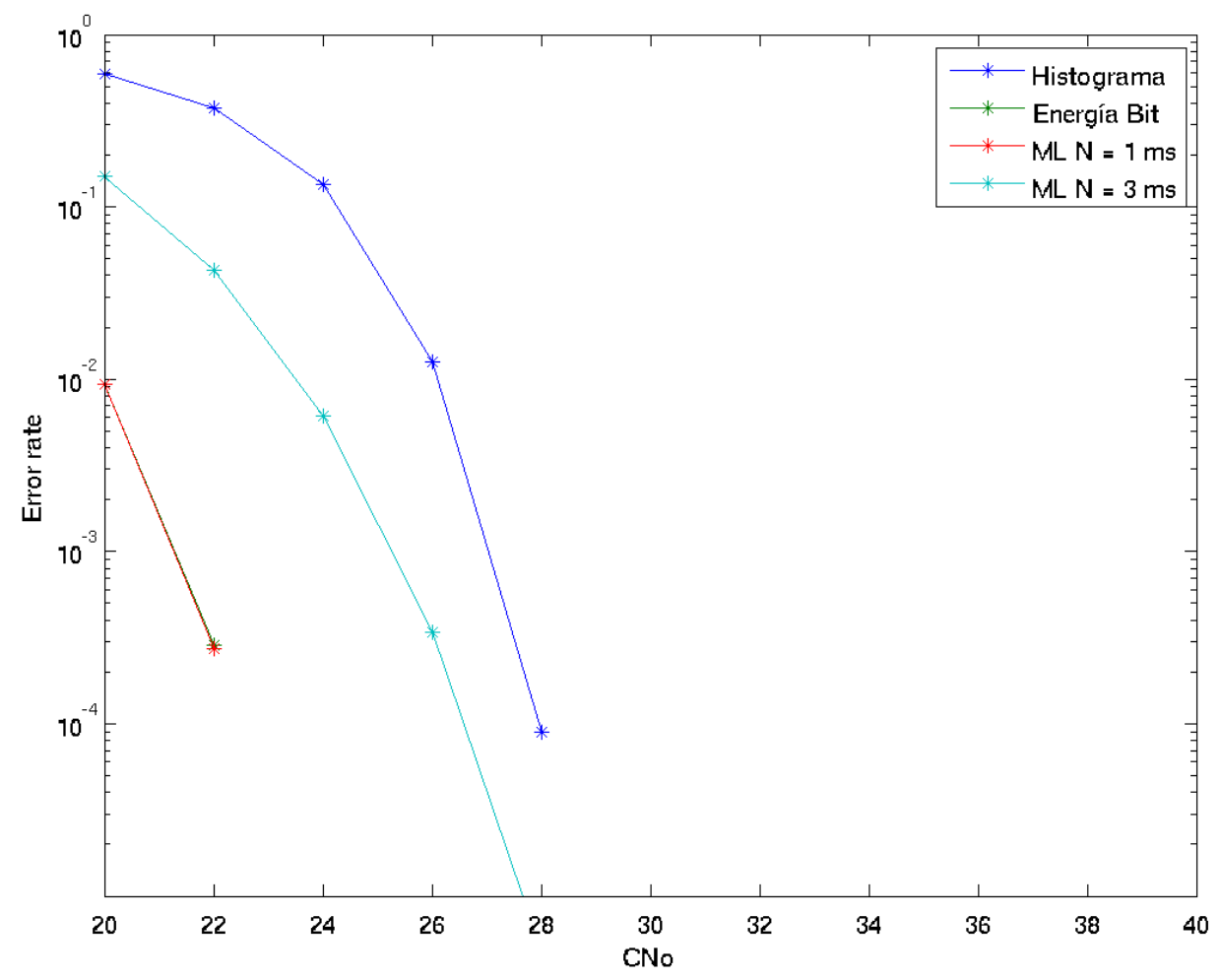

Figura C.7: Simulación de las probabilidades de error con $F=50$ de los métodos histograma, máxima energía de bit y dos variantes del método de máxima verosimilitud presentado en este apéndice para valores $N=1$ y $N=3$.

probabilidad de error superior a la del histograma. Sin embargo tiene en su favor que lo hace procesando muestras de correlación de $3 \mathrm{~ms}$, por lo que la tasa de actualización de los lazos de seguimiento necesarios para generar las muestras de entrada puede reducirse a un tercio de lo que demandan los otros métodos. Su probabilidad de error, aunque no es la mejor de las presentadas, es satisfactoria para el rango de valores de $C / N_{o}$ de trabajo habituales, y además puede ser regulada mediante un control de la cantidad $F$ de flancos que se procesan antes de tomar una decisión final respecto del alineamiento.

\section{C.6.3. Efecto de normalización no ideal}

En la Sección C.2 se señaló que es fundamental la normalización de las amplitudes de la secuencia de entrada. En este punto ya es fácil comprender que la razón de esto es que el método se basa en la interpretación de la secuencia de las amplitudes de los miembros de la secuencia para determinar donde caen los flancos de bit en el intervalo de observación.

En una implementación práctica la amplitud de las muestras de correlación es desconocida para el receptor ya que depende de factores como la potencia con la que arriba la señal a la antena, la potencia y la distribución del ruido, los amplificadores y atenuadores 


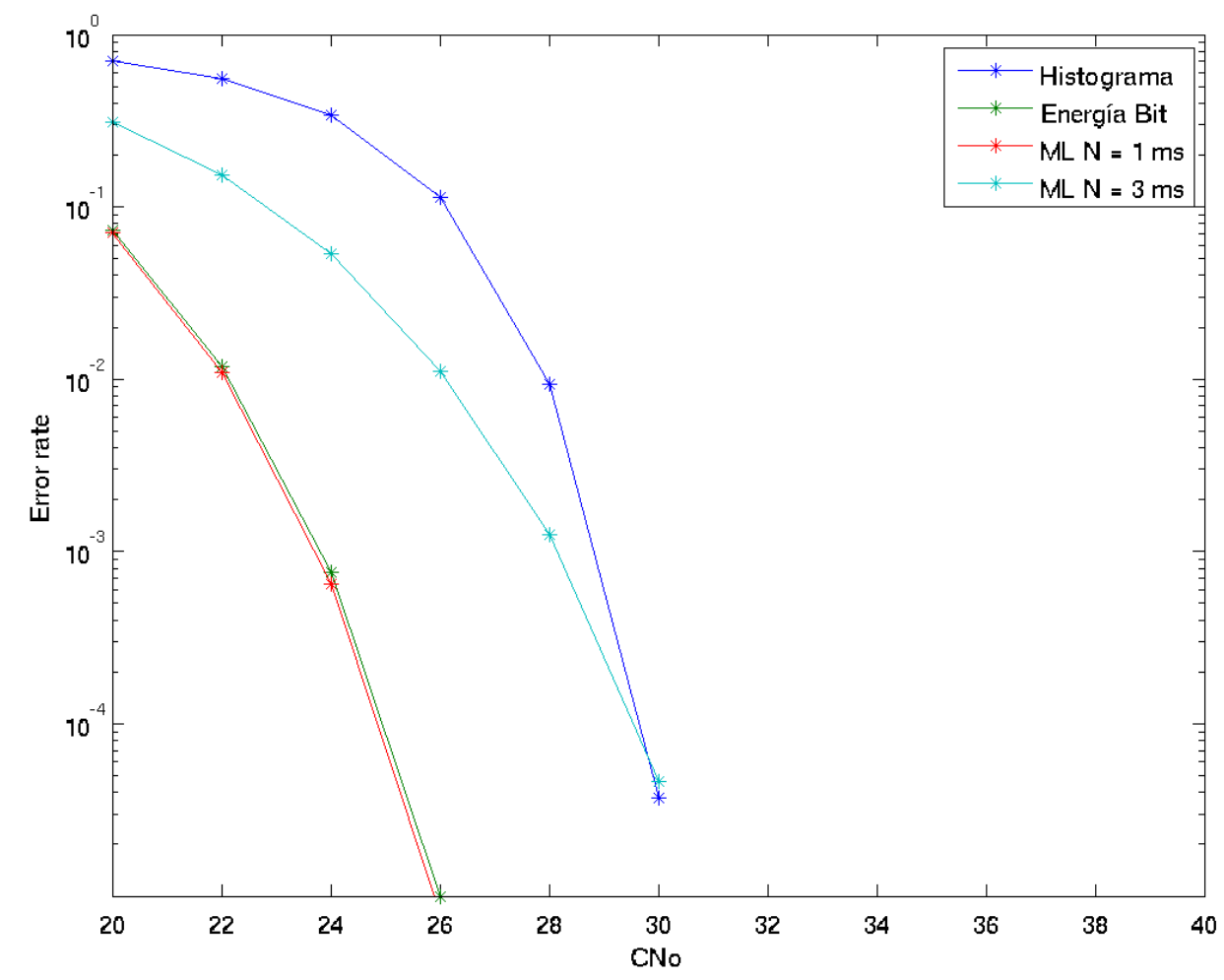

Figura C.8: Simulación de las probabilidades de error con $F=25$ de los métodos histograma, máxima energía de bit y dos variantes del método de máxima verosimilitud presentado en este apéndice para valores $N=1$ y $N=3$.

en la sección analógica, los factores de escala que resultan de la codificación discreta de la señal, etc.

La normalización de las amplitudes de la entrada requiere entonces de que el receptor realice una estimación de la amplitud de la señal basada en las amplitudes observadas de los resultados de las correlaciones, y normalice la secuencia utilizando esa estimación antes de procesarlos con el algoritmo de detección de alineamiento.

La forma más simple de realizar de esta estimación es con un filtro ventana que promedie las amplitudes de las últimas $M$ correlaciones no afectadas por flancos. Bajo la suposición de la que amplitud de la señal puede variar con constantes relativamente lentas comparado con la dinámica del filtro ventana, entonces la media de la estimación de amplitud así calculada coincide con la amplitud verdadera de la señal.

La determinación de cuales correlaciones no fueron afectadas por flancos puede también realizarse de forma muy simple para el caso de correlaciones de $3 \mathrm{~ms}$ : si en la secuencia se presentan tres integraciones consecutivas con el mismo signo, entonces las amplitudes de la primera, la tercera, o de ninguna de ellas estarán afectadas por flancos de bit, pero nunca la amplitud de la segunda (o de lo contrario provocaría una inversión de 


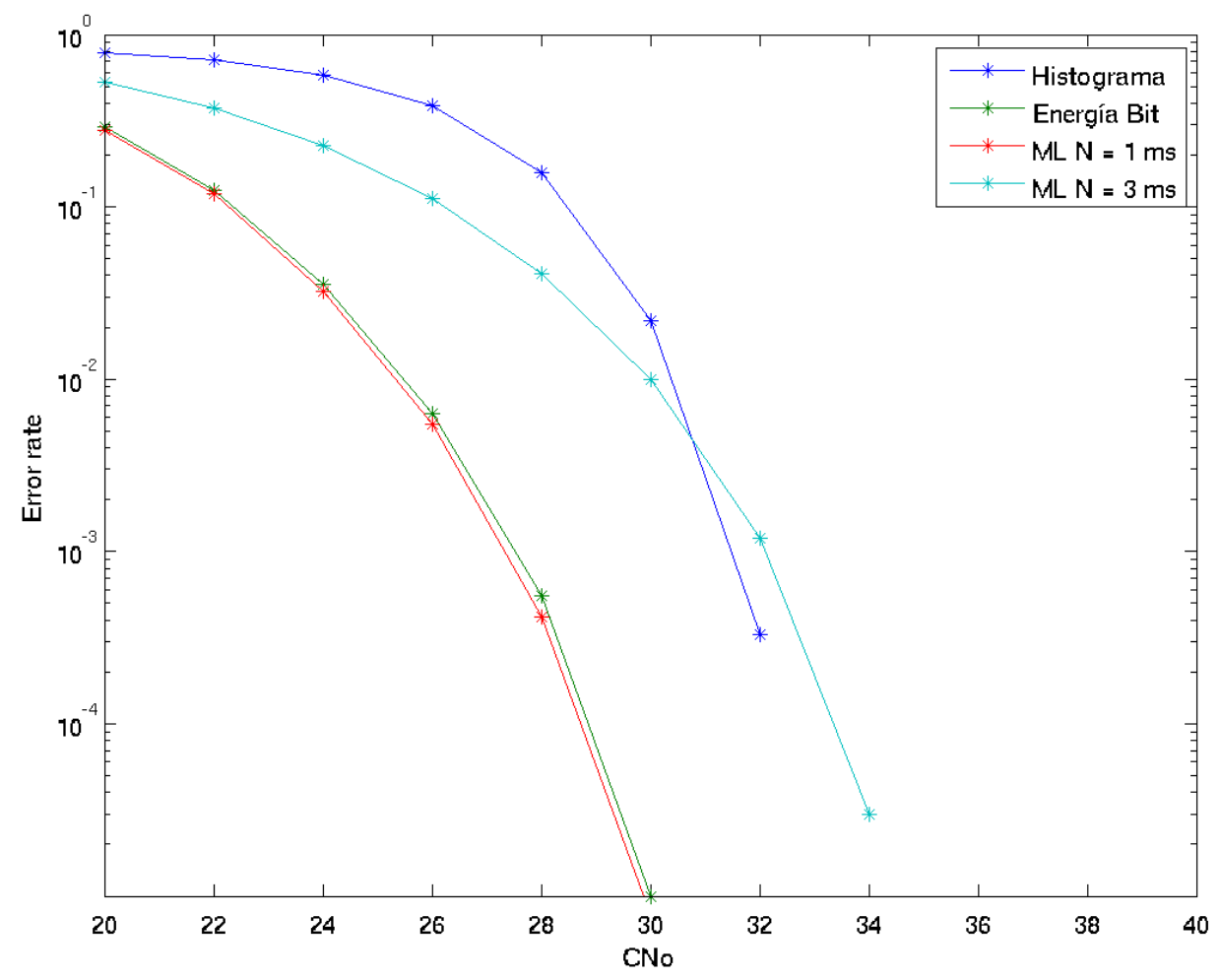

Figura C.9: Simulación de las probabilidades de error con $F=10$ de los métodos histograma, máxima energía de bit y dos variantes del método de máxima verosimilitud presentado en este apéndice para valores $N=1$ y $N=3$.

signo entre la primera y la tercera). Si bien esto no detecta todas las integraciones no afectadas, esto no es necesario para obtener una estimación de la amplitud de la señal. Por supuesto métodos semejantes también se pueden aplicar con otras duraciones del tiempo de integración.

El problema restante es que para cualquier valor finito de $M$ la estimación de la amplitud será imperfecta, mostrando una varianza que es función del largo $M$ y de la relación $C / N_{o}$ de la señal. Esta imperfección deteriora el funcionamiento del algoritmo de detección de alineamiento, porque dificulta la diferenciación entre los posibles valores que puede tomar cada elemento de la secuencia de entrada.

La Figura C.10 muestra los resultados de una serie de simulaciones que comparan la operación del algoritmo en condiciones ideales (normalización perfecta) contra la de una serie de implementaciones que utilizan normalización con ventanas móviles de largos $M=4,8$ y 16 .

Se ve en la figura que efectivamente la estimación de la amplitud mediante promediado degrada la probabilidad de error del algoritmo, y que la degradación es mayor cuanto menor es la longitud de la ventana móvil. Sin embargo en todos los casos la degradación 


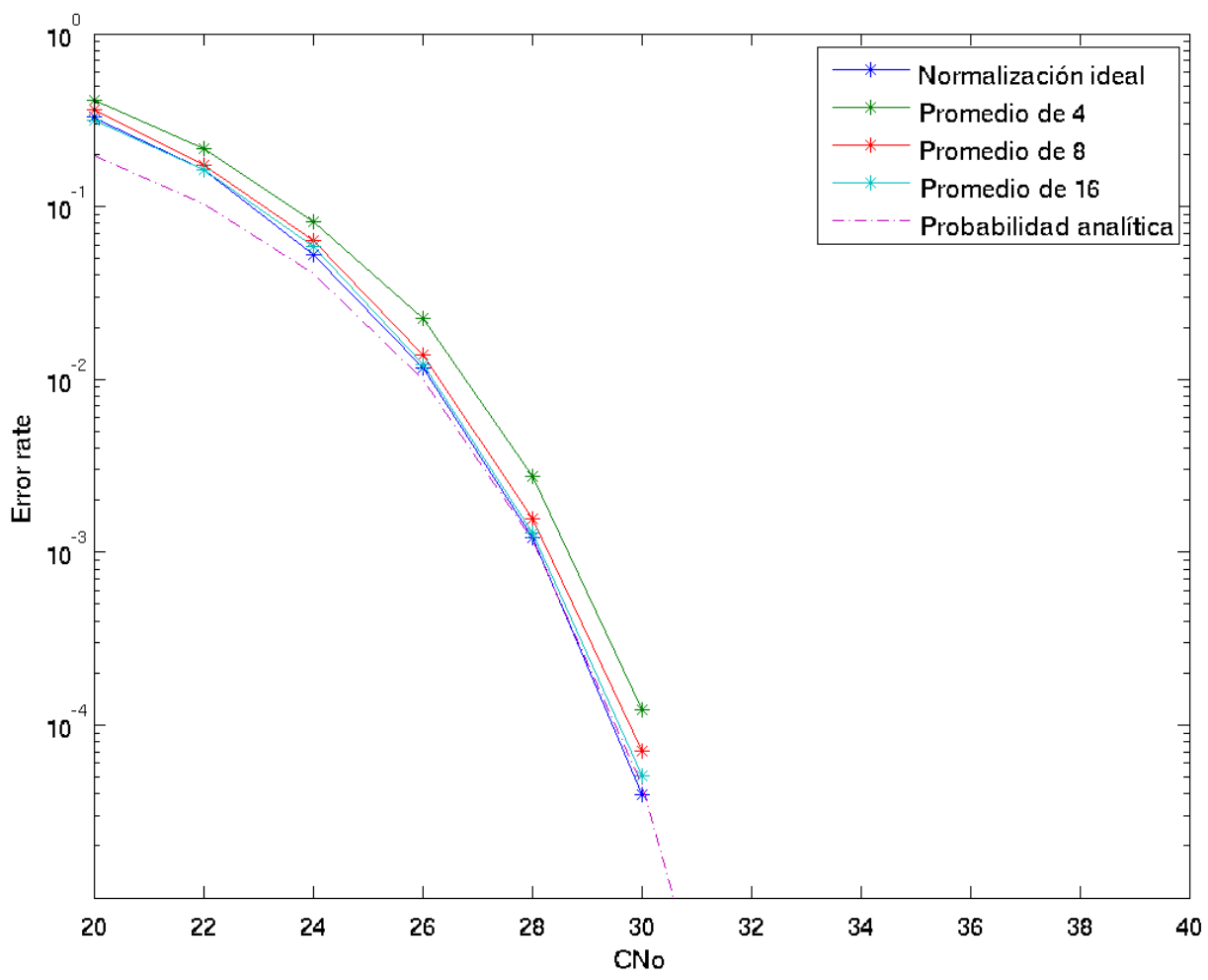

Figura C.10: Efecto de la utilización de normalización no ideal sobre la probabilidad de error del método de detección de alineamiento para $N=3$ y $F=25$.

es equivalente a una reducción en la relación $C / N_{o}$ de la señal de $1 \mathrm{~dB}$, y para $M=16$ es prácticamente despreciable.

Se puede concluir entonces que la normalización mediante un promedio móvil de las amplitudes de las correlaciones previas no alteradas por flancos no afecta fatalmente el algoritmo y permite una implementación sencilla del mismo. 



\section{Bibliografía}

[1] P. A. Roncagliolo, J. G. García, and C. H. Muravchik. Optimized carrier tracking loop design for real-time high-dynamics GNSS receivers. International Journal of Navigation and Observation, 2012:18, 2012. doi: 10.1155/2012/651039.

[2] Interface specification IS-SPS-200G - NAVSTAR GPS space segment/navigation user interfaces, September 2012.

[3] J. Spilker and B. W. Parkinson. Global Positioning System: Theory and Applications, volume I. American Institute of Aeronautics and Astronautics (AIAA), 1996.

[4] E. D. Kaplan. Understanding GPS: Principles and Applications. Artech House, 1996.

[5] W. Enderle, C. Arbinger, and C. Junqueira P. Milani. A simple and low cost twoantennas concept for the tracking of a sounding rocket trajectory using GPS. In Proceedings of ION GPS, 2000.

[6] M. Markgraf, O. Montenbruck, F. Hassenpflug, P. Turner, and B. Bull. A low cost GPS system for real-time tracking of sounding rockets. In ESA SP, volume 471, pages 495-502. European Space Agency Publications, 2001.

[7] M. Markgraf, O. Montenbruck, and F. Hassenpflug. A flexible GPS antenna concept for sounding rockets. In DLR-GSOC, volume TN 01-04. Deutsches Zentrum für Luftund Raumfahrt, 2001.

[8] M. Markgraf, F. Hassenpflug, J. Ettl, and P. Turner. IGAS (Innovative GPS Antenna System) a novel GPS antenna concept for spin-stabilized sounding rockets. In 19th Symposium on European Rocket and Balloon Programmes and Related Research, 2009.

[9] T. Drescher, W. Kreuzer, and J. Nielson. Rocket trajectory correction using strapon GPS guided thrusters. In IEEE Position Location and Navigation Symposium, 1998. 
[10] A. Grillenberger and M. Markgraf. Flight test results of a novel integrated GPS receiver for sounding rockets. In 20th ESA Symposium on European Rocket 8 Balloon, 2011.

[11] A. Svendsen, I. J. Gupta, and C. C. Chen. Satellite coverage for GPS antennas on small spinning projectiles. In IEEE International Symposium on Antennas and Propagation (APSURSI), pages 468-471, 2011.

[12] T. Minowa. Polyhedral GPS receiver system for attitude determination. In Vehicular Technology Conference, volume 6, pages 4108 - 4112 Vol. 6, sept. 2004. doi: 10.1109/VETECF.2004.1404852.

[13] P. A. Roncagliolo, J. G. García, P. I. Mercader., D. R. Fuhrmann, and C. H. Muravchik. Maximum-likelihood attitude estimation using GPS signals. Digit. Signal Process., 17:1089-1100, November 2007. ISSN 1051-2004. doi: 10.1016/j.dsp.2006. 09.001. URL http://portal.acm.org/citation.cfm?id=1294370.1294544.

[14] G. L. Puga, P. A. Roncagliolo, and J. G. Garcia. Low computational cost GNSS GPS/GLONASS maximum likelihood bit synchronization method. In Proceedings of the 13th Argentine Symposium on Technology (JAIIO/AST 2012), La Plata, Buenos Aires, Argentina, pages 204-215, 2012.

[15] G. L. Puga, P. A. Roncagliolo, J. Cogo, and J. G. García. Multi-millisecond GNSS maximum likelihood bit synchronization method. In SPACOMM 2013, The Fifth International Conference on Advances in Satellite and Space Communications, pages 34-39, 2013.

[16] J. A. Buisson, T. B. McCaskill, and J. E. Thompson. Range navigation using the Timation II satellite. Technical report, Space Metrology Branch, Space Systems Division, 1973. URL http://www.dtic.mil/dtic/tr/fulltext/u2/524988.pdf.

[17] C. J. Hegarty and E. Chatre. Evolution of the global navigation satellite system (GNSS). Proceedings of the IEEE, 96(12):1902-1917, Dec 2008. ISSN 0018-9219. doi: 10.1109/JPROC.2008.2006090.

[18] Ian Sample. Europe and US clash on satellite system, 12 2003. URL http://www . theguardian.com/uk/2003/dec/08/world.internationaleducationnews.

[19] GALILEO fact sheet, 2 2013. URL download.esa.int/docs/Galileo_IOV_ Launch/Galileo_factsheet_2012.pdf.

[20] G. Gibbons, D. A. Divis, and P. Gutierrez. The GNSS quartet - harmonizing GPS, GLONASS, BeiDou and Galileo. Inside GNSS, January 2013. URL http: //www. insidegnss. com/node/3375. 
[21] G. Hein. GNSS interoperability: Achieving a global system of systems or "does everything have to be the same?". Inside GNSS, pages 57-60, January 2006. URL http://www. insidegnss. com/node/391.

[22] GPS control segment facts, 2014. URL http://www.gps.gov/systems/gps/ control/.

[23] GPS space segment facts, 2014. URL http://www.gps.gov/systems/gps/space/.

[24] J. Bao-Yen Tsui. Fundamentals of Global Positioning System Receivers: a software approach. Wiley, 2nd edition, 2005.

[25] Notice advisory to NAVSTAR users (NANU) 2012034, 2014. URL ftp://tycho. usno.navy.mil/.

[26] Selective availabiliy, 2014. URL http://www.gps.gov/systems/gps/ modernization/sa/.

[27] Modernized signals, 2014. URL http://www.gps.gov/systems/gps/ modernization/civilsignals/.

[28] Interface specification IS-SPS-705C - NAVSTAR GPS space segment/user segment L5 interface, September 2012.

[29] Interface specification IS-SPS-800C - NAVSTAR GPS space segment/user segment L1C interface, September 2012.

[30] T. A. Stansell, K. W. Hudnut, and R. G. Keegan. Future wave: L1C signal performance and receiver design, April 2011. URL http://gpsworld.com/ gnss-systemgps-modernizationfuture-wave-11401/.

[31] S. Erker, S. Thölert, J. Furthner, and M. Meurer. L5 - the new GPS signal. Proceedings of IAIN, pages 27-30, 2009.

[32] D. Zou, Z. Deng, J. Huang, H. Liu, and L. Yang. A study of neuman hoffman codes for GNSS application. In Wireless Communications, Networking and Mobile Computing, 2009. WiCom '09. 5th International Conference on, pages 1-4, Sept 2009. doi: 10.1109/WICOM.2009.5305353.

[33] GLONASS interface control document, 2002.

[34] Brazil hosts russia's GLONASS satellite navigation system, February 2013. URL http://www.washingtontimes.com/news/2013/feb/19/ brazil-hosts-russian-satellite-navigation-system/. 
[35] D. A. Divis. Russians consider IGS as congress moves to limit GLONASS, foreign GNSS monitoring stations on U.S. soil, 12 2013. URL http://www.insidegnss . com/node/3830.

[36] G. Gibbons. Russia approves CDMA signals for GLONASS, discussing common signal design. Inside GNSS, April 2008. URL http://www.insidegnss.com/node/ 648.

[37] R. J. Cohen. GLONASS and radio astronomy. In B. M. Lewis and D. T. Emerson, editors, Spectrum Management for Radio Astronomy: proceedings of the IUCAF summer school held at Green Bank, West Virginia, June 9-14, 2002, 2002.

[38] T. Mirgorodskaya. GLONASS government policy, status and modernization plans, July 2013.

[39] R. E. Ziemer and W. H. Tranter. Principles of Communication - Systems, Modulation and Noise. John Wiley \& Sons, 2002.

[40] S. Li, J. Sun, J. Li, and Y. Yan. A modified histogram bit synchronization algorithm for GNSS receivers. In Information Science and Engineering (ICISE), 2010 2nd International Conference on, pages 1720-1723, Dec 2010. doi: 10.1109/ICISE.2010. 5691411.

[41] M. Kokkonen and S. Pietila. A new bit synchronization method for a GPS receiver. In Position Location and Navigation Symposium, 2002 IEEE, pages 85-90, 2002. doi: 10.1109/PLANS.2002.998893.

[42] C. L. Liu and J. W. Layland. Scheduling algorithms for multiprogramming in a hard-real-time environment. J. ACM, 20(1):46-61, January 1973. ISSN 0004-5411. doi: 10.1145/321738.321743. URL http://doi .acm.org/10.1145/321738. 321743.

[43] P. Fortescue, G. Swinerd, and J. Stark, editors. Spacecraft Systems Engineering. Wiley, 4th edition, 2011.

[44] W. David Woods and F. O'Brien. Apollo 15 - launch and reaching earth orbit, 1971.

[45] Commercial Directorate / Technical Support Division. Vega User's Manual. Arianespace, 2006.

[46] O. Montenbruck, M. Markgraf, P. Turner, W. Engler, and G. Schmitt. GPS tracking of sounding rockets - a european perspective. In ESA Workshop on Satellite Navigation User Equipment Technologies NAVITEC, 2001.

[47] Delta-II - Payload Planners Guide. United Launch alliance, December 2007. 
[48] P. A. Roncagliolo, J. G. García, and C. H. Muravchik. Data-bits asynchronous tracking loop scheme for high performance real-time GNSS receivers. In Proceedings of SPACOMM 2012, 2012.

[49] M. Petovello, E. Falletti, and M. Pini. Are carrier-to-noise algorithms equivalent in all situations? Inside GNSS, 2010.

[50] S. Friedenthal, A. Moore, and R. Steiner. A Practical Guide to SysML - The Systems Modeling Language. Morgan Kauffman, 2008. 